Studien aus dem Max-Planck-Institut

für ausländisches und internationales Sozialrecht

Dongmei Liu

Reformen des Sozialleistungsrechts

in der Volksrepublik China

Unter besonderer Berücksichtigung der Rolle der Verfassung und des Einflusses internationaler Organisationen 
Studien aus dem Max-Planck-Institut

für ausländisches und internationales Sozialrecht

Band 52 
Dongmei Liu

Reformen des Sozialleistungsrechts in der Volksrepublik China

Unter besonderer Berücksichtigung der Rolle der Verfassung und des Einflusses internationaler Organisationen 
Die Deutsche Nationalbibliothek verzeichnet diese Publikation in der Deutschen Nationalbibliografie; detaillierte bibliografische Daten sind im Internet über http://dnb.d-nb.de abrufbar.

Zugl.: München, Univ., Diss., 2010

ISBN 978-3-8329-6410-8

\begin{abstract}
1. Auflage 2011
(c) Nomos Verlagsgesellschaft, Baden-Baden 2011. Printed in Germany. Alle Rechte, auch die des Nachdrucks von Auszügen, der fotomechanischen Wiedergabe und der Übersetzung, vorbehalten. Gedruckt auf alterungsbeständigem Papier.
\end{abstract}


Die vorliegende Arbeit entstand während meiner Tätigkeit als Doktorandin und wissenschaftliche Mitarbeiterin am Max-Planck-Institut für ausländisches und internationales Sozialrecht in München. Sie wurde im Wintersemester 2010/2011 von der juristischen Fakultät der Ludwig-Maximilians-Universität München als Dissertation angenommen. Für die Veröffentlichung wurden die Rechtsänderungen bis zum 30.11.2010 berücksichtigt.

Ich danke hiermit meinem Doktorvater, Herrn Prof. Dr. Ulrich Becker, LL.M. (EHI), Direktor des Max-Planck-Instituts für Sozialrecht, ganz herzlich für die Aufnahme in das Doktorandenkolleg „Einfluss des Verfassungsrechts und des internationalen Rechts auf die Ausgestaltung der sozialen Sicherheit" wie für seine Unterstützung und Betreuung beim Entstehen meiner Arbeit. Ferner danke ich Herrn Prof. Dr. Stefan Korioth für die schnelle Erstellung des Zweitgutachtens. Ebenso gilt mein Dank Herrn Prof. Dr. Hans F. Zacher, von dessen reichem Erfahrungsschatz ich profitieren durfte.

Herzlicher Dank gilt auch allen Mitarbeiterinnen und Mitarbeitern des Max-PlanckInstituts für Sozialrecht. Ganz besonderen Dank möchte ich Frau Dr. Barbara Darimont aussprechen, die über die Jahre meine Arbeit stets sorgfältig gelesen und mir viele inhaltliche sowie sprachliche Hinweise gegeben hat. Des Weiteren möchte ich Herrn Dr. Peter A. Köhler für seine konstruktive Kritik zu einer frühen Version meiner Arbeit danken. Die Mitglieder des Doktorandenkollegs, Herr Dr. Quirin Vergho, Frau Anna Karina Gibek und Frau Viktoria Fülöp, haben in vielen Gruppendiskussionen auch zum Entstehen dieser Arbeit beigetragen. Bedanken möchte ich mich bei Herrn Si Liu, der meine Arbeit nicht nur einmal sprachlich korrigiert hat.

Ohne Unterstützung meiner Familie, insbesondere meines Ehemannes und meiner Mutter hätte meine Promotion in Deutschland nicht abgeschlossen werden können. Ihnen ist deshalb dieses Buch gewidmet. 
Inhaltsübersicht

Inhaltsverzeichnis

Tabellenverzeichnis

Abkürzungsverzeichnis

$\begin{array}{ll}\text { Einführung } & 21\end{array}$

A. Zielsetzung und Fragestellung $\quad 21$

B. Gegenstand der Untersuchung 22

C. Methode der Untersuchung 23

D. Aufbau der Arbeit 24

\section{Erster Teil: Hintergrund}

- historische, gesellschaftliche, wirtschaftliche und politische Rahmenbedingungen 25
A. Traditionen: Sozialstruktur und Rechtssystem 25
B. Beginn des Transformationsprozesses seit 1840 30
C. Entwicklung seit Gründung der Volksrepublik im Jahre 1949

\section{Zweiter Teil: Die Verfassung und die soziale Sicherheit}

- die für die soziale Sicherheit relevanten Staatsprinzipien

A. Normen der Volksrepublik China $\quad 55$

B. Die Verfassung $\quad 64$

C. Soziale Sicherheit in der Verfassung $\quad 88$

D. Ergebnis 93

Dritter Teil: Entwicklungen der sozialen Sicherheit

- Geschichte, Systematisierung und Reformen 95
A. Begriffe
B. Entstehung und Entwicklungsgeschichte
C. Systematisierung und Systemanalyse
D. Darstellung und Analyse wichtiger Reformen 
Vierter Teil : Einfluss internationaler Organisationen

- äußere Faktoren der Umwandlung der sozialen Sicherheit

A. Beteiligung Chinas an den internationalen Organisationen 231

B. Forschungsumfang 234

C. Wirkungsweise und Einfluss internationaler Organisationen 236

D. Zusammenfassung 285

Fünfter Teil: Schlussbetrachtung 287

A. Ideologische Trends $\quad 287$

B. Modellvorschläge $\quad 292$

C. Forderung nach einer neuen theoretischen Grundlage 294

D. Ausblick: Soziale Sicherheit als Bestandteil der Staatsordnung 296

$\begin{array}{ll}\text { Literaturverzeichnis } & 299\end{array}$

$\begin{array}{ll}\text { Normenverzeichnis } & 317\end{array}$

Statistische Daten 
Inhaltsverzeichnis

Tabellenverzeichnis

Abkürzungsverzeichnis

Einführung

A. Zielsetzung und Fragestellung 21

B. Gegenstand der Untersuchung 22

C. Methode der Untersuchung 23

D. Aufbau der Arbeit 24

\section{Erster Teil: Hintergrund}

- historische, gesellschaftliche, wirtschaftliche und politische Rahmenbedingungen 25

A. Traditionen: Sozialstruktur und Rechtssystem 25

I. Die traditionelle Sozialstruktur und Kultur 26

II. Die traditionellen Rechtsgedanken und das Rechtssystem 28

B. Beginn des Transformationsprozesses seit $1840 \quad 30$

$\begin{array}{ll}\text { I. Veränderung der politischen Struktur } & 30\end{array}$

II. Beginn der Rechtsrezeption $\quad 31$

C. Entwicklung seit Gründung der Volksrepublik im Jahre 1949

I. Wirtschaftliche und gesellschaftliche Modernisierung 33

1. Industrialisierung und Hukou-Registrierung 33

2. Modernisierungsprozess seit $1978 \quad 35$

a) Modernisierungsziele 35

b) Wirtschaftsreform 36

c) Beitritt zur WTO: Verknüpfung mit der Globalwirtschaft 38

3. Aufbau eines modernen Rechtssystems 40

a) Wiederbelebung der Rechtsrezeption $\quad 40$

b) Sozialistischer Rechtsstaat chinesischer Prägung 41

4. Aufbau einer „Harmonischen Gesellschaft“ 42

II. Staatsstruktur $\quad 45$

1. Staat und Gesellschaft: begrenzter Pluralismus? 45

2. Zentrale und lokale Ebene: Zentralismus oder Quasi-Föderalismus? 47 
a) Gewaltenkonzentration und Verwaltungsaufbau $\quad 47$

b) Finanzföderalismus? $\quad 49$

D. Zusammenfassung

\section{Zweiter Teil: Die Verfassung und die soziale Sicherheit}

- die für die soziale Sicherheit relevanten Staatsprinzipien

A. Normen der Volksrepublik China 55

I. Das Rechtssystem

1. Begriffe $\quad 56$

2. Aufbau des Rechtssystems

II. Die politischen Richtlinien der KP Chinas 59

III. Die staatlichen Politnormen $\quad 62$

IV. Transformation innerhalb des Normensystems 63

B. Die Verfassung 64

I. Verfassungsgeschichte $\quad 65$

1. Frühere Verfassungen 65

2. Die Verfassung von 1982

a) Von der „Verfassung der Revolution“ zur „Verfassung der Reform“ 67

b) Verfassungsänderung seit 1988

II. Grundsätze der Verfassung: Staat, Partei und Bürger 72

1. Volkssouveränität und Demokratischer Zentralismus 72

2. Führungsrolle der KP Chinas $\quad 74$

3. Grundrechte und Grundpflichten der Bürger 76

III. Kleine Schritte des chinesischen Konstitutionalismus? 78

1. Forderung nach einer Kontrolle der Verfassungsmäßigkeit 79

a) Organe der Kontrolle der Verfassungsmäßigkeit 79

b) Antragsberechtigung der Kontrolle der Verfassungsmäßigkeit 80

c) Der gegenwärtige Zustand der Kontrolle der Verfassungsmäßigkeit und der Sun-Zhigang Fall $\quad 81$

2. Anwendung der Verfassung durch die Gerichte 83

a) Die Entscheidungen des obersten Volksgerichts von 1955 und von 198683

b) Abweichung der Volksgerichte seit 1988 und der Qi-Yüling Fall 84

IV. Zusammenfassung $\quad 87$

C. Soziale Sicherheit in der Verfassung $\quad 88$

I. Soziale Sicherheit in den früheren Verfassungen $\quad 89$

II. Soziale Sicherheit in der geltenden Verfassung 91 


\section{Dritter Teil: Entwicklung der sozialen Sicherheit}

- Geschichte, Systematisierung und Reformen

$\begin{array}{ll}\text { A. Begriffe } & 96\end{array}$

I. 社会保障 (Soziale Sicherheit) 96

II. 社会福利 (Soziale Wohlfahrt) 98

III. 社会法 (Sozialrecht) und 社会保障法 (Recht der sozialen Sicherheit) 99

B. Entstehung und Entwicklungsgeschichte 102

I. Soziale Absicherung von 1949 bis 1985

1. Soziale Absicherung in der Stadt 103

a) Arbeiterversicherung 103

b) Beamtenversorgung 105

2. Soziale Absicherung für die ländliche Bevölkerung 106

a) Das Fünf-Garantien-System 107

b) Das kooperative medizinische System 107

II. Umgestaltung der sozialen Sicherheit seit $1985 \quad 108$

1. 1985 - 1993: Notwendigkeit der soziale Sicherheit für die Wirtschaftsreform

2. 1993 - 2003: Soziale Sicherheit als Bestandteil der sozialistischen Marktwirtschaft 111

a) Umgestaltung der Sozialversicherung für Beschäftigte in Unternehmen 112

b) Aufbau der Sicherung des Existenzminimums für die städtische Bevölkerung 114

c) Verbesserung der Sozialsicherung für die ländliche Bevölkerung 115

d) Verteilung der Verwaltungszuständigkeit 116

3. 2003 bis heute: Soziale Sicherheit als Bestandteil der Staatsordnung 116

III. Pilotprojekte als chinesische Besonderheit 120

IV. Vertikale Verteilung der Finanzverantwortung für die Reformen 121

V. Zusammenfassung 122

C. Systematisierung und Systemanalyse 125

$\begin{array}{ll}\text { I. Systematisierung } & 125\end{array}$

1. Systematisierung in den amtlichen Texten 125

2. Systematisierung in der Literatur 126

3. Systematisierung in dieser Arbeit 129

II. Systemanalyse 133 
1. Verwaltungszuständigkeit und Träger der sozialen Sicherheit

a) Verwaltungszuständigkeit

aa) Das Ministerium für Personalwesen und soziale Sicherheit

bb) Das Ministerium für Zivile Angelegenheiten

cc) Weitere zuständige Ministerien und Behörden

b) Träger der sozialen Sicherheit

aa) Sozialversicherungsträger

bb) Vorstand des Nationalen Fonds für soziale Sicherheit

2. Vorsorgesysteme

a) Sozialversicherung für Beschäftigte in Unternehmen 138

aa) Rechtliche Grundlagen 138

bb) Grundrentenversicherung 139

(1) Versichertenkreis und Finanzierung 139

(2) Voraussetzungen und Umfang der Leistungen 140

cc) Grundkrankenversicherung 141

(1) Versichertenkreis und Finanzierung 142

(2) Leistungen 142

dd) Arbeitslosenversicherung 143

(1) Versichertenkreis und Finanzierung 143

(2) Voraussetzungen und Umfang der Leistungen 144

ee) Arbeitsunfallversicherung 145

(1) Versichertenkreis und Finanzierung 145

(2) Leistungen 146

ff) Mutterschaftsversicherung 146

b) Grundkrankenversicherung für die städtischen Bewohner 147

aa) Versichertenkreis und Finanzierung 147

bb) Leistungen 148

c) Sozialversicherung für die ländliche Bevölkerung 148

aa) Das neue kooperative medizinische System 148

(1) Finanzierung 149

(2) Leistungen 150

bb) Altersversicherung für die ländliche Bevölkerung 150

(1) Pilotplan von $1992 \quad 150$

(2) Pilotplan von 2009

d) Besondere Vorsorgesysteme 152

aa) Beamtenversorgung 152 
(1) Versorgungskreis

(2) Finanzierung und Leistungen

bb) Vorsorge für Armeeangehörige 154

3. Hilfesysteme 154

a) Sozialhilfe auf dem Land 155

aa) Naturkatastrophenhilfe 155

bb) Das Fünf-Garantien-System 156

cc) Sicherung des Existenzminimums für die ländliche Bevölkerung 156

dd) Ländliche medizinische Hilfe 157

ee) Armutsbekämpfung 158

b) Sozialhilfe in der Stadt $\quad 159$

aa) Sicherung des Existenzminimums für die städtische Bevölkerung $\quad 159$

bb) Hilfe für Obdachlose in den Städten $\quad 160$

cc) Wohnungshilfe 160

dd) Städtische medizinische Hilfe 161

4. Förderungssysteme 161

a) Allgemeine Wohlfahrt 162

aa) Beschäftigungsförderung $\quad 162$

bb) Bildungsförderung 163

cc) Medizinische Dienstleistung 163

b) Kollektive Wohlfahrt 164

c) Spezielle Wohlfahrt 165

5. Sonderversorgungssysteme 166

III. Zusammenfassung 167

D. Darstellung und Analyse wichtiger Reformen 167

$\begin{array}{ll}\text { I. Alterssicherung } & 168\end{array}$

1. Reform der Grundrentenversicherung für Beschäftigte in Unternehmen 169

a) Umwandlung zum Modell „Solidarfonds mit Individualkonto“ 170

aa) Einführung des Teilkapitaldeckungsverfahrens 170

bb) Übergangskosten 172

cc) Auffüllung der Individualkonten 174

b) Risiken der Sozialversicherungsfonds 176

c) Lösungsmöglichkeiten 178

aa) Ein beitragsbezogenes System mit Umlageverfahren? 178

bb) Verlagerung der Planungsebene 181

2. Zusammenführung der Alterssicherungssysteme 183 
a) Reform des Pensionssystems für Staatsbedienstete 183

b) Koordinierung der Altersversicherungssysteme 185

3. Würdigung 187

II. Gesundheitssicherung 187

1. Tradition des Gesundheitswesens 188

2. Gesundheitsreform 1985 - $2005 \quad 189$

a) Wirtschaftlicher Hintergrund und Orientierungslinien 189

b) An der Selbstverantwortung orientierte Reform der Gesundheitsabsicherung 190

c) Marktorientierte Reform der öffentlichen Gesundheitsdienste 193

d) „ein ungerechtes Gesundheitssystem“ 194

3. Neue Runde der Gesundheitsreformen 195

a) Übereinstimmung: Verstärkung der Regierungsverantwortung 196

b) Kontroverse: Finanzierungsmodell der Gesundheitsabsicherung 198

4. Ein gemischtes System? 201

III. Beschäftigungsförderung und Arbeitslosensicherung 203

1. Beschäftigungspolitik in der Periode der Planwirtschaft 204

2. Seit dem Aufbau der sozialistischen Marktwirtschaft 205

a) 1980 - 2002: Flexible Beschäftigungspolitik und Arbeitslosensicherung 205

b) Die aktive Beschäftigungspolitik 207

aa) Beschäftigungspolitik $2002-2005 \quad 208$

bb) Beschäftigungspolitik seit $2006 \quad 209$

c) Arbeitslosensicherung 211

aa) Arbeitslosenversicherung 212

bb) Sicherung des Existenzminimums für die städtische Bevölkerung 215

3. Zwischenergebnis 217

IV. Zwischen Land und Stadt: Soziale Versicherungen für die Wanderarbeiter 218

1. Begriff und Geschichte 219

2. Leitlinien für die Wanderarbeiterfrage 221

3. Soziale Versicherungen für die Wanderarbeiter 222

a) Modelle der Wanderarbeiterversicherung 222

aa) Shanghai-Modell 223

bb) Shenzhen-Modell 224

cc) Vergleich der Modelle 225

b) Entwicklungen der Wanderarbeiterversicherung 226

$\begin{array}{ll}\text { V. Fazit } & 229\end{array}$ 


\section{Vierter Teil : Einfluss internationaler Organisationen}

- äußere Faktoren der Umwandlung der sozialen Sicherheit

A. Beteiligung Chinas an den internationalen Organisationen 231

B. Forschungsumfang 234

C. Wirkungsweise und Einfluss internationaler Organisationen 236

I. Menschenrechte als grundlegende Prinzipien 236

1. Menschenrechtliche Regelungen der UNO über soziale Sicherheit 236

2. Umsetzung der Menschenrechtskonventionen in China 239

a) Ratifikation der Menschenrechtskonventionen 239

b) Umsetzung ins chinesische Recht 242

aa) In die Verfassung von 1982

bb) In andere Gesetze 244

(1) Gesetz zum Schutz von Minderjährigen 245

(2) Gesetz zur Gewährleistung der Rechte von Frauen 246

(3) Gesetz zum Schutz von behinderten Menschen 247

3. Einflussanalyse 249

II. ILO-Standards als Rahmen der sozialen Sicherheit 250

1. Ziele und Aufgaben der ILO 250

2. Die ILO-Standards für soziale Sicherheit 251

3. Einführung der ILO-Standards in China 253

a) Ratifizierung der ILO-Konventionen in China 253

b) Einfluss der ILO-Standards auf das chinesische Recht 257

aa) Einfluss auf das Arbeitsgesetz 257

bb) Einfluss auf die Regelungen zum Arbeitsunfall 260

cc) Umsetzung im Gesetz zum Schutz von behinderten Menschen 261

4. Einflussanalyse 262

III. Aktivitäten der internationalen Organisationen 263

1. Aktionsprogramme der UNO-Organisationen in China 263

2. Gemeinsame Aktionen der UNO-Organisationen 264

a) Millenniums-Entwicklungsziele und „Gesellschaft des Kleinen Wohlstands“ 264

b) UNDAF und Fünfjahresplan 266

3. Einzelne Aktivitäten der UNO-Organisationen 269

a) Aktivitäten der ILO 269

aa) Aktionsprogramme 270

(1) Die Decent Work Agenda 270 
(2) Kooperationsprogramme in China: MOU und DWCP

bb) Kooperationen

(1) Aufbau und Ausweitung der Sozialversicherung

(2) Beschäftigungsförderung und soziale Sicherung

b) Aktivitäten der Weltbank

aa) Aufgaben und Arbeitsweisen der Weltbank

bb) Die Beziehung zwischen China und der Weltbank

cc) Aktivitäten im Bereich der sozialen Sicherheit

(1) Rentenversicherung

(2) Armutsbekämpfung

(3) Gesundheitssicherung auf dem Land

D. Zusammenfassung

Fünfter Teil: Schlussbetrachtung

A. Ideologische Trends

B. Modellvorschläge

C. Forderung nach einer neuen theoretischen Grundlage

D. Ausblick: Soziale Sicherheit als Bestandteil der Staatsordnung

Literaturverzeichnis

I. Chinesische Literatur

II. Westliche Literatur

Normenverzeichnis

I. Politische Normen

1. Politische Richtlinien der KP Chinas

2. Staatliche Politnormen

a) Staatliche Entwicklungspläne

b) Beschäftigungs- und Wanderarbeiterpolitik

c) Armutsbekämpfung und Sozialhilfe

d) Alterssicherung

e) Gesundheitswesen

f) Versorgung für Staatsbedienstete

g) Soziale Wohlfahrt 
h) Finanzwesen

II. Rechtliche Normen $\quad 322$

1. Gesetze 322

2. Exekutivrechtsnormen 324 
Tabellenverzeichnis

Tabelle 1: Modernisierungsprozess im Anfangsstadium des Sozialismus 36

Tabelle 2: Ginikoeffizienten Chinas 43

Tabelle 3: Wandel des Steuersystems in China $\quad 50$

Tabelle 4: Einnahmenquote der Zentralregierung 1955-2004 51

Tabelle 5: Normensysteme der VR China 64

Tabelle 6: Die Verfassungen der VR China 69

Tabelle 7: Verfassungsänderungen seit 1988

Tabelle 8: Staatsorgane der VR China $\quad 73$

Tabelle 9: Soziale Sicherheit in den früheren Verfassungen 90

Tabelle 10: Soziale Sicherheit in der geltenden Verfassung 92

Tabelle 11: Die Zahl der versicherten Beschäftigten in den Städten 114

Tabelle 12: Systematisierung in der Literatur 128

Tabelle 13: Systematisierung in dieser Arbeit 132

Tabelle 14: Gesamte Gesundheitsausgaben 1980-2006 190

Tabelle 15: Prozentuale Aufteilung der Bevölkerung nach Zweigen der Gesundheitssicherung 191

Tabelle 16: Arbeitslosenversicherung 214

Tabelle 17: Unterhaltssicherung für Arbeitslose in den Städten 217

Tabelle 18: Die von China unterzeichneten UNO-Menschenrechtskonventionen 241

Tabelle 19: ILO-Konventionen über soziale Sicherheit seit 1952

Tabelle 20: Die von China ratifizierten ILO-Konventionen 254

Tabelle 21: Wege und Formen der Einflussnahme 286 


\section{Abkürzungsverzeichnis}

Abs.

ACGB

ACWF

Art.

Aufl.

BIP

BJRB

BSP

bzw.

ca.

CDPF

CEF

d.h.

DWCP

ECOSOC

etc.

f.

FS

FDC

FZRB

GATT

gem.

GGB

GMRB

Hrsg.

IGH

IGO

ILO

IMF

inkl.

IPD

$\mathrm{JKB}$

$\mathrm{KP}$

MFN

MOU

Mio.

MOLSS

Mrd.

n. Chr.
Absatz

Der Allchinesische Gewerkschaftsbund

All-China Women Federation

Artikel

Auflage

Bruttoinlandsprodukt

北京日报 (Beijing Zeitung)

Bruttosozialprodukts

beziehungsweise

circa

China Disabled Persons' Federation

China Employment Forum

das heißt

Decent Work Country Programme

Economic and Social Council

et cetera

und folgende

Festschrift

financial defined contribution

法制日报 (Fazhi Zeitung)

General Agreement on Tariffs and Trade gemäß

国务院公报 (Amtsblatt des Staatsrats) 光明日报 (Guangming Zeitung)

Herausgeber

Internationales Gerichtshof

intergovernmental organization

International Labour Organization

International Monetary Fund

inklusive

implizite voraussichtliche Verschuldung

健康报 (Jiankang Zeitung)

Kommunistische Partei

Most Favoured Nation

Memorandum of Understanding

Million

Ministry of Labor and Social Security

Milliarde

nach Christo 
NDC

NFZM

NGOs

NVK

$\mathrm{OSH}$

RMB

RMRB

S.

UNDAF

UNDP

UNO

USA

usw.

v. Chr.

vgl.

VR

WHO

WTO

XJB

z. B.

ZfRV

$21 \mathrm{CBH}$ notional defined contribution

南方周末 (Nanfang Zeitung)

Nicht-Regierungs-Organisationen

Nationaler Volkskongress

occupational safety and health

人民币 (Renminbi, die chinesische Währung)

人民日报 (Renmin Zeitung)

Seite

United Nations Development Assistance Framework United Nations Development Programme

United Nations Organization

United States

und so weiter

vor Christo

vergleiche

Volksrepublik

World Health Organization

World Trade Organization

新京报 (Xinjing Zeitung)

zum Beispiel

Zeitschrift für Rechtsvergleichung

21世纪经济报道 (21st Century Business Herald) 


\section{Einführung}

\section{A. Zielsetzung und Fragestellung}

In den letzten 30 Jahren hat die Volksrepublik China durch Einführung einer Marktwirtschaft und Aufbau einer engen Verknüpfung mit der Weltwirtschaft ein rasantes Wirtschaftswachstum zurückgelegt. Der Veränderung der Wirtschaftsstruktur entsprechend wurde die soziale Sicherheit umgebaut. In diesem noch andauernden umfangreichen Umbauprozess wirken die sozialistischen Grundlagen, die marktwirtschaftlichen Faktoren sowie die traditionellen Werte über die Beziehung zwischen Staat und Einzelnen nebeneinander. Aus diesem Grund sind die chinesischen Erfahrungen im Bereich der sozialen Sicherheit wegen ihrer Besonderheit und Komplexität für die Erforschung der sozialrechtlichen und sozialpolitischen Reformen in den Entwicklungs- und Transformationsländern von besonderem Interesse.

In deutscher Sprache wird der Entwicklungsgang der sozialen Sicherheit und des Sozialleistungsrechts Chinas seit langer Zeit beobachtet. ${ }^{1}$ Allerdings ist es für die deutschen Leser - für die chinesischen Beobachter vielleicht auch - schwierig, in der heutigen Zeit die Entwicklungsrichtung zu erfassen, da eine stabile theoretische Grundlage und eine klare, langfristig angelegte Orientierung der Reform zurzeit noch fehlt. Angesichts dieser Umstände wird in der vorliegenden Arbeit versucht, nicht nur die bestehenden sozialen Sicherungssysteme darzustellen und ihre Reformprozesse zu analysieren, sondern auch den politischen, gesellschaftlichen, wirtschaftlichen sowie globalen Kontext aufzuzeigen, damit sich die deutschen Leser ein umfassendes Bild über die chinesische soziale Sicherheit und deren institutionellen Hintergründe machen können.

Folgende Fragen werden in dieser Arbeit bearbeitet:

1. Wie und warum entsteht soziale Sicherheit in der Volksrepublik? Wie wandelt sie sich im Laufe der wirtschaftlichen und gesellschaftlichen Transformationen?

2. Welche Rolle spielt in diesem Zusammenhang die chinesische Verfassung? Wie wurden die Systemänderungen durch die Verfassung legitimiert?

3. Wie haben internationale Faktoren auf diesen Transformationsprozess von auBen Einfluss genommen?

Wegen der Verflechtung und des Konflikts verschieden wirkender Kräfte besitzt die chinesische soziale Sicherheit zurzeit einen gemischten Charakter. In diesem Bereich existieren die traditionellen Gedanken, die sozialistischen Traditionen sowie die westlichen Einflüsse sowohl beim theoretischen Aufbau als auch bei der Modellauswahl ne-

1 Fan, Jinming, Alterssicherung in China, 1999; Darimont, Sozialversicherungsrecht der V.R. China, 2004; Darimont, in: Kupfer (Hrsg.), "Sozialer Sprengstoff in China?" - Dimensionen sozialer Herausforderungen in der Volksrepublik, S. 67-78; Zhang, Wei, Sozialwesen in China, 2005; Xu, Cong, Betriebliche Altersversorgung in der Bundesrepublik Deutschland und der Volksrepublik China im Vergleich, 2008. 
beneinander. Für die stabile Entwicklung der sozialen Sicherheit ist eine grundlegende Übereinstimmung über die Harmonisierung der oben erwähnten Faktoren notwendig. $\mathrm{Ob}$ und inwieweit diese Übereinstimmung nun erreicht wird, wird durch eine detaillierte Analyse am Ende dieser Arbeit dargestellt.

\section{B. Gegenstand der Untersuchung}

Hintergrund dieser Untersuchung ist die Transformation Chinas von einer Agrarzivilisation hin zum modernen Staat, die seit dem 19. Jahrhundert wegen externem Veränderungsdruck begonnen hat und in der Ära der Volksrepublik durch die Festlegung der staatlichen Entwicklungsziele und -strategien beschleunigt wird. Die Untersuchung konzentriert sich hauptsächlich auf die Periode der „Reform und Öffnung“, die von 1978 bis jetzt andauert, in der der chinesische Modernisierungsprozess eine wichtige Wendung zurückgelegt hat: Nachdem ein relativ vollständiges Industriesystem in der Mao-Zedong-Ära (1949-1978) aufgebaut wurde, hat sich das Wirtschaftssystem von einem autarken System zu einem sich öffnenden System, von der Planwirtschaft zur Marktwirtschaft gewandelt. ${ }^{2}$ Um die Koordinaten der sozialen Sicherheit im Staatsleben und ihre Umwandlungsspuren in dieser rasanten Transformation zu bestimmen, sind viele Faktoren, wie die gesellschaftlichen, ökonomischen, politischen und historischen Bedingungen im ersten Teil nebeneinander zu untersuchen.

Ein wichtiger Charakter der chinesischen Modernisierung ist die Bewahrung der zentralen traditionellen Werte und Institutionen, während zugleich nach der Industrialisierung und einer modernen Staatsform gestrebt wird. Deutlich wird dies in der chinesischen Verfassung und ihren Entwicklungen in den vergangenen 60 Jahren. Deshalb ist die Erforschung der chinesischen Verfassung für diese Arbeit von besonderer Bedeutung: Es findet sich darin nicht nur die ausdrückliche verfassungsrechtliche Bestimmung der staatlichen Verantwortung für soziale Sicherheit und der ausführliche Katalog sozialer Grundrechte der Bürger. Darüber hinaus lassen sich in der Verfassung die Regelungen über das Staatswesen identifizieren sowie die grundlegenden staatlichen Prinzipien und Systeme, ferner die Darstellung der chinesischen Geschichte und der staatlichen Aufgaben. Sie alle bilden zusammen die Rahmenbedingungen der sozialen Sicherheit. Durch die Analyse der häufigen Verfassungsänderungen wird die Richtung der wirtschaftlichen und politischen Reformen aufgezeigt, die den massiven Umbau der sozialen Sicherheit seit den 1980er Jahren direkt bedingt.

Als ein Staat, der geschichtlich eine einzigartige Rechtskultur hat und über keine verfassungsrechtliche Tradition verfügt, erweist sich das durch Rezeption der westlichen und sowjetischen Rechtssysteme aufgebaute moderne chinesische Rechtssystem bis jetzt als nicht völlig kompatibel mit den gesellschaftlichen Bedingungen. Im Rahmen

2 Über die chinesische Transformation in der Periode der Volksrepublik ausführlich siehe: 胡鞍钢, 中国政治经济史论 (1949-1976) (Hu, Angang, Geschichte der politischen Ökonomie in China 1949-1976), S. 3ff. 
der gegenwärtigen staatlichen Organisationsstruktur spielen nicht die Verfassung und die sozialrechtlichen Verordnungen, sondern die politischen Entscheidungen eine bestimmende Rolle bei der Ausgestaltung der sozialen Sicherheit. Demzufolge beschränkt sich die Untersuchung nicht nur auf den rechtlichen Rahmen. Vielmehr konzentriert sie sich auch auf die politischen Entscheidungen der KP Chinas und die staatlichen Politnormen, da sie als einer Art „Vorbereitung“ der rechtlichen Normen dienen, Leitlinien der Gesetzgebung darstellen sowie als Ergänzung für die Durchsetzung des Rechts im chinesischen Staatssystem funktionieren. ${ }^{3}$

Ein anderer wichtiger Charakter der chinesischen Modernisierung ist der tiefe Einfluss der äußeren Triebkräfte. Die passive Anpassung am veränderten Weltsystem wurde in der Periode der Volksrepublik allmählich durch die aktive Beteiligungspolitik ersetzt. Mit der Festlegung der Öffnungspolitik hat sich China in dem zunehmenden Globalisierungsprozess dafür entschieden, von den ausländischen sowie internationalen Erfahrungen zu profitieren. ${ }^{4}$ In diesem Prozess haben die internationalen Organisationen mit ihren völkerrechtlichen Kompetenzen und Kooperationsmechanismen eine aktive Rolle gespielt. Hauptsächlich werden die UNO, die ILO und die Weltbank in dieser Arbeit untersucht. Durch ihre Einflussmechanismen, wozu die von ihnen erlassenen Normen, Modellvorschläge sowie andere sozialpolitische Aktivitäten gehören, haben sie bedeutenden Einfluss auf die Reform der sozialen Sicherheit in China ausgeübt.

\section{Methode der Untersuchung}

Angesichts der Situation, dass die chinesische Transformation noch lange andauern wird, werden sich die sozialen Sicherungssysteme und das Sozialleistungsrecht, den sozioökonomischen Lagen entsprechend, in ständiger Regulierung und Umwandlung befinden. Für die Erforschung eines sich transformierenden Systems sind die Darstellung der Entwicklungsgeschichte und die Analyse der Rahmenbedingungen sowie des Entwicklungsgangs von besonderer Bedeutung. Demzufolge zieht sich eine Verflechtung der historischen Methode, der deskriptiven Methode und der analysierenden Methode durch diese Arbeit.

Die Systematisierung der sozialen Sicherheit wird vorwiegend mit der deskriptiven Methode dargestellt. Um die Entwicklungsorientierung dieses noch nicht ausgereiften Bereichs zu erfassen, stützt sich die Beschreibung im Allgemeinen auf eine induktive Forschungsmethode: Durch Darstellung, Analyse und Zusammenfassung von Erfahrungen einzelner Systeme und Bereiche wird versucht, die möglichen Grundlagen und Kernelemente der chinesischen sozialen Sicherheit herauszuarbeiten.

Bei der Beschreibung kommt auch die vergleichende Methode zur Anwendung. Die chinesischen Rechtsbegriffe werden im Vergleich zu den westlichen Definitionen er-

3 Ausführlich: Zweiter Teil, Normen der Volksrepublik China.

4 邓队小平文选第三卷 (Deng, Xiaoping, Ausgewählte Werke von Deng Xiaoping, Vol. 3), S. 373. 
klärt. Vor allem hilft der Rechtsvergleich, das Recht besser zu verstehen. ${ }^{5}$ Es handelt sich dabei jedoch nicht um eine Rechtsvergleichungsarbeit im eigentlichen Sinn. Die vergleichende Methode dient hier nur dem Ziel, das chinesische Rechtssystem dem deutschen Betrachter verständlich zu erklären. Darüber hinaus werden die chinesischen Gesetze zur sozialen Sicherheit, die nach den Ratifikationen der internationalen Übereinkommen entsprechend verändert oder neu ausgearbeitet wurden, mit den Regelungen der Übereinkommen verglichen. Man könnte hier von einer vertikalen Vergleichung6 der internationalen Rechtsordnungen mit den nationalen Gesetzen sprechen oder - wie Becker - von einem rechtsordnungsübergreifenden Vergleich ${ }^{7}$, da internationales und supranationales Recht im Teil der jeweiligen Rechtsordnung ist und damit immer eigenen Bewertungsmaßstäben unterliegt. Da „gleichlautendes Recht wegen seiner Einbettung in einen konkreten gesellschaftlichen und kulturellen Kontext zu verschiedenen Ergebnissen führen kann"8, werden nicht nur der Wortlaut der chinesischen Gesetze, sondern auch die inhaltliche Bedeutung der Rechtsordnungen ausführlich analysiert, um die Übereinstimmung und die Unterschiede mit den internationalen Übereinkommen darstellen zu können.

\section{Aufbau der Arbeit}

Die Dissertation ist in fünf Teile gegliedert. Zunächst werden die historischen, gesellschaftlichen und ökonomischen Rahmenbedingungen im ersten Teil dargestellt. Darauf aufbauend wird die Rolle der Verfassung im zweiten Teil erklärt und die Systematisierung der sozialen Sicherheit im dritten Teil erörtert. Im dritten Teil werden auch die wichtigen Reformen im Bereich der sozialen Sicherheit ausführlich analysiert. Der vierte Teil ist die Darstellung und Analyse des Einflusses internationaler Institutionen. Diesem Teil folgt die Schlussbetrachtung.

5 Becker, in: Becker/Kaufmann/Maydell/Schmähl/Zacher (Hrsg.), Alterssicherung in Deutschland, FS für Franz Ruland zum 65. Geburtstag, S. 575.

6 Zacher, in: ders. (Hrsg.), Sozialrechtsvergleich im Bezugsrahmen internationalen und supranationalen Rechts, S. $21 \mathrm{ff}$.

7 Becker, in: ders. (Hrsg.), Rechtsdogmatik und Rechtsvergleich im Sozialrecht, S. 22.

8 Becker, in: ders. (Hrsg.), Rechtsdogmatik und Rechtsvergleich im Sozialrecht, S. 21. 


\section{Erster Teil: Hintergrund}

- historische, gesellschaftliche, wirtschaftliche und politische Rahmenbedingungen

„The fundamental problem in china's modernization is that china is really a civilization pretending to be a nation-state". ${ }^{1}$ Die Verschmelzung einer modernen Staatsform mit dem Kern einer eigenen Zivilisation macht es für westliche Beobachter schwierig, die wesentlichen Charaktere Chinas zu begreifen. Sie betrachten und beurteilen wie Pye die chinesische Transformation immer noch unter dem Gesichtspunkt des westlichen Nationalstaats. Für die Chinesen ist es auch schwierig, bei der rasanten wirtschaftlichen und gesellschaftlichen Transformation - insbesondere in der Periode der „Reform und Öffnung“" seit 1978, die als ,die größte Umwandlung Chinas in den letzten tausend Jahren" bezeichnet wird, ${ }^{2}$ den Entwicklungsgang des Staates klar zu erkennen.

Aber aus Pye's Bemerkung über China können zwei Fragen, die für diese Arbeit relevant sind, abgeleitet werden:

1. Wenn Konstitutionalismus und Rechtsstaatlichkeit die Fundamente eines modernen westlichen Nationalstaates sind, die aber wegen den geschichtlichen Erfahrungen Chinas in der chinesischen politischen Kultur keine wesentliche Bedeutung besitzt, worauf gründet die Volksrepublik ihre politische Legitimität? Welche Rolle spielt dabei die Verfassung?

2. In einem vom Westen dominierten Zeitalter wurden die internationalen Organisationen und das System des internationalen Rechts nach westlichen Prinzipien aufgebaut. Wenn eine völlige Verwestlichung für China unmöglich ist, ${ }^{3}$ inwiefern können die internationalen Standards von China übernommen werden oder mit anderen Worten: Inwiefern kann China im Zeitalter der Globalisierung einen Kompromiss mit dem internationalen System schließen?

\section{A. Traditionen: Sozialstruktur und Rechtssystem}

Eine Betrachtung aus den geschichtlichen Perspektiven erleichtert den Zugang zum Verständnis der modernen chinesischen Gesellschaft. Die epochalen Ereignisse der Kaiserreiche beeinflussen noch heute die Gesellschafts- und Politikstruktur Chinas.

1 Pye, in: Unger (Hrsg.), Chinese Nationalism, S. 109.

2 王绍光/胡鞍钢/周建明, 第二代改革战略: 积极推进国家制度建设 (Wang, Shaoguang/Hu, Angang/Zhou, Jianming, Neue Reformstrategien: Förderung der Strukturierung des Staatssystems), in: 战略与管理 (Strategy and Management), 2003/2, S. 90.

3 Huntington, The Clash of Civilizations and the Remaking of World Order, S. 79. 
Die traditionelle chinesische Gesellschaft basiert auf einer geographisch geprägten Kleinbauernwirtschaft. Die klimatischen und topographischen Bedingungen sind mitunter wichtige Indikatoren, die das Schicksal des Landes entscheidend beeinflussten. ${ }^{4}$ Auf dem chinesischen Festland herrscht kontinentales Monsunklima. Der ostasiatische Monsun führt im Sommer zu 80\% der jährlichen Niederschlagsmenge. Er fördert die Entwicklung des Getreideanbaus, verursacht aber auch häufige Überschwemmungen und lange Dürreperioden im Osten. Im niederschlagsärmeren Westen und Norden lebten nomadische Völker, die oft in der Erntezeit Bauern überfielen und ausplünderten. Die Große Mauer zeugt von den Aggressionen dieser Zeit und der Notwendigkeit eines effektiven Schutzes der Bauern gegen diese Übergriffe. Riesige Bewässerungssysteme, der Bedarf an Naturkatastrophenhilfe sowie Kriege zwischen Bauern und Nomadenvölkern förderten das Entstehen von zentralisierten und bürokratisch politischen Institutionen. ${ }^{5}$

Seit der Etablierung des chinesischen Zentralismus in der Qin-Dynastie (221 v. Chr. - 207 v. Chr.) strebt China auch heute noch danach, mit Hilfe des Zentralismus die Stabilität des Vielvölkerstaates aufrecht zu erhalten. Die politischen Institutionen der chinesischen Kaiserreiche unterschieden sich grundlegend von der Struktur des Feudalismus in Europa: ${ }^{6}$ Es fehlte in China grundsätzlich die Schicht von Feudaladligen sowie eine regionale Autonomie. Eine Machtverteilung zwischen weltlichen und geistlichen Gewalten hatte es ebenfalls nicht gegeben. Das Zusammenleben innerhalb der Familie war das Fundament der Gesellschaft.

In dieser autarken Kleinbauerngesellschaft nahmen die Bürger die Unterdrückung durch die ewigen monarchischen oder religiösen Gewalten nicht wahr. Sie stellten keine Forderung danach, die subjektiven Rechte des Individuums zu bewahren, sondern legten großen Wert auf die familiäre Kooperation, Solidarität und Ordnung. An der Spitze der Macht betrachtete man den Kaiser mehr wie ein Familienoberhaupt, als ein Herrscher des Landes. Er erfüllte seine Aufgabe - die Aufrechterhaltung einer einheitlichen und geordneten Gesellschaft - mit Hilfe von bürokratischen Institutionen. Die Beamten wurden durch Staatsprüfungen oder Empfehlungen direkt aus der Mitte der Bevölkerung ausgewählt. Der Kaiser sollte human, gerecht und tugendhaft regieren. Anderenfalls verlor er das „Mandat des Himmels“,7 und konnte deshalb „,zu Recht“ durch Volksrebellion gestürzt werden. Die Legitimation des Regimes basierte grundsätzlich

4 Siehe: 黄仁宇 (Huang, Ray), China: A Macro-History, S. $23 \mathrm{ff}$.

5 黄仁宇 (Huang, Ray), China: A Macro-History, S. 23ff.

6 黄仁宇, 资本主义与二十一世纪 (Huang, Ray, Kapitalismus und das 21. Jahrhundert), S. 16 ff.

7 In der chinesischen Kultur ist „,der Himmel“ das Symbol der Naturregeln. Der Kaiser wird als , der Sohn des Himmels“ benannt. Das bedeutet, dass er vom Himmel ausgewählt wird, das Land zu führen. Es gab in der chinesischen Geschichte acht einheitliche (oder halb-einheitliche) Dynastien, ihre Begründer stammten aus verschiedenen Nationen und Schichten (Sie sind König (die QinDynastie), Beamter (Han), Adlige (Sui und Tang), General (Song), Bauer (Ming), Häuptling vom Nomadenvolk (Yuan und Qing)). 
nicht auf Blutsverwandtschaft, Nationalität oder Religionszugehörigkeit, sondern auf der Anerkennung und Fortsetzung der herrschenden weltlichen Kultur.

Den Kern dieser weltlichen Kultur bildet der Konfuzianismus, der aus der ZhouDynastie (1122 v. Chr. - 221 v. Chr.), einem Zeitalter des Lehnswesens, stammte. ${ }^{8}$ In der Ost-Zhou-Dynastie (770 v. Chr. - 221 v. Chr.) verlor der Herrscher von Zhou die Kontrolle über seine Fürstenstaaten. Das Land geriet über 500 Jahre lang in Chaos und Krieg. Dies führte zur Entstehung des Konfuzianismus, der „die Einigung unter dem Himmel"9 sowie die öffentliche Ordnung betont.

Seit der Han-Dynastie (206 v. Chr. - 220 n. Chr.) war Konfuzianismus die politische Grundlage der chinesischen Gesellschaft und bildete mit dem Taoismus und dem chinesischen Buddhismus den Hauptteil der chinesischen Kultur. Das Ideal des Konfuzianismus ist die „Große Gemeinsamkeit“ (大同 dàtóng):

„Zurzeit, als der große Weg herrschte, war die Welt gemeinsamer Besitz. ... Darum liebten die Menschen nicht nur ihre eigenen Eltern und versorgten nicht nur ihre eigenen Kinder. Die Alten konnten in Ruhe ihrem Ende entgegensehen; die Erwachsenen hatten ihre Arbeit; die Witwer und Witwen, die Waisen und Kinderlosen und die Kranken hatten alle ihre Pflege. ... Das war die Zeit der großen Gemeinsamkeit."10

Da die „Große Gemeinsamkeit“ damals nicht verwirklicht werden konnte, hat der Philosoph Kongzi (551 v. Chr. - 479 v. Chr.) den „Kleinen Wohlstand (小康 xiăokāng)“ als Zwischenstufe seines Ideals beschrieben und die „Sitte“ als ein Mittel zum Zweck betont:

„Nun aber, da der Große Weg sich verborgen hat, ist die Weltherrschaft Familienerbe geworden. Jeder liebt zunächst seine Eltern, jeder ist besorgt für seine Kinder. Die Güter und die Arbeit dienen dem eigenen Nutzen. Dass Herrscher ihre Macht auf Söhne vererben, ist nun die Sitte. ... Man gebraucht die Sitte und das Recht als Grundlage, um das Verhältnis von Fürst und Diener zu ordnen, ... um Regeln und Ordnungen zu schaffen, ... Das heißt die Zeit des Kleinen Wohlstands. “11

Der zentrale Begriff des Konfuzianismus ist die „Menschlichkeit“ (仁 rén), die sich durch zwischenmenschliche liebende Fürsorge auszeichnet. Die Lehre der „,humanen Politik“ ist das Gegengewicht zur Autorität, die oft zur Tyrannei führt. „Die humane Politik des Herrschers"12 wurde als ein notwendiger Weg zur Erreichung einer stabilen und harmonischen Gesellschaft bezeichnet. Aus Humanität erwächst die Ordnung des menschlichen Verhaltens, nämlich die „Sitte“ (礼 lǐ). Sie umfasst Begriffe wie Ethik, Moral, Sippensystem und Standesordnung. ${ }^{13}$ Die Gesellschaft wurde durch das morali-

8 Repräsentanten von Konfuzialnismus im Zeitalter Ost-Zhou: Kongzi (551 B. C. - 479 B. C.), Mengzi (372 B. C. -289 B. C.), Xunzi (313 B. C. - 238 B. C.).

9 孟子, 梁惠王上 (Mengzi, König Hui von Liang), übersetzt von Wilhelm, Richard, in: Die Lehrgespräche des Meisters Meng K'o, S. 46.

10 孔, 礼记, 礼运 (Kongzi, Die Entwicklung der Sitte), in: Li Gi, Das Buch der Sitte, S. 30ff.

11 孔, 礼记, 礼运 (Kongzi, Die Entwicklung der Sitte), in: Li Gi, Das Buch der Sitte,S. 30ff.

12 孟子, 离娄下 (Mengzi, Lilou), in: Die Lehrgespräche des Meisters Meng K'o, S. 123ff.

13 Siehe Mi, Jian, in: ZfRV, 1989, S. 24ff.; Chen, Jianfu, Chinese Law: Towards an Understanding of Chinese Law, Its Nature and Development, S. 8. 
sche Gesetz der „Sitte“ nach dem Prinzip der „Familien-Hierarchie“ geregelt. Der Kaiser steht als höchstes Symbol des Patriarchats an der Spitze.

Kongzi (551 v. Chr. - 479 v. Chr.) ist der Meinung, dass für eine menschliche Gesellschaft „Gleichheit“ sogar wichtiger als „Wohlstand“ ist:

„Es einen Herrscher nicht quält, dass die seinen gering an Zahl sind; ihn quält es, wenn nicht jeder hat, was ihm gebührt; ihn quält nicht Armut, was ihn quält, ist, wenn nicht Frieden unter ihnen herrscht." 14

Der Konfuzianismus legt großen Wert auf das Supremat des Staates und der Gesellschaft vor dem Individuum, den Vorrang der Pflicht und die Unterordnung der Rechte des Einzelnen. ${ }^{15}$ Um die Ausgewogenheit und die Balance in einer großen agrarischen Gesellschaft aufrechtzuerhalten, wurden die Autonomie der Regionen, die Entwicklung des Handelsverkehrs und die Akkumulation des privaten Eigentums während der Periode der Monarchie stark eingeschränkt.

In der chinesischen Kleinbauerngesellschaft war das Ackerland die Grundsicherung jeder Familie. Die Familienangehörigen hatten die Pflicht, Alte, Kinder, Kranke und Behinderte zu versorgen. Die Regierung errichtete Aufnahmelager für Bettler, Alte, Kranke und Behinderte, die keine Familie hatten. Auf dem chinesischen Festland führten Dürre und Hochwasser oft zu Hungersnöten und Unruhen. Naturkatastrophen stellten die größte Bedrohung für das Wohl der Bürger und die Stabilität der Gesellschaft dar. ${ }^{16}$ Seit der Han-Dynastie hatte die Regierung deshalb Getreidevorräte angelegt und bei Hungersnöten die Vorräte an die Bürger verteilt. Seit der Sui-Dynastie (581 - 618) spielte die gegenseitige Hilfe der Bewohner unter Führung der Regierung auch eine große Rolle in diesem System. Getreidelager wurden von der lokalen Gemeinschaft betrieben. ${ }^{17}$ Die Tradition von „Verantwortung des Staates“ im Bereich der sozialen Sicherheit wird sichtbar durch die chinesische Geschichte und hat noch heute bedeutenden Einfluss auf die chinesische Sozialpolitik. 18

\section{Die traditionellen Rechtsgedanken und das Rechtssystem}

Die traditionellen chinesischen Rechtsgedanken stehen im Gegensatz zur westlichen Idee der subjektiven Rechte des Individuums. Sie entsprechen genau den Anforderun-

14 论语, 第十六章 ( Konfuzius Gespräche der Meisters Kung XVI), S. 111.

15 Huntington, The Clash of Civilizations and the Remaking of World Order, S. 225.

16 Siehe: 郑功成, 自然灾害与社会安全 (Zheng, Gongcheng, Naturkatastrophen und die soziale Sicherheit), in: 郑杭生, 中国社会发展研究报告2004 (Zheng, Hangsheng (Hrsg.), Research Reports on China Social Development 2004), S. 29ff.

17 唐钧, 中国社会救助制度的变迁与评估 (Tang, Jun, Kommentar über das chinesische System der Sozialhilfe), in: 郑功成, 中国社会保障制度变迁与评估 (Zheng, Gongcheng (Hrsg.), Kommentar über die chinesischen Systeme der Sozialen Sicherheit), S. 204ff.

18 唐钧, 中国社会救助制度的变迁与评估 (Tang, Jun, Kommentar über das chinesische System der Sozialhilfe), in: 郑功成, 中国社会保障制度变迁与评估 (Zheng, Gongcheng (Hrsg.), Kommentar über die chinesischen Systeme der Sozialen Sicherheit), S. 204ff. 
gen der chinesischen Kultur, betonen das gemeinsame Existenzrecht und die Pflicht des Individuums gegenüber der Familie und dem Staat. „Sitte“ und „Humanität“ sind die wichtigsten Werte der zwischenmenschlichen Beziehung. Wichtigstes Ziel ist es, die Stabilität der Gesellschaft und die öffentliche Ordnung aufrechtzuerhalten.

Hai, Rui (1514 - 1587), ein hochgeschätzter Beamter der Ming-Dynastie, war der Ansicht, dass die Gesetze nicht nur buchstabengetreu, sondern auch nach dem Wesen der „Sitte und Humanität“ ausgelegt und durchgesetzt werden sollten. Seine Grundsätze sind:

„Mein Vorschlag geht dahin, dass es bei der Urteilsfindung besser ist, gegen den jüngeren als gegen den älteren Bruder zu entscheiden, eher gegen den Neffen als gegen den Onkel, eher gegen den Reichen als gegen den Armen, und eher gegen den hartnäckigen Gerissenen als den unbeholfen Ehrlichen. Betrifft der Fall einen Eigentumsstreit, so ist es besser, gegen das Mitglied der Gentry als gegen den kleinen Mann zu entscheiden, um damit der schwächeren Seite Beistand zu leisten. Hat der Fall aber mit Höflichkeit und Status zu tun, so ist es besser, gegen den kleinen Mann als gegen das Mitglied der Gentry zu entscheiden: Das Ziel ist die Aufrechterhaltung unserer Ordnung und unseres Systems. “19

Wie bereits oben erwähnt, sind „Sitte“, „Humanität“, der Vorrang der Pflicht des Einzelnen und das Prinzip der „Familien-Hierarchie“ die elementaren Merkmale der chinesischen Kultur und damit auch der traditionellen Rechtsgedanken. ${ }^{20}$ Davon bildet die „Humanität“ die zentrale Grundlage der Rechtskultur und des Rechtssystems. ${ }^{21}$ Auf das „Mensch-Sein“ wird großen Wert gelegt. Aber der „Mensch“ im chinesischen Sinne existiert nicht als ein „einzelnes Individuum“, sondern als Mitglied einer Familie und des Landes. Nach der Lehre des Konfuzianismus sollen der Staat und die Einzelnen zu einem einheitlichen Ganzen verschmelzen, entsprechend wurden die Gedanken, die die Rechte des Einzelnen vorrangig gewährleisten und die Staatsmacht vertikal teilen, nicht in die traditionelle chinesische Gesellschaft übernommen.

Die „Sitte“ übernahm in gewissem Maße die Funktion der Verfassung und der Gesetze. Sie war die Grundlage für Justizentscheidungen. Das Gesetz spielte dagegen nur eine untergeordnete Rolle. ${ }^{22}$ Das traditionelle chinesische System des geschriebenen Rechts ist ein Komplex verschiedener Gesetze. Es umfasst das Strafrecht, das Zivilrecht, das Verwaltungsrecht, das Prozessrecht usw. Das Strafrecht und das Verwaltungsrecht sind die wichtigsten Bestandteile dieses Rechtssystems. Es gibt aber keine klare Unterteilung in verschiedene Rechtsbereiche. Administrations- und Justizbefugnisse wurden auf den lokalen Ebenen einheitlich ausgeübt. Die lokale Regierung war

19 In: 海瑞集 (Hai, Rui, Das Gesamtwerk von Hai Rui), S.117, Übersetzung in: Huang, Ray, 1587, Ein Jahr wie jedes andere, der Niedergang der Ming, S. 222f.

20 陈顾远, 中国文化与中国法系 (Chen, Guyuan, Die chinesische Kultur und das chinesische Rechtssystem), S.38 ff.

21 张晋藩, 中国法律的传统与近代转型 (Zhang, Jinfan, The Tradition and Modern Transition of Chinese Law), S. 27ff.

22 张晋藩, 中国法律的传统与近代转型 (Zhang, Jinfan, The Tradition and Modern Transition of Chinese Law), S. 23ff. 
auch gleichzeitig das Justizorgan und das Regierungsoberhaupt hatte auch die gerichtliche Zuständigkeit, Rechtsstreitigkeiten zu verhandeln und zu entscheiden. ${ }^{23}$

\section{B. Beginn des Transformationsprozesses seit 1840}

\section{Veränderung der politischen Struktur}

Die chinesische Geschichte der Neuzeit (1840 - 1949) begann mit der Invasion der westlichen Mächte seit 1840. China war seitdem nicht mehr „,die Mitte unter dem Himmel“", sondern geriet zu einem halbkolonialen Land. Der Ansturm des Westens führte zur gesellschaftlichen Umwandlung in China. Anfangs brachen die traditionellen politischen Institutionen zusammen. 1911 ging die Monarchie unter und die traditionelle Kultur, die früher als Grundstein der Gesellschaft bezeichnet wurde, wurde zum ersten Mal von einer Bedeutungskrise getroffen. „Nations were constructed in some large part out of antagonism to others":24 im 19. und 20. Jahrhundert wurde China durch die westliche Invasion gezwungen, auf das Ideal der „großen Gemeinschaft unter dem Himmel“ zu verzichten und stattdessen eine ,chinesische Nation“ zu bilden. ${ }^{25}$ Durch diesen Begriffswechsel erlangte China die äußere Form eines Nationalstaats.

Seitdem ist die Wiederkehr eines mächtigen Chinas immer ein Motiv, das für die chinesischen Revolutionen erstrangige Bedeutung hat. China sieht sich auch immer mit der Frage konfrontiert, ob es sich völlig nach dem Westen orientieren soll. Einige Intellektuelle traten damals für eine vollständige Verwestlichung ein, andere förderten eine reformistische Strategie, nämlich die Methode „Ti-Yong (中体西用 zhōngtĩxīyòng)“: Chinesische Gedanken und Staatsstruktur sollen als grundlegender Rahmen fungieren, während moderne westliche Technik zu praktischen Zwecken eingesetzt werden soll. Im Konflikt zwischen den beiden Ausrichtungen bewegte sich China in der Tat auf einem reformistischen Weg: Es strebte einerseits eine Industrialisierung und Modernisierung an, anderseits versuchte es auch, die zentralen Werte und Institutionen der traditionellen Kultur zu bewahren.

Nach dem Zusammenbruch der Qing-Dynastie (1636 - 1911) geriet China in kürzester Zeit in einen Zustand der Spaltung und Anarchie. In den 20er Jahren des 20. Jahrhunderts wurde der Föderalismus als ein Lösungsweg für die Umstrukturierung der politischen Institutionen von den Eliten diskutiert und ausprobiert. ${ }^{26}$ Die Provinzen erklärten nacheinander ihre Unabhängigkeit und versuchten, eigene Verfassungen zu kon-

23 张晋藩, 中国法律的传统与近代转型 (Zhang, Jinfan, The Tradition and Modern Transition of Chinese Law), S. 209ff.

24 Giddens, The Third Way, S. 134.

25 Siehe: Levenson, Confucian China and its modern Fate (儒教中国及其现代命运), S. 80ff.

26 省宪运动 (Bewegung der Provinz-Verfassung), siehe: 何勤华李秀清, 外国法与中国法 - 二 十世纪中国移植外国法反思 (He, Qinhua/Li, Xiuqing, Der chinesische Rezeptionsprozess des ausländischen Rechts im 20. Jahrhundert), S. 142ff. 
stituieren. Diese Bewegung erreichte ihr Ziel aber nicht, weil eine föderalistische Staatsstruktur der chinesischen Tradition und dem damaligen Zustand nicht entsprach. Schließlich ist China schon seit über 2000 Jahren ein zentralistisches Land gewesen. Eine Regel ergibt sich aus der Jahrtausend langen Geschichte und wird von den chinesischen Bürgern völlig akzeptiert: Spaltung bedeutet Chaos, Krieg und Verfall. Nur die Vereinigung und eine mächtige Zentrale können ein friedliches und erfolgreiches China gewährleisten.

Die chinesischen Revolutionen erzielten zuerst auf der Ebene des staatlichen Systems Erfolg. Ein neues republikanisches Staatssystem wurde in der ersten Hälfe des 20. Jahrhunderts aufgebaut. Die Staatsmacht zerfiel aber weder vertikal in Bund und Länder, noch horizontal in Legislative, Exekutive und Judikative. Im Gegenteil, die Bedrohung des Landes führte zur Herausbildung einer stärkeren Zentralmacht.

\section{Beginn der Rechtsrezeption}

Der Transformationsprozess des chinesischen Rechtssystems nach westlichem Vorbild wurde durch externen Druck eingeleitet. Nach den Opiumkriegen erwarben die westlichen Staaten von der Qing-Regierung die „Konsulargerichtsbarkeit“.27 Sie erklärten aber ihre Bereitschaft, darauf verzichten zu können, sobald die chinesische Regierung das chinesische Rechtssystem ,verbessert“. Um die Souveränität des Staates zu verteidigen, begann die Qing-Regierung seit dem Anfang des 20. Jahrhunderts, das traditionelle Rechtssystem zu verändern.

Aus diesem Grund war der rechtliche Rezeptionsprozess Chinas zu Beginn von Instrumentalismus und Pragmatismus geprägt. Gesetze wurden direkt aus dem westeuropäischen oder japanischen Recht übersetzt und mit Hilfe der ausländischen Juristen formuliert. In den letzten zehn Jahren der Qing-Dynastie wurde ein System von ,sechs Gesetzen" aufgebaut, das das bürgerliche Recht, das Zivilprozessrecht, das Strafrecht, das Strafprozessrecht, das Verwaltungsrecht und das Gerichtsverfassungsrecht umfasst. Dieses Rechtssystem wurde später in der Periode der Republik (1912 - 1949) umgebaut und als „Vollständige Sammlung der sechs Gesetze“ bezeichnet. Das gemischte System von Administration und Justizorgan wurde ebenfalls nach dem westlichen Prinzip der Gewaltentrennung konzipiert.

Instrumentalismus in der rechtlichen Rezeption ist insbesondere bei der Konstituierung der Verfassung in Erscheinung getreten. ${ }^{28}$ Die Verfassungsänderungen wurden nach Maßstab der konkreten Bedürfnisse der Politiker vorgenommen. Die Qing-

27 Die Konsulargerichtsbarkeit der westlichen Staaten war im 19. Jahrhunderts in China verbereitet. Sie bezeichnete die vollständige Immunität der westlichen Staatsbürger vor der chinesischen Gerichtsbarkeit. Dieses Prinzip wurde nach dem zweiten Weltkrieg in China abgeschafft. Ausführlich vgl. 张晋藩, 中国法律的传统与近代转型 (Zhang, Jinfan, The Tradition and Modern Transition of Chinese Law), S. 300ff.

28 王人博, 宪政的中国语境 (Wang, Renbo, Chinese Understanding of Constitutionalism), in: 法学 研究 (Journal of Law), 2001/2, S. 133ff. 
Regierung versuchte, einen monarchischen Konstitutionalismus $\mathrm{zu}$ verankern, ${ }^{29}$ während die Revolutionäre für ein System der Kabinett-Verantwortlichkeit ${ }^{30}$ und die Militärmachthaber für ein Präsidialsystem ${ }^{31}$ in den Verfassungen plädierten.

Die chinesischen Intellektuellen haben bei den rechtlichen Rezeptionsprozessen eine sehr aktive Rolle gespielt. Sie sind davon überzeugt, dass die Macht der westlichen Staaten auf ihre Politik- und Rechtssysteme zurückzuführen sei. Ein nach dem westlichen Modell aufgebautes Rechtssystem könne China nicht nur aus Krisen retten, sondern auch wieder zu Reichtum und Macht verhelfen. ${ }^{32}$ Wonach sie strebten, war aber lediglich eine positive Auswirkung des Rechtssystems auf die Machtstellung des Staates. Die Logik der westlichen Rechtstheorien, soweit sie dem Ziel der Wiederkehr eines mächtigen Chinas nicht zu dienen schien, wurde verzerrt oder ignoriert. Deswegen hatte China zwar inzwischen ein Rechtssystem nach dem westlichen Vorbild aufgebaut, aber die westlichen Rechtsgedanken nicht wirklich übernommen. Zum Beispiel wurde der Begriff „Menschenrechte“ durch „Rechte der Volksmassen“ ersetzt, 33 und der „Staat“ wurde als „Gesamtheit der chinesischen Völker“ verstanden. Durch die Ersetzung der Begriffe lebten die traditionellen Gedanken über das Verhältnis zwischen Individuum und Staat weiter.

Das übernommene Rechtssystem erwies sich als inkompatibel mit den gesellschaftlichen Bedingungen. Es fehlte bei dem neuen Rechtssystem an einer traditionellen, kulturellen und wirtschaftlichen Übereinstimmung. In der Neuzeit war Agrarkultur wie früher immer noch der überwiegende Faktor der chinesischen Volkswirtschaft, allein die Verwestlichung des Rechtsystems und der Staatsorganisation konnte eine Modernisierung der Gesellschaft nicht herbeiführen.

\section{Entwicklung seit Gründung der Volksrepublik im Jahre 1949}

Die Gründung der Volksrepublik im Jahre 1949 bildet das Ende der chinesischen Neuzeit. Sie bezeichnet die Befreiung eines halbkolonialen Landes zu einem unabhängigen Staat. Infolgedessen versucht die Volksrepublik weiter, sich zu einem mächtigen, modernen Staat zu entwickeln. Die Umgestaltung der ökonomischen Basis hat seitdem erst angefangen.

Die chinesische Modernisierung ist ein großes Experiment. „Sozialismus“ und „Nationalstaat" sind die Formen, die nach vielfältigen Versuchen als geeignete Mittel zur

29 1908, 钦定宪法大纲 (Die kaiserlich genehmigten Richtlinien der Verfassung).

30 1912, 中华民国临时约法 (Die Provisorische Verfassung der Republik China).

31 1914，中华民国约法 (Die Verfassung der Republik China).

32 Vgl. 王人博, 宪政的中国语境 (Wang, Renbo, Chinese Understanding of Constitutionalism), in: 法学研究 (Journal of Law), 2001/2, S. 141ff.

33 郑贤君, 20世纪中国宪政思想体系及演进特征 (Zheng, Xianjün, Der chinesische Konstitutionalismus im 20. Jahrhundert), in: 法商研究 (Journal of Law and Commerce), 2001/3, S.124ff. 
chinesischen Modernisierung bezeichnet werden. ${ }^{34}$ Damit wird das historische Erbe des Zentralismus bewahrt. In diesem großen Experiment sind viele aus dem Westen eingeführte oder aus den chinesischen Erfahrungen stammende Doktrinen und Konzepte nur Instrumente, die für die Lösung der chinesischen Fragen verwertet werden, aber zuletzt korrigiert oder verworfen wurden und werden. Die Begriffe „Sozialismus“, „Demokratie“ sowie „Konstitutionalismus“ werden jetzt mit „chinesischer Prägung“ erklärt, die Planwirtschaft wird zurzeit in gewissem Maße mit der Marktwirtschaft ersetzt.

\section{Wirtschaftliche und gesellschaftliche Modernisierung}

\section{Industrialisierung und Hukou-Registrierung}

Bei der Schlüsselfrage der chinesischen Modernisierung geht es darum, dass das auf Kleinbauernwirtschaft basierende Wirtschaftssystem in ein Industrie- und Handelssystem umgestaltet werden muss. ${ }^{35}$ Seit der Gründung der Volksrepublik wurde dieser Umgestaltungsprozess vom Staat im Rahmen der Planwirtschaft tatkräftig angetrieben.

Nach einer Reihe von Aggressions-, Welt- und Bürgerkriegen war die Situation in China schlecht. Die Wirtschaftsblockade der westlichen Staaten nötigte die chinesische Regierung, ein Wirtschaftssystem aus eigener Kraft aufzubauen. Um die Strategie der sozialistischen Industrialisierung durchführen zu können, wendeten die Kommunistische Partei (KP) Chinas und die Regierung nach der Verstaatlichung der Privatindustrie und der Kollektivierung der Landwirtschaft die Methode der sogenannten „Preisschere“ an. Sie bedeutet nämlich eine unterschiedliche Preisentwicklung zwischen Industrie und Landwirtschaft, damit die Schwerindustrie vorrangig entwickelt werden kann. In dem planwirtschaftlichen System von zentralisiertem Aufkauf und Absatz konnten die städtischen Bewohner mehr Getreide- und Warenzulagen als die ländlichen Bewohner vom Staat erhalten. Dieses künstliche Ungleichgewicht des dualistischen Wirtschaftssystems bedurfte aber eines Mechanismus, der die freie Zirkulation von Arbeitskräften und Produktionsfaktoren zwischen Stadt und Land verhindern konnte. Das strikte HukouRegistrierungssystem war folglich unvermeidlich.

Das Einwohnerregistrierungssystem wurde zuerst im Jahr 1951 in den Städten aufgebaut und danach auf dem Land erweitert. In der frühen Phase wurde es nicht als strikter Kontrollmechanismus, sondern nur für die Überprüfung der Migration konstruiert. ${ }^{36}$ Die Bevölkerung konnte in den 50er Jahren des 20. Jahrhunderts frei in die Städte abwandern. Die Freizügigkeit der Bürger wurde als Grundrecht in die Verfassung von

34 邓小平文选第三卷 (Deng, Xiaoping, Ausgewählte Werke von Deng Xiaoping, Dritter Band), S. $207 \mathrm{ff}$.

35 黄仁宇, 资本主义与二十一世纪 (Huang, Ray, Kapitalismus und das 21. Jahrhundert), S. 475.

36 Siehe: 陈金永, 中国户籍制度改革和城乡人口迁移 (Chen, Jinyong, The Hukou-System and Rural-Urban Migration in China), in: 中国劳动经济学 (China Labor Economics), 2004/1, S. 108ff. 
1954 geschrieben. ${ }^{37}$ Aber parallel zur Vertiefung der Industrialisierung wurden die Städte mit der vermehrten Zunahme der ländlichen Bevölkerung belastet. ${ }^{38}$ Im Jahre 1958 wurden die „Regeln über die Hukou-Registrierung“39 eingeführt. Die Regierung wurde ermächtigt, ein Hukou-Registrierungssystem aufzubauen, damit sie die Wanderung der Bevölkerung und die Staatsverwaltung umfassend kontrollieren konnte.

Mit dem strikten Registrierungssystem wurde die Bevölkerung in zwei Gruppen eingeteilt, nämlich die Bevölkerung mit Land-Hukou und die Bevölkerung mit StadtHukou. Ohne Sondergenehmigung durften die Landbewohner nicht in die Städte abwandern. Der Urbanisierungsprozess wurde dadurch verlangsamt. Vom Ende der 1950er Jahre bis 1978 blieb der Anteil der ländlichen Bevölkerung an der Gesamtbevölkerung stets bei ca. $83 \% .40$ Die sozialen Sicherungssysteme für die zwei Gruppen waren auch unterschiedlich. Während die Städter die Arbeiterversicherung und Beamtenversorgung genossen, erlangten auf dem Land zwei kollektive Systeme Bedeutung: das Fünf-Garantien-System und das kooperative medizinische System.

Durch Ausbeutung der Landwirtschaft wurde das Ziel der chinesischen Industrialisierung erreicht. In einem Vierteljahrhundert verwandelte sich China von einem völligen Agrarland in einen relativ industrialisierten Staat. Ein unabhängiges, relativ vollständiges Industriesystem hatte sich herausgebildet. 1952 machte die Bruttoproduktion der Industrie 30\% des BSP aus, 1975 war sie schon auf 72\% angestiegen. Mitte der 70er Jahre war China der sechstgrößte Industriestaat der Welt. ${ }^{41}$ In den Bereichen Ausbildung, Gesundheit und soziale Sicherheit hatte China ebenfalls große Fortschritte erzielt.

Durch diese Industrialisierungsstrategie wurde eine Grundlage für die wirtschaftliche Entwicklung geschafft. Sie erreichte aber nach 20 Jahren ihre Grenze. China brauchte neue Theorien und Strategien, um seine Modernisierung fortzusetzen. In der Kulturrevolution (1966 - 1976) versuchte Mao, Zedong, durch Verneinung der traditionellen Kultur und eine radikale Massenbewegung gegen das bürokratische Politiksystem ein neues demokratisches Staatswesen herauszubilden. Aber nach zehn Jahren der Unruhen musste China die Richtung ändern, es ging auf die „Negation der Negation“ zu, die traditionelle Kultur kehrte in der Verbindung mit der Marktwirtschaft zurück. 42

Seit Ende der 1970er Jahre befindet sich China in der Phase der „Reform und Öffnung". Die Wohn- und Arbeitsmärkte sind liberaler geworden. Die staatlichen Zulagen für die städtische Bevölkerung wurden aufgehoben. Die strikte Einwohnerregistrierung hat sich den wirtschaftlichen und gesellschaftlichen Entwicklungen entsprechend ver-

37 Art. 90 II der Verfassung von 1954.

38 罗瑞卿, 关于中华人民共和国户口登记条例草案的说明 (Luo, Ruiqing, Erklärung über den Entwurf der „Regeln über die Hukou-Registrierung“), in: 人民日报 (RMRB), 10. 01. 1958.

39 中华人民共和国户口登记条例 (Regeln über Hukou-Registrierung), vom 09. 01. 1958.

40 中国统计年鉴 1996 (China Statistical Yearbook 1996), http://www.stats.gov.cn/tjsj/ndsj/ (Stand: 15. 07. 2010).

41 Meisner, The Deng Xiaoping Era, S. 188ff.

42 关海庭, 文化大革命与当代中国改革模式的选择 (Guan, Haiting, The Cultural Revolution and the Selection of Contemporary China's Reform Model), in: 当代中国史研究 (Contemporary China History Studies), 2007/7, S. 58ff. 
ändert. Das Registrierungssystem wurde allmählich nach seiner ursprünglichen Funktion als eine Anmeldungs- und Überprüfungsinstitution wiederhergestellt. Die dualistische Hukou-Registrierung wurde nun in manchen Provinzen durch eine einheitliche Bewohner-Registrierung ersetzt. Die „Verfügung eines legalen ständigen Wohnsitzes“ ist dort die Hauptvoraussetzung für die Aufenthaltgenehmigung. Der Anteil der ländlichen Bevölkerung ist von über 80\% der gesamten Bevölkerung (1980) auf 56\% (2006) deutlich gesunken. ${ }^{43}$

Die Auswirkung der chinesischen planwirtschaftlichen Industrialisierung - die dualistische Struktur der Gesellschaft - bleibt dennoch bestehen. Die sozialen Sicherungssysteme für städtische und ländliche Bewohner sind zurzeit noch sehr unterschiedlich. Die „,neuen Stadtbewohner“, die aber noch über ein Land-Hukou verfügen, werden bei Ausbildung, Beschäftigung, Sozialversicherung noch unterschiedlich behandelt, weil die Regierungen der Städte befürchten, das rasante Bevölkerungswachstum nicht bewältigen zu können. In den größten Städten wie Beijing und Shanghai ist die Einschränkung der Niederlassung sogar heute strenger als früher. ${ }^{44}$ Andererseits möchten viele Wanderarbeiter, die schon einen ständigen Wohnsitz in den Städten haben, ihren LandHukou nicht gegen einen Stadt-Hukou eintauschen, weil sie als ländliche Bewohner eigenes Land besitzen. Außerdem dürfen sie mehrere Kinder haben, da die Familienpolitik auf dem Land flexibler als in der Stadt ist. 45

Im Jahre 2008 wurde in dem 3. Plenum des 17. Zentralkomitees der KP Chinas betont, die wirtschaftliche und gesellschaftliche Integration von Städten und Land zu fördern, damit die dualistische Struktur der Gesellschaft beseitigt wird. ${ }^{46}$ Die städtischen und ländlichen Sicherungssysteme miteinander in Einklang zu bringen, wird zurzeit als eine wichtige Aufgabe der chinesischen Regierung bezeichnet.

\section{Modernisierungsprozess seit 1978}

\section{a) Modernisierungsziele}

Nach der Kulturrevolution begann die Ära der „Reform und Öffnung“. Im 3. Plenum des 11. Zentralkomitees der KP Chinas vom 18. 12. 1978 wurde festgelegt, dass der Schwerpunkt der staatlichen Aufgaben sich vom Klassenkampf zur Modernisierung ändern müsse. Danach hat die Partei ein Ziel aufgestellt, die sozialistische Modernisierung in drei Schritten zu verwirklichen. ${ }^{47}$ Der erste Schritt war die Verdoppelung des

43 中国统计年鉴1996 (China Statistical Yearbook 1996), http://www.stats.gov.cn/tjsj/ndsj/ (Stand: 15. 07. 2010).

44 UNDP, China Human Development Report 2005, S.103.

45 景天鬼唐均/张时飞, 城乡统筹就业 — 浙江省义乌市的实践 (Jing, Tiankui/Tang, Jun/Zhang, Shifei, Eine einheitliche Beschäftigungspolitik für Stadt und Land - die Praxis aus Yiwu in der Provinz Zhejiang), in: 浙江经济 (Zhejiang Economy), 2002/19, S. 15.

46 中国共产党第十七届中央委员会第三次全体会议公报 (Bulletin des 3. Plenums des 17. Zentralkomitees der KP Chinas), vom 12. 10. 2008, in: 人民日报 (RMRB), 13. 10. 2008.

47 赵紫阴, 在中国共产党第十三次全国代表大会上的报告 (Zhao, Ziyang, Bericht auf dem 13. Parteitag der KP Chinas), vom 12. 10. 1987, in: 光明日报 (GMRB), 04. 11. 1987. 
Pro-Kopf-Bruttosozialprodukts (BSP) von 1980, wodurch die Nahrungs- und Kleidungsfrage gelöst werden sollte. Als zweiter Schritt sollte sich das Pro-Kopf-BSP bis Ende des 20. Jahrhunderts nochmals verdoppeln und auf 1000 US-Dollar steigen. Das Lebensniveau erreicht damit den sogenannten „Kleinen Wohlstand“48. Die moderne Definition des „Kleinen Wohlstands“ umfasst nicht nur das Lebensniveau sondern auch die allseitigen wirtschaftlichen, politischen und gesellschaftlichen Entwicklungen. Dafür wurde ein System der Planziffern über den ,allseitigen Kleinen Wohlstand“ aufgebaut. 49 Der dritte Schritt ist bis Mitte des 21. Jahrhunderts das Pro-Kopf-BSP auf 4000 US-Dollar zu steigern, um das Niveau eines mittelmäßig entwickelten Staats zu erreichen. Die chinesische Modernisierung würde bis dahin weitgehend abgeschlossen sein.

\section{Tabelle 1: Modernisierungsprozess im „Anfangsstadium des Sozialismus“}

\begin{tabular}{|l|l|}
\hline 1956 & $\begin{array}{l}\text { Vollendung der Verstaatlichung der Privatindustrie und der } \\
\text { Kollektivierung der Landwirtschaft }\end{array}$ \\
\hline 1978 & Beginn der Phase „Reform und Öffnung“ \\
\hline bis Ende der 1980er Jahre & $\begin{array}{l}\text { „Ausreichende Versorgung mit Kleidung und Nahrung“ (Ver- } \\
\text { doppelung des Pro-Kopf-BSP von 1980) }\end{array}$ \\
\hline $\begin{array}{l}\text { bis Ende des 20. Jahrhun- } \\
\text { derts }\end{array}$ & $\begin{array}{l}\text { „Kleiner Wohlstand“ } \\
\text { (Pro-Kopf-BSP 1000 US-Dollar) }\end{array}$ \\
\hline $\begin{array}{l}\text { bis Mitte des 21. Jahrhun- } \\
\text { derts }\end{array}$ & $\begin{array}{l}\text { Vollendung der chinesischen Modernisierung } \\
\text { (Pro-Kopf-BSP 4000 US-Dollar) }\end{array}$ \\
\hline
\end{tabular}

\section{b) Wirtschaftsreform}

Ausgangspunkt der Wirtschaftsreform ist die Veröffentlichung des Zeitungsartikels „Die Praxis ist das einzige Kriterium der Wahrheit" ${ }^{50}$ und das 3. Plenum des 11. Zentralkomitees der KP Chinas von 1978. Dadurch wurde eine grundsätzliche Übereinstimmung bezogen auf die Einführung der liberalen Wirtschaft erreicht. Die sozialistische Planwirtschaft wurde seitdem allmählich zu einer sogenannten sozialistischen Marktwirtschaft umgestaltet.

Die Wirtschaftsreform wurde zuerst in der Landwirtschaft, dann allmählich im Industriesystem durchgeführt. Auf dem Land wurden die Volkskommunen aufgelöst und das Haushaltsverantwortungssystem ${ }^{51}$ eingeführt. Bei diesem System handelt es sich

48 Siehe: Erster Teil, die traditionelle Sozialstruktur und Kultur.

49 国家发改委小康项目课题组, 全面建设小康社会指标体系 (Forschungsgruppe des Staatskommission für Entwicklung und Reform, Das System der Planziffern über den allseitigen Kleinen Wohlstand), in: 经济日报 (Economic Daily), 14. 10. 2009.

50 胡福明, 实践是检验真理的唯一标准 (Hu, Fuming, Die Praxis ist das einzige Kriterium der Wahrheit ), in: 光明日报 (GMRB), 11.05. 1978.

51 Art. 8 Abs. 1 der Verfassung von 1982:

„Die ländlichen kollektiven Wirtschaftsorganisationen führen ein duales Bewirtschaftungssystem durch, das die Bewirtschaftung durch vertragliche Übernahme auf Haushaltsbasis als seine 
um ein Pachtsystem, bei dem Agrarland an die Bauerfamilien zur eigenverantwortlichen Bewirtschaftung verpachtet wurde. Die landwirtschaftliche Reform verbesserte die Lebensbedingungen der Bauern, führte aber auch dazu, dass das vom Kollektiv unterstützte Fünf-Garantien-System und das kooperative medizinische System zusammenbrachen. Die in der Landwirtschaft nicht mehr benötigten Arbeitskräfte wanderten in die Städte, um Arbeit zu finden.

In den Städten begann im Jahre 1984 mit dem „Beschluss des Zentralkomitees der KP Chinas über die Wirtschaftsreform"52 die Reform der staatlichen Unternehmen. Die staatlichen Unternehmen erhielten zunächst die Autonomie, selbständig zu produzieren und zu verkaufen. ${ }^{53}$ Individualwirtschaft und ausländische Investitionen wurden auch zugelassen. Im Jahre 1988 wurde der Schutz der Individualwirtschaft in die Verfassung aufgenommen. ${ }^{54}$ In der Revision von 1999 wurden die Individualwirtschaft, die Privatwirtschaft und andere Wirtschaftsformen, die nicht vom Staats- bzw. Kollektiveigentum umfasst sind, als wichtige Teile der sozialistischen Marktwirtschaft benannt. 55 1992 wurde die Errichtung einer sozialistischen Marktwirtschaft im 14. Zentralkomitee der KP Chinas festgelegt und danach in die Verfassung eingeführt. Bei der sogenannten sozialistischen Marktwirtschaft handelt es sich um eine auf öffentlichem Eigentum, das als Hauptform der Volkswirtschaft benannt wird, und auf makroökonomischer Steuerung des Staates basierende Marktwirtschaft. 56 Ein neues System der Einkommensverteilung wurde nach dem Prinzip „Priorität der Effizienz unter gleichzeitiger Berücksichtigung von Gerechtigkeit“57 aufgebaut.

Kurz gesagt ist die Wirtschaftreform von 1978 bis 1994 ein Prozess der wirtschaftlichen Dezentralisierung, Liberalisierung und Privatisierung. Der Staat hatte nach 30 Jahren Zentralverwaltungswirtschaft seine wirtschaftliche Befugnisse teils den lokalen Regierungen übertragen und das wirtschaftliche Interesse an die Unternehmen und die Bürger abgegeben. Die lokalen Regierungen und staatlichen Unternehmen erlangten vermehrt wirtschaftliche Autonomien, die Beschränkung auf Nicht-Volks- bzw. Privateigentum wurde gelockert. Dadurch wurde die Initiative der lokalen Regierungen für Wirtschaftsentwicklung entfacht und das Wirtschaftspotential aktiviert. Die wirtschaft-

Grundlage mit Vergütung je nach Produktionsertrag verbindet. Produktion, Versorgung und Absatz, Kredit und Konsum und andere Formen der genossenschaftlichen Wirtschaft auf dem Land sind die sozialistische Wirtschaft des Kollektiveigentums der werktätigen Massen. Die Werktätigen, die Mitglieder der Organisationen der ländlichen Kollektivwirtschaft sind, haben das Recht, im Rahmen der gesetzlichen Bestimmungen Parzellen zur privaten Nutzung auf Acker- und Bergland zu bewirtschaften, häusliche Nebenerwerbstätigkeiten zu betreiben und privaten Viehbestand zu besitzen.“ Revision von 1993, 6. Verfassungszusatz.

52 中共中央关于经济体制改革的决定, vom 20. 10. 1984, in: 人民日报 (RMRB), 21. 20. 1984.

53 Art. 16 der Verfassung von 1982, Revision von 1993, 8. Verfassungszusatz.

54 Art. 11 der Verfassung von 1982, Revision von 1988, 1. Verfassungszusatz.

55 Art. 11 der Verfassung von 1982, Revision von 1999, 16. Verfassungszusatz.

56 中共中央关于建立社会主义市场经济体制若干问题的决定 (Beschluss des Zentralkomitees der KP China über einige Fragen zur Errichtung einer sozialistischen Marktwirtschaft), vom 14. 11. 1993, in: 人民日报 (RMRB), 17. 11. 1993.

57 Nr. 2 des Beschlusses des Zentralkomitees der KP Chinas über einige Fragen zur Errichtung einer sozialistischen Marktwirtschaft von 1993. 
lichen Entwicklungen erforderten Verfassungsänderungen, die die unternehmerischen Interessen nach Wirtschaftsautonomie und Eigentumsgarantie schützen.

Die Reformen hatten einen Wirtschaftsaufschwung bewirkt, führten aber auch zu wirtschaftlichem Lokalpatriotismus und Finanzschwäche der Zentralregierung. Seit 1994 starteten die Finanzreform und die landesweite Integration des Binnenmarkts. Die Finanzreform umfasst eine Steuerreform, nämlich den Aufbau eines neuen Systems der Steuereinnahmenaufteilung, und die Verstärkung der makroökonomischen Steuerung der Zentralregierung. Auf der Basis der Marktwirtschaft bildete sich die Tendenz einer wirtschaftlichen Re-Zentralisierung heraus.

\section{c) Beitritt zur WTO: Verknüpfung mit der Globalwirtschaft}

Die wirtschaftliche Globalisierung wird von China als eine große Chance für die Erfüllung der staatlichen Entwicklungsziele angesehen. In diesem Zusammenhang wurde der Beitritt zur WTO einerseits als ein wichtiger Beitrag zur Strategie des „friedlichen Aufstiegs" eines großen Staats betrachtet, andererseits zur Beschleunigung der inländischen Wirtschaftsreform gefördert. ${ }^{58}$ Der Beitritt im Jahre 2001 kennzeichnet innerhalb der chinesischen Geschichte die erste Initiative zu einer Verknüpfung mit dem Weltwirtschaftssystem. Durch eine vertiefte wirtschaftliche Öffnung nach Außen versucht China wirtschaftliche Spannungen mit den internationalen Handelspartnern zu vermeiden, die Vervollständigung des sozialistischen Marktwirtschaftssystems und die Verschmelzung mit der Weltwirtschaft zu beschleunigen.

Nach dem Beitritt sind für China die Regeln der WTO verpflichtend. Alle wirtschaftlichen Gesetze und Verordnungen, die den Regeln der WTO nicht entsprechen, müssen abgeändert werden. Im Prozess des Beitritts wurde eine Vielzahl an Handelsregeln verbessert, ${ }^{59}$ viele Verwaltungsverordnungen wurden dafür aufgehoben. Seit dem Beitritt wird die Reform des Rechtssystems in großem Umfang betrieben. Mehrere Gesetze und Verordnungen, die dem internationalen Handelsstandard entsprechen, wurden verabschiedet und durchgesetzt. Im Jahre 2001 wurde eine Reihe von Maßnahmen für die Reform des Registrierungssystems erlassen, um sich an die WTO-Klausel über die Freizügigkeit anzupassen. 60

Beim Beitritt erhielt China die Zustimmung von den USA und anderen Mitgliedsländern zur Einführung von MFN-Zöllen und das Versprechen der Abschaffung von Quotenbeschränkungen für Textilien und Bekleidung. Der Preis, den China seinerseits hierfür zahlt, ist aber sehr hoch: die massive Korrektur des Wirtschaftsrechts, die Abschaffung der nichttarifären Handelshemmnisse, die Zollverminderung und die Öffnung des Dienstleistungssektors. Diese Veränderungen haben einen sehr tiefen und umfangrei-

58 Bhattasali/Li/Martin, Impacts and Policy Implications of WTO Accession for China, in: ders. (Hrsg.), China and the WTO: Accession, Policy Reform, and Poverty Reduction Strategies, S. 1.

59 Weltbank, China and the WTO, S. 1.

60 景天鬼斗唐均张时飞, 城乡统筹就业 — 浙江省义乌市的实践 (Jing, Tiankui/Tang, Jun/Zhang, Shifei, Eine einheitliche Beschäftigungspolitik für Stadt und Land - die Praxis aus Yiwu in der Provinz Zhejiang), in: 浙江经济 (Zhejiang Economy), 2002/19, S. 15. 
chen Einfluss auf die Produktionsindustrie, den Dienstleistungssektor und die Landwirtschaft ausgeübt.

Insbesondere ist die Auswirkung des Beitritts auf die Landwirtschaft und die staatlichen Unternehmen dramatisch. Im Agrarsektor sind die Beschränkungen für China strenger als für andere Entwicklungsländer. Die Verpflichtung zur Verringerung von landwirtschaftlichem Einfuhrschutz und Abschaffung von Subventionen für die Landwirtschaft führt zur Verschlechterung der Einkommenssituation von Bauern. ${ }^{61}$ Demzufolge nimmt die Zahl der abwandernden ländlichen Arbeitskräfte zu. Durch die Strukturänderung der Staatsunternehmen, die durch den Beitritt zur WTO beschleunigt und verstärkt wurden, hat sich die Beschäftigungslage in den Städten weiter verschlechtert. ${ }^{62}$ China sieht sich demzufolge mit einer umfassenden Regulierung des Arbeitsmarktes konfrontiert. 63

Die wirtschaftliche Globalisierung hat der WTO eine mögliche Chance gegeben, im Bereich der Sozialpolitik eine Rolle zu spielen. Obwohl die Idee, ein Weltsozialrecht durch die Verknüpfung von „Trade \& Labour“ auszugestalten, bisher immer noch von den Gegnern als Protektionismus im Welthandel angesehen und als Utopie bezeichnet wird, ${ }^{64}$ hat der Versuch des Aufbaus eines solchen Mechanismus schon Wirkung im rechtlichen Bereich in China gezeigt. Manche chinesische Experten sind der Meinung, dass eine allgemeine Tendenz für die Einführung von Sozialklauseln in die WTO besteht. ${ }^{65}$ China sollte die gesetzgeberische Vorbereitung, wie z. B. die Verknüpfung des chinesischen Rechts mit den internationalen Arbeitsstandards, berïcksichtigen. 66

61 温铁军, 我们到底要什么 (Wen, Tiejun, Was wollen wir eigentlich?), S. 150ff; Anderson/Huang/ Ianchovichina, in: Bhattasali/Li/Martin (Hrsg.), China and the WTO, Accession, Policy Reform, and Poverty Reduction Strategies, S. 101ff.

62 莫荣, 当前中国就业形势与加入WTO后的政策建议 (Mo, Rong, Vorschläge zur Beschäftigungspolitik nach dem Eintritt in die WTO), in: 郑功成/郑宇硕, 全球化下的劳工与社会保障 (Zheng, Gongcheng/Zheng, Yüshuo, Arbeiter und soziale Sicherheit in Zeiten der Globalisierung), S. $266 \mathrm{ff}$.

63 莫荣，中国就业报告2001-2002 (Mo, Rong (Hrsg.), China Employment Report 2001-2002), S. 6.

64 Maydell, in: Becker/Maydell/Nußberger (Hrsg.), Die Implementierung internationaler Sozialstandards: Zur Durchsetzung und Herausbildung von Standards auf überstaatlicher Ebene, S. 11.

65 许国庆/邵宏华夏申, 论贸易竞争与劳工标准 (Xu/Shao/Xia, Handelswettbewerb und Sozialklauseln), in: 国际贸易 (Intertrade), 1996/9, S. 32; 余云霞, 国际劳工标准: 演变与争议 (She, Yun$x i a$, International Labor Standards: Evolution and Controversy), S. 16ff; 刘波, 国际贸易与国际劳 工标准问题的历史演进及理论评析 ( Liu, Bo, Historical Evolution and Theoretical Analysis of International Trade and Labor Standards), in: 现代法学 (Modern Law Science), 2006/5, S. 128.

66 何平, 加入WTO对中国社会保障的影响与对策 (He, Ping, Einfluss des WTO-Beitritts auf die chinesische Sozialsicherung), in: 宏观经济研究 (Macroeconomics), 2002/3, S. 20; 刘波, 国际贸 易与国际劳工标准问题的历史演进及理论评析 (Liu, Bo, Historical Evolution and Theoretical Analysis of International Trade and Labor Standards), in: 现代法学 (Modern Law Science), 2006/5, S. 128. 


\section{a) Wiederbelebung der Rechtsrezeption}

Die Modernisierung des chinesischen Rechtssystems verläuft bis heute noch wie in der chinesischen Neuzeit entlang eines Rechtsrezeptionsprozesses. In der Anfangsphase der Volksrepublik wurde aber die Richtung geändert. Die Gesetze der Republik China (1912-1949) wurden ganz abgeschafft. 67 China hat sich seitdem vom westlichen Vorbild getrennt und sich dem sowjetischen Rechtssystem zugewendet. Seit 1953 begann eine Periode intensiver Gesetzgebung. Das sowjetische Rechtssystem und die sowjetische Rechtstheorien, insbesondere die Theorie des „Klassenkampfs“, wurden von der Volksrepublik China rezipiert. 68

Die Rechtsrezeption der Volksrepublik China war anfänglich ganz wie früher vom Pragmatismus geprägt. Die Verfassung und das Rechtssystem wurden für den Aufbau eines modernen Staates als die notwendigen Institutionen angesehen, waren allerdings noch keine Kernelemente des Staatslebens. Die politischen Richtlinien der KP Chinas spielten lange Zeit eine entscheidende Rolle. ${ }^{69}$ In der radikalen Kulturrevolution wurden die juristischen Organe abgeschafft, der Nationale Volkskongress wurde in zehn Jahren (1965-1975) nicht einberufen, die Gesetzgebungsarbeit hörte ganz auf. Die Leitlinien, Beschlüsse der KP Chinas und des Staatsrats traten an die Stelle des Rechts. ${ }^{70}$

Die Erfahrungen aus der Kulturrevolution führten in der KP Chinas zu der Erkenntnis, dass der Aufbau der Rechtsordnung und die Institutionalisierung der Demokratie für die Stabilität und die Entwicklung eines modernen Staates sehr wichtig sind. „Um die Überlegenheit im Vergleich zum Kapitalismus zu erkämpfen, muss China von den nützlichen Ergebnissen der Zivilisationen der ganzen Menschheit profitieren“. ${ }^{71}$ Mit diesem Leitgedanken von Deng-Xiaoping begann die umfangreiche Rechtsrezeption seit Ende der 1970er Jahre wieder in China.

Die Wirtschaftsreform beschleunigt die Rechtsrezeption. Der Beitritt Chinas zur WTO treibt den Gesetzgeber zur Eile. Das chinesische Rechtssystem muss sich jetzt den internationalen Handelsregelungen anpassen. Die Implementation der WTORegelungen erfordert die Einführung einer großen Menge an Rechtsnormen in den Be-

67 中共中央关于废除国民党六法全书与确定解放区司法原则的指示 (Anweisung der KP Chinas über die Abschaffung der Vollständigen Sammlung der Sechs Gesetze der Volkspartei und die Festlegung der Grundsätze der Justiz in den befreiten Gebieten), in: 中共中央文件选集第十八册 (Ausgewählte Dokumenten des Zentralkomitees der KP Chinas, Vol. 18), S. 150ff.

68 何勤华李秀清, 外国法与中国法 一 二十世纪中国移植外国法反思 (He, Qinhua/Li, Xiuqing, Der chinesische Rezeptionsprozess des ausländischen Rechts im 20. Jahrhundert), S. 173ff.

69 蔡定剑刘丹，从政策社会到法治社会 — 兼论政策对法制建设的消极影响 (Cai, Dingjian/Liu, Dan, From the Society in Policy to the Society in Rule of Law), in: 黄之英, 中国法治之路 (Huang, Zhiying (Hrsg.), The Road to The China's Rule of Law), S. 83ff.

70 蔡定剑, 中国人民代表大会制度 (Cai, Dingjian, The Institution of the Chinese People's Congress), S. 64ff.

71 邓小平文选第三卷 (Deng, Xiaoping, Ausgewählte Werke von Deng Xiaoping, Dritter Band), S. 373. 
reichen des Handelsrechts, des Wettbewerbsrechts und des Verwaltungsrechts. Die Verbesserung des Rechtssystems und die Aufstellung neuer Gesetze sowie Verordnungen werden in großem Umfang zur Entfaltung gebracht.

In der 160-jährigen Geschichte der Rechtsrezeptionen ist dies die tiefgreifendste Veränderung des chinesischen Rechtssystems. Viele westliche Rechtsbegriffe wie z. B. Rechtsstaatlichkeit werden bereits im chinesischen Recht benutzt. China geht erst allmählich den Weg, „Herrschaft durch den Menschen“ durch „Herrschaft durch Recht“ zu ersetzen. In Art. 5 Abs. 4 der Verfassung von 1982 heißt es: "Keine Organisation oder kein Individuum darf das Privileg genießen, die Verfassung und die Gesetze zu überschreiten."

\section{b) Sozialistischer Rechtsstaat chinesischer Prägung}

Bis heute hat sich das hauptsächlich mittels Rechtsrezeption aufgebaute Rechtssystem der gesellschaftlichen, wirtschaftlichen und politischen Lage nicht völlig angepasst. ${ }^{72}$ Die traditionelle Mischung von Verwaltung und Justiz sowie die informelle Streitbeilegung haben immer noch bedeutende Einflüsse. Manche westliche Beobachter sind der Meinung, dass wenn gesetzliche Regelungen zwar vorhanden seien, diese aber nicht real wirksam seien, stelle dies die Existenz eines allgemein und unbedingt geltenden Rechtssystems grundsätzlich in Frage. ${ }^{73}$ Es ist aber nicht zu übersehen, dass das chinesische Rechtssystem seit Ende der 1970er Jahre in großem Maße einem Wandel unterworfen ist.

Im „Beschluss des Zentralkomitees der KP Chinas über einige Fragen zur Errichtung einer sozialistischen Marktwirtschaft" von 1993 wurde festgelegt, dass ein der sozialistischen Marktwirtschaft angepasstes Rechtssystem gegen Ende des 20. Jahrhunderts aufgebaut wird. Schwerpunkt der Gesetzgebung in dieser Phase ist die Ausarbeitung des Wirtschaftsrechts. Im Jahre 1997 ist von der KP Chinas festgelegt worden, das sozialistische Rechtssystem weiter zu vervollständigen und bis 2010 ein sozialistisches Rechtssystem chinesischer Prägung zu etablieren. ${ }^{74} 1999$ wurden „,das Prinzip des Regierens des Staates gemäß dem Recht“ und der „Aufbau eines sozialistischen Rechtsstaats“ in die revidierte Verfassung eingeführt. 75

In den letzten 30 Jahren hat ein umfassendes Rechtssystem mit der Verfassung als Kernstück in China in Grundzügen Gestalt angenommen. Die KP Chinas und die Regierung versuchen zurzeit den Staat im Rahmen der Gesetze zu regieren, statt hauptsächlich durch die politischen Richtlinien und die Politnormen. Das Justizsystem wird fortwährend ausgebaut. Die Einheit und die Autorität des sozialistischen Rechts zu bewah-

72 Vgl. Becker, in: Becker/Zheng/Darimont (Hrsg.), Grundfragen und Organisation der Sozialversicherung in China und Deutschland, S. 12ff.

73 Siehe: Ahl, in: Blätter für deutsche und internationale Politik, 11/2006, S.1382ff; Senger, Einführung in das chinesische Recht, S. 222; Keller, in: American Journal of Comparative Law, 4/1994, S. $711 \mathrm{ff}$.

74 江泽民, 在中国共产党第十五次全国代表大会上的报告 (Jiang, Zemin, Bericht auf dem 15. Parteitag der KP Chinas), vom 12.09. 1997, in: 人民日报 (RMRB), 22. 09. 1997.

75 Art. 5 Abs. 1 der Verfassung von 1982, Revision von 1999, 13. Verfassungszusatz. 
ren wird in der neuen Phase als eine wichtige Aufgabe des Staates und der Partei bezeichnet. 76

Das chinesische Rechtssystem wurde nicht nur durch das westliche Vorbild inspiriert, sondern ist auch chinesisch geprägt. Die chinesische Rechtsstaatlichkeit unterscheidet sich vom westlichen Verfassungsstaat hauptsächlich durch die Betonung der „Demokratischen Diktatur des Volks“, 77 der sozialistischen Modernisierung sowie der Führungsrolle der KP Chinas. ${ }^{78}$ Die Entwicklungsperspektive des chinesischen sozialistischen Rechtsstaates wird wahrscheinlich in der Zukunft ,rule by law" lauten, aber nicht ,rule of law“.79 Das Rechtssystem wird noch lange Zeit, wie im 20. Jahrhundert, den Charakter des Instrumentalismus beibehalten. Es dient vor allem dem Ziel der staatlichen Modernisierung und gewährleistet primär die wirtschaftlichen Erfolge. Die eingeführten westlichen Begriffe wie Demokratie, Menschenrechte, Konstitutionalismus werden noch mit der „,chinesischen Prägung“ - die Betonung von Vorrang der Existenz und Entwicklung des Kollektivs sowie die traditionelle Gewaltenkonzentration - verstanden 80 .

\section{Aufbau einer „Harmonischen Gesellschaft“}

Am Ende des 20. Jahrhunderts hat China das Zwischenziel der Modernisierung „Kleiner Wohlstand“ - im Wesentlichen erreicht, ${ }^{81}$ derzeit wird der dritte Schritt konkretisiert.

Der Konflikt zwischen Gleichheit und Effizienz zeigt sich als ein schwieriges Problem im chinesischen Modernisierungsprozess. Als ein sozialistischer Staat betonte die Volksrepublik China in der Phase der Planwirtschaft die Gewährleistung von Gleichheit

76 中共中央关于构建社会主义和谐社会若干重大问题的决定 (Beschluss des Zentralkomitees der KP Chinas über einige wichtige Fragen zur Strukturierung einer harmonischen sozialistischen Gesellschaft), vom 11. 10. 2006, in: 人民日报 (RMRB), 19.10. 2006.

77 Siehe: 毛泽东, 论人民民主专政 (Mao, Zedong, On the People's Democratic Dictatorship), in: 毛泽东选集第四卷 (Ausgewählte Werke von Mao Zengdong, Vol. 4), S. 273:

„Who are the people? At the present stage in china, they are the working class, the peasantry, the urban petty bourgeoisie and the national bourgeoisie. These classes, led by the working class and the Communist Party, unite to form their own state and elect their own government; the enforce their dictatorship over the running dogs of imperialism - the landlord class and bureaucratbourgeoisie, as well as the representatives of those classes, the Kuomintang reactionaries and their accomplices - suppress them, allow them only to behave themselves and not to be unruly in word or deed. ... Democracy is practiced within the ranks of the people, who enjoy the rights of freedom of speech, assembly, association and so on. The right to vote belongs only to the people, not to the reactionaries. The combination of these two aspects, democracy for the people and dictatorship over the reactionaries, is the people's democratic dictatorship."

78 Präambel der Verfassung von 1982.

79 Vgl. Peerenboom, China's Long March toward Rule of Law, S. 558ff.

80 Ausführlich siehe: Zweiter Teil: Die Verfassung - die für den Systemaufbau relevanten Staatsprinzipien.

81 江泽民, 在中国共产党第十六次全国代表大会上的报告 (Jiang, Zemin, Bericht auf dem 16. Parteitag der KP Chinas), vom 08. 11. 2002, in: 人民日报 (RMRB), 17. 11. 2002. 
und Gerechtigkeit in der Gesellschaft. Aber seit dem Beginn der Wirtschaftsreform wurde die politische Parole umgewandelt in die Formulierung: „Effizienz genießt Priorität, Gleichheit sollte dabei auch berücksichtigt werden" ${ }^{\prime 82}$ - so lautete die Richtlinie in den letzten 20 Jahren des 20. Jahrhunderts. Ausgehend von dieser Richtlinie wurde eine Reihe von wirtschaftlichen sowie sozialen Regelungen und Maßnahmen formuliert, die die Wirtschaftsentwicklung als ein überragendes Ziel betrachteten, dabei jedoch die soziale Gleichheit außer Acht ließen. Diese einseitige Bevorzugung ökonomischer Effizienz führte zur rasanten Polarisierung zwischen Arm und Reich, zu Disparitäten zwischen Stadt und Land, sowie zu regionalen Entwicklungsdisparitäten. ${ }^{83}$ Mit einem Ginikoeffizienten von mittlerweile $0.47(2005)^{84}$ ist die bei 0.40 angesetzte Alarmschwelle sozialer Ungleichheit nach internationalen Maßstäben bereits überschritten. ${ }^{85}$ In den öffentlichen Einrichtungen, z.B. in den Bereichen Ausbildung, Gesundheitswesen und sozialer Sicherheit, herrscht die Tendenz zur Kommerzialisierung, da die staatlichen Ausgaben hierfür ungenügend sind. 86

\section{Tabelle 2: Ginikoeffizienten Chinas}

\begin{tabular}{|l|l|l|l|l|l|l|l|}
\hline Jahr & 1975 & 1980 & 1985 & 1990 & 1995 & 2000 & 2005 \\
\hline Ginikoeffizient & 0.14 & 0.16 & 0.19 & 0.23 & 0.38 & 0.417 & 0.47 \\
\hline
\end{tabular}

Quelle: 中国统计年鉴 (China Statistical Yearbook) 1978-2005

Nach 30 Jahren Reform und Öffnung sieht sich China nun mit einer neuen Situation konfrontiert. Die wirtschaftlichen Ziele wurden rechtzeitig erreicht. Aber die wachsende Ungleichheit der Einkommensverteilung und die gesellschaftlichen Ungleichgewichte, die durch die rapide und ungleichmäßige Wirtschaftsentwicklung erzeugt wurden, müssen ausgeglichen werden. Die Parole „Effizienz genießt Priorität“ hat sich verwandelt in „Gleichgewicht von Gleichheit und Effizienz, besondere Berücksichtigung der Gleichheit bei der abermaligen Einkommensverteilung". 87 Nach der staatlichen Entscheidung sollen die Diskrepanz zwischen arm und reich und die regionalen Disparitäten verrin-

82 中共中央关于建立社会主义市场经济体制若干问题的决定 (Beschluss des Zentralkomitees der KP Chinas über einige Fragen zur Errichtung einer sozialistischen Marktwirtschaft), vom 14. 11. 1993, in: 人民日报 (RMRB), 17. 11. 1993.

83 World Bank, China Country Economic Memorandum: Promoting Growth with Equity, S. 27ff.

84 Quelle: http://www.stats.gov.cn/tjsj/qtsj/gjsj/2008/t20090611_402564867.htm (Stand: 15. 07. 2010).

85 王绍光/胡鞍钢/丁元竹, 经济繁荣背后的社会不稳定 (Wang, Shaoguang/Hu, Angang/Ding, Yuanzhu, Hinter der blühenden Wirtschaft ist die soziale Instabilität), in: 战略与管理 (Strategy \& Management), 2002/3, S. 28.

86 吕炜, 公平增长与公共支出的政策安排 ( $L u ̈$, Wei, Policy Arrangement for Fair Growth and Public Expenditure), in: 经济社会体制比较 (Comparative Ecomonic \& Social Systems), 2004/5, S. $12 \mathrm{ff}$.

87 胡锦涛, 在中国共产党第十七次全国代表大会上的报告 (Hu, Jintao, Bericht auf dem 17. Parteitag der KP Chinas), vom 15. 10. 2007, in: 人民日报 (RMRB), 25. 10. 2007. 
gert werden. Die soziale Gerechtigkeit und Gleichheit sind wiederherzustellen. Sie bilden allesamt die Hauptaufgaben in dieser Phase. ${ }^{88}$

Aus diesem Grund wurde eine neue Entwicklungstheorie mit dem Namen der „Harmonischen Gesellschaft (和谐社会 héxié shèhuì)“von der KP Chinas aufgestellt. Diese Theorie basiert auf dem Staatsziel des „Kleinen Wohlstands“. Ihr theoretischer Ursprung kann auf das konfuzianische Ideal der „Großen Gemeinsamkeit“ zurückgeführt werden. In der traditionellen chinesischen Kultur bedeutet der Begriff „Harmonie“ einen koordinierenden und ordentlichen Zustand der menschlichen Gesellschaft, der Beziehung zwischen Mensch und der natürlichen Umwelt sowie des Menschen selbst. Diese Werte werden im Konfuzianismus und Taoismus sehr hoch eingeschätzt.

Das Konzept der „Harmonischen Gesellschaft“ wurde zuerst in dem Bericht des 16. Parteitags der KP über den „Aufbau einer Gesellschaft des Kleinen Wohlstands“ im Jahre 2002 formuliert ${ }^{89}$ und danach näher definiert. Um eine harmonische Gesellschaft aufzubauen, ist anzustreben, ,alle Bürger ihren Bildungsanspruch zu gewährleisten, ihr Arbeitsentgelt zu sichern, bei Krankheit und beim Alter die Versorgung zu garantieren sowie ihren Bedarf an Wohnung zu befriedigen“.90 Das uralte Ideal der „Großen Gemeinsamkeit" setzt sich in diesem Konzept fort und bildet zusammen mit den modernen Entwicklungszielen die theoretischen Grundlagen dieser „Harmonischen Gesellschaft“.

Es umfasst folgende Aspekte einer idealen Gesellschaft:

- Demokratie und Gleichheit,

- Gerechtigkeit und Gleichheit,

- Ehrlichkeit und Freundlichkeit,

- Lebendigkeit der Gesellschaft,

- Stabilität und Ordnung,

- harmonische Beziehung zwischen Mensch und natürlicher Umwelt. ${ }^{91}$

Die Aufstellung der Theorie der ,harmonischen Gesellschaft“ kennzeichnet den Zustand, dass China nach 30 Jahren Wirtschaftsreform und Öffnung in eine neue Periode eingetreten ist. Man steht einerseits einer glänzenden Zukunft von „Wiedererstehen der chinesischen Nation“ gegenüber, ${ }^{92}$ andererseits einer Periode der ,ausgeprägten Widersprüche“.93 Die wachsenden gesellschaftlichen und ökonomischen sowie ökologischen Probleme wie die Entwicklungsdisparitäten, die Ungleichheit und Ungerechtig-

88 中共中央关于制定国民经济和社会发展第11个五年规划的建议 (Vorschläge des Zentralkomitees der KP Chinas zum 11. Fünfjahresplan), vom 11. 10. 2005, in: 人民日报 (RMRB), 19. 10. 2005.

89 江泽民, 在中国共产党第十六次全国代表大会上的报告 (Jiang, Zemin, Bericht auf dem 16. Parteitag der KP Chinas), vom 08. 11. 2002.

90 胡锦涛, 在中国共产党第十七次全国代表大会上的报告 $(\mathrm{Hu}$, Jintao, Bericht auf dem 17 . Parteitag der KP Chinas), vom 15. 10. 2007, in: 人民日报 (RMRB), 25. 10. 2007.

91 中共中央关于构建社会主义和谐社会若干重大问题的决定 (Beschluss des Zentralkomitees der KP Chinas über einige wichtige Fragen zur Strukturierung einer harmonischen sozialistischen Gesellschaft), vom 11. 10. 2006, in: 人民日报 (RMRB), 19. 10. 2006.

92 胡锦涛, 在中国共产党第十七次全国代表大会上的报告 (Hu, Jintao, Bericht auf dem 17. Parteitag der KP Chinas), vom 15. 10. 2007, in: 人民日报 (RMRB), 25. 10. 2007.

93 Vgl. Holbig, in: China aktuell, 2005/6, S. 14. 
keit der Einkommensverteilung, die Energieknappheit und die Umweltverschmutzung fordern eine Regulierung der Wirtschafts- und Sozialpolitik, sowie den Aufbau eines neuen Wertesystems. Die neue Theorie der „Harmonischen Gesellschaft“ begreift deswegen das Wohl der Menschen als ein Hauptanliegen, und hat eine allseitige, ausgeglichene und nachhaltige Entwicklung als Grundanforderung. ${ }^{94}$ Nach der Aufstellung dieser Theorie orientiert sich die Regierungsmethode an dem ,wissenschaftlichen Entwicklungskonzept"“:95 Der Kern dieses Konzepts liegt darin, das Wohl der Menschen in den Mittelpunkt zu stellen. Dafür hat die gesellschaftliche Entwicklung erstrangige Bedeutung. Die Allseitigkeit, Koordinierung und Nachhaltigkeit der Entwicklung sind zu berücksichtigen. Die grundlegende Entwicklungsmethode ist die einheitliche Planung unter Berücksichtigung verschiedener spezielle Verhältnisse.

\section{Staatsstruktur}

\section{Staat und Gesellschaft: begrenzter Pluralismus?}

Vor der Wirtschaftsreform besaß das chinesische Politiksystem die Merkmale von Totalitarismus und Zentralismus. Einerseits war die ganze Staatsmacht in den Händen der Zentralregierung und damit der KP konzentriert, andererseits verwaltete der Staat die sozialen Angelegenheiten auf allen Gebieten. 96

Wirtschaftliche Entwicklung und sozialer Wandel förderten die Reform der politischen Institutionen. „Eine fortschreitende Reform auf Basis der politischen Stabilität“997 kennzeichnet das Merkmal der politischen Reform in China. Wie bei den wirtschaftlichen Reformen werden die Reformmaßnahmen durch Pilotprojekte erprobt und danach korrigiert. Das Hauptziel der politischen Reform ist die rationelle Macht- und Pflichtverteilung zwischen Staat und Gesellschaft, der führenden Partei und der Regierung, der zentralen und lokalen Ebene, sowie der Regierung und den Unternehmen. ${ }^{98}$ Damit kann sich das politische System der veränderten Wirtschafts- und Gesellschaftsstruktur anpassen.

94 胡锦涛, 在中国共产党第十七次全国代表大会上的报告 (Hu, Jintao, Bericht auf dem 17 . Parteitag der KP Chinas), vom 15. 10. 2007, in: 人民日报 (RMRB), 25. 10. 2007.

95 Bericht des Generalsekretärs Hu Jintao auf dem 17. Parteitag der KP Chinas von 2007.

96 刘作翔, 民主乎? 集权乎? 一 理论界关于新威权主义的论争 (Liu, Zuoxiang, Demokratie oder Autorität? - Die theoretische Diskussion über , Neo-Autorität”), in: 理论导刊 (Journal of Socialist Theory Guide), 1989/4, S. 42.

97 徐湘林, 以政治稳定为基础的中国渐进政治改革 (Xu, Xianglin, China's Progressive Political Reform on the Basic of Political Stability), in: 战略与管理 (Strategy and Management), 2000/5, S. $16 \mathrm{ff}$.

98 何增科, 渐进政治改革与民主的转型 (He, Zengke, Progressive Political Reform and Transformation of Democracy), in: 北京行政学院学报 (Journal of Beijing Administrative College), 2004/3, S.10ff. 
Nach der Meinung mancher Gelehrten tritt das chinesische Regime zurzeit in eine Phase des sogenannten Post-Totalitarismus 99 ein, der sich aus dem sozialistischen Totalitarismus heraus entwickelt und dabei den größten Teil der sozialistischen Institutionen wie die Einparteienpolitik übernimmt. Die politischen Führer steuern den Modernisierungsprozess. Im Vergleich mit dem früheren sozialistischen Regime ist die Kontrolle des Staates über die Gesellschaft, Wirtschaft und Kultur nunmehr lockerer, in den wirtschaftlichen und sozialen Bereichen ist ein begrenzter Pluralismus zu verzeichnen. 100

Seit langer Zeit spielte die chinesische Regierung eine totalitäre Rolle im öffentlichen Leben. Sie kontrollierte die Wirtschaftsentwicklung und sorgte für das Alltagsleben der Bürger. In der aktuellen Entwicklungsphase wird sich die Regierungsfunktion in zweierlei Hinsicht ändern: Einerseits wird die Wirtschaftsentwicklung durch den freien Markt vorangetrieben, wobei die Regierung durch makroökonomische Maßnahmen die Entwicklungsrichtung steuert. Andererseits wird die Selbstverwaltung der Gesellschaft vorangetrieben. Die Regierung beschränkt die Aktivitäten auf ihre Kernkompetenzen. Die „Regierungen der Dienstleistung“ sollten ihre Funktion für öffentliche Angelegenheiten verstärken, ein System der öffentlichen Dienstleistung wird aufgebaut. 101

Die direkten Mitwirkungsrechte der Bürger in politischen Angelegenheiten werden allerdings weiterhin eingeschränkt. ${ }^{102}$ Manche Intellektuelle neigen zu der Ansicht, dass die wirtschaftliche Entwicklung den Aufbau eines dynamischen Bürgertums und einer extensiven Mittelschicht fördere, dies schaffe in der Zukunft die gesellschaftliche Grundlage für einen politischen Pluralismus. ${ }^{103}$ Manche sind aber der Auffassung, dass die westliche „liberale Demokratie“ und „Wahldemokratie“ keine „universalen Werte“ seien. China sollte und könnte ein eigenes System der politischen Ideologie aufbauen, das sich von der legitimationsstiftenden Kraft der westlich-geprägten Vorstellungen von „Demokratie“ und „Autokratie“ löst. ${ }^{104}$

99 萧功秦, 中国后全能型的权威政治 (Xiao, Gongqin, China's post totalitarian Regime), in: 战略 与管理 (Strategy and Management), 2002/6, S. 82ff; 刘作翔, 民主乎？集权乎？一 理论界关于 新威权主义的论争 (Liu, Zuoxiang, Demokratie oder Autorität? - Die theoretische Diskussion über „Neo-Autorität”), in: 理论导刊 (Journal of Socialist Theory Guide), 1989/4, S. 42ff.

100 何增科, 20世纪80年代末以来中国关于政治改革和民主化的探讨 (He, Zengke, About China's Political System Reform and Democratization since 1980's), in: 北京行政学院学报 (Journal of Beijing Administrative College), 2002/6, S. 18.

101 Beschluss des Zentralkomitees der KP Chinas über einige wichtige Fragen zur Strukturierung einer harmonischen sozialistischen Gesellschaft von 2006.

102 刘作翔, 民主乎? 集权乎? 一 理论界关于新威权主义的论争 (Liu, Zuoxiang, Demokratie oder Autorität? - Die theoretische Diskussion über „Neo-Autorität”), in: 理论导刊 (Journal of Socialist Theory Guide), 1989/4, S. 42.

103 萧功秦, 从发展政治学看中国转型体制 (Xiao, Gongqin, China' politische Transformation vom Standpunkt der Entwicklungspolitologie), in: 浙江学刊 (Zhejiang Academic Journal), 2005/5, S. $100 \mathrm{ff}$.

104 王绍光，民主四讲 (Wang, Shaoguang, Gespräche über „Demokratie“), S. 242ff.; 王绍光/潘维, 共和国60年: 回顾与展望 (Wang, Shaoguang/Pan, Wei, 60 Jahre Volksrepublik: Rückblick und Ausblick), in: 开放时代 (Opentimes), 2008/1, S. 13ff. 
Der Begriff „Demokratie“ wird in China grundsätzlich positiv bewertet. 105 Die Politiker vertreten auch die Ansicht, dass Demokratie, Rechtsstaatlichkeit sowie Menschenrechte nicht nur dem Westen gehören, sondern gemeinsame menschliche Wertmaßstäbe sind. 106 In den politischen Dokumenten wird der Aufbau eines sozialistisch demokratischen Politiksystems seit den 1990er Jahren stets betont. ${ }^{107}$ Es wird zurzeit aber nicht versucht, die „sozialistische Demokratie“ offiziell zu definieren und zu konkretisieren. ${ }^{108}$ Für das Verständnis der „sozialistischen Demokratie“ ist es wichtig, dass das Wort „Demokratie“ in der Verfassung oft mit Bestimmungswörtern wie „Zentralismus“ und „Volksdiktatur“ eingeschränkt wird. ${ }^{109}$ In der Praxis wird der Demokratisierungsprozess allmählich dadurch vorangetrieben, dass die Selbstverwaltung der Dörfer110 und der städtischen Einwohner ${ }^{111}$ auf den untersten gesellschaftlichen Organisationsebenen, ${ }^{112}$ sowie die Verbesserung des demokratischen Zentralismus auf den obersten Ebenen der KP Chinas ${ }^{113}$ zurzeit schon durch die Gesetze bestimmt oder in den politischen Entscheidungen festgelegt werden.

\section{Zentrale und lokale Ebene: Zentralismus oder Quasi-Föderalismus?}

\section{a) Gewaltenkonzentration und Verwaltungsaufbau}

Seit 2000 Jahren stützt sich China auf zentralistische politische Institutionen. Als ein Land mit großer territorialer Ausdehnung und regionalen Disparitäten ist China allerdings immer mit dem Konflikt von Einheit und Spaltung konfrontiert. In einem immer wieder aufgeführten chinesischen Theaterstück verhält es sich so, dass ,auf lang andau-

105 俞可平, 民主是个好东西 (Yü, Keping, Democracy is A Good Thing), in: 北京日报 (BJRB), 23. 10. 2006; 王绍光，民主四讲 (Wang, Shaoguang, Gespräche über „Demokratie“), S. 242ff.

106 温家宝, 关于社会主义初级阶段的历史任务和我国对外政策的几个问题 (Wen, Jiabao, Über die historischen Aufgaben der sozialistischen Anfangsphase und einige Fragen der Außerpolitik Chinas), in: 光明日报 (GMRB), 26. 02. 2007.

107 江泽民，在中国共产党第十五次全国代表大会上的报告 (Jiang, Zemin, Bericht auf dem 15. Parteitag der KP Chinas), vom 12. 09. 1997, in: 人民日报 (RMRB), 22. 09. 1997; 温家宝，在第 十届全国人民代表大会第二次会议上的政府工作报告 (Wen, Jiabao, Report on the Work of the Government at the Second Session of the Tenth National People's Congress on March 5, 2004), in: 人民日报 (RMRB), 17. 03. 2004.

108 Siehe: 邓小平文选第三卷 (Deng, Xiaoping, Ausgewählte Schriften von Deng Xiaoping, Dritter Band), S. 240.

109 Ausführlich: Zweiter Teil: Grundsätze der Verfassung.

110 中华人民共和国农村居民委员会组织法（Gesetz über die Organisation der Ortsanschüsse), vom 04. 11. 1998.

111 中华人民共和国城市居民委员会组织法 (Gesetz über die Organisation der städtischen Wohnbevölkerungsausschüsse), vom 26. 12. 1989.

112 温家宝，在第十届全国人民代表大会第二次会议上的政府工作报告 (Wen, Jiabao, Report on the Work of the Government at the Second Session of the Tenth National People's Congress on March 5, 2004), in: 人民日报 (RMRB), 17. 03. 2004.

113 江泽民, 在庆祝建党八十周年大会上的讲话 (The Speeches at the Symposium on The Talk at the Celebration Meeting for the 80th Anniversary of CCP Founding by Jiang Zemin), in: 人民日报 (RMRB), 02. 07. 2001. 
ernde Einheit die Trennung und auf lang andauernde Trennung die Einheit folgen muss". 114

Die Volksrepublik erbte das traditionelle zentralistische Politiksystem und ergänzte es durch die sozialistische Ideologie. Mit ihrer Befugnis zur Einstellung und Entlassung des Personals bis auf Provinzebene kontrolliert die zentrale Ebene die lokalen Ebenen. Nur ein Prinzip der Gewaltenteilung zwischen der zentralen und lokalen Ebene wird in der chinesischen Verfassung festgelegt:

„Die Teilung der Funktionen und Gewalten zwischen den zentralen und lokalen Ebenen lässt sich von dem Prinzip leiten, die Initiative und den Enthusiasmus der lokalen Ebenen unter der einheitlichen Leitung der Zentralen voll und ganz zu entfalten.“115

Im „Beschluss des Zentralkomitees der KP Chinas über einige Fragen zur Vervollkommnung einer sozialistischen Marktwirtschaft" wird das Verteilungsprinzip im Bereich der Finanzen, Steuern und sozialen Sicherheit konkretisiert:

„Die Teilung der Funktionen und Gewalten zwischen der zentralen und den lokalen Ebenen im Bereich der Finanzen, Steuern, Investitionen und sozialen Sicherheit sollte Schritt für Schritt in Ordnung gebracht werden. Die landesweiten und überprovinzialen Angelegenheiten werden von der zentralen Ebene geleitet, um die Einheit von Recht, Dekret und Markt zu gewährleisten. Die regionalen Angelegenheiten im eignen Verwaltungsgebiet werden von den lokalen Ebenen geführt, um die Arbeitsleistung zu erhöhen, die Verwaltungskosten zu reduzieren und die Vitalität der Administration zu aktivieren. Die von den zentralen und lokalen Ebenen zusammen verwalteten Angelegenheiten sollen nach verschiedenen Bedingungen behandelt werden, die jeweiligen Verwaltungsbereiche und die Haupt- und Nebenrolle sind zu unterscheiden. “116

Seitdem das System von Präfekturen und Kreisen in der Qin-Dynastie (221 v. Chr. 207 v. Chr.) festgelegt wurde, hat die chinesische administrative Gliederung ihre Grundstruktur über 2000 Jahren lang beibehalten. In der Yuan-Dynastie (1271 - 1368) wurden Provinzen eingerichtet, die Vier-Stufen-Struktur des Verwaltungssystems wurde seitdem von den aufeinander folgenden Zentralregierungen benutzt.

Diese Verwaltungsstruktur wurde in der Volksrepublik weitergeführt. In der chinesischen Verfassung von 1982 ist das ganze Land ebenfalls in vier Stufen (Land, Provinz, Kreis, Gemeinde) unterteilt. 117 Tatsächlich wurde aber noch eine Bezirksebene zwischen der Provinzebene und der Kreisebene eingeführt. Das Land gliedert sich nun in 23 Provinzen, fünf autonome Gebiete (Xinjiang, Innere Mongolei, Guangxi, Ningxia,

114 罗贯中, 三国演义 (Luo, Guanzhong, Die drei Reiche), S.1.

115 Art. 3. Abs. IV der Verfassung von 1982.

116 中共中央关于完善社会主义市场经济体制若干问题的决定 (Beschluss des Zentralkomitees der KP Chinas über einige Fragen zur Vervollkommnung einer sozialistischen Marktwirtschaft), vom 21. 10. 2003, in: 人民日报 (RMRB), 22. 10. 2003.

117 Art. 30 der Verfassung von 1982. 
Xizang), vier Regierungsunmittelbare Städte (Beijing, Tianjin, Shanghai, Chongqing) und zwei Sonderverwaltungsregionen (Hongkong, Macao). ${ }^{118}$

\title{
Verwaltungsaufbau
}

\author{
Die Zentrale \\ re Städte 4, Sonderverwaltungsregionen 2) \\ Bezirkebene (Bezirke, Städte, autonome Bezirke, insgesamt 333) \\ Kreisebene ( Kreise, Städte, autonome Kreise, insgesamt 2862) \\ Gemeindeebene (41636 Gemeinden)
}

Provinzebene (insgesamt 34, Provinzen 23, autonome Gebiete 5, Regierungsunmittelba-

\section{b) Finanzföderalismus?}

Nach Gründung der Volksrepublik ist China im Bereich der Finanzen und Steuern immer auf der Suche nach einem Ausgleich zwischen Zentralisierung und Dezentralisierung. Um sich an die Wirtschaftslage anzupassen, wurde das Finanzsystem häufig verändert. Unverändert ist jedoch, dass die zentrale Ebene die alleinige Kompetenz zur Steuergesetzgebung hat. Die Veränderungen des Finanzsystems werden unter der mächtigen Kontrolle der zentralen Ebene durchgeführt. Die zentrale Ebene behält immer ihre leitende Rolle und reguliert nach den konkreten Umständen die Beziehung mit der lokalen Ebene.

Das Finanzsystem in der Periode der Planwirtschaft wurde als ein „großer Topf“ bezeichnet. Durch einheitliche Einnahmen und Ausgaben kontrollierte die Zentralregierung die lokalen Finanzen. Parallel mit der Wirtschaftsreform wurde die Reform der finanziellen Dezentralisierung seit 1980 eingeleitet. Die Zentralregierung übertrug nach und nach den lokalen Regierungen ihre Finanzbefugnisse und die entsprechenden Verwaltungsbefugnisse. Im Jahre 1988 erreichte die dezentralisierte Finanzreform ihren Höhepunkt: eine radikale finanzielle Dezentralisierung. Die lokalen Regierungen haben seitdem die volle Verantwortlichkeit für ihr Finanzwesen übernommen, die Zentralregierung kassierte nur nach bestimmten Quoten die Einnahmen der lokalen Regierungen ein. ${ }^{119}$

118 民政部，中华人民共和国行政区划统计表 (Ministerium für Zivile Angelegenheiten, Verwaltungsaufbau der Volksrepublik China), http://qhs.mca.gov.cn/article/zlzx/qhtj/200711/20071100003177.shtml (Stand 15. 07. 2010).

119 国务院关于地方实行财政包干办法的决定 (Beschluss des Staatsrats über die volle finanzielle Veranwortlichkeit der lokalen Regierungen), vom 28. 07. 1988，国发 (1988) Nr. 50. 
Das System der fiskalischen Vollverantwortung der lokalen Regierungen wurde allerdings von Anfang an als eine Übergangsregelung geplant und aufgebaut. Um die Reformen des Preis- und Steuersystems inzwischen durchführen zu können, entschied die Zentralregierung, ihre Finanzbefugnisse weiter abzutreten und ging dabei das Risiko ein, dass die Einnahmenquoten der Zentralregierung noch deutlicher sanken. ${ }^{120}$ Die gesamte Staatseinnahmenquote ist zwischen 1978 und 1994 von 31, 2\% auf 11, 2\% des BIP gesunken. ${ }^{121}$ Kaum ein anderer Staat hatte ein vergleichbar dezentralisiertes Finanzsystem wie China in den Jahren 1988 - 1994. ${ }^{122}$ Nach der Meinung von Wang, Shaoguang 123 hat die Finanzreform von 1988 die Untergrenze der Dezentralisierung überschritten. Die Möglichkeiten der Zentralregierung, makroökonomisch zu kontrollieren, wurden dadurch stark geschwächt. Diese radikale Reform hat aber dennoch nicht zum Zusammenbruch der zentralen Ebene geführt, weil die chinesische zentralisierte Staatsstruktur nicht von der kurzfristigen Finanzreform insgesamt beeinträchtigt wurde. Seit 1994 ist die Steuerreform wieder in eine zentralisierte Phase eingetreten: der Aufbau des Systems der Steuereinnahmenaufteilung.

\section{Tabelle 3: Wandel des Steuersystems in China}

\begin{tabular}{|l|l|}
\hline 1950 & „Großer Topf“: einheitliche Einnahmen und Ausgaben der Zentralregierung \\
\hline 1958 & Beschränkte finanzielle Dezentralisierung \\
\hline 1968 & Einheitliche Einnahmen und Ausgaben \\
\hline 1980 & „verschiedene Herde“: Reform der finanziellen Dezentralisierung \\
\hline 1988 & Voll-Verantwortlichkeit der lokalen Regierungen \\
\hline 1994 & Aufbau des Systems der Steuereinnahmenaufteilung \\
\hline
\end{tabular}

Da die Mängel dieses Systems mit der zunehmenden Liberalisierung des Markts immer deutlicher geworden waren, entschied die Zentralregierung im Jahre 2003, das Finanzsystem noch mal zu reformieren. ${ }^{124}$ Seit 1994 ist die Steuerreform wieder in eine zentralisierte Phase eingetreten: der Aufbau des Systems der Steuereinnahmenaufteilung. Das neue System wird von der Weltbank als Finanzföderalismus bezeichnet. ${ }^{125}$

120 周冰/李美嵩, 策略性过渡性制度安排 — 中国财政大包干体制研究 (Zhou, Bing/Li, Meisong, A Stratgic Transitional Institution Arrangement - A Case about Fiscal All-Round Responsibility System of China in 1980s), in: 浙江大学学报 (Journal of Zhejiang University), 2006/11, S. 59ff.

121 中国统计年鉴 (China Statistical Yearbook) 2002, S. 265, http://www.stats.gov.cn/tjsj/ndsj/ (Stand: 15. 07. 2010).

122 World Bank, China: Revenue Mobilization and Tax Policy, S. 76ff.

123 王绍光, 分权的底限 (Wang, Shaoguang, Die Untergrenze der Dezentralisierung). In diesem Aufsatz hat der chinesische Politologe Wan, Shaoguang durch den Vergleich mit anderen Staaten (Einnahmenquote, Umverteilungsfähigkeit und Fähigkeit für Makro-Stabilität der Zentralregierung) einen Schluß gezogen, dass China damals die Untergrenze der Dezentralisierung schon überschritten hatte.

124 国务院关于实行分税制财政管理体制的决定 (Beschluss des Staatsrats über die Durchführung des Finanzverwaltungssystems der Steuereinnahmenaufteilung), vom 15. 12. 1993.

125 World Bank, China National Development and Sub-National Finance, S. 2ff. 
Die Zentrale verfügt wie immer über die Gesetzgebungsbefugnis für alle Steuern. ${ }^{126}$ Aber die Einkünfte der Zentral- und Lokalregierungen werden nach Steuerarten eindeutig verteilt. Die Steuern werden in Zentral-, Lokal- und Verbundsteuern aufgeteilt. Der Zentralregierung stehen die wichtigen Steuerarten zu, ${ }^{127}$ dadurch fließen ihr die Einnahmen wieder zu. Die Einnahmequote der Zentralregierung ist Schritt für Schritt von 22\% der Staatseinnahmen 1993 auf 54,9\% im Jahr 2004 angestiegen. ${ }^{128}$

\section{Tabelle 4: Einnahmenquote der Zentralregierung 1955-2004}

\begin{tabular}{|c|c|c|}
\hline Jahr & $\begin{array}{c}\text { Gesamte Staatseinnahmen } \\
(\text { Mrd.RMB })\end{array}$ & $\begin{array}{c}\text { Einnahmenquote der Zentralregierung } \\
(\%)\end{array}$ \\
\hline 1955 & 28.02 & 77.6 \\
\hline 1980 & 115.99 & 24.5 \\
\hline 1985 & 200.48 & 38.4 \\
\hline 1990 & 293.71 & 33.8 \\
\hline 1995 & 624.22 & 52.2 \\
\hline 2000 & 1339.52 & 52.2 \\
\hline 2004 & 2639.65 & 54.9 \\
\hline
\end{tabular}

Quelle: 中国统计年鉴2005 (China Statistical Yearbook 2005).

Das System der Steuereinnahmenaufteilung stellt sich dennoch weiterhin als reformbedürftig dar. Es hat nur die Einnahmenverteilung zwischen den Zentral- und Provinzregierungen neu festgelegt, aber nicht die Ausgabenverteilung entsprechend korrigiert. Im Beschluss des Staatsrats von 1993 wurden die zentralen und lokalen Ausgabenbefugnisse allgemein geregelt. ${ }^{129}$ Die lokalen Regierungen (hautptsächlich die Regierungen auf Kreisebene), die weiterhin für die regionalen öffentlichen Angelegenheiten wie Bildungswesen, Gesundheitswesen und soziale Sicherung verantwortlich sind, geraten wegen des Absinkens des territorialen Einkommensanteils in Schwierigkeiten, diese Ausgaben aus eigener Finanzkraft zu tragen. ${ }^{130}$ Diese fiskalische Lücke sollte von der

126 Nr. 2 des Beschlusses des Staatsrats über die Durchführung des Finanzverwaltungssystems der Steuereinnahmeaufteilung von 1993.

127 Nr. 3.2 des Beschlusses des Staatsrats über die Durchführung des Finanzverwaltungssystems der Steuereinnahmeaufteilung von 1993: „Das feste zentrale Einkommen umfasst: Zölle; vom Zoll vertretungsweise erhobene Verbrauchs- und Mehrwertsteuer; Verbrauchssteuer; Einkommensteuer zentraler Unternehmen, territorialer Banken, der Banken des ausländischen Kapitals und anderer Kreditunternehmen; zusammengefasst abgeliefertes Einkommen der Eisenbahnabteilungen, Hauptstellen der Banken und Versicherungshauptgesellschaften; von zentralen Unternehmen abgelieferter Gewinn. ... Das gemeinsame zentral-territoriale Einkommen umfasst: Mehrwertsteuer (der zentrale Anteil 75\%); Ressourcensteuer; Wertpapierhandelssteuer.“

128 中国财政年鉴2004 (Finanzjahresbuch China 2004) (Stand: 15. 07. 2010).

129 Nr. 3.1 des Beschlusses des Staatsrats von 1993: „Die zentralen Finanzen übernehmen die Kosten der Landesverteidigung, Ausgaben für auswärtige Beziehungen, Kosten der zentralen Verwaltung, ... und die auf zentraler Ebene getragenen Ausgaben für Kultur, Bildungswesen, Gesundheit und Wissenschaft. Die territorialen Finanzen übernehmen territoriale Verwaltungskosten, ... territoriale Ausgaben für Kultur, Bildungswesen, Gesundheit, ..."

130 World Bank, China National Development and Sub-National Finance, S. 36. 
vertikalen Finanzumverteilung geschlossen werden oder von einer Verlagerung der sachlichen Befugnisse behoben werden.

Eine funktionierende Umverteilung wurde bisher noch nicht völlig aufgebaut. Die Beträge der Umverteilung werden hauptsächlich von der Zentral- und Provinzregierung durch Verhandelungen bestimmt. Dieses Modell wird als „unrationell“" und „ungerecht“ kritisiert. ${ }^{131}$ Die Regierungen auf Kreisebene erhalten durch die Umverteilung oft nicht genügend Finanzmittel, da die meisten Geldmittel von den oberen Verwaltungsebenen kassiert werden. Eine Formalisierung der Umverteilung wurde seit 1995 teilweise eingeführt, aber spielt jetzt nur eine sehr kleine Rolle im Umverteilungssystem. ${ }^{132}$ Außerdem verstärkt die Steuereinnahmenaufteilung die finanziellen Disparitäten zwischen den armen und reichen Gebieten, da die Regelung über die Steuer-Rückerstattung vom zentralen Fiskus an die lokale Ebene ${ }^{133}$ einer Begünstigung zugunsten der reichen Gebiete vorsieht. ${ }^{134}$ Die nächsten Schritte der Finanzreform sind die weitere Festlegung der sachlichen Befugniserteilung zwischen den Zentral- und Lokalregierungen sowie die Verbesserung der vertikalen Umverteilung. ${ }^{135}$

Um die zunehmende Disparität der Einkommensverteilung zwischen den verschiedenen Regionen und Bereichen anzugleichen, verstärkt die Zentralregierung ständig die makroökonomische Steuerung. Zollamt, Steuerbehörde, die Behörde für Industrie und Handel sowie die Behörde für staatlichen Grund und Boden werden jetzt vertikal von der Zentral- oder Provinzregierung geleitet. Die regionale Befugnis für die Gesetzgebung wird auch stärker eingeschränkt. Darüber hinaus werden die Ausgabenbefugnisse für die lokalen öffentlichen Angelegenheiten auch teilweise auf die höheren Regierungsebenen verlagert. 136

Zusammenfassend kann gesagt werden, dass die chinesische Modernisierung in einer festgelegten Richtung und unter strenger Kontrolle der zentralen Ebene verläuft. Die zentrale Ebene hat die volle Initiative für ökonomische Zentralisierung und Dezentralisierung in der Hand. Es gibt bis heute noch keine wesentliche Veränderung in der traditionellen Struktur der zentralisierten Machtausübung.

131 龙朝晖仍建新, 政府间财政转移支付: 问题及政策建议 (Long, Zhaohui/Deng, Jianxin, Chinese Intergovernmental Fiscal Transfer System: Problems and Policy Suggestions), in: 改革 (Reform), 2005/7, S. 40.

132 龙朝晖/邓建新, 政府间财政转移支付: 问题及政策建议 (Long, Zhaohui/Deng, Jianxin, Chinese Intergovernmental Fiscal Transfer System: Problems and Policy Suggestions), in: 改革 (Reform), 2005/7, S. 39.

133 Siehe: Nr. 3. 3 des Beschlusses des Staatsrats über die Durchführung des Finanzverwaltungssystems der Steuereinnahmeaufteilung von 1993: Festlegung des vom zentralen Fiskus an die Territorien zurückzuerstattenden Steuereinkommens.

134 国务院发展研究中心课题组, 中国政府间财政转移支付制度的现状, 问题与完善 (Forschungszentrum des Staatsrats für Entwicklung, Zustand und Probleme des fiskalischen Umverteilungssystems zwischen Regierungen und Verbesserungsvorschläge), in: 经济要参 (Economic Reference), 2005/28.

135 Beschluss des Zentralkomitees der KP Chinas über einige wichtige Fragen zur Strukturierung einer harmonischen sozialistischen Gesellschaft von 2006.

136 席斯, 新财税体制改革发力, 事权上移是短期重点 ( Xi, Si, Die neue Runde der Finanz- und Steuerreform), in: 经济观察报 (The Economic Observer), vom 18. 03. 2007. 
Wenn man die Transformation Chinas nur als Transformation eines sozialistischen Staats betrachtet, wird man ihre Bedeutung unterschätzen. Als eine alte Zivilisation wurde China seit Mitte des 19. Jahrhunderts von äußeren Faktoren dazu gezwungen, sich der veränderten Weltstruktur anzupassen und sich zu einem modernen Staat zu entwickeln. Die chinesische Transformation beschreitet einen reformistischen Weg: 137 Einerseits beteiligt sich China an den internationalen Institutionen und versucht die Gesellschaft zu modernisieren, andererseits bewahrt es seine traditionellen Grundwerte und Institutionen.

Seit 1978 erfährt die chinesische Transformation eine Beschleunigungsphase. Die Volkswirtschaft wächst rasant, der Urbanisierungsprozess wird enorm beschleunigt, das Öffnungsniveau wird Schritt für Schritt erhöht. Die Einführung der Marktwirtschaft fördert die Wirtschaftsentwicklung, führt auch zur rasanten Gesellschaftsveränderung und zu sozialen Disparitäten. Um die Disparitäten zwischen Stadt und Land, den verschiedenen Gebieten und gesellschaftlichen Schichten anzugleichen, sind die Umverteilungsfähigkeit des Staates und die sozialpolitischen Aktionen sowie Initiativen zu verstärken. Ferner muss ein neues fundamentales Staatssystem aufgrund der eigenen Traditionen und Erfahrungen strukturiert werden. ${ }^{138}$

Die wirtschaftliche Entwicklung hat unmittelbare Wirkung in Bezug auf die soziale Sicherheit. In der Periode der Planwirtschaft wurde ein Modell der Trennung von Stadt und Land mit hohem Leistungsniveau angewandt. In der Phase der Wirtschaftsreformen wurden neue soziale Versicherungssysteme mit verstärkter Eigenverantwortung der Bürger aufgebaut, die zurzeit aber verbessert werden müssen. In der Planung „einer harmonischen Gesellschaft" nimmt die soziale Sicherheit eine hohe Bedeutung ein. Wie der traditionelle Gedanke der "staatlichen Verantwortung" sich auf die soziale Sicherheit in diesem Prozess gewandelt hat, wird in den folgenden Teilen mit der Darstellung und Analyse der Reformen der Sozialleistungssysteme ausführlich diskutiert.

137 俞可平, 现代化和全球化双重变奏下的中国文化发展逻辑 (Yü, Keping, The Logic of Chinese Cultural Development under Variation of Modernization and Globalization), in: 学术月刊 (Academic Monthly), 2006/4, S. 14ff.

138 Ausführlich siehe: 王绍光/胡鞍钢/周建明, 第二代改革战略: 积极推进国家制度建设 (Wang, Shaoguang/Hu, Angang/Zhou, Jianming, Neue Reformstrategien: Förderung der Strukturierung des Staatssystems), in: 战略与管理 (Strategy and Management), 2003/2, S. $90 \mathrm{ff}$. 


\section{Zweiter Teil: Die Verfassung und die soziale Sicherheit \\ - die für die soziale Sicherheit relevanten Staatsprinzipien}

In der gegenwärtigen chinesischen Verfassung ist der Aufbau der sozialen Sicherheit nicht nur als verbürgte Grundrechtsposition der Bürger festgelegt, sondern wird als Verantwortung des Staates betont. Der Verfassungsgeber hat einen ausführlichen Kata$\log$ über die soziale Sicherheit in die Verfassung geschrieben. Aber die Rolle der Verfassung in diesem Bereich kann nicht allein vom Verfassungstext her verstanden werden; sie ergibt sich erst aus dem politischen Kontext. Insbesondere in China, wo die Tradition der Gewaltenkonzentration und die Einparteienpolitik herrschen, gerät die Verfassung bis heute noch in eine prekäre Situation. Die Verfassung spielt im Staatsleben eine schwer zu beschreibende Rolle. Um die Verfassungsdurchführung und die Beziehung zwischen der Verfassung und der sozialen Sicherheit zu beurteilen, werden in diesem Teil zuerst

1. die Stellung der chinesischen Verfassung im Rechts- und Politiksystem,

2. die wesentlichen Elemente der chinesischen Verfassung und

3. die Grundprinzipien des Staates in der Verfassung

analysiert und danach die verfassungsrechtlichen Regelungen über die soziale Sicherheit dargestellt.

\section{A. Normen der Volksrepublik China}

Nach über 160 Jahren Rechtsrezeption kann in China noch nicht begrifflich von einem Rechtsstaat im westlichen Sinne ausgegangen werden. Obwohl sich das traditionelle Rechtssystem - die Kombination von „Sitte“ und „Strafe“ - ganz zersetzt hat, bildet das geschriebene Rechtssystem zurzeit nicht die einzigen staatlichen Normen. Die derzeitigen Normen der Volksrepublik China sind die politischen Richtlinien der KP Chinas, das geschriebene Rechtssystem und die staatlichen Politnormen. ${ }^{1}$ Diese Normenstruktur dient hauptsächlich der politischen Zweckmäßigkeit, ergänzt in gewissem Maße auch die Schwächen des noch unreifen Rechtssystems.

\section{Das Rechtssystem}

Manche westliche Beobachter haben bis heute noch Zweifel, ob ein Rechtssystem in China real existiert oder funktioniert. ${ }^{2} A h l$ ist der Meinung, dass das wesentliche

1 Vgl. Senger, Einführung in das chinesische Recht, S. 198ff.

2 Siehe. Ahl, in: Blätter für deutsche und internationale Politik, 11/2006, S. 1383; Senger, Einführung in das chinesische Recht, S. 222; Keller, in: American Journal of Comparative Law, 1994, S. $711 \mathrm{ff}$. 
Merkmal eines Rechtsstaates westlicher Prägung die Bindung der Machtträger an das Recht sei, im Falle Chinas sei aber die Politik dem Recht übergeordnet. ${ }^{3}$ Manche sind der Auffassung, dass wenn politische Richtlinien der Partei Vorrang vor Gesetz besäßen, verliere dann das Recht an Rationalität und Konsistenz. Ohne Autonomie und Vorrang des Rechts sei ein umfassendes institutionalisiertes Rechtssystem nicht vorstellbar. 4

Um die Realität des chinesischen Rechtssystems zu beurteilen, ist zunächst erforderlich, das chinesische Verständnis von „Recht“ und „Rechtssystem“ näher zu erläutern.

\section{Begriffe}

Das chinesische Wort ,法 (fă)“ ”bzw. ,法律 (fălü)“ entspricht in der Gegenwart dem englischen Wort „law“.5 Der Hauptunterschied zwischen ,,法“ und dem deutschen Wort „Recht“ liegt darin, dass das deutsche Wort „Recht“ sowohl objektives wie auch subjektives Recht bedeutet, demgegenüber bedeutet das chinesische Wort ,法“ nur objektives Recht. 6 Subjektives Recht wird im chinesischen Sprachgebrauch als „权利 (quánlì)“ bezeichnet. In der Literatur wurde der Begriff ,, 法“ wie folgt definiert:

„Recht (法) ist die Gesamtbezeichnung für die den Willen der herrschenden Klasse verkörpernden, vom Staat erlassenen oder anerkannten Verhaltensnormen, deren Einhaltung die staatliche Zwangsmacht gewährleistet. “7

In bestimmten Fällen bezeichnet „法“ bzw. ,法律“ auch „Gesetz“. In China werden Gesetze vom Nationalen Volkskongress und seinem Ständigen Ausschuss erlassen. Das chinesische Rechtssystem umfasst nicht nur die Gesetze, sondern auch die vom Staatsrat erlassenen Exekutivrechtsnormen sowie die von den lokalen Volkskongressen erlassenen territoriale Rechtsnormen, die aber nicht als „Gesetz“, sondern als „Regeln“ (条 例 tiáolì), „Vorschriften“ (规定 guīdìng) oder „Maßnahmen“ (办法 bànfă) benannt werden. Manche westliche Juristen bezeichnen die chinesischen Normen, die von der KP Chinas oder von den staatlichen Verwaltungsorganen veröffentlicht werden, auch als Rechtsnormen, ${ }^{8}$ die in China aber überhaupt nicht zum „Recht“ gezählt werden. Die Parteinormen der KP Chinas und die staatlichen Politnormen verfügen über keine juristische Zwangsnatur und sind nicht gerichtlich einklagbar. Im Falle der Nichterfüllung drohen also keine juristischen Sanktionen. ${ }^{9}$ Um die Parteinormen und die staatlichen

3 Ahl, in: Blätter für deutsche und internationale Politik, 11/2006, S. 1382.

4 Keller, in: American Journal of Comparative Law, 1994, S. $711 \mathrm{ff}$.

5 Vgl. Senger, in: ZfRV, 2006/7, S. 47; 李步云, 法理学 (Li, Buyun (Hrsg.), Rechtstheorien), S. 22.

6 Siehe: 李步云, 法理学 (Li, Buyun (Hrsg.), Rechtstheorien), S. 22; 张文显, 法理学 (Zhang, Wenxian (Hrsg.), Jurisprudence), S. 99.

7 Siehe: 张文显, 法理学 (Zhang, Wenxian (Hrsg.), Jurisprudence), S. 102; Senger, Einführung in das chinesische Recht, S. 176.

8 Wie Münzel, People's Republic of China, in: International Encyclopedia of Comparative Law, 67ff; Heuser, Einführung in die Chinesische Rechtskultur, S. 206.

9 Vgl. Senger, in: ZfRV, 2006/7, S. 52, 58. 
Politnormen juristisch verbindlich zu erklären, sind sie in Rechtsformen umzusetzen oder zu transformieren.

\section{Aufbau des Rechtssystems}

Nach dem Gesetzgebungsplan des Ständigen Ausschusses des Nationalen Volkskongresses besteht das chinesische Rechtssystem, das 2010 völlig etabliert werden sollte, aus sieben Rechtsgebieten und hat drei Rechtsstufen. ${ }^{10}$

Das Rechtssystem wird nach den bestimmten sozialen Beziehungen und RegelungsMethoden in sieben „Rechtsgebiete“ eingeteilt: ${ }^{11}$

- Verfassung und mit der Verfassung zusammenhängendes Recht,

- Zivil- und Handelsrecht,

- Verwaltungsrecht,

- Wirtschaftsrecht,

- Sozialrecht (inkl. Arbeitsgesetz, Arbeitsvertragsgesetz, Sozialversicherungsgesetz, Gesetze für berufliche Sicherheit und Gesundheit, Gesetze für Sozialhilfe und soziale Wohlfahrt),

- Strafrecht,

- Verfahrensrecht.

Bezüglich der „drei Rechtsstufen“ existiert folgende Rangfolge

- Verfassung und Gesetze,

- Exekutivrechtsnormen (administrative Verordnungen des Staatsrats) und

- territoriale Rechtsnormen (inkl. lokale Verordnungen, 12 AutonomieVerordnungen und Einzelverordnungen der autonomen Gebiete ${ }^{13}$ ).

Bevor die Verfassung von 1982 in Kraft trat, war der Nationale Volkskongress das einzige Gesetzgebungsorgan der Volksrepublik. Erst in der Verfassung von 1982 erlangten der Ständige Ausschuss des Nationalen Volkskongress, der Staatsrat und die lokalen Volkskongresse mit ihren Ständigen Ausschüssen auch Gesetzgebungsbefugnisse. ${ }^{14}$

Die Verfassung wird als „Muttergesetz“ und „Grundgesetz“ bezeichnet. Sie hat die höchste gesetzliche Autorität. ${ }^{15}$ Der Nationale Volkskongress ist das höchste Staatsorgan und höchste Gesetzgebungsorgan. Die Revision der Verfassung verlangt die $\mathrm{Zu}$ -

10 Siehe: 吴邦国, 在十届全国人大常委会第二次会议上的讲话 (Wu, Bangguo, Gespräche in der zweiten Versammlung des Ständigen Ausschusses des zehnten Volkskongresses), vom 26. 04. 2003, in: 人民日报 (RMRB), vom 27. 04. 2003.

11 Ausführlich vgl. 乔晓阳, 关于中国特色社会主义法律体系的构成, 特征和内容 (Qiao, Xiaoyang, Das sozialistische Rechtssystem chinesischer Prägung), in: 全国人大干部培训讲义 (Lehrmaterial des Nationalen Volkskongresses), S. 156ff.

12 Art. 100 der Verfassung von 1982.

13 Art. 116 der Verfassung von 1982.

14 Art. 67 Abs. 2, Art. 89 Abs. 1, Art. 100 der Verfassung von 1982.

15 Präambel der Verfassung von 1982, 13. Abschnitt. 
stimmung von zwei Drittel Mehrheit des Nationalen Volkskongresses. ${ }^{16}$ Die Gesetze werden von dem Nationalen Volkskongress und seinem Ständigen Ausschuss erlassen, ${ }^{17}$ sie haben Vorrang vor den Exekutivrechtsnormen und den territorialen Rechtsnormen.

Der Staatsrat legt gemäß der Verfassung und den Gesetzen Exekutivrechtsnormen fest, die zu folgenden Angelegenheiten Bestimmungen treffen können:

- Angelegenheiten, deren Festlegung in Verwaltungsrechtsnormen zur Durchführung eines Gesetzes erforderlich ist;

- Angelegenheiten, in denen der Staatsrat gemäß Art. 89 der Verfassung die Verwaltungskompetenz hat. ${ }^{18}$

Die Exekutivrechtsnormen werden als „Regeln“, „Vorschriften“, „Maßnahmen“ bezeichnet. ${ }^{19}$ Das Verfahren zur Festsetzung der Exekutivrechtsnormen wird durch die rechtlichen Vorschriften geregelt, deren Bekanntmachung und dessen Inkraftsetzen es des Befehls des Staatsrats mit der Unterschrift des Ministerpräsidenten bedarf. ${ }^{20}$

Die lokalen Volkskongresse auf Provinzebene und deren Ständigen Ausschüsse, die Volkskongresse von größeren Städten und deren Ständige Ausschüsse können lokale Verordnungen unter der Voraussetzung, dass diese nicht mit der Verfassung, den Gesetzen und den Exekutivrechtsnormen in Widerspruch stehen, erlassen. ${ }^{21}$ Diese Verordnungen haben den Zweck, Gesetze und Exekutivrechtsnormen nach den tatsächlichen Umständen des Verwaltungsgebiets durchzuführen, sowie die territorialen Angelegenheiten zu regeln.22 Die Volkskongresse der autonomen Gebiete können nach den politischen, wirtschaftlichen und kulturellen Besonderheiten der Volksgruppen Autonomieund Einzelverordnungen festlegen, die jedoch nicht mit den Grundprinzipien der Gesetze oder Exekutivrechtsnormen in Widerspruch stehen dürfen. ${ }^{23}$

Die Ministerien und die Komitees des Staatsrats sowie die Regierungen auf Provinzebene, die Hauptstädte der Provinzen und die großen Städte können gemäß den Gesetzen, den Exekutivrechtsnormen und territorialen Rechtsnormen Verwaltungsvorschriften festlegen. ${ }^{24}$ Fraglich ist, ob diese Vorschriften als „Rechtsnormen“ bezeichnet werden können. In der Verfassung von 1982 gibt es keine Regeln über die Verwaltungsvorschriften. Nach der Erklärung des Ständigen Ausschusses des Nationalen Volkskongresses werden sie nicht von den drei Rechtsstufen umfasst. ${ }^{25}$ Bevor das Verwaltungsprozessgesetz im Jahre 1990 in Kraft trat, waren die Verwaltungsvorschriften nicht bin-

16 Art. 64 Abs.1 der Verfassung von 1982.

$17 \S 7$ Gesetzgebungsgesetz.

$18 \S 56$ Gesetzgebungsgesetz.

19 行政法规制定程序条例 (Regeln für das Verfahren zur Festsetzung von Exekutivrechtsnormen), 国务院令第321号, vom 16. 11.2001, ab 01.01. 2002 in Kraft.

$20 § 27$ Abs. 1 Regeln für das Verfahren zur Festsetzung von Exekutivrechtsnormen.

$21 \S 63$ Gesetzgebungsgesetz.

$22 \S 64$ Gesetzgebungsgesetz.

$23 \S 66$ Gesetzgebungsgesetz.

$24 \S \S 71,73$ Gesetzgebungsgesetz.

25 汤耀国, 中国法律体系将如期形成 (Tang, Yaoguo, Ausgestaltung des chinesischen Rechtssystems), in: 瞭望新闻周刊 (Liaowang Newsweek), vom 12.03. 2007. 
dend für die Entscheidungen der Volksgerichte. Nach dem Inkrafttreten des Verwaltungsprozessgesetzes können die Volksgerichte bei der Behandlung von Verwaltungssachen die Verwaltungsvorschriften „berücksichtigen“.26 Zudem haben die Gerichte das Recht, eine Normenkontrolle der Verwaltungsvorschriften durchzuführen. ${ }^{27}$

Im Gesetzgebungsgesetz ist folgendes festgelegt: „Dieses Gesetz gilt für die Festlegung, Änderung und Aufhebung von Gesetzen, Exekutivrechtsnormen, territorialen Rechtsnormen, Autonomie-Verordnungen und Einzelverordnungen. Die Festlegung, Änderung und Aufhebung von Vorschriften der Abteilungen des Staatsrats und von Vorschriften der territorialen Regierungen wird gemäß den einschlägigen Bestimmungen dieses Gesetzes durchgeführt." 28 Die Angelegenheiten, die in den Verwaltungsvorschriften geregelt werden, sollen für die Durchführung von Gesetzen, Exekutivrechtsnormen und territorialen Rechtsnormen erforderlich sein oder zu der konkreten Verwaltung dieses Verwaltungsgebietes gehören. ${ }^{29}$ Die Verwaltungsvorschriften werden von den ständigen Sitzungen des Ministeriums oder der lokalen Regierungen beschlossen. ${ }^{30}$

Die soeben erwähnten Regelungen zeigen, dass die Verwaltungsvorschriften zwar rechtliche Berücksichtigung finden, allerdings mangelt es diesen Vorschriften an der Qualifizierung als vollwertige Rechtsnormen, weshalb sie auch nicht von der Normenhierarchie erfasst werden. Sie bilden nur ergänzende Vorschriften für die Durchführung der Rechtsnormen und die Verwaltungsarbeit der lokalen Regierung, damit die territorialen Disparitäten berücksichtigt werden können.

\section{Die politischen Richtlinien der KP Chinas}

Wegen der chinesischen Einparteienpolitik spielen die politischen Richtlinien der KP Chinas eine erhebliche Rolle im chinesischen Normensystem. ${ }^{31}$ Das System der politischen Richtlinien der KP Chinas umfasst Leitlinien (路线 lùxiàn), Grundsätze (方针 fāngzhēn) sowie Programme (政策 zhèngcè), die die ideologische Sphäre bestimmen und die staatlichen Entwicklungsrichtungen zeigen. Sie werden normalerweise als Bestimmungen oder Beschlüsse der KP Chinas veröffentlicht, ein einheitliches System der Terminologie und die klare Trennung der Kompetenzen existieren aber nicht.

$26 \S 53$ Abs. 1 Verwaltungsprozessgesetz vom 04. 04. 1989, Übersetzung in: Heuser, Sozialistischer Rechtsstaat und Verwaltungsrecht in der VR China (1982-2003), S. 244 ff.

27 最高人民法院关于审理行政案件适用法律规范问题的座谈会纪要 (Gesprächsnotizen des Obersten Volksgerichts über die Anwendung von Gesetzen und Verordnungen bei Behandlung von Verwaltungssachen), 法 (2004) 96 号 , http://www.law-lib.com/law/law_view.asp?id=84794 (Stand: 15. 07. 2010).

$28 \S 2$ Gesetzgebungsgesetz.

$29 \S \S 71,73$ Gesetzgebungsgesetz.

$30 § 75$ Gesetzgebungsgesetz.

31 Vgl. Darimont, Sozialversicherungsrecht der V. R. China, S. 28; von Senger, Einführung in das chinesische Recht, S. 290ff; 蔡定剑刘丹，从政策社会到法治社会 - 兼论政策对法制建设的消极 影响 (Cai, Dingjian/Liu, Dan, From the Society in Policy to the Society in Rule of Law), in: 黄之 英, 中国法治之路 (Huang, Zhiying, The Road to The China's Rule of Law), S. 83ff. 
Schon im Jahre 1949 hat das Zentralkomitee der KP Chinas ein Prinzip festgelegt: „Bevor das neue Recht des Volks erlassen wird, wird die juristische Arbeit aufgrund der politischen Richtlinien der KP Chinas und der Richtlinien, Befehle, Bestimmungen der Volksregierung sowie der Volksbefreiungsarmee durchgeführt". 32 Die politischen Richtlinien der KP und die Politnormen der Regierung haben seitdem eine wichtige Funktion im Staatsleben der Volksrepublik ausgeübt. Insbesondere spielten sie in der Kulturrevolution eine gewichtige Rolle, da die Gesetzgebung und die Justiz damals ins Stocken gerieten. In der Phase von „Reform und Öffnung“ hat die KP Chinas das neue Prinzip „Regieren des Staates gemäß dem Recht“ festgelegt. ${ }^{33}$ Die politischen Richtlinien der KP beschränken sich derzeit meistens auf die Grundsätze der staatlichen Entwicklungsorientierung.

Die politischen Richtlinien werden allein vom Zentralkomitee der KP Chinas festgelegt. Sie haben keine rechtliche Bindungskraft. Allerdings besitzen sie in gewissem MaBe die entscheidende Bedeutung für das chinesische Staatsleben. ${ }^{34}$ Sie sind die ideologischen Grundsätze für die Gesetzgebung und die Verwaltung. Die wichtigsten und grundlegendsten politischen Richtlinien sind in die Verfassung umzusetzen. Die Partei befürwortet, dass die wichtige Kenntnisse und Erfahrungen der Partei, deren Korrektheit schon in der Praxis bewiesen wurde, in die Verfassung geschrieben werden sollten. 35 Die für längerfristig bedeutenden politischen Richtlinien werden auch als Gesetze umgesetzt.

Zurzeit legt die KP Chinas hauptsächlich die staatlichen Prinzipien, die wirtschaftlichen und gesellschaftlichen Entwicklungen, die Verfassungsänderungen und die Fünfjahrespläne fest. Der Begriff des „Sozialismus im Anfangsstadium“ wurde von der KP Chinas geschaffen und in die Präambel der Verfassung geschrieben. ${ }^{36}$ Damit ist ge-

32 中共中央关于废除国民党六法全书与确定解放区司法原则的指示 (Anweisung des Zentralkomitees der KP Chinas über die Abschaffung der Vollständigen Sammlung der Sechs Gesetze der Volkspartei und die Festlegung der Grundsätze der Justiz in den befreiten Gebieten), vom 22. 02. 1949, in: 中共中央文件选集第十八册 (Ausgewählte Dokumenten des Zentralkomitees der KP Chinas, Vol. 18), S. 150.

33 江泽民, 在中国共产党第十五次全国代表大会上的报告 (Jiang, Zemin, Bericht auf dem 15. Parteitag der KP Chinas), vom 12.09.1997, in: 人民日报 (RMRB), 22. 09. 1997.

$34 \mathrm{Vgl}$. 俞可平, 中国公民社会的制度环境 (Yü, Keping, Institutional Environment of China's Civil Society), S. $19 \mathrm{ff}$.

35 王兆国, 宪法修正案草案的说明 (Wang, Zhaoguo, Erklärung über den Entwurf der Verfassungsänderung), in: 人民日报 (RMRB), 09.03.2004.

36 Präambel der Verfassung von 1982, 7. Abschnitt:

„Unter der Führung der Kommunistischen Partei Chinas und angeleitet durch den MarxismusLeninismus, die Mao-Zedong-Ideen, die Deng-Xiaoping-Theorie und die wichtigen Gedanken der „Dreifachen Repräsentation“ werden die Volksmassen aller Nationalitäten in China weiterhin an der demokratischen Diktatur des Volkes, am sozialistischen Weg sowie an Reform und Öffnung festhalten, ununterbrochen die sozialistischen Institutionen verbessern, die sozialistische Marktwirtschaft und die sozialistische Demokratie entwickeln, das sozialistische Rechtssystem vervollkommnen und gestützt auf die eigene Kraft in harter Arbeit Industrie, Landwirtschaft, Landesverteidigung sowie Wissenschaft und Technik Schritt für schritt modernisieren, die aufeinander abgestimmte Entwicklung der materiellen, politischen und geistigen Zivilisation fördern und unser Land zu einem wohlhabenden und starken, demokratischen und zivilisierten sozialistischen Staat aufbauen." 
meint, dass die Volksmassen aller Nationalitäten des ganzen Landes durch die KP geführt und zusammengeschlossen werden, der Wirtschaftsaufbau als Schwerpunkt zu betrachten ist und an den „Vier Grundprinzipien“ sowie an der Reform und Öffnung festzuhalten ist. 37

Die allgemeinen Entwicklungsrichtungen des Staates werden durch Beschlüsse der KP Chinas festgelegt, wie z. B. Beschluss über die Errichtung einer sozialistischen Marktwirtschaft, ${ }^{38}$ Beschluss über die Vervollkommnung einer sozialistischen Marktwirtschaft, ${ }^{39}$ und Beschluss über die Strukturierung einer harmonischen sozialistischen Gesellschaft. 40

Die wichtigsten Richtlinien der KP Chinas werden im Revisionsverfahren in die Verfassung geschrieben. Beispielsweise ist die Konstituierung der Verfassung von 1982 die Konkretisierung der politischen Leitlinien, die in dem 3. Plenum des 11. Zentralkomitees der KP (1978) und dem Beschluss der KP Chinas über einige historische Fragen (1981) festgelegt wurden, um die Politik des Klassenkampfes in Richtung Wirtschaftsentwicklung zu ändern. ${ }^{41}$ Danach wurde die Verfassung bis jetzt viermal (1988, 1993, 1999, 2004) nach den wichtigen Schlussfolgerungen der Parteitage und den Verfassungsänderungsvorschlägen der KP Chinas revidiert. ${ }^{42}$

Der Fünfjahresplan für die gesellschaftlichen und wirtschaftlichen Entwicklungen wird nach den Vorschlägen der KP Chinas ausgearbeitet. Z. B. am 11. 10. 2005 veröffentlichte die KP Chinas die Vorschläge zum 11. Fünfjahresplan. ${ }^{43}$ Nach den Vorschlägen wurde der Fünfjahresplan vom Staatsrat ausgearbeitet und vom Nationalen Volkskongress gebilligt. ${ }^{44}$

37 中国共产党章程 (Statut der KP Chinas), revidiert am 21. 10. 2007, in: 人民日报 (RMRB), 26. 10. 2007.

38 中共中央关于建立社会主义市场经济体制若干问题的决定 (Beschluss des Zentralkomitees der KP Chinas über einige Fragen zur Errichtung einer sozialistischen Marktwirtschaft), vom 14. 11. 1993, in: 人民日报 (RMRB), 17. 11. 1993.

39 中共中央关于完善社会主义市场经济体制若干问题的决定 (Beschluss des Zentralkomitees der KP Chinas über einige Fragen zur Vervollkommnung einer sozialistischen Marktwirtschaft), vom 21. 10. 2003, in: 人民日报 (RMRB), 21.10. 2003.

40 中共中央关于构建社会主义和谐社会若干重大问题的决定 (Beschluss des Zentralkomitees der KP Chinas über einige wichtige Fragen zur Strukturierung einer harmonischen sozialistischen Gesellschaft), vom 11. 10. 2006, in: 人民日报 (RMRB), 19. 10. 2006.

41 杨景宇, 宪法的稳定和与时俱进 (Yang, Jingyü, Die Stabilität der Verfassung und die fortsetzende Entwicklung), vom 16. 12. 2003, http://www.people.com.cn/GB/shizheng/1026/2249281.html (Stand: 12. 12. 2009).

42 中共中央关于修改中华人民共和国宪法个别条款的建议 (Vorschlag des Zentralkomitees der KP Chinas zur Revision von Teile der Verfassung), vom 28. 02. 1988, 14. 02. 1993, 22. 01. 1999, 12. 12. 2003, in: 王培英, 中国宪法文献通编 (Wang, Peiying (Hrsg.), Dokumentensammlung über die chinesischen Verfassungen).

43 中共中央关于制定国民经济和社会发展第11个五年规划的建议 (Vorschläge des Zentralkomitees der KP Chinas zum 11. Fünfjahresplan), vom 11. 10. 2005, in: 人民日报 (RMRB), vom 19. 10. 2005.

44 国民经济和社会发展第十一个五年规划 (Der 11. Fünfjahresplan für die volkswirtschaftliche und gesellschaftliche Entwicklung 2006-2010), gebilligt vom NVK am 14. 03. 2006. 
Für die wichtigen Angelegenheiten des Staates erlässt die Zentralregierung oft zusammen mit dem Zentralkomitee der KP Chinas politische Normen. ${ }^{45}$ Sie arbeitet auch allein Politnormen aus, die die verschiedenen Aspekte der gesellschaftlichen und wirtschaftlichen Entwicklungen des Staates betreffen. Die staatlichen Politnormen werden oft unter „Beschluss (决定 júedìng)“”, ,Bekanntmachung (通知 tōngzhī)“, „Leitansichten (意见 yìjiàn)“ veröffentlicht. Die Ausarbeitung und Veröffentlichung der staatlichen Politnormen ist nicht an das Festsetzungsverfahren der Verwaltungsnormen gebunden, demzufolge verfügen sie nicht über die Zwangsnatur des Rechts und gehören nicht zum Rechtssystem. 46 Sie werden von den Verwaltungsorganen verschiedener Ebenen durchgesetzt. Mit Medien, Sitzungen und Ausgabe der Dokumente werden sie unter den Volksmassen veröffentlicht.

Im Vergleich mit den politischen Richtlinien der KP Chinas, die die grundlegende Richtungsorientierung des Staates bestimmen, regeln die staatlichen Politnormen hauptsächlich die konkreten Angelegenheiten bestimmter öffentlicher Verwaltungsbereiche. ${ }^{47}$ Die staatlichen Politnormen erweisen sich insbesondere als wirkungsvoll in den neuen gesellschaftlichen und wirtschaftlichen Bereichen, in denen noch kein Gesetzesrecht vorhanden ist oder die Schaffung der rechtlichen Normen wegen schnell veränderter Umstände nicht realistisch ist. Im Bereich der Sozialversicherung existiert zurzeit eine große Zahl an staatlichen Politnormen. Für die Rentenversicherung und die Krankenversicherung gibt es bis heute noch keine Exekutivrechtsnormen, sondern nur die Beschlüsse des Staatsrats. Erst wenn die praktischen Erfahrungen der Reform im Wesentlichen ausgereift vorliegen, ${ }^{48}$ werden rechtliche Regelungen aufgrund der Reformerfahrungen ausgearbeitet.

Vom Charakter her sind staatliche Politnormen kurzweilig und flexibel. ${ }^{49}$ Ohne Beschränkung des Gesetzgebungsverfahrens können sie schnell verändert werden, um sich

45 Z. B. die Mitteilungen des Zentralkomitees der KP Chinas und des Staatsrats über die Vertiefung der Gesundheitsreform vom 17. 03. 2009, die Ansichten des Zentralkomitees der KP Chinas und Staatsrats über die Förderung von Behindertenwesen vom 28. 03. 2008, der Beschluss des Zentralkomitees der KP Chinas und des Staatsrats über Festigung der Gesundheitsarbeit auf dem Land vom 19. 10. 2002, die Bekanntmachung des Zentralkomitees der KP Chinas und des Staatsrats über die weitere Durchführung der Wiederbeschäftigungsmaßnahmen für die entlassenen Arbeitnehmer und die Arbeitslosen vom 30. 09. 2002.

46 Vgl. Senger, Einführung in das chinesische Recht, S. 198 ff.

47 Z. B. die Ansichten des Staatsrats zur Lösung der Probleme der Wanderarbeiter vom 27. 03. 2006, die Mitteilung des Staatsrats über die Errichtung des Sicherungssystems des Existenzminimums für die städtische Bevölkerung vom 02. 09. 1997, der Beschluss des Staatsrats über die Errichtung eines Grundkrankenversicherungssystems für Arbeitnehmer in Städten und Gemeinden vom 14. 12. 1998, die Leitlinien des Staatsrats über die Entwicklung der städtischen kommunalen medizinischen Dienstleistungen vom 21. 02. 2006.

$48 \S 8$ Regeln für das Verfahren zur Festsetzung von Exekutivrechtsnormen von 2001.

49 Vgl. Senger, Einführung in das chinesische Recht, S. 198 ff; 蔡定剑/刘丹, 从政策社会到法治社 会 - 兼论政策对法制建设的消极影响 (Cai, Dingjian/Liu, Dan, From the Society in Policy to 
der Entwicklung der Gesellschaft anzupassen. Je nach den Umständen können sie in rechtliche Verordnungen transformiert werden.

\section{Transformation innerhalb des Normensystems}

In der Phase der Planwirtschaft wurden die Partei, die Regierung und die Gesellschaft völlig nach dem Prinzip des „demokratischen Zentralismus“ organisiert. Die Partei und die Regierung steuerten direkt die wirtschaftliche Entwicklung. Dementsprechend spielten die politischen Richtlinien und die Politnormen eine wichtigere Rolle als die rechtlichen Normen im Staatsleben. Die Entwicklung des Rechtssystems wurde demzufolge lange Zeit ignoriert und beschränkt. Dieses Regierungsmodell wurde in der Phase der sozialistischen Marktwirtschaft von der zunehmenden wirtschaftlichen und gesellschaftlichen Pluralisierung zu Reformen herausgefordert. Der Aufbau des Rechtssystems wurde seit dem Jahre 1978 beschleunigt. ${ }^{50}$ „Regieren gemäß dem Recht“" ist zurzeit als ein grundlegendes Staatsprinzip in der Verfassung festgelegt.

Das gemischte System der rechtlichen Normen, politischen Richtlinien und staatlichen Politnormen ist allerdings zurzeit weiter das Grundmodell des chinesischen Normensystems, da dieses System die politische Stabilität und die Entwicklungseffizienz dieser Transformationsphase gewährleistet. Außerdem wurden die Voraussetzungen für die Durchsetzbarkeit der politischen Normen der Partei und der Regierung - das staatliche Organisationsprinzip des Demokratischen Zentralismus und die Führungsrolle der KP - noch nicht von der Entwicklung der Marktwirtschaft und des Privateigentums in ihren Grundfesten erschüttert.

Mit der Vervollkommnung des Rechtssystems werden die Grenzen der drei Normensysteme deutlicher. Trotzdem gibt es keine formellen Regelungen zur Festlegung und Durchsetzung der politischen Normen. Ob die politischen Normen der Partei und Regierung in der Zukunft noch parallel mit dem Rechtssystem existieren und eine wichtige Rolle im Staatsleben spielen werden, hängt von der Entwicklung des Staatswesens ab.

the Society in Rule of Law), in: 黄之英, 中国法治之路 (Huang, Zhiying, The Road to The China's Rule of Law), S. 86ff.

50 中国共产党第十一届三中全会公报 (Bulletin des 3. Plenums des 11. Zentralkomitees der KP Chinas), vom 22. 12. 1978, in: 人民日报 (RMRB), 24. 12. 1978. 
Tabelle 5: Normensysteme der VR China

\begin{tabular}{|l|l|l|l|}
\hline & $\begin{array}{l}\text { Politische Richtlinien der } \\
\text { KP Chinas }\end{array}$ & Rechtssystem & $\begin{array}{l}\text { Staatliche Politnormen } \\
\text { der Zentralregierung }\end{array}$ \\
\hline Normengeber & die KP Chinas & $\begin{array}{l}\text { NVK, der Ständige Aus- } \\
\text { schuss des NVK, die Zent- } \\
\text { ralregierung }\end{array}$ & die Zentralregierung \\
\hline Namen & $\begin{array}{l}\text { Bestimmung, Beschluss, } \\
\text { Vorschlag }\end{array}$ & $\begin{array}{l}\text { Gesetz, Regeln, Bestim- } \\
\text { mung, Methode }\end{array}$ & $\begin{array}{l}\text { Beschluss, Bekanntma- } \\
\text { chung, Leitansichten }\end{array}$ \\
\hline Charakter & $\begin{array}{l}\text { Appellcharakter, leitender } \\
\text { Charakter }\end{array}$ & Zwangscharakter & $\begin{array}{l}\text { Appellcharakter, leiten- } \\
\text { der Charakter }\end{array}$ \\
\hline Gegenstand & $\begin{array}{l}\text { ideologischen Grundsätze, } \\
\text { staatliche Entwicklungs- } \\
\text { orientierung }\end{array}$ & Grundsystem des Staates & $\begin{array}{l}\text { Konkrete Angelegenhei- } \\
\text { ten der staatlichen Ver- } \\
\text { waltung, } \\
\text { mittel- und kurzfristige } \\
\text { Entwicklungsstrategie }\end{array}$ \\
\hline Umsetzbarkeit & $\begin{array}{l}\text { Umsetzung in die Verfas- } \\
\text { sung, rechtliche Regelun- } \\
\text { gen und Politnormen }\end{array}$ & & $\begin{array}{l}\text { Umsetzung in das } \\
\text { Rechtssystem }\end{array}$ \\
\hline
\end{tabular}

\section{B. Die Verfassung}

Wenn ein Staat ohne Gewaltenteilung keine Verfassung besitzt, wie die französische Erklärung der Menschen- und Bürgerrechte von 178951 definiert, dann existiert in China bis heute keine Verfassung im westlichen Sinne. Nach dem Wortlaut der Verfassung von 1982 ist die chinesische Verfassung eine „Gesetzesform“, die „die Errungenschaften des Kampfes der Volksmassen bestätigt und die grundlegende Staatsordnung sowie die grundlegenden Aufgaben des Staates festlegt". 52 In der Verfassung wird das staatliche Organisationsprinzip „Demokratischer Zentralismus“53 festgelegt, um ,alle Kräfte auf die sozialistische Modernisierung zu konzentrieren“, damit das grundlegende Ziel des Staates - Aufbau ,eines wohlhabenden und mächtigen, demokratischen und zivilisierten sozialistischen Staates" - verwirklicht werden kann. ${ }^{54}$ Das bedeutet, dass die erstrangige Aufgabe der derzeitigen Verfassung die Verwirklichung der chinesischen Modernisierung ist. Die Festlegung der Staatsordnung und die Gewährleistung von Bürgerrechten müssen im Dienste der Erfordernisse der Modernisierung stehen. Dafür spielen die chinesischen Traditionen der Gewaltenkonzentration und der Kollektivrechte die entscheidende Rolle.

51 Art. 16 der Erklärung der Menschen- und Bürgerrechte (Déclaration des Droits de l'Homme et du Citoyen), vom 26. 08. 1789: Toute société dans laquelle la garantie des droits n'est pas assurée, ni la séparation des pouvoirs déterminée, n'a point de constitution.

52 Präambel der Verfassung von 1982, 13. Abschnitt.

53 Art. 3. Abs. 1 der Verfassung von 1982: Die Staatsorgane der Volksrepublik China werden das Prinzip des Demokratischen Zentralismus an.

54 Präambel der Verfassung von 1982, 7. Abschnitt. 


\section{Verfassungsgeschichte}

Das Suchen nach einem den chinesischen Verhältnissen entsprechenden Weg der Modernisierung führte zu einem häufigen Wechsel der politischen Richtlinien. Seit der Gründung der Volksrepublik China wurden schon vier Verfassungen und eine vorläufige Verfassung verabschiedet, die die wechselnden politischen Richtlinien Chinas widergespiegelt haben. Nach der Meinung mancher chinesischer Juristen können die Verfassungen nach drei Typen unterschieden werden: Verfassung der Revolution, Verfassung der Reform und Verfassung des Konstitutionalismus. ${ }^{55}$

Die chinesischen Verfassungen von 1954, 1975 und 1978 werden als „Verfassungen der Revolution“ bezeichnet. Die Verfassung von 1954 legte als Ziel den Aufbau eines sozialistischen Staats fest. Die Verfassungen von 1975, 1978 betonten den Klassenkampf. Demgegenüber dient die Verfassung von 1982 in erster Linie der wirtschaftlichen Modernisierung und wird eine „Verfassung der Reform“ genannt. ${ }^{56}$ Nach der Meinung mancher Juristen existiert eine „Verfassung des Konstitutionalismus“ in China heute noch nicht, aber sie haben schon lange über den Aufbau eines „Verfassungsstaats“ diskutiert.

In allen Verfassungen der Volksrepublik wurden das grundlegende Staatsziel, das zentralisierte staatliche Organisationsprinzip sowie die Führungsrolle der KP festgeschrieben.

\section{Frühere Verfassungen}

Das „Gemeinsame Programm“ (Präambel, 7 Kapitel, 60 Artikel) wurde als vorläufige Verfassung von der Politischen Konsultativkonferenz des Chinesischen Volkes im Jahre 1949 angenommen. In diesem Programm wurde die Volksrepublik noch nicht als ein sozialistischer, sondern als ein neu-demokratischer, d. h. ein volksdemokratischer Staat ${ }^{57}$ vorläufig gesehen, weil die Bodenreform und die sozialistische Umgestaltung der Privatindustrie - Aufbau der ökonomischen Basis eines sozialistischen Staats - damals noch nicht begonnen hatten.

Die nach fünf Jahren erlassene Verfassung von 1954 (Präambel, 4 Kapitel, 106 Artikel) ist auch noch keine sozialistische Verfassung, sondern eine „Verfassung der Über-

55 夏勇, 中国宪法改革的几个基本理论问题 (Xia, Yong, Several Theoretical Issues Confronting Constitutional Reform in China), in: 中国社会科学 (Social Sciences in China), 2003/3, S. 4 ff; 陈 端洪, 由富强到自由: 中国宪法的价值取向与司法化的可能 (Chen, Duanhong, Von Wohlstand bis Freiheit: Wertorientierung der chinesischen Verfassung und die Möglichkeit der unmittelbaren Anwendung durch die Gerichte). in: 法制日报 (FZRB), 05. 12. 2002

56 Siehe: 夏勇, 中国宪法改革的几个基本理论问题 (Xia, Yong, Several Theoretical Issues Confronting Constitutional Reform in China), in: 中国社会科学 (Social Sciences in China), 2003/3, S. 4 ff.

57 Art. 1 des Gemeinsamen Programms. 
gangsperiode“. .58 In dieser Verfassung wurde die grundlegende staatliche Aufgabe in der Übergangsperiode, nämlich in der Periode seit Gründung der Volksrepublik bis Vollendung eines sozialistischen Systems, vorgeschrieben: Die sozialistische Industrialisierung werde allmählich verwirklicht, die sozialistische Umgestaltung von Landwirtschaft, Handwerk sowie kapitalistischer Industrie und Handel würden Schritt für Schritt vollendet. ${ }^{59}$ In der Übergangsperiode umfasste das Eigentumssystem an den Produktionsmitteln von Volkseigentum, Kollektiveigentum, Privateigentum und Kapitalisteneigentum. Weil die Übergangsperiode voraussichtlich ungefähr 15 Jahre dauern würde, 60 wurde die Verfassung von 1954 von Anfang an als eine Verfassung auf Zeit betrachtet.

Bis 1956 wurden die Verstaatlichung der Privatindustrie und der Kollektivierung der Landwirtschaft im Großen und Ganzen erledigt. Seit dem Jahre 1970 begann das Politbüro der KP Chinas schon mit der Arbeit der Verfassungsänderung, die wegen der instabilen politischen Situation in der Kulturrevolution fünf Jahre lang dauerte. Am 13. 01. 1975 wurde die neue Verfassung vom vierten Nationalen Volkskongress angenommen. In der Verfassung von 1975 (Präambel, 4 Kapitel, 30 Artikel) wurde die Volksrepublik schließlich als ein sozialistischer Staat bezeichnet.61 Die Grundlage des sozialistischen Wirtschaftssystems ist das Volkseigentum und das Kollektiveigentum. ${ }^{62}$ Die Grundrichtlinie des Staats lautet Weiterführung der Revolution unter der Diktatur des Proletariats, um den Klassenkampf und den Kampf zwischen Sozialismus und Kapitalismus zu überwinden.63 Die „Große Demokratie“ der Volksmassen, nämlich freie Meinungsäußerung, offene Aussprachen, große Diskussion und Wandzeitung mit groBen Schriftzeichen, wurde als die neuen Formen der sozialistischen Revolution in die Verfassung von 1975 festgeschrieben. ${ }^{64}$ Die Staatsanwaltschaften wurden abgeschafft, die Rechtsfälle musste von den Volksmassen verurteilt werden. 65 Außer der Betonung der Diktatur des Volks wurde die Führungsfunktion der KP Chinas verstärkt. Die Partei hatte die Oberbefehlsmacht des Militärs. 66 Der Nationale Volkskongress ist „das höchste Organ der Staatsmacht unter Führung der KP Chinas"67 geworden.

Das politische Experiment der Verbindung der extremen zentralisierten Staatsmacht mit der „Großen Demokratie“ der Volksmassen ist gescheitert. Die nach der Kulturrevolution erlassene Verfassung von 1978 (Präambel, 4 Kapitel, 60 Artikel) ist nur eine „restaurierende“ Verfassung, ${ }^{68}$ die die Grundsätze der Verfassung von 1954 teilweise

58 毛泽东, 关于中华人民共和国宪法草案, in: 毛泽东文集 (Mao, Zedong, Über den Verfassungsentwurf der Volksrepublik China, in: Gesamtwerk von Mao Zedong), S. 325ff.

59 Präambel der Verfassung von 1954.

60 Siehe: 蔡定剑, 宪法精解 (Cai, Dingjian, Constitution: A intensive Reading), S. 44.

61 Art. 1 der Verfassung von 1975.

62 Art. 5 der Verfassung von 1975.

63 Präambel der Verfassung von 1975.

64 Art. 13 der Verfassung von 1975.

65 Art. 25 Abs. 3 der Verfassung von 1975.

66 Art. 15 der Verfassung von 1975.

67 Art. 16 Abs. 1 der Verfassung von 1975.

68 Siehe: 蔡定剑, 宪法精解 (Cai, Dingjian, Constitution: A intensive Reading), S. 66. 
wiederherstellt, die Regelungen der Verfassung von 1975 über Klassenkampf, die Massenbewegung und das Volkseigentum noch bewahrt. Als die Volksrepublik in die Phase „Reform und Öffnung“ getreten ist, war die Verfassung von 1978 nicht geeignet für die veränderte Situation. Eine neue Verfassung musste ausgearbeitet werden.

\section{Die Verfassung von 1982}

\section{a) Von der „Verfassung der Revolution“ zur „Verfassung der Reform“}

In dem 3. Plenum des 11. Zentralkomitees der KP Chinas hat die sozialistische Modernisierung als die grundlegende staatliche Aufgabe den Klassenkampf ersetzt. Die KP fasste die Erfahrungen der Kulturrevolution zusammen, zog daraus die Schlussfolgerung, dass die chinesische Modernisierung ohne Institutionalisierung der Demokratie und Aufbau einer Rechtsordnung nicht verwirklicht werden kann. 69 Die Entscheidung der KP Chinas, ein in Gesetzen verankertes demokratisches Staatssystem aufzubauen, wurde als Grundlage in die neue Verfassung aufgenommen. ${ }^{70}$ Darüber hinaus kamen die angemessene Beschränkung der Staatsmacht, die Trennung von Partei und Regierung, die Festlegung der Verfassung als höchste gesetzliche Autorität sowie die Betonung der Grundrechte der Bürger in der Verfassung von 1982 zum Ausdruck. Erstmals ist im Verfassungstext festgelegt, dass „keine Organisation oder kein Individuum das Privileg genießen darf, die Verfassung und die Gesetze zu überschreiten“. 71

Die Verfassung von 1982 gliedert sich wie die ehemaligen Verfassungen der Volksrepublik in eine Präambel und vier Kapitel. Die ausführliche Präambel zieht zuerst einen Rückblick auf die chinesische Geschichte seit der Neuzeit, legt danach die Grundaufgaben und Grundprinzipien des Staats fest, die im Kapitel I „Allgemeine Grundsätze“" weiter konkretisiert werden. Die Aussagen über Grundrechte und Grundpflichten der Bürger, die früher hinter dem Staatsaufbau in Kapitel III geregelt wurden, finden sich jetzt in Kapitel II. Der Staatsaufbau ist im Kapitel III geregelt. Kapitel IV behandelt die Staatsflagge, das Staatswappen, die Nationalhymne und die Hauptstadt.

Die Verfassung von 1982 setzt das Prinzip der Verfassung von 1954 fort: die Verfassung soll nunmehr von der Realität ausgehen, muss aber gleichzeitig auch die zukünftige Entwicklung berücksichtigen. ${ }^{72}$ In der Verfassung von 1982 bleibt die Volksrepublik ein sozialistischer Staat, der aber später den Zusatz „im Anfangsstadium“ erhält. ${ }^{73}$ Das sozialistische Gemeineigentum an den Produktionsmitteln ist - wie in den Verfas-

69 中共中央关于建国以来党的若干历史问题的决议 (Resolution on Certain Questions in the History of Our Party since the Founding of the People's Republic of China), vom 27. 06. 1981.

70 彭真, 关于中华人民共和国宪法修改草案的报告 (Peng, Zhen, Bericht über den Revisionsentwurf der Verfassung der Volksrepublik China), vom 26. 11. 1982. in: 王培英, 中国宪法文献通编 (Wang, Peiying (Hrsg.), Dokumentensammlung über die chinesischen Verfassungen), S. 54.

71 Art. 5 Abs. 4 der Verfassung von 1982.

72 彭真, 关于中华人民共和国宪法修改草案的报告 (Peng, Zhen, Bericht über den Revisionsentwurf der Verfassung), vom 26. 11. 1982. in: 王培英, 中国宪法文献通编 (Wang, Peiying (Hrsg.), Dokumentensammlung über die chinesischen Verfassungen), S. 57.

73 Revision von 1993, 3. Verfassungszusatz. 
sungen von 1975 und von 1978 - weiterhin die Grundlage des Wirtschaftssystems der Volksrepublik, ${ }^{74}$ aber der wirtschaftlichen Reform entsprechend werden die anderen Eigentumsformen allmählich in der Verfassung anerkannt. Am Anfang wird die individuelle Wirtschaft als eine Ergänzung des Gemeineigentums vom Staat unterstützt, ${ }^{75}$ schließlich werden die Wirtschaftsformen des nichtöffentlichen Eigentums als „wichtiger Bestandteil der sozialistischen Marktwirtschaft" bezeichnet. ${ }^{76}$

Nach dem Parteibericht von 1987 ist das „Anfangsstadium des Sozialismus“ eine lange Phase, die von der Vollendung der Verstaatlichung von Privatindustrie und der Kollektivierung der Landwirtschaft bis zur Verwirklichung der sozialistischen Modernisierung ungefähr 100 Jahre (1956 - Mitte des 21. Jahrhunderts) dauert. ${ }^{77}$ Die Grundaufgabe im Anfangsstadium des Sozialismus - die sozialistische Modernisierung muss im Rahmen der „Vier Grundprinzipien“, die von Deng Xiaoping im Jahre 1979 als Leitgedanken aufgestellt wurden, ${ }^{78}$ durchgeführt werden:

- „Unter der Führung der KP und

- angeleitet durch den Marxismus-Leninismus und die Maozedong-Ideen

- werden die Volksmassen aller Nationalitäten weiterhin an der demokratischen Diktatur des Volkes festhalten und

- den sozialistischen Weg folgen." "79

Die Festlegung der „Vier Grundprinzipien“ in der Verfassung gewährleistet die politische und ideologische Permanenz, damit die Wirtschaftsreformen in einer stabilen politischen Lage durchgeführt werden können. Die Verfassung von 1982 wurde nach ihrem Inkrafttreten viermal revidiert (1988, 1993, 1999, 2004), aber die „vier Grundprinzipien“" wurden durch keine der Verfassungsänderungen angetastet.

74 Art. 6 Abs. 1 der Verfassung von 1982.

75 Art. 11 der Verfassung von 1982, Revision von 1988, 1. Verfassungszusatz.

76 Art. 11 Abs. 1 der Verfassung von 1982, Revision von 1999, 16. Verfassungszusatz.

77 赵紫阳, 在中国共产党第十三次全国代表大会上的报告 (Zhao, Ziyang, Report at the 13th National Congress of the Communist Party of China on October 12, 1987), in: 光明日报 (GMRB), 04. 11. 1987.

78 Siehe: 邓小平文选 (1975-1982) (Deng, Xiaoping, Ausgewählte Werke von Deng Xiaoping, 19751982), S. 151.

79 Präambel der Verfassung von 1982, 7. Abschnitt 
Tabelle 6: Die Verfassungen der VR China

\begin{tabular}{|c|c|c|}
\hline Verfassung & Wesen & Stichworte \\
\hline $\begin{array}{l}\text { Das Gemein- } \\
\text { same Pro- } \\
\text { gramm }\end{array}$ & vorläufige Verfassung & $\begin{array}{l}\text { Hauptaufgabe: } \\
\text { Aufbau eines volksdemokratischer Staates }\end{array}$ \\
\hline $\begin{array}{l}\text { Verfassung } \\
\text { von } 1954\end{array}$ & $\begin{array}{l}\text { volksdemokratische Verfas- } \\
\text { sung in der Übergangsperiode }\end{array}$ & $\begin{array}{l}\text { Hauptaufgabe: } \\
\text { sozialistische Industrialisierung und Um- } \\
\text { wandlung von Landwirtschaft, Handwerk, } \\
\text { kapitalistischer Industrie sowie Handel. } \\
\text { Eigentumssystem: } \\
\text { Volkseigentum, Kollektiveigentum, Privat- } \\
\text { eigentum und Kapitalisteneigentum }\end{array}$ \\
\hline $\begin{array}{l}\text { Verfassung } \\
\text { von } 1975\end{array}$ & $\begin{array}{l}\text { sozialistische Verfassung in } \\
\text { der Kulturrevolution }\end{array}$ & $\begin{array}{l}\text { Richtlinien: } \\
\text { Weiterführung der Revolution unter Diktatur } \\
\text { des Proletariats, Klassenkampf, Große De- } \\
\text { mokratie, Verstärkung der Führungsfunktion } \\
\text { der KP Chinas } \\
\text { Eigentumssystem: } \\
\text { Volkseigentum, Kollektiveigentum }\end{array}$ \\
\hline $\begin{array}{l}\text { Verfassung } \\
\text { von } 1978\end{array}$ & $\begin{array}{l}\text { „restaurierende“ } \\
\text { sozialistische Verfassung }\end{array}$ & $\begin{array}{l}\text { Richtlinien: } \\
\text { Klassenkampf, Massenbewegung } \\
\text { Eigentumssystem: } \\
\text { Volkseigentum } \\
\text { Kollektiveigentum }\end{array}$ \\
\hline $\begin{array}{l}\text { Verfassung } \\
\text { von } 1982\end{array}$ & $\begin{array}{l}\text { sozialistische Verfassung im } \\
\text { „Anfangsstadium des Sozia- } \\
\text { lismus“ }\end{array}$ & $\begin{array}{l}\text { Hauptaufgabe: } \\
\text { sozialistische Modernisierung } \\
\text { Richtlinien: } \\
\text { Führung der Partei, sozialistische Ideologie, } \\
\text { Reform und Öffnung } \\
\text { Eigentumssystem: } \\
\text { Gemeineigentum, individuelle Wirtschaft, } \\
\text { Privatwirtschaft }\end{array}$ \\
\hline
\end{tabular}

b) Verfassungsänderung seit 1988

Seit der Festlegung der Grundaufgabe der Modernisierung im Jahre 1978 ist die politische Lage in China stabiler als früher. Aber die rasanten wirtschaftlichen Umwandlungen führten zu häufigen Modifizierungen der Verfassungsregelungen. In etwa 20 Jahren wurde die Verfassung viermal modifiziert. Die häufigen Änderungen der Verfassung beruhen auf den ideologischen Neuerungen der KP Chinas und reflektieren zutreffend die wirtschaftlichen und gesellschaftlichen Wandel.

Die Modifikationen konzentrierten sich zuerst auf wirtschaftliche Reformen. In der Revision von 1988 wurde die Privatwirtschaft wie die individuelle Wirtschaft als Ergänzung der sozialistischen Gemeineigentumswirtschaft vom Staat gestattet und beaufsichtigt. ${ }^{80}$ Später wurde das nichtöffentliche Wirtschaften als „wichtiger Bestandteil der sozialistischen Marktwirtschaft" neben dem öffentlichen Wirtschaften aufgewertet (1999) ${ }^{81}$ und ermuntert (2004). ${ }^{82}$ Der Artikel zur ländlichen Volkskommunen wurde

80 Art. 11 Abs. 2 der Verfassung von 1982, Revision von 1988, 1. Verfassungszusatz.

81 Art. 11 Abs. 1 der Verfassung von 1982, Revision von 1999, 16. Verfassungszusatz. 
1993 gestrichen, stattdessen wurden das landwirtschaftliche Haushaltsverantwortungssystem (1993) und das duale Bewirtschaftungssystem (1999) in Art. 8 Abs. 1 eingeführt. Der Staat führt seit 1993 ,eine sozialistische Marktwirtschaft“ durch, ${ }^{83}$ entsprechend wurden die „staatlichen Betriebe“ danach in „staatseigene Unternehmen“ verwandelt. 84

Der siebte Abschnitt der Präambel, in dem die Grundaufgaben, die Leitgedanken und das Staatsziel festgesetzt wurden, hat am meisten Änderungen erfahren: 1993 wurden „Anfangsstadium des Sozialismus“, „gemäß der Theorie vom Aufbau des Sozialismus mit chinesischer Prägung“, „Festhaltung an Reform und Öffnung“ sowie „Aufbau zu einem wohlhabenden und mächtigen, demokratischen und zivilisierten sozialistischen Staat“ in den siebten Abschnitt eingeschrieben. ${ }^{85} 1999$ wurde betont: „Unser Land wird sich noch lange Zeit im Anfangsstadium des Sozialismus befinden“. „DengXiaoping-Theorie“ als Leitgedanke und „Entwicklung der sozialistischen Marktwirtschaft" wurden 1999 in den siebten Abschnitt aufgenommen. ${ }^{86}$ Die Verfassungsänderung von 2004 ist eine Umsetzung der auf dem 16. Parteitag (2002) vorgegebenen Leitlinien. Die Leitlinien der KP von „Dreifache Repräsentation“, „Förderung der aufeinander abgestimmten Entwicklung der materiellen, politischen und geistigen Zivilisation“ wurden 2004 in die Verfassung neu eingeführt. Außerdem wurde der Satz ,auf dem Weg des Aufbaus des Sozialismus mit chinesischen Prägung“ durch ,auf dem Weg des Sozialismus chinesischer Prägung " verbessert. 87

Die jüngste Verfassungsrevision vom März 2004 ist die bislang umfangsreichste Revision der geltenden Verfassung: insgesamt wurden 14 Verfassungszusätze aufgenommen. Bei dieser Verfassungsrevision wurde nicht nur das Wirtschaftssystem, sondern auch die sozialen Grundrechte der Bürger berücksichtigt. Die Einführung der Errichtung der dem Niveau der wirtschaftlichen Entwicklung entsprechenden Systeme der sozialen Sicherheit ${ }^{88}$ ist auf den ersten Blick der Ausgleich des ungleichmäßigen Wirtschaftswachstums und die Zusicherung eines Teilhaberechts aller Bürger am gesamtwirtschaftlichen Wohlstand. Dieser Verfassungszusatz erscheint aber von noch fundamentalerer Bedeutung für die soziale Sicherheit: Begleitet von anderen wichtigen Modifikationen wie die Einführung der Schutz der Menschenrechte 89 und der Errichtung eines sozialistischen Rechtsstaats ${ }^{90}$ bildet dieser Verfassungszusatz eine der institutionellen Stützen des Staates und zudem eine der Verfassungsgrundlagen für die soziale Sicherheit.

82 Art. 11 Abs. 2 der Verfassung von 1982, Revision von 2004, 21. Verfassungszusatz.

83 Art. 15 der Verfassung von 1982, Revision von 1993, 7. Verfassungszusatz.

84 Art. 7, 16, 42 der Verfassung von 1982, 5., 8., 10. Verfassungszusatz.

85 Präambel der Verfassung, 3. Verfassungszusatz.

86 Präambel der Verfassung, 12. Verfassungszusatz.

87 Präambel der Verfassung, 18. Verfassungszusatz.

88 Art. 14 Abs. 4 der Verfassung von 1982, Revision von 2004, 23. Verfassungszusatz.

89 Neu eingeführt Art: 33 Abs. 3 der Verfassung von 1982, Revision von 2004, 24. Verfassungszusatz.

90 Neu eingeführt Art. 5 Abs. 1 der Verfassung von 1982, Revision von 1999, 13. Verfassungszusatz. 


\section{Tabelle 7: Verfassungsänderungen seit 1988}

\begin{tabular}{|c|c|}
\hline Revision von 1988 & $\begin{array}{l}\text { Art. 11: Anerkennung des nichtöffentlichen Eigentums } \\
\text { Art. 10 Abs. 4: Übertragen der Bodennutzungsrechte }\end{array}$ \\
\hline Revision von 1993 & $\begin{array}{l}\text { Präambel, 7. Abschnitt: Anfangsstadium des Sozialismus; gemäß der } \\
\text { Theorie des Sozialismus mit chinesischer Prägung; Aufbau eines wohl- } \\
\text { habenden und mächtigen, demokratischen und zivilisierten sozialisti- } \\
\text { schen Staates } \\
\text { Präambel, 10. Abschnitt: Bestehen und Entwicklung des Systems der } \\
\text { Mehrparteienzusammenarbeit und der politischen Konsultation unter der } \\
\text { Führung der KP Chinas auf lange Zeit } \\
\text { Art. 7, Art. 42 Abs. 3: ,die staatseigene Wirtschaft“ statt „,der staatlichen } \\
\text { Wirtschaft““ } \\
\text { Art. 8 Abs. 1: das landwirtschaftliche Haushaltsverantwortungssystem } \\
\text { Art. 15: Durchführung der sozialistischen Marktwirtschaft und Verbesse- } \\
\text { rung der Makrosteuerung } \\
\text { Art. 16: das Recht der staatseigenen Unternehmen auf selbständige Be- } \\
\text { wirtschaftung im Rahmen der gesetzlichen Vorschriften } \\
\text { Art. 17: das Recht der kollektiven Wirtschaftsorganisationen auf unab- } \\
\text { hängige wirtschaftliche Tätigkeit im Rahmen der Gesetze } \\
\text { Art. 98: Amtszeit der lokalen Volkskongresse }\end{array}$ \\
\hline Revision von 1999 & $\begin{array}{l}\text { Präambel, 7. Abschnitt: Noch für lange Zeit im Anfangsstadium des } \\
\text { Sozialismus; auf dem Weg des Aufbaus eines Sozialismus mit chinesi- } \\
\text { scher Prägung; Deng-Xiaoping-Theorie } \\
\text { Art. } 5 \text { Abs. 1: Aufbau eines sozialistischen Rechtsstaates } \\
\text { Art. 6: Gemeineigentum als Hauptteil des Wirtschaftssystems, andere } \\
\text { Eigentumsformen entwickeln sich daneben. } \\
\text { Art. } 8 \text { Abs. 1: das duale Bewirtschaftungssystem } \\
\text { Art. 11: die nichtöffentlichen Wirtschaften als wichtiger Bestandteil der } \\
\text { sozialistischen Marktwirtschaft } \\
\text { Art. 28: landesverräterische und andere die Sicherheit des Staats gefähr- } \\
\text { dende Tätigkeiten }\end{array}$ \\
\hline Revision von 2004 & $\begin{array}{l}\text { Präambel, 7. Abschnitt: Dreifache Repräsentation; Sozialismus chinesi- } \\
\text { scher Prägung; die aufeinander abgestimmte Entwicklung der materiel- } \\
\text { len, politischen und geistigen Zivilisation } \\
\text { Präambel, 10. Abschnitt: eine breite patriotische Einheitsfront } \\
\text { Art. } 10 \text { Abs. 3: Entschädigung für Einziehung von Boden } \\
\text { Art. 11 Abs. 2: staatliche Ermunterung, Unterstützung und Leitung des } \\
\text { Nichtöffentlichen Eigentums } \\
\text { Art. 13: Eigentumsrecht der Bürger } \\
\text { Art. 14. Abs. 4: Errichtung und Vervollständigung des Systems der sozia- } \\
\text { len Sicherheit } \\
\text { Art. } 33 \text { Abs. 3: Schutz der Menschenrechte } \\
\text { Art. 59 Abs. 1: Abgeordneten des NVK } \\
\text { Art. 67, Art. 80, Art. 89: Notstand } \\
\text { Art. 81: Ausübung der Staatsangelegenheiten vom Staatspräsident } \\
\text { Art. 98: Amtszeit der lokalen Volkskongresse } \\
\text { Art. 136 Abs. 2: Nationalhymne }\end{array}$ \\
\hline
\end{tabular}




\section{Volkssouveränität und Demokratischer Zentralismus}

Gemäß Art. 2 der Verfassung von 1982 gehört alle Macht in der Volksrepublik China dem Volk. Die Organe, durch die das Volk die Staatsmacht ausübt, sind der Nationale Volkskongress und die lokalen Volkskongresse der verschiedenen Ebenen. Das höchste Organ der Staatsmacht ist der Nationale Volkskongress mit seinem Ständigen Ausschuss. ${ }^{91}$ Der Nationalen Volkskongress übt folgende Kompetenzen aus:

- Gesetzgebung,

- Überwachung der Durchführung der Verfassung,

- Wahl, Ernennung und Abberufung von Staatsführern,

- Entscheidungen über wichtige Staatsangelegenheiten. ${ }^{92}$

Die Staatsmacht wird durch das Organisationsprinzip des „Demokratischen Zentralismus“ zentralisiert. Der Demokratische Zentralismus bedeutet nach der Auffassung von Mao, Zedong „Zentralisierung auf der Basis der Demokratie, und Demokratie unter zentraler Führung".93 In der Verfassung von 1982 wird der Demokratische Zentralismus unter drei Aspekten betrachtet, nämlich Demokratische Wahlen, Gewaltenkonzentration und Vertikaler Zentralismus (Art. 3 Abs. 1 der Verfassung von 1982).

Obwohl in der Volksrepublik keine allgemeinen Wahlen existieren, heißt es in Art. 3 Abs. 2 der Verfassung von 1982: „Der Nationale Volkskongress und die lokalen Volkskongresse der verschiedenen Ebenen werden durch demokratische Wahlen gebildet, sind dem Volk verantwortlich und stehen unter seiner Aufsicht." Während die Abgeordneten der Volkskongresse der Kreis- und Gemeindenebenen von den Wählern direkt gewählt werden, werden die Abgeordneten der Volkskongresse von der Kreisebene aufwärts indirekt gewählt. Deng, Xiaoping hat gehofft, dass die allgemeine Wahl in der Mitte des 21. Jahrhunderts verwirklicht werden kann. 94

Das Kompetenzverteilungsprinzip zwischen Verwaltung, Rechtsprechung und Staatsanwaltschaft ist nicht die gegenseitige Kontrolle, sondern die arbeitsteilige Kooperation und Koordination. „Alle Organe der Staatsverwaltung, alle Staatsorgane der Rechtsprechung und alle Organe der Staatsanwaltschaft werden von den Volkskongressen geschaffen, sind ihnen verantwortlich und unterliegen ihrer Aufsicht" (Art. 3 Abs. 3 der Verfassung von 1982).

Nach Art. 3 Abs. 4 der Verfassung von 1982 bedeutet Vertikaler Zentralismus, dass „die Teilung der Funktionen und Gewalten zwischen den zentralen und den lokalen Staatsorganen [...] sich von dem Prinzip leiten [lässt], die Initiative und den Enthusias-

91 Art. 57 der Verfassung von 1982.

92 Art. 62-64 der Verfassung von 1982.

93 毛泽东选集 (Ausgewählte Werke von Mao Zedong), S. 1058.

94 邓小平文选第三卷 (Deng, Xiaoping, Ausgewählte Werke von Deng Xiaoping, Dritter Band), S. 220. 
mus der lokalen Organe unter der einheitlichen Leitung der Zentralen voll und ganz zu entfalten“.

Der Demokratische Zentralismus wird seit Gründung der Volksrepublik als das grundlegende Organisations- und Führungsprinzip in allen der vier Verfassungen und der vorläufigen Verfassung ausdrücklich festgehalten. Die Volksrepublik China hat von Anfang an nicht nur die Gewaltenteilung und die Mehrparteienpolitik der westlichen Staaten, sondern auch das Zweikammersystem sowie den Föderalismus, die von seinem Vorbild in den 1950er Jahren - der Sowjetunion - eingeführt wurden, abgelehnt.

Die Entscheidung Chinas, seinen traditionellen hochgradigen Zentralismus zu bewahren, beruht auf zwei Gründen. Zunächst basiert die Entscheidung auf den historischen Erfahrungen. China ist ein Vielvölkerstaat und hat eine große Bevölkerungszahl. Die Entwicklungsdisparitäten zwischen den verschiedenen Regionen sind relativ groß. Dies führte in der chinesischen Geschichte oft zu Konflikten und Kriegen. Die chinesische Geschichte hat wiederholt bewiesen: Nur wenn China unter der Führung einer starken Zentralmacht seine Einheit und Stabilität aufrechterhalten kann, kann das Land blühend und mächtig sein und das Volk kann in Frieden leben. ${ }^{95}$

\section{Tabelle 8: Staatsorgane der VR China}

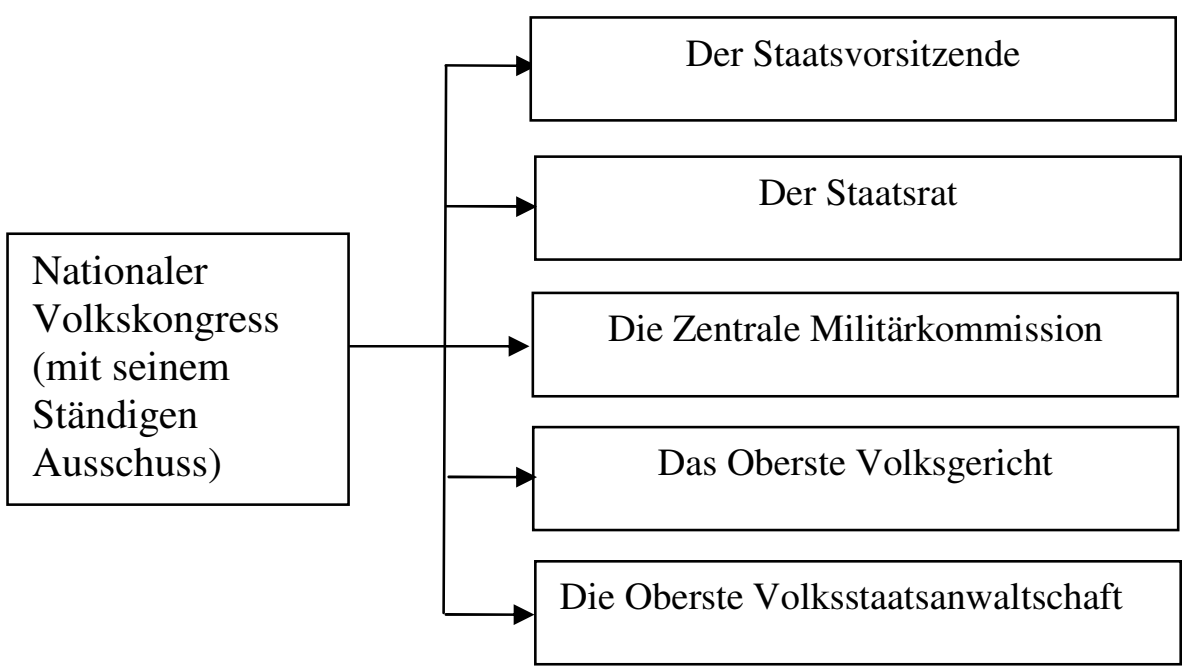

Diese Entscheidung beruht auch auf den gegenwärtigen wirtschaftlichen und politischen Lagen. Die Volksrepublik konzentriert sich seit ihrer Gründung auf den Aufbau einer neuen ökonomischen Basis des Staates. Ein zentralisiertes Einkammersystem kann - nach der Meinung von Deng, Xiaoping - viele unnötige Verwicklungen vermeiden. Wenn die politische Orientierung richtig sei, sei dieses System sehr vorteilhaft. 96 Die staatliche Entwicklungsstrategie und die staatliche Aufgabe der Modernisierung können

95 国务院新闻办公室，中国的民主政治建设白皮书 (Presseamt des Staatsrats, Aufbau der politischen Demokratie in China), vom 19. 10. 2005.

96 邓小平文选第三卷 (Deng, Xiaoping, Ausgewählte Werke von Deng Xiaoping, Vol. 3), S. 220. 
dadurch über eine lange Periode konsequent umgesetzt werden, alle Ressourcen und Kräfte des Staates können darauf konzentriert werden. ${ }^{97}$ Kurz gesagt, das System des Volkskongresses und die Festlegung des Demokratischen Zentralismus entsprechen der Forderung der Effizienz, die für die Modernisierung eines großen, armen und komplexen Entwicklungslandes sehr wichtig ist.

\section{Führungsrolle der KP Chinas}

Die Führungsrolle der KP Chinas, die in der Verfassung ausdrücklich festgelegt ist, ${ }^{98}$ ist einerseits wie das parlamentarische Einkammersystem der konzentrierte Ausdruck des chinesischen Organisationsprinzips des hochgradigen Zentralismus, andererseits die Gewährleistung des sozialistischen Wegs der chinesischen Modernisierung. Die Führung der KP wird allerdings nicht durch die Verfassung begründet, sondern lediglich als eine Tatsache juristisch abgesichert. 99

Die Legitimität der Führungsrolle der KP in der Verfassung basiert auf ihrer Stellung als „die Vorhut der chinesischen Arbeiterklasse und zugleich die Vorhut des chinesischen Volks und der chinesischen Nation".100 Auf dem 16. Parteitage im November 2002 wurde die Formel der „Dreifachen Repräsentation“ in das Statut der KP und später im Jahre 2004 in die Verfassung eingeführt. Danach repräsentiert die KP Chinas die fortschrittlichen Produktivkräfte, die moderne Zivilisation und die Grundinteressen der breiten Bevölkerung. Das bedeutet, dass die KP sich der gesellschaftlichen Entwicklung anpassend von einer revolutionären Partei zu einer Volkspartei geändert hat. Die KP behält also ihre Eigenschaft „,der Elite des chinesischen Volks“. Dadurch wird sie legitimiert, das chinesische Volk im Modernisierungsprozess weiter zu führen.

Die Führung der KP ist zurzeit hauptsächlich eine politische, ideologische und personelle Führung. Das heißt, die KP legt die politischen Richtlinien fest, die die staatlichen Entwicklungsrichtungen und die ideologischen Orientierungen bestimmen. Die politischen Richtlinien der Partei werden vom Volkskongress durch Tätigkeit der Gesetzgebung in die Verfassung und die Gesetze umgesetzt. Die Partei führt das Volk beim Erlass und bei der Befolgung sowie Vollstreckung der Verfassung und der Gesetze. Durch die organisatorische und personelle Führung der Partei werden die Bestimmungen der Partei durchgeführt. ${ }^{101}$ Die KP empfiehlt Funktionäre zu führenden Positionen der staatlichen Organisationen. Die Parteikomitees in den verschiedenen Organisa-

97 国务院新闻办公室, 中国的民主政治建设白皮书 (Presseamt des Staatsrats, Aufbau der politischen Demokratie in China), vom 19. 10. 2005.

98 Präambel der Verfassung von 1982, 7. Abschnitt.

99 Senger, in: ZfRV, 2006/7, S. 48.

100 中国共产党章程 (Statut der Kommunistischen Partei Chinas), in: 人民日报 (RMRB), 26. 10. 2007.

101 蔡定剑, 中国人民代表大会制度 (Cai, Dingjian, The Institution of the Chinese People's Congress), S. $32 \mathrm{ff}$. 
tionen der jeweiligen Ebenen und ihre Mitglieder setzen die politischen Richtlinien der Partei sowie wichtige Entscheidungen um. ${ }^{102}$

Volkssouveränität, Führung durch die KP Chinas und Aufbau eines Rechtsstaats sind die drei Kernelemente der politischen Kultur Chinas, die in der geltenden chinesischen Verfassung festgelegt sind. Die Beziehung der drei Elemente wird zurzeit wie folgend gefasst: Das höchste Organ der Staatsmacht ist der Nationale Volkskongress. Die KP steht faktisch an der Spitze des staatlichen politischen Systems, genießt die höchste politische, organisatorische und ideologische Kontrolle über staatliche Aktivitäten. Demgegenüber hat die Verfassung die höchste Autorität im Rechtssystem. 103

Bis heute gestaltet sich noch keine wirkliche Machtbeschränkung für die KP, aber parallel zur Vertiefung der chinesischen Modernisierung und der gesellschaftlichen Umwandlung gibt es eine langsame, dennoch andauernde Änderung in der Beziehung der drei Kernelemente. Erst in der Verfassung von 1982 wird die Führung der KP konstitutionell beschränkt: Keine Organisation oder kein Individuum darf das Privileg genießen, die Verfassung und die Gesetze zu überschreiten. ${ }^{104}$ Nach dem Wortlaut der Verfassung muss die KP die Verfassung zur grundlegenden Richtlinie ihres Handelns erheben und ist verpflichtet, die Würde der Verfassung zu schützen und die Durchführung der Verfassung zu gewährleisten. ${ }^{105}$ Im Statut der KP wird auch festgehalten: Die Partei müsse im Rahmen der Verfassung und der Gesetze des Staates handeln. ${ }^{106}$ Die Trennung von Partei, Staat und Regierung ist der erste Schritt der politischen Reform. ${ }^{107}$ Die Führung der Partei beschränkt sich zurzeit auf die politische Führung Festlegung der politischen Prinzipien, politischen Richtungen, wichtigen politischen Entscheidungen sowie Personalempfehlungen an die Staatsorgane. ${ }^{108}$ Die Hauptdurchführungsweise der politischen Führung hat sich auch geändert. Die politischen Richtlinien der Partei sollen jetzt nicht mehr direkt das Recht und die Regierungsentscheidungen ersetzen, sondern sie sollen im Gesetzgebungsverfahren zu Recht und damit zum Staatswillen werden. 109

102 Eine ausführliche Übersicht siehe: Heilmann, Das politische System der Volksrepublik China, S. 89.

103 Vgl. 蔡定剑, 中国人民代表大会制度 (Cai, Dingjian, The Institution of the Chinese People's Congress), S. 31.

104 Art. 5 Abs. 5 der Verfassung von 1982.

105 Präambel der Verfassung von 1982, 13. Abschnitt.

106 Allgemeine Grundsätze des Statuts der Kommunistischen Partei Chinas.

107 邓小平文选第三卷 (Deng, Xiaoping, Ausgewählte Werke von Deng Xiaoping, Dritter Band), S. $176 \mathrm{ff}$.

108 赵紫阴, 在中国共产党第十三次全国代表大会上的报告 (Zhao, Ziyang, Report at the 13th National Congress of the Communist Party of China), vom 12. 10. 1987, in: 光明日报 (GMRB), 04. 11. 1987.

109 Zhao, Ziyang, Report at the 13th National Congress of the Communist Party of China von 1987. 


\section{Grundrechte und Grundpflichten der Bürger}

In der Verfassung von 1954 wurden die Grundrechte und die Grundpflichten der Bürger in 19 Artikeln (Art. 85-103) geregelt, davon betreffen 15 Artikel (Art. 85-99) die Grundrechte und vier Artikel die Grundpflichten der Bürger (Pflicht der Befolgung der Verfassung und Gesetze; Pflicht der Wahrung des öffentlichen Eigentums und der öffentlichen Ordnung; Pflicht der Entrichtung der Steuern; Pflicht der Verteidigung des Staates). Die Verfassung von 1982 hat im Prinzip die Vorschriften der Verfassung von 1954 über Grundrechte übernommen und nur auf die Freizügigkeit der Bürger verzichtet.

Nach Art. 33-56 (Kapitel II der Verfassung von 1982) besitzen alle Bürger der Volksrepublik folgende Grundrechte und Grundpflichten:

- Gleichheit vor dem Recht,

- das aktive und das passive Wahlrecht,

- Freiheit der Rede, der Publikation, der Versammlung, der Vereinigung, der Durchführung von Straßenumzügen und Demonstrationen,

- Glaubensfreiheit,

- Freiheit der Person,

- Persönliche Würde,

- Unverletzlichkeit der Wohnung,

- Korrespondenzfreiheit,

- Freiheit zur Äußerung von Kritik, Vorschläge, Anrufung, Anklage sowie Anzeige gegenüber Staatsorgan oder Staatsfunktionär, Recht auf Schadensersatz infolge der Verletzung der Bürgerrechte durch Staatsorgane oder Staatsfunktionäre,

- Recht und Pflicht zu arbeiten,

- Recht auf Erholung,

- Rente und Sozialversicherung,

- Ausbildung,

- Freiheit zur wissenschaftlichen Forschung, zum literarischen und künstlerischen Schaffen und zu anderen kulturellen Betätigungen,

- Gleichheit von Mann und Frau,

- Schutz für Ehe, Familie, Mutter und Kind, Pflicht zur Familienplanung, Erziehung und Unterhalt,

- Sicherung der Einheit des Landes und Geschlossenheit aller Nationalitäten,

- Verteidigung des Staates, Militärdienst,

- Entrichtung von Steuern,

Dieser Grundrechtskatalog stellt eine ausführliche Auflistung dar. Allerdings werden die Grundrechte der Bürger in China unter dem Vorbehalt der kollektiven Interessen verstanden und gewährleistet. In der Ideologie des Sozialismus ist die Gleichheit ein erstrangiger Ausdruck der sozialen Gerechtigkeit. Demzufolge wird die Gewährleistung der kollektiven Interessen - das Recht auf allgemeine Existenz und Entwicklung - als 
vorrangiges Ziel berücksichtigt, ${ }^{110}$ obwohl sie nicht ausdrücklich auf der Liste der Grundrechte in der Verfassung steht. Aus dem Verfassungstext über die staatliche Aufgabe im Anfangsstadium des Sozialismus - die Kräfte auf die sozialistische Modernisierung zu konzentrieren ${ }^{111}$ - kann man den Kerngedanken über Grundrechte und Grundpflichten der Bürger erfassen: Den Lebensstandard des Volkes von der Armut zur ,,ausreichenden Versorgung mit Kleidung und Nahrung“ dann zu einem „Kleinen Wohlstand" zu verbessern,112 ist die Aufgabe des Staates. Der Einzelne steht auch in der Pflicht, sich dieser Aufgabe zu widmen.

Die staatliche Verantwortung gegenüber Einzelnen wird ausführlich geregelt. Für die gesellschaftliche Entwicklung und die Lebensstandardsicherung der Bürger muss der Staat Verantwortung auf sich nehmen. Kapitel I der Verfassung von 1982 (Allgemeine Grundsätze) enthält in großem Maße Regelungen über die staatliche Verantwortung für die Wirtschaftsentwicklung, den Aufbau des Rechtsstaates und das Sozialwesen. Im Kapitel II wird die staatliche Pflicht zur Gewährleistung der Grundrechte der Bürger insbesondere der sozialen Grundrechte, z. B. soziale Sicherung, Bildung, Schutz von Familien - ausführlich dargestellt.

Es ist aber schwer zu unterscheiden, welche kollektiven Gedanken der Verfassung der chinesischen Tradition sowie Geschichte und welche der sozialistischen Ideologie entstammen. In der chinesischen Gesellschaft sind die Ideen über die öffentliche Gewalt, die Freiheit der Bürger und die positiven Rechte des Einzelnen im Vergleich mit den westlichen Gedanken sehr unterschiedlich. ${ }^{113}$ Der traditionelle Gedanke über die Verschmelzung von Staat, Gesellschaft und Individuum lebt bis heute noch in der chinesischen Verfassung weiter. Manche Intellektuelle sind auch der Auffassung, dass der Staat und die Bürger sich zusammenschließen sollten, um ein wohlhabendes und mächtiges China aufzubauen. Dies sei viel wichtiger als die Betonung der Grundrechte des Einzelnen. ${ }^{114}$

Mit diesem Gedanken und der Forderung nach der Konzentration aller Kräfte im Modernisierungsprozess wird ein Mechanismus für die Machtbeschränkung und den Grundrechtsschutz aufgebaut, aber die wirtschaftliche Entwicklung hat Priorität. In der Verfassung findet sich zwar schon ein Grundrechtskatalog, aber er enthält lediglich einen Auftrag an den Gesetzgeber, den Grundrechtsschutz durch einfache Gesetze zu

110 郑贤君, 论我国宪政模式的走向 (Zheng, Xianjun, Verfassungsmodell der Volksrepublik China), in: 中国法学 (China Legal Science), 2003/1, S. 19; 国务院新闻办公室, 中国的人权状况 (Presseamt des Staatsrats, Menschenrechtssituation in China), vom 01. 11. 1991.

111 Präambel der Verfassung von 1982, 7. Abschnitt.

112 赵紫阴, 在中国共产党第十三次全国代表大会上的报告(Zhao, Ziyang, Report at the 13th National Congress of the Communist Party of China), vom 12. 10. 1987.

113 Ausführlich vgl. 陈端洪, 宪治与主权 (Chen, Duanhong, Constitutionality and Sovereignty), S. $28 \mathrm{ff}$.

114 Siehe: 王人博, 中国近代的宪政思潮 (Wang, Renbo, Constitutional Trend in modern China), S. 66; 房宁, 影响当代中国的三大社会思潮 (Fang, Ning, Drei wichtigste ideologische Tendenzen in der gegenwärtigen Epoche Chinas), in: 陈明明, 权利, 责任与国家 (Chen, Mingming (Hrsg.), Recht, Verantwortung und Staat), S. 265ff. 
konkretisieren. ${ }^{115}$ Eine Institution für die Prüfung der Verfassungsmäßigkeit von Rechtnormen und Verwaltungsakten wird in der Verfassung und in dem Gesetzgebungsgesetz konstruiert. In der Praxis funktioniert sie aber noch nicht. Eine unmittelbare Bindung der Staatsgewalt an die Grundrechte existiert bis heute noch nicht.

Parallel zum Eintritt in die internationalen wirtschaftlichen Institutionen zeigt das chinesische Verständnis für Menschenrechte allmählich eine Tendenz hin zur beschränkten Anerkennung der westlichen Wertegemeinschaft. Bis heute hat China 26 internationale Menschenrechtskonventionen ratifiziert oder unterzeichnet. ${ }^{116} 2001$ ratifizierte der Nationale Volkskongress den Internationalen Pakt über wirtschaftliche, soziale und kulturelle Rechte. Der internationale Pakt über bürgerliche und politische Rechte wurde im Oktober 1998 von der Zentralregierung unterzeichnet, aber bislang noch nicht vom Nationalen Volkskongress ratifiziert. Im März 2004 wurde eine Verfassungsänderung vom Nationalen Volkskongress angenommen, wodurch „der Staat die Menschenrechte respektiert und schützt" (Art. 33 Abs. 3) in der Verfassung festgehalten wurde. Dies kann einerseits als politisches Signal für einen „Anschluss an den internationalen Menschenrechtsdiskurs“, andererseits als Rahmen für die zukünftige Gesetzgebungsarbeit gewertet werden. ${ }^{117}$

\section{Kleine Schritte des chinesischen Konstitutionalismus?}

Nach der Kulturrevolution wurde die Forderung nach einem System zur Einschränkung und Überwachung von Machtbefugnissen des Staates immer wieder gestellt. Bei der Verfassungsänderung von 1982 wurde die Einsetzung eines Zweikammersystems sowie einer Verfassungskommission beim Ständigen Ausschuss des Nationalen Volkskongresses von der Kommission für Verfassungsänderung diskutiert. ${ }^{118}$ Bei der Revision von 2004 gab es wieder Vorschläge von Juristen für die Einrichtung einer Verfassungsüberwachungskommission und für die Feststellung der Unabhängigkeit des Volksgerichts. 119 Diese Vorschläge fanden bislang keine Mehrheit im Nationalen Volkskongress. In der Verfassung bleibt der Nationale Volkskongress mit seinem Ständigen Ausschuss das einzige Organ für die Überwachung der Durchführung der Verfassung. ${ }^{120}$ Die Forderung der Bürger, insbesondere der Juristen, eine spezielle Institution

115 Ahl, in: Blätter für deutsche und internationale Politik, 2006/11, S. 1385.

116 Ausführlich: Vierter Teil, Umsetzung und Einfluss der Menschenrechtskonventionen in China.

117 Vgl. Holbig, in: China aktuell, 2004/4, S. 267; Ahl, in: Blätter für deutsche und internationale Politik, 2006/11, S. 1385.

118 蔡定剑, 宪法精解 (Cai, Dingjian, Constitution: A intensive Reading), S. 91ff.

119 蔡定剑, 宪法精解 (Cai, Dingjian, Constitution: A intensive Reading), S. 120.

120 Art. 62 der Verfassung von 1982:

„Der Nationale Volkskongress übt folgende Funktionen und Gewalten aus: (1) Abänderung der Verfassung; (2) Überwachung der Durchführung der Verfassung; (3) Ausarbeitung und Abänderung von grundlegenden Gesetzen über Strafsachen, zivile Angelegenheiten, die Staatsorgane und andere Angelegenheit; ..." 
für die Verfassungsmäßigkeitsprüfung und Verfassungsstreitigkeiten einzurichten, hat noch keinen großen Erfolg.

\section{Forderung nach einer Kontrolle der Verfassungsmäßigkeit}

a) Organe der Kontrolle der Verfassungsmäßigkeit

Das chinesische System der Kontrolle der Verfassungsmäßigkeit basiert auf dem Prinzip der Volkssouveränität und der Demokratischen Zentralismus: Der Nationale Volkskongress übt als das höchste Staatsorgan im Namen des Volkes die Staatsmacht einheitlich und allseitig aus. Er ist nicht nur das höchste Organ für die Gesetzgebung, sondern auch das Organ für die Überwachung der Durchführung der Verfassung. ${ }^{121}$ Der Nationale Volkskongress hat auch die Befugnis, die von seinem Ständigen Ausschuss festgelegte Gesetzte zu ändern oder zu annullieren und die vom Ständigen Ausschuss genehmigten Autonomie- und Einzelverordnungen, die gegen die Verfassung verstoßen, aufzuheben. ${ }^{122}$

Für die Kontrolle der Verfassungsmäßigkeit ist der Ständige Ausschuss des Nationalen Volkskongresses hauptsächlich zuständig. Gemäß Art. 67 der Verfassung von 1982 und $\S 88$ Abs. 2 Gesetzgebungsgesetz übt der Ständige Ausschuss des Nationalen Volkskongress die gesamten Funktionen der Verfassungsmäßigkeitsprüfung aus:

- Auslegung der Verfassung und Überwachung ihrer Durchführung (Art. 67 Abs. 2 der Verfassung),

- Auslegung der Gesetze (Art. 67 Abs. 4 der Verfassung),

- Aufhebung von administrativen Verordnungen und Vorschriften, Entscheidungen und Anordnungen des Staatsrats, die im Widerspruch zur Verfassung und zu den Gesetzen stehen (Art. 67 Abs. 7 der Verfassung),

- Aufhebung von lokalen Verordnungen und Vorschriften und Beschlüssen der Organe der Staatsmacht der Provinzen, autonomen Gebiete und regierungsunmittelbaren Städte, die im Widerspruch zur Verfassung, zu den Gesetzen und zu administrativen Verordnungen und Vorschriften stehen (Art. 67 Abs. 8 der Verfassung).

Im Gesetzgebungsgesetz wird die Zuständigkeit für die Änderung oder Aufhebung der Gesetze, Exekutivrechtsnormen, territorialen Rechtsnormen, Autonomie- und Einzelverordnungen sowie Verwaltungsvorschriften weiter konkreter geregelt. Für die Änderung und Aufhebung der ,nicht angemessenen“ Vorschriften der Abteilungen des Staatsrats und der territorialen Regierungen ist der Staatsrat zuständig. ${ }^{123}$ Die von den Ständigen Ausschüssen der lokalen Volkskongresse erlassenen oder genehmigten territorialen Rechtsnormen können von den lokalen Volkskongressen geändert oder aufgehoben werden. ${ }^{124}$ Die Ständigen Ausschüsse der lokalen Volkskongresse haben das

121 Art. 62 Abs. 2 der Verfassung von 1982.

122 Art. 62 Abs. 3 der Verfassung von 1982; § 88 Abs. 1 Gesetzgebungsgesetz.

$123 \S 88$ Abs. 3 Gesetzgebungsgesetz.

$124 \S 88$ Abs. 4 Gesetzgebungsgesetz. 
Recht, unzweckmäßige Vorschriften aufzuheben, die von der Volksregierung auf derselben Ebene festgelegt worden sind. ${ }^{125}$ Die Regierungen auf Provinzebene können die von den Regierungen auf niedrigerer Ebene festgelegten Vorschriften ändern oder aufheben. 126

\section{b) Antragsberechtigung der Kontrolle der Verfassungsmäßigkeit}

Gemäß $§ 90$ des Gesetzgebungsgesetzes können nicht nur die Staatsorgane, sondern auch gesellschaftliche Körperschaften, Unternehmen und Institutionen sowie Bürger einen Antrag auf die Verfassungsmäßigkeitsprüfung im Ständigen Ausschuss des Nationalen Volkskongresses stellen. Die Regelungen über die verschiedenen Antragssubjekte sind aber unterschiedlich.

Wenn der Staatsrat, die Zentrale Militärkommission, das Oberste Volksgericht, die Oberste Volksstaatsanwaltschaft oder der Ständige Ausschuss der Volkskongresse auf Provinzebene der Ansicht ist, dass Exekutivrechtsnormen, territoriale Rechtsnormen oder Autonomie- oder Einzelverordnung der Verfassung oder den Gesetzen widersprechen, können sie schriftlich verlangen, dass der Ständige Ausschuss des Nationalen Volkskongresses dies prüft. Die Arbeitsorgane des Ständigen Ausschusses teilen die Sache dem betreffenden Fachausschuss zu, der die Prüfung durchführt und seine Ansicht dazu vorlegt ( $\$ 90$ Abs. 1 Gesetzgebungsgesetz).

Demgegenüber können andere als die im vorigen Absatz genannten Staatsorgane, gesellschaftliche Körperschaften, Unternehmen und Institutionen sowie Bürger sich schriftlich mit dem Vorschlag an den Ständigen Ausschuss des Nationalen Volkskongresses wenden, eine Überprüfung durchzuführen. Die Arbeitsorgane des Ständigen Ausschusses prüfen den Vorschlag und übergeben die Sache erforderlichenfalls dem betreffenden Fachausschuss, der die Prüfung durchführt und seine Ansicht dazu vorlegt (§ 90 Abs. 2 Gesetzgebungsgesetz).

Wenn Fachausschüsse des Nationalen Volkskongresses bei der Prüfung zu der Ansicht gelangen, dass die oben erwähnten rechtlichen Normen im Widerspruch zur Verfassung oder zu Gesetzen stehen, können sie dem festlegenden Organ schriftlich die Ansicht vorlegen, zu der sie bei der Prüfung gelangt sind. Das festlegende Organ muss die Vorschrift innerhalb von zwei Monaten überprüfen und seine Ansicht zu ihrer Änderung oder Nichtänderung vorlegen. Wenn das festlegende Organ die Vorschrift nicht ändert, können der Rechtsausschuss und die betreffenden Fachausschüsse des Nationalen Volkskongresses schriftlich einen Vorschlag zur Aufhebung der Konferenz des Ausschussvorsitzenden vorlegen. 127

$125 \S 88$ Abs. 5 Gesetzgebungsgesetz.

$126 \S 88$ Abs. 6 Gesetzgebungsgesetz.

$127 \S 91$ Gesetzgebungsgesetz. 
c) Der gegenwärtige Zustand der Kontrolle der Verfassungsmäßigkeit und der SunZhigang Fall

Das chinesische System der Kontrolle der Verfassungsmäßigkeit umfasst die vorherige Prüfung und die nachträgliche Prüfung. ${ }^{28}$ Bislang hat der Nationale Volkskongress nur die Befugnis der vorherigen Prüfung ausgeübt: Er hat 1990 und 1993 die Bestimmungen angenommen, dass die Grundgesetze der Sonderverwaltungsregionen Hongkong und Macao „verfassungsmäßig“ sind. ${ }^{129}$ Das nachträgliche Prüfungsrecht wird bis heute noch nicht wirklich ausgeführt. Weil die staatlichen Institutionen nach dem konzentrierten Organisationsprinzip der ,,arbeitsteiligen Kooperation und Koordination" funktionieren, werden die Streitigkeiten zwischen den Staatsorganen normalerweise durch interne Konsultationen gelöst. Demzufolge ist es in der Praxis kaum möglich, die Verfassungsmäßigkeitsprüfung durch die Staatsorgane auf Verlangen vorzulegen.

Der erste Vorschlag der Bürger an den Ständigen Ausschuss des Nationalen Volkskongresses, die vom Staatsrat im Jahre 1982 erlassenen „Maßnahmen zur Unterbringung und Rückführung von Obdachlosen in den Städten“130 zu prüfen, wurde am 15. 05. 2003 vorgelegt. Bei diesem Vorschlag handelt es sich um den Sun-Zhigang Fall:

Sun, Zhigang war ein 27-Jähriger aus der Provinz Hubei. Er arbeitete als Grafiker für eine Kleidungsfirma in Guangzhou (die Hauptstadt der Provinz Guangdong). Am 17. März 2003 wurde er in der Nacht von der Polizei auf der Straße aufgefordert, seinen Personalausweis vorzuzeigen. Weil er keinen Ausweis dabei hatte, wurde er von der Polizei gemäß den „Maßnahmen zur Unterbringung und Rückführung von Obdachlosen in den Städten“ ins Polizeibüro mitgenommen und später als Obdachloser aufgenommen. Im Auffanglager wurde er von acht Insassen verprügelt und erlag am 20. März 2003 seinen schweren Körperverletzungen. ${ }^{131}$

Das Mittlere Volksgericht Guangzhou entschied am 09. 06. 2003 den Fall als Körperverletzung mit Todesfolge. Die angeklagten Insassen des Auffanglagers wurden wegen Körperverletzung, ein Polizist und fünf Angestellte des Auffanglagers wurden wegen Dienstvernachlässigung zu Todesstrafen oder Freiheitsstrafen verurteilt. Die Familie von Sun, Zhigang bekam eine staatliche Entschädigung. Aber der Fall entwickelte sich weiter. Am 14. 05. 2003 haben drei Juristen sich mit einem schriftlichen Vorschlag an den Ständigen Ausschuss des Nationalen Volkskongresses gerichtet. Sie sind der Auffassung, dass die „Maßnahmen zur Unterbringung und Rückführung von Obdachlosen in den Städten“ (Verwaltungsrechtsnormen des Staatsrats) den Verwaltungsbehör-

128 牛龙云, 从孙志刚事件透视中国违宪审查制度 (Niu, Longyun, Perspektive des chinesischen Systems der Kontrolle der Verfassungsmäßigkeit aus dem Sung-Zhigang Fall), in: 瞭望 (Liaowang), vom 05. 06. 2004.

129 Siehe: 王振民, 中国违宪审查制度 (Wang, Zhenmin, Das chinesische System der Kontrolle der Verfassungsmäßigkeit), S. 109ff.

130 城市流浪乞讨人员收容遣送办法 (Maßnahmen zum Unterbringung und Rückführung von Obdachlosen in den Städten), 国发 (1982) 79号, vom 12. 05. 1982, aufgehoben am 01. 08. 2003.

131 Urteil des mittleren Volksgerichts Guangzhou über Sun-Zhigang Fall, vom 09. 06. 2003, http://www.lawtime.cn/info/wenshu/pjxscpwsyishen/2006110942543.html (Stand: 15. 07. 2010). 
den die Befugnis erteile, die körperliche Freiheit der Bürger zu rauben oder zu beschränken. Dies verstoße gegen die Verfassung und das Gesetzgebungsgesetz. Gemäß 8 Abs. 5 Gesetzgebungsgesetz können die Zwangsmaßnahmen und Sanktionen, welche die körperliche Freiheit beschränken, nur durch Gesetze festgelegt werden. Die „Maßnahmen zur Unterbringung und Rückführung von Obdachlosen in den Städten“ gehören deswegen zu den „die Zuständigkeit überschrittenen“132 und „gegen Bestimmungen höherrangigen Rechts verstoßenen"133 Verwaltungsrechtsnormen. Sie sollten nach § 87 und $\S 88$ Gesetzgebungsgesetz geändert oder aufgehoben werden. ${ }^{134}$

Die offiziellen Behörden bewahrten über die Verfassungsmäßigkeitsprüfung Stillschweigen, aber ein Beamter der Nachrichtenbehörde des Ständigen Ausschusses des Nationalen Volkskongresses hat am 05. 06. 2004 einen Artikel veröffentlicht. ${ }^{135}$ Damit hat er „das mögliche Verfahren und das Ergebnis dieses Falles“ analysiert: Sind der betreffende Fachausschuss und der Rechtsausschuss des Nationalen Volkskongresses bei der Überprüfung der Ansicht, dass die „Maßnahmen zur Unterbringung und Rückführung von Obdachlosen in den Städten“ der Verfassung oder Gesetzen widersprechen, können sie dem Staatsrat eine schriftliche Überprüfungsansicht vorlegen. Der Staatsrat entscheidet selbst über die Aufhebung oder Änderung der Maßnahmen. Es ist kaum möglich, diese Maßnahmen der Versammlung des Ständigen Ausschusses zur Beratung und Entscheidung zu unterbreiten. ${ }^{136}$

Der Staatsrat hat dieses Mal sehr schnell auf die Berufung der Bürger reagiert. Am 20. 06. 2003 wurden die „Verwaltungsmaßnahmen zur Hilfe von Obdachlosen in den

$132 \S 87$ Abs. 1 Gesetzgebungsgesetz.

$133 \S 87$ Abs. 2 Gesetzgebungsgesetz.

134 Ausführlich siehe: 王振民, 中国违宪审查制度 (Wang, Zhenmin, Das chinesische System der Verfassungsmäßigkeitsprüfung), S. $157 \mathrm{ff}$.

135 牛龙云, 从孙志刚事件透视中国违宪审查制度 (Niu, Longyun, Perspektive des chinesischen Systems der Kontrolle der Verfassungsmäßigkeit aus Sung-Zhigang Fall), in: 瞭望 (Liaowang), vom 05. 06. 2004.

$136 \S 91$ Gesetzgebungsgesetz:

„Kommt der betreffende Fachausschuss des NVK bei der Überprüfung zu der Ansicht, dass Exekutivrechtsnormen, lokale Verordnungen, Autonomie-Verordnungen und Einzelverordnungen der Verfassung oder Gesetzen widersprechen, kann er den erlassenden Behörde eine schriftliche Überprüfungsansicht vorlegen; es kann auch ein vom Rechtsausschuss und dem betreffenden Fachausschuss einberufene gemeinsame Überprüfungsversammlung die erlassende Behörde auffordern, die Umstände zu erläutern und der erlassenden Behörde eine schriftliche Überprüfungsansicht vorgelegt werden. Die erlassende Behörde hat binnen zweier Monate zu prüfen, ob sie eine Änderung befürwortet, und nimmt mit dem Rechtsausschuss des NVK sowie dem betreffenden Fachausschuss Rücksprache. Sind der Rechtsausschuss des NVK und der betreffende Fachausschuss der Ansicht, dass Exekutivrechtsnormen, lokale Verordnungen, Autonomie- und Einzelverordnungen der Verfassung oder Gesetzen widersprechen, und nimmt die erlassende Behörde keine Änderung vor, können sie bei der Ausschussvorsitzendenversammlung eine schriftliche Überprüfungsansicht und einen Aufhebungsantrag vorlegen; die Ausschussvorsitzendenversammlung beschließt darüber, sie der Versammlung des Ständigen Ausschusses zur Beratung und Entscheidung zu unterbreiten.“ Übersetzung in: Heuser, „,sozialistischer Rechtsstaat“ und Verwaltungsrecht in der VR China 19822002, S. 363. 
Städten“137 erlassen. Diese neuen Maßnahmen sind am 01. 08. 2003 in Kraft getreten und die alten Maßnahmen wurden gleichzeitig aufgehoben. Aber die drei Juristen haben ihr Hauptziel - den Mechanismus der Kontrolle der Verfassungsmäßigkeit einzuschalten - nicht erreicht. Der Ständige Ausschuss des Nationalen Volkskongresses hat nur dem Staatsrat den Vorschlag der Bürger mit Aktenvermerken weitergeleitet. Nach dem Sun-Zhigang Fall haben einige Bürger dem Ständigen Ausschuss des Nationalen Volkskongresses auch Vorschläge für eine Überprüfung einiger Rechtsnormen bezüglich der Vereinbarkeit mit der Verfassung vorgelegt, ${ }^{138}$ die aber bislang noch nicht beachtet wurden.

\section{Anwendung der Verfassung durch die Gerichte}

Während die Juristen und die Bürger anstreben, die Grundrechte durch die Verfassungsmäßigkeitsprüfung zu gewährleisten, versuchen die Volksgerichte, durch Rechtsprechung verfassungsrechtliche Befugnisse zu erlangen. Der erste Schritt ist die direkte Anwendung der Verfassungsregelungen durch die Gerichte.

\section{a) Die Entscheidungen des Obersten Volksgerichts von 1955 und von 1986}

Gemäß Art. 3 Abs. 3 der Verfassung von 1982 werden alle Organe der Staatsverwaltung, der Rechtsprechung und der Staatsanwaltschaft von den Volkskongressen ins Leben gerufen, sind ihnen verantwortlich und unterliegen ihrer Aufsicht. Die Auslegungsbefugnis der Verfassung und Gesetze hat allein der Ständige Ausschuss des Nationalen Volkskongresses. ${ }^{139}$ Die Volksgerichte haben überhaupt keine Befugnisse für die Kontrolle der Verfassungsmäßigkeit und die Auslegung der Verfassung. Nach der Rechtsprechung des Obersten Volksgerichts von 1955 und 1986 dürfen sie die Verfassung nicht unmittelbar in ihren Entscheidungen anwenden.

Im Jahre 1955 war das Oberste Volksgericht in seiner schriftlichen Antwort an dem Oberen Volksgericht der Provinz Xinjiang der Auffassung, dass die Verfassung als „Muttergesetz von allen Gesetzen“ in den Urteilen der Straffälle nicht unmittelbar als Grundlage für Schuldzuweisung und Strafmaß angewendet werden sollten. ${ }^{140} 1986$ hat das Oberste Volksgericht in seiner Entscheidung über die Anwendung der Rechtsnormen in den rechtlichen Urkunden eine Liste der rechtlichen Normen, die von den

137 城市生活无着的流浪乞讨人员救助管理办法 (国务院令第381号), vom 21.07. 2003.

138 Z. B. die Vorschläge zur Verfassungsmäßigkeitsprüfung zu „Vorläufige Regeln über Beamte“ (2003), Hukou-System, Renteneintrittsalter der Frauen, ausführlich siehe: 蔡定剑, 中国社会转型 时期的宪政发展 (Cai Dingjian, Die konstitutionelle Entwicklung im Transformationsprozess der chinesischen Gesellschaft), in: 华东政法学院学报 (Journal of the East China University of Political Science and Law), 2006/4, S. 10ff.

139 Art. 67 Abs. 1, 4 der Verfassung von 1982.

140 最高人民法院关于在刑事判决中不宜援引宪法作论罪科刑的依据的批复 (最高人民法院研字 第11298号), vom 30. 07. 1955, http://www.law-lib.com/law/law_view.asp?id=1012 (Stand: 15. 07. 2010). 
Volksgerichten bei den Verhandlungen über die zivilrechtlichen und wirtschaftlichen Streitigkeiten zitiert werden können, ausgegeben: ${ }^{141}$

- Gesetze,

- Exekutivrechtsnormen des Staatsrats,

- lokale Verordnungen, die von den lokalen Volkskongressen und ihren Ständigen Ausschüssen auf Provinzebene erlassen werden und nicht gegen Verfassung, Gesetze und Exekutivrechtsnormen verstoßen,

- Autonomie-Verordnungen und Einzelverordnungen der Regionen mit nationaler Autonomie.

Die Verfassung steht nicht auf dieser Liste. In dem im Jahre 1989 vom Nationalen Volkskongress angenommene Verwaltungsprozessgesetz wurde auch geregelt, dass die Volksgerichte der Verhandlung von verwaltungsrechtlichen Fällen nur Gesetze, Exekutivrechtsnormen und territoriale Rechtsnormen zugrunde legen dürfen. ${ }^{142}$

\section{b) Abweichung der Volksgerichte seit 1988 und der Qi-Yüling Fall}

Von dem Prinzip, dass die Volksgerichte die Regelungen der Verfassung nicht unmittelbar in den Entscheidungen anwenden dürfen, weichen die Volksgerichte seit 1988 ab. ${ }^{143}$ Das Oberste Volksgericht hat 1988 in seiner Entscheidung über die Klausel eines Arbeitsvertrages, die die Haftung des Arbeitsgebers für Arbeitsunfälle ausschloss, für nichtig erklärt und sich in diesem Zusammenhang auf die Verfassung berufen. ${ }^{144}$

Bei einem Arbeitsunfall in der Stadt Tianjin ist ein Arbeitnehmer verletzt und später an einer Infektion gestorben. Die Familienangehörigen des Toten forderten von der Arbeitgeberin Schadensersatz. Die Arbeitgeberin hat die Forderung abgelehnt und sich dabei auf eine Klausel im Arbeitsvertrag berufen, wonach die Haftung der Arbeitgeberin für Verletzungen oder Tod durch einen Arbeitsunfall ausgeschlossen wurde. Weil es damals in den Allgemeinen Grundsätzen des Zivilrechts und anderen Rechtsnormen keine Verbotsklausel über einen Haftungsausschluss des Arbeitsgebers für Arbeitsunfälle gab, hat das lokale Volksgericht den Fall dem Obersten Volksgericht vorgelegt und um Anweisung gebeten.

Damals waren das chinesische Zivilrecht und das Arbeitsrecht ziemlich mangelhaft. Es gab weder ein Arbeitsgesetz noch ein Arbeitsvertragsgesetz. ${ }^{145}$ Mangels anderer rechtlichen Regelungen hat sich das Oberste Volksgericht auf die Verfassung berufen. Es hat am 14. 10. 1988 entschieden, dass der Arbeitsschutz als Recht der Arbeitnehmer

141 最高人民法院关于人民法院制作的法律文书应如何引用法律规范性文件的批复 (法研复 (1986) 31号), vom 28. 10. 1986, http://www.51labour.com/lawcenter/lawshow-18232.html (Stand: 15. 07. 2010).

$142 \S 52$ Verwaltungsprozessgesetz von 1989.

143 Ausführlich vgl. 王禹, 中国宪法司法化: 案例评析 (Wang, Yü, Anwendung der Verfassung durch die Gerichte in China: Fallanalysen), S. 1ff.

144 最高人民法院关于雇工合同“工伤概不负责“是否有效的批复 (88民他字第1号)，vom 14. 10. 1988, http://www.law-lib.com/law/law_view.asp?id=5305 (Stand: 15. 07. 2010).

145 Das chinesische Arbeitsgesetz ist erst im Jahre 1995, das Arbeitsvertragsgesetz ist im Jahre 2008 in Kraft getreten. 
in der Verfassung festgelegt sei. Die Klausel des Arbeitsvertrags, die die Haftung des Arbeitgebers für Arbeitsunfälle ausgeschlossen habe, verstoße gegen die Verfassung und die einschlägigen Gesetze sowie gegen die gesellschaftliche Moral. Sie solle für nichtig erklärt werden. ${ }^{146}$

Diese Entscheidung wurde überwiegend positiv bewertet. ${ }^{147}$ Das lokale Volksgericht hat in seiner Schlichtungsurkunde die Entscheidung des Obersten Volksgerichts zitiert und die Klausel des Arbeitsvertrags für nichtig erklärt. Das Gericht entschied im Dezember 1988, dass die Beklagte gemäß § 106 Abs. 2 und $§ 119$ der Allgemeinen Grundsätze des Zivilrechts schadensersatzpflichtig war. ${ }^{148}$

Bei diesem Fall stützt sich die Entscheidung des Gerichts nicht direkt auf die Verfassung, sondern auf die zivilrechtlichen Regelungen. Nach 13 Jahren hat das Oberste Volksgericht eine neue Entscheidung über die Anwendung der Verfassung veröffentlicht, die mit der alten Konvention ganz gebrochen hat.

Im Jahre 1990 hat die Klägerin Qi, Yüling die Zulassungsprüfung der Fachschulen in der Provinz Shandong bestanden. Aber ihre Zulassung zu einer Handelsfachschule wurde von der Beklagten Chen, Xiaoqi vom Gymnasium abgeholt. Unter dem Namen von Qi, Yüling hat die Beklagte die Fachschule besucht, ihr Vater hat ihre persönlichen Urkunden mit Hilfe der lokalen Bildungsbehörde gefälscht. Nach der dreijährigen Fachbildung wurde die Beklagte unter dem Namen der Klägerin von einer Bank angestellt. Im Jahre 1999 hat die Klägerin diese Situation erkannt und eine Klage beim lokalen Volksgericht eingereicht. Sie hat geltend gemacht, dass die Beklagten ihr Namensrecht und Bildungsrecht verletzt habe. ${ }^{149}$

Das Obere Volksgericht der Provinz Shandong hat den Fall mit der Frage, ob das Bildungsrecht der Klägerin von den Beklagten verletzt wurde, dem Obersten Volksgericht vorgelegt. Das Oberste Volksgericht vertritt die Auffassung, dass die Beklagten das Grundrecht der Klägerin auf Bildung durch die Verletzung des Namenrechts verletzt hätten, dies sollte zur zivilrechtlichen Verantwortung führen. 150 Das Obere Volksgericht entschied unmittelbar gemäß Art. 46 der Verfassung (Bildungsrecht der Bürger), dem Bildungsgesetz, den Allgemeinen Grundsätzen des Zivilrechts sowie dem

146 最高人民法院关于雇工合同“工伤概不负责“是否有效的批复 (88民他字第1号), vom 14. 10. 1988, http://www.law-lib.com/law/law_view.asp?id=5305 (Stand: 15. 07. 2010).

147 Siehe: 杨飞, 试论劳动宪法 (Yang, Fei, On Labor Constitution), in: 林嘉, 社会法评论 (Lin, Jia (Hrsg.), Social Law Review), 2008, Vol. 3, S. 84.

148 张连起, 张国秒诉张学珍损害赔偿纠纷案 (Zhang-Lianqi Fall), 天津市塘沽区人民法院, vom 24. 12. 1988, in: 中华人民共和国最高人民法院公报 (Bulletin des Obersten Volksgerichts der Volksrepublik China), 1989年第1号, vom 20.03.1989.

149 Siehe: 王禹, 中国宪法司法化: 案例评析 (Wang, Yü, Anwendung der Verfassung durch die Gericht in China: Fallanalysen), S. 145ff.

150 最高人民法院关于以侵犯姓名权的手段侵犯宪法保护的公民受教育的基本权利是否应承担民 事责任的批复, 法释 (2001) 25号, vom 13.08. 2001, http://www.law-

lib.com/law/law_view.asp?id=15994 (Stand: 15. 07. 2010). 
Zivilprozessgesetz, dass in dem Verhalten der Beklagten eine Verletzung des Namensrechts und des Bildungsrechts der Klägerin lag. 151

Das Oberste Volksgericht hat am 13. 08. 2001 seine Entscheidung über den QiYüling Fall veröffentlicht. An demselben Tag hat der Richter Huang, Songyou, der damalige Präsident des Zivilgerichts des Obersten Volksgerichts, einen Aufsatz über diese Entscheidung in der Zeitung des Volksgerichts veröffentlicht. Er betonte, dass diese Entscheidung nicht nur als Antwort auf die Frage des lokalen Gerichts über die Gültigkeit der Gesetze betrachtet werden könne. Sie habe einen Präzedenzfall der unmittelbaren Anwendung der Verfassung durch die Gerichte geschaffen. Er ist der Auffassung: „Alle verfassungsrechtlichen Streitigkeiten sollen von den Volksgerichten nach dem allgemeinen gerichtlichen Verfahren verhandelt werden. Bei der Verhandlung wird die Verfassung als die Grundlage der Entscheidung unmittelbar vom Gericht angewendet." $" 152$

Die Entscheidung des Obersten Volksgerichts und der Artikel von Huang, Songyou über den Qi-Yüling Fall haben eine hitzige Diskussion über die Anwendung der Verfassung ausgelöst. Erstens sind viele Juristen der Meinung, dass diese Entscheidung unnötig sei. Das Bildungsrecht der Bürger werde schon durch das chinesische Bildungsgesetz ausführlich geregelt. Es sei unnötig, sich unmittelbar auf die Verfassung zu berufen. ${ }^{153}$ Zweitens besteht Zweifel, ob ein Individuum das Bildungsrecht eines anderen Bürgers verletzen kann. Gemäß der Verfassung und dem Bildungsgesetz haben nur Staat, Gesellschaft, Familien und Bildungsinstitutionen die Pflicht, das Bildungsrecht der Bürger zu gewährleisten und deswegen können nur sie das Bildungsrecht der Bürger verletzen. ${ }^{154}$ Die Auffassung von Richter Huang, Songyou, alle Verfassungsstreitigkeiten durch Volksgerichte zu verhandeln, wird kritisiert, weil das eine grundlegende Veränderung des Organisationsprinzips der Staatsmacht bedeutet, die Volksgerichte wären dadurch unabhängig von den Volkskongressen. ${ }^{155}$

151 山东省高级人民法院民事判决书, (1999) 鲁民终字第258号, vom 23. 08. 2001, zitiert nach: 王 振民，中国违宪审查制度 (Wang, Zhenmin, Das chinesische System der Kontrolle der Verfassungsmäßigkeit), S. 206ff.

152 黄松有, 宪法司法化及其意义 (Huang, Songyou, Die unmittelbare Anwendung der Verfassung durch die Gerichte und deren Bedeutung), in: 人民法院报 (Volksgerichtszeitung), 13. 08. 2001.

153 江平, 宪法司法化四人谈 (Gespräche von vier Juristen über die Anwendung der Verfassung durch die Gerichte), in: 南方周末 (NFZM), 13. 09. 2001; 童之伟, 宪法司法化引出的是是非非 - 宪 法司法适用研究中的几个问题 (Tong, Zhiwei, Einige Fragen über die Untersuchung der Anwendung der Verfassung), in: 法学 (Law Science), 2001/11, S. 3ff; 梁慧星, 最高法院关于侵犯受教 育权案的法释 (2001) 25号批复评析 (Liang, Huixing, Kommentar der Rechtssprechung (2001) Nr.25), in: 法学天地 (Rechtswissenschaft), 2002/4, S. 11ff.

154 Siehe: 梁慧星, 最高法院关于侵犯受教育权案的法释 (2001) 25号批复评析 (Liang, Huixing, Kommentar zur Rechtssprechung (2001) Nr.25), in: 法学天地 (Rechtswissenschaft), 2002/4, S. $11 \mathrm{ff}$.

155 童之伟, 宪法司法化引出的是是非非 - 宪法司法适用研究中的几个问题 (Tong, Zhiwei, Einige Fragen über die Untersuchung der Anwendung der Verfassung), in: 法学 (Law Science), 2001/11, S. 3ff; 强世功, 宪法司法化的悖论 (Qiang, Shigong, Paradoxes in Discourse of Constitutional Adjudication), in: 中国社会科学 (Social Sciences in China), 2003/3, Nr. 2, S. 24. 
Der Qi-Yüling Fall ist offensichtlich ein Versuch des Obersten Volksgerichts, durch die sogenannte „unmittelbare Anwendung der Verfassungsartikel“ die Befugnisse für die Verfassungsbeschwerde sowie die Kontrolle der Verfassungsmäßigkeit zu erlangen. ${ }^{156}$ Der Richter Huang, Songyou hat sogar den Qi-Yüling Fall mit dem amerikanischen Marbury V. Madison Fall gleichgesetzt und das US-Gerichtsmodell als Vorbild vorgeschlagen. ${ }^{157}$

Obwohl die Volksgerichte seit 1988 schon vielmals in ihren Entscheidungen die Verfassung direkt zitiert haben, 158 gibt es bisher noch keine deutliche Änderung der Verfassungsinstitutionen. Nach dem Qi-Yüling Fall wurde bislang keine Rechtsprechung des Obersten Volksgerichts über die Anwendung der Verfassung mehr gesprochen. Die hitzige Diskussion über die Anwendung der Verfassung hat sich allmählich gelegt. Im derzeitigen Rahmen der Gewaltenkonzentration gibt es kaum Möglichkeit für die Volksgerichte, verfassungsrechtliche Befugnisse der Volkskongresse auszuüben. Zurzeit schlagen manche Juristen vor, eine Verfassungskommission oder ein Verfassungsgericht unter dem Nationalen Volkskongress oder unter dem Ständigen Ausschuss des Nationalen Volkskongresses zu errichten. ${ }^{159}$ Einige Juristen vertreten die Auffassung, dass die Entwürfe für die unmittelbare Anwendung der Verfassung zurzeit nicht notwendig und sogar unmöglich seien. ${ }^{160}$ Die chinesische Verfassung sei bislang noch eine „Verfassung der Reform“. Erst wenn die Staatsaufgabe der Modernisierung vollendet und die Freiheit des Einzelnen als primärer Wert des Staates betrachtet würde, könnte eine Institution für die Verwirklichung des Konstitutionalismus notwendig werden.

\section{Zusammenfassung}

Im Vergleich mit den westlichen Staaten, in denen das Gesetz für den Zusammenhalt des Staates von zentraler Bedeutung ist, sind die staatlichen Institutionen Chinas von der Tradition der zentralisierten Staatsform und der Betonung von Einheit und Stabilität konsolidiert, dafür spielen die rechtlichen Gedanken und die Verfassung keine entscheidende Rolle.

156 Vgl. 强世功, 宪法司法化的悖论 (Qiang, Shigong, Paradoxes in Discourse of Constitutional Adjudication), in: 中国社会科学 (Social Sciences in China), 2003/3, No. 2, S. $20 \mathrm{ff}$.

157 黄松有, 宪法司法化及其意义 (Huang, Songyou, Die unmittelbare Anwendung der Verfassung durch die Gerichte und deren Bedeutung), in: 人民法院报 (Volksgerichtszeitung), 13. 08. 2001.

158 如沈涯夫, 牟春霖诽谤案, 王发英案等等 (wie Shen-Yafu Fall, Mou-Chunlin Fall von 1988, Wang-Faying Fall von 1988), ausführlich siehe: 王禹, 中国宪法司法化: 案例评析 (Wang, Yü, Anwendung der Verfassung durch die Gerichte in China: Fallanalysen), S. 1ff; auch: 王振民, 中国 违宪审查制度 (Wang, Zhenmin, Das chinesische System der Kontrolle der Verfassungsmäßigkeit), S. $193 \mathrm{ff}$.

159 江平, 宪法司法化四人谈 (Gespräche von vier Juristen über die Anwendung der Verfassung durch die Gerichte), in: 南方周末 (NFZM), 13. 09. 2001.

160 陈端洪, 由富强到自由: 中国宪法的价值取向与司法化的可能 (Chen, Duanhong, Von Wohlstand bis Freiheit: Wertorientierung der chinesischen Verfassung und die Möglichkeit der unmittelbaren Anwendung durch die Gerichte), in: 法制日报 (FZRB), 05. 12. 2002. 
Seit der Gründung der Volksrepublik ist der Wiederaufbau eines wohlhabenden und mächtigen Staats das überwiegende Ziel Chinas. Dazu dient die chinesische Verfassung mit ihrem instrumentalen Charakter: Sie legitimiert in Gesetzform die grundlegende Staatsordnung, die staatlichen Aufgaben sowie die wichtigsten Prinzipien im Staatsleben und rechtfertigt die neuen ökonomischen und politischen Erfolge. ${ }^{161}$ Das Wirtschaftssystem ist ein wichtiger Bestandteil der chinesischen Modernisierung und deswegen auch ein wichtiger Teil der Verfassung. Die wirtschaftlichen Transformationen haben die Regelungen der Verfassung über das Wirtschaftsystem oft durchbrochen. Diese Regelungen mussten deshalb durch häufige Verfassungsänderungen den wirtschaftlichen Entwicklungen angepasst werden. Die Verfassung stellt also zurzeit in erster Linie nicht eine Beschränkung der Staatsmacht dar.

Angesichts dieser Situation verzögert der Staat die Errichtung einer aktiv wirkenden Institution für die Kontrolle der Verfassungsmäßigkeit und die Garantie einklagbarer Grundrechte der Bürger. Solche Institutionen könnten das Tempo der wirtschaftlichen Entwicklung verringern und sogar die staatlichen Organisationsprinzipien zersetzen, daraufhin könnte die Modernisierungsstrategie verhindert werden.

Aber der derzeitige Status der Verfassung sollte nicht als ein ewiges elastisches Instrumentarium zur Steuerung der staatlichen Entwicklungsrichtung zu verstehen sein. Wie die Verfassung von 1954 als eine Verfassung der volksdemokratischen Periode befristet war, ist die gegenwärtige Verfassung auch nur eine Verfassung im „Anfangsstadium des Sozialismus“. Wenn die Grundaufgaben des Staates in dieser Periode erledigt sein werden, werden die Verfassung und die darin enthaltenen Staatsordnungen, Organisationsprinzipien sowie staatlichen Aufgaben entsprechend verändert sein. In der Praxis ist eine kleine, aber stetige Umwandlung schon bemerkbar. Einige Veränderungen sind auch bei den Verfassungsänderungen zu verzeichnen:

- sozialistischer Rechtsstaat (Art. 5 der Verfassung von 1982, Revision von 1999),

- Gewährleistung der Menschenrechte (Art. 33 Abs. 3 der Verfassung von 1982, Revision von 2004),

- Veränderung der KP Chinas von „Vorhut der chinesischen Arbeiterklasse“ zur Volkspartei (Präambel der Verfassung von 1982, Revision von 2004).

Es ist vorauszusehen, dass die qualitative Veränderung der Verfassung mit der Vollendung der Modernisierung eintreten wird. Aber welche Staatsform in der Zukunft in China gestaltet wird, und ob die chinesische Verfassung in Wirklichkeit eine „Verfassung des Konstitutionalismus" wird, ist noch unklar.

\section{Soziale Sicherheit in der Verfassung}

Die oben erläuterten grundlegenden Staatsprinzipien und sozialen Entwicklungen, die sich in der chinesischen Verfassung konzentriert widerspiegeln, bilden den Schlüs-

161 Präambel der Verfassung von 1982, 13. Abschnitt. 
sel zum Verständnis der chinesischen sozialen Sicherheit. Man kann in den Verfassungsänderungen die entsprechenden Spuren für die Umwandlungen dieses Bereiches finden.

In dieser Arbeit wird die Ausgestaltung der sozialen Sicherheit im chinesischen Modernisierungsprozess, hauptsächlich in der Periode „Reform und Öffnung“, behandelt. Die in der Verfassung von 1982 festgelegte grundlegende Aufgabe des Staates im Anfangsstadium des Sozialismus, nämlich die Kräfte auf dem Weg des Sozialismus chinesischer Prägung auf die sozialistische Modernisierung zu konzentrieren, ${ }^{162}$ bestimmt die Grundlagen der sozialen Sicherheit. Die traditionellen Werte über die kollektive Subsistenz und Entwicklung, die Verantwortung des Staates sowie die Einheit der Rechte und Pflichten der Bürger haben noch Einfluss auf die soziale Sicherheit. Mit der Vertiefung der wirtschaftlichen Reform wird eine neue Regulierung der Beziehungen zwischen Staat, Gesellschaft und Individuum notwendig. Die neue staatliche Aufgabe, nach der Erreichung des „Kleinen Wohlstands“ eine aufeinander abgestimmte Entwicklung der materiellen, politischen und geistigen Zivilisation ${ }^{163} \mathrm{zu}$ fördern, hat den Aufbau der Sozialleistungssysteme von einem Zusatzprogramm für die wirtschaftliche Entwicklung zu einer wichtigen institutionellen Stütze des Staats befördert.

\section{Soziale Sicherheit in den früheren Verfassungen}

In allen Verfassungen der Volksrepublik hat die soziale Sicherheit eine Stellung gefunden. 1949 wurde zuerst die Errichtung eines Entschädigungs- und Vorzugsbehandlungssystems für die Soldaten sowie die Familienangehörigen der revolutionären Märtyrer und der Soldaten in dem „Gemeinsamen Programm der Politischen Konsultativkonferenz des Chinesischen Volkes“ geregelt. ${ }^{164}$ Außerdem wurde festgeschrieben, dass eine Arbeiterversicherung und der spezielle Arbeitsschutz für Frauen Schritt für Schritt durchgeführt werden sollte. 165

In der Verfassung von 1954 kann man im dritten Kapitel „Grundrechte und Grundpflichten der Bürger" die Vorschriften über die soziale Sicherheit finden, die sich aber nur auf ,das Recht der Bürger auf Arbeit“ und „Rechte der Werktätigen auf Erholung und soziale Sicherung" beschränken:

(1) Nach Art. 91 der Verfassung von 1954 haben die Bürger der Volksrepublik das Recht zu arbeiten. Um dieses Recht der Bürger zu gewährleisten erweitert der Staat die Beschäftigung, verbessert die Arbeitsbedingung und das Arbeitsentgelt durch Entwicklung der Volkswirtschaft.

(2) Die Werktätigen haben Erholungsrecht (Art. 92 der Verfassung von 1954).

162 Präambel der Verfassung von 1982, 7. Abschnitt.

163 Präambel der Verfassung von 1982, 7. Abschnitt. Revision von 2004, 18. Verfassungszusatz.

164 Art. 25 des Gemeinsamen Programms der Politischen Konsultativkonferenz des Chinesischen Volks.

165 Art. 32 des Gemeinsamen Programms der Politischen Konsultativkonferenz des Chinesischen Volks. 
(3) Die Werktätigen haben das Recht auf materielle Unterstützung im Alter, in Krankheitsfällen oder bei Arbeitsunfähigkeit. Der Staat sorgt für die Sozialversicherung, die Sozialhilfe und die medizinischen Dienstleistungen (Art. 93 der Verfassung von 1954).

\section{Tabelle 9: Soziale Sicherheit in den früheren Verfassungen}

\begin{tabular}{|l|l|}
\hline $\begin{array}{l}\text { Das Gemeinsame } \\
\text { Programm }\end{array}$ & $\begin{array}{l}\text { Art. 25: } \\
\text { Entschädigungs- und Versorgungssystem für Familienangehörige der } \\
\text { revolutionäre Märtyrer und Soldaten } \\
\text { Art. 32: } \\
\text { Arbeiterversicherung, spezieller Arbeitsschutz }\end{array}$ \\
\hline Verfassung von 1954 & $\begin{array}{l}\text { Art. 91: } \\
\text { Das Recht der Bürger Auf Arbeit } \\
\text { Art. 92: } \\
\text { Erholungsrecht der Werktätigen } \\
\text { Art. 93: } \\
\text { Das Recht der Werktätigen auf materielle Unterstützung im Alter, in } \\
\text { Krankheitsfällen oder bei Arbeitsunfähigkeit; die Pflicht des Staates für } \\
\text { Errichtung des Systems der Sozialversicherung, der Sozialhilfe und der } \\
\text { medizinischen Dienstleistungen }\end{array}$ \\
\hline Verfassung von 1975 & $\begin{array}{l}\text { Art. 27 Abs. 2: } \\
\text { Die Bürger haben das Recht auf Arbeit und das Recht auf Bildung. Die } \\
\text { Werktätigen haben das Recht auf Erholung und materielle Unterstützung } \\
\text { im Alter, in Krankheitsfällen oder bei Arbeitsunfähigkeit. }\end{array}$ \\
& $\begin{array}{l}\text { Art. 48: } \\
\text { Das Recht der Bürger auf Arbeit; die Pflicht des Staats für Arbeitsförde- } \\
\text { rung, Erhöhung des Arbeitsentgelts, Verbesserung von Arbeitsbedingungen } \\
\text { und Arbeitsschutz, kollektive Wohlfahrt. } \\
\text { Art. 49: } \\
\text { Erholungsrecht der Werktätigen } \\
\text { Art. 50: } \\
\text { Das Recht der Werktätigen auf materielle Unterstützung im Alter, in } \\
\text { Krankheitsfällen oder bei Arbeitsunfähigkeit; die Pflicht des Staates für } \\
\text { Errichtung des Systems der Sozialversicherung, der Sozialhilfe und der } \\
\text { medizinischen Dienstleistungen; Sonderversorgung für Familienangehöri- } \\
\text { ge der revolutionären Märtyrer und Soldaten }\end{array}$ \\
\hline Verfassung von 1978 \\
\end{tabular}

Das Modell der „sozialen Sicherung aufgrund der Vollbeschäftigung“ ist seitdem gegründet. Der Staat verfolgte in den Städten der sozialen Sicherungspolitik „Vollbeschäftigung, niedrigen Lohn und hohes Sicherungsniveau“, 166 um die wirtschaftlichen Kräfte auf die Industrialisierung zu konzentrieren.

166 崔风/孙启泮, 从历次制宪与修宪看中国社会保障的发展 (Cui, Feng/Sun, Qipan, Eine Betrachtung der Entwicklung der sozialen Sicherheit Chinas von den Verfassungsänderungen aus), in: 社 会保障制度 (Social Security System), 2006/2, S. 58. 
In der Verfassung von 1975 und von 1978 wurde dieses Modell immer wieder bekräftigt. Statt einer Vereinfachung im Art. 27 Abs. 2 der Verfassung von $1975^{167}$ wurde dieses Prinzip in der Verfassung von 1978 wie in der Verfassung von 1954 wieder in drei Artikel niedergeschrieben und schrittweite konkretisiert. 168 Nach Artikel 48 der Verfassung von 1978 (Recht der Bürger zu arbeiten) hat der Staat die Pflichten, Arbeitsbeschäftigung zu arrangieren, Arbeitsentgelt Schritt für Schritt zu erhöhen, Arbeitsbedingungen $\mathrm{zu}$ verbessern, Arbeitsschutz zu verstärken sowie kollektive Wohlfahrt zu erweitern, um das Recht der Bürger auf Arbeit zu gewährleisten. Übereinstimmend mit dem Erholungsrecht der Werktätigen ist der Staat nach Art. 49 der Verfassung von 1978 für die Festsetzung der Arbeitszeit und des Erholungssystems verantwortlich. In Art. 50 wurde neben dem Recht der Werktätigen auf materielle Unterstützung die Sonderversorgung für Soldaten und ihre Familienangehörigen wieder niedergeschrieben.

\section{Soziale Sicherheit in der geltenden Verfassung}

Im Vergleich mit den früheren Verfassungen kennzeichnet sich die soziale Sicherheit in der Verfassung von 1982 durch folgende neue Entwicklungen:

(1) Nach Art. 42 der Verfassung von 1982 ist „Arbeiten“ nicht nur das Recht, sondern auch die Pflicht der Bürger (Art. 42 Abs. 1). Die Werktätigen sollten mit dem Bewusstsein, Herren des Landes zu sein, an ihre Arbeit herangehen (Art. 42 Abs. 3 Satz 2). Dafür befürworte der Staat einen sozialistischen Arbeitswettbewerb (Art. 42 Abs. 3 Satz 3).

(2) In der Verfassung von 1982 bilden die klassische Dreiteilung über die Rechte der Werktätigen im Kapitel II „Grundrechte und Grundpflichten der Bürger“ noch den Hauptteil der sozialen Sicherheit. Aber das der Regelung betreffende Rechtssubjekt hat sich teilweise geändert. Die Rechtssubjekte, die das Recht auf materielle Unterstützung auf Seiten des Staates und der Gesellschaft haben, sind nicht nur die „Werktätigen“, sondern alle Bürger. ${ }^{169}$ Diese Erweiterung rechtfertigt die Errichtung der Arbeitslosenversicherung, die nicht von der Arbeiterversicherung umfasst wurde, und den Aufbau der umfassenden Hilfesysteme für alle Bürger. Das Ruhestandssystem für die Arbeitnehmer der Betriebe und Institutionen sowie für die Funktionäre der Staatsorgane wird separat in Art. 44 der Verfassung von 1982 geregelt.

(3) Eine weitere Entwicklung ist der im Jahre 2004 eingeführte Art. 33 Abs. 3. Nach Art. 33 Abs. 3 respektiert und gewährleistet der Staat Menschenrechte. Manche westliche Beobachter sind der Meinung, dass dies teilweise ein politisches Signal für den An-

167 Art. 27 Abs. 2 der Verfassung von 1975: „Die Bürger haben das Recht zu arbeiten und das Recht auf Bildung. Die Werktätigen haben das Recht auf Erholung und materielle Unterstützung im Alter, in Krankheitsfällen oder bei Arbeitsunfähigkeit.“

168 Art. 48, 49, 50 der Verfassung von 1978.

169 Art. 45 Abs. 1 der Verfassung von 1982. 
schluss an den internationalen Menschenrechtsdiskurs darstelle, ${ }^{170}$ die juristische Bedeutung sei mangels verfassungsgerichtlicher Mechanismen stark beschränkt. ${ }^{171}$ Denkbar ist auch diese Regelung als ein Zeichen für den Aufbau einer theoretischen Grundlage und die zukünftige Erweiterung des Rechtsubjekts und -objekts der sozialen Sicherheit zu verstehen.

(4) Zum ersten Mal wird die spezielle Wohlfahrt für behinderte Menschen in Art. 45 Abs. 3 eingeführt.

(5) Die Verantwortung des Staates für Errichtung der Systeme der sozialen Sicherheit findet man in der Verfassung von 1982 nicht nur im Kapitel „Grundrechte und Grundpflichten der Bürger“. Es gibt im ersten Kapitel „Allgemeine Grundsätze“ auch Regelungen, die für die soziale Sicherheit relevant sind. Die staatlichen Verantwortungen für Bildungseinrichtungen, Gesundheitswesen, Massensport, Kultur, die in China als allgemeine Wohlfahrt betrachtet werden, werden in Art. 19, 21, 22 der Verfassung von 1982 geregelt.

\section{Tabelle 10: Soziale Sicherheit in der geltenden Verfassung}

\begin{tabular}{|c|c|}
\hline $\begin{array}{l}\text { Verfassung von } \\
1982\end{array}$ & $\begin{array}{l}\text { Art. 19, 20, 21: } \\
\text { Rahmenregelungen für staatliche Verantwortung für Einrichtung von Bil- } \\
\text { dung, Gesundheitswesen, Massensport, Kultur usw. } \\
\text { Art. 42: } \\
\text { Das Recht und die Pflicht der Bürger zu arbeiten; die Pflicht des Staats für } \\
\text { Beschäftigungsförderung, Arbeitsschutz, Arbeitsbedingung, Erhöhung des } \\
\text { Arbeitsentgelts und Sozialwohlfahrt } \\
\text { Art. 43: } \\
\text { Erholungsrecht der Werktätigen; Pflicht des Staats für Entwicklung der } \\
\text { Einrichtungen für Erholung } \\
\text { Art. 44: } \\
\text { Ruhestandsystem } \\
\text { Art. 45: } \\
\text { Das Recht der Bürger auf materielle Unterstützung im Alter, in Krank- } \\
\text { heitsfälle oder bei Arbeitsunfähigkeit; die Pflicht des Staates für Errich- } \\
\text { tung des Systems der Sozialversicherung, der Sozialhilfe und der medizi- } \\
\text { nischen Dienstleistungen; } \\
\text { Sonderversorgung für Familienangehörige der revolutionäre Märtyrer und } \\
\text { Soldaten; spezielle Wohlfahrt für Behinderte }\end{array}$ \\
\hline Revision von 2004 & $\begin{array}{l}\text { Art. } 14 \text { Abs. 4: } \\
\text { Staatliche Verantwortung für Errichtung und Vervollständigung der Syste- } \\
\text { me der sozialen Sicherheit } \\
\text { Art. } 33 \text { Abs. 3: } \\
\text { Schutz der Menschenrechte }\end{array}$ \\
\hline
\end{tabular}

Im Jahre 2004 wurde ein neuer Absatz in Art. 14 (staatliche Förderung des Wirtschaftssystems) in die Verfassung eingeführt: „Der Staat errichtet und vervollständigt

170 Vgl. Ahl, in: Blätter für deutsche und internationale Politik 2006/11, S. 1381ff.

171 Vgl. Holbig, in: China aktuell, 2004/4, S. 267. 
Systeme der sozialen Sicherheit, die dem Niveau der wirtschaftlichen Entwicklung entsprechen" (Art. 14 Abs. 4). Dadurch ist der Doppelcharakter der Systeme der sozialen Sicherheit in der geltenden Verfassung festgelegt. Einerseits übernehmen diese Systeme die Aufgabe, die Grundrechte der Bürger zu gewährleisten, andererseits bilden sie eine staatliche Institution, die teilweise ein Bestandteil des staatlichen Wirtschaftssystems ist und von der wirtschaftlichen Entwicklung abhängig ist. Die Bürger haben Anspruch, dadurch am Wirtschaftswachstum teilzuhaben, aber die wirtschaftliche Entwicklung und die Erfüllung der Grundaufgabe des Staates dürfen nicht durch ein zu hohes Leistungsniveau behindert werden.

\section{Ergebnis}

Die geltende Verfassung enthält sowohl die Grundprinzipien des Staates, die seit der Gründung der Volksrepublik festgelegt werden und grundsätzlich nicht angetastet werden dürfen - wie die Volkssouveränität, die Führungsrolle der KP Chinas, der sozialistische Weg und das Organisationsprinzip des Demokratischen Zentralismus, als auch die Richtlinien, die der Veränderung des leitenden Entwicklungsgedankens oft anpassend korrigiert werden, wie die Darlegung über die Entwicklungsphasen des Sozialismus, über das Eigentumssystem und das Wirtschaftssystem. Die Darstellung zeigt, dass die Umwandlung der staatlichen Richtlinien bezogen auf die soziale Sicherheit eng mit der Änderung des Wirtschafts- sowie Eigentumssystems verknüpft ist. Bei dieser Umwandlung wurde das Recht der Bürger auf Arbeit und soziale Sicherheit teilweise getrennt, die staatliche Verantwortung für die Errichtung der Sozialleistungssysteme festgelegt, die Wirtschaftsbedingung für das Leistungsniveau ausdrücklich betont. 172

Welche Rolle hat die Verfassung in diesem Zusammenhang gespielt? Die Darstellung zeigt, dass noch kein umfassender theoretischer Rahmen der sozialen Sicherheit aus den Verfassungsregelungen hergeleitet wurde. Ein funktionierender Mechanismus des sozialen Grundrechtsschutzes für die Bürger wurde auch noch nicht aufgebaut. Vielmehr werden durch die Verfassungsänderung die politischen Entscheidungen über die soziale Sicherheit legitimiert, die Systemänderungen gerechtfertigt. Zurzeit wird die Errichtung der sozialen Sicherungssysteme in China hauptsächlich als staatliche Verantwortung betrachtet und durch politische Normen geleitet. Ob und inwiefern diese Situation sich in der Zukunft ändert, ist von der weiteren Entwicklung der staatlichen Systeme abhängig.

172 Die Umgestaltung der sozialen Sicherheit wird im dritten Teil dieser Arbeit ausführlich dargestellt. 


\section{Dritter Teil: Entwicklung der sozialen Sicherheit}

- Geschichte, Systematisierung und Reformen

Mit dem ersten und dem zweiten Teil dieser Arbeit wurden die allgemeinen gesellschaftlichen, wirtschaftlichen, politischen, rechtlichen sowie historischen Rahmenbedingungen der sozialen Sicherheit in China dargestellt, um dem Leser die Komplexität der „chinesischen Fragen“ unter einem „Makroblick“ zu verdeutlichen. Die historischen Erfahrungen und die gegenwärtige Lage Chinas sprechen dafür, dass die chinesische soziale Sicherheit sich unter dem westlichen Einfluss mit intensiver „chinesischen Prägung" bildet. Im Folgenden werden die Struktur, die Einzelheiten und die Entwicklungstendenzen der sozialen Sicherheit untersucht. Zuerst eine kurze Übersicht über den Entwicklungsprozess und die wesentlichen Merkmale dieses Bereiches:

1. Seit der Gründung der Volksrepublik hat der Staat der sozialistischen Planwirtschaft entsprechend umfassende soziale Sicherungssysteme für die Bürger aufgebaut. Aufgrund der politischen Entscheidung für die Industrialisierung 1 war eine Differenzierung der sozialen Sicherung für die städtische und die ländliche Bevölkerung notwendig.

2. Parallel zur Wirtschaftsreform wird die soziale Sicherheit umgewandelt. Die neu aufgebauten Sicherungssysteme waren zunächst durch die finanziellen Mittel des Staates begrenzt. Außerdem wurde die Eigenverantwortung der Bürger durch die Parole „Effizienz genießt Priorität“2 gestärkt.

3. Mit der wirtschaftlichen Re-Zentralisierung hat die Einnahmenquote der Zentralregierung stark zugenommen. Der Appell zu ,einer harmonischen Gesellschaft“, die sozialistische Forderung der Gerechtigkeit und der traditionelle Gedanke über „Ausgewogenheit und Balance“ haben die Richtung der Reform der sozialen Sicherheit nun wieder zu „Führen durch Staat“ und „Verantwortung der Regierung" verändert.

4. Die Umgestaltung der sozialen Sicherheit geht wie die Wirtschaftsreform Schritt für Schritt voran durch Pilotprojekte. In diesem Bereich existiert eine Vielzahl an politischen Richtlinien und staatlichen Politnormen. Es gibt noch kein einheitliches Rechtssystem für die soziale Sicherheit.

5. Ein neuer Rahmen der sozialen Sicherheit für alle Bürger, insbesondere in der anfänglichen Gestalt der Sozialversicherungen, wurde schon aufgebaut. Aber die einheitliche und umfassende Planung für die soziale Sicherung aller städtischen und ländlichen Bevölkerung wird noch von der negativen Wirkung der chinesischen Industrialisierung - die dualistische Sozialstruktur - beschränkt. Es fehlen zurzeit noch ausreichende Verknüpfungen zwischen den verschiedenen Systemen.

1 Ausführlich vgl. Erster Teil, Industrialisierung und Hukou-Registrierung.

2 Ausführlich vgl. Erster Teil, Modernisierungsprozess seit 1978. 


\section{A. Begriffe}

\section{I. 社会保障 (Soziale Sicherheit)}

Der chinesische Begriff, „社会保障 (shèhuì băozhàng)“, der das Äquivalent des deutschen Begriffs „soziale Sicherheit“ ist, ist eine Übersetzung des amerikanischen Begriffs ,,social security“, 3 der erstmals im „Social Security Act“ von 1935 benutzt wurde. Diese Norm enthält Regelungen über die Arbeitslosenversicherung, Alterssicherung und Gesundheitsleistungen. Vorher wurden ähnliche Regelungen schon in Europa, insbesondere in Deutschland seit Ende des 19. Jahrhunderts aufgestellt. ${ }^{4}$ Danach wurde der Begriff „social security“ in der Atlantik-Charta von $1941^{5}$ und in den BeverigdeReport 6 aufgenommen. Im Jahre 1944 versuchte die Internationale Arbeitsorganisation (ILO) in ihrer Philadelphia-Konferenz ${ }^{7}$ zu verdeutlichen, was unter ,social security“ zu verstehen ist. ${ }^{8}$ In ihrem Übereinkommen Nr. 102 über die Mindestnormen der sozialen Sicherheit ${ }^{9}$ wurden folgende Sozialleistungen genannt: ärztliche Betreuung, Krankengeld, Leistungen bei Mutterschaft, bei Invalidität, bei Alter, an Hinterbliebene, bei Arbeitsunfällen und Berufskrankheiten, bei Arbeitslosigkeit sowie Familienleistungen.

Seitdem ist dieser Begriff weltweit anerkannt. Die ILO hat im Jahre 1984 eine Definition über ,social security"gegeben:

„The protection which society provides for its members, through a series of public measures, against the economic and social distress that otherwise would be caused by the stoppage or substantial reduction of earnings resulting from sickness, maternity, employment injury, unemployment, invalidity, old age and death, the provision of medical care, and the provision of subsidies for families with children." 10

$3 \mathrm{Vgl}$. 华迎放, 社会保障 (Hua, Yingfang (Hrsg.), Soziale Sicherheit), S. 2; 郑功成, 社会保障学 (Zheng, Gongcheng (Hrsg.), Social Security), S. 4; 黎建飞, 社会保障法 (Li, Jianfei (Hrsg.), Recht der sozialen Sicherheit), S. 2; 林嘉, 社会保障法的理念, 实践与创新 (Lin, Jia, Theory, Practice and Innovaion on Social Security Law), S. 4; 史探径, 我国社会保障法的几个理论问题 (Shi, Tanjing, Einige theoretische Fragen über das chinesische Recht der sozialen Sicherheit), in: 法 学研究 (Journal of Law), 1998/4, S. 18ff.

4 Schmid, Sozialrecht und Recht der sozialen Sicherheit, S. 44; Kaufmann, Sicherheit als soziologisches und sozialpolitisches Problem, S. 92.

5 The Atlantic Charter, vom 14. 08. 1941.

6 Beveridge, Social Insurance and Allied Services: Report by Sir Willian Beveridge, 1942.

7 Erklärung über die Ziele und Zwecke der Internationalen Arbeitsorganisation, vom 10. 05. 1944.

8 Erklärung von Philadelphia III. F): Ausbau von Maßnahmen der sozialen Sicherheit, um allen, die eines solchen Schutzes bedürfen, ein Mindesteinkommen zu sichern, und um umfassende ärztliche Betreuung zu gewährleisten, ...

9 ILO, Übereinkommen über die Mindestnormen der Sozialen Sicherheit, 1952.

10 International Labour Office, Introduction to social security, 1984, S. 3. 
Danach wurden dieser Begriff und die ILO-Definition über soziale Sicherheit in China anerkannt. ${ }^{11} \mathrm{Im}$ "Vorschlag der KP Chinas für den 7. Fünfjahresplan"12 und im 7. Fünfjahresplan für die wirtschaftliche und gesellschaftliche Entwicklung (1986-1990) wurde, 社会保障“ erstmals offiziell verwendet. Mit diesem Fünfjahresplan wurde festgelegt, dass neue Systeme der sozialen Sicherheit, die Sozialversicherung, Sozialhilfe, soziale Wohlfahrt und Sonderversorgung umfassen und der neuen wirtschaftlichen und gesellschaftlichen Situation entsprechen, schrittweise zu gestalten sind. ${ }^{13}$ Es gab aber keine offizielle Definition für den Begriff der sozialen Sicherheit. Der Geltungsbereich war auch nicht vollständig festgelegt.

Während der Wirtschaftsreform und der gesellschaftlichen Entwicklung erweitert sich der Geltungsbereich der sozialen Sicherheit in den offiziellen Dokumenten, wie z. B. die Wohnungspolitik, die genossenschaftliche Hilfe sowie das kommerzielle Versicherungswesen werden zurzeit als Bestandteile der sozialen Sicherheit bezeichnet. ${ }^{14}$

In der chinesischen Literatur hat sich eine allgemeine Definition der sozialen Sicherheit nicht gebildet. Im engeren Sinne beschränkt sich die soziale Sicherheit auf ,die durch Gesetzgebung vorgeschriebenen Maßnahmen der materiellen Hilfe des Staats für Mitglieder der Gesellschaft im Falle von Krankheit, Alter, Unfall, Arbeitsunfähigkeit oder bei Naturkatastrophen". 15 Im weiteren Sinne ist soziale Sicherheit ein Inbegriff von Sozialversicherung, Sozialhilfe, sozialer Wohlfahrt, medizinischer Vorsorgung, staatlicher und betrieblicher Zuschüsse sowie gegenseitiger Hilfe, ${ }^{16}$ der nicht nur die Lebenssituation der Bürger garantiert, sondern auch den Lebensstandard der Bürger verbessert. 17

Bei allen unterschiedlichen Auffassungen über „soziale Sicherheit“ und „Systeme der sozialen Sicherheit" besteht in der chinesischen Literatur zumindest Einigkeit über folgende Elemente: Ziel der sozialen Sicherheit ist Gewährleistung der sozialen Gleichheit und Gerechtigkeit sowie der Teilhabe aller Bürger an den gesellschaftlichen und wirtschaftlichen Entwicklungen. Die Systeme der sozialen Sicherheit werden durch Gesetzgebung beschlossen, sie bilden ein Mechanismus für die Verteilung und die Umver-

11 史探径, 我国社会保障法的几个理论问题 (Shi, Tanjing, Einige theoretische Fragen über das chinesische Recht der sozialen Sicherheit), in: 法学研究 (Journal of Law), 1998/4, S. 18.

12 中共中央关于制定国民经济和社会发展第七个五年计划的建议 (Vorschlag des Zentralkomitees der KP Chinas über Ausarbeitung des 7. Fünfjahresplans für die wirtschaftliche und gesellschaftliche Entwicklung), vom 23. 09. 1985.

13 国民经济和社会发展第七个五年计划 (1986-1990) (Der 7. Fünfjahresplan für die wirtschaftliche und gesellschaftliche Entwicklung 1986-1990).

14 Siehe: 国务院新闻办公室, 中国的劳动和社会保障状况的白皮书 (Presseamt des Staatsrats, Arbeit und Sozialabsicherung in China), 04/2002, Übersetzung in Beijing Rundschau 2002, Nr. 20; 陈佳贵，中国社会保障发展报告1997-2001 (Chen, Jiagui (Hrsg.), China Social Security System Development Report 1997-2001), S. 39; 中共中央关于建立社会主义市场经济体制若干问题的 决定 (Beschluss des Zentralkomitees der KP Chinas über einige Fragen zur Errichtung einer sozialistischen Marktwirtschaft), vom 14. 11. 1993, in: 人民日报 (RMRB), 17. 11. 1993.

15 黎建飞, 社会保障法 (Li, Jianfei (Hrsg.), Das Recht der sozialen Sicherheit), S. 2.

16 郑功成, 社会保障学 (Zheng, Gongcheng (Hrsg.), Social Security), S. 7.

17 林嘉, 社会保障法的理念, 实践与创新 (Lin, Jia, Theory, Practice and Innovaion on Socail Security Law), S. 8. 
teilung von Volkseinkommen. Der Staat ist für die Errichtung der Systeme der sozialen Sicherheit verantwortlich. ${ }^{18}$

In dieser Arbeit wird der Begriff der sozialen Sicherheit im weiteren Sinne verstanden. Eine neue konkretere Systematisierung wird benutzt. Soziale Sicherheit unterteilt sich in die Bereiche Sozialvorsorge (Sozialversicherungen, besondere Vorsorgesysteme), Sozialhilfe, soziale Förderung (Beschäftigungsförderung, Bildungsförderung, soziale Wohlfahrteinrichtungen) und Sonderversorgung.

\section{II. 社会福利 (Soziale Wohlfahrt)}

Die Begriffe ,welfare state“ und „Sozialstaat“" werden im Chinesischen als ,社会福 利国家 (shèhuì fúlì guójiā)“ bezeichnet und allein für die westlichen Industriestaaten, die ,privatkapitalistisch gesteuert" 19 sind, verwendet, um sie vom chinesischen sozialistischen Typ der sozialen Sicherheit zu unterscheiden. Der Umfang des Begriffs ist gleich oder weiter als soziale Sicherheit und Sozialpolitik. Alle sozialpolitischen Maßnahmen, Einrichtungen und Leistungen wie z. B. Sozialversicherung, Sozialhilfe, öffentliche Einrichtungen für Kultur, Bildung, Gesundheit, die der Staat zur Sicherung und Verbesserung des Lebensstandards sowie zur Steigerung des Wohlergehens seiner Bürger ergreift, werden von diesem Begriff umfasst. ${ }^{20}$ Im westlichen Verständnis wird „soziale Wohlfahrt“ also im weiten Sinne verstanden.

Demgegenüber ist der chinesische Begriff „soziale Wohlfahrt“ (社会福利 shèhuì fúlì) ziemlich eng gefasst. Soziale Wohlfahrt ist im chinesischen Sprachgebrauch ein Bestandteil der sozialen Sicherheit. Ziel der Errichtung der Systeme der sozialen Wohlfahrt ist nicht die Sicherung des Existenzbedürfnisses der Bürger, sondern die Verbesserung der sozialen Position aller Mitglieder der Gesellschaft. ${ }^{21}$ Der Begriff der sozialen Wohlfahrt bezeichnet nur die vom Staat oder vom Kollektiv finanzierten öffentlichen Einrichtungen, Leistungen oder Zuschüsse für Bildung, Kultur, Gesundheit, Wohnung sowie Familie (einschließlich allgemeine Wohlfahrt, kollektive Wohlfahrt und spezielle Wohlfahrt). Eine noch enger gefasste Definition der sozialen Wohlfahrt bezieht sich auf

18 Siehe: 陈良谨, 社会保障教程 (Chen, Liangjin (Hrsg.), Soziale Sicherheit), S. 11; 华迎放, 社会 保障 (Hua, Yingfang (Hrsg.), Soziale Sicherheit), S. 3; 郑功成, 社会保障学 (Zheng, Gongcheng (Hrsg.), Social Security), S. 7; 黎建飞, 社会保障法 (Li, Jianfei (Hrsg.), Recht der sozialen Sicherheit), S. 2; 林嘉, 社会保障法的理念, 实践与创新 (Lin, Jia, Theory, Practice and Innovaion on Social Security Law), S. 8; 韩君玲, 劳动与社会保障法简明教程 (Han, Junling, Grundlage des Arbeitsrechts und Sozialrechts), S. 164; 史探径, 我国社会保障法的几个理论问题 (Shi, Tanjing, Einige theoretische Fragen über das chinesische Recht der sozialen Sicherheit), in: 法学研究 (Journal of Law), 1998/4, S. 18ff.

19 Kaufmann, Sozialpolitik und Sozialstaat: Soziologische Analysen, S. 190.

20 Siehe: 林嘉, 社会保障法的理念, 实践与创新 (Lin, Jia, Theory, Practice and Innovaion on Social Security Law), S. 10; 华迎放，社会保障 (Hua, Yingfang (Hrsg.), Soziale Sicherheit), S. 376.

21 华迎放, 社会保障 (Hua, Yingfang (Hrsg.), Soziale Sicherheit), S. 9; 林嘉, 社会保障法的理念, 实践与创新 (Lin, Jia, Theory, Practice and Innovaion on Socail Security Law), S. 10. 
die öffentlichen Dienstleistungen und Einrichtungen für besondere Bürgergruppen wie Alte, Kinder, Behinderte usw., die auch als „spezielle Wohlfahrt“ benannt wird. ${ }^{22}$

Die chinesische soziale Wohlfahrt verfügt nämlich über reinen Förderungscharakter. Sie dient primär der Gleichheit und ist in der Regel auf Steuerfinanzierung angewiesen. ${ }^{23}$ In dieser Arbeit erfolgt die Systematisierung auf jener von Zacher. ${ }^{24}$ Dementsprechend wird der Begriff „Systeme der sozialen Wohlfahrt“ durch „Förderungssysteme“" ersetzt.

\section{III. 社会法 (Sozialrecht)，社会保障法 (Recht der sozialen Sicherheit)}

Der Begriff ,社会法 shèhuìfă “ (Sozialrecht) wird in China erst seit dem Aufbau der sozialistischen Marktwirtschaft verwendet. ${ }^{25}$ Das erste Mal wurde dieser Begriff im Jahr 1993 in einem Forschungsbericht der Chinesischen Akademie für Sozialwissenschaft vorgelegt. In diesem Bericht besteht das sozialistisch marktwirtschaftliche Rechtssystem hauptsächlich aus drei Teilen, nämlich dem Zivil- und Handelsrecht, dem Wirtschaftsrecht und dem Sozialrecht. Das Sozialrecht umfasst das Arbeitsrecht, das Recht der sozialen Sicherheit und andere Rechtsgebiete. ${ }^{26}$

Der Ständige Ausschuss des Nationalen Volkskongresses hat 2001 in seinem Tätigkeitsbericht das chinesische Recht in sieben Rechtsbereiche eingeteilt: Verfassung und mit der Verfassung zusammenhängendes Recht, Zivil- und Handelsrecht, Verwaltungsrecht, Wirtschaftsrecht, Sozialrecht, Strafrecht, Verfahrensrecht. ${ }^{27}$ Das Sozialrecht ist seitdem ein offiziell anerkanntes Rechtsgebiet des chinesischen Rechtssystems. In den amtlichen Dokumenten wird das Sozialrecht definiert als „Gesamtheit der rechtlichen Normen, die das Arbeitsverhältnis, das Verhältnis der sozialen Sicherheit und der sozia-

22 华建敏, 加快建设中国特色社会保障体系 (Hua, Jianmin, Das System der sozialen Sicherheit chinesischer Prägung), in: 社会保障制度 (Social Security System), 2008/3, S. 6.

23 Zacher, in: ders. (Hrsg.), Alterssicherung im Rechtsvergleich, S. 84.

24 Zacher, in: Maydell/Eichenhofer (Hrsg.), Abhandlungen zum Sozialrecht, S. $257 \mathrm{ff}$.

25 林嘉, 社会保障法的社会法本质 - 兼论劳动法与社会法的关系 (Lin, Jia, Das sozialrechtliche Wesen des Rechts der sozialen Sicherheit und das Verhältnis zwischen Arbeitsrecht und Recht der sozialen Sicherheit), in: 法学家 (Jurists' Review), 2002/1, S. 117.

26 中国社会科学院法学所课题组, 建立社会主义市场经济法律体系的理论思考和对策建议 (Studiegruppe des Forschungsinstituts für Rechtswissenschaf an der Chinesischen Akademie für Sozialwissenschaft, Theoretische Überlegung und Vorschläge zum Aufbau des sozialistisch marktwirtschaftlichen Rechtssystems), in: 法学研究 (Journal of Law), 1993/6, S. 11ff.

27 全国人民代表大会常务委员会工作报告 (2001) (Tätigkeitsbericht des Ständigen Ausschusses des Nationalen Volkskongresses 2001), vom 09. 03. 2001, in: 人民日报 (RMRB), 20. 03. 2001. 
len Wohlfahrt sowie den Schutz der besonderen Personengruppen regeln“.28 Folgende Gesetze werden als Sozialrecht bezeichnet: 29

- Gesetze über Arbeitsverhältnisse, Arbeitsschutz und soziale Sicherheit, wie z. B. Arbeitsgesetz, Arbeitsvertragsgesetz, Beschäftigungsförderungsgesetz, Gewerbegesetz, Sozialversicherungsgesetz, Gesetz für berufliche Sicherheit, Gesetz zur Verhütung und Bekämpfung der Berufskrankheit, Sozialhilfegesetz, Gesetz für soziale Wohlfahrt;

- Gesetze zum Schutz der Rechte und Interessen der besonderen Personengruppen, wie z. B. Behindertengesetz, Gesetze zum Schutz der Minderjährigen, der Frauen, der Alten, der Bauern.

In der chinesischen Literatur wird das Sozialrecht übereinstimmend als Recht mit doppelter Eigenschaft mit Bezügen zum öffentlichen und privaten Recht bezeichnet und einem dritten Zweig des Rechtssystems neben öffentlichem und privatem Recht zugeordnet. ${ }^{30}$ In den akademischen Kreisen ist zurzeit folgende Frage noch nicht abschließend geklärt: „Was ist eigentlich Sozialrecht?“ Als Sozialrecht im weiteren Sinne werden alle rechtlichen Regelungen erfasst, die ,der Staat zum Zweck der Lösung der sozialen Fragen aufgestellt hat und die den Charakter des dritten Rechtszweigs besitzen".31 Beispielsweise Arbeitsrecht, Recht der sozialen Sicherheit, Wirtschaftsrecht, Umweltrecht, Bildungsrecht, Gesundheitsrecht, Wohnungsrecht, Landwirtschaftsrecht. In einem engeren Sinne umfasst das Sozialrecht Arbeitsrecht und Recht der sozialen Sicherheit. ${ }^{32}$ In einem anderen noch engeren Sinne wird das Arbeitsrecht aus dem Sozialrecht ausgeschlossen; als Sozialrecht werden das Recht der sozialen Sicherheit, das Recht zum Schutz der schwachen Personengruppen und das Bildungsrecht verstanden. ${ }^{33}$

28 乔晓阴, 关于中国特色社会主义法律体系的构成, 特征和内容 (Qiao, Xiaoyang, Bestand, Charakter und Inhalt des sozialistischen Rechtssystems chinesischer Prägung), in: 全国人大干部培训 讲义 (Lehrmaterial des Nationalen Volkskongresses), S. 156ff.

29 乔哓阴, 关于中国特色社会主义法律体系的构成, 特征和内容 (Qiao, Xiaoyang, Bestand, Charakter und Inhalt des sozialistischen Rechtssystems chinesischer Prägung), in: 全国人大干部培训 讲义 (Lehrmaterial des Nationalen Volkskongresses), S. 156.

30 王全兴/管斌, 经济法与社会法关系初探 (Wang, Quanxing/Guan, Bin, A study on the relationship between ecomonic law and social law, in: 现代法学 (Modern Law Science), 2003/4, S. 114; 林嘉, 社会保障法的社会法本质 - 兼论劳动法与社会法的关系 (Lin, Jia, Das sozialrechtliche Wesen des Rechts der sozialen Sicherheit und das Verhältnis zwischen Arbeitsrecht und Recht der sozialen Sicherheit), in: 法学家 (Jurists' Review), 2002/1, S. 117; 郑尚元, 社会法的定位和未来 (Zheng, Shangyuan, On the Status and Future of Social Law), in: 中国法学 (China Legal Science), 2003/5, S. 126; 董保华, 社会法元论 (Dong, Baohua, Sozialrecht), S. 11; 史探径, 我国社会保 障法的几个理论问题 (Shi, Tanjing, Einige theoretische Fragen über das chinesische Recht der sozialen Sicherheit), in: 法学研究 (Journal of Law), 1998/4, S. 21.

31 王全兴/管斌, 经济法与社会法关系初探 (Wang, Quanxing/Guan, Bin, A study on the relationship between ecomonic law and social law, in: 现代法学 (Modern Law Science), 2003/4, S. 115.

32 林嘉, 社会保障法的社会法本质 - 兼论劳动法与社会法的关系 (Lin, Jia, Das sozialrechtliche Wesen des Rechts der sozialen Sicherheit und das Verhältnis zwischen Arbeitsrecht und Recht der sozialen Sicherheit), in: 法学家 (Jurists' Review), 2002/1, S. 118.

33 郑尚元, 社会法的存在与社会法理论探索 (Zheng, Shangyuan, The Existence of Social Law and the Theoretical Detective of Social Law), in: 法律科学 (Law Science), 2003/3, S. 47. 
Zusammenfassend lässt sich sagen, dass der Begriff des Sozialrechts in China neu eingeführt wurde. Es gibt noch keine allgemeine Übereinstimmung über den Inhalt und den Umfang des Sozialrechts. Dieser Begriff wird in China normalerweise weiter als in Deutschland verstanden. Hauptsächlich erfasst er das Recht der sozialen Sicherheit und das Arbeitsrecht.

Obwohl der Aufbau eines Sozialrechtssystems schon offiziell vom Gesetzgeber bestimmt wurde, ist der Weg zur Kodifizierung noch sehr weit. Das Arbeitsvertragsgesetz und das Beschäftigungsförderungsgesetz sind am 01. 01. 2008 in Kraft getreten. Das Sozialversicherungsgesetz wurde 2010 erlassen, aber es tritt erst im 01. 07. 2011 in Kraft. Für einige wichtige Rechtsgebiete wie das Sozialhilfegesetz existieren zurzeit nur Entwürfe.

Ganz gleich wie das Sozialrecht definiert wird, das Recht der sozialen Sicherheit ist der wichtigste Bestandteil des Sozialrechts. In der Literatur wird der Begriff „,das Recht der sozialen Sicherheit“ übereinstimmend definiert als „Gesamtheit der rechtlichen Normen, die das Verhältnis der sozialen Sicherheit wie Sozialversicherung, Sozialhilfe, Sozialwohlfahrt und Sonderversorgung regelt".34 Die Rechtssubjekte sind der Staat, die Gesellschaft und die einzelnen Mitglieder der Gesellschaft. Zielsetzung des Rechts der sozialen Sicherheit ist in erster Linie die Sicherung der grundlegenden Lebensbedürfnisse und darüber hinaus die Verbesserung des Lebensstandards aller Mitglieder der Gesellschaft. 35

Von den Bereichen des Wirtschafts- und Arbeitsrechts unterscheidet sich das Recht der sozialen Sicherheit hauptsächlich durch sein Regelungsobjekt. Nach der Meinung mancher chinesischen Juristen ist das Wirtschaftsrecht ein allseitiges Eingreifen des Staates in das Volkswirtschaftssystem. Es regelt die wirtschaftlichen Verhältnisse. Das Regelungsobjekt des Rechts der sozialen Sicherheit ist das Verhältnis zwischen Staat, Individuum, Träger der sozialen Sicherung sowie der Arbeitseinheit im Bereich der sozialen Sicherung. Demgegenüber regelt das Arbeitsrecht das Arbeitsverhältnis zwischen Arbeitnehmer und Arbeitgeber. ${ }^{36}$ Das Recht der sozialen Sicherheit hat eine enge Verbindung mit dem Arbeitsrecht. Die beiden Rechtszweige überschneiden sich in vielen Bereichen. Zurzeit werden die Sozialversicherung und die Sozialwohlfahrt für Arbeit-

34 黎建飞, 社会保障法 (Li, Jianfei (Hrsg.), Recht der sozialen Sicherheit), S. 5; 林嘉, 社会保障法 的理念, 实践与创新 (Lin, Jia, Theory, Practice and Innovaion on Social Security Law), S. 15; 韩 君玲, 劳动与社会保障法简明教程 (Han, Junling, Grundlage des Arbeitsrechts und Sozialrechts), S. 164; 贾俊玲, 劳动法和社会保障法学 (Jia, Junling (Hrsg.), Arbeitsrecht und Recht der sozialen Sicherheit), S. 232; 覃有土/焚启荣, 社会保障法 (Qin, Youtu/Fan, Qirong, Recht der sozialen Sicherheit), S. 69.

35 史探径, 我国社会保障法的几个理论问题 (Shi, Tanjing, Einige theoretische Fragen über das chinesische Recht der sozialen Sicherheit), in: 法学研究 (Journal of Law), 1998/4, S. 18ff; 韩君 玲, 劳动与社会保障法简明教程 (Han, Junling, Grundlage des Arbeitsrechts und Sozialrechts), S. 164.

36 贾俊玲, 劳动法和社会保障法学 (Jia, Junling (Hrsg.), Arbeitsrecht und Recht der sozialen Sicherheit), S. 243; 王全兴/管斌, 经济法与社会法关系初探 (Wang, Quanxing/Guan, Bin, A study on the relationship between ecomonic law and social law), in: 现代法学 (Modern Law Science), 2003/4, S. 115. 
nehmer (§70-§76) sowie die Beschäftigungsförderung (§10-§15) im Arbeitsgesetz von 1994 geregelt.

\section{B. Entstehung und Entwicklungsgeschichte}

Der bisherige Entwicklungsprozess der sozialen Sicherheit in der Volksrepublik China kann durch die Wirtschaftsreform in zwei Phasen unterschieden werden. Ein wichtiges Kennzeichen ist die Umwandlung der Rolle des Staates, der Gesellschaft und des Einzelnen. Vor der Wirtschaftsreform übernahmen der Staat und das Kollektiv die Hauptverantwortung für die soziale Sicherheit. Seit der Wirtschaftsreform wird die gemeinsame Verantwortung betont. Die Reform tendiert zurzeit zur „Führung der Regierung und Mitverantwortung der Gesellschaft und des Einzelnen“37.

\section{Soziale Absicherung von 1949 bis 1985}

Die Verabschiedung der „Regeln über die Arbeiterversicherung“ am 26. 02. $1951^{38}$ kennzeichnet den Beginn des Aufbaus der sozialen Sicherheit in der Volksrepublik. Danach wurden zahlreiche Rechts- und Verwaltungsverordnungen für diesen Bereich erlassen. Für die sozialistische Industrialisierung und die Förderung der gesellschaftlichen Stabilität in der Periode der Planwirtschaft hatten die sozialen Sicherungssysteme eine wichtige Rolle gespielt.

Die Sicherungssysteme für die städtische und die ländliche Bevölkerung wurden nach der Leitlinie „Bauer hat Boden, Arbeiter hat Arbeiterversicherung“39 unterschiedlich errichtet. Die ländlichen Bewohner hatten Anspruch auf die Zuteilung von Boden, demgegenüber hatten die städtischen Bewohner, die über keinen Boden als Grundlebenssicherung verfügen (Der Boden in den Städten ist Staatseigentum. Art. 10 Abs. 1 der Verfassung von 1982), Anspruch auf Arbeitsplatz und soziale Sicherung. Während ein besonders konzentriertes und einheitliches Sicherungssystem für Arbeitsplatz, Rente, Krankheit, Arbeitsunfall und Familienleistungen in den Städten vom Staat aufgrund der Planwirtschaft praktiziert wurde, beschränkte sich die staatliche Verantwortung für die soziale Sicherung der ländlichen Bevölkerung hauptsächlich auf Hilfe in Katastrophenfällen. Das Kollektiv garantierte Landbewohnern Arbeitsplatz, Lohn, Gesundheitund Altersversorgung. Zwei kollektive soziale Sicherungssysteme erlangten auf dem Land wichtige Bedeutung: das Fünf-Garantien-System und das kooperative medizinische System. 40

37 郑功成, 社会保障学 (Zheng, Gongcheng (Hrsg.), Social Security), S. 67.

38 中华人民共和国劳动保险条例, vom 26.02.1951.

39 Siehe: 陈佳贵, 中国社会保障发展报告1997-2001 (Chen, Jiagui, China Social Security System Development Report 1997-2001), S. 39.

40 Vgl. Zhang, Wei, Sozialwesen in China, S. 68. 


\section{Soziale Absicherung in der Stadt}

\section{a) Arbeiterversicherung}

Die „Regeln über die Arbeiterversicherung“ sind am 01. 03. 1951 in Kraft getreten. Sie wurden zuerst nur probeweise, dann allgemein durchgeführt. ${ }^{41}$ Bis heute wurden diese Regeln noch nicht völlig aufgehoben. ${ }^{42}$

Ziel der Errichtung der Arbeiterversicherung ist es, die Gesundheit der Beschäftigten in Unternehmen zu schützen und gegen Risiken, wie Unfall, Alter, Tod und Mutterschaft, zu sichern. ${ }^{43}$ Der Geltungsbereich der Regeln beschränkte sich 1951 nur auf die Staatsbetriebe und andere Betriebsformen, die mehr als 100 Arbeitnehmer anstellten, sowie Betriebe in dem Bereich Infrastruktur, Postwesen und Luftfahrt. ${ }^{44} 1953$ erweiterte sich der Geltungsbereich auf Betriebe der Schwerindustrie, der Bergwerke und der Verkehrsbranche sowie auf die staatlichen Baufirmen. ${ }^{45} 1956$ erweiterte sich der Geltungsbereich noch mal. Die Zahl der Arbeitnehmer, die von der Arbeiterversicherung erfasst wurden, betrug seitdem $94 \%$ der Gesamtzahl der Beschäftigten in Unternehmen. 46

Vor der Kulturrevolution war der Nationale Gewerkschaftsbund für die Durchführung der Arbeiterversicherung zuständig. ${ }^{47}$ Die Betriebe finanzierten allein den Beitrag und die Kosten. ${ }^{48}$ Sie hatten monatlich $3 \%$ der gesamten Lohnsumme aller ihren Arbeitnehmer in den Arbeiterversicherungsfonds zu zahlen. ${ }^{49}$ Nach dem Eintritt in die Arbeiterversicherung überwiesen die Betriebe den Gesamtbeitrag in den ersten zwei Monaten auf das Konto des Nationalen Gewerkschaftsbundes, ab dem dritten Monat wurde nur 30\% des Beitrags als ,,allgemeiner Arbeiterversicherungsfonds“ auf das Konto des Nationalen Gewerkschaftsbundes, die restlichen 70\% als „Arbeiterversicherungsfonds“" auf das Konto der Betriebsgewerkschaft überwiesen. Der Arbeiterversicherungsfonds der Betriebsgewerkschaft diente zur Finanzierung von Hinterbliebenengeld, Zuschüssen und Hilfsfonds. ${ }^{50}$ Das Restguthaben des Arbeiterversicherungsfonds wurde auf die Konten der Gewerkschaften auf Provinz- oder Stadtebene oder auf die Konten der Branchengewerkschaften überwiesen und als Ausgleichsarbeiterversicherungsfonds benutzt. $^{51}$ Mit dem allgemeinen Arbeiterversicherungsfonds finanzierte der Nationale

$41 \S 2$ der Regeln über die Arbeiterversicherung von 1951.

42 Ausführlich vgl. 高书生, 社会保障改革何去何从 (Gao, Shusheng, Die Reform der sozialen Sicherheit steht am Scheideweg), S. 24.

43 Art. 1 der Regeln über die Arbeiterversicherung von 1951.

$44 \S 2$ der Regeln über die Arbeiterversicherung von 1951.

$45 \S 2$ der Regeln über die Arbeiterversicherung von 1953.

46 高书生, 社会保障改革何去何从(Gao, Shusheng, Die Reform der sozialen Sicherheit steht am Scheideweg), S. 30.

$47 \S 29$ der Regeln über die Arbeiterversicherung von 1953.

$48 \S 7$ der Regeln über die Arbeiterversicherung von 1953.

$49 \S 8$ der Regeln über die Arbeiterversicherung von 1953.

50 § 9 Abs. 2 der Regeln über die Arbeiterversicherung von 1953.

$51 \S 21$ Abs. 2 der Regeln über die Arbeiterversicherung von 1953. 
Gewerkschaftsbund kollektives Wohlfahrtswesen, wie z. B. Erholungsheime, Altersheime, Waisenhäuser. 52

Die Leistungen der Arbeiterversicherung umfassten die Leistungen im Falle des Arbeitsunfalls (§12), der Krankheit (§13), des Tods (§14), des Alters (§15), der Mutterschaft (\$16) und die Leistungen der kollektiven Wohlfahrt (§17). Die Verwandten des Arbeitnehmers in auf- und absteigender Linie, für die der Arbeitnehmer unterhaltspflichtig war, erhielten bei Krankheit, Tod und Mutterschaft Zuwendungen von den Betrieben. ${ }^{53}$ Die Betriebe finanzierten direkt den Großteil der Leistungen, der Arbeiterversicherungsfonds zahlte nur Hinterbliebenengeld, Zuschüsse und Hilfsgelder.

In der Arbeiterversicherung gab es keine Regeln über die Arbeitslosenversicherung, weil die Konstrukteure der Arbeiterversicherung der Meinung waren, die Arbeitslosigkeit sei eine Frage, die von dem Imperialismus und der Volkspartei hinterlassen worden sei und die durch die Entwicklung der Produktivkraft gelöst werde. ${ }^{54}$ In einem sozialistischen Staat sollte das Phänomen der Arbeitslosigkeit nicht existieren.55 Die Regierung beseitigte dieses Problem mit dem strikten Kündigungsverbot. ${ }^{56}$ Die überflüssigen städtischen Arbeitskräfte wurden auf das Land geschickt.

Die Arbeiterversicherungsregeln wurden mit den „Vorläufigen Bestimmungen des Staatsrats über die Regelung des Ruhestandes von Arbeitern und Bediensteten "57 und den „Vorläufigen Bestimmungen des Staatsrats über die Regelung des Rücktrittes von Arbeitern und Bediensteten"58 ergänzt. Damit hatte der Staatsrat die Leistung der Rentenversicherung landesweit vereinheitlicht. Das Rentensystem der betrieblichen Arbeitnehmer wurde seitdem ein eigenständiges System. ${ }^{59} 1978$ wurde das betriebliche Rentensystem mit der Verabschiedung der „Vorläufigen Maßnahmen des Staatsrats zur Pensionierung und zum Ausscheiden von Arbeitern" verbessert. 60

Während der Kulturrevolution waren die Tätigkeiten der Gewerkschaften ins Stocken geraten. Die Regierung konnte die Durchführung der Arbeiterversicherung nicht mehr kontrollieren. 1969 verkündete das Finanzministerium „Einige Reformansichten

$52 \S 21$ Abs. 1 der Regeln über die Arbeiterversicherung von 1953.

$53 \S 13$ Abs. 5, § 14 Abs. 4, § 16 Abs. 6 der Regeln über die Arbeiterversicherung von 1953.

54 中央人民政府政务院关于劳动就业问题的决定 (Beschluss des Staatsverwaltungsrats zu den Fragen über Arbeit und Beschäftigung), vom 06. 08. 1952.

55 高书生, 社会保障改革何去何从 (Gao, Shusheng, Am Scheideweg steht die Reform der sozialen Sicherheit), S. 26.

56 中央人民政府政务院关于劳动就业问题的决定 (Beschluss des Staatsverwaltungsrats zu Fragen von Arbeit und Beschäftigung) vom 06. 08. 1952.

57 国务院关于工人职员退休处理的暂行规定 (Vorläufige Bestimmung des Staatsrats über die Regelung des Ruhestandes von Arbeitern und Bediensteten), vom 09. 02. 1958.

58 国务院关于工人职员退职处理的暂行规定 (Vorläufige Bestimmung des Staatsrats über die Regelung des Rücktrittes von Arbeitern und Bediensteten), vom 08. 03. 1958.

59 郑功成, 社会保障学 (Zheng, Gongcheng (Hrsg.), Social Security), S. 68; Darimont, Sozialversicherungsrecht der V. R. China, S. 37.

60 国务院关于工人退休退职的暂行办法 (Vorläufigen Maßnahmen des Staatsrats zur Pensionierung und zum Ausscheiden von Arbeitern), vom 02.06. 1978，国发 (1978) 104 号. 
zur Finanzarbeit in staatlichen Unternehmen (Entwurf)“.61 Die Arbeiterversicherungsfonds wurden damit aufgelöst, die Unternehmen mussten seitdem alle Kosten der Arbeiterversicherung allein tragen. Die Arbeiterversicherung verlor seine überbetriebliche Ausgleichsfunktion und wandelte sich in eine „Betriebsversicherung“ um. ${ }^{62}$ Aber die Leistungen der Arbeiterversicherung konnten in der Planwirtschaft noch in großem Maßstab von Betrieben durchgeführt werden. Bis zum Anfang der Wirtschaftsreform wurde die Arbeiterversicherung noch praktiziert.

\section{b) Beamtenversorgung}

Die in den Staats- und Parteiorganen sowie in den öffentlichen Institutionen tätigen Beamten waren in ein eigenes Beamtenversorgungssystem einbezogen. Der Versuch der Regierung in den 1950er Jahren, die verschiedenen sozialen Sicherungssysteme für Arbeiter und Beamten zu vereinheitlichen, war erfolglos. ${ }^{63}$

Seit 1950 wurde das Beamtenversorgungssystem durch viele Verordnungen Schritt für Schritt aufgebaut. Eine einheitliche Verordnung (wie die Arbeiterversicherung) für die Beamtenversorgung gab es nicht, sondern viele einzelne:

- im Jahr 1950 die „Vorläufigen Regeln für Auszeichnung und Entschädigung von revolutionärer Verwundeten und Gefallenden",64

- im Jahr 1955 die „Vorläufigen Maßnahmen über die Leistungen während der Krankheit für Beamte in den Staatsorganen ", 65

- im Jahr 1955 die „Bekanntmachung über den Mutterschaftsurlaub für Beamtinnen", 66

- für die Altersversorgung im Jahr 1955 die „Vorläufigen Maßnahmen über Pensionierung für Beamte in den Staatsorganen "67 und

- im Jahr 1958 die „Vorläufigen Regeln über Pensionierung für Arbeiter und Beamte"68, die die Regelung aus dem Jahr 1955 ersetzte,

- für die Gesundheitsversorgung im Jahr 1955 die „Bekanntmachung über die medizinische Behandlung der Kinder der Beamten in den Staatsorganen“, 69

- im Jahr 1956 die „Vorläufigen Bestimmungen über Zuwendungen der gefallenen und an Krankheit gestorbener Beamten in den Staatsorganen“.70

61 关于国营企业财务工作中的几项制度的改革意见 (草案) (Einige Reformansichten zum System der Finanzarbeit in staatlichen Unternehmen), 02.1969.

62 Darimont, Sozialversicherungsrecht der V. R. China, S. 38; 郑功成, 社会保障学 (Zheng, Gongcheng (Hrsg.), Social Security), S. 69.

63 高书生, 社会保障改革何去何从(Gao, Shusheng, Die Reform der sozialen Sicherheit steht am Scheideweg), S. 42.

64 革命工作人员伤亡裹恤暂行条例, vom 11. 12. 1950.

65 国家机关工作人员病假期间生活待遇试行办法, vom 29.12. 1955.

66 关于女工作人员生产假期的通知, vom 26. 0. 1955.

67 国家机关工作人员退休处理暂行办法, vom 29.12. 1955, aufgehoben am 09. 02. 1958.

68 关于工人职员退休处理的暂行办法 von 1958 .

69 关于国家机关工作人员子女医疗问题的通知 von 1955 .

70 关于处理牺牲病故的国家机关工作人员的补助问题的暂行规定 von 1956. 
Bis Ende 1956 wurde ein umfassendes Sicherungssystem für Beamte etabliert. Die Leistungen der Beamtenversorgung waren im Falle von Krankheit, Unfall, Arbeitsunfähigkeit und Versorgung für Familienangehörige ähnlich denen der Arbeiterversicherung. Nur bei den Leistungen und Altersgrenzen der Pensionierung waren die beiden Systeme unterschiedlich. Im Jahre 1978 verabschiedete der Staatsrat eine erneute Regelung über die Pensionierung von Beamten und Arbeitern. Die Altersgrenze der Beamten lag beim 60. Lebensjahr für Männer und beim 55. Lebensjahr für Frauen, während bei den Arbeitern das 60. Lebensjahr für Männer und das 50. Lebensjahr für Frauen galt.71

\section{Soziale Absicherung für die ländliche Bevölkerung}

Nach der Gründung der Volksrepublik wurde die Agrarreform landesweit durchgeführt. Die Bauern bekamen Boden als grundlegende Lebenssicherung. Auf dieser Basis hatte die Regierung zunächst ein System der Naturkatastrophenhilfe für die ländliche Bevölkerung errichtet, da das chinesische Festland die Naturkatastrophen wie Dürren und Überschwemmungen oft erleidet. Dies bedroht den Lebensunterhalt der Bauern. ${ }^{72}$ Ein Großteil der Versorgung fand wie früher innerhalb der Familien statt.

Mit der Vollendung der Kollektivierung in den 1950er Jahren veränderte sich die Struktur der Landwirtschaft grundlegend. Auf dem Land wurden überall Volkskommunen errichtet. Die Kleinbauernwirtschaft wurde seitdem durch die Kollektivwirtschaft ersetzt. Darüber hinaus wandelte sich das ländliche Sicherungssystem vom Modell , Familienversorgung mit Bodensicherung“ zu „Kollektivsicherung, Familienversorgung und Bodensicherung". ${ }^{73}$ Die Familien waren immer noch hauptsächlich für die Altersund Behindertenversorgung verantwortlich. Seit 1956 wurde diese Familienversorgung von einem kollektiven Fünf-Garantien-System ergänzt. Darüber hinaus gewährleistete ein kooperatives Gesundheitssystem der ländlichen Bevölkerung eine primäre medizinische Versorgung. Dafür hatte der Staat ein Drei-Stufen-Netz der Gesundheitsinstitutionen aufgebaut. Die weitere Entwicklung der staatlichen sozialen Sicherung für die ländliche Bevölkerung wurde allerdings von der Industrialisierungspolitik lange Zeit auf eine Minimumsicherung beschränkt.

71 国务院关于安置老弱病残干部的暂行办法 (Vorläufige Maßnahmen des Staatsrats zur Versorgung alter und kranker Kader) und 国务院关于工人退休退职的暂行办法 (Vorläufige Maßnahmen des Staatsrats zur Pensionierung und zum Ausscheiden von Arbeitern), 国发 (1978) 104号, vom 02. 06. 1978.

72 Siehe: 郑功成, 自然灾害与社会安全 (Zheng, Gongcheng, Naturkatastrophe und soziale Sicherheit), in: 郑杭生, 中国社会发展研究报告 (Zheng, Hangsheng ( Hrsg.), Research Reports on China Social Development 2004), S. 29 ff.

73 华迎放, 社会保障 (Hua, Yingfang (Hrsg.), Soziale Sicherheit), S. 326. 
a) Das Fünf-Garantien-System

Das Fünf-Garantien-System wurde zum ersten Mal im „Entwicklungsgrundriss der nationalen Landwirtschaft 1956 - 1967“74 und später in der „Mustersatzung für landwirtschaftliche Produktionsgenossenschaften höherer Stufe" vom 30. 06. 1956 geregelt. ${ }^{75}$ Nach diesen Regelungen wurden Alte, Behinderte und Waisen, die weder unterhaltspflichtige Angehörige noch eigene Einkünfte haben oder nicht mehr arbeitsfähig sind, von den Produktionsgenossenschaften Essen, Kleidung, Wohnung, medizinischer Versorgung und Bestattung garantiert. Das Kollektiv sollte auch dafür sorgen, dass die Jungen die Erziehung und die Toten ein angemessenes Begräbnis erhalten können.

Bis 1958 wurden schon 150.000 Altersheime auf dem Land errichtet. 3.000.000 Alte wohnten in den Altersheimen. Noch mehr „Fünf-Garantien-Haushalte“ lebten im Kollektiv und wurden von den Kollektivmitgliedern versorgt. ${ }^{76}$ Diese Errungenschaft verschwand jedoch schnell, da die Kollektive in der Phase der „Drei-JahresNaturkatastrophen“ (1959-1961) die Fünf-Garantien nicht mehr finanzieren konnten. Im Jahre 1962 gab es nur noch 30.000 Altersheime auf dem Land.

\section{b) Das kooperative medizinische System}

Das ländliche kooperative medizinische System war ein System der gegenseitigen Hilfe, das mit der staatlichen Unterstützung von den Bauern in den 1950er Jahren gegründet wurde. Am Anfang der 1950er Jahre entstanden die ersten genossenschaftlichen Krankenstationen in einigen Provinzen. Das Kollektiv und die Bauern brachten Geldmittel für die Krankenstation auf, bei Krankheit konnten die Mitglieder der Genossenschaft von der finanziellen Beschwernis teilweise entlastet werden.

Die Regierung bemühte sich seit den 1950 Jahren auch darum, ein umfangreiches Gesundheitsnetz auf der Kreisebene zu errichten. Ein ländliches Drei-Stufen-Netz zur Prävention und Gesundheitserhaltung, nämlich „Krankenhaus auf der Kreisebene, Gesundheitsstation auf der Gemeindeebene und Sanitätsstation auf der Dorfebene“, versorgte die Bauern mit einem primären medizinischen Dienst. ${ }^{77}$ Das Gesundheitsnetz hatte mit den landwirtschaftlichen Produktionsgenossenschaften eine notwendige Bedingung für die Popularisierung des kooperativen medizinischen Systems geschaffen. Seit den 1960er Jahren verbreitete sich diese kooperative Gesundheitsversorgung Schritt für Schritt auf dem ganzen Land.

Der „Bericht über die Schwerpunktlegung der Gesundheitsarbeit auf den Dörfern“78 vom Gesundheitsministerium wurde vom Zentralkomitee der KP Chinas an die entspre-

74 1956 - 1967年全国农业发展纲要 (1956-1967 Grundriss für die Entwicklung der Landwirtschaft), vom 23. 01. 1956.

$75 \S 53$ der Mustersatzung für die landwirtschaftlichen Produktionsgenossenschaften höherer Stufe (高 级农业生产合作社示范章程), vom 30. 06. 1956.

76 华迎放，社会保障 (Hua, Yingfang (Hrsg.), Soziale Sicherheit), S. 329.

77 华迎放, 社会保障 (Hua, Yingfang (Hrsg.), Soziale Sicherheit), S. 328; Zhang, Wei, Sozialwesen in China, S. 70ff.

78 卫生部关于把卫生工作重点放到农村的报告, vom 11.08. 1965. 
chenden Regierungsorgane am 21. 09. 1965 weitergeleitet und angewiesen, den Inhalt zu befolgen und das ländliche Gesundheitssystem auszuweiten. Diese Anweisung wurde in den folgenden Jahren tatkräftig umgesetzt. Bis 1976 wurden $90 \%$ der ländlichen Bevölkerung vom kooperativen medizinischen System erfasst. ${ }^{79}$

Die ländliche kooperative Gesundheitsversorgung umfasste vielseitige medizinische Leistungen von Behandlung, Gesundheitsschutz, Rehabilitation und Prävention. Die „Barfußärzte“80 versorgten Kranke in den Dörfern mit der traditionellen chinesischen und der westlichen Medizin. Die mobilen Gesundheitsteams aus den städtischen Krankenhäusern wanderten auf das Land und erhöhten das Behandlungsniveau. Die Krankenhäuser auf Kreisebene konnten staatliche Zuwendungen erhalten. Mit niedrigen Kosten wurde die Gesundheitssituation auf dem Land deutlich verbessert. Die durchschnittliche Lebenserwartung ist von 35 Jahren (1949) auf 68 Jahre (1984) gestiegen.

\section{Umgestaltung der sozialen Sicherheit seit 1985}

Die soziale Absicherung von 1949 bis 1985 basierte auf dem sozialistischen Volkseigentum und der Planwirtschaft. Die Änderung der wirtschaftlichen Grundlage hatte einen Reformbedarf der sozialen Sicherheit nach sich gezogen. Der Wandel der Sozialstruktur hatte ebenfalls zu den Reformen der sozialen Sicherheit geführt.

Auf dem Land wurden die Volkskommunen der kollektiven Sicherung mit der Dekollektivierung und der Einführung des Haushaltsverantwortungssystems aufgelöst, das kooperative medizinische System war fast total zusammengebrochen. 1986 genossen nur ca. 5\% der ländlichen Bevölkerung die kollektive Gesundheitssicherung. ${ }^{81}$ Die Bauern mussten seitdem die Kosten für Medikamente und medizinische Behandlungen, die mit der Inflation und der Kommerzialisierung des Gesundheitswesens stetig gestiegen waren, selbst finanzieren. Dies führte zur Verschlechterung der Gesundheitssituation auf dem Land und zum Phänomen „Krankheit führt zur Armut“. Aufgrund der mangelnden Finanzierung durch das Kollektiv geriet das Fünf-Garantien-System ebenfalls in Schwierigkeiten.

In den Städten waren die Arbeitsverhältnisse viel komplizierter und vielfältiger als früher. Die Pluralisierung der Wirtschaftsformen und der Aufbau eines freien Arbeitsmarkts erforderten, dass die alten sozialen Sicherungssysteme in die den neuen wirtschaftlichen Bedingungen entsprechenden Systeme umzugestalten seien. Jedoch war die alte soziale Sicherung nur noch bedingt funktionsfähig, da seit der Kulturrevolution die Arbeiterversicherung zu einer „Betriebsversicherung“ geworden war und die staatlichen Betriebe lange Zeit eine schwere finanzielle Belastung durch die Leistungen an die Sozialsicherung zu tragen hatten. Dadurch gerieten manche in eine schwierige wirtschaftli-

79 华迎放，社会保障 (Hua, Yingfang (Hrsg.), Soziale Sicherheit), S. 328.

80 Als Barfußärzte (赤脚医生) wurden die dörflichen Ärzte bezeichnet. Sie erhielten keine akademische medizinische Ausbildung und betätigten sich normalerweise als Bauern. Mit ihrer Hilfe wurde eine Minimumsicherung der medizinischen Versorgung in den Dörfern gewährleistet.

81 华迎放，社会保障 (Hua, Yingfang (Hrsg.), Soziale Sicherheit), S. 332. 
che Lage. Außerdem fehlte dem kostenlosen Gesundheitssystem die Kontrolle über die Verwendung der medizinischen Ressourcen.

Die Wirtschaftsreform wurde seit 1978 als eine zentrale Aufgabe des Staates schrittweise ausgeführt, andere Arbeiten mussten im Umfeld dieser zentralen Aufgabe geplant werden. ${ }^{82}$ Diese Situation bedingte die Umgestaltung der sozialen Sicherheit. Nach einem Forschungsbericht ${ }^{83}$ des Staatsrats sollte die soziale Sicherheit als Bestandteil des Wirtschaftssystems im Dienst der Wirtschaftreform stehen. Das Leistungsniveau der sozialen Sicherungssysteme müsse sich dem Entwicklungsniveau der Wirtschaftsreform anpassen. Bei der Umstrukturierung der sozialen Sicherheit seien die Interessen derjenigen, die unter den alten Systemen abgesichert waren, zu berücksichtigen, damit die gesellschaftliche Stabilität nicht gefährdet werde.

\section{1985 - 1993: Notwendigkeit der sozialen Sicherheit für die Wirtschaftsreform}

Der erste Schritt der Umgestaltung der sozialen Sicherheit begann in der Mitte der 1980er Jahre. Im Jahre 1985 wurde die Reform erst in dem „Vorschlag der KP Chinas über die Ausarbeitung des siebten Fünfjahresplans für wirtschaftliche und gesellschaftliche Entwicklung“ eingeleitet: „Entsprechend der neuen Situation von Reform und Öffnung müssen neue Systeme der sozialen Sicherheit, die vielfältige Formen und Programme umfassen, errichtet werden."84 Im 7. Fünfjahresplan (1986 - 1990) wurde die Errichtung neuer Systeme der sozialen Sicherheit offiziell in den staatlichen Entwicklungsplan aufgenommen. Es wurde geplant, eine anfängliche Gestalt der sozialistischen sozialen Sicherheit mit chinesischer Prägung in der Periode des 7. Fünfjahresplans schrittweise voranzutreiben. 85

In dieser Periode wurde die soziale Sicherheit hauptsächlich als ein ,ergänzendes Projekt für die Reform der staatlichen Unternehmen" 86 angesehen. In dem Vorschlag der KP Chinas wurde die Errichtung verschiedener Versicherungssysteme der Staatsorgane und Betriebe hervorgehoben und als ,wichtige Bedingung für das Gelingen der Wirtschaftsreform und die gesellschaftliche Stabilität" benannt. Es wurde auch betont,

82 江泽民, 在中国共产党第十四次全国代表大会上的报告 (Jiang, Zemin, Bericht auf dem 14. Parteitag der KP Chinas), vom12. 10. 1992

83 中国社会保障的体制选择与经济分析课题组, 社会保障: 经济分析与体制建议 (Forschungsgruppe des Staatsrats für Systementscheidung und Wirtschaftsanalyse des chinesischen System der sozialen Sicherheit, Soziale Sicherheit: Wirtschaftsanalysen und Vorschläge für die Systementscheidung), in: 改革 (Reform), 1994/5, S. 17ff.

84 中共中央关于制定国民经济和社会发展第七个五年计划的建议 (Vorschlag des Zentralkomitees der KP Chinas zur Ausarbeitung des 7. Fünfjahresplans für wirtschaftliche und gesellschaftliche Entwicklung), vom 23.09. 1985.

85 国民经济和社会发展第七个五年计划 (1986-1990) (Der 7. Fünfjahresplan für wirtschaftliche und gesellschaftliche Entwicklung 1986-1990).

86 郑功成, 社会保障学 (Zheng, Gongcheng (Hrsg.), Social Security), S. 74. 
dass nicht nur der Staat und die Unternehmen, sondern auch das Individuum für den Sozialsicherungsfonds verantwortlich seien. ${ }^{87}$

Die Reform hatte zuerst mit dem Aufbau der Grundrentenversicherung und der Arbeitslosenversicherung angefangen. Der Staatsrat hatte am 12. 07. 1986 die „Vorläufige Bestimmung zur Durchsetzung des Arbeitsvertragssystems in staatlichen Unternehmen“88 erlassen, damit wurde die „eiserne Schüssel“, nämlich der gesicherte Arbeitsplatz in staatlichen Betrieben, durch ein Arbeitsvertragssystem ersetzt. Das Arbeitsverhältnis ist seitdem kündbar. Gemäß dieser Vorschrift führte der Staat ein Sozialversicherungssystem für die Rente der Arbeiter ein. Der Rentenversicherungsfonds wurde durch Beiträge der Betriebe und der Arbeiter sowie durch Zuschüsse des Staates finanziert. ${ }^{89}$ Um die Durchführung des neu errichteten Arbeitsvertragssystems zu koordinieren, wurde die „Vorläufige Bestimmung zur Auf-Arbeit-Wartenden-Versicherung der staatlichen Unternehmen"90 am selben Tag erlassen. Diese vorläufige Bestimmung stellt die erste rechtliche Verordnung der Volksrepublik über die Arbeitslosenversicherung dar. Da die Begriffe „Arbeitslose“ und „Arbeitslosigkeit“ damals in China nicht verwendet wurden, wurde die Arbeitslosenversicherung als „Auf-Arbeit-WartendenVersicherung“ genannt. Der Betrieb zahlte 1\% der Gesamtlohnsumme seiner Arbeitnehmer als Beiträge für den Fonds der Versicherung. ${ }^{91}$

In den 1980er Jahren hatte die Reform der Rentenversicherung auch in einigen Städten begonnen. Aufgrund der konkreten Erfahrungen verschiedener Städte hatte der Staatsrat im Jahre 1991 den „Beschluss des Staatsrats zur Reform des Rentenversicherungssystems für Beschäftigte in Unternehmen“92 erlassen. Dabei wurde mit unterschiedlichen Modellen der Rentenversicherung in verschiedenen Provinzen, Autonomen Gebieten und Regierungsunmittelbaren Städten experimentiert. ${ }^{93}$ Ein Drei-SäulenModell der Altersversicherung der staatlichen Unternehmen war in diesem Beschluss festgelegt: eine Grundrentenversicherung, eine betriebliche Zusatzaltersversicherung und eine private Altersversicherung. ${ }^{94}$ Der Grundrentenversicherungsfonds wurde nach dem Prinzip „Ausgaben bestimmen Einnahmen“ errichtet. 95 Also praktizierte die Ren-

87 中共中央关于制定国民经济和社会发展第七个五年计划的建议 (Vorschlag des Zentralkomitees der KP Chinas zur Ausarbeitung des 7. Fünfjahresplans), vom 23. 09. 1985.

88 国营企业实行劳动合同制暂行规定, vom 12.07. 1986.

89 § 26 der Vorläufigen Bestimmung zur Durchsetzung vom Arbeitsvertragssystem in staatlichen Unternehmen von 1986.

90 国营企业职工待业保险暂行规定, vom 12.07. 1986.

$91 \S 3$ der Vorläufigen Bestimmung zur Arbeit-Wartenden-Versicherung der staatlichen Unternehmen von 1986.

92 国务院关于企业职工养老保险制度改革的决定，国发 (1991) 33号，vom 26. 06. 1991.

93 Nr. 1 des Beschlusses des Staatsrats zur Reform des Rentenversicherungssystems für Beschäftigte in Unternehmen von 1991.

94 Nr. 2 des Beschlusses des Staatsrats zur Reform des Rentenversicherungssystems für Beschäftigte in Unternehmen von 1991.

95 Nr. 3 des Beschlusses des Staatsrats zur Reform des Rentenversicherungssystems für Beschäftigte in Unternehmen von 1991. 
tenversicherung damals im Wesentlichen noch ein Umlageverfahren. Die Beitragsquoten wurden von den lokalen Regierungen bestimmt. 96

Um die Durchführung der „Regeln über die Änderung des Wirtschaftsführungssystems der Industrieunternehmen im Volkseigentum“97 zu koordinieren wurde die „Vorläufige Bestimmung zur Auf-Arbeit-Wartenden-Versicherung der staatlichen Unternehmen“ von der „Bestimmung zur Auf-Arbeit-Wartenden-Versicherung der staatseigenen Unternehmen“" am 01. 05. 1993 ersetzt. ${ }^{98}$ Der Deckungsbereich dieser Versicherung wurde dadurch weiter erweitert.

\section{1993 - 2003: Soziale Sicherheit als Bestandteil der sozialistischen Marktwirt- schaft}

Im Jahre 1993 wurde die soziale Sicherheit im „Beschluss des Zentral-Komitees der KP Chinas über einige Fragen zur Errichtung einer sozialistischen Marktwirtschaft" ${ }^{\star 99}$ als einer der wichtigen Bestandteile der sozialistischen Marktwirtschaft bezeichnet. ${ }^{100}$ Die Grundsätze für den Aufbau der sozialen Sicherheit sind in diesem Beschluss festgelegt:

„Die sozialen Sicherungssysteme werden auf mehreren Ebenen errichtet. Die Politik für die soziale Sicherheit wird im ganzen Land vereinheitlicht. Das Leistungsniveau wird der Wirtschaftsentwicklung und der Belastungsfähigkeit in allen Bereichen angepasst. Die konkreten Maßnahmen für die städtische und die ländliche Bevölkerung sollen weiterhin Differenzen aufweisen ."101

1993 - 2003 wurde die Reform allseitig ausgeführt. Die Hauptaufgaben in dieser Periode waren:

- Vervollkommnung der Renten- und Arbeitslosenversicherung für Beschäftigte in Unternehmen, Errichtung einer Arbeitsunfallversicherung, ${ }^{102}$

- Entwicklung der ländlichen Altersversicherung und des kooperativen medizinischen Systems, 103

- Errichtung der einheitlichen Verwaltungsorgane der sozialen Sicherheit. 104

96 Nr. 3 des Beschlusses des Staatsrats zur Reform des Rentenversicherungssystems für Beschäftigte in Unternehmen von 1991.

97 全民所有制工业企业转换经营机制条例, vom 23.07. 1992，国务院令第103号.

98 国有企业职工待业保险规定, vom 12.04.1993, 国务院令第110号.

99 中共中央关于建立社会主义市场经济体制若干问题的决定, vom 14. 11. 1993, Übersetzung in: China Aktuell, 1993, S. 1084ff.

100 Nr. 2 des Beschlusses des Zentralkomitees der KP Chinas über einige Fragen zur Errichtung einer sozialistischen Marktwirtschaft von 1993.

101 Nr. 26 des Beschlusses des Zentralkomitees der KP Chinas von 1993.

102 Nr. 27 des Beschlusses des Zentralkomitees der KP Chinas von 1993.

103 Nr. 27 des Beschlusses des Zentralkomitees der KP Chinas von 1993.

104 Nr. 28 des Beschlusses des Zentralkomitees der KP Chinas von 1993. 
a) Umgestaltung der Sozialversicherung für Beschäftigte in Unternehmen

Das im Jahre 1994 in Kraft getretene Arbeitsgesetz sah vor, dass das Sozialversicherungssystem für Beschäftigte in Unternehmen Rentenversicherung, Krankenversicherung, Arbeitsunfall- und Berufskrankenversicherung, Arbeitslosenversicherung sowie Mutterschaftsversicherung erfasst. 105 Bei der Reform wurde das Hauptgewicht auf die Rentenversicherung und die Arbeitslosenversicherung gelegt. ${ }^{106} \mathrm{Um}$ „die finanzielle Belastung der Unternehmen zu mildern, die Regulierung der Organisationsstruktur der staatlichen Betriebe zu fördern, die wirtschaftliche Effizienz und die Wettbewerbsfähigkeit der Unternehmen zu erhöhen"107 wurde die Verantwortung der Arbeitnehmer für die Finanzierung der sozialen Versicherungen verstärkt. Das alte Modell der städtischen Beschäftigung ,hohe Beschäftigungsrate, niedriger Lohn, hohe soziale Sicherung" wurde allmählich dadurch ersetzt.

Bei der Grundrentenversicherung wurden das Grundprinzip der gemeinsamen Finanzierung von Arbeitseinheiten und Arbeitnehmer sowie das Finanzierungsmodell des „Teilkapitaldeckungsverfahren“, also die Verbindung eines Solidarfonds mit individuellen Konten, erst im „Beschluss des Zentralkomitees der KP Chinas über einige Fragen zur Errichtung einer sozialistischen Marktwirtschaft“ von 1993 vorgelegt, 108 dann in der „Bekanntmachung des Staatsrats über Vertiefung der Reform des Rentenversicherungssystems für Beschäftigte in Unternehmen“ von $1995^{109}$ festgelegt. Nach zwei Jahren landesweit verbreitete Pilotprojekte hat der Staatsrat im Jahre 1997 den „Beschluss über die Errichtung eines einheitlichen Grundrentenversicherungssystems für Beschäftigte in Unternehmen" 110 erlassen, damit wurde eine einheitliche Rentenversicherung in allen Städten und Gemeinden praktiziert. Der monatliche Beitragssatz der Unternehmen betrug 20\% der Lohnsumme aller Arbeitnehmer, und die Arbeitnehmer zahlten 4\% - 8\% ihres Lohnes als Beitrag. ${ }^{111}$ Der Deckungsbereich der Grundrentenversicherung wurde schrittweise auf alle Unternehmen in den Städten vergrößert. 112

1999 hat der Staatsrat die „Regeln über die Arbeitslosenversicherung“ erlassen, ${ }^{113}$ die die erste formelle rechtliche Verordnung für die neuen Sozialversicherungssysteme darstellt. Für die anderen Sozialversicherungszweige, nämlich die Grundkrankenversicherung, die Arbeitsunfallversicherung und die Mutterschaftsversicherung, wurden auch eine Reihe von staatlichen Politnormen, rechtlichen Normen oder Verwaltungsvorschriften ausgearbeitet. Im Jahre 1994 hat das Arbeitsministerium die „Vorläufigen

$105 \S 73$ Arbeitsgesetz von 1994.

106 Nr. 27 des Beschlusses des Zentralkomitees der KP Chinas von 1993.

107 Nr. 27 des Beschlusses des Zentralkomitees der KP Chinas von 1993.

108 Nr. 27 des Beschlusses des Zentralkomitees der KP Chinas von 1993.

109 关于深化企业职工养老保险制度改革的通知，国发 (1995) 6号, vom 01.03. 1995.

110 国务院关于建立统一的企业职工基本养老保险制度的决定，国发 (1997) 26号，vom 16. 07. 1997, Übersetzung in: Darimont, Sozialversicherungsrecht der V. R. China, S. $208 \mathrm{ff}$.

111 Nr. 3 des Beschlusses des Staatsrats über die Grundrentenversicherung von 1997.

112 Nr. 6 des Beschlusses des Staatsrats über die Grundrentenversicherung von 1997.

113 失业保险条例 (Regeln über die Arbeitslosenversicherung), vom 22. 01. 1999, Übersetzung in: Darimont, Sozialversicherungsrecht der V. R. China, S. 220ff. 
Maßnahmen über die Mutterschaftsversicherung von Beschäftigten in Betrieben“114 erlassen. Im Jahre 1996 wurden die „Vorläufigen Maßnahmen über die Arbeitsunfallversicherung von Beschäftigten in Betrieben"115 vom Arbeitsministerium verkündet, die 2003 durch die „Regeln über Arbeitsunfallversicherung"116 ersetzt wurden. Für die Gesundheitsversorgung der Beschäftigten hat der Staatsrat im Jahre 1998 den „Beschluss über die Errichtung eines Grundkrankenversicherungssystems für Arbeitnehmer in Städten und Gemeinden"117 veröffentlicht.

Das Grundmodell der Krankenversicherung wurde wie das Modell der Rentenversicherung auch im Beschluss über die Errichtung einer sozialistischen Marktwirtschaft von 1993 vorgeschrieben. Wie die Rentenversicherung wurde die Grundkrankenversicherung von den Arbeitseinheiten und den Arbeitnehmern zusammen finanziert und sie funktionierte nach dem Modell der Verbindung des Solidarfonds mit individuellen Konten. ${ }^{118}$ Seit 1994 wurden die Pilotprojekte der Grundkrankenversicherung zuerst in der Stadt Zhenjiang und der Stadt Jiujiang, später landesweit eingeführt. Mit dem Beschluss des Staatsrats über die Grundkrankenversicherung von 1998 war ein einheitlicher Rahmen der Grundkrankenversicherung festgelegt. In diesem Beschluss wurde vorgeschrieben, dass die Einrichtung der Grundkrankenversicherung Ende 1999 im Wesentlichen erledigt sein sollte. ${ }^{119}$ Aber diese Arbeit ging nicht zügig voran. Bis Ende 1999 nahmen nur 5.939.000 städtische Arbeitnehmer von insgesamt 121.300.000 städtischen Arbeitnehmern an der Grundkrankenversicherung teil. ${ }^{120}$

Von 1993 bis 2003 wurden verschiedene Sozialversicherungen für betriebliche Arbeitnehmer in Städten errichtet. Seitdem entwickelt sich die Versorgung für Arbeitnehmer grundsätzlich im Rahmen der obligatorischen Sozialversicherungen. Der versicherte Personenkreis wurde Schritt für Schritt erweitert. Um die gesellschaftliche Stabilität zu gewährleisten wurde das alte Sozialversicherungssystem nicht völlig aufgehoben, viele Regelungen aus den 1950er bis 1970er Jahren gelten auch heute noch.

114 企业职工生育保险试行办法 (Vorläufigen Maßnahmen über die Mutterschaftsversicherung von Beschäftigten in Betrieben), 劳部发 (1994) Nr. 504, vom 14. 12. 1994.

115 企业职工工伤保险试行办法 (Vorläufigen Maßnahmen über die Arbeitsunfallversicherung von Beschäftigten in Betrieben), 劳部发 (1996) Nr. 266, vom 12.08. 1996.

116 工伤保险条例 (Regeln über die Unfallversicherung), vom 27. 4. 2003.

117 国务院关于建立城镇职工基本医疗保险制度的决定, 国发 (1998) 44号, Übersetzung in: Darimont, Sozialversicherungsrecht der V. R. China, S. 213ff.

118 Nr. 27 des Beschlusses des Zentralkomitees der KP Chinas über einige Fragen zur Errichtung einer sozialistischen Marktwirtschaft von 1993.

119 Nr. 7 des Beschlusses des Staatsrats über die Errichtung eines Grundkrankenversicherungssystems für Beschäftigte in Städten und Gemeinden von 1998.

120 1999劳动和社会保障事业发展统计公报 (Statistisches Bulletin über Arbeit und soziale Sicherheit 1999), http://w1.mohrss.gov.cn/gb/zwxx/2005-12/14/content_99532.htm (Stand: 15. 07. 2010). 
Tabelle 11: Die Zahl der versicherten Beschäftigten in den Städten

\begin{tabular}{|l|l|l|l|l|l|}
\hline $\begin{array}{l}\text { Sozialversicherungen } \\
\text { für Beschäftigte }\end{array}$ & $\begin{array}{l}2003 \\
\text { Gesamtzahl } \\
\text { der Beschäftig- } \\
\text { ten in Städten } \\
\text { (in Mio.): } \\
256.39\end{array}$ & $\begin{array}{l}2004 \\
\text { Gesamtzahl } \\
\text { der Beschäftig- } \\
\text { ten in Städten } \\
\text { (in Mio.): } \\
264.76\end{array}$ & $\begin{array}{l}2005 \\
\text { Gesamtzahl } \\
\text { der Beschäftig- } \\
\text { ten in Städten } \\
\text { (in Mio.): } \\
273.31\end{array}$ & $\begin{array}{l}2006 \\
\text { Gesamtzahl } \\
\text { der Beschäf- } \\
\text { tigten in } \\
\text { Städten (in } \\
\text { Mio.): 283.10 }\end{array}$ & $\begin{array}{l}2007 \\
\text { Gesamtzahl } \\
\text { der Beschäf- } \\
\text { tigten in } \\
\text { Städten (in } \\
\text { Mio.): } 293.50\end{array}$ \\
\hline Grundrentenversicherung & 155.06 & 163.53 & 174.87 & 187.66 & 201.37 \\
\hline Grundkrankenversicherung & 109.02 & 124.04 & 137,83 & 157.32 & 180.20 \\
\hline Arbeitslosenversicherung & 103.73 & 105.84 & 106.48 & 111.87 & 116.45 \\
\hline Arbeitsunfallversicherung & 49.96 & 68.45 & 84.78 & 102.68 & 121.73 \\
\hline Mutterschaftsversicherung & 36.55 & 43.84 & 54.08 & 64.59 & 77.75 \\
\hline
\end{tabular}

Quelle: 劳动和社会保障事业发展统计公报 (Statistisches Bulletin über Arbeit und soziale Sicherheit) http://www.molss.gov.cn/index/index.htm.

\section{b) Aufbau der Sicherung des Existenzminimums für die städtische Bevölkerung}

Vor der Wirtschaftsreform waren die Bedürftigen der Sozialhilfe hauptsächlich nur die Bürger, die keine Existenzgrundlage, keine Arbeitsfähigkeit und keine familiäre Unterstützung hatten. Die Zahl dieser Personengruppe war ziemlich niedrig (ca. 0.6 Millionen). ${ }^{121}$ Seit Anfang der 1990er Jahre bis in das neue Jahrtausend hinein hat die Zahl der armen Stadtbevölkerung wegen der wirtschaftlichen Strukturänderung drastisch zugenommen. Den Hauptteil der armen Bevölkerung bildeten zu dieser Zeit Arbeitslose, ausgegliederte Arbeitnehmer und Rentner, deren Renten nicht rechtzeitig ausgezahlt wurden. Gegenwärtig stagniert die Zahl der Armen in den Städten und es zählen vornehmlich Arbeitslose zur armen Bevölkerung. Die Zahl der Bedürftigen liegt nach der Vermutung der Experten zwischen 15 - 31 Millionen Personen. ${ }^{122}$

1993 wurde die Sicherung des Existenzminimums für die städtische Bevölkerung zuerst in der Stadt Shanghai errichtet. Die zentrale Regierung hatte die ShanghaiErfahrung anerkannt und begann das städtische Sozialhilfesystem landesweit zu reformieren. In anderen Städten wie Qingdao, Dalian, Changsha, Beijing wurden Pilotprojekte durchgeführt. 1997 hatte der Staatsrat in der „Mitteilung über die landesweite Errichtung der Sicherung des Existenzminimums für die städtische Bevölkerung" gefordert, bis Ende 1999 die Sicherung des Existenzminimums in allen Städten aufzubauen. ${ }^{123}$ Im Jahre 1999 wurden die „Regeln zur Sicherung des Existenzminimums für die städtische Bevölkerung“" erlassen. 124

121 华迎放，社会保障 (Hua, Yingfang (Hrsg.), Soziale Sicherheit), S. 366.

122 陈佳贵, 中国社会保障发展报告 1997-2001 (Chen, Jiagui (Hrsg.), China Social Security System Development Report 1997-2001), S. 207ff.

123 国务院关于在全国建立城市居民最低生活保障制度的通知，国发 (1997) 29号，vom 02.09. 1997.

124 城市居民最低生活保障条例 (Regeln zur Sicherung des Existenzminimums für die städtische Bevölkerung), 国发 (1999) Nr. 271, vom 28.09. 1999. 
c) Verbesserung der sozialen Absicherung für die ländliche Bevölkerung

Im Beschluss über die Errichtung einer sozialistischen Marktwirtschaft von 1993 wurden zwei Sicherungssysteme für die ländliche Bevölkerung erläutert:

„Die Alterssicherung der Bauern stützt sich in erster Linie auf die Familie, die mit der Unterstützung der Kommune verbunden wird. In manchen Gebieten kann eine Altersversicherung mit einem individuellen Konto durchgeführt werden. Das ländliche kooperative medizinische System soll weiter entfaltet und verbessert werden. $" 125$

In der Tat war das traditionelle Altersicherungsmodell „Familie mit Kommune“ mit der Dekollektivierung und der Politik der Familienplanung ins Stocken geraten. Es war für die ländliche Bevölkerung notwendig, ein neues Alterssicherungsmodell aufzubauen. Seit Anfang der 1990er Jahre hatte die Regierung Pilotprojekte für eine soziale Altersversicherung auf dem Land ausgeführt. Bei dieser Sicherung handelt es sich um ein System des Individualkontos. Die versicherten Bauern und die Kommune zahlten dafür Beträge. Bis 1998 hatten 9.24\% der ländlichen Bevölkerung an diesem Programm teilgenommen. In der Praxis wurde es aber als fehlerhaft angesehen und seit 1998 reorganisiert. Die soziale Altersversicherung für Bauern entwickelte sich seitdem im Wesentlichen nur in den reichen Küstengebieten. ${ }^{126}$

Während eine Sicherung des Existenzminimums in den Städten eingeführt wurde, wurde auf dem Land das Fünf-Garantien-System verbessert. 1994 erließ der Staatsrat die „Regeln über die Arbeit der Versorgung mit den Fünf-Garantien auf dem Land““.127 Die Regierungen auf Gemeindenebene sind seitdem für die Durchführung der Arbeit der Fünf-Garantien verantwortlich. ${ }^{128}$ Nach den Regeln wird das System durch das Dorf oder die Gemeinde finanziert. Wenn es kollektive Betriebe im Dorf gibt, können die Kosten auch von den kollektiven Betrieben übernommen werden. ${ }^{129}$

Seit den 1990er Jahren versucht die Regierung, das kooperative medizinische System auf dem Land wieder aufzubauen. 1996 war die Deckungsrate des medizinischen Systems von 5\% im Jahr 1986 auf 10\% der ländlichen Bevölkerung gestiegen. ${ }^{130}$ Die lokalen Regierungen bemühten sich darum, die ländlichen Gesundheitsinstitutionen, nämlich das dreistufige Netz zur Prävention und Gesundheitserhaltung und die medizinischen Hilfe für Armutsfamilien wieder zu festigen und zu verbessern. Ein neues kooperatives medizinisches System mit Sicherung bei schweren Krankheiten wurde ab 2002 etabliert. 131

125 Nr. 27 des Beschlusses des Zentralkomitees der KP Chinas über einige Fragen zur Errichtung einer sozialistischen Marktwirtschaft von 1993.

126 陈佳贵/王延中, 中国社会保障发展报告 2001-2004 (Chen, Jiagui/Wang, Yanzhong (Hrsg.), China Social Security System Development Report 2001-2004), S. 48.

127 农村五保供养工作条例, 国务院令第141号, vom 23.01. 1994.

128 § 3 der Regeln über die Arbeit der Versorgung mit den fünf Garantien auf dem Land von 1994.

$129 \S 11$ der Regeln über die Arbeit der Versorgung mit den fünf Garantien auf dem Land von 1994.

130 华迎放，社会保障 (Hua, Yingfang (Hrsg.), Soziale Sicherheit), S. 332.

131 中共中央、国务院关于进一步加强农村卫生工作的决定 (Beschluss des Zentralkomitees der KP Chinas und des Staatsrats über Festigung der Gesundheitsarbeit auf dem Land), 中发 (2002) 13号, 
d) Verteilung der Verwaltungszuständigkeit

Vor 1998 waren viele Regierungsorgane an der Arbeit der sozialen Sicherheit beteiligt. Das Arbeitsministerium war für die Sozialversicherung für Beschäftigte in Unternehmen verantwortlich, das Personalministerium war für die soziale Vorsorge der Staatsbedienstete, das Ministerium für Zivile Angelegenheiten war für die soziale Altersversicherung der Landbevölkerung und die Sozialhilfe sowie die Sonderversorgung, das Gesundheitsministerium für das Gesundheitswesen, das kooperative medizinische System und die Gesundheitsversorgung der Staatsbediensteten zuständig. Die Gewerkschaften übernahmen auch einen Teil der Arbeit der kollektiven Wohlfahrt, wie z. B. Kultur- und Sportveranstaltungen. Außerdem hatte der Staatsrat die Abteilungen von Stromindustrie, Eisenbahn, Post- und Fernmeldewesen, Wasserwirtschaftswesen, Finanzen, Zivilluftfahrt, usw. genehmigt, das Rentenversicherungswesen ihrer Branche selbst zu verwalten. 132

Im Jahre 1998 war das ehemalige Arbeitsministerium zum Ministerium für Arbeit und soziale Sicherheit umgewandelt worden. Seitdem übernahm das Ministerium für Arbeit und soziale Sicherheit die Verwaltungszuständigkeit der gesamten Sozialversicherung für Beschäftigte in Unternehmen, der Grundkrankenversicherung für Beamte sowie der ländlichen Altersversicherung. Das Ministerium für Zivile Angelegenheiten war weiter für Sozialhilfe, soziale Wohlfahrt und Sonderversorgung zuständig. Das neue kooperative medizinische System wurde vom Gesundheitsministerium verwaltet.

\section{2003 bis heute: Soziale Sicherheit als Bestandteil der Staatsordnung}

Im Jahre 2000 erarbeitete der Staatsrat die „Mitteilung über den Pilotplan zur Verbesserung der sozialen Sicherheit in den Städten“.133 Die Schwerpunkte des Pilotplans bezogen sich auf die Verbesserung der Grundrentenversicherung für Beschäftigte in Unternehmen, Grundkrankenversicherung und Arbeitslosenversicherung sowie der städtischen Sicherung des Existenzminimums. Ziel des Pilotplans war die Errichtung der „von dem Unternehmen unabhängigen Systeme der sozialen Sicherheit mit mehreren Finanzierungsquellen, reguliertem Systembetrieb und sozialisierten Verwaltungsorganen". 134

Die Provinz Liaoning wurde als erste für ein Pilotprojekt ausgewählt. Die beiden Prioritäten der Pilotprojekte waren Zusammenlegung der Grundlebenssicherung für die ausgegliederten Arbeitnehmer mit der Arbeitslosenversicherung und Auffüllung des

vom 19. 10. 2002; 国务院新闻办公室，中国的社会保障状况和政策白皮书 (Presseamt des Staatsrats, Soziale Sicherheit und Sozialpolitik in China), vom 07. 06. 2005.

132 Siehe: 郑功成, 社会保障学 (Zheng, Gongcheng (Hrsg.), Social Security), S. 255.

133 国务院关于完善城镇社会保障体系的试点方案，国发 (2000) 42号, vom 25. 12. 2000.

134 Abschnitt 1. der Mitteilung über den Pilotplan zur Verbesserung der Systeme der sozialen Sicherheit in den Städten von 2000. 
Individualkontos der Grundrentenversicherung. ${ }^{135}$ Das Liaoning-Pilotprojekt begann im Juni 2001 und dauerte bis Ende 2003. ${ }^{136}$ Aufgrund der Erfahrungen des Pilotplans wurde die Reform vorangetrieben. Im „Beschluss des Zentralkomitees der KP Chinas über einige Fragen zur Vervollkommnung einer sozialistischen Marktwirtschaft" (2003) ${ }^{137}$ wurden die Hauptaufgaben für die soziale Sicherheit weiter konkretisiert: 138

- Vervollkommnung der Grundsozialversicherung und der Sicherung des Existenzminimums für die städtische Bevölkerung,

- Erforschung der Reform der Beamtenvorsorge und der Sicherung des Existenzminimums für die ländliche Bevölkerung,

- Verstärkung der Verwaltung und Überwachung des Sozialversicherungsfonds.

Im Jahre 2004 wurde die Errichtung der „dem Niveau der wirtschaftlichen Entwicklung entsprechenden" Systeme der sozialen Sicherheit in die Verfassung aufgenommen. ${ }^{139}$ Seitdem wird die soziale Sicherheit als eines der grundlegenden Systeme des Staates angesehen. 140

Von 1985 bis 2005 hatte China einen neuen Rahmen der sozialen Sicherheit errichtet, ohne die gesellschaftliche Stabilität schwer zu beeinträchtigen. Allerdings stießen die neugebauten Systeme lange Zeit auf Schwierigkeiten. Die neuen Grundversicherungssysteme, insbesondere die Grundrentenversicherung und die Grundkrankenversicherung, gerieten in Finanzierungs- und Verwaltungsproblemen. ${ }^{141}$ Die Deckungsraten der Sozialversicherungen waren noch ziemlich niedrig. Bis Ende 2005 hatte die Grundrentenversicherung beispielsweise nur $64 \%$ der betrieblichen Beschäftigten abgedeckt. ${ }^{142}$ Für die städtischen Bewohner, die nicht bei Unternehmen oder öffentlichen Institutionen arbeiteten, gab es bis 2005 noch keine soziale Krankenversicherung. Das Leistungsniveau der neugebauten Systeme war im Vergleich zur Vergangenheit stark gesunken. Nicht nur auf dem Land, sondern auch in den Städten bereitete sich das neue Phänomen „Armutsrisiko wegen Alter und Krankheit“" aus. ${ }^{143}$

135 辽宁省完善城镇社会保障体系试点实施方案 (Pilotplan der Provinz Liaoning zur Verbesserung des städtischen Systems der sozialen Sicherheit), zugestimmt am 06. 07. 2001 vom Staatsrat.

136 Siehe: Darimont, Sozialversicherungsrecht der V. R. China, S. 113ff.

137 中共中央关于完善社会主义市场经济体制若干问题的决定 (Beschluss des Zentralkomitees der KP Chinas über einige Fragen zur Vervollkommnung einer sozialistischen Marktwirtschaft), vom 21. 10. 2003.

138 Nr. 30 des Beschlusses des Zentralkomitees der KP Chinas über einige Fragen zur Vervollkommnung einer sozialistischen Marktwirtschaft von 2003.

139 Art. 14 Abs. 4 der Verfassung von 1982, Revision von 2004, 23. Verfassungszusatz.

140 郑功成, 社会保障学 (Zheng, Gongcheng (Hrsg.), Social Security), S. 76.

141 劳动和社会保障部, 劳动和社会保障事业发展十一五规划纲要 (Ministerium für Arbeit und Soziale Sicherheit, Der 11. Fünfjahresentwicklungsplan für Arbeit und soziale Sicherheit (20062010).

142 劳动和社会保障事业发展统计公报 2005 (Statistisches Bulletin über Arbeit und soziale Sicherheit 2005), http://w1.mohrss.gov.cn/gb/zwxx/2006-06/12/content_119277.htm (Stand: 15. 07. 2010).

143 Vgl. Darimont, in: " Sozialer Sprengstoff in China?" - Dimensionen sozialer Herausforderungen in der Volksrepublik, S. 67ff. 
Eine Hauptursache für die Finanzierungsschwierigkeiten der sozialen Sicherung war, dass die Regierung am Anfang der Reform aufgrund ihrer mangelnden finanziellen Ressourcen. Außerdem versuchte die Regierung durch die politische Parole „Effizienz genießt Priorität", die beinhaltet, dass der Einzelne mehr Verantwortung übernehmen soll, sich der finanziellen Belastung durch die Sicherungssysteme zu entledigen. Z. B. probierte die Regierung durch Erhöhung des Beitragssatzes der Unternehmen die Bestandsrenten zu finanzieren, ebenso wie sie auf die individuellen Konten der Arbeitnehmer zugriff, indem sie mit diesem Geld die Bestandsrenten zahlte. Ein anderes Beispiel war die Abschaffung der finanziellen Unterstützung für die grundlegende medizinische Versorgung. ${ }^{144}$

Seit 2005 wandelte sich die politische Parole „Effizienz genießt Priorität“ in „Gleichgewicht von Gleichheit und Effizienz“. ${ }^{145}$ Im 6. Plenum des 16. Zentralkomitees der KP Chinas wurde das Sozialwesen als eine der wichtigsten Fragen behandelt. Im Beschluss des Zentralkomitees wurde gefordert, eine harmonische Gesellschaft aufzubauen und bis 2020 im Wesentlichen ein umfassendes System der sozialen Sicherung zu errichten, das alle städtische und ländliche Bevölkerung erfasst. ${ }^{146}$ Diese staatliche Aufgabe wurde im „Beschluss des Zentralkomitees der KP Chinas über einige wichtige Fragen zur Strukturierung einer harmonischen sozialistischen Gesellschaft" ausführlicher formuliert und betrifft alle Zweige der sozialen Sicherheit. ${ }^{147}$ Um bis 2020 das Ziel ,Jeder genießt Grundlebenssicherung, jeder genießt medizinische Grundversorgung"148 zu erreichen, hat der Staat die finanzielle Unterstützung für die öffentlichen Dienstleistungen seit 2006 stetig aufgestockt.

Nach der Steuerreform 1994 bleibt die Einnahmenquote der Zentralregierung stetig über 50\% der gesamten Staatseinnahmen. Der Staat verfügt nun wieder über reichliche Mittel, die finanzielle Unterstützung für das Sozialwesen aufzustocken. Im Jahre 2006 wurde das Gesetz über die Schulpflicht revidiert. ${ }^{149}$ Die neunjährige allgemeine Schulpflicht, die seit Ende der 1990er Jahre gebührenpflichtig war, ist seit 01. 09. 2006 wieder kostenlos. 150 Die Regierungen verschiedener Ebene finanzieren die allgemeine Schulpflicht. ${ }^{151}$ Auch im Jahre 2006 hat der Staatsrat die „Regeln über die Versorgung

144 葛延风, 社会保障制度遭遇变局 (Ge, Yanfeng, Notstand der sozialen Sicherheit), in: 中国改革 (Die chinesischen Reformen), 2005/1, S. 31ff; 陈佳贵, 中国社会保障发展报告 1997-2001 (Chen, Jiagui (Hrsg.), China Social Security System Development Report 1997-2001), S. 26 ff.

145 中国共产党十六届五中全会公报 (Bulletin des 5. Plenums des 16. Zentralkomitees der KP Chinas), vom 11. 10.2005, in: 人民日报 (RMRB), 12.10. 2005.

146 中国共产党十六届六中全会公报 (Bulletin des 6. Plenums des 16. Zentralkomitees der KP Chinas), vom 11. 10. 2006. in: 人民日报 (RMRB), 12. 10. 2006.

147 Abschnitt 4. des Beschlusses des Zentralkomitees der KP Chinas über einigen wichtigen Fragen zur Strukturierung einer harmonischen sozialistischen Gesellschaft von 2006, ausführlich vgl. Dritter Teil, Systematisierung in den amtlichen Texten.

148 胡锦涛, 在中国共产党第十七次全国代表大会上的报告 $(\mathrm{Hu}$, Jintao, Bericht auf dem 17. Parteitag der KP Chinas), vom 15. 10. 2007, in: 人民日报 (RMRB), 25. 10. 2007.

149 中华人民共和国义务教育法 von 1986, revidiert am 29. 06. 2006.

$150 \S 2$ Abs. 2 Gesetz über Schulpflicht.

$151 \S 42$ Abs. 1 Gesetz über Schulpflicht. 
mit den Fünf-Garantien auf dem Land" modifiziert, die Regierungen verschiedener Ebene finanzieren nun das Fünf-Garantien-System zusammen, welches früher lediglich vom Kollektiv gezahlt wurde. 152 Von 2003 bis 2007 hatte der Staat insgesamt 1950 Mrd. RMB für die soziale Sicherung ausgegeben, im Vergleich zu den vergangenen fünf Jahren waren die Ausgaben um 141\% gestiegen. 153

Darüber hinaus hat die auf dem 5. Plenum des 16. Zentralkomitees der KP Chinas verabschiedete politische Entscheidung, das Entwicklungsmodell zu verändern, ${ }^{154}$ den Ausbau der sozialen Sicherheit beschleunigt. Nach dieser Entscheidung ist das Wirtschaftswachstum, das sich hauptsächlich auf die Ankurbelung durch Investition und Export stützt, zur Erweiterung der Inlandsnachfrage - besonders des Konsumbedarfs zu fördern. Dafür müssen die Verbesserungsprogramme der sozialen Sicherung, insbesondere die Reform des Gesundheitswesens und der Alterssicherung, beschleunigt werden, um die Ersparnisrate der Familien zu verringen. 155

Seit 2006 wurde eine Vielzahl an sozialpolitischen Maßnahmen einschließlich der Sicherung des Existenzminimums für die ländliche Bevölkerung (2007), der ländliche Altersversicherung (2009) sowie der Gesundheitsreform (2009) durchgeführt. Die Deckungsraten der sozialen Sicherungssysteme haben sich wesentlich vergrößert. ${ }^{156} \mathrm{Z}$. B. hat das neue kooperative medizinische System bis Ende 2009 über 90\% der ländlichen Bevölkerung erfasst. 2007 begannen das Pilotprojekt der einheitlichen Entwicklungsplanung von Stadt und Land und die Integration der sozialen Sicherungssysteme. Die einheitliche Verwaltung der Grundrentenversicherung für Beschäftigte in Unternehmen wurde von der Kreis- und Bezirkebene auf die Provinzebene verlagert. Im Jahre 2008 wurde das staatliche Verwaltungssystem noch mal reformiert, Das Ministerium für Arbeit und soziale Sicherheit und das Personalministerium wurden durch das Ministerium für Personalwesen und soziale Sicherheit ersetzt.

Das Sozialversicherungsgesetz wurde im Jahre 2010 erlassen. Damit wird der Rahmen eines alle ländliche und städtische Bevölkerung umfassenden Sozialversicherungssystems festgelegt. Die Grundsätze, die Zweige, die Träger sowie die Aufsicht der Sozialversicherungen werden erstmal durch ein spezielles Gesetz einheitlich geregelt. Für die sozialen Altersversicherungen wird das Grundmodell „Solidarfonds mit Individualkonto" gesetzlich bestimmt. ${ }^{157}$ In diesem Gesetz wird auch festgelegt, dass die einheitliche Planung des Fonds der Grundrentenversicherung auf Nationalebene Schritt für Schritt zu vervollkommnen ist, während die anderen Versicherungsfonds auf Provinz-

152 农村五保供养工作条例 (Regeln über die Arbeit der Versorgung mit den fünf Garantien auf dem Land), 国务院令 Nr. 456, vom 01.03. 2006.

1532008 年政府工作报告 (Tätigkeitsbericht des Staatsrats 2008), vom 05. 03. 2008.

154 中共中央关于制定国民经济和社会发展第11个五年规划的建议 (Vorschlag des Zentralkomitees der KP Chinas zum 11. Fünfjahresplan), vom 11. 10. 2005, in: 人民日报 (RMRB), vom 19. 10. 2005.

155 Vgl. World Bank, Country Partnership Strategy for the People's Republic of China - for the Period 2006-2010, S. 8.

156 2008年政府工作报告 (Tätigkeitsbericht des Staatsrats 2008), vom 05. 03. 2008.

$157 \S 11$ Sozialversicherungsgesetz von 2010. 
ebene verwaltet werden. ${ }^{158}$ Ein überregionalen Mechanismus für die Übertragung und Fortsetzung der Sozialversicherungsbeziehungen ist zu schaffen. ${ }^{159}$

\section{Pilotprojekte als chinesische Besonderheit}

Das Modell der chinesischen Reform lautet: „Pilotprojekte probeweise ausführen allmählich verbreiten - vereinheitlichen und allseitig durchführen“. 160 Das bedeutet, dass vor der Etablierung eines neuen Systems zuerst verschiedene Pläne in kleineren Gebieten erprobt werden. Durch die Pilotprojekte werden die Reformpläne verbessert, um schließlich landesweit vereinheitlichen zu können. Das alte System wird Schritt für Schritt durch das Neue ersetzt, lange Zeit bestehen die beiden Systeme nebeneinander.

Fast alle Reformpläne der sozialen Sicherheit werden langfristig erprobt. Bereits 1982 wurde in der Stadt Changzhou und Chongqing Wirtschaftsreformen erprobt, von denen sich ein Teil auf die Sozialversicherung bezog. ${ }^{161}$ Die Reform des Gesundheitssystems begann im Jahre 1988, der Staatsrat hat vier Städte mittlerer Größe für den Pilotplan ausgewählt. 162 Bis zur Vereinheitlichung der Grundkrankenversicherung für die städtischen Arbeitnehmer im Jahre 1998 wurden Pilotprojekte 1994 und 1996 in 40 Städten verbreitet. Das Pilotprojekt des neuen kooperativen medizinischen Systems hat im Jahre $2003^{163}$ und das Pilotprojekt der Grundkrankenversicherung für die städtischen Bewohner hat erst im Jahre 2007164 angefangen. Der Aufbau eines alle Bürger umfassenden Gesundheitssystems ist zurzeit noch nicht vollendet.

Ein ähnliches Beispiel ist die Reform der Altersversicherung. Seit 1989 wurde die Rentenversicherung mit dem Modell „Solidarfonds mit individuellen Konten“ zuerst in der Stadt Shenzhen und in der Provinz Hainan experimentiert. ${ }^{165}$ Nach acht Jahren wurde die Grundrentenversicherung mit dem Beschluss des Staatsrats landesweit vereinheitlicht. Dieses Modell wurde aber wegen seiner Durchführbarkeit heftig kritisiert. Der Staatsrat hat sich nach langer Diskussion entschieden, eine Reihe Pilotpläne zur

$158 \S 64$ Abs. 3 Sozialversicherungsgesetz von 2010.

$159 \S \S 19,32,52$ Sozialversicherungsgesetz von 2010.

160 杨方方, 从缺位到归位 - 中国转型期社会保险中的政府责任 (Yang, Fangfang, Von der Abkehr bis zur Wiederkehr - die staatliche Verantwortung für die Sozialversicherung im chinesischen Transformationsprozess), S. 4.

161 Siehe: 高书生, 社会保障改革何去何从 (Gao, Shusheng, Die Reform der sozialen Sicherheit steht am Scheideweg), S. 78.

162 高书生, 社会保障改革何去何从 (Gao, Shusheng, Die Reform der sozialen Sicherheit steht am Scheideweg), S. 100.

163 卫生部，财政部，农业部，关于建立新型农村合作医疗制度的意见 (Gesundheitsministerium, Finanzministerium, Landwirtschaftsministerium, Vorschläge zum Aufbau des neuen ländlichen kooperativen medizinischen Systems)，国办发 (2003) Nr. 3, vom 10. 03. 2003.

164 国务院关于开展城镇居民基本医疗保险试点的指导意见 (Leitlinien des Staatsrats über Entfaltung des Pilotprojekts der Grundkrankenversicherung für städtische Bewohner), 国发 (2007) 20 号, vom 10. 07. 2007.

165 国家体改委, 1989年经济体制改革要点 (Ausschuss des Staatsrats für Reformplanung, Schwerpunkte der Wirtschaftsreform von 1989), vom 04. 03. 1989. 
Verbesserung des Grundrentensystems in der Provinz Liaoning, ${ }^{166}$ Heilongjiang und Jilin durchzuführen. Um die Kontinuität der Sozialpolitik zu bewahren, wird das Grundrentensystem bis jetzt nur aufgrund des im Jahre 1997 festgelegten Rahmens reguliert.

Ein Mechanismus, der die Reformerfahrungen rechtzeitig zusammenfasst, die Fehler des Reformplans genau identifiziert und berichtigt, hat sich allerdings dadurch nicht gebildet. ${ }^{167}$ Die Pilotprojekte werden manchmal nur als Formsache durchgesetzt. Die sozialpolitischen Entscheidungen wurden kaum wegen den Ergebnissen der Pilotprojekte verändert.

\section{$I V$. Vertikale Verteilung der Finanzverantwortung für die Reformen}

Nach dem territorialen Prinzip der Administration sind die lokalen Regierungen für die regionalen Verwaltungsaufgaben der sozialen Sicherheit verantwortlich. Bezüglich der Ausgaben für die soziale Sicherheit wird die Befugniserteilung zwischen den verschiedenen Regierungsebenen jedoch nicht klargestellt. Nach dem Beschluss des Staatsrats über die Steuereinnahmenaufteilung von 1993 übernimmt die Zentralregierung die auf zentraler Ebene getragenen Ausgaben für die öffentlichen Angelegenheiten wie Bildungswesen, Gesundheitswesen usw. Demgegenüber sind die lokalen Regierungen für die territorialen Ausgaben der öffentlichen Angelegenheiten verantwortlich. ${ }^{168}$ Dies wird allerdings nicht unbedingt eingehalten. Um große Reformen der sozialen Sicherung vorantreiben zu können, hat die Zentralregierung die finanzielle Hauptverantwortung der Reformprogramme getragen, da die lokalen Regierungen wegen mangelnder Finanzen die Kosten nicht übernehmen konnten. Beispielsweise trug die Zentralregierung 1998-2003 über 70\% der Gesamtkosten für die seit 1998 durchgeführte Lebenssicherung der ausgegliederten Arbeitnehmer der Staatsbetriebe, ${ }^{169}$ obwohl sie nach dem Reformplan nur knapp 50\% der Kosten übernehmen sollte. ${ }^{170}$

Eine im Pilotplan klar geregelte Kostenverteilung zwischen den Zentral- und Provinzregierungen ist die seit 2001 durchgeführte Auffüllung der Individualkonten der Grundrentenversicherung. ${ }^{171}$ Nach dem Pilotplan von 2001172 und 2004173 wurden

166 国务院关于完善城镇社会保障体系的试点方案 (Mitteilung des Staatsrats über den Pilotplan zur Verbesserung des Systems der sozialen Sicherheit in den Städten), 国发 (2000) 42号, vom 25. 12. 2000.

167 葛延风, 社会保障制度遭遇变局 (Ge, Yanfeng, Notstand der sozialen Sicherheit), in: 中国改革 (Die chinesischen Reformen), 2005/1, S. 33.

168 Nr. 3.1 des Beschlusses des Staatsrats über die Durchführung des Finanzverwaltungssystems der Steuereinnahmeaufteilung von 1993.

169 Ausführlich: Dritter Teil, 1980-2002: Flexible Beschäftigungspolitik und Arbeitslosensicherung.

170 杨方方, 关于中央政府和地方政府社会保障责任划分的几点看法 (Yang, Fangfang, Über die Verteilung der Verantwortung für soziale Sicherheit zwischen zentraler und lokaler Regierung), in: 经济体制改革 (Reform of Economic System), 2003/3, S. 19.

171 Ausführlich: Dritter Teil, Auffüllung der Individualkonten.

172 听取辽宁省关于完善城镇社会保障体系试点方案有关问题汇报的会议纪要 (Zusammenfassendes Protokoll der Aussprache über den Liaoning-Pilotplan), 国阅 (2001) 28 号. 
die Zuschüsse für die Auffüllung der Individualkonten zu 75\% von den zentralen und $25 \%$ von den lokalen Finanzhaushalten übernommen. In der Reform der Grundrentenversicherung hat die Zentralregierung bisher ca. $90 \%$ der Gesamtzuschüsse getragen. ${ }^{174}$ Außerdem hat sie den hauptsächlich für die Alterssicherung benötigten Nationalen Fonds für soziale Sicherheit im Jahre 2000 gegründet, der völlig aus zentralen Geldmitteln finanziert wird. ${ }^{175}$

Darüber hinaus wurde in den staatlichen Plänen bestimmt, dass der Zentrale Haushalt und der lokale Haushalt jeweils 50\% der Gesamtzuschüsse für das ländliche kooperative medizinische System ${ }^{176}$ und die Grundkrankenversicherung der städtischen Bewohner ${ }^{177}$ finanzieren. Im Jahre 2009 wurde eine „Basisrente“ in die ländliche Altersversicherung eingeführt. Die Zentralregierung übernimmt die volle finanzielle Verantwortung der Basisrente in den Westgebieten. In den Ostengebieten trägt sie 50\% der Basisrente. ${ }^{178}$

\section{Zusammenfassung}

Ähnlich wie die europäische Entstehung der modernen sozialen Sicherheit ${ }^{179}$ kann die chinesische Entwicklung mit historischen Stichworten, wie Industrialisierung, Urbanisierung und der Einführung der freien Marktwirtschaft sowie einer funktionsfähigen Bürokratie, umrissen werden. Die Unterschiede zwischen den beiden Entwicklungspfaden betreffen im Wesentlich den Zeitpunkt, die Weise und den Grad der Intervention der staatlichen Verantwortung, die von den historischen, politischen und ökonomischen Grundlagen des Staates bedingt sind.

Die Wirtschaftsreform seit den 1980er Jahren, die dem Wesen nach eine begrenzte Einführung der liberalen Wirtschaftsformen darstellt, führt zur Regulierung der Verantwortungsverteilung zwischen Staat, Gesellschaft und Individuum, folglich auch zur Umgestaltung der sozialen Sicherheit. Die Umgestaltung begann mit der Reform der Sicherungssysteme für Beschäftigte in Unternehmen und erweitert sich allmählich zur

173 国务院试点工作小组, 关于在吉林和黑龙江进行完善城镇社会保障体系试点工作的意见 (Ansichten des Staatsrats über den Pilotplan in Jilin und Heilongjiang), vom 07. 02. 2004.

174 杨方方, 从缺位到归位 - 中国转型期社会保险中的政府责任 (Yang, Fangfang, Von der Abkehr bis zur Wiederkehr - die staatliche Verantwortung für die Sozialversicherung im chinesischen Transformationsprozess), S. 175.

175 Ausführlich: Dritter Teil, Vorstand des Nationalen Fonds für soziale Sicherheit.

176 卫生部，财政部，农业部，关于建立新型农村合作医疗制度的意见 (Gesundheitsministerium, Finanzministerium, Landwirtschaftsministerium, Vorschläge zum Aufbau des neuen ländlichen kooperativen medizinischen Systems)，国办发 (2003) Nr. 3, vom 10.03. 2003.

177 国务院关于开展城镇居民基本医疗保险试点的指导意见 (Leitlinien des Staatsrats über die Entfaltung des Pilotprojekts der Grundkrankenversicherung für die städtische Bewohner), 国发 (2007) 20 号, vom 10. 07. 2007.

178 国务院关于开展新型农村社会养老保险试点的指导意见 (Leitansichten des Staatsrats über das Pilotprojekt der neuen ländlichen Altersversicherung), 国发 (2009) 32号, vom 01. 09. 2009.

179 Siehe: Köhler/Zacher, in: ders. (Hrsg.), Ein Jahrhundert Sozialversicherung: in der Bundesrepublik Deutschland, Frankreich, Großbritannien, Österreich und der Schweiz, S. 15. 
Sicherung aller Bürger. Die Pflicht des Einzelnen für die soziale Sicherheit wird inzwischen eingeführt.

Mit der Vertiefung der Wirtschaftsreform geht die Reform der sozialen Sicherheit schrittweise voran. Nach dem WTO-Beitritt hat die Richtung der sozialpolitischen Entscheidung sich erkennbar verändert. Gegenüber der besonderen Berücksichtigung der Errichtung der Sozialversicherungen für die städtischen Beschäftigten in den 1990er Jahren wendet sich die Regierung seit dem Anfang des 21. Jahrhunderts der Beschäftigungsförderung, Sozialhilfe, Sicherung für die ländliche Bevölkerung und schließlich der Integration der städtischen und ländlichen Systeme zu. Eine Reihe von politischen und rechtlichen Regelungen wurde seit 2001 erlassen:

Armutsbekämpfung auf dem Land, 2001,180

Existenzminimumsicherung für die städtische Bevölkerung, 2001,181

das neue kooperative medizinische System für die ländliche Bevölkerung, 2002,182

die Beschäftigungsförderung, 2002,183

die ländliche medizinische Hilfe, 2003,184

die städtische medizinische Hilfe, 2005, 185

Verstärkung der Beschäftigungs- und Wiederbeschäftigungsarbeit, 2005, 186

Wanderarbeitersicherung, 2006, 187

Beschäftigungsförderungsgesetz, 2007,188

Grundkrankenversicherung für die städtischen Bewohner, 2009,189

180 中国农村扶贫开发纲要 2001-2010 (Programme der Armutsbekämpfung auf dem Land 20012010), vom 19. 09. 2001.

181 国务院办公厅关于进一步加强城市居民最低生活保障工作的通知 (Mitteilung der Generalkanzlei des Staatsrats über die weitere Durchführung der Sicherung des Existenzminimums für die städtische Bevölkerung), 国办发 (2001)87号, vom 12.11. 2001.

182 中共中央国务院关于进一步加强农村卫生工作的决定 (Beschluss des Zentralkomitees der KP Chinas und des Staatsrats über Festigung der Gesundheitsarbeit auf dem Land), 中发 (2002) 13号, vom 19. 10. 2002.

183 中共中央, 国务院关于进一步做好下岗失业人员再就业工作的通知 (Bekanntmachung des Zentralkomitees der KP Chinas und des Staatsrats über die weitere Durchführung der Wiederbeschäftigungsmaßnahmen für die entlassenen Arbeitnehmer und die Arbeitslosen), 中发 (2002) 12号, vom 30. 09. 2002.

184 民政部，卫生部，财政部，关于实施农村医疗救助的意见，民发 (2003) 158号，vom 18. 11. 2003.

185 民政部, 卫生部, 劳动保障部, 财政部, 关于建立城市医疗救助制度试点工作的意见 (Ministerium für zivile Angelegenheiten, Gesundheitsministerium, Ministerium für Arbeit und soziale Sicherheit, Finanzministerium, Mitteilung über den Pilotplan der städtischen medizinischen Hilfe), vom 26. 02. 2005.

186 国务院关于进一步加强就业再就业工作的通知 (Mitteilung des Staatsrats über die Verstärkung der Beschäftigungs- und Wiederbeschäftigungsarbeit)，国发 (2005) 36号, vom 08. 11. 2005.

187 国务院关于解决农民工问题的若干意见 (Ansichten des Staatsrats zur Lösung der Probleme der Wanderarbeiter), 国发 (2006) 5号, vom 27. 03. 2006.

188 中华人民共和国就业促进法, vom 30. 08. 2007.

189 人力资源和社会保障部, 财政部, 关于全面开展城镇居民基本医疗保险工作的通知 (Ministerium für Personalwesen und soziale Sicherheit, Finanzministerium, Bekanntmachung über die lan- 
die ländliche Altersversicherung, 2009.190

Daraus kann man schließen, dass nach der marktorientierten und dezentralisierten Reform der sozialen Versicherungssysteme in den 1990er Jahren - die in derselben liberalen Richtung mit der Wirtschaftsreform tritt - fördern die gesellschaftliche Entwicklung nicht die weitere Liberalisierung sondern eine Gegenbewegung im Bereich der sozialen Sicherheit. Die Regierung hat darin tiefer einzugreifen und mehr Verantwortung zu übernehmen, um die zunehmenden sozialen Disparitäten auszugleichen. Die oben erwähnten Maßnahmen erweisen sich in der Praxis als wirksam für die Gewährleistung der gesellschaftlichen Stabilität - demgegenüber gibt es stets heftige Kritik an der in den 1990er Jahren festgelegten Leitlinie der sozialen Versicherung.

Die Umgestaltung der sozialen Sicherungssysteme läuft auf einem Weg ,chinesischer Prägung": Zuerst werden die Grundlinien der Reform in den politischen Entscheidungen der KP Chinas für langfristige staatliche Aufgaben bestimmt, dann werden die sozialpolitischen Entscheidungen durch staatliche Politnormen und Verwaltungsvorschriften konkretisiert. Durch Pilotprojekte wird mit den neuen Systemen in verschiedenen Gebieten experimentiert. Wenn die Pilotphase erfolgreich abgeschlossen wird, vereinheitlicht der Staat die lokalen Regelungen und erlässt nationale Rechtsvorschriften.

Darüber hinaus kann gefolgert werden, dass bei der Umgestaltung der sozialen Sicherheit - wie bei der Wirtschaftsreform - den theoretischen Fragen lange Zeit absichtlich ausgewichen wurde. Nach dem Motto der Reformpolitik muss man „...den Fluss überqueren, indem man nach Steinen tastet"191. Das bedeutet, dass man sich an die Lösungen herantastet. In diesem Sinne ist im Gegensatz zum alten rein sozialistischen System aus den Jahren 1949-1985 das neue System lange unbestimmt geblieben und wird häufig korrigiert. Diese Arbeitsweise verleiht der Konstruierung des neuen Systems mehr Flexibilität, führt aber auch dazu, dass das neu errichtete System oft nach politischen Richtlinien berichtigt werden muss und deswegen als „ein neues Kleid mit vielen Flicken" bezeichnet wird. ${ }^{192}$

Drei Beschlüsse der KP Chinas, nämlich der „Beschluss über einige Fragen zur Errichtung einer sozialistischen Marktwirtschaft“ von 1993, der „Beschluss über einige Fragen zur Vervollkommnung einer sozialistischen Marktwirtschaft" von 2003 und der „Beschluss über einige wichtige Fragen zur Strukturierung einer harmonischen sozialistischen Gesellschaft" von 2006 sind die wichtigsten programmatischen Dokumente in den verschiedenen Phasen der Umgestaltung der chinesischen sozialen Sicherheit. Allerdings fehlt zurzeit noch ein komplettes Wertesystem für die Sozialpolitik und das

desweite Entfaltung der Grundkrankenversicherung für die städtischen Bewohner), 人社部发2009 (35)号, vom 08. 04. 2009.

190 国务院关于开展新型农村社会养老保险试点的指导意见 (Leitansichten des Staatsrats über das Pilotprojekt der neuen ländlichen Altersversicherung), 国发 (2009) 32号, vom 01. 09. 2009.

191 陈云, 经济形势与经验教训 (Chen, Yun, Wirtschaftslage und Erfahrungen), in: 陈云文选第三卷 (Ausgewählte Werke von Chen, Yun, Vol. 3), S. 279.

192 杨方方, 从缺位到归位 - 中国转型期社会保险中的政府责任 (Yang, Fangfang, Von der Abkehr bis zur Wiederkehr - die staatliche Verantwortung für die Sozialversicherung im chinesischen Transformationsprozess), S. 6 . 
Sozialleistungsrecht. Fragen bezüglich des Gemeinwohlcharakters des Gesundheitssystems, der Verantwortung des Staates sowie der Gleichbehandlung der verschiedenen Personengruppen sind noch nicht in den rechtlichen Regelungen geklärt. Der Aufbau eines entsprechenden Rechtssystems bleibt auch hinter der Errichtung der sozialen Sicherung zurück.

\section{Systematisierung und Systemanalyse}

\section{Systematisierung}

Die Systematisierung und Ordnung des Rechtsstoffs ist ein wesentliches Mittel zur Erzielung dogmatischer Aussagen, die die Funktionsweise des Rechts erklären. ${ }^{193}$ Bevor die wichtigen Reformen des Sozialleistungsrechts und der Sozialpolitik Chinas ausführlich dargestellt und analysiert werden, wird zuerst eine Systematisierung durchgeführt.

\section{Systematisierung in den amtlichen Texten}

Eine Systematisierung der sozialen Sicherheit wurde erstmals im „Vorschlag der KP Chinas zum 7. Fünfjahresplan“ verwendet. ${ }^{194}$ Nach der Formulierung dieses Vorschlags unterteilt sich die chinesische soziale Sicherheit in Sozialversicherung, Sozialhilfe, Sozialwohlfahrt und Sonderversorgung. 195

Bei diesem Vorschlag wurde geplant, ein Gesamtsystem der Sozialversicherung, das verschiedene Sozialversicherungszweige, insbesondere eine Auf-Arbeit-WartendenVersicherung für Arbeitnehmer in Betrieben, für Funktionäre der Staatsorgane und Institutionen sowie für Selbständige erfasst, schrittweise aufzubauen. ${ }^{196}$ Die Regierungen verschiedener Ebenen sind für die Planung der sozialen Wohlfahrt verantwortlich. Die Betriebe und Arbeitseinheiten richten das kollektive Wohlfahrtswesen für ihre Belegschaften ein.

Der Plan führte auch eine Reihe konkreter Sondereinrichtungen der Sozialwohlfahrt für Kinder, Alte und Behinderte sowie Erholungsheime und Sanatorien auf. ${ }^{197}$ Die Sonderversorgung umfasst Lebenssicherung der behinderten Soldaten, Entschädigungsund Unterstützungsgeld für die Hinterbliebene von Märtyrern und Gefallenen sowie

193 Becker, in: ders. (Hrsg.), Rechtsdogmatik und Rechtsvergleich im Sozialrecht, S. 14.

194 中共中央关于制定国民经济和社会发展第七个五年计划的建议 (Vorschlag des Zentralkomitees der KP Chinas zum 7. Fünfjahresplan), vom 23. 09. 1985.

195 Nr. 62, Nr. 63 des Vorschlags des Zentralkomitees der KP zum 7. Fünfjahresplan von 1985.

196 Nr. 62 des Vorschlags des Zentralkomitees der KP zum 7. Fünfjahresplan von 1985.

197 Nr. 63 des Vorschlags des Zentralkomitees der KP zum 7. Fünfjahresplan von 1985. 
Vorzugsbehandlung für Familienangehörige der Soldaten. ${ }^{198}$ Behinderte und Einwohner mit niedrigem Einkommen sind hauptsächlich die Zielgruppen der Sozialhilfe. ${ }^{199}$

In den folgenden 20 Jahren wurde dieser Plan mit den wirtschaftlichen und gesellschaftlichen Entwicklungen allmählich umgesetzt. Ein umfassendes System der sozialen Sicherung, das alle städtischen und ländlichen Bewohner abdeckt, ist in den amtlichen Dokumenten zurzeit wie folgt vorgesehen:

- Alterssicherungen: die Grundrentenversicherung für städtische Beschäftigte, die Beamtenalterssicherung, die ländliche Alterssicherung,

- Krankenversicherungen: die Grundkrankenversicherung für städtische Beschäftigte, die Grundkrankenversicherung für die städtischen Bewohner, das neue kooperative medizinische System für die ländliche Bevölkerung,

- andere Sozialversicherungen für Beschäftigte in Unternehmen: Arbeitslosenversicherung, Arbeitsunfallversicherung, Mutterschaftsversicherung,

- Sozialhilfe: die Sicherung des Existenzminimums für die städtische Bevölkerung, die Sicherung des Existenzminimums für die ländliche Bevölkerung, das Fünf-Garantien-System, die Naturkatastrophenhilfe, das Hilfssystem für Obdachlose in den Städten,

- Soziale Wohlfahrt: insbesondere Wohlfahrtwesen für Alte, Behinderte und Waisenkinder,

- Sonderversorgung für Soldaten und ihre Familienangehörigen,

- die genossenschaftliche Hilfe, die Wohltätigkeiten und das kommerzielle Versicherungswesen (als Ergänzung zum System der sozialen Sicherheit),

- Wohnungshilfe: kostengünstige Wohnungen für die städtischen Familien mit niedrigem Einkommen. ${ }^{200}$

\section{Systematisierung in der Literatur}

Wie aus den amtlichen Dokumenten hervorgeht, werden Sozialversicherung, Sozialhilfe, Sozialwohlfahrt und Sonderversorgung in der rechtswissenschaftlichen Diskussion als die vier grundlegenden Bereiche der sozialen Sicherheit bezeichnet. ${ }^{201}$ Der Umfang und der Inhalt der Begriffe werden wie folgt definiert:

198 Nr. 63 des Vorschlags des Zentralkomitees der KP zum 7. Fünfjahresplan von 1985.

199 Nr. 63 des Vorschlags des Zentralkomitees der KP zum 7. Fünfjahresplan von 1985.

200 国务院新闻办公室, 中国的劳动和社会保障状况的白皮书 (Presseamt des Staatsrats, Arbeit und Sozialabsicherung in China), 04/2002, Übersetzung in Beijing Rundschau 2002; 中共中央关 于建立社会主义市场经济体制若干问题的决定 (Beschluss des Zentralkomitees der KP Chinas über einige Fragen zur Errichtung einer sozialistischen Marktwirtschaft), vom 14. 11. 1993; 中共 中央关于构建社会主义和谐社会若干重大问题的决定 (Beschluss des Zentralkomitees der KP Chinas über einige wichtige Fragen zur Strukturierung einer harmonischen sozialistischen Gesellschaft), vom 11. 10. 2006.

201 林嘉, 社会保障法的理念, 实践与创新 (Lin, Jia, Theory, Practice and Innovation on Social Security Law), S. 11; 韩君玲, 劳动与社会保障法 (Han, Junling, Grundlage des Arbeitsrechts und Sozialrechts), S. 165. 
Sozialversicherung ist ein obligatorisches System, welches der Staat durch Gesetzgebung beschließt, um den Arbeitnehmern bei einem kurzfristigen oder langfristigen Verlust der Arbeitsfähigkeit oder der Arbeitslosigkeit die notwendige materielle Hilfe zukommen zu lassen. Sozialversicherung wird von dem Staat, den Arbeitseinheiten und den Einzelnen finanziert und besteht aus der Grundrentenversicherung, der Grundkrankenversicherung, der Arbeitslosenversicherung, der Arbeitsunfallversicherung und der Mutterschaftsversicherung. ${ }^{202}$

Bei der Sozialhilfe gewährt der Staat den Bürgern, die nicht in der Lage sind, ihr Existenzminimum zu sichern, das Lebensnotwendigste. Sozialhilfe umfasst Naturkatastrophenhilfe, Sicherung des Existenzminimums, das Fünf-Garantien-System usw. 203

Unter sozialer Wohlfahrt werden die öffentlichen Einrichtungen und Maßnahmen für die Verbesserung des allgemeinen Lebensstandards verstanden. Zur sozialen Wohlfahrt gehören allgemeine Wohlfahrt für alle Bürger, Arbeitseinheitwohlfahrt sowie spezielle Wohlfahrt für Alte, Behinderte, Waisenkinder. ${ }^{204}$

Sonderversorgung ist ein Sicherungssystem, bei dem der Staat einer besonderen Personengruppe, die sich um den Staat und die Gesellschaft Verdienste erworben hat, Entschädigungen gewährt und Auszeichnungen verleiht. Das System der Sonderversorgung umfasst vorwiegend die Vorzugsbehandlung für Soldaten und ihre Familienangehörige sowie die Hinterbliebenen von Gefallenen. 205

Bei dieser Systematisierung wird die Sozialversicherung als der typische und wichtigste Bereich der sozialen Absicherung bezeichnet. Sie unterscheidet sich von anderen Sicherungssystemen hauptsächlich durch die Beitragsfinanzierung. Die steuerfinanzierten Sozialleistungen sind unterteilt in bedürftigkeitsabhängige Systeme (Sozialhilfe), Systeme mit Förderungscharakter (soziale Wohlfahrt) und Systeme für Entschädigung sowie Vorzugsbehandlung der Staatsbediensteten (Sonderversorgung).

202 Siehe: 林嘉, 社会保障法的理念, 实践与创新 (Lin, Jia, Theory, Practice and Innovation on Social Security Law), S. 11; 韩君玲, 劳动与社会保障法 (Han, Junling, Grundlage des Arbeitsrechts und Sozialrechts), S. 165; 华迎放, 社会保障 (Hua, Yingfang (Hrsg.), Soziale Sicherheit), S.4; 黎建飞, 社会保障法 (Li, Jianfei (Hrsg.), Recht der sozialen Sicherheit), S. 29; 郑功成, 社 会保障学 (Zheng, Gongcheng (Hrsg.), Social Security), S. 53.

203 韩君玲, 劳动与社会保障法(Han, Junling, Grundlage des Arbeitsrechts und Sozialrechts), S. 165; auch Darimont, Sozialversicherungsrecht der V. R. China, S. 32.

204 in: 国务院新闻办公室, 中国的劳动和社会保障状况的白皮书 (Presseamt des Staatsrats, Arbeit und Sozialabsicherung in China), 04/2002, Übersetzung in: Beijing Rundschau 2002, Nr. 20.

205 郑功成, 社会保障学 (Zheng, Gongcheng (Hrsg.), Social Security), S. 399; 黎建飞, 社会保障法 (Li, Jianfei (Hrsg.), Recht der sozialen Sicherheit), S. 216; 林嘉, 社会保障法的理念, 实践与创 新 (Lin, Jia, Theory, Practice and Innovation on Social Security Law), S. 272. 


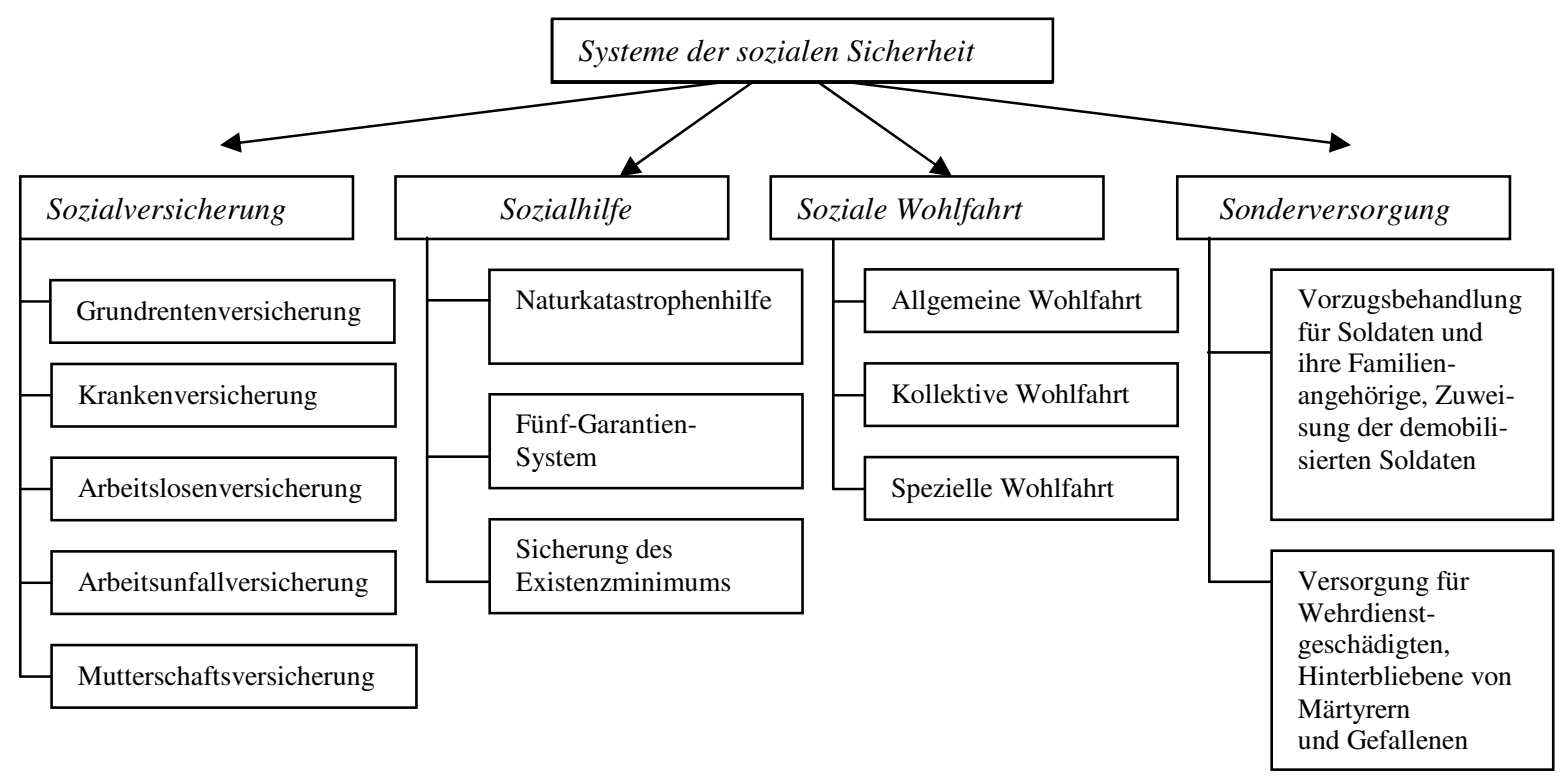

Die akademische Systematisierung bleibt aber hinter der Entwicklung der sozialen Sicherheit zurück. Sie ist noch von der Entwicklungsperiode des „Zusatzprojekts der Wirtschaftsreform“ und des „Bestandteils der Marktwirtschaft“206 geprägt und richtet die Aufmerksamkeit nur auf die Sozialversicherungen für Beschäftigte in Unternehmen. Z. B. steht der Umfang des Begriffs der Sozialversicherung nach der Definition nur noch mit der Sozialversicherung für städtische Beschäftigte, die im Arbeitsgesetz geregelt wird, im Einklang. Die neuen sozialen Versicherungszweige, wie die ländliche Alterssicherung, die Grundkrankenversicherung für die städtischen Bewohner und das neue kooperative medizinische System für die ländliche Bevölkerung sind der Definition nach keine Sozialversicherungen, weil die Teilnahme an solchen Systemen derzeitig nicht obligatorisch, sondern freiwillig ist. In der Literatur werden die ländliche Alterssicherung und das neue kooperative medizinische System manchmal als „Systeme der sozialen Sicherheit auf dem Land“" separat eingeführt. 207 Gleichfalls kann die risikospezifische Beamtenversorgung, die nicht-beitragsfinanziert sowie nicht-bedürftigkeitsabhängig ist, und über keinen Entschädigungscharakter verfügt, nicht von den vier Bereichen der sozialen Sicherheit erfasst werden und wird deshalb auch kaum in der Literatur erforscht. Dies zeigt, dass die konventionelle Systematisierung und Begriffsdefinition sich den Stand der Entwicklung der sozialen Sicherheit nicht angepasst haben.

206 Ausführlich vgl. Dritter Teil, Umgestaltung der sozialen Sicherheit seit 1985.

207 华迎放, 社会保障 (Hua, Yingfang (Hrsg.), Soziale Sicherheit), S. 325ff.; 贾俊玲, 劳动法和社会 保障法学 (Jia, Junling (Hrsg.), Arbeitsrecht und Recht der sozialen Sicherheit), S. 373ff. 
Da die oben dargestellte akademische Systematisierung der derzeitigen Lage der chinesischen sozialen Sicherheit nicht entspricht, wird in dieser Arbeit eine eigene Systematisierung durchgeführt. Sie beruht größtenteils auf der Systematisierung von Hans $F$. Zacher, ${ }^{208}$ wonach das Sozialrecht auf zweifache Weise auf die Geschichte einer sozialen Lage abgestellt werden könne: auf eine Vorgeschichte der Vorsorge, die typisch ist für die Sozialversicherung, oder eine Vorgeschichte der Verantwortung, beispielsweise bei der Entschädigung für Kriegsopfer. Fehlt eine Vorgeschichte, könne das Sozialrecht nur an die soziale Situation anknüpfen. Die Ziele des Sozialrechts bildeten das Existenzminimum, die Gleichheit, die Sicherheit und die Wohlstandsteilhabe. ${ }^{209}$

Diesen Strukturelementen nach hat Zacher drei Grundtypen des Sozialrechts unterschieden, die sich durch jeweils spezifische Möglichkeiten und Grenzen auszeichnen: ${ }^{210}$

- Vorsorgesysteme: Vorsorgesysteme schützen gegenüber bestimmten „sozialen Risiken“. Sie sind auf objektive Tatbestände hin angelegt, und werden an die abstrakten Leistungen geknüpft. Vorsorge beschränkt sich auf die, die vorsorgefähig und vorsorgebedürftig sind. Sie ist deshalb tendenziell gruppenbezogen. Vorsorgesysteme können finanziell autonom aufgebaut werden. Beitragsgetragene Vorsorge wird gemeinhin als Sozialversicherung bezeichnet. Die primäre soziale Leistung der Vorsorge ist Sicherheit. Der Gleichheit dient Vorsorge, indem sie Vorsorgeschwachen zur Vorsorge verhilft. Darüber hinaus ist ihr Verhältnis zur Gleichheit mehrdeutig. Wohlstandteilhabe kann durch Vorsorge grundsätzlich bewahrt, nicht aber gesteigert werden.

- Entschädigungssysteme: Entschädigungssysteme bauen auf Tatbeständen auf, die dadurch gekennzeichnet sind, dass Einzelne aus Ursachen, für die das Gemeinwesen verantwortlich ist oder doch die Verantwortung von Rechts wegen übernimmt, geschädigt wurden. An diese Tatbestände knüpfen sie abstrakte Leistungen. Sie sind grundsätzlich Ausdruck nationaler Solidarität. Dem entspricht ihre Finanzierung aus allgemeinen Haushaltsmitteln. Ihrem Wesen nach sind sie nicht auf Gruppen beschränkt, sondern schützen alle Staatsbürger, an denen sich die Verantwortung realisiert.

Entschädigungssysteme können dem Ziel der Sicherheit und der Gleichheit zugeordnet werden. Dem Ziel des Existenzminimums dienen sie in dem Maße, in dem sie die Betroffenen davor schützen, unter das Existenzminimum zu fallen. Wohlstandsteilhabe können sie garantieren, indem sie erreichte Wohlstandsanteile erhalten.

- Situationsbezogene Systeme umfassen folgende Systeme: Vorsorge-analoge Systeme, die gegen „soziale Risiken“ schützen und aus Steuern finanziert werden; Hilfssysteme, die dazu bestimmt sind, dringend notwendige Bedarfe zu decken, die anderweitig nicht gedeckt sind. Sie gewährleisten vor allem das Existenzminimum; Förderungssysteme, die die soziale Position von Einzelnen, Familien oder Gruppen verbessern. Sie dienen primär der Gleichheit.

208 Zacher, in: Maydell/Eichenhofer (Hrsg.), Abhandlungen zum Sozialrecht, S. $266 \mathrm{ff}$.

209 Zacher, in: Maydell/Eichenhofer (Hrsg.), Abhandlungen zum Sozialrecht, S. 266.

210 Zacher, in: Maydell/Eichenhofer (Hrsg.), Abhandlungen zum Sozialrecht, S. $268 \mathrm{ff}$. 
Diese Aufteilung ist viel umfangreicher als die klassische Systematisierung in der chinesischen Literatur. Auf der Basis dieser drei Grundtypen wird eine eigene Systematisierung den chinesischen Besonderheiten entsprechend vorgenommen.

In der vorliegenden Arbeit wird die Kategorie „Entschädigungssysteme“ durch "Sonderversorgungssysteme“ ersetzt. In China existiert vor allem die durch Haushaltsmittel finanzierte Sonderversorgung für Soldaten und ihre Familienangehörigen. „Entschädigung (赔偿 péicháng)“ ist im Chinesischen ein Begriff mit negativer Konnotation und entspricht im Deutschen eher dem Gedanken des deliktischen Schadensersatzes. Das ab 1995 in Kraft getretene Staatsentschädigungsgesetz 211 ist eine reine verwaltungsrechtliche Regelung, das den Entschädigungsanspruch des Geschädigten und die Pflicht der Staatsbehörde regelt, wenn Staatsbehörden und ihre Beamten in rechtswidriger Ausübung von Amtsbefugnissen Bürger, juristische Personen oder andere Organisationen in ihren legalen Rechte und Interessen verletzen und damit schädigen. ${ }^{212}$ Demgegenüber beinhaltet die „Sonderversorgung (优抚 yōufú)“ im Chinesischen neben der Entschädigung auch eine Vorzugsbehandlung, die zur speziellen Wohlfahrt zählt. In diesem Zusammenhang dienen die Sonderversorgungssysteme nicht nur einer Entschädigung, sondern auch der Bevorzugung und Auszeichnung der Soldaten und ihrer Familienangehörigen. ${ }^{213}$

Bei der Systematisierung von Zacher werden die risikospezifischen Systeme in Vorsorgesysteme, die geschichtsbezogen sind, und vorsorgeanaloge Systeme, die situationsbezogen sind, eingeordnet. Vor allem können die beitragsbezogenen Sozialversicherungen in Vorsorge eingeordnet werden. Die beitragsbezogenen Systeme können in China zurzeit weiter in obligatorischer Vorsorge (die Sozialversicherungen für Beschäftigten in Unternehmen) und Vorsorge auf freiwilliger Basis (die Sozialversicherungen für die nicht-beschäftigten städtischen Bewohner und für die ländliche Bevölkerung) unterteilt werden. Für die Sozialversicherungen auf freiwilliger Basis sind die staatlichen Zuschüsse zurzeit derart hoch, dass sie im gewissen Maße keine Zuschüsse mehr darstellen, sondern einer staatlichen Finanzierung gleichen. ${ }^{214}$ Insbesondere wenn man die ländliche Altersversicherung in Vorsorgesysteme und vorsorgeanaloge Systeme differenziert, ist die vorliegende Systematisierung problematisch. Nach dem Pilotplan von $2009^{215}$ umfasst die ländliche Altersversicherung ein Individualkonto und eine Basisrente, die Basisrente wird von der Regierung durch Steuermittel allein finanziert. Die ländliche Rentenversicherung stellt daher ein Mischsystem zwischen Vorsorge und vorsorgeanalogem System dar. Da die freiwilligen Sozialversicherungen nun in der Pilotphase sind, ist noch unklar, ob sie in Zukunft obligatorische Systeme werden, und ob

211 中华人民共和国国家赔偿法, vom 12. 05. 1994, revidiert am 29. 04. 2010.

$212 \S 2$ Staatsentschädigungsgesetz von 1994, Übersetzung von Münzel, http://lehrstuhl.jura.unigoettingen.de/chinarecht/940512.htm (Stand: 15. 07. 2010).

213 Ausführlich: Dritter Teil, Systemanalyse, Sonderversorgungssysteme.

214 Ausführlich: Dritter Teil, Systemanalyse, Vorsorgesysteme.

215 国务院关于开展新型农村社会养老保险试点的指导意见 (Leitansichten des Staatsrats über das Pilotprojekt der neuen ländlichen Altersversicherung), 国发 (2009) 32号, vom 01. 09. 2009. 
die staatlichen Unterstützungen mit der Vervollkommnung der Systeme reduziert werden oder sich in eine allgemeine Staatsbürgersicherung umwandeln werden.

Ähnlich steht es mit dem Problem der Beamtenversorgung, die sowohl durch Beiträge als auch durch Haushaltsmittel finanziert wird. Die Beamten werden wie die Beschäftigten in Unternehmen in die Grundkrankenversicherung für Arbeitnehmer in den Städten mit einbezogen. Dafür zahlen sie Beiträge. Darüber hinaus genießen sie zusätzliche Gesundheitszuschüsse, die wie die anderen Beamtenversorgungen durch das Finanzbudget gedeckt werden. Im Beamtengesetz von 2005 wurde geregelt, dass der Staat ein System der „Beamten-Versicherung“ errichten soll. Allerdings wurden bislang noch keine konkreten Regelungen oder Reformpläne dafür erlassen. Ob diese „Versicherung“ allein vom Staat finanziert wird oder die Beamten dazu auch einen Beitrag leisten müssen, bleibt offen.

Angesichts dieser Umstände, dass ein gemischtes Finanzierungsmodell (Beitragsfinanzierung mit Steuerfinanzierung) in den risikospezifischen Systemen überall verwendet wird, und die Entwicklungsrichtung bislang noch unklar ist, ist eine Einordnung nach Geschichte und Situation in Vorsorgesysteme oder vorsorgeanaloge Systeme zurzeit für die chinesischen risikospezifischen Systeme nicht geeignet. In dieser Arbeit werden sie deshalb allgemein als Vorsorgesysteme bezeichnet und eingeordnet. Sie dienen primär dem Ziel der Sicherheit.

Grundsätzlich werden die chinesischen Systeme der soziale Sicherheit in vier Grundtypen unterteilt: Vorsorgesysteme, Hilfesysteme, Förderungssysteme und Sonderversorgungssysteme. Als reine situationsbezogene, steuerfinanzierte Systeme unterscheiden sich die Sozialhilfe und die Sozialförderung durch ihre Zielverfolgung. Hilfesysteme sind bedürftigkeitsabhängige Systeme, sie dienen dem Existenzminimum. Dagegen werden Förderungssysteme für den Ausgleich eines erhöhten Bedarfs errichtet, sie dienen hauptsächlich der Chancengleichheit und der Wohlstandsteilhabe aller Bürger. 
Systeme der sozialen Sicherheit in der Volksrepublik China

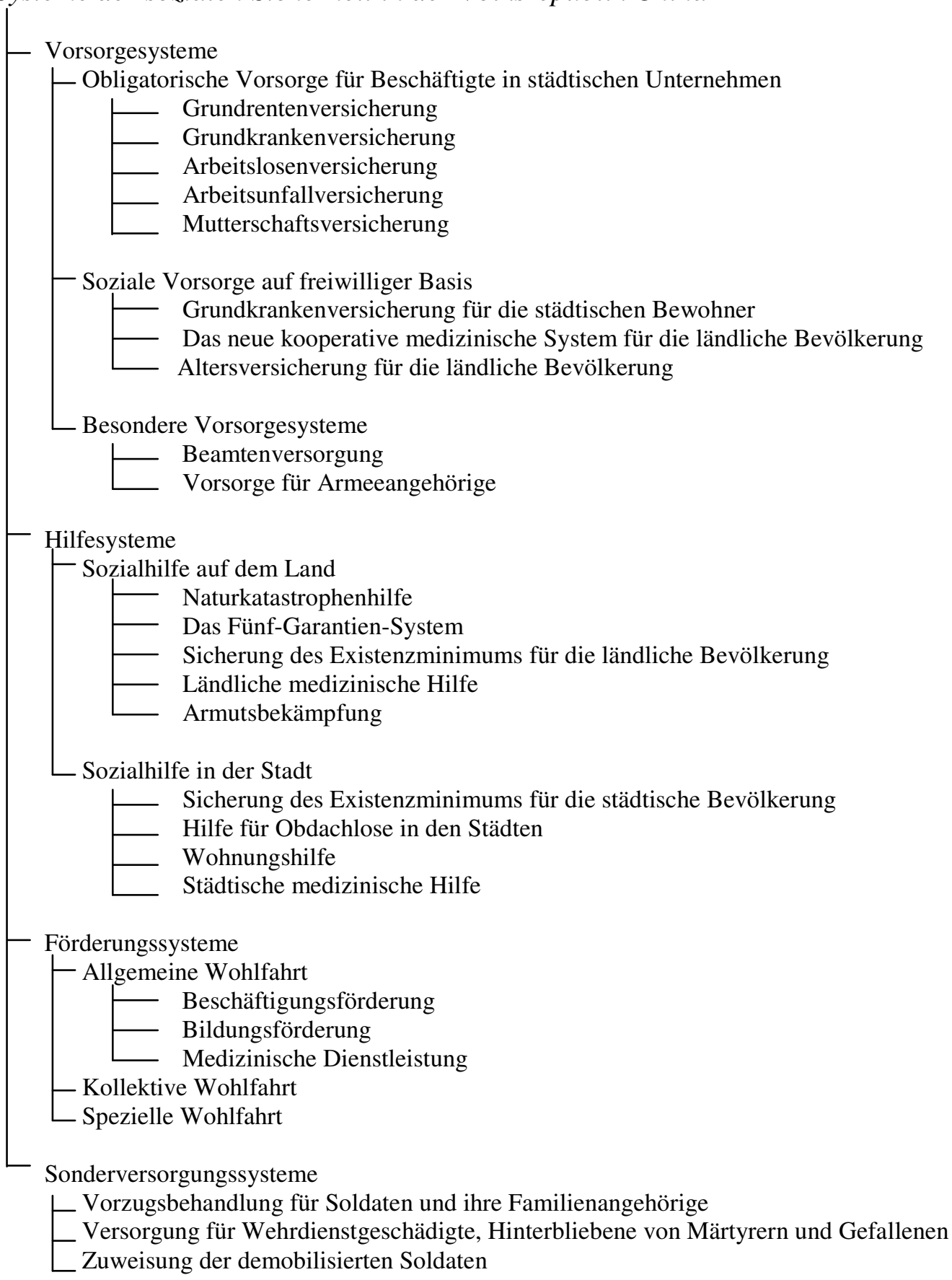




\section{Systemanalyse}

Im Rahmen der oben erwähnten Systematisierung werden die Merkmale der verschiedenen Leistungssysteme, einschließlich ihrer rechtlichen Grundlagen, der einbezogenen Personenkreise, der Finanzierungsmittel sowie der Leistungen dargestellt. Da die Angelegenheiten im Bereich der sozialen Sicherheit hauptsächlich von den lokalen Regierungen behandelt werden, werden die konkreten Durchführungsregelungen und Standards auch auf den lokalen Ebenen (hauptsächlich Kreisebene und Bezirkebene) festgelegt. Dafür erlässt die Zentralebene gewöhnlich nur die grundsätzlichen Leitlinien. Zurzeit befinden sich viele neu errichtete Sicherungszweige in der Pilotphase. Für sie fehlen noch rechtliche Regelungen und die staatlichen politischen Leitlinien sind zu allgemein gehalten.

\section{Verwaltungszuständigkeit und Träger der sozialen Sicherheit}

\section{a) Verwaltungszuständigkeit}

Auf der zentralen Ebene wird die Zuständigkeit für Verwaltung und Aufsicht der sozialen Sicherheit auf verschiedenen Ministerien und Behörden des Staatsrats verteilt. Das Ministerium für Personalwesen und soziale Sicherheit und das Ministerium für Zivile Angelegenheiten sowie das Gesundheitsministerium übernehmen den größten Teil der Verwaltungsarbeit. Die anderen betroffenen Ministerien und Behörden wie das Finanzministerium und das Rechnungsprüfungsamt sind teilweise für die Verwaltung und Überwachung der Arbeit der sozialen Sicherheit verantwortlich.

Auf den lokalen Regierungsebenen (Provinz, Bezirke, Kreise) wird die Verwaltungszuständigkeit der sozialen Sicherheit wie auf der zentralen Ebene auf verschiedene Behörden verteilt. Diese Behörden sind Bestandteil der lokalen Regierung und haben die Weisungen der oberen Verwaltungsorgane zu befolgen.

\section{aa) Das Ministerium für Personalwesen und soziale Sicherheit}

1982 wurden die damalige staatliche Personalbehörde und die Arbeitsbehörde erstmals zum Ministerium für Arbeit und Personalwesen zusammengelegt, das aber im Jahre 1988 wieder in ein Arbeitsministerium und ein Personalministerium geteilt wurde. 1998 wurde das Arbeitsministerium zum Ministerium für Arbeit und soziale Sicherheit umgewandelt und war für die gesamte Sozialversicherung der Arbeitnehmer in Städten und die ländliche Altersversicherung zuständig, demgegenüber wurde die Beamtenversorgung durch das Personalministerium übernommen.

Im Jahr 2008 wurden das Personalministerium und das Ministerium für Arbeit und sozialen Sicherheit wieder vereinigt. Das neue Ministerium für Personalwesen und soziale Sicherheit ist derzeitig für die Sozialversicherung der städtischen Beschäftigten, die Beamtenversorgung, die Grundkrankenversicherung für die städtischen Bewohner, die 
Altersversicherung für die ländliche Bevölkerung und die Beschäftigungsförderung zuständig.

Die Kompetenzen des Ministeriums für Personalwesen und soziale Sicherheit im Bereich der sozialen Sicherheit sind:216

- Ausarbeitung von Gesetzesentwürfen, Arbeitsplänen, Grundrichtlinien der Sozialversicherung und Beamtenversorgung,

- Verwaltung der Sozialversicherungszweige,

- Überwachung des Sozialversicherungsfonds.

Die Verwaltungsabteilung für Personalwesen und soziale Sicherheit auf den lokalen Ebenen werden auch danach errichtet.

bb) Das Ministerium für Zivile Angelegenheiten

Das Ministerium für interne Angelegenheiten, das im Jahre 1949 errichtet wurde, war der Vorgänger des Ministeriums für Zivile Angelegenheiten. Es wurde im Jahre 1954 umgewandelt. Dieses Ministerium wurde in der Kulturrevolution aufgehoben und erst im Jahre 1978 wieder hergestellt. Das Ministerium für Zivile Angelegenheiten ist zurzeit für Sozialhilfe, Sozialwohlfahrt und Sonderversorgung zuständig.

Die Kompetenzen des Ministeriums für Zivile Angelegenheiten im Bereich der sozialen Sicherheit sind:

- Ausarbeitung der Gesetzesentwürfe, Richtlinien, Entwicklungspläne für die zivile Angelegenheiten,

- Durchführung und Überwachung der Arbeiten von Sozialhilfe, Sozialwohlfahrt und Sonderversorgung.

cc) Weitere zuständige Ministerien und Behörden

Andere Ministerien und Behörden sind auch mit der sozialen Sicherheit beschäftigt. Das Gesundheitsministerium ist für Gesundheitswesen und das ländliche kooperative medizinische System zuständig. Das Finanzministerium und das Rechnungsprüfungsamt sind für die Finanzkontrolle und Aufsicht der Sozialsicherungsfonds verantwortlich. Die Arbeit der Armutsbekämpfung wird von der Abteilung für Armutsbekämpfung beim Staatsrat geleitet.

Einige öffentliche Organisationen und Körperschaften, wie der Nationale Gewerkschaftsbund, der Nationale Frauenbund sowie der chinesische Behindertenbund wirken auch in verschiedenem Umfang bei der Verwaltung der Systeme der sozialen Sicherheit mit. 217

216 Siehe: 郑功成, 社会保障学 (Zheng, Gongcheng (Hrsg.), Social Security), S. 249ff.

217 郑功成, 社会保障学 (Zheng, Gongcheng (Hrsg.), Social Security), S. 251. 


\section{aa) Sozialversicherungsträger}

Für die Durchführung von Sozialversicherungsleistungen sind die Sozialversicherungsträger (社会保险经办机构 shèhuì băoxiăn jīngbàn jīgòu) auf verschiedenen Regierungsebenen zuständig. Bei den Sozialversicherungsträgern handelt es sich um öffentliche Institutionen mit eigener Rechtspersönlichkeit. ${ }^{218}$ Sie werden von den Regierungsbehörden für Personalwesen und soziale Sicherheit als ihnen unmittelbar untergeordnete Organe errichtet und geleitet. Das Verwaltungszentrum der Sozialversicherung auf Staatsebene, das direkt dem Ministerium für Personalwesen und soziale Sicherheit unterstellt ist, ist das oberste Verwaltungsorgan der Sozialversicherungsträger. Sozialversicherungsträger auf den lokalen Ebenen (Provinz, Bezirke, Kreise) werden als das „Verwaltungszentrum des Sozialversicherungsfonds“ oder das „Verwaltungsorgan der Sozialversicherung" benannt. Sie bilden die Verwaltungsorgane der lokalen Regierungsbehörden für Personalwesen und soziale Sicherheit, haben aber die Weisungen der oberen Verwaltungsorganisationen zu befolgen. Die Hauptaufgabe der lokalen Sozialversicherungsträger ist die Verwaltung der Fonds der Renten-, Arbeitslosen-, Krankenversicherung usw. Ihre konkreten Verwaltungstätigkeiten sind:

- Registrierung der Beitragszahler,

- Einzug der Beiträge,

- Überprüfung und Auszahlung der Versicherungsleistungen,

- Budgetplanung, Schlussabrechnung und Nachprüfung der Sozialversicherungsfonds,

- Informationssammlung und -verwaltung. ${ }^{219}$

Je nach Sozialversicherungszweig werden eigene spezielle Konten des Fonds bei staatlichen kommerziellen Banken eröffnet. Die Eröffnung und Verwaltung dieser Konten werden nach der Regelung der „Trennung von Einnahmen und Ausgaben“ durchgeführt. 220 Für die Verwaltung eines Sozialversicherungsfonds hat diese Regelung zur Folge, dass insgesamt drei spezielle Konten eröffnet werden. Das „Einnahmekonto“ des Sozialversicherungsträgers wird für Einnahmen der Beiträge verwendet. ${ }^{221}$ Der Fonds im Einnahmekonto fließt am Monatsende auf das „spezielle Finanzkonto“, das vom Finanzamt der Regierung eingerichtet wird. Die staatlichen Zuschüsse fließen auch in das Finanzkonto ein. ${ }^{222}$ Für die Ausgaben wird der Fonds vom speziellen Finanzkonto auf das „Ausgabenkonto“ des Sozialversicherungsträgers überwiesen. ${ }^{223}$

$218 \S \S 2,3$ der Vorläufigen Regeln über die Registrierung und Verwaltung der öffentlichen Institutionen von 1998.

219 Ausführlich: 华迎放, 社会保障 (Hua, Yingfang (Hrsg.), Soziale Sicherheit), S. 237ff.

220 § 6 社会保险基金财务制度 (Finanzordnung des Sozialversicherungsfonds), 财社字( 1999) 60号, vom 15. 06. 1999.

$221 \S 16$ Finanzordnung des Sozialversicherungsfonds von 1999.

$222 \S 29$ Finanzordnung des Sozialversicherungsfonds von 1999.

$223 \S 24$ Finanzordnung des Sozialversicherungsfonds von 1999. 
bb) Vorstand des Nationalen Fonds für soziale Sicherheit

Der Nationale Fonds für soziale Sicherheit wurde vom Staatsrat im Jahre 2000 als eine öffentliche Institution und eine unabhängige öffentliche Körperschaft gegründet. Der Vorstand des Nationalen Fonds für soziale Sicherheit ist direkt dem Staatsrat unterstellt und für die Verwaltung sowie die Anlage des Fonds verantwortlich. Seine Hauptaufgabe ist die Werterhaltung und Wertsteigerung des Fonds.

Der Nationale Fonds für soziale Sicherheit ist ein „strategischer Reservefonds“ für den zukünftigen Ausgleich der Finanzlücken der sozialen Sicherungssysteme. Er wird hauptsächlich für die Alterssicherung benötigt, da die chinesische Bevölkerung in der Zukunft eine starke Überalterung aufweisen wird. ${ }^{224}$ Gemäß den „Vorläufigen Maßnahmen zur Verwaltung und Investition des Nationalen Fonds für soziale Sicherheit“ besteht der Fonds aus folgenden Investitionsmitteln: 225

- die staatliche Geldzuwendung aus dem zentralen Haushaltplan,

- die mit der Verringerung der Staatsanteile an börsengängigen Gesellschaften aufgebrachten Mittel,

- die durch anderen vom Staatsrat genehmigten Weisen aufgebrachten Mittel,

- Investitionsgewinne,

- Aktienanteile.

2001 hat der Staatsrat eine Verwaltungsvorschrift zur Verringerung der Staatsanteile ausgegeben. Danach müssen die Aktiengesellschaften, an denen der Staat Aktien hält, bei den Ausgaben von Aktien die Staatsaktien in Höhe von 10\% des zu finanzierenden Betrags verkaufen. 226 Die mit der Verringerung der Staatsanteile aufgebrachten Mittel fließen in den Nationalen Fonds für soziale Sicherheit ein. ${ }^{227}$ Dies war früher eine wichtige Kapitalquelle des Nationalen Fonds für soziale Sicherheit. Aber wegen dem nachfolgenden Absinken des Aktienmarkts hat der Staatsrat sich dafür entschieden, die Durchführung dieser Maßnahme zu beenden. Im „Beschluss des Zentralkomitees der KP Chinas über einige Fragen zur Vervollkommnung einer sozialistischen Marktwirtschaft" wurde festgelegt, dass der Fonds der sozialen Sicherheit von vielfältigen Maßnahmen, inkl. des Übertragens staatlicher Vermögenswerte unterstützt werden sollte. ${ }^{228}$ Im Jahre 2009 wurde die „Durchführungsmaßnahmen zum Übertragen der Staatsanteile

224 Siehe: 项怀诚, 关于全国社会保障基金的几个问题 (Xiang, Huaicheng, Über einige Fragen des Nationalen Fonds für soziale Sicherheit), in: 社会保障制度 (Social Security System), 2006/6, S. $10 \mathrm{ff}$.

$225 \S 2$ 全国社会保障基金投资管理暂行办法 (Vorläufige Maßnahmen zur Verwaltung und Investition des Nationalen Fonds für soziale Sicherheit), vom 13. 12. 2001.

$226 \S 5$ 减持国有股筹集社会保障资金管理暂行办法 (Vorläufige Verwaltungsmaßnahmen zur Verringerung der Staatsanteile und zur Finanzierung des Fonds der sozialen Sicherheit), 国发 (2001) 22号, vom 06. 06. 2001.

$227 \S 4$ Vorläufige Verwaltungsmaßnahmen zur Verringerung der Staatsanteile und zur Finanzierung des Fonds der sozialen Sicherheit von 2001.

228 Nr. 9 Beschluss des Zentralkomitees der KP Chinas über einige Fragen zur Vervollkommnung einer sozialistischen Marktwirtschaft von 2003. 
auf den Nationalen Fonds für soziale Sicherheit“229 erlassen, danach übertragen die Aktiengesellschaften bei der ersten Ausgabe von Aktien ihre Staatsaktien in Höhe von $10 \%$ auf den Nationalen Fonds für soziale Sicherheit. ${ }^{230}$

Der Vorstand des Nationalen Fonds für soziale Sicherheit wird beauftragt, den Nationalen Fonds für soziale Sicherheit, die staatlichen Zuschüsse für die individuellen Konten der Grundrentenversicherung sowie die ehemaligen Branchenrentenversicherungsfonds $\mathrm{zu}$ bewirtschaften und $\mathrm{zu}$ verwalten. ${ }^{231}$ Die Befugnisse des Vorstands sind:232

- Festlegung und Durchführung der Investitionsstrategie des Fonds,

- Auswahl und Beauftragung von Investitionsträgern und Treuhändern des Fonds, Überwachung der Investition und der Treuhand des Fonds, direkte Investition des Fonds im bestimmten Rahmen,

- Finanzverwaltung und Buchhaltung des Fonds,

- Bekanntgabe der finanziellen Zustände des Fonds wie Vermögen, Gewinne, Bargeldfluss usw.

Der Vorstand des Nationalen Fonds für soziale Sicherheit hat keine Befugnis, den Fonds selbst zu verwenden. Er darf nur gemäß dem vom Finanzministerium und vom Ministerium für Personalwesen und soziale Sicherheit zusammen erlassenen Befehl in entsprechender Weise Geldmittel zur Verfügung stellen.

Bis Ende 2006 betrug der Nationale Fonds der sozialen Sicherheit insgesamt 282.8 Milliarden RMB. Der Fonds wird zurzeit hauptsächlich in den nationalen Kapitalmarkt für Spareinlagen, Staatsschulden sowie Aktien investiert. 233

\section{Vorsorgesysteme}

In die Vorsorgesysteme sind die Systeme der Sozialversicherung und die besonderen Vorsorgesysteme für Staatsbedienstete eingeordnet. Unter Sozialversicherung werden nicht nur die Sozialversicherungen für Beschäftigte in Unternehmen (wie bei der klassischen Systematisierung), sondern auch die Krankenversicherung für die städtischen Bewohner, das neue kooperative medizinische System und die Altersversicherung für die ländliche Bevölkerung verstanden. Diese drei Versicherungen befinden sich zurzeit noch in der Pilotphase und verfügen über keinen obligatorischen Charakter.

229 财政部，国资委，证监会，社保基金会，境内证券市场转持部分国有股充实全国社会保障基金 实施办法，财企 (2009) 94号, vom 19.06. 2009.

$230 \S 5$ Durchführungsmaßnahmen zum Übertragen der Staatsanteile auf den Nationalen Fonds für soziale Sicherheit.

231 2006年全国社会保障基金年度报告 (Jahresbericht des Nationalen Fonds für soziale Sicherheit 2006), http://www.ssf.gov.cn/xxgk/tzycb/cwbg/200904/t20090427_905.html (Stand: 15. 07. 2010).

$232 \S 6$ Vorläufige Maßnahmen zur Verwaltung und Investition des Nationalen Fonds für soziale Sicherheit; Jahresbericht des Nationalen Fonds für soziale Sicherheit 2006.

233 项怀诚, 关于全国社会保障基金的几个问题 (Xiang, Huaicheng, Über einige Fragen des Nationalen Fonds für soziale Sicherheit), in: 社会保障制度 (Social Security System), 2006/6, S. 10ff. 
a) Sozialversicherung für Beschäftigte in Unternehmen

aa) Rechtliche Grundlagen

Das Sozialversicherungsgesetz wurde erst im Jahre 2010 erlassen. ${ }^{234}$ Es tritt am 01. 07. 2011 in Kraft. Dieses Gesetz enthält nur sehr allgemeine Regelungen über Sozialversicherungszweige, Sozialversicherungsfonds, Sozialversicherungsträger sowie Aufsicht der Sozialversicherungen. Für konkrete Maßnahmen wird auf spezielle Vorschriften verwiesen. Gemäß dem Sozialversicherungsgesetz errichtet der Staat Grundkrankenversicherungen, Grundrentenversicherungen, Arbeitsunfallversicherung, Arbeitslosenversicherung sowie Mutterschaftsversicherung. 235

Die rechtlichen Grundsätze der Sozialversicherung für Beschäftigte in Unternehmen werden bereits im Arbeitsgesetz von 1994 geregelt, da das Sozialversicherungsrecht für Arbeitnehmer im chinesischen Rechtssystem auch als ein Teilbereich des Arbeitsrechts angesehen wird. ${ }^{236}$ Im Arbeitsgesetz von 1994 bestimmt § 73 Abs. 1:

„Die Werktätigen erhalten bei Vorliegen folgender Umstände Leistungen der Sozialversicherung:

(1) im Ruhestand;

(2) bei Krankheit und Verletzung;

(3) bei Invalidität oder Berufskrankheit;

(4) bei Arbeitslosigkeit;

(5) bei Mutterschaft. “237

Gem. $§ 2$ Abs. 1 Arbeitsgesetz gilt dieses Gesetz für die Unternehmen, die Individualbetriebe und die Werktätigen, die mit ihnen Arbeitsverhältnisse begründen. Gegenüber den Staatsbehörden, den öffentlichen Institutionen, den gesellschaftlichen Körperschaften und den Werktätigen, die mit ihnen Arbeitsvertragsbeziehungen aufbauen, wird dieses Gesetz entsprechend angewandt. ${ }^{238}$ Nach dem Wortlaut sind die „Werktätigen“ im Sinne des Arbeitsgesetzes also grundsätzlich die Beschäftigten in Unternehmen. Ein obligatorisches Gesamtsystem der Sozialversicherung für die Werktätigen in Arbeitseinheiten, das gegenüber den oben im $§ 73$ Abs. 1 Arbeitsgesetz erwähnten „sozialen Risiken“" schützt, wurde gem. Art. 45 der Verfassung von 1982 und dem Arbeitsgesetz aufgebaut. Es erfasst die Grundrentenversicherung, die Grundkrankenversicherung, die Arbeitslosenversicherung, die Arbeitsunfallversicherung sowie die Mutterschaftsversicherung.

234 中华人民共和国社会保险法 (Sozialversicherungsgesetz), vom 28. 10. 2010.

235 § 2 Soziaversicherungsgesetz von 2010.

236 9. Kapitel des Arbeitsgesetzes von 1994: Sozialversicherung und Sozialwohlfahrt.

237 übersetzt von Münzel, http://lehrstuhl.jura.uni-goettingen.de/chinarecht/940705b.htm (Stand 15. 07. 2010).

$238 \S 2$ Abs. 2 Arbeitsgesetz von 1994. 


\section{bb) Grundrentenversicherung}

Für die Altersversicherung in Unternehmen wird zurzeit nach dem Vorschlag der Weltbank 239 ein Drei-Säulen-Modell aufgebaut: eine gesetzliche Grundrentenversicherung, eine betriebliche Zusatzaltersversicherung und eine kommerzielle Zusatzaltersversicherung. ${ }^{240}$ Die erste Säule ist eine obligatorische Rentenversicherung, die zweite und dritte Säule sind freiwillig. Bei der betrieblichen Zusatzaltersversicherung wird das Kapitaldeckungsverfahren durchgeführt. ${ }^{241}$ Sie wird kommerziell verwaltet und existiert zurzeit nur in den staatlichen Großunternehmen und in manchen lokalen Unternehmen des Küstengebiets. In dieser Arbeit wird nur die obligatorische Säule, nämlich die Grundrentenversicherung, untersucht.

Für die Grundrentenversicherung wurde noch keine spezielle rechtliche Regelung erlassen. Die geltenden ,politischen“ Regelungen sind der „Beschluss des Staatsrats über die Errichtung eines einheitlichen Grundrentenversicherungssystems für Beschäftigte in Unternehmen“ von 1997242 und der „Beschluss des Staatsrats über die Vervollkommnung des Grundrentenversicherungssystems für Beschäftigte in Unternehmen" von 2005.243

\section{(1) Versichertenkreis und Finanzierung}

Der versicherte Personenkreis der Grundrentenversicherung umfasst grundsätzlich die Arbeitnehmer der städtischen Unternehmen und der Individualbetriebe. ${ }^{244}$ Die Arbeitnehmer derjenigen öffentlichen Institutionen, die wie Unternehmen verwaltet werden, werden im Prinzip in die Rentenversicherung mit einbezogen. ${ }^{245}$ Diese Regelung ist vereinbar mit $\S 2$ Abs. 2 des Arbeitsgesetzes. ${ }^{246}$ Die Selbständigen und Teilzeitarbeiter in Städten werden seit 2006 auch von der Grundrentenversicherung umfasst, damit der Kreis der Versicherungspflichtigen erweitert wird. 247

239 Weltbank, China 2020, Old Age Security, S. 6.

240 Nr. 2 des Beschlusses des Staatsrats über die Errichtung eines einheitlichen Grundrentenversicherungssystems für Beschäftigte in Unternehmen von 1997; Nr. 9 des Beschlusses des Staatsrats über die Vervollkommnung des Grundrentenversicherungssystems für Beschäftigte in Unternehmen von 2005.

241 Siehe: 郑秉文, 社会保障体制改革攻坚 (Zheng, Bingwen, Reform der sozialen Sicherheit), S. 206ff.

242 国务院关于建立统一的企业职工基本养老保险制度的决定，国发 (1997) 26号，vom 16. 07. 1997, Übersetztung in: Darimont, Sozialversicherungsrecht der V. R. China, S. $208 \mathrm{ff}$.

243 国务院关于完善企业职工基本养老保险制度的决定，国发 (2005) 38号, vom 03. 12. 2005.

244 Nr. 1 des Beschlusses des Staatsrats über die Errichtung eines einheitlichen Grundrentenversicherungssystems für Beschäftigte in Unternehmen von 1997.

245 Nr. 10 des Beschlusses des Staatsrats über die Errichtung eines einheitlichen Grundrentenversicherungssystems für Beschäftigte in Unternehmen von 1997.

$246 \S 2$ Abs. 2 Arbeitsgesetz: „Gegenüber Behörden, öffentliche Institutionen und gesellschaftlichen Körperschaften und denjenigen Arbeitenden, die mit ihnen Arbeitsvertragsbeziehungen errichten, wird dies Gesetz entsprechend angewandt."

247 Nr. 3 des Beschlusses des Staatsrats über die Vervollkommnung des Grundrentenversicherungssystems für Beschäftigte in Unternehmen von 2005. 
Die Grundrentenversicherung wird hauptsächlich durch Beiträge der Unternehmen und der versicherten Personen finanziert. Der monatliche Beitragssatz der Unternehmen beträgt 20\% der Lohnsumme aller Arbeitnehmer und die Arbeitnehmer zahlen 8\% ihres Lohnes als Beitrag. ${ }^{248}$ Der Beitragssatz der Selbständigen und der Teilzeitarbeiter ist $20 \%$ der durchschnittlichen Lohnsumme der lokalen Arbeitnehmer, davon werden 8\% auf die individuellen Konten eingezahlt. 249

Das Finanzierungsmodell der Grundrentenversicherung ist eine Verbindung des Solidarfonds mit dem Individualkonto, 250 die nach einem Modell des „Teilkapitaldeckungsverfahrens" funktioniert, welches sowohl Elemente des Umlageverfahrens als auch des Kapitaldeckungsverfahrens enthält. ${ }^{251}$ Die individuellen Konten werden im Kapitaldeckungsverfahren verwaltet. Früher wurden die von den Unternehmen gezahlten Beiträge teils für den Solidarfonds im Umlageverfahren verwendet und teils auf die individuellen Konten der Versicherten überwiesen (3\%), während die von den Versicherten gezahlten Beiträge vollständig auf die individuellen Konten eingezahlt wurden. ${ }^{252}$ Seit 2006 werden die von den Unternehmen gezahlten Beiträge nur für den Solidarfonds verwendet. 253

\section{(2) Voraussetzungen und Umfang der Leistungen}

Für den Bezug der Grundrente muss die versicherte Person folgende drei Voraussetzungen erfüllen: das Erreichen des Rentenalters, das Erreichen der Dienstzeit und die Erfüllung der Anwartschaftszeit. Für verschiedene Gruppen sind die Renteneintrittsgrenzen unterschiedlich. Normalerweise arbeiten Männer bis zum 60. Lebensjahr, während Frauen mit dem 55. Lebensjahr (Kader) oder 50. Lebensjahr (Arbeiterinnen) in Rente gehen. ${ }^{254}$ Ein früherer Eintritt in die Rente ist erlaubt: Arbeitnehmer, welche die Voraussetzung der Dienstzeit erfüllt haben (Kader haben mindestens 20 Jahre gearbeitet, Arbeiter mindestens 10 Jahre), können früher in Rente gehen. ${ }^{255}$

248 Nr. 3 des Beschlusses des Staatsrats über die Errichtung eines einheitlichen Grundrentenversicherungssystems für Beschäftigte in Unternehmen von 1997.

249 Nr. 3 des Beschlusses des Staatsrats über die Vervollkommnung des Grundrentenversicherungssystems für Beschäftigte in Unternehmen von 2005.

250 Nr. 1 des Beschlusses des Staatsrats über die Errichtung eines einheitlichen Grundrentenversicherungssystems für Beschäftigte in Unternehmen von 1997.

251 Ausführlich: Dritter Teil, Darstellung und Analyse wichtiger Reformen: Umwandlung zum Modell „Solidarfonds mit Individualkonto“.

252 国务院新闻办公室, 中国的劳动和社会保障状况的白皮书 (Presseamt des Staatsrats, Arbeit und Sozialabsicherung in China), 04/2002, Übersetzung in Beijing Rundschau 2002.

253 Nr. 6 des Beschlusses des Staatsrats über die Vervollkommnung des Grundrentenversicherungssystems für Beschäftigte in Unternehmen von 2005.

254 国务院关于工人退休退职的暂行办法 (Vorläufige Maßnahmen des Staatsrats zur Pensionierung und zum Ausscheiden von Arbeitern), vom 24. 05. 1978; 国务院关于安置老弱病残干部的暂行 办法 (Vorläufige Maßnahmen des Staatsrats zur Versorgung alter und kranker Kader), vom 24. 05. 1978 .

$255 \S 88$ Beamtengesetz von 2005; 国务院关于工人退休退职的暂行办法 (Vorläufige Maßnahme des Staatsrats zur Pensionierung und zum Ausscheiden von Arbeitern), vom 24. 05. 1978. 
Mit der Erfüllung der Anwartschaftszeit (mindestens 15 Jahre) kann der Arbeitnehmer die Grundrente erhalten. Die Grundrente setzt sich aus der Basisrente und der Rente des individuellen Kontos zusammen. Das Monatsniveau der Basisrente beträgt nach dem Beschluss von 1997 20\% des monatlichen Durchschnittslohnes des Beschäftigten der Provinz- oder Bezirksebene. Das Niveau der Rente aus dem individuellen Konto beträgt 1/120 der auf das individuelle Konto eingezahlten Summe. Falls der Arbeitnehmer nach Eintritt in den Ruhestand keine 15 Jahre Beiträge zusammengezahlt hat, erhält er keine Basisrente. Das Guthaben des Individualkontos wird auf einmal an den Betreffenden ausgezahlt. 256

Im Beschluss von 2005 wurde die Berechnungsmethode der Grundrente reformiert. Danach wird die Basisrente aufgrund des lokalen Durchschnittslohns und des eigenen Durchschnittslohns des Arbeitnehmers bestimmt. Ein Jahr Beitragszahlung entspricht $1 \%$ der Basisrente. Die Berechnungsmethode der Rente aus dem individuellen Konto wurde auch korrigiert. Nun beträgt das Monatsniveau nicht mehr genau 1/120 der eingezahlten Summe. Die im Voraus berechnete Zahl der Auszahlungsmonate wird durch die durchschnittliche Lebenserwartung der städtischen Bevölkerung, das Renteneintrittsalter des Arbeitnehmers sowie andere Faktoren bestimmt. 257

Für die ,alte“ und ,mittlere“ Generation der Arbeitnehmer werden Übergangsmodelle eingeführt. Die vor der Durchführung des Beschlusses von 1997 schon in den Ruhestand getretenen Arbeitnehmer erhalten weiterhin die Rente, die nach den ursprünglichen staatlichen Regelungen bestimmt werden. ${ }^{258}$ Für die Arbeitnehmer, die vor der Durchführung des Beschlusses von 1997 am Arbeitsleben teilgenommen haben, jedoch danach in den Ruhestand getreten sind, und insgesamt über 15 Jahre Beiträge gezahlt haben, wird als Kompensation für die niedrigere Lohnersatzrate außer der Grundrente eine Übergangsrente ausgezahlt. Die Übergangsrente wird aus dem Rentenversicherungsfonds beglichen. 259

\section{cc) Grundkrankenversicherung}

Mit dem „Beschluss des Staatsrats über die Errichtung eines Grundkrankenversicherungssystems für Arbeitnehmer in Städten und Gemeinden“ vom 14. 12. $1998^{260}$ ist ein einheitlicher Rahmen der gesetzlichen Grundkrankenversicherung festgelegt. Die Prinzipien bei der Errichtung der Grundkrankenversicherung sind:

256 Nr. 5 Satz 1 des Beschlusses des Staatsrats über die Errichtung eines einheitlichen Grundrentenversicherungssystems für Beschäftigte in Unternehmen von 1997; Nr. 6 des Beschlusses des Staatsrats über die Vervollkommnung des Grundrentenversicherungssystems für Beschäftigte in Unternehmen von 2005.

257 Nr. 6 des Beschlusses des Staatsrats über die Vervollkommnung des Grundrentenversicherungssystems für Beschäftigte in Unternehmen von 2005.

258 Nr. 5 Satz 2 des Beschlusses des Staatsrats über die Errichtung eines einheitlichen Grundrentenversicherungssystems für Beschäftigte in Unternehmen von 1997.

259 Nr. 5 Satz 3 des Beschlusses des Staatsrats über die Errichtung eines einheitlichen Grundrentenversicherungssystems für Beschäftigte in Unternehmen von 1997.

260 国务院关于建立城镇职工基本医疗保险制度的决定, 国发 (1998) 44号, Übersetzung in: Darimont, Sozialversicherungsrecht der V. R. China, S. 213ff. 
„Das Niveau der Grundkrankenversicherung muss dem Entwicklungsniveau der Produktivkraft in der Anfangsphase des Sozialismus entsprechen. Alle Arbeitseinheiten in Städten und Gemeinden und deren Beschäftigte haben an der Grundkrankenversicherung teilzunehmen. Die Kosten der Grundkrankenversicherung werden von Arbeitseinheiten und Arbeitnehmer gemeinsam getragen. Der Grundkrankenversicherungsfonds ist eine Verbindung des Solidarfonds mit individuellen Konten."261

\section{(1) Versichertenkreis und Finanzierung}

Der Deckungsbereich der Grundkrankenversicherung ist am weitesten im Vergleich mit anderen Versicherungszweigen für Arbeitnehmer. Alle Arbeitseinheiten in Städten und Gemeinden, inkl. Unternehmen (staatliche Unternehmen, kollektive Unternehmen, Unternehmen mit ausländischem Kapital, Privatbetriebe usw.), staatliche Verwaltungsorgane, öffentliche Institutionen, gesellschaftliche Körperschaft, gemeinnützige Einrichtungen und deren Belegschaften haben an der Grundkrankenversicherung teilzunehmen. Ob Betriebe in ländlichen Kreisen und deren Arbeitnehmer sowie Besitzer der individuellen Wirtschaft und deren Mitarbeiter an der Grundkrankenversicherung teilnehmen sollen, wird von den Regierungen auf Provinzebene bestimmt. ${ }^{262}$

Arbeitseinheiten und Arbeitnehmer finanzieren die Kosten der Grundkrankenversicherung zusammen. Gegenwärtig ist der Beitragssatz der Arbeitseinheiten 6\% der Lohnsumme und der Beitragssatz der Arbeitnehmer 2\% ihres Lohnes. 263 Die Grundkrankenversicherung funktioniert ähnlich wie die Grundrentenversicherung nach einem Modell der Verbindung des Solidarfonds mit individuellen Konten. Die von den Arbeitseinheiten gezahlten Beiträge werden teils für den Solidarfonds verwendet und teils auf die individuellen Konten (30\%) überwiesen.

\section{(2) Leistungen}

Die konkreten Auszahlungsstandards werden von der Stadtregierung festgelegt. Der Solidarfonds wird hauptsächlich für die Zahlung der Kosten für stationäre und ambulante Behandlungen einiger schwerer chronischer Krankheiten verwendet, während der Versicherte die Kosten für ambulante Behandlungen von seinem individuellen Konto zahlt. ${ }^{264}$ Die Höchst- und Mindestauszahlungsgrenzen des Solidarfonds sind festgelegt:

„Prinzipiell liegt das Auszahlungsminimum bei ungefähr 10\% des lokalen durchschnittlichen Jahreslohnes. Die höchste Auszahlungsgrenze beträgt grundsätzlich ungefähr das Vierfache des Jah-

261 Nr. 1 des Beschlusses des Staatsrats über die Errichtung eines Grundkrankenversicherungssystems für Arbeitnehmer in Städten und Gemeinden von 1998: Aufgaben und Prinzipien der Reform.

262 Nr. 2 des Beschlusses des Staatsrats über die Errichtung eines Grundkrankenversicherungssystems für Arbeitnehmer in Städten und Gemeinden von 1998: Deckungsbereich und Beitragserhebung.

263 Nr. 2 des Beschlusses des Staatsrats über die Errichtung eines Grundkrankenversicherungssystems für Arbeitnehmer in Städten und Gemeinden von 1998: Deckungsbereich und Beitragserhebung.

264 Nr. 3 des Beschlusses des Staatsrats über die Errichtung eines Grundkrankenversicherungssystems für Arbeitnehmer in Städten und Gemeinden von 1998: Errichtung des Solidarfonds und individueller Konten. 
reslohnes. Liegen die Krankenkosten unter dem Standard des Auszahlungsminimums, dann sind sie vom individuellen Konto oder von der Person selbst zu zahlen. Liegen die Krankenkosten über dem Standard der Mindestauszahlungsgrenze und unter der Höchstauszahlungsgrenze, werden sie im Wesentlichen aus dem Fonds bezahlt. Der Einzelne hat auch einen bestimmten Anteil zu übernehmen. Krankenkosten, welche die höchste Auszahlungsgrenze überschreiten, können durch private Krankenversicherungen abgedeckt werden. “265

Die höchste Auszahlungsgrenze beträgt seit 2010 ungefähr das Sechsfache des durchschnittlichen Jahreslohnes. 266 Damit das medizinische Leistungsniveau nicht unterschritten wird, werden ein zusätzliches betriebliches Krankenversicherungssystem für Arbeitnehmer, ein eigenes zusätzliches Krankenversicherungssystem für Beamte und öffentliche Bedienstete 267 und ein soziales medizinisches Unterstützungssystem für Bedürftige aufgebaut. Bei hohen medizinischen Kosten ist ein System der gegenseitigen Hilfe einzuführen. ${ }^{268}$ Trotzdem ist das Krankversicherungssystem für die Arbeitnehmer eine eindeutige Senkung des Leistungsniveaus im Vergleich zu der früheren medizinischen Versorgung. Sie müssen jetzt Beiträge zahlen, aber der Erstattungsanteil der Krankenversorgungskosten ist niedriger als vorher, da früher das System größtenteils kostenlos war. ${ }^{269}$

\section{dd) Arbeitslosenversicherung}

Die „Regeln über die Arbeitslosenversicherung“270 ist am 22. 01.1999 in Kraft getreten. Die „Bestimmung zur Auf-Arbeit-Wartenden-Versicherung der staatlichen Unternehmen“"von 1993 wurde am selbigen Tag aufgehoben.

\section{(1) Versichertenkreis und Finanzierung}

Die Arbeitslosenversicherung umfasst alle Unternehmen und öffentliche Institutionen in Städten und Gemeinden sowie deren Arbeitnehmer. ${ }^{271}$

Auf welcher Regierungsebene die Arbeitslosenversicherungsfonds errichtet und verwaltet werden, wird grundsätzlich von den Provinzregierungen festgelegt. In den regierungsunmittelbaren Städten und den Städten auf Bezirkebene ist ein einheitlicher Ar-

265 Nr. 3 des Beschlusses des Staatsrats über die Errichtung eines Grundkrankenversicherungssystems für Arbeitnehmer in Städten und Gemeinden von 1998: Errichtung des Solidarfonds und individueller Konten.

266 国务院医药卫生体制改革近期重点实施方案 (2009-2011) (Durchführungsplans des Staatsrats für die Gesundheitsreform 2009-2011)，国发 (2009) 12号, vom 18. 03. 2009.

267 Nr. 6 des Beschlusses des Staatsrats über die Errichtung eines Grundkrankenversicherungssystems für Arbeitnehmer in Städten und Gemeinden von 1998: Krankenbehandlungen von entsprechendem Personal geeignet lösen.

268 国务院新闻办公室, 中国的社会保障状况和政策白皮书 (Presseamt des Staatsrats, Soziale Sicherheit und Sozialpolitik in China), vom 07. 06. 2005.

269 Vgl. Zhang, Wei, Sozialwesen in China, 2005, S. 174.

270 失业保险条例 (Regeln über die Arbeitslosenversicherung), vom 22. 01. 1999.

$271 \S 2$ der Regeln über die Arbeitslosenversicherung von 1999. 
beitslosenversicherungsfonds durchzuführen. ${ }^{272}$ Gem. $\S 5$ der Regeln über die Arbeitslosenversicherung setzt sich der Arbeitslosenversicherungsfonds folgendermaßen zusammen:

- aus Arbeitslosenversicherungsbeiträgen, die von den Unternehmen und öffentlichen Institutionen sowie deren Arbeitnehmern zu zahlen sind. 273 Städtische Unternehmen und öffentliche Institutionen zahlen 2\% der Gesamtlohnsumme und die Arbeitnehmer zahlen 1\% ihres Lohnes als Arbeitslosenversicherungsbeiträge, 274

- aus Zinsen der Arbeitslosenversicherungsfonds,

- aus staatlichen Zuschüssen,

- aus anderen Quellen, die rechtmäßig in die Arbeitslosenversicherungsfonds eingefügt werden.

Wenn der Arbeitslosenversicherungsfonds für die Ausgaben nicht ausreicht, werden die Kapitallücken durch den Ausgleichsfonds und die lokalen Finanzzuschüsse aufgefüllt. Die Ausgleichsfonds der Arbeitslosenversicherung werden von den Regierungen auf Provinzebene errichtet. ${ }^{275}$ Die Regierungen auf Provinzebene können auch nach der Genehmigung des Staatsrats den Prozentsatz des Arbeitslosenversicherungsbeitrags korrigieren. 276

(2) Voraussetzungen und Umfang der Leistungen

Der Arbeitslosenversicherungsfonds wird für folgende Ausgaben verwendet:277

- Arbeitslosengeld,

- Zuschüsse für Krankenkosten während des Bezugs von Arbeitslosengeld,

- Bestattungszuschüsse im Todesfall während des Bezugs von Arbeitslosengeld und Hinterbliebenenrente für Ehepartner und Verwandte ersten Grades, für deren Lebensunterhalt der Verstorbene gesorgt hat,

- Zuschüsse für Berufsausbildung und Arbeitsvermittlung während des Bezugs von Arbeitslosengeld,

- Andere Kosten in Bezug auf Arbeitslosenversicherung, welche der Staatsrat festgelegt oder genehmigt hat.

Um Arbeitslosengeld beziehen zu können, müssen fünf Voraussetzungen gleichzeitig erfüllt sein: Der Arbeitgeber und der Arbeitnehmer haben sich mindestens ein Jahr an der Arbeitslosenversicherung beteiligt und die Beiträge der Arbeitslosenversicherung gezahlt. Die Beschäftigung ist unfreiwillig unterbrochen worden. Die Arbeitslosigkeit wurde gemeldet und es besteht Bereitschaft zur Arbeitsaufnahme. ${ }^{278}$ Die Höhe des

$272 \S 7$ der Regeln über die Arbeitslosenversicherung von 1999.

$273 \S 5$ Abs. 1 der Regeln über die Arbeitslosenversicherung von 1999.

$274 \S 6$ der Regeln über die Arbeitslosenversicherung von 1999.

$275 \S 8$ der Regeln über die Arbeitslosenversicherung von 1999.

$276 \S 9$ der Regeln über die Arbeitslosenversicherung von 1999.

277 § 10 der Regeln über die Arbeitslosenversicherung von 1999.

$278 \S 14$ der Regeln über die Arbeitslosenversicherung von 1999. 
Arbeitslosengeldes wird von den Regierungen auf Provinzebene festgelegt. Sie hat unter dem Niveau des lokalen Mindestlohnes und über dem Existenzminimum zu liegen. ${ }^{279}$

Die Dauer des Bezugs von Arbeitslosengeld richtet sich nach der Dauer der Beitragszahlung. Die Höchstdauer für den Bezug von Arbeitslosengeld beträgt 24 Monate. 280 Der Bezug von Arbeitslosengeld und anderen Leistungen der Arbeitslosenversicherung ist einzustellen, wenn eine der folgenden Umstände innerhalb der Zeit des Erhalts von Arbeitslosengeld eintritt:

- Wiederbeschäftigung,

- Einberufung zum Wehrdienst,

- Abwanderung ins Ausland,

- Erhalt von Leistungen aus der Rentenversicherung,

- Verurteilung zur Freiheitsstrafe,

- unbegründetes Ablehnen einer von den offiziellen Arbeitsvermittlungsagenturen vermittelten Arbeit und

- $\quad$ andere durch rechtliche Verordnungen festgelegten Umstände. 281

ee) Arbeitsunfallversicherung

Seit Ende der 1980er Jahre begann die Regierung mit der Reform der Arbeitsunfallversicherung. Die „Regeln über die Arbeitsunfallversicherung“ des Staatsrats wurden am 27. 04. 2003 veröffentlicht und sind am 01. 01. 2004 in Kraft getreten. ${ }^{282}$

\section{(1) Versichertenkreis und Finanzierung}

Die Arbeitsunfallversicherung wird allein von den Unternehmen finanziert. Jegliche Unternehmensformen, auch Selbständige mit abhängigen Arbeitern, sollen an der Unfallversicherung teilnehmen. ${ }^{283}$ Die Arbeitsunfallversicherung funktioniert nach den Prinzipien „Ausgaben bestimmen Einnahmen, Ausgeglichenheit zwischen Einnahmen und Ausgaben“ im Umlageverfahren. ${ }^{284}$ Der Unfallversicherungsfonds setzt sich aus Beiträgen der Unternehmen, Zinsen des Unfallversicherungsfonds und anderen Geldmittel zusammen. ${ }^{285}$ Die einheitliche Verwaltungsebene des Fonds wird von den Regierungen auf Provinzebene festgelegt. In den regierungsunmittelbaren Städten und Städten auf Bezirkebene ist der Fonds auf Stadtebene einheitlich zu verwalten. ${ }^{286}$

Die Höhe der Beiträge hängt von der Branche und der Gefahrenklasse des Betriebs ab. Der Staat legt nach dem Unfallrisiko der verschiedenen Branchen differenzierte Beitragsquoten für die Branchen (Differentialquote) und entsprechend der Situation der

$279 \S 18$ der Regeln über die Arbeitslosenversicherung von 1999.

$280 § 17$ der Regeln über die Arbeitslosenversicherung von 1999.

$281 \S 15$ der Regeln über die Arbeitslosenversicherung von 1999.

282 工伤保险条例 (Regeln über die Arbeitsunfallversicherung), vom 27. 4. 2003.

$283 \S 2$ der Arbeitsunfallsversicherungsregeln von 2003.

$284 \S 8$ Abs. 1 der Arbeitsunfallsversicherungsregeln von 2003.

$285 \S 7$ Abs. 1 der Arbeitsunfallsversicherungsregeln von 2003.

$286 \S 11$ Abs. 1 der Arbeitsunfallsversicherungsregeln von 2003. 
Unfallversicherungsbeitragsverwendung und der Unfallquote innerhalb jeder Branche die Beitragsstufen (floatende Quote) fest. ${ }^{287}$ Das Ministerium für Arbeit und soziale Sicherheit (nun das Ministerium für Personalwesen und soziale Sicherheit) ist für den Plan der Differentialquote und der floatenden Quote verantwortlich. 288

\section{(2) Leistungen}

Unter Arbeitsunfällen werden Unfälle während der Arbeitszeit und am Arbeitsplatz, Berufskrankheiten, Wegeunfälle, 289 Tod während der Arbeitszeit und am Arbeitsplatz verstanden. 290 Der Unfallversicherungsfonds wird für die Unfallversicherungsleistungen, die Beurteilung der Arbeitsfähigkeit der verletzten Arbeitnehmer sowie andere Kosten der Arbeitsunfallversicherung verwendet. ${ }^{291}$ Die Unfallversicherungsleistungen umfassen Behandlungskosten, Kosten für Rehabilitation, Behindertenzuschüsse, Pflegekosten für die verletzten Arbeitnehmer sowie Hinterbliebenenrente und Sterbegeld. ${ }^{292}$ Für Präventionsmaßnahmen gegen Unfälle und Berufskrankheiten trägt die Arbeitsunfallversicherung bislang noch keine Kosten. ${ }^{293}$

\section{ff) Mutterschaftsversicherung}

Arbeitnehmerinnen in städtischen Betrieben haben gemäß den „Vorläufigen Maßnahmen über die Mutterschaftsversicherung von Beschäftigten in Betrieben“ das Recht, finanzielle Unterstützung bei Mutterschaft, Geburt und Stillperiode zu bekommen.294 Die Unternehmen finanzieren allein die Beiträge. Der Beitragssatz wird von der lokalen Regierung (Stadtregierung oder Kreisregierung) festgelegt. Die lokale Regierung kann nach den Umständen der Ausgaben den Beitragssatz verändern, aber darf die in diesen Maßnahmen festgelegte Höchstgrenze (1\% der Lohnsumme aller Arbeitnehmer des Regierungsgebiets) nicht überschreiten. ${ }^{295}$

$287 \S 8$ Abs. 2 der Arbeitsunfallsversicherungsregeln von 2003.

$288 \S 9$ der Arbeitsunfallsversicherungsregeln von 2003.

289 Der Staatsrat hat im Entwurf für die Revision der Unfallversicherungsregeln vorgeschlagen, die Wegeunfälle aus den Regeln zu streichen. Siehe: 国务院关于修改工伤保险条例的决定（征求意 见稿) (Nr. 1 der Bestimmung des Staates über die Revision der Regeln über die Arbeitsunfallversicherung) (Entwurf), vom 24. 07. 2009, http://www.gov.cn/zwhd/content_1374000.htm (Stand: 15. 07. 2010).

$290 \S \S 14,15$ der Arbeitsunfallsversicherungsregeln von 2003.

$291 \S 12$ der Arbeitsunfallsversicherungsregeln von 2003.

$292 \S \S 29 f f$ der Arbeitsunfallsversicherungsregeln von 2003.

293 Gemäß dem Entwurf für die Revision der Unfallversicherungsregeln wird der Unfallversicherungsfonds auch für die Kosten für Unfallprävention verwendet. Nr. 6 der Bestimmung des Staates über die Revision der Arbeitsunfallversicherungsregeln (Entwurf) von 2009.

294 企业职工生育保险试行办法 (Vorläufige Maßnahmen über die Mutterschaftsversicherung von Beschäftigten in Betrieben), 劳部发 (1994) Nr. 504.

$295 \S 4$ der Vorläufigen Maßnahmen über die Mutterschaftsversicherung von Beschäftigten in Betrieben von 1994. 
Die Mutterschaftsversicherungsfonds werden wie die Fonds der Unfallversicherung nach dem Prinzip „Ausgaben bestimmen Einnahmen“ errichtet. ${ }^{296}$ Vom Mutterschaftsversicherungsfonds werden die Zuschüsse für Geburt und die Kosten der ärztlichen Behandlung bei Geburt und Stillperiode ausgegeben. Der Zuschuss innerhalb dem Schwangerschafts- und Wochenbetturlaub beträgt eine durchschnittliche Lohnsumme pro Jahr im Betrieb. 297

\section{b) Grundkrankenversicherung für die städtischen Bewohner}

Seit 2007 wurden die Pilotprojekte der Grundkrankenversicherung für die städtischen Bewohner in verschiedenen Städten und Gemeinden eingeführt. Dafür hat der Staatsrat am 10. 07. 2007 die „Leitlinien des Staatsrats über Entfaltung des Pilotprojekts der Grundkrankenversicherung für die städtischen Bewohner" veröffentlicht. ${ }^{298}$ Seit 2009 wird die Grundkrankenversicherung für die städtischen Bewohner in allen Städten durchgeführt. ${ }^{299}$

\section{aa) Versichertenkreis und Finanzierung}

Da die obligatorische Grundkrankenversicherung für Beschäftigte in Unternehmen die Familienangehörigen der Arbeitnehmer und die anderen Stadtbewohner nicht erfasst, wird eine eigene Grundkrankenversicherung für die nicht beschäftigten Stadtbewohner, insbesondere für die Kinder und Schüler, aufgebaut. Die Teilnahme an der Grundkrankenversicherung ist zurzeit freiwillig. 300

Die Grundkrankenversicherung für die städtischen Bewohner wird durch Beiträge der versicherten Personen und Zuschüsse der Regierung finanziert. In der Pilotphase wird die Beitragshöhe von der Stadtregierung nach dem Entwicklungsniveau der lokalen Wirtschaft, dem Gesundheitsbedarf der verschiedenen Versichertengruppen sowie der Finanzierungsfähigkeit der Bewohner und der Regierung festgelegt. ${ }^{301}$ Nach dem Pilotplan von 2007 bekam der Teilnehmer von der Regierung mindestens $40 \mathrm{RMB} \mathrm{Zu-}$ schuss pro Jahr, dafür übernahm die Zentralregierung 20 RMB Zuschuss pro Person für

$296 \S 4$ der Vorläufigen Maßnahmen über die Mutterschaftsversicherung von Beschäftigten in Betrieben von 1994.

$297 \S 5$ der Vorläufigen Maßnahmen über die Mutterschaftsversicherung von Beschäftigten in Betrieben von 1994.

298 国务院关于开展城镇居民基本医疗保险试点的指导意见 (Leitlinien des Staatsrats über die Entfaltung des Pilotprojekts der Grundkrankenversicherung für die städtische Bewohner), 国发 (2007) 20 号, vom 10.07. 2007.

299 人力资源和社会保障部, 财政部, 关于全面开展城镇居民基本医疗保险工作的通知 (Ministerium für Personalwesen und soziale Sicherheit, Finanzministerium, Bekanntmachung über die landesweite Entfaltung der Grundkrankenversicherung für die städtischen Bewohner), 人社部发2009 (35) 号, vom 08. 04. 2009.

300 Nr. 3 der Leitlinien des Staatsrats über die Entfaltung des Pilotprojekts der Grundkrankenversicherung für die städtischen Bewohner.

301 Nr. 4 der Leitlinien des Staatsrats über die Entfaltung des Pilotprojekts der Grundkrankenversicherung für die städtischen Bewohner. 
die versicherten Bewohner der mittleren und westlichen Gebiete. ${ }^{302} 2008$ wurde der Mindeststandard des Zuschusses verdoppelt. ${ }^{303} \mathrm{Im}$ „Durchführungsplan des Staatsrats für die Gesundheitsreform 2009 - 2011“ wurde gefordert, die Zuschüsse aus dem zentralen und lokalen Finanzbudget im Jahre 2010 jeweils auf 120 RMB pro Kopf zu erhöhen. ${ }^{304}$ Für schwerbehinderte Kinder und Schüler, arme Alte über dem 60. Lebensjahr und Bewohner in ärmeren Gebieten werden die Zuschüsse der lokalen und zentralen Regierung erhöht. Die Versicherung funktioniert nach dem Prinzip „Einnahmen bestimmen Ausgaben“im Umlageverfahren. 305

\section{bb) Leistungen}

Der Krankenversicherungsfonds wird hauptsächlich für die Kosten der stationären Behandlungen und der ambulanten Behandlungen einiger chronischer Krankheiten verwendet. Die konkreten Auszahlungsstandards sowie die Höchst- und Mindestauszahlungsgrenzen werden von der Stadtregierung nach dem Prinzip „Einnahmen bestimmen Ausgaben“ festgelegt. Die höchste Auszahlungsgrenze beträgt seit 2010 wie die Grundkrankenversicherung für Beschäftigte ungefähr das Sechsfache des durchschnittlichen Jahreslohnes. ${ }^{306}$

\section{c) Sozialversicherungen für die ländliche Bevölkerung}

aa) Das neue kooperative medizinische System für die ländliche Bevölkerung

Gemäß dem „Beschluss des Zentralkomitees der KP Chinas und des Staatsrats über Festigung der Gesundheitsarbeit auf dem Land" von $2002^{307}$ werden die Pilotprojekte des neuen kooperativen medizinischen Systems seit 2003 durchgeführt. 308 Das Ziel der Errichtung eines neuen Sicherungssystems der Gesundheitsversorgung für die ländliche Bevölkerung ist die Beseitigung von Mängeln der Gesundheitsversorgung und „Armut

302 Nr. 5 der Leitlinien des Staatsrats über die Entfaltung des Pilotprojekts der Grundkrankenversicherung für die städtischen Bewohner.

303 人力资源与社会保障部, 关于做好 2008 年城镇居民基本医疗保险试点工作的通知 (Ministerium für Personalwesen und soziale Sicherheit, Bekanntmachung über die weitere Durchführung des Pilotprojekts der Grundkrankenversicherung für die städtischen Bewohner im Jahr 2008), 人社部 发 (2008) 39号.

304 国务院医药卫生体制改革近期重点实施方案 (2009-2011), 国发 (2009) 12号, vom 18. 03. 2009.

305 Nr. 6 der Leitlinien des Staatsrats über die Entfaltung des Pilotprojekts der Grundkrankenversicherung für die städtischen Bewohner.

306 Durchführungsplans des Staatsrats für die Gesundheitsreform 2009-2011.

307 中共中央、国务院关于进一步加强农村卫生工作的决定 (Beschluss des Zentralkomitees der KP Chinas und des Staatsrats über Festigung der Gesundheitsarbeit auf dem Land), 中发 (2002) 13号, vom 19. 10. 2002.

308 卫生部，财政部，农业部，关于建立新型农村合作医疗制度的意见（Gesundheitsministerium， Finanzministerium, Landwirtschaftsministerium, Vorschläge zum Aufbau des neuen ländlichen kooperativen medizinischen Systems)，国办发 (2003) Nr. 3, vom 10. 03. 2003. 
wegen schwerer Krankheiten“ auf dem Land, 309 die nach dem Zusammenbruch des alten kooperativen medizinischen Systems auftraten. Seit 2006 wird die Vervollkommnung des neuen ländlichen medizinischen Systems beschleunigt. Im Jahre 2008 wurde es landesweit aufgebaut. 310 Nach der offiziellen Statistik betrug bis Ende 2009 die Zahl der versicherten Bauern schon 0.83 Mrd. Personen (94\% der ländlichen Bevölkerung). 311

\section{(1) Finanzierung}

Das alte ländliche kooperative medizinische System ${ }^{312}$ war ein System der gegenseitigen Hilfe mit staatlicher Unterstützung. Es wurde hauptsächlich durch das ländliche Kollektiv, nämlich die Gemeinde oder das Dorf, die die unteren Verwaltungsorgane bilden, finanziert. Demgegenüber wird das neue ländliche medizinische System - obwohl es weiterhin als „kooperatives System“ bezeichnet und vom Gesundheitsministerium verwaltet wird - im Wesentlichen durch Beiträge der Bauern und Zuschüsse der Regierungen verschiedener Ebenen (Regierungen auf Kreis-, Provinz- und Zentralebene) finanziert. Demgegenüber spielt die finanzielle Unterstützung der kollektiven Wirtschaft nur eine kleine Rolle.

Die Fonds des ländlichen kooperativen medizinischen Systems werden auf Kreisebene errichtet und verwaltet. Sie funktionieren nach dem Prinzip „Einkommen bestimmen Ausgaben“ im Umlageverfahren. ${ }^{313}$ Die Teilnahme der Bauern an diesem medizinischen System ist freiwillig. Die Bauern, das Kollektiv und die Regierungen finanzieren das System gemeinsam. ${ }^{314}$ Ein Bauer zahlt mindestens 10 RMB pro Jahr als Beitrag; der Staatshaushalt und der lokale Haushalt finanzieren jeweils 10 RMB pro Kopf als Zuschuss; die Gemeinden und Dörfer sollen das medizinische System auch finanziell unterstützen, falls sie kollektive Betriebe haben. Dafür sollen die Kreisregierungen konkrete Standards festlegen. 315 Die Zuschüsse aus dem zentralen und lokalen Finanzbudget wurden im Jahre 2006 jeweils auf 20 RMB pro Kopf ${ }^{316}$ und im Jahre 2008 auf 40

309 Nr. 18 des Beschlusses des Zentralkomitees der KP Chinas und des Staatsrats über Festigung der Gesundheitsarbeit auf dem Land von 2002.

310 卫生部, 财政部, 关于做好2008年新型农村合作医疗工作的通知 (Bekanntmachung des Gesundheitsministeriums und Finanzministeriums über die Arbeit des neuen ländlichen kooperativen medizinischen Systems im Jahre 2008)，卫农卫发 (2008) 17号, vom 13. 03. 2008.

311 2009年卫生事业发展情况简报 (statistisches Bulletin über Gesundheitswesen 2009), http://www.moh.gov.cn/publicfiles/business/htmlfiles/mohwsbwstjxxzx/s8208/201001/45652.htm (Stand: 15. 07. 2010).

312 Ausführlich vgl. Dritter Teil, Soziale Absicherung von 1949 bis 1985.

313 Nr. 1, 2 der Vorschläge zum Aufbau des neuen ländlichen kooperativen medizinischen Systems von 2003.

314 Nr. 1 der Vorschläge zum Aufbau des neuen ländlichen kooperativen medizinischen Systems von 2003.

315 Nr. 3 der Vorschläge zum Aufbau des neuen ländlichen kooperativen medizinischen Systems von 2003.

316 关于加快推进新型农村合作医疗试点工作的通知 (Bekanntmachung über die Beschleunigung der Arbeit der Pilotprojekte des neuen ländlichen kooperativen medizinischen Systems), 卫农卫发 (2006) 13 号, vom 10. 01. 2006. 
RMB pro Kopf ${ }^{317}$ gesteigert. Im Jahre 2010 wurden sie wie bei der Krankenversicherung für die städtischen Bewohner auf 120 RMB erhöht. ${ }^{318}$ Der Beitragssatz der Bauern wurde auch im Jahre 2008 auf 20 RMB pro Jahr erhöht. 319

\section{(2) Leistungen}

Der Fonds des ländlichen kooperativen medizinischen Systems wird hauptsächlich wie der Fonds der Grundkrankenversicherung für die städtischen Bewohner - für die Kosten der stationären Behandlungen und der ambulanten Behandlungen von schweren Krankheiten verwendet. Der Umfang und das Niveau der Leistungen werden von der Kreisregierung festgelegt. 320 Die höchste Auszahlungsgrenze beträgt im Jahre 2010 grundsätzlich das Sechsfache des durchschnittlichen Einkommens der Bauern im Regierungsgebiet. ${ }^{321}$ Versicherte Bauern, die innerhalb eines Versicherungsjahres die Fonds des medizinischen Systems nicht beanspruchen, erhalten eine kostenlose Gesundheitsuntersuchung. ${ }^{322}$

\section{bb) Altersversicherung für die ländliche Bevölkerung}

\section{(1) Pilotplan von 1992}

Das Modell der Alterssicherung für Bauern war lange Zeit eine Verbindung der staatlichen Bodensicherung mit der Absicherung durch die Familie und dem kollektiven Fünf-Garantien-System als Ergänzung. ${ }^{323}$ Seit 1987 begann das Ministerium für Zivile Angelegenheiten Pilotprojekte zum Aufbau einer sozialen Altersversicherung für die ländliche Bevölkerung durchzuführen. Im Jahre 1992 wurde der „Basisplan für die ländliche Altersversicherung auf Kreisebene“ (Pilotplan) verabschiedet. 324

Nach diesem Plan können die ländlichen Bewohner zwischen dem 20. - 60. Lebensjahr an der Altersversicherung teilnehmen. ${ }^{325}$ Die ländliche Alterssicherung wird hauptsächlich vom Einzelnen durch Beiträge finanziert, dazu kommen die kollektiven Zuschüsse und die staatlichen Steuerbegünstigungen. ${ }^{326}$ Die Beitragshöhe ist in 10

317 Nr. 2 der Bekanntmachung des Gesundheitsministeriums und Finanzministeriums über die Arbeit des neuen ländlichen kooperativen medizinischen Systems im Jahre 2008.

318 Nr. 1 des Durchführungsplans des Staatsrats für die Gesundheitsreform 2009-2011.

319 Nr. 2 Bekanntmachung des Gesundheitsministeriums und Finanzministeriums über die Arbeit des neuen ländlichen kooperativen medizinischen Systems im Jahre 2008.

320 Nr. 4 der Vorschläge zum Aufbau des neuen ländlichen kooperativen medizinischen Systems von 2003.

321 Durchführungsplan des Staatsrats für die Gesundheitsreform 2009-2011.

322 Nr. 4 der Vorschläge zum Aufbau des neuen ländlichen kooperativen medizinischen Systems von 2003.

323 Siehe: 国务院关于开展新型农村社会养老保险试点的指导意见 (Leitansichten des Staatsrats über das Pilotprojekt der neuen ländlichen Altersversicherung), 国发 (2009) 32号, vom 01. 09. 2009.

324 县级农村社会养老保险基本方案 (试行)，民办发 (1992) 2号, vom 03.01. 1992.

325 Nr. 2 des Basisplans für die ländliche Altersversicherung auf Kreisebene von 1992.

326 Nr. 3 des Basisplans für die ländliche Altersversicherung auf Kreisebene von 1992. 
Stufen (von 2 RMB bis 20 RMB pro Monat) festgelegt. Je nach seiner finanziellen Möglichkeit kann der Teilnehmer den Beitrag auf ein Individualkonto einzahlen. ${ }^{327}$ Die Rentenauszahlung beginnt ab dem 60. Lebensjahr und richtet sich nach der Höhe und Dauer der Einzahlungen. ${ }^{328}$

Die Zahl der an der ländlichen Altersversicherung teilnehmenden Landbewohner betrug im Jahre 1998 ca. 80.25 Millionen Personen. 3291998 wurde die Verwaltungszuständigkeit der ländlichen Altersversicherung vom Ministerium für Arbeit und soziale Sicherheit übernommen. Wegen dem Phänomen der ,zu hohen Belastung der Bauern“330 in den 1990er Jahren wurde die ländliche Altersversicherung allerdings in vielen Gebieten als Belastung der Bauern angesehen. Der Staatsrat hatte im Jahre 1999 entschieden, die ländliche Altersversicherung zu regulieren und die Ausweitung der Versicherung zu beenden. ${ }^{331}$ Seitdem stagnierte die Altersversicherung. Die Beteiligung der ländlichen Bevölkerung war sehr gering. Die Zahl der Versicherten betrug 2007 nur ca. 52 Millionen Personen. ${ }^{332}$

\section{(2) Pilotplan von 2009}

Nach 10 Jahren Stagnation wurde die ländliche Altersversicherung wieder in Gang gesetzt. Im Jahre 2009 wurden die „Leitansichten über das Pilotprojekt der neuen ländlichen Altersversicherung“ 333 ausgearbeitet. Das ziel der Errichtung einen neuen ländlichen Altersversicherung wird in den Leitansichten festgelegt: „eine grundlegende, flexible und nachhaltige Versicherung mit hoher Deckungsrate".334

Das städtische Rentenversicherungsmodell „Solidarfonds mit Individualkonto“ wird danach auch für die ländliche Altersversicherung verwendet. Der Unterschied liegt darin, dass der Solidarfonds als „Basisrente“ bezeichnet und von der Regierung durch Steuermittel allein finanziert wird. ${ }^{335}$ Das Individualkonto wird wie beim Pilotplan von 1992 weiterhin durch Beiträge der versicherten Person und Zuschüsse des Kollektivs

327 Nr. 4 des Basisplans für die ländliche Alterversicherung auf Kreisebene von 1992.

328 Nr. 4 des Basisplans für die ländliche Alterversicherung auf Kreisebene von 1992.

3291998 劳动和社会保障事业发展统计公报 (Statistisches Bulletin über Arbeit und soziale Sicherheit 1998), http://www.molss.gov.cn/index/index.htm (Stand: 15. 07. 2010).

330 Eine Hauptursache des Phänomens von ,zu hohen Belastung der Bauer“ ist die Finanzreform von 1994. Mit dem System der Steuereinnahmenaufteilung fließen die Einnahmen nach der zentralen Regierung zu, aber die Regierungen unterer Ebene sind weiter für die Ausgaben von Bildung, Gesundheit usw. verantwortlich (vgl. Erster Teil, Finanzsystem). Um die fiskalische Lücke auszufüllen versuchten die lokalen Regierungen, mehr Steuer und Gebühren von Bauern zu kassieren. Dies führte in vielen Gebieten zu Unruhe auf dem Land. Dieses Problem wurde seit dem Anfang des 21. Jahrhunderts durch die Verstärkung der vertikalen Umverteilung und die Aufhebung der Landwirtschaftssteuer im Jahre 2006 entschärft.

331 国务院批转整顿保险业工作小组保险业整顿与改革方案的通知 (Mitteilung des Staatsrats über die Regulierung und die Reform des Versicherungswesens)，国发 (1999) 14号, vom 02.07. 1999.

3322007 劳动和社会保障事业发展统计公报 (Statistisches Bulletin über Arbeit und soziale Sicherheit 2007), http://www.molss.gov.cn/index/index.htm (Stand: 15. 07. 2010).

333 国务院关于开展新型农村社会养老保险试点的指导意见，国发 (2009) 32号, vom 01. 09. 2009.

334 Nr. 1 der Leitansichten des Staatsrats von 2009.

335 Nr. 4 der Leitansichten des Staatsrats von 2009. 
und der Regierung finanziert. 336 Falls der alte Pilotplan in einem Regierungsgebiet durchgeführt wurde, wird er durch den neuen Plan ersetzt. Die Gelder des alten Individualkontos werden auf das neue Konto überwiesen. ${ }^{337}$

Nach Vollendung des 16. Lebensjahres können die ländlichen Bewohner an der Altersversicherung teilnehmen. Die Beitragshöhe besteht zurzeit aus 5 Stufen (von 100 RMB bis 500 RMB pro Jahr). Die lokale Regierung kann den konkreten Umständen ihres Regierungsgebiets entsprechend die Beitragshöhe korrigieren. ${ }^{338}$ Die Alterversicherungsfonds werden zurzeit auf Kreisebene verwaltet. 339

$\mathrm{Ab}$ dem 60. Lebensjahr genießt die versicherte Person die Altersrente. ${ }^{340}$ Die Basisrente beträgt zurzeit 55 RMB pro Monat, dies kann von der lokalen Regierung durch Zuschüsse erhöht werden. Die Rente aus dem Individualkonto beträgt 1/139 der auf das Konto eingezahlten Summe. Beim Todesfall der versicherten Person kann die Restsumme der eingezahlten Beiträge vererbt werden. ${ }^{341}$

\section{d) Besondere Vorsorgesysteme}

aa) Beamtenversorgung

\section{(1) Versorgungskreis}

Gemäß dem Beamtengesetz von $2005^{342}$ werden Beamte als Arbeitspersonal bezeichnet, das ein öffentliches Amt wahrnimmt, in den Stellenplan der Staatsverwaltung aufgenommen wird, und für das der Fiskus Gehalt und Sozialleistung übernimmt. ${ }^{343}$ Im Kreis der Beamten sind nach der Auslegung des Nationalen Volkskongresses die Bürobeamten der KP, der anderen rechtmäßigen Parteien, der Volkskongresse, der Regierungen, der Politischen Konsultativkonferenzen, der Gerichte und der Staatsanwaltschaften eingeschlossen. ${ }^{344}$ Die Angestellten der öffentlichen Institutionen, die von den Staatsorganen für das öffentliche Gemeinwohl errichtet werden und sich hauptsächlich mit Bildungswesen, Wissenschaft, Kultur sowie Gesundheitswesen beschäftigen, ${ }^{345}$ werden normalerweise von der Beamtenversorgung erfasst. Das Personalministerium war bis 2007 für die Beamtenversorgung zuständig. Zu Beginn des Jahres 2008 wurde

336 Nr. 5 der Leitansichten des Staatsrats von 2009.

337 Nr. 12 der Leitansichten des Staatsrats von 2009.

338 Nr. 4 der Leitansichten des Staatsrats von 2009.

339 Nr. 9 der Leitansichten des Staatsrats von 2009.

340 Nr. 3 der Leitansichten des Staatsrats von 2009.

341 Nr. 6 der Leitansichten des Staatsrats von 2009.

342 中华人民共和国公务员法 (Beamtengesetz der Volksrepublik China), vom 27. 04. 2005, in Kraft ab 01. 01. 2006.

$343 \S 2$ Beamtengesetz von 2005.

344 中华人民共和国公务员法释义 (Auslegung des Beamtengesetzes der VR China), http://www.npc.gov.cn/npc/flsyywd/xingzheng/2005-08/05/content_353282.htm (Stand: 15. 07. 2010) .

$345 \S 2$ 事业单位登记管理暂行条例 (Vorläufige Regeln über die Registrierung und Verwaltung der öffentlichen Institutionen), 国务院令第252号, vom 25. 10. 1998. 
die Zuständigkeit der Beamtenversorgung vom Ministerium für Personalwesen und soziale Sicherheit übernommen.

\section{(2) Finanzierung und Leistungen}

Gemäß dem Beamtengesetz sollte der Staat ein System der Beamtenversicherung errichten, um zu gewährleisten, dass Beamte im Ruhestand, bei Krankheit, Dienstunfall, Mutterschaft Hilfe und Ausgleich erhalten. ${ }^{346}$ Derzeit werden allerdings nur Pilotprojekte der Beamtenversicherung auf lokaler Ebene initiiert. Ein landesweit einheitliches Sozialversicherungssystem für die Beamten existiert noch nicht. Allein bei der sozialen Krankenversicherung wird bereits die Grundkrankenversicherung der Beschäftigten in den Städten auch für Beamte praktiziert. Nach dem Beschluss des Staatsrats wird sie von den Arbeitseinheiten und Beschäftigten zusammen finanziert. ${ }^{347}$ Außer den Leistungen der Grundkrankenversicherung erhalten die Beamten spezielle Zuschüsse bei Krankheitsbehandlungen. ${ }^{348}$

Für die Beamten wird ein eigenes Pensionssystem errichtet. Der Beamte wird pensioniert, wenn er das staatlich festgesetzte Pensionsalter erreicht hat oder völlig arbeitsunfähig geworden ist. ${ }^{349}$ Das Pensionsalter ist nicht im Beamtengesetz geregelt. Normalerweise gehen Männer mit dem 60. Lebensjahr, Frauen mit dem 55. Lebensjahr in Pension. 350 Der Beamte kann auf Antrag vorzeitig pensioniert werden, wenn er eine der folgenden Bedingungen erfüllt: 351

- mit einer Dienstzeit von 30 Jahren,

- mit einer Dienstzeit von 20 Jahren, wenn dem Beamten bis zum staatlich festgesetzten Pensionierungsalter noch weniger als 5 Jahre fehlen,

- wenn er eine andere staatlich festgesetzte Bedingung für eine vorzeitige Pensionierung erfüllt.

Außer den Leistungen im Alter und bei Krankheit erhalten die Beamten Wohnungszuschüsse $^{352}$ sowie andere besondere Sozialleistungen. ${ }^{353}$ Gemäß dem Beamtengesetz sind die Kosten für die Versicherungen, die Wohlfahrtleistungen und die Pensionen der Beamten in den staatlichen Finanzhaushalt aufzunehmen. ${ }^{354}$

$346 § 77$ Beamtengesetz von 2005.

347 Nr. 1 des Beschluss des Staatsrats über die Grundkrankenversicherung von 1998.

348 劳动保障部, 财政部, 关于实行国家公务员医疗补助的意见 (Ministerium für Arbeit und soziale Sicherheit, Finanzministerium, Ansichten über die Gewährung der Zuschüsse bei Krankenbehandlungen der Beamten), vom 29. 04. 2000.

$349 \S 87$ Beamtengesetz von 2005.

350 Vorläufige Maßnahmen des Staatsrats zur Versorgung alter und kranker Kader von 1978.

$351 \S 88$ Beamtengesetz von 2005.

$352 \S 74$ Beamtengesetz von 2005.

$353 \S 76$ Abs. 1 Beamtengesetz von 2005.

$354 \S 79$ Beamtengesetz von 2005. 
bb) Vorsorge für Armeeangehörige

Für die Armeeangehörigen hat der Staat ein eigenes umfassendes Vorsorgesystem errichtet. Seit den 1990er Jahren wurde versucht, ein Sozialversicherungssystem für Armeeangehörige aufzubauen. Gemäß $\S 60$ Abs. 2 Landesverteidigungsgesetz von 1997355 wurde der „Auszuführende Plan über das Versicherungssystem für Armeeangehörige“356 von der Zentralen Militärkommission und dem Staatsrat im Jahre 1998 erlassen. Ziel der Errichtung des Sozialversicherungssystems für das Militär ist die Anpassung des Sicherungssystems der Armeeangehörigen an die Reform des allgemeinen Sozialsicherungssystems und die Verknüpfung mit anderen sozialen Kranken- und Rentenversicherungssystemen. 357

In dem Plan über die Versicherung für Armeeangehörige ist vorgesehen, dass eine Versicherung für Verwundete und Gefallene, eine Krankenversicherung und eine Rentenversicherung für demobilisierte Soldaten sowie andere Versicherungen errichtet werden. Der Staat und die versicherten Armeeangehörigen finanzieren den Versicherungsfonds gemeinsam. Die Versicherung für Verwundete und Gefallene wurde ab dem 01. 08. 1998358 und die Krankenversicherung für demobilisierte Soldaten wurde ab dem 01. 01. 2001359 eingeführt. Ein Sozialversicherungssystem für Ehepartner der Armeeangehörigen, die die Armeeangehörigen begleiten und deshalb nicht beschäftigt sind, wurde im Jahr 2004 errichtet. ${ }^{360}$ Für Ehepartner der Armeeangehörige werden individuelle Konten der Krankenversicherung und der Rentenversicherung eingerichtet. Sie werden vom Staat und dem Einzelnen gemeinsam finanziert. Nach der Entlassung der Armeeangehörigen werden die Konten in die allgemeinen Sozialversicherungen überführt.

\section{Hilfesysteme}

Vor der Wirtschaftsreform wurden die chinesischen Bürger zum größten Teil von zwei Systemen der sozialen Sicherung erfasst. Das eine galt in den Städten und entsprach dem Motto der „,vollen Beschäftigung mit der vollen staatlichen Sicherung“,361 das andere war die kollektive Sicherung auf dem Land. Die staatliche Verantwortung bei der Sozialhilfe beschränkte sich hauptsächlich auf die Naturkatastrophenhilfe und

355 中华人民共和国国防法, vom 14.03.1997, 中华人民共和国主席令第84号.

356 军人保险制度实施方案 (Durchführungsplan des Sozialversicherungssystems für Armeeangehörige), zitiert nach: 郑功成, 社会保障学 (Zheng, Gongcheng (Hrsg.), Social Security), S. 412 ff.

357 郑功成, 社会保障学 (Zheng, Gongcheng (Hrsg.), Social Security), S. 413.

358 中国人民解放军军人伤亡保险暂行规定 (Vorläufige Bestimmung über die Versicherung für verwundete und gefallene Armeeangehörige), vom 01. 08. 2008.

359 中国人民解放军军人退役医疗保险暂行办法 (Vorläufige Maßnahmen über die Krankenversicherung für demobilisierte Soldaten), vom 01. 01. 2001.

360 中国人民解放军军人配偶随军未就业期间社会保险暂行办法 (Vorläufige Maßnahmen über die Sozialversicherung für die nicht beschäftigten Ehepartner der Armeeangehörige in der Zeit der Begleitung), vom 25. 12.2003, 国办发 (2003) 102号.

361 Ausführlich: Zweiter Teil, Soziale Sicherheit in den früheren Verfassungen. 
die Hilfe für jene Bevölkerungsgruppe, die keine Arbeitsfähigkeit, keine familiäre Unterstützung und keine eigenen Mittel zur Lebensexistenz hatten. Mit der Dekollektivierung auf dem Land und der Regulierung der wirtschaftlichen Struktur in den Städten wurde das System der Sozialhilfe reformiert. Zurzeit erfassen die chinesische Hilfesysteme Naturkatastrophenhilfe, Fünf-Garantien-System, Sicherung des Existenzminimums, medizinische Hilfe, Hilfe für Obdachlose, Wohnungshilfe, Bildungshilfe, Justizhilfe und Armutsbekämpfung. Das Ministerium für Zivile Angelegenheiten und die Behörden für zivile Angelegenheiten auf verschiedenen Regierungsebenen sind für die Verwaltung der Sozialhilfe zuständig.

\section{a) Sozialhilfe auf dem Land}

\section{aa) Naturkatastrophenhilfe}

Als ein Agrarland, das oft von Naturkatastrophen heimgesucht wird, hat China eine lange Geschichte und Tradition bei der Naturkatastrophenhilfe. Die zentrale und die lokalen Regierungen sehen Ausgaben für die Beistandsleistung in Katastrophenfällen jährlich in ihren Haushaltsplänen vor, um Katastrophengeschädigte unterzubringen und zu unterstützen. Im Jahre 1983 wurden die Richtlinien für Naturkatastrophenhilfe in der 8. Nationalen Sitzung für zivile Angelegenheiten aufgestellt:

- Stützung auf die Volksmasse und das Kollektiv,

- Selbsthilfe durch Arbeit,

- gegenseitige Hilfe und Zusammenarbeit,

- $\quad$ staatliche Hilfe und Unterstützung als Ergänzung. ${ }^{362}$

Das Ministerium und die Behörde für zivile Angelegenheiten sind dafür verantwortlich, den Katastrophenopfern materielle Hilfe zu gewähren, Selbsthilfe der Katastrophenopfer zu organisieren und die gegenseitige Hilfe zu leiten. Auf dem Land wurden Sparvereine zur gegenseitigen Hilfe und Getreidespeicher für Notfälle überall gegründet. 363 Seit 1988 versucht das Ministerium für Zivile Angelegenheiten, die Pilotprojekte einer kooperativen Katastrophenversicherung durchzuführen. $364 \mathrm{Im}$ Falle sehr schwerer und schwerer Naturkatastrophen in ärmeren Gebieten bekommen die Katastrophengeschädigten vom Staat materielle Hilfe wie Lebensmittelunterstützung, Hilfsgeld usw. 365

362 第八次全国民政会议 (1983) 会议纪要 (Protokoll der 8. nationalen Sitzung für zivile Angelegenheiten 1983), 中办发 (1983) 53号.

363 Siehe: Zhang, Wei, Sozialwesen in China, S. 212.

364 民政部, 关于抓紧进行救灾合作保险试点准备工作的通知 (Mitteilung des Ministeriums für zivile Angelegenheiten über Vorbereitung der Pilotarbeit der kooperativen Katastrophenversicherung)，民农函（1988）第13号, vom 12.01.1988.

365 陈佳贵/王延中，中国社会保障发展报告 2001-2004 (Chen, Jiagui/Wang, Yanzhong, China social security system development report 2001-2004), S. 24. 
Die „Regeln über die Arbeit der Versorgung mit den Fünf-Garantien auf dem Land“ wurden im Jahre 2006 modifiziert, damit die lokalen Regierungen statt des Kollektivs das Fünf-Garantien-System finanzieren. ${ }^{366}$ In manchen Gebieten gibt es zurzeit noch Kollektivwirtschaften, die das Fünf-Garantien-System mit Zuschüssen zu unterstützen haben.

Die Berechtigten sind die alten, die behinderten Dorfbewohner oder Dorfbewohner unter Vollendung des 16. Lebensjahres, die keine Arbeitsfähigkeit, keine eigene Einkünfte und keine gesetzliche Unterhaltspflichtige haben, oder die Verpflichteten unterhaltsunfähig sind. ${ }^{367}$ Sie können selbst entscheiden, in einem Pflegewohnheim oder zu Hause zu wohnen. 368 Die lokale Regierung garantiert den Berechtigten

(1) Lebensmittel und Brennmaterial,

(2) Kleidung, Bettzeug, Taschengeld,

(3) Wohnraum,

(4) medizinische Versorgung und Pflege,

(5) Bestattungskosten. 369

Die Leistungen der Fünf-Garantien umfassen also sowohl materielle Leistungen als auch Geldleistungen. Das Lebensniveau der Berechtigten darf nicht niedriger als das durchschnittliche Lebensniveau der örtlichen Dorfbewohner sein. ${ }^{370}$ Die Bildungskosten der berechtigten Kinder und Jugendlichen werden auch von diesem System übernommen. ${ }^{371}$ Die Zentralregierung gewährt den lokalen Regierungen, die finanzielle Schwierigkeiten haben, Zuschüsse für das System der Fünf-Garantien. ${ }^{372}$

\section{cc) Sicherung des Existenzminimums für die ländliche Bevölkerung}

Seit 1994 hat das Ministerium für Zivile Angelegenheiten versucht, Pilotprojekte für die ländliche Sicherung des Existenzminimums in verschiedenen Gebieten durchzuführen. ${ }^{373}$ Nach 13 Jahren hat der Staatsrat schließlich im Jahre 2007 beschlossen, das System der Sicherung des Existenzminimums landesweit für die ländliche Bevölkerung zu errichten. ${ }^{374}$ Bis Ende 2007 wurde das Sicherungssystem des Existenzminimums

366 农村五保供养工作条例 (Regeln über die Arbeit der Versorgung mit den Fünf-Garantien auf dem Land), 国务院令第456号, vom 01. 03. 2006.

$367 \S 6$ Regeln über die Arbeit der Versorgung mit den Fünf-Garantien auf dem Land von 2006.

$368 \S 12$ Regeln über die Arbeit der Versorgung mit den Fünf-Garantien auf dem Land von 2006.

$369 \S 9$ Abs. 1 Regeln über die Arbeit der Versorgung mit den Fünf-Garantien auf dem Land von 2006.

$370 \S 10$ Abs. 1 Regeln über die Arbeit der Versorgung mit den Fünf-Garantien auf dem Land von 2006.

371 § 9 Abs. 1 Regeln über die Arbeit der Versorgung mit den Fünf-Garantien auf dem Land von 2006.

$372 \S 11$ Abs. 2 Regeln über die Arbeit der Versorgung mit den Fünf-Garantien auf dem Land von 2006.

373 Ausführlich vgl. 关信平/黄晓燕, 中国农村居民最低生活保障制度及运行机制 (Guan, Xinping/Huang, Xiaoyan, The Running Mechanics of the Minimum Living Standard System for Rural Residents in China), in: 社会保障研究 (Social Security Studies), 2006/1, S. 195ff.

374 国务院关于在全国建立农村最低生活保障制度的通知 (Mitteilung des Staatsrats über die landesweite Errichtung des Sicherungssystems des Existenzminimums für die ländliche Bevölkerung), 国发 (2007)19号, vom 11.07. 2007. 
auf dem Land bereits aufgebaut. ${ }^{375}$ Die lokalen Regierungen tragen die Verantwortung für die Errichtung des Sicherungssystems des Existenzminimums für die ländliche $\mathrm{Be}$ völkerung. ${ }^{376}$

Im Vergleich mit dem Fünf-Garantien-System für die arbeitsunfähigen Personen, die keine Unterhaltspflichtige haben, ist die ländliche Existenzminimumssicherung ein Hilfssystem für die armen ländlichen Familien. Wenn das Pro-Kopf-Einkommen einer Familie unter dem lokalen Standard des Existenzminimums liegt, kann die arme Familie einen Antrag auf Sicherung des Existenzminimums an die Gemeinderegierung stellen. 377 Nach Prüfung durch die Regierung erhält die Familie Geldleistungen, die dem Differenzbetrag zwischen dem Pro-Kopf-Einkommen der Familie und der lokalen Richtnorm des Existenzminimums entspricht. 378

Die ländliche Existenzminimumssicherung ist eng verknüpft mit der Armutsbekämpfung, damit die arbeitsfähigen Bedürftigen sich durch Arbeit selbst helfen können. 379

\section{dd) Ländliche medizinische Hilfe}

Gemäß dem „Beschluss des Zentralkomitees der KP Chinas und des Staatsrats über die weitere Festigung der ländlichen medizinischen Versorgung “380 haben das Ministerium für Zivile Angelegenheiten, das Gesundheitsministerium und das Finanzministerium im Jahre 2003 die „Ansichten zur Durchführung der ländlichen medizinischen Hilfe“381 veröffentlicht. Bis Ende 2005 wurde das System der ländlichen medizinischen Hilfe landesweit errichtet. 382

Die Bedürftigen der ländlichen medizinischen Hilfe sind die Fünf-GarantienHaushalte und die Mitglieder der armen Bauernfamilien, die an schweren Krankheiten leiden und die Behandlungskosten deshalb nicht selbst tragen können. ${ }^{383}$ In den vom neuen kooperativen medizinischen System erfassten Gebieten können die Bedürftigen finanzielle Hilfe für die Teilnahme am kooperativen medizinischen System erhalten.

375 民政部, 2007年民政事业发展统计公报 (Ministerium für zivile Angelegenheiten, Statistisches Bulletin über zivile Angelegenheiten 2007), http://www.mca.gov.cn/accessory/200801/1201137990924.doc (Stand: 15. 07. 2010).

376 Nr. 2 der Mitteilung des Staatsrats über die landesweite Errichtung des Sicherungssystems des Existenzminimums für ländliche Bevölkerung von 2007.

377 Nr. 4 der Mitteilung des Staatsrats über die landesweite Errichtung des Sicherungssystems des Existenzminimums für ländliche Bevölkerung von 2007.

378 Nr. 3 der Mitteilung des Staatsrats über die landesweite Errichtung des Sicherungssystems des Existenzminimums für ländliche Bevölkerung von 2007.

379 Nr. 2 der Mitteilung des Staatsrats über die landesweite Errichtung des Sicherungssystems des Existenzminimums für ländliche Bevölkerung von 2007.

380 中共中央，国务院关于进一步加强农村卫生工作的决定，中发 (2002) 13号, vom 19. 10. 2002.

381 民政部，卫生部，财政部，关于实施农村医疗救助的意见，民发 (2003) 158号，vom 18. 11. 2003.

382 民政部，卫生部，财政部，关于加快推进农村医疗救助工作的通知 (Ministerium für Zivile Angelegenheiten, Gesundheitsministerium, Finanzministerium, Bekanntmachung über die Beschleunigung der Arbeit der ländlichen medizinischen Hilfe), 民发 (2005) 121号, vom 15. 08. 2005.

383 Nr. 2 der Ansichten zur Durchführung der ländlichen medizinischen Hilfe von 2003. 
Bei besonders schweren Krankheiten können sie noch weitere medizinische Hilfe bekommen. Die noch nicht am kooperativen medizinischen System teilnehmenden Bedürftigen bekommen bei schweren Krankheiten direkt die medizinische Hilfe. ${ }^{384}$

Für die ländliche medizinische Hilfe sind Hilfsfonds von den lokalen Regierungen errichtet worden. Das Hilfssystem wird hauptsächlich durch die lokale Regierung finanziert, die Zentralregierung unterstützt die medizinischen Hilfssysteme der mittleren und westlichen armen Gebiete durch spezielle Umverteilungsmaßnahmen. ${ }^{385}$

\section{ee) Armutsbekämpfung}

Die ländliche Existenzminimumssicherung ist nur ein Teil der chinesischen Armutshilfe. Der Kern der chinesischen Sozialpolitik für Armutshilfe auf dem Land ist die Armutsbekämpfung, die als eine wichtige Entwicklungsstrategie der chinesischen Regierung seit 1986 auf dem Land durchgeführt wird. ${ }^{386}$

Aufgrund der wirtschaftlichen Entwicklung wurde die Zahl der armen ländlichen Bevölkerung bis 1986 deutlich vermindert. Dennoch ist Armutsbekämpfung nach wie vor eine schwierige Aufgabe der chinesischen Regierung. Die Zahl der ländlichen armen Bevölkerung betrug im Jahre 1986 noch 125 Mio. Menschen. ${ }^{387}$ Seit 1986 hat die Zentralregierung die traditionelle Linie der Armutshilfe reformiert und landesweit aktive Armutsbekämpfungsmaßnahmen durchgeführt. Eine Leitungsgruppe für Armutsbekämpfung und Entwicklung wurde beim Staatsrat errichtet, das Ministerium für Zivile Angelegenheiten nimmt bei der Arbeit der Armutsbekämpfung nun die zweite Stelle ein.

Nach der Richtlinie der Armutsbekämpfung gewährt der Staat Hilfen (wie staatliche Subvention, Sonderdarlehen, usw.) ${ }^{388}$ zur Verbesserung der Bedingungen für die wirtschaftliche Entwicklung der armen Gebiete, die Regierungen auf Provinzebene legen aufgrund der staatlichen Ziele und Forderungen die Planung fest und organisieren deren Durchführung. 389 Der Armutshilfsfonds wird unter Leitung der Regierung für die Verbesserung der Wirtschaftsstruktur und die Erschließung der örtlichen Ressourcen der armen Gebiete benutzt, damit die Bauern aus eigener Kraft der Armut abhelfen kön-

384 Nr. 3 der Ansichten zur Durchführung der ländlichen medizinischen Hilfe von 2003.

385 Nr. 6 der Ansichten zur Durchführung der ländlichen medizinischen Hilfe von 2003.

386 国务院新闻办公室, 中国的农村扶贫开发白皮书 (Presseamt des Staatsrats, Weißbuch über die ländliche Armutsbekämpfung und Erschließung in China), 10/2001.

387 国务院新闻办公室, 中国的农村扶贫开发白皮书 (Presseamt des Staatsrats, Weißbuch über die ländliche Armutsbekämpfung und Erschließung in China), 10/2001.

388 国务院扶贫办, 中国农村扶贫开发纲要2001-2010 (Abteilung für Armutsbekämpfung und Entwicklung beim Staatsrat, Programme der Armutsbekämpfung auf dem Land 2001-2010), vom 19. 09. 2001, http://www.cpad.gov.cn/data/2006/0303/article_232.htm (Stand: 15. 07. 2010).

$389 \S 85$ Abs. 1 Landwirtschaftsgesetz von 2002. 
nen. ${ }^{390}$ Bis 2006 wurde die Zahl der armen Bevölkerung auf 23. 65 Mio. Menschen vermindert. 391

\section{b) Sozialhilfe in der Stadt}

\section{aa) Sicherung des Existenzminimums für die städtische Bevölkerung}

1999 hat der Staatsrat die „Regeln zur Sicherung des Existenzminimums für die städtische Bevölkerung“" erlassen. ${ }^{392}$ Nun wird das Sicherungssystem für das Existenzminimum in allen Städten und Kreisen errichtet. Die Behörden für zivile Angelegenheiten auf den verschiedenen Ebenen sind für die Verwaltung der Existenzsicherung zuständig. Im Auftrag der Verwaltungsorgane können die Einwohnerausschüsse ${ }^{393}$ die Tätigkeiten und die Dienstarbeiten der Existenzsicherung übernehmen. 394

Die Berechtigten sind die städtischen Bewohner mit Stadt-Hukou, bei denen das ProKopf-Einkommen der zusammenlebenden Familienangehörigen unter dem lokalen Standard des Existenzminimums liegt. ${ }^{395}$ Als Berechtigte werden drei Gruppen bezeichnet:

- städtische Bewohner, die keine Einkünfte, keine Arbeitsfähigkeit und keine gesetzlichen Unterhaltspflichtigen haben;

- Arbeitslose, deren Pro-Kopf-Einkommen ihrer Familie unter dem lokalen Standard des Existenzminimums liegt;

- Arbeitnehmer und ausgegliederte Arbeitnehmer, deren Pro-Kopf-Einkommen ihrer Familien unter dem lokalen Standard des Existenzminimums liegt . 396

Die arme städtische Familie kann einen Antrag auf Sicherung des Existenzminimums schriftlich an die Wohngebietsdienststelle oder die Gemeinderegierung stellen. ${ }^{397}$ Nach Prüfung und Genehmigung der lokalen Behörde für zivile Angelegenheiten erhält die Familie Geldleistung, 398 die dem Differenzbetrag zwischen dem Pro-Kopf-Einkommen der Familie und der Richtnorm des Existenzminimums entspricht. ${ }^{399}$ Die lokalen Re-

$390 § 85$ Abs. 2 Landwirtschaftsgesetz von 2002.

391 国务院扶贫办, 中国农村扶贫开发概要 (Abteilung für Armutsbekämpfung und Entwicklung beim Staatsrat, Übersicht über Armutsbekämpfung und Erschließung auf dem Land), vom 28. 09. 2006. http://www.cpad.gov.cn/data/2006/0928/article_3099.htm (Stand: 15. 07. 2010).

392 城市居民最低生活保障条例 (Regeln zur Sicherung des Existenzminimums für die städtische Bevölkerung), 国发 (1999) Nr. 271, vom 28.09. 1999.

393 Die Einwohnerausschüsse sind die Selbstverwaltungsorgane der städtischen Bewohner im Wohnviertel.

394 § 4 der Regeln zur Sicherung des Existenzminimums für die städtische Bevölkerung von 1999.

$395 \$ 2$ Abs. 1 der Regeln zur Sicherung des Existenzminimums für die städtische Bevölkerung von 1999.

396 Nr. 2 der Mitteilung des Staatsrats über die Errichtung des Sicherungssystems des Existenzminimums für die städtische Bevölkerung von 1997.

397 Nr. 4 der Mitteilung des Staatsrats über die landesweite Errichtung des Sicherungssystems des Existenzminimums für ländliche Bevölkerung von 2007.

398 § 7 der Regeln zur Sicherung des Existenzminimums für die städtische Bevölkerung von 1999.

399 § 8 der Regeln zur Sicherung des Existenzminimums für die städtische Bevölkerung von 1999. 
gierungen legen die Höhe des Existenzminimums fest. ${ }^{400}$ Der konkrete Betrag des Existenzminimums ist in den verschiedenen Städten unterschiedlich und wird mit der Verbesserung des allgemeinen Lebensniveaus und der Preisänderung der Lebensmittel reguliert. ${ }^{401} 2010$ beträgt der Monatsbetrag landesweit durchschnittlich 162 RMB pro Person. 402

\section{bb) Hilfe für Obdachlose in den Städten}

Die „Maßnahmen zur Unterbringung und Rückführung von Obdachlosen in den Städten“ von 1982,403 die ursprünglich als Hilfsmaßnahmen gedacht waren, wurden wegen ihres Zwangscharakters immer mehr als Maßnahmen der öffentlichen Sicherheit angesehen, da sie den Verwaltungsbehörden die Befugnis erteilen, die körperliche Freiheit der Bürger zu beschränken. 2003 wurde diese Vorschrift von den „Verwaltungsmaßnahmen zur Hilfe von Obdachlosen in den Städten“404 ersetzt. ${ }^{405}$ Die Maßnahmen zur Hilfe der Obdachlosen werden seitdem als reine Sozialhilfe bezeichnet.

„Obdachlose“ im Sinne der Vorschrift sind die in den Städten umherstreifenden Personen, die nicht selbst Unterkunft und Verpflegung aufbringen können, nicht bei Verwandten oder Freunden aufgenommen werden, und über keine Sicherung des Existenzminimums verfügen. 406 Nach dieser Vorschrift sollen die Regierungen der Städte Hilfsstationen für die provisorische Hilfe für Obdachlose errichten. 407 Die Hilfsstation soll den Bedürftigen Essen, Unterkunft, medizinische Versorgung gewähren und ihnen bei der Rückkehr an den Wohnsitz helfen. ${ }^{408}$

\section{cc) Wohnungshilfe}

Seit 2004 wurde ein System der Wohnungshilfe mit der Veröffentlichung der „Maßnahmen zur Wohnungshilfe mit niedriger Miete für Familien mit niedrigem Einkommen in den Städten“ aufgebaut. ${ }^{409}$ Im Jahre 2007 wurde diese Vorschrift aufgehoben, neun

$400 \S 6$ der Regeln zur Sicherung des Existenzminimums für die städtische Bevölkerung von 1999.

401 国务院关于在全国建立城市居民最低生活保障制度的通知 (Mitteilung des Staatsrats über die Errichtung des Sicherungssystems des Existenzminimums für die städtische Bevölkerung), 国发 (1997) 29号, vom 02.09. 1997.

402 民政部, 2010年4月份全国县以上城市低保数据 (Ministerium für zivile Angelegenheiten, Statistische Daten der städtischen Existenzsicherung vom 04. 2010), http://cws.mca.gov.cn/article/tjsj/dbsj/201004/20100400073454.shtml (Stand: 15. 07. 2010).

403 城市流浪乞讨人员收容遣送办法, 国发 (1982) 79号, vom 12.05. 1982.

404 城市生活无着的流浪乞讨人员救助管理办法, 国务院令第381号, vom 18. 06. 2003.

405 Ausführlich: Zweiter Teil: Die Verfassung, Sun-Zhigang Fall.

406 民政部, 城市生活无着的流浪乞讨人员救助管理办法实施细则 (Ministerium für zivile Angelegenheiten, Detaillierte Vorschrift über Verwaltungsmaßnahmen zur Hilfe von Obdachlosen in den Städten), vom 21. 07. 2003.

$407 \S 2$ Abs. 2 Verwaltungsmaßnahmen zur Hilfe von Obdachlosen in den Städten von 2003.

$408 \S 7$ Verwaltungsmaßnahmen zur Hilfe von Obdachlosen in den Städten von 2003.

409 城镇最低收入家庭廉租住房管理办法, vom 31. 12. 2003. 
Ministerien und Kommissionen des Staatsrats haben die „Maßnahmen zur Sicherung der Wohnungen mit niedriger Miete“ 410 gemeinsam erlassen.

Die städtischen Familien mit niedrigem Einkommen können Wohngeld von den lokalen Regierungen bekommen, oder die lokalen Regierungen vermieten ihnen Wohnungen zu günstigen Mietpreisen. ${ }^{411}$ Die zentrale Regierung und die lokalen Regierungen finanzieren das System der Wohnungshilfe zusammen. ${ }^{412}$ Die konkreten Kriterien für die Wohnungsfläche, die Antragsbedingungen usw. werden von den lokalen Regierungen auf Kreisebene bestimmt. ${ }^{413}$

\section{dd) Städtische medizinische Hilfe}

Seit 2005 werden die Pilotprojekte der städtischen medizinischen Hilfe in verschiedenen Städten durchgeführt 414 . Ähnlich wie bei der ländlichen medizinischen Hilfe werden Fonds für die städtische medizinische Hilfe in den Städten errichtet und hauptsächlich von den Regierungen der verschiedenen Ebenen finanziert. ${ }^{415}$

Die Bedürftigen der städtischen medizinischen Hilfe sind die städtischen Bewohner, die die Sicherung des Existenzminimums genießen und nicht an der Grundkrankenversicherung für städtische Beschäftigte teilnehmen, oder die Teilnehmer der Grundkrankenversicherung für städtische Beschäftigte, die aber mit den medizinischen Kosten überfordert sind, oder andere Bewohner mit besonderen Schwierigkeiten. ${ }^{416}$

\section{Förderungssysteme}

Soziale Förderung dient dem Ziel der Verbesserung der Lebensbedingungen aller Bürger, insbesondere der Verbesserung der Lebensbedingungen besonderer Gruppen, welche sich in der Gesellschaft in einer ungünstigen Lage befinden, wie Alte, Behinderte, Kinder, Frauen, usw. In dieser Arbeit werden die allgemeinen Wohlfahrtleistungen (wie Arbeitsförderung, Bildungsförderung, Gesundheitseinrichtung), die kollektive Wohlfahrtleistungen innerhalb der Arbeitseinheiten und die spezielle Wohlfahrtleistungen für besondere Gruppen als soziale Förderung bezeichnet.

410 廉租住房保障办法, vom 08. 11. 2007.

$411 \S 5$ der Maßnahmen zur Wohnungshilfe von 2007.

$412 \S \S 9,10,11$ der Maßnahmen zur Wohnungshilfe von 2007.

413 § 6 der Maßnahmen zur Wohnungshilfe von 2007.

414 民政部, 卫生部, 劳动保障部, 财政部, 关于建立城市医疗救助制度试点工作的意见 (Ministerium für zivile Angelegenheiten, Gesundheitsministerium, Ministerium für Arbeit und soziale Sicherheit, Finanzministerium, Mitteilung über den Pilotplan der städtischen medizinischen Hilfe), vom 26. 02. 2005.

415 Nr. 2 der Mitteilung über den Pilotplan der städtischen medizinischen Hilfe von 2005.

416 Nr. 2 der Mitteilung über den Pilotplan der städtischen medizinischen Hilfe von 2005. 


\section{a) Allgemeine Wohlfahrt}

\section{aa) Beschäftigungsförderung}

Mit der Veröffentlichung der „Bekanntmachung des Zentralkomitees der KP Chinas und des Staatsrats über die weitere Durchführung der Wiederbeschäftigungsmaßnahmen für die entlassenen Arbeitnehmer und die Arbeitslosen“ von $2002^{417}$ wurde eine „aktive Beschäftigungspolitik“ in China eingeführt. Der Ausbau der Beschäftigungsrate wird seitdem als ein Hauptziel der staatlichen Entwicklungsstrategie durchgeführt. ${ }^{418}$ Die Richtlinie der aktiven Beschäftigungspolitik wurde in der „Mitteilung des Staatsrats über die weitere Verstärkung der Beschäftigung- und Wiederbeschäftigungsarbeit" von $2005^{419}$ betont und schließlich 2007 im Beschäftigungsförderungsgesetz ${ }^{420}$ niedergelegt: Die Arbeitenden entscheiden selbständig über die Beschäftigung, diese wird ebenfalls durch den Markt reguliert und durch die Regierung gefördert.

Das Beschäftigungsförderungsgesetz ist sowohl eine Umsetzung der politischen Richtlinien als auch eine Konkretisierung der in der Verfassung und dem Arbeitsgesetz festgeschriebenen Regelungen über die Beschäftigung. Die aktive Beschäftigungspolitik ist zunächst in Art. 42 der Verfassung von 1982 (das Recht und die Pflicht der Bürger zu arbeiten) geregelt: Durch verschiedene Maßnahmen schafft der Staat die Bedingungen für Beschäftigung. ${ }^{421} \mathrm{Im}$ Arbeitsgesetz wird diese Regelung im zweiten Kapitel über die Beschäftigungsförderung konkretisiert. Gem. § 10 Abs. 1 des Arbeitsgesetzes schafft der Staat durch die Förderung der wirtschaftlichen und gesellschaftlichen Entwicklung die Bedingungen für die Beschäftigung und eröffnet Gelegenheiten zur Ausweitung der Beschäftigung. Demgegenüber haben die Werktätigen gleichberechtigt das Recht, bei der Beschäftigung und der Berufsauswahl gleichbehandelt zu werden. ${ }^{422}$

Die aktive Beschäftigungspolitik umfasst im weiteren Sinne alle Maßnahmen und Sozialleistungen, die der Arbeitsplatzschaffung und der Lebenssicherung der Arbeitslosen dienen. Ein Koordinationssystem zur Beschäftigungsförderung wird eingerichtet. Die Erweiterung der Beschäftigung genießt Priorität in der wirtschaftlichen und gesellschaftlichen Entwicklung. ${ }^{423}$ Darüber hinaus ist der Staat verantwortlich, das System der Arbeitslosenversicherung zu errichten, den Grundlebensstandard der Arbeitslosen zu gewährleisten und die Wiederbeschäftigung der Arbeitslosen zu fördern. 424

417 中共中央, 国务院关于进一步做好下岗失业人员再就业工作的通知 (Bekanntmachung des Zentralkomitees der KP Chinas und des Staatsrats über die Durchführung der Wiederbeschäftigungsmaßnahmen für die entlassenen Arbeitnehmer und die Arbeitslosen), 中发 (2002) 12号, vom 30. 09. 2002.

418 Nr. 3 Beschluss des Zentralkomitees der KP Chinas über einige wichtigen Fragen zur Strukturierung einer harmonischen sozialistischen Gesellschaft, vom 11. 10. 2006.

419 国务院关于进一步加强就业再就业工作的通知，国发 (2005) 36号, vom 04. 11. 2005.

420 中华人民共和国就业促进法 (Beschäftigungsförderungsgesetz der Volksrepublik China), vom 30. 08. 2007, ab 01. 01. 2008 in Kraft.

421 Art. 42 Abs. 2 Satz 1 der Verfassung von 1982.

$422 \S 3$ Abs. 1 des Arbeitsgesetzes von 1994.

423 § 2 Beschäftigungsförderungsgesetz von 2007.

$424 \S 16$ Beschäftigungsförderungsgesetz von 2007. 
Im engeren Sinne umfasst die Beschäftigungsförderung eine Reihe von Förderungsleistungen. Gemäß dem Beschäftigungsförderungsgesetz werden Systeme der öffentlichen Beschäftigungsdienste für Arbeitssuchende, ${ }^{425}$ Berufsbildungssysteme, ${ }^{426}$ Systeme der Beschäftigungshilfe ${ }^{427}$ und Spezialfonds für Beschäftigungsförderung ${ }^{428}$ von den Regierungen der verschiedenen Ebenen errichtet, die der Unterstützung der Stellenvermittlung und Umschulung dienen. ${ }^{429}$ Durch Vorzugsbehandlungen wie Steuerermäßigung bzw. -befreiung und Bereitstellung von Krediten versucht die Regierung, die Wiederbeschäftigung der Arbeitslosen und die Unterstützung für spezielle Gruppen wie Behinderte zu fördern. ${ }^{430}$ Die Politik für die Beschäftigung in der Stadt und auf dem Land wird vereinheitlicht, die Migration der ländlichen Arbeitskräfte wird ordnungsgemäß angeleitet. ${ }^{431}$ Die Regierung errichtet ein Informationsnetz und einen Stellenvermittlungsservice, um die Wanderarbeiter zu organisieren. ${ }^{432}$

\section{bb) Bildungsförderung}

Nach der chinesischen Verfassung und dem Bildungsgesetz hat der Staat die Pflicht, das Bildungswesen und die Bildungseinrichtungen zu entwickeln. ${ }^{433}$ Seit 2006 ist der Schulbesuch während der neunjährigen Schulpflicht kostenlos. ${ }^{434}$ Die allgemeine Schulpflicht bezieht sich auf die sechsjährige Grundschulbildung und die dreijährige Mittelschulbildung der Unterstufe. Die Schüler aus armen Familien werden von den Kosten für Lehrbücher befreit und erhalten Zuschüsse für den Lebensunterhalt. ${ }^{435}$ Der Staat richtet für die Studenten der Hochschule Stipendien und Darlehn ein, außerdem können die Studenten aus armen Familien Zuschüsse oder Ermäßigung bzw. Befreiung der Ausbildungskosten beantragen. 436

\section{cc) Medizinische Dienstleistung}

Die chinesischen Gesundheitssysteme umfassen die Gesundheitsabsicherung, die grundlegende öffentliche Gesundheitsversorgung, die medizinische Betreuung und die

$425 \S \S 35 \mathrm{ff}$. Beschäftigungsförderungsgesetz von 2007.

$426 \S \S 44 \mathrm{ff}$. Beschäftigungsförderungsgesetz von 2007.

$427 \S \S 52 \mathrm{ff}$. Beschäftigungsförderungsgesetz von 2007.

$428 \S 15$ Beschäftigungsförderungsgesetz von 2007.

$429 \S 15$ Abs. 3 Beschäftigungsförderungsgesetz von 2007.

$430 \S \S 17,19$ Beschäftigungsförderungsgesetz von 2007.

$431 \S 20$ Beschäftigungsförderungsgesetz von 2007.

432 国务院新闻办公室, 中国的劳动和社会保障状况的白皮书 (Presseamt des Staatsrats, Arbeit und Sozialabsicherung in China), 04/2002.

433 Art. 19 der Verfassung von 1982.

$434 \S 2$ Schulpflichtgesetz von 2006.

$435 \S 44$ Abs. 2 Schulpflichtgesetz von 2006.

$436 \S 54$ 中华人民共和国高等教育法 (Ausbildungsgesetz) vom 29. 08. 1998, ab 01. 01. 1999 in Kraft. 
Grundarzneiversorgung. ${ }^{437}$ Während das System der Gesundheitsabsicherung, das aus den Krankenversicherungen und medizinischen Hilfsmaßnahmen besteht, von dem Staat, der Gesellschaft und dem Einzelnen zusammen finanziert wird, werden die grundlegenden medizinischen Dienstleistungen, die die öffentlichen Gesundheitseinrichtungen und Maßnahmen zur Prävention, Behandlung und Gesundheitserhaltung erfassen, als Förderungssysteme bezeichnet und vom Staat allein finanziert. Bis 2010 sind das System der städtischen kommunalen Gesundheitseinrichtung 438 und das ländliche dreistufige Gesundheitsnetz (Krankenhäuser auf der Kreisebene, Gesundheitsstationen auf der Gemeindeebene, Gesundheitsstationen auf der Dorfebene) ${ }^{439}$ fertig zu stellen. Seit 2009 wird eine Datenbank der medizinischen Dienstleistungen für alle Bürger errichtet. Für Alte, Kinder und Frauen werden Gesundheitsuntersuchungen regelmäßig durchgeführt. ${ }^{440}$

\section{b) Kollektive Wohlfahrt}

Die kollektive Wohlfahrt (oder Arbeitseinheitswohlfahrt) stellt die Wohlfahrtsleistungen innerhalb eines Kollektivs dar. Sie war in der Periode der Planwirtschaft ein wichtiger Bestandteil der sozialen Wohlfahrt. Die Arbeitseinheiten (Unternehmen und öffentliche Institutionen) galten damals nicht nur als Produktionseinheiten, sondern auch als soziale Gemeinden und Lebensgemeinschaften. ${ }^{441}$ Sie versorgten Wohnungen und Gesundheits-, Erziehungs- sowie Bildungsanstalten wie Kindergärten, Schulen, Kantinen, Krankenhäuser, Kultur- und Sporteinrichtungen für ihre Beschäftigten und die Familienangehörigen der Beschäftigten. Die Kosten der Wohlfahrtsleistungen wurden von den Arbeitseinheiten allein getragen.

Im Arbeitsgesetz von 1994 ist geregelt, dass die Arbeitseinheiten günstige Bedingungen dafür schaffen müssen, die kollektive Wohlfahrt zu verbessern und die Sozialleistungen für die Arbeitenden anzuheben. ${ }^{442}$ Allerdings wurden die Arbeitseinheiten aufgrund der Durchführung der neuen Politik ,Sozialisierung der sozialen Wohlfahrt“443 seit Ende der 1990er Jahren in gewissem Maße von den sozialen Aufgaben befreit. Die Schulen und Krankenhäuser der Arbeitseinheiten wurden den Stadtregie-

437 胡锦涛, 在中国共产党第十七次全国代表大会上的报告 $(H u$, Jintao, Bericht auf dem 17. Parteitag der Kommunistischen Partei Chinas), vom 15. 10. 2007. Ausführlich vgl. Dritter Teil, neue Runde der Gesundheitsreform.

438 国务院关于发展城市社区卫生服务的指导意见 (Leitlinien des Staatsrats über die Entwicklung der städtischen kommunalen medizinischen Dienstleistungen), 国发 (2006) 10号, vom 21. 02. 2006.

439 中共中央国务院关于进一步加强农村卫生工作的决定 (Beschluss des Zentralkomitees der KP Chinas und des Staatsrats über die weitere Festigung der ländlichen medizinischen Versorgung ), 中发 (2002) 13号, vom 19.10. 2002.

440 Nr. 4 des Durchführungsplans des Staatsrats für die Gesundheitsreform 2009-2011.

441 Zhang, Wei, Sozialwesen in China, S. 51.

$442 \S 76$ Abs. 2 Arbeitsgesetz von 1994.

443 民政部, 关于加快实现社会福利社会化的意见 (Ansichten des Ministeriums für zivile Angelegenheiten zur Beschleunigung der Sozialisierung der sozialen Wohlfahrt), 国办发 (2000) 19号, vom 27. 02. 2000. 
rungen übergeben. ${ }^{444}$ Die Stadtviertel übernahmen auch einen Teil der Wohlfahrtseinrichtungen und Dienstleistungen. ${ }^{445}$ Die kollektive Wohlfahrt beschränkt sich zurzeit hauptsächlich auf verschiedene Zuschüsse der Arbeitseinheiten für ihre Arbeitnehmer.

\section{c) Spezielle Wohlfahrt}

Im Gegensatz zur allgemeinen Wohlfahrt, die für alle Bürger errichtet wird, ist die spezielle Wohlfahrt ein Wohlfahrtssystem für bestimmte schwache Bürgergruppen. Die spezielle Wohlfahrt erfasst die öffentlichen Einrichtungen und Dienstleistungen für Alte, Minderjährige, Behinderte und Frauen. Die Regierung ist für die Errichtung und Finanzierung der speziellen Wohlfahrt verantwortlich. Der Staat hat dafür das „Gesetz zur Gewährleistung der Rechte von alten Menschen“,446 das „Gesetz zum Schutz von behinderten Menschen“,447 das „Gesetz zur Gewährleistung der Rechte von Frauen“448 und das „Gesetz zum Schutz von Minderjährigen“449 erlassen.

Das „Gesetz zur Gewährleitung der Rechte von alten Menschen“ von 1996 regelt den Unterhalt der alten Menschen innerhalb der Familie, die soziale Sicherung für alte Menschen und die Teilhabe der alten Menschen am Leben in der Gemeinschaft. Der Staat gewährt den Grundlebensunterhalt und die medizinische Versorgung für alte Menschen, ermuntert und unterstützt die Errichtung der öffentlichen Einrichtungen wie Altersheim, Sanatorium sowie Vergnügungs- und Sportstätten für Senioren. Bei dem öffentlichen Verkehr, der ärztlichen Behandlung usw. werden die alten Menschen bevorzugt behandelt. 450

Die Sicherheit und Gesundheit der Frauen im Arbeitsleben, während der Menstruation und bei der Schwangerschaft werden durch spezielle Maßnahmen und Regelungen besonders geschützt. ${ }^{451}$ Außerdem werden spezielle Einrichtungen wie Frauenkrankenhäuser, Aktionsstätte für Frauen errichtet.

Der Staat gewährt den Kindern und Jugendlichen besonderen Schutz wie Gesundheitsleistungen und Bildungshilfe, errichtet Kindergärten, Schulen, Pionierhäuser usw. Der Eintritt zu den öffentlichen Wohlfahrteinrichtungen wie Sportstadien, Museen, Kulturhäuser sollen für die Minderjährigen und Studenten kostenlos oder günstig sein.

444 国家经贸委, 财政部, 教育部, 卫生部, 劳动和社会保障部, 关于进一步推进国有企业分离办 社会职能工作的意见 (Kommission für Wirtschaft und Handel, Finanzministerium, Ministerium für Bildungswesen, Gesundheitsministerium, Ministerium für Arbeit und soziale Sicherheit, Ansichten zur Befreiung der Staatsunternehmen von den sozialen Aufgaben), 国经贸企改 (2002) 267号, vom 26. 04. 2002.

445 民政部等关于加快实现社会福利社会化的意见 (Ansichten des Ministeriums für zivile Angelegenheiten zur Beschleunigung der Sozialisierung der sozialen Wohlfahrt), 国办发 (2000) 19号, vom 27. 02. 2000.

446 中华人民共和国老年人权益保障法, vom 29.08. 1996.

447 中华人民共和国残疾人保障法, vom 28. 12. 1990, revidiert am 24. 04. 2008.

448 中华人民共和国妇女权益保障法, vom 01. 10. 1992, revidiert am 28. 08. 2005.

449 中华人民共和国未成年人保护法, vom 04. 09. 1991, revidiert am 29. 12. 2006.

450 § 20ff Gesetz zum Schutz der Rechte von alten Menschen von 1996.

$451 \S \S 26 f f$. Gesetz zum Schutz der Rechte von Frauen von 1992. 
Mit dem „Gesetz zum Schutz von behinderten Menschen“ wird angestrebt, die Benachteiligung von behinderten Menschen zu beseitigen und die gleichberechtigte Teilhabe von behinderten Menschen am Leben in der Gesellschaft zu gewährleisten. ${ }^{452}$ Die staatliche Verantwortung für Rehabilitation, Bildung, Beschäftigung, Kulturleben, soziale Sicherung und Barrierefreiheit der Behinderten werden im Behindertengesetz geregelt.

\section{Sonderversorgungssysteme}

Gemäß Art. 45 Abs. 2 der Verfassung von 1982 haben der Staat und die Gesellschaft die Pflicht, den Lebensunterhalt von invaliden Armeeangehörigen zu sichern, den Familienangehörigen der Märtyrer Beihilfe zu gewähren und die Familienangehörigen des militärischen Personals bevorzugt zu behandeln. ${ }^{453}$ Dafür hat der Staat einige Gesetze und Verordnungen wie das Militärdienstgesetz ${ }^{454}$, die Regeln zur Sonderversorgung für Soldaten 455 und die Regeln zur Auszeichnung der revolutionären Märtyrer ${ }^{456}$ erlassen.

Das Sonderversorgungssystem ist ein besonderes System der sozialen Sicherheit für Soldaten im Dienst, Soldaten, die in der Mobilität eingeschränkt sind, geschädigte Soldaten, Familienangehörige der Soldaten, Hinterbliebene von Märtyrern und verstorbene Soldaten ${ }^{457}$ sowie in der Ausübung ihres Dienstes verwundete oder verstorbene Staatsbeamte und Polizisten. ${ }^{458}$ Die Sonderversorgung umfasst folgende staatliche Maßnahmen:

Unterstützungsgeld sowie Unterhalt für Hinterbliebene von Märtyrern, verstorbenen Soldaten, Staatsbeamten und Polizisten, 459

- Invalidengeld für die in der Ausübung ihres Dienstes geschädigten Soldaten, Beamten und Polizisten, ${ }^{460}$

- Zuweisung der in der Mobilität eingeschränkten Soldaten in die Arbeitseinheiten, 461

$452 \S 1$ Gesetz zum Schutz der behinderten Menschen von 2008.

453 Art. 45 Abs. 2 der Verfassung von 1982: „Der Staat und die Gesellschaft sichern den Lebensunterhalt von invaliden Armeeangehörigen, gewähren den Familienangehörigen der Märtyrer Beihilfe und behandeln die Familienangehörigen des militärischen Personals mit Vorzug.“

454 中华人民共和国兵役法, vom 31. 05. 1984, revidiert am 29.12. 1998.

455 军人抚恤优待条例 (Regeln zur Unterstützung und Vorzugsbehandlung für Armeeangehörige), vom 01. 10. 2004.

456 革命烈士襄扬条例, vom 04. 06. 1980.

457 § 2 der Regeln zur Unterstützung und Vorzugsbehandlung für Armeeangehörige vom 2004.

458 民政部，关于国家机关工作人员，人民警察伤亡抚恤有关问题的通知 (Ministerium für zivile Angelegenheiten, Mitteilung über die Sonderversorgung für Staatsbeamte und Polizisten), 民函 (2004) 334号.

$459 \S \S 7$ ff. Regeln zur Unterstützung und Vorzugsbehandlung für Armeeangehörige; Mitteilung über die Sonderversorgung für Staatsbeamte und Polizisten.

$460 \S \S 20 f f$. Regeln zur Unterstützung und Vorzugsbehandlung für Armeeangehörige; Mitteilung über die Sonderversorgung für Staatsbeamte und Polizisten. 
- Vorzugsbehandlung (einschließlich Geldleistungen) für Soldaten im Dienst, geschädigte Soldaten und ihre Familienangehörige sowie Hinterbliebene von Märtyrern. 462

\section{Zusammenfassung}

Die bislang einschneidendsten Veränderungen der chinesischen sozialen Sicherheit liegen im Bereich der Vorsorge. Die alten Vorsorgesysteme, die die Betriebssicherung für Arbeitnehmer, die Kollektivsicherung für Bauer und die Staatssicherung für Staatsbedienstete umfassten, werden nun mit der wirtschaftlichen Privatisierung und der Einführung der Verantwortung des Einzelnen (beitragsgetragene Vorsorge) umstrukturiert. Die neuen Vorsorgesysteme sind sowohl hinsichtlich den Zweigen als auch den Finanzierungsmöglichkeiten vielfältiger als die alten Systeme.

Parallel zur Vergrößerung der Einkommensschere - eine der Nebenwirkungen der wirtschaftlichen Liberalisierung - übernehmen die Hilfesysteme zurzeit mehrere Aufgaben, den armen Bürgern zu helfen. Neue Systeme der Sozialhilfe wie Sicherung des Existenzminimums, Wohnungshilfe sowie medizinische Hilfe wurden dafür aufgebaut. Demgegenüber wurden die Förderungssysteme und die Sonderversorgung weniger von den wirtschaftlichen Veränderungen beeinflusst. Da diese Bereiche eine relative Stabilität aufweisen, wurde für sie seit den 1990er Jahren eine Reihe von rechtlichen Regelungen erlassen. Für fast alle Zweige der allgemeinen und speziellen Wohlfahrt hat der Staat Gesetze ausgearbeitet. Demgegenüber gibt es zurzeit noch eine große Menge an staatlichen Politnormen oder Verwaltungsvorschriften für Zweige der Sozialversicherung und der Sozialhilfe, die sich nun noch in der Phase der Pilotprojekte befinden.

\section{Darstellung und Analyse wichtiger Reformen}

Im Jahre 2003 hat das Forschungszentrum des Staatsrats in einem Forschungsbericht eingestanden, dass es nach ca. 20 Jahren Reform in den chinesischen Systemen der sozialen Sicherheit noch sehr viele Probleme existiert. Insbesondere geraten einige neu errichtete Sozialversicherungszweige, wie Rentenversicherung, Krankenversicherung und Arbeitslosenversicherung in Schwierigkeiten. 463 Die Deckungsraten der Sozialversicherungszweige sind noch ziemlich niedrig. Z. B. umfasste die Rentenversicherung im Jahre 2002 nur knapp 50\% der Gesamtzahl der Beschäftigten in Städten und Gemeinden, bei der Grundkrankenversicherung betrug die Deckungsrate nur 32\%. Die Bei-

$461 \S 56$ Militärdienstgesetz von 1984.

$462 \S \S 31 \mathrm{ff}$ Regeln zur Unterstützung und Vorzugsbehandlung für Armeeangehörige.

463 Siehe: 葛延风, 问题与对策：中国社保制度改革 (Ge, Yanfeng, Probleme und Gegenmaßnahmen: Reforme der sozialen Sicherheit in China), in: 中国行政管理 (Chinese Public Administration), 2003/9, S. $17 \mathrm{ff}$. 
tragssätze von Arbeitgebern und Arbeitnehmern bei manchen Sozialversicherungszweigen sind zu hoch bemessen am Durchschnittslohn der Arbeitnehmer. Die Leistungsniveaus sind jedoch vergleichsweise niedrig. Das Verwaltungssystem der Sozialversicherung ist lückenhaft. Es fehlt noch ein wirksamer Kontrollmechanismus für die Verwaltung und die Überwachung.

Insbesondere im Bereich der Gesundheitsversorgung hat die Öffentlichkeit seit der Krise des öffentlichen Gesundheitsdienstes 2003 (SARS-Krise) die Gesundheitsreform in Frage gestellt. ${ }^{464}$ In einem anderen Bericht des Forschungszentrums des Staatrates für Entwicklung wurde offen zugegeben, dass die Gesundheitsreform ihr Ziel nicht erreicht hat. 465

Dies hat eine hitzige Diskussion über die weitere Reform der sozialen Sicherheit ausgelöst. Nicht nur die durchgeführten Reformpläne, sondern auch die Leitlinien werden von der Öffentlichkeit mit Skepsis aufgenommen. Die Kernfrage liegt darin, was für ein Grundmodell der sozialen Sicherheit in China geeignet ist. ${ }^{466}$ Darüber hinaus wird die Frage, inwiefern der Staat für die soziale Sicherheit Verantwortung übernehmen soll, ausführlich diskutiert. ${ }^{467}$ Das grundlegende Reformmodell - durch Pilotpläne die Reformen allmählich voranzutreiben, den theoretischen Fragen absichtlich auszuweichen, damit der Reformprozess nicht von den theoretischen Streitigkeiten behindert wird - erweist sich wegen der Abwesenheit einer klaren und stabilen theoretischen Grundlage sowie eines integrierten und langfristigen Reformplans immer mehr als Hindernis für die weitere Entwicklung der sozialen Sicherheit. Ein typisches Beispiel ist die mehrjährige und zögernde Ausarbeitung des Sozialversicherungsgesetzes. Wegen Meinungsverschiedenheiten dauerte die Entwurfsarbeit des Sozialversicherungsgesetzes seit 1994 über 15 Jahre lang an. Erst am 28. 10. 2010 wurde das Sozialversicherungsgesetz vom Nationalen Volkskongress erlassen.

\section{Alterssicherung}

Die gesamte Alterssicherung wird in China hauptsächlich in drei Bestandteile unterteilt: die Rentenversicherung für Beschäftigte in den städtischen Unternehmen, die Alterssicherung für die ländliche Bevölkerung und die Altersversorgung für Staatsbediens-

464 王绍光, 中国公共卫生的危机与转机 (Wang, Shaoguang, Krise und Wendung der öffentlichen Gesundheitsdienst in China), in: 比较 (Comparative Studies), 2003/7, S. 52ff.

465 国务院发展研究中心, 对中国医疗卫生体制改革的评价与建议 (Forschungszentrum des Staatsrats für Entwicklung, Kommentar und Vorschläge zur Reform des Gesundheitssystems Chinas), in: 中国发展评论 (China Development Review), 2005/3, Heft 7-1.

466 景天鬼, 大力推进与国情相适应的社会保障制度建设 (Jing, Tiankui, Vorantreiben des Aufbaus eines der Lage des Staates anpassenden System der sozialen Sicherheit), in: 理论前沿 (Theory Front), 2007/18, S. 5ff.

467 Siehe: 杨方方, 从缺位到归位 - 中国转型期社会保险中的政府责任 (Yang, Fangfang, Von der Abkehr bis zur Wiederkehr - die staatliche Verantwortung für die Sozialversicherung im chinesischen Transformationsprozess); 潘屹, 论中国国家福利的重构 (Pan, $Y i$, Wiederaufbau der sozialen Sicherung in China), in: 经济与社会体制比较 (Comparative Economic \& Social Systems), 2007/2, S. 58ff. 
tete. ${ }^{468}$ In der Periode der Planwirtschaft wurden die drei Systeme von verschiedenen Regierungsorganen verwaltet, ihre Strukturen, Leistungen und Finanzierungen waren sehr unterschiedlich. ${ }^{469}$ Zurzeit ist das Ministerium für Personalwesen und soziale Sicherheit für die Verwaltung der drei Systeme zuständig. Nun wird in der Literatur diskutiert, ob eine einheitliche Grundalterssicherung für alle Bürger etabliert werden soll, ${ }^{470}$ oder zumindest - wie Verknüpfungen zwischen den drei Systemen erreicht werden können. ${ }^{471}$

\section{Reform der Grundrentenversicherung für Beschäftigte in Unternehmen}

Im Vergleich mit der betrieblichen Altersversicherung in der Periode der Planwirtschaft ist der Reformplan der Grundrentenversicherung hauptsächlich durch folgende Veränderungen gekennzeichnet: Zuerst wurde das Ein-Säule-Modell durch ein DreiSäulen-Modell ersetzt. Früher war die Rentenversicherung ein Teil der umfassenden Arbeiterversicherung. Der Staat versucht zurzeit, ein Drei-Säulen-Modell der Altersversicherung, nämlich eine gesetzliche Grundrentenversicherung, eine betriebliche Zusatzaltersversicherung und eine private Altersversicherung zu errichten. Der Betrieb und der Staat waren in der Periode der Planwirtschaft für die Finanzierung der Arbeiterversicherung verantwortlich, stattdessen wird nun die neugebaute Grundrentenversicherung vom Staat, Unternehmen und Arbeitnehmern gemeinsam finanziert. Darüber hinaus sollte die Grundrentenversicherung nach dem Beschluss des Staatsrats aus einem leistungsdefinierten System des Solidarfonds und einem beitragsdefinierten System des Individualkontos bestehen. Während beim Solidarfonds weiterhin ein Umlageverfahren angewendet wird, wird ein Kapitaldeckungsverfahren für das Individualkonto eingeführt.

Zurzeit wird allerdings nur das Prinzip der gemeinsamen Finanzierung zügig durchgeführt. Beim Drei-Säulen-Modell wurde eine Grundrentenversicherung etabliert, die betriebliche und private Zusatzaltersversicherungen kommen bisher kaum zum Tragen. Das Teilkapitaldeckungsverfahren der Grundrentenversicherung funktioniert größtenteils wie ein faktisches Umlageverfahren. Klar ist, dass die Reform der Rentenversicherung noch nicht ihr Ziel erreicht hat, zahlreiche Bereiche bedürfen weiterhin der Umgestaltung.

468 Ausführlich vgl. Dritter Teil, Vorsorgesysteme.

469 Vgl. Leisering/Gong/Hussain, People's Republic of China, Old-Age Pensions for the Rural Areas: From Land Reform to Globalization, S. viii.

470 李迎生, 中国社会保障制度改革的目标定位新探 (Li, Yingsheng, An Exploration of the Basic Goals of Social Security System Reform in China), in: 社会 (Society), 2006/2, S. 175ff.

471 Leisering/Gong/Hussain, People's Republic of China, Old-Age Pensions for the Rural Areas: From Land Reform to Globalization, S. 141ff. 


\section{aa) Einführung des Teilkapitaldeckungsverfahrens}

Die Einführung des Teilkapitaldeckungsverfahrens war schon im Jahre 1995 im Beschluss des Staatsrats festgelegt. Allerdings besteht über dieses Modell Zweifel. Die Diskussion über ein angemessenes Grundmodell der chinesischen Rentenversicherung dauert bis jetzt noch stark an.

Es ist zunächst notwendig, sich mit den betreffenden Begriffen auseinander zu setzen:

Zur Finanzierung der Rentenversicherung werden zwei Methoden, nämlich das Umlageverfahren und das Kapitaldeckungsverfahren verwendet. Beim Umlageverfahren werden die einbezahlten Beiträge unmittelbar für die Finanzierung der erbrachten Leistungen herangezogen, während beim Kapitaldeckungsverfahren Kapitalrücklagen für jeden Versicherten bis zur Pensionierung angespart werden. Damit werden die Leistungen bestritten. ${ }^{472}$ Für die Auszahlung der Leistungen kommen auch zwei Methode zur Anwendung, die sich im beitragsbezogenen Plan (defined-contribution) oder im leistungsbezogenen Plan (defined-benefit) auszeichnen. Beim beitragsbezogenen Plan sind die zu zahlenden Beiträge im Voraus festgelegt, die Höhe der Leistungen richtet sich nach der Höhe der Beiträge und den hieraus erwirtschafteten Erträgen. Demgegenüber ist beim leistungsbezogenen Plan die Höhe der Leistungen nach einer Formel im Voraus festgelegt und garantiert, während die Höhe des Beitrags unbestimmt ist. 473 Durch Kombinationen verschiedener Finanzierungs- und Auszahlungsmethoden können sich vier Grundmodelle der Rentenversicherung herausbilden: das leistungsbezogene Modell im Umlageverfahren, das beitragsbezogene Modell im Umlageverfahren, das leistungsbezogene Modell im Kapitaldeckungsverfahren und schließlich das beitragsbezogene Modell im Kapitaldeckungsverfahren.

Bis 1995 wurde in China ein leistungsbezogenes Rentensystem im Umlageverfahren durchgeführt. ${ }^{474}$ Angesichts der Prognose der rasch zunehmenden Überalterung der Bevölkerung und der Reform der Staatsunternehmen 475 wurde dieses System seit der Wirtschaftsreform als nicht mehr finanzierbar angesehen. ${ }^{476}$ Aus diesem Grund wurde

472 Vgl. 葛延风, 完善城镇职工养老保险制度的思路与对策 (Ge, Yanfeng, Approaches and Policies to Enhance the Workers' Pension System in Urban Areas), in: 陈佳贵/王延中, 中国社会保障发 展报告2001-2004 (Chen, Jiagui/Wang, Yanzhong (Hrsg.), China Social Security System Development Report 2001-2004), S. 198.

473 Vgl. Becker, in: Becker/Kaufmann/Maydell/Schmähl/Zacher (Hrsg.), Alterssicherung in Deutschland, FS für Franz Ruland zum 65. Geburtstag, S. 585; 葛延风, 完善城镇职工养老保险制度的思 路与对策 (Ge, Yanfeng, Approaches and Policies to Enhance the Workers' Pension System in Urban Areas), in: 陈佳贵/王延中, 中国社会保障发展报告2001-2004 (Chen, Jiagui/Wang, Yanzhong (Hrsg.), China Social Security System Development Report 2001-2004), S. 198.

474 Weltbank, China 2020, Old Age Security, S. 2.

475 Weltbank, China 2020, Old Age Security, S. 1.

476 中国社会保障的体制选择与经济分析课题组, 社会保障: 经济分析与体制建议 (Forschungsgruppe des Staatsrats für soziale Sicherheit, Soziale Sicherheit: Wirtschaftsanalysen und Vor- 
ein neues Finanzierungsmodell „Solidarfonds mit Individualkonto“, welches nach einem „Teilkapitaldeckungsverfahren“ - Solidarfonds im Umlageverfahren, Individualkonto im Kapitaldeckungsverfahren - funktioniert, als eine angemessene Lösung für die Rentenversicherung von verschiedenen Ökonomen, Forschungsgruppen sowie internationalen Organisationen - insbesondere der Weltbank - vorgeschlagen. ${ }^{477}$ Nach der Meinung der Weltbank hätte China in den 1990er Jahren eine „goldene Chance“ für die Einführung des kapitalgedeckten Individualkontos: niedrige implizite voraussichtliche Verschuldung (IPD) des Rentensystems (knapp 50\% BIP) und hohes Wirtschaftswachstum. Durch Vereinheitlichung der Rentenversicherungssysteme, Strukturänderung des Arbeitsmarktes und Verkauf des Staatseigentums sei es wahrscheinlich möglich, die Übergangskosten der Rentenversicherungsreform in China leicht auszugleichen. 478

Nach dem Vorschlag der Forschungsgruppe des Staatsrats für soziale Sicherheit sollte ein Mischungssystem, das ein beitragsbezogenes System (im Kapitaldeckungsverfahren) und ein leistungsbezogenes System (im Umlageverfahren) umfasst, und darin das beitragsbezogene System einen größeren Teil besetzt, etabliert werden. ${ }^{479}$ Dies entspricht den damaligen Leitlinien der sozialen Sicherheit, nämlich die Betonung der Selbstverantwortung des Einzelnen und die Entlastung der Unternehmen und des Staates von Finanzlasten. Die Forschungsgruppe war der Meinung, dass die Initiative von Individuen für Arbeit und Akkumulation durch die Einführung des Individualkontos angereizt werden könne. ${ }^{480}$ Die seit 1991 in den Sonderwirtschaftszonen Hainan und Shenzhen erprobten Pilotpläne stimmten mit diesem Vorschlag überein, da es ein Modell ,große Individualkonten mit kleinen Solidarfonds“ war. Die auf das Individualkonto eingezahlten Beiträge betrugen beim Hainan-Modell 18\%, beim Shenzhen-Modell $22 \%$ des Lohnes des Arbeitnehmers. ${ }^{481}$

Demgegenüber war das damalige Arbeitsministerium der Ansicht, dass die Übergangskosten für die Einführung eines großen Individualkontos im Kapitaldeckungsverfahren zu hoch seien und nicht von der Regierung und den Unternehmen getragen wer-

schläge für die Systementscheidung), in: 改革 (Reform), 1994/5, S. 17ff; Weltbank, China 2020, Old Age Security, S. 4.

477 中国社会保障的体制选择与经济分析课题组, 社会保障: 经济分析与体制建议 (Forschungsgruppe des Staatsrats für soziale Sicherheit, Soziale Sicherheit: Wirtschaftsanalysen und Vorschläge für die Systementscheidung), in: 改革 (Reform), 1994/5, S. 71; Weltbank, China 2020, Old Age Security, S. 4; 劳动部联合国开发计划署/国际劳工组织北京局, 中国社会保险制度改革 与立法 (Ministerium für Arbeit und soziale Sicherheit/UND/ILO, Reform und Gesetzgebung des chinesischen Sozialversicherungssystems), S. 336.

478 Weltbank, China 2020, Old Age Security, S. 9.

479 中国社会保障的体制选择与经济分析课题组, 社会保障: 经济分析与体制建议 (Forschungsgruppe des Staatsrats für soziale Sicherheit, Soziale Sicherheit: Wirtschaftsanalysen und Vorschläge für die Systementscheidung), in: 改革 (Reform), 1994/5, S. 71.

480 中国社会保障的体制选择与经济分析课题组, 社会保障: 经济分析与体制建议 (Forschungsgruppe des Staatsrats für soziale Sicherheit, Soziale Sicherheit: Wirtschaftsanalysen und Vorschläge für die Systementscheidung), in: 改革 (Reform), 1994/5, S. 71.

481 Ausführlich siehe: 高书生, 社会保障改革何去何从 (Gao, Shusheng, Die Reform der sozialen Sicherheit steht am Scheideweg), S. 81. 
den könnten. ${ }^{482}$ Das Arbeitsministerium schlug in den Reformplänen vor, kein Individualkonto oder nur ein „kleines Individualkonto“ in die Rentenversicherung einzuführen. 483

Im Beschluss der KP Chinas über die Errichtung einer sozialistischen Marktwirtschaft von 1993 wurde das Grundmodell „Solidarfonds mit Individualkonto“ festgelegt. ${ }^{484}$ Angesichts der unterschiedlichen Meinungen wurden in der nachher veröffentlichten „Bekanntmachung des Staatsrats über die Vertiefung der Reform des Rentenversicherungssystems für Beschäftigte in Unternehmen“ von 1995 zwei Modelle von „Solidarfonds mit Individualkonto" gestellt, bei einem (Plan vom Staatskommission für Reform des Wirtschaftssystems) betragen die in das Individualkonto eingezahlte Beiträge ca. 16\% des Lohnes des Arbeitnehmers, dafür finanzieren der Arbeitgeber und der Arbeitnehmer jeweilig 50\% des Individualkontos, anfänglich kann der Arbeitnehmer nur 3\% seines Lohnes auf das Individualkonto überweisen, dann wird der Beitragssatz alle zwei Jahre um 1\% angehoben, bis er schließlich 8\% des Lohnes der Arbeitnehmer erreicht; bei dem Plan vom Arbeitsministerium wird der Beitragssatz von der lokalen Regierung auf Bezirkebene festgelegt. 485 Außerdem durften die lokalen Regierungen sich für ein eigenes Modell entscheiden. Dies hatte einen sehr chaotischen Effekt auf den Umfang des Individualkontos. Bevor der Beitragssatz des Individualkontos im Jahre 1997 durch den „Beschluss des Staatsrats über die Errichtung eines einheitlichen Grundrentenversicherungssystems für Beschäftigte in Unternehmen“ landesweit auf $11 \%$ des Lohnes des Arbeitnehmers vereinheitlicht wurde, waren die Größen der Individualkonten in verschiedenen Provinzen von $4 \%$ bis $17 \%$ sehr unterschiedlich. ${ }^{486}$

\section{bb) Übergangskosten}

Die ,alte Generation“ der Arbeitnehmer, die vor der Einführung des Individualkontos schon von den Unternehmen beschäftigt wurden, hatten in der Vergangenheit keine Kapitalstöcke in ihren Individualkonten angelegt. Diese Kapitallücke sollte in einem bestimmten Zeitraum ausgeglichen werden. Manche Ökonomen schlugen vor, durch Übertragen staatlicher Vermögenswerte, ${ }^{487}$ Errichtung eines Rentenfonds, ${ }^{488}$ Steuer-

482 Siehe: 高书生, 社会保障改革何去何从 (Gao, Shusheng, Die Reform der sozialen Sicherheit steht am Scheideweg), S. 96.

483 高书生, 社会保障改革何去何从 (Gao, Shusheng, Die Reform der sozialen Sicherheit steht am Scheideweg), S. 122.

484 Nr. 27 des Beschlusses des Zentralkomitees der KP Chinas über einige Fragen zur Errichtung einer sozialistischen Marktwirtschaft von 1993.

485 Bekanntmachung des Staatsrats über Vertiefung der Reform des Rentenversicherungssystems für Beschäftigte in Unternehmen“ von 1995.

486 高书生, 社会保障改革何去何从 (Gao, Shusheng, Die Reform der sozialen Sicherheit steht am Scheideweg), S. 126.

487 吴敬轧林毅夫，关于划拨国有资产归还国家对老职工社会保障基金欠账的建议（Wu，Jinglian/Lin,Yifu, Vorschlag zur Bezahlung der Staatsschulden beim Übertragen staatlicher Vermögenswerte in den Fonds der sozialen Sicherheit für die ,alten“ Arbeitsnehmer, in: 比较 (Comparative Studies), 2003/6, Nr. 6, S. 1ff; 刘遵义, 关于中国社会养老保障体系的基本构想 (Liu, 
erhöhungen, Minderausgaben im Staatshaushalt sowie Staatsschuldverschreibung 489 die Übergangskosten auszugleichen. Im Beschluss des Staatesrates über die Grundrentenversicherung von 1997 wurde aber nicht geregelt, wodurch die Übergangskosten gedeckt werden sollten. Die Regierung neigte wegen ihrer Finanzschwäche 490 dazu, die Kosten hauptsächlich durch die Erhöhung des Beitragssatzes der Unternehmen und die Ausweitung der Deckungsrate allmählich abzutragen. 491

Das im Jahre 1997 vereinheitlichte Rentenversicherungssystem geriet von Anfang an in finanzielle Schwierigkeiten. Mit der Strukturregulierung der Staatsunternehmen wurden eine große Anzahl Arbeitnehmer aus den Unternehmen ausgegliedert oder frühzeitig in Rente geschickt. Die Zahl der Rentner war schneller als die der Beitragszahler gestiegen. Der Beitragssatz der Unternehmen war höher als 20\%, in einigen Städten war der Beitragssatz sogar über 30\%.492 Viele Unternehmen konnten die hohe Belastung der Beitragszahlung nicht finanzieren und weigerten sich, an der Rentenversicherung teilzunehmen oder die Beiträge zu zahlen. Die Deckungsrate der Rentenversicherung blieb lange Zeit nur bei ca. 30\% der städtischen Bevölkerung. 493 Da ein beträchtlicher Teil der Beiträge auf die Individualkonten floss, konnten die Ausgaben der Bestandrenten nicht von den Solidarfonds ausgeglichen werden. Die Gelder der Individualkonten wurden fast ausnahmslos landesweit für die Bestandrenten verwendet. Dies führte zum Phänomen der „leeren Individualkonten“ der Versicherten. Die Rentenversicherung funktionierte im Wesentlichen nicht wie geplant nach einem Teilkapitaldeckungsverfahren, sondern nach einem faktischen Umlageverfahren. Trotzdem wurden die Renten und sogar Löhne in vielen Provinzen verspätet oder gar nicht ausgezahlt. Bis 2004 betrugen die Schulden der Individualkonten 740 Mrd. RMB. ${ }^{494}$

Zunyi, Grundplan über das soziale Altersversorgungssystem Chinas), in: 比较 (Comparative Studies), 2003/6, Nr. 6, S. 27.

488 中国社会保障的体制选择与经济分析课题组, 社会保障: 经济分析与体制建议 (Forschungsgruppe des Staatsrats für soziale Sicherheit, Soziale Sicherheit: Wirtschaftsanalysen und Vorschläge für die Systementscheidung), in: 改革 (Reform), 1994/5, S. 72.

489 Weltbank, China 2020, Old Age Security, S. 8.

490 Ausführlich: Erster Teil, Finanzsystem.

491 项怀诚, 关于全国社会保障基金的几个问题 (Xiang, Huaicheng, Über einige Fragen des Nationalen Fonds für soziale Sicherheit), in: 社会保障制度 (Social Security System), 2006/6, S. 11.

492 项怀诚, 关于全国社会保障基金的几个问题 (Xiang, Huaicheng, Über einige Fragen des Nationalen Fonds für soziale Sicherheit), in: 社会保障制度 (Social Security System), 2006/6, S. 11; 葛 延风, 完善城镇职工养老保险制度的思路与对策 (Ge, Yanfeng, Approaches and Policies to Enhance the Workers' Pension System in Urban Areas), in: 中国社会保障发展报告 2001-2004 (China Social Security System Development Report 2001-2004), S. 184.

493 项怀诚, 关于全国社会保障基金的几个问题 (Xiang, Huaicheng, Über einige Fragen des Nationalen Fonds für soziale Sicherheit), in: 社会保障制度 (Social Security System), 2006/6, S. 11.

494 项怀诚, 关于全国社会保障基金的几个问题 (Xiang, Huaicheng, Über einige Fragen des Nationalen Fonds für soziale Sicherheit), in: 社会保障制度 (Social Security System), 2006/6, S. 11. 
Angesichts dieser Situation begann die Regierung seit 1998 immer mehr Zuschüsse für den Ausgleich der Übergangskosten zu gewähren. ${ }^{495} 1998$ - 2006 wurden insgesamt 360.8 Mrd. RMB staatliche Zuschüsse an die Solidarfonds überwiesen, um das große Loch der Rentenkassen auszufüllen. 496 Die Verwaltungskosten der Sozialversicherung wurden durch den Finanzhauhalt übernommen. ${ }^{497}$ Außerdem wurde der Nationale Fonds für soziale Sicherheit für den zukünftigen Ausgleich der Finanzlücken im Jahre 2000 gegründet. Seit 2001 wurden die Individualkonten in elf Provinzen durch Pilotprojekte teilweise aufgefüllt.

\section{cc) Auffüllung der Individualkonten}

Seit 2000 wurde das Modell „Solidarfonds mit Individualkonto“ wegen den Finanzierungsschwierigkeiten skeptisch betrachtet. Manche Experten waren der Meinung, das Individualkonto sei nicht für die Lage Chinas geeignet, die Rentenversicherung sollte sich wieder dem Umlageverfahren zuwenden. ${ }^{498}$ Allerdings befürworteten die meisten Experten und Forschungsinstitute damals noch die Beibehaltung des Teilkapitaldeckungsverfahrens. ${ }^{499}$ Aufgrund der Forschungsberichte der staatlichen Forschungsinstitute hatte der Staatsrat im „Pilotplan zur Verbesserung der sozialen Sicherheit in den Städten“" von 2000 genehmigt, das Grundrentenversicherungssystem für Beschäftigte in Unternehmen zu korrigieren und 2001 in der Provinz Liaoning und später auch in anderen Provinzen neue Pilotprojekte durchzuführen. 500

Bezüglich der Individualkonten wurden folgende Regelungen in dem Pilotplan festgelegt: ${ }^{501}$ Der Beitragssatz des Unternehmens beträgt allgemein 20\% der Gesamtlohnsumme des Unternehmens. Die Beiträge der Unternehmen fließen nicht mehr teilweise in das Individualkonto sondern komplett in den Solidarfonds ein. Das Individualkonto wird von $11 \%$ des Lohnes des Arbeitnehmers auf $8 \%$ verringert und allein durch den Beitrag des Arbeitnehmers finanziert. Der Solidarfonds und das Individualkonto werden

495 Ausführlich siehe: 杨方方, 从缺位到归位 - 中国转型期社会保险中的政府责任 (Yang, Fangfang, Von der Abkehr bis zur Wiederkehr - die staatliche Verantwortung für die Sozialversicherung im chinesischen Transformationsprozess), S. 168ff.

496 王延中/胡继晔，划拨国有股充实社保基金的思路与对策 (Wang, Yanzhong/Hu, Jiye, Approaches and Policies to Appropriate State-Shares to Transfer to Social Security Fund), in: 中国社 会保障发展报告 2001-2004 (China Social Security System Development Report 2001-2004), S. 245.

497 企业职工基本养老保险基金实行收支两条线管理暂行规定 ( $\$ 7$ Abs. 2 Vorläufige Regeln über die ,zwei Verwaltungslinien von Einnahmen und Ausgaben“des Fonds der Grundrentenversicherung für Beschäftigte in Unternehmen), veröffentlicht vom Finanzministerium am 27. 01. 1998, 财社字 (1998) 6号.

498 Ausführlich: 高书生, 社会保障改革何去何从 (Gao, Shusheng, Die Reform der sozialen Sicherheit steht am Scheideweg), S. 151.

499 高书生, 社会保障改革何去何从 (Gao, Shusheng, Die Reform der sozialen Sicherheit steht am Scheideweg), S. 152, 159.

500 国务院关于完善城镇社会保障体系的试点方案，国发 (2000) 42号, vom 25. 12. 2000.

501 Nr. 2 des Pilotplans zur Verbesserung des Systems der sozialen Sicherheit in den Städten von 2000. 
getrennt verwaltet, das Geld der Individualkonten darf nicht vom Solidarfonds verwendet werden.

Erst beim Liaoning-Pilotprojekt wurde der Plan „Verkleinerung und Auffüllung der Individualkonten“ erprobt. Ab Juli 2001 durften in der Provinz Liaoning die Gelder der Individualkonten nicht mehr für die Auszahlung der Bestandrente verwendet werden, das Defizit des Solidarfonds wurde durch die zentralen und lokalen Finanzhaushalte gedeckt. Für die Auffüllung der Individualkonten wurden die Zuschüsse 2001 - 2003 zu $75 \%$ von den zentralen und zu $25 \%$ von den lokalen Finanzhaushalten übernommen, die zentrale Regierung hatte dafür 3.6 Mrd. RMB gewährt. 502 Durch diese Maßnahmen wurde das Teilkapitaldeckungsverfahren in der Provinz Liaoning in die Tat umgesetzt, bis Ende 2006 betrug der Fonds der Individualkonten provinzweit schon 28.2 Mrd. RMB. ${ }^{503}$ Die Gelder der Individualkonten werden von den lokalen Sozialversicherungsträgern auf ein Spezialkonto des Rentenversicherungsfonds auf Provinzebene überwiesen und zentral verwaltet. 504

Allerdings kann das Liaoning-Modell nicht komplett von den anderen Provinzen übernommen werden. Die Zentralregierung gewährte 2001 - 2003 für das LiaoningPilotprojekt insgesamt 26.8 Mrd. RMB Zuschüsse, 2004 betrugen die Zuschüsse der Zentralregierung für Liaoning's Sicherungssysteme noch 11 Mrd. RMB. ${ }^{05}$ Das bedeutet, dass das Liaoning-Modell ohne staatliche Unterstützung nicht aufrechterhalten werden kann. Die Liaoning-Erfahrung landesweit einzuführen, ist für die Zentralregierung finanziell untragbar. Bei den folgenden Pilotplänen in der Provinz Heilongjiang und Jilin 2004 wurden die Individualkonten anfänglich nur mit 5\% des Lohnes des Arbeitnehmers aufgefüllt. 2006 war die anfängliche Auffüllungsrate in anderen acht Provinzen noch mal auf 3\% des Lohnes gesunken. 506 Das Verwaltungsmodell der Individualkonten unterscheidet sich in diesen Provinzen und Städten auch vom Liaoning-Modell: Die Gelder der Individualkonten werden nicht auf Provinzebene zentralisiert, sondern direkt von den lokalen Sozialversicherungsträger für die Bestandrenten verwendet. Die staatlichen Zuschüsse für Auffüllung der Individualkonten werden auf ein Spezialkonto auf Provinzebene überwiesen und von den Provinzregierungen verwaltet. Zurzeit werden die Verwaltung und die Bewirtschaftung der staatlichen Zuschüsse tendenziell auf Nati-

502 高书生, 社会保障改革何去何从(Gao, Shusheng, Die Reform der sozialen Sicherheit steht am Scheideweg), S. 188.

503 高西庆徐菁, 对个人账户管理体制的思考 - 对下一步改革的一个建议 (Gao, Xiqing/Xu, Jing, The Trading Platform for Social Security Products: A Reform Proposal), in: 比较 (Comparative Studies), Nr. 31, 2007, 7, S. 91.

504 辽宁省做实基本养老保险个人账户工作评估报告 (Bericht der Provinz Liaoning über die Arbeit von Auffüllung der Individualkonten der Grundrentenversicherung), in: 完善城镇社会保障体系试 点辽宁篇 (Vervollkommnung der sozialen Sicherheit in den Städten: Liaoning-Pilotprojekt), S. $377 \mathrm{ff}$.

505 高书生, 社会保障改革何去何从(Gao, Shusheng, Die Reform der sozialen Sicherheit steht am Scheideweg), S. 185.

506 易纲/李凯, 转型名义账户制: 探索中国养老保障体制改革的新思路 ( Yi, Gang/Li, Kai, Transitional Notional Defined Contribution Scheme: A new Potion of China's Social Security Pension Reform), in: 比较 (Comparative Studies), 2007/3, Nr. 29, S. 34. 
onalebene zentralisiert. Am Ende des Jahres 2006 beauftragten die neun Provinzen, regierungsunmittelbare Städte und Autonome Gebiete (ausschließlich Liaoning und Shanghai) den Vorstand des Nationalen Fonds für soziale Sicherheit, die staatlichen Zuschüsse zu verwalten und zu bewirtschaften. Der Vorstand des Nationalen Fonds garantiert ihnen eine Mindestrendite, die zurzeit 3.5\% beträgt. 507

Die Verringerung des Individualkontos von 11\% auf 8\% wurde 2005 im „Beschluss des Staatsrats über die Vervollkommnung des Grundrentenversicherungssystems für Beschäftigte in Unternehmen" 508 anerkannt. Es wurde auch in diesem Beschluss festgestellt, dass die Auffüllung der Individualkonten als eine der Hauptaufgaben der sozialen Sicherheit schrittweise erfüllt werden sollte. ${ }^{509}$ Es gab in den Fonds der Individualkonten 2006 insgesamt $48.5 \mathrm{Mrd}$. RMB, ${ }^{510}$ allerdings betrugen bis Ende 2005 die Schulden der Individualkonten schon 800 Mrd. RMB. 511

\section{b) Risiken der Sozialversicherungsfonds}

Die mühsam vorankommende Rentenversicherungsreform stößt auch auf andere Probleme, wie die Verwaltung und die Investition der Sozialversicherungsfonds.

Gemäß $§ 6$ der Finanzordnung der Sozialversicherungsfonds von 1999 müssen spezielle Finanzkonten für die Sozialversicherungsfonds eingerichtet werden. Die Sozialversicherungsfonds müssen nach den Richtlinien „Trennung von Einnahmen und Ausgaben“ und „Zweckgebundene Verwendung der Gelder“ verwaltet werden. Das bedeutet, dass sie weder für andere Zwecke noch für den Ausgleich des Haushaltsplans der Regierung verwendet werden dürfen. Außer den Schwankungsreserven dürfen die Überschüsse der Fonds nur auf der Bank deponiert oder in Staatsanleihen investiert werden, andere direkte oder indirekte Investitionsformen sind verboten. 512

Der Grund für die strikte Beschränkung der Investitionsmöglichkeiten liegt darin, dass die Gelder der Sozialversicherungsfonds lange Zeit nicht effektiv kontrolliert wurden. 1993 wurde in den „Regeln über die Verwaltung des Rentenversicherungsfonds für Beschäftigte in Unternehmen" geregelt, dass die Verwaltungsorgane der Sozialversicherungsfonds die staatlichen Banken und Treuhandgesellschaften beauftragen dürfen, die

507 张翔/胡润峰/任波/付涛, 社保抉择 (Zhang, Xiang/Hu, Runfeng/Ren, Bo/Fu, Tao, Eine neue Entscheidung für soziale Sicherheit steht bevor ), in: 财经 (Finanzen und Ökonomie), 2006/26.

508 国务院关于完善企业职工养老保险制度改革的决定(Beschluss des Staatsrats über die Vervollkommnung des Grundrentenversicherungssystems für Beschäftigte in Unternehmen), 国发 (2005) 38 号, vom 03. 12. 2005.

509 Nr. 1 des Beschlusses des Staatsrats über die Vervollkommnung des Grundrentenversicherungssystems für Beschäftigte in Unternehmen von 2005.

510 劳动和社会保障部，近年来我国社会保险基本情况 (Ministerium für Arbeit und soziale Sicherheit, Zustand der Sozialversicherungen in den letzten Jahren), http://www.molss.gov.cn/gb/news/2007-11/29/content_212193.htm (Stand: 15. 07. 2010).

511 高西庆徐菁, 对个人账户管理体制的思考 - 对下一步改革的一个建议 (Gao, Xiqing/Xu, Jing, The Trading Platform for Social Security Products: A Reform Proposal), in: 比较 (Comparative Studies), 2007/7, Nr. 31, S. 90.

$512 \S 27$ der Finanzordnung der Sozialversicherungsfonds von 1999. 
Gelder der Fonds als Darlehen zu gewähren. 513 Die Investitionen der Sozialversicherungsfonds waren seitdem fast unkontrollierbar, obwohl das Arbeitsministerium und das Finanzministerium später diesen Fehler wahrnahmen und im Jahre 1994 durch die „Vorläufigen Regeln über die Verstärkung der Investitionsverwaltung der Sozialversicherungsfonds für Beschäftigte in Unternehmen" 514 die oben genannte Regelung ersetzten.

Allerdings wurde die Finanzordnung von 1999 nicht strikt durchgeführt. Nach der Ankündigung der Rechnungsprüfung durch den staatlichen Rechnungshof wurden die Gelder der Sozialversicherungsfonds (inkl. Fonds der Grundrentenversicherung, der Grundkrankenversicherung und der Arbeitslosenversicherung) vor 20002.347 Mrd. RMB, 2000 - 20064.788 Mrd. RMB (ausschließlich Sozialversicherungsfonds von Shanghai und Xizang, die separat geprüft wurden) zweckentfremdet oder veruntreut. ${ }^{515}$ In Shanghai wurden 32.9 Mrd. RMB Sozialversicherungsgelder (inkl. auch der Fonds der betrieblichen Zusatzaltersversicherung) veruntreut, davon wurden allein $20 \mathrm{Mrd}$. RMB in den Immobilienmarkt investiert. 516

Es gibt zwei Hauptursachen für diese Fälle. Eine ist der Mangel an einem wirksamen Überwachungsmechanismus. Die Aufsichtsrechte der Sozialversicherungsfonds liegen nach den Verwaltungsregeln des Ministeriums für Arbeit und soziale Sicherheit bei der Behörde für soziale Sicherheit, die regelmäßig interne Rechnungsprüfungen vornehmen muss, ${ }^{517}$ bei der Aufsichtskommission für die Sozialversicherungsfonds, die aus Vertretern der Verwaltungsbehörde, Unternehmen, Beschäftigte sowie Rentner besteht und über die Überwachungsbefugnis für den Rentenversicherungsfonds und die Verwaltungskosten verfügt ${ }^{518}$ sowie bei der Finanz- und Rechnungsprüfungsbehörde, der Aufsichtsbehörde und der Gewerkschaft. ${ }^{519}$ Diese parallelen Verantwortlichkeiten führen zu Unklarheiten in der Aufgabenwahrnehmung. 520 In der Tat fehlt ein wirksames Kontrollsystem der Sozialversicherungsfonds. ${ }^{521}$ Die lokale Regierung, die Behörde für soziale Sicherheit, die Sozialversicherungsträger sowie die Finanz- und Steuerbe-

513 § 21 Abs. 2 Regeln über die Verwaltung des Rentenversicherungsfonds für Beschäftigte in Unternehmen), veröffentlicht vom Arbeitsministerium am 02. 07. 1993.

514 财政部, 劳动部, 关于加强企业职工社会保险基金投资管理的规定，(1994）财社字第59号, vom 22. 11. 1994.

515 国家审计署, 审计结果公告2006第6号 (Staatsrechnungsprïfungsbüro, Rechnungsprüfungsankündigung 2006, 6), veröffentlicht am 24. 11. 2006, http://www.audit.gov.cn/cysite/chpage/c516/ doclist.html (Stand: 15. 07. 2010).

516 http://bj.house.sina.com.cn/news/2008-03-26/0728244703.html (Stand: 15. 07. 2010).

517 § 23 企业职工养老保险基金管理规定 (Regeln über die Verwaltung des Rentenversicherungsfonds für Beschäftigte in Unternehmen), veröffentlicht vom Arbeitsministerium am 02. 07. 1993.

518 § 24 Regeln über die Verwaltung des Rentenversicherungsfonds für Beschäftigte in Unternehmen von 1993.

$519 \S 25$ Regeln über die Verwaltung des Rentenversicherungsfonds für Beschäftigte in Unternehmen von 1993.

520 Vgl. Reimann, in: Arbeits- und Sozialversicherung in China und Deutschland: Rechtsvergleichende Betrachtungen, S. 535.

521 Vgl. Lin, Yi/Zhang, Song, in: Becker/Zheng/Darimont, Grundfragen und Organisation der Sozialversicherung in China und Deutschland, S. 191. 
hörde, die über die Handlungsbefugnis der Sozialversicherungsfonds verfügen, verwenden oft die Gelder der Sozialversicherungsfonds oder die staatlichen Zuschüsse für andere Zwecke. ${ }^{522}$

Außerdem versuchen die lokalen Regierungen und Verwaltungsbehörden, durch Investition mit den Fonds höhere Gewinne zu erzielen. Weil die derzeitige Kapitalertragsrate der Staatsanleihen sehr gering $(2 \%$ - 3\%) sind, werden die Gelder der Sozialversicherungsfonds eigenmächtig in andere Kapitalmärkte, wie die risikoreichen Aktienmärkte oder die Immobilienmärkten, investiert. Aber die zurzeit noch nicht funktionsund leistungsfähigen chinesischen Kapitalmärkte können eine stabile Kapitalertragsrate der Sozialversicherungsfonds nicht garantieren, und der Mangel an Aufsicht der Investitionen führt oft zur Kapitalverlust und Korruption. 523

\section{c) Lösungsmöglichkeiten}

aa) Ein beitragsbezogenes System mit Umlageverfahren?

Während die Regierung die negativen Wirkungen der Rentenversicherungsreform bekämpft, bewerten die Experten das Teilkapitaldeckungsverfahren neu. Da die völlige Auffüllung der Individualkonten nicht vom Staatshaushalt finanziert werden kann, und die derzeitigen chinesischen Verwaltungssysteme sowie Kapitalmärkte die Sicherung und Aufwertung der Sozialversicherungsfonds nicht garantieren können, sind manche Experten wieder zu den umlagefinanzierten Systemen, bei denen die Verwaltungsrisiken der Sozialversicherungsfonds und die Übergangskosten vergleichweise niedrig sind, geneigt.

Gao, Shusheng und Ge, Yanfeng sind der Meinung, dass ein leistungsbezogenes Umlageverfahren die Auswirkung der Bevölkerungsüberalterung auch beseitigen könne. Die notwendigen Voraussetzungen dafür sind:524 Das Grundrentenversicherungssystem sollte alle Arbeitnehmer und Beamte umfassen. Die Lohnersatzrate sollte niedrig sein. Nach Gao beträgt die Lohnersatzrate ca. 40\% des durchschnittlichen Lohnes des Versicherten. Außerdem sollte das Rentenalter erhöht werden. Nach Gao sollten die Frauen wie die Männer erst mit dem 65. Lebensjahr in Rente gehen.

Ge, Yanfeng schlägt vor, dass der Rahmen der Rentenversicherung, das Modell „Solidarfonds mit Individualkonto“ bleiben könne. Für die Arbeitnehmer in Unternehmen sollten die Individualkonten aber in eine freiwillige Zusatzaltersversicherung mit Kapitaldeckungsverfahren umgewandelt werden, die durch die staatliche Steuerbegünstigung

522 张翔/胡润峰/任波/付涛, 社保抉择 (Zhang, Xiang/Hu, Runfeng/Ren, Bo/Fu, Tao, Eine neue Entscheidung für soziale Sicherheit steht bevor), in: 财经 (Finanzen und Ökonomie), 2006/26.

523 郑秉文, 中国产生社保案的制度原因及解决办法 (Zheng, Bingwen, Zu den Ursachen der gegenwärtigen Krise der Sozialversicherungsfonds und die Lösungsmöglichkeiten), in: 国际经济评 论 (International Economic Review), 2007/5-6, S. 46.

524 Siehe: 高书生, 社会保障改革何去何从(Gao, Shusheng, Reform der sozialen Sicherheit steht am Scheideweg), S. 235ff; 葛延风，完善城镇职工养老保险制度的思路与对策 (Ge, Yanfeng, Approaches and Policies to Enhance the Workers' Pension System in Urban Areas), in: 陈佳贵/王延 中, 中国社会保障发展报告 2001-2004 (Chen, Jiagui/Wang, Yanzhong (Hrsg.), China Social Security System Development Report 2001-2004), S. 197ff. 
angespornt werde. Für Beamte und Angestellte der öffentlichen Institutionen sollte ein einheitliches Zusatzalterssicherungssystem eingeführt werden. ${ }^{525}$

Demgegenüber sind viele Experten zurzeit der Auffassung, dass ein anderes Modell der Rentenversicherung, das als ,notional defined contribution (NDC)“ benannt und seit den 1990er Jahren in Schweden, ${ }^{526}$ Italien, Polen und Lettland usw. eingeführt wurde, eine mögliche Lösung darstellen könnte. ${ }^{527}$

Das NDC-System ist ein beitragsbezogenes Rentensystem (defined contribution) im Umlageverfahren (pay-as-you-go). ${ }^{528}$ In einem NDC-System werden die geleisteten Beiträge mit den Zinsen auf einem fiktiven Individualkonto gut geschrieben. Gegenüber dem ,financial defined contribution (FDC)“ System, bei dem die Gelder tatsächlich investiert werden, werden die Beiträge allerdings nicht real ,funded", genauer betrachtet werden die Gelder im Individualkonto nicht in die Kapitalmärkte investiert. ${ }^{529}$ Die Leistungen sind von den Beiträgen abhängig, aber die interne Rendite des NDCSystems ist von der Regierung nach Produktivitätswachstum, Wachstum der Arbeitskräfte sowie die mit Beitrag und Leistungszahlung verbundenen Faktoren festgelegt, und nicht von der Rendite der Finanzmärkte abhängig. 530

Die Weltbank bezeichnete im Jahre 2001 das chinesische Rentensystem als ein ,quasi-NDC System“.531 2003 schlug der chinesische Ökonom Zheng, Bingwen vor, das NDC-Modell offiziell in China einzuführen. Er ist der Meinung: Wenn die Individualkonten mit dem NDC-Modell betrieben würden, würden die Übergangskosten und das Problem „leere Individualkonten“ nicht mehr existieren. Die notwendigen Voraussetzungen für das Funktionieren des Kapitaldeckungsverfahrens - die funktionsfähigen

525 葛延风, 完善城镇职工养老保险制度的思路与对策 (Ge, Yanfeng, Approaches and Policies to Enhance the Workers' Pension System in Urban Areas), in: 陈佳贵/王延中, 中国社会保障发展 报告 2001-2004 (Chen, Jiagui/Wang, Yanzhong (Hrsg.), China Social Security System Development Report 2001-2004), S. 197ff.

526 Über das schwedische Grundrentensystem siehe: Köhler, Grundrentensysteme im Rechtsvergleich, in: Zeitschrift für die gesamte Versicheurngswissenschaft, Band 87, S. 653-684.

527 中国经济研究和咨询项目组, 中国社会保障体制改革: 问题和建议 (Chinese Ecomonic Research and Advisory Programme, Social Security Reform in China: Issues and Options I), in: 比较 (Comparative Studies), 2006/5, Nr. 24, S. 33ff.; 易纲/李凯, 转型名义账户制: 探索中国养老保 障体制改革的新思路 ( $Y i, G a n g / L i, K a i$, Transitional Notional Defined Contribution Scheme: A new Option of China's Social Security Pension Reform), in: 比较 (Comparative Studies), 2007/3, Nr. 29, S. 33ff; 郑秉文, 社会保障体制改革攻坚 (Zheng, Bingwen, Reform des System der sozialen Sicherheit), S. 20ff; Williamson,/孙策，中国养老保险制度改革: 从FDC层次向NDC层次转 换 (Williamson./Sun, Do Notional Defined Contribution Accounts Make Sense as Part of the OldAge Security Mix for China?), in: 经济社会体制比较 (Comparative Economic \& Social Systems), 2004/3, S. 77.

528 Siehe: Palmer, in: Holzmann/Palmer (Hrsg.), Pension Reform - Issues and Prospects for NonFinancial Defined Contribution (NDC) Schemes, S. 18.

529 Ausführlich vgl. Palmer, in: Holzmann/Palmer (Hrsg.), Pension Reform - Issues and Prospects for Non-Financial Defined Contribution (NDC) Schemes, S. 18; Diamond/Barr, Social Security Reform in China: Issues and Options II, in: 比较 (Comparative Studies), 2006/7, Nr. 25, S. 101.

530 Holzmann/Palmer, in: ders. (Hrsg.), Pension Reform - Issues and Prospects for Non-Financial Defined Contribution (NDC) Schemes, S. 4.

531 Fox/Palmer, in: New Ideas about Old Age Security, S. 109. 
Kapitalmärkte und eine vollkommene institutionelle Infrastruktur - seien beim NDCModell obsolet. Die Anreizfunktion des Individualkontos bestehe aber weiter mit dem beitragsdefinierten Charakter. 5322006 hat eine Forschungsgruppe, die aus chinesischen und ausländischen Ökonomen bestand, in ihrem Forschungsbericht die Einführung des NDC-Modells in China als sehr vorteilhaft bewertet: ${ }^{533}$ Mit dem NDC-Modell würden die Gelder der Individualkonten nicht durch die Unsicherheiten der Kapitalmärkte und Verwaltungssysteme gefährdet, dies sei zurzeit für China von besonderer Bedeutung. Das NDC-Modell könne als ein Übergangssystem in der Zukunft leicht in ein kapitalgedecktes System umgewandelt werden, wenn die notwendigen Bedingungen dafür vorhanden sind.

Demgegenüber vertreten die Ökonomen Gao, Xiqing und $X u$, Jing die Ansicht, dass die Einführung des NDC-Modells nur unter zwei Voraussetzungen möglich sei. ${ }^{534}$ Die erste Voraussetzung sei das Vorliegen eines funktionsfähigen Verwaltungssystems, in dem die Einnahmen und Ausgaben des Versicherungsfonds sowie die Bewirtschaftung der Gelder real unter institutioneller Kontrolle laufen könnten. Die zweite sei das Vertrauen der Versicherten in die Nachhaltigkeit des Systems. Da diese Voraussetzungen zurzeit in China noch nicht erfüllt würden, seien die weitere Durchführung des Teilkapitaldeckungsverfahrens und die Auffüllung der Individualkonten wahrscheinlich die realistischeren Entscheidungen. Dafür sollte die zentrale Regierung ein einheitliches Verwaltungssystem der Individualkonten auf Nationalebene errichten, die Versicherten sollten an Verwaltung und Überwachung der Fonds der Individualkonten teilnehmen.

Die Frage, ob das Finanzierungsmodell der Grundrentenversicherung verändert werden soll, beantwortet die Regierung zurzeit nicht. Im staatlichen Plan für Arbeit und soziale Sicherheit wurde weiterhin festgesetzt, dass die Individualkonten der Rentenversicherung Schritt für Schritt aufgefüllt werden sollten. ${ }^{535}$ Allerdings wurden keine neuen Maßnahmen seit 2006 dafür ausgearbeitet. Da die Zentralregierung nach der Finanzreform über reichliche Geldmittel verfügt und einen Nationalen Fonds für den zukünftigen Ausgleich der Finanzlücken der Alterssicherung gegründet hat, ${ }^{536}$ ist sie zurzeit nicht über eine drohende Rentenkrise besorgt. ${ }^{537}$ Es gibt also keinen dringenden Re-

532 郑秉文，欧亚六国社会保障名义账户制利弊分析及其对中国的启示 (Zheng, Bingwen, Strengths and Limitations of the NDC Approach in the Social Security of Six European-Asian Countries and its Feasibility for China), in: 世界经济与政治 (World Economics and International Politics ), 2003/5, S. 56ff.

533 中国经济研究和咨询项目组, 中国社会保障体制改革: 问题和建议 (Chinese Ecomonic Research and Advisory Programme, Social Security Reform in China: Issues and Options I), in: 比较 (Comparative Studies), 2006/5, Nr. 24, S. 52ff.

534 高西庆/徐菁, 对个人账户管理体制的思考 - 对下一步改革的一个建议 (Gao, Xiqing/Xu, Jing, The Trading Platform for Social Security Products: A Reform Proposal), in: 比较 (Comparative Studies), 2007/7, Nr. 31, S. 92ff.

535 劳动和社会保障事业十一五规划纲要 (2006-2010) (Der 11. Fünfjahresplan für Arbeit und soziale Sicherheit), http://w1.mohrss.gov.cn/gb/zt/2006-11/08/content_146879.htm (Stand: 15. 07. 2010).

536 Ausführlich: Dritter Teil, Entwicklung der sozialen Sicherheit, Systemanalyse, Vorstand des Nationalen Fonds für soziale Sicherheit.

537 杨华云, 养老金空账规模约为 1.3 万亿 (Yang, Huayun, Die Schulden der Individualkonten betragen ca.1300 Mrd. RMB), in: 新京报 (XJB), vom 14. 07. 2010. 
formbedarf des Finanzierungsmodells. Die Arbeitsschwerpunkte der Regierung im Bereich der Alterssicherung liegen nun in der Verlagerung der Planungs- und Verwaltungsebene, sowie in der Einführung des Modells „Solidarfonds mit Individualkonto“ in die ländliche Altersversicherung und das Pensionssystem der Staatsbediensteten.

Die Festlegung des Modells der Alterssicherung hängt eng mit der Festlegung des Grundmodells sowie der theoretischen Grundlagen der sozialen Sicherheit zusammen, die seit langer Zeit in China intensiv diskutiert werden. Die Entwicklungstendenz wird im Schlussteil der Arbeit vertiefend untersucht. 538

\section{bb) Verlagerung der Planungsebene}

Bis 2007 wurden die Rentenversicherungsfonds hauptsächlich von mehr als 2000 lokalen Sozialversicherungsträgern auf Stadt- oder Kreisebene separat verwaltet. ${ }^{539}$ Die Beitragszahlung, Fondsverwaltung und Rentenniveaus der verschiedenen Gebiete waren sogar innerhalb einer Provinz sehr unterschiedlich. ${ }^{540}$ Demzufolge waren die Übertragung und die Fortsetzung der Sozialversicherungsbeziehungen der Arbeitnehmer zwischen den verschiedenen Verwaltungsgebieten sehr schwierig. Dies verhinderte die adäquate Risikostreuung der Solidarfonds und die Arbeitsmarktmobilität. Ganz gleich was für ein Finanzierungsmodell durchgeführt wird, die einheitliche Planung der Grundrentenversicherungsfonds auf Nationalebene wird als eine notwendige Bedingung und als ein Ziel der Grundrentenversicherung von den meisten Experten vorgeschlagen. 541

Dieser Vorschlag wurde von der Regierung akzeptiert. ${ }^{542}$ Aber zurzeit kann eine landesweite einheitliche Planung der Rentenversicherung wegen den hohen wirtschaft-

538 Ausführlich: Fünfter Teil, Schlussbetrachtung.

539 郑秉文, 关于加快推进省级社保统筹的建议 (Zheng, Bingwen, Vorschlag über Beschleunigung der einheitlichen Planung und Verwaltung der Sozialversicherungsfonds auf Provinzebene), in: 中 国经贸导刊 (China Economic \& Trade Herald) 2007/18, S. 9ff.

540 Vgl. 穆怀中/柳清瑞, 中国养老保险制度改革关键问题研究 (Mu, Huaizhong/Liu, Qingrui, The Research on the Key Issues about China's Pension System Reforms), S. 67ff.

541 高西庆/徐菁, 对个人账户管理体制的思考 - 对下一步改革的一个建议 (Gao, Xiqing/Xu, Jing, The Trading Platform for Social Security Products: A Reform Proposal), in: 比较 (Comparative Studies), 2007/7, Nr. 31, S. 89ff; 中国经济研究和咨询项目组, 中国社会保障体制改革：问题和 建议 (Chinese Ecomonic Research and Advisory Programme, Social Security Reform in China: Issues and Options I), in: 比较 (Comparative Studies), 2006/5, Nr. 24, S. 66; 易纲李凯, 转型名义 账户制: 探索中国养老保障体制改革的新思路 ( Yi, Gang/Li, Kai, Transitional Notional Defined Contribution Scheme: A new Option of China's Social Security Pension Reform), in: 比较 (Comparative Studies), 2007/3, Nr. 29, S. 40; 葛延风, 完善城镇职工养老保险制度的思路与对策 (Ge, Yanfeng, Approaches and Policies to Enhance the Workers' Pension System in Urban Areas), in: 陈佳贵/王延中, 中国社会保障发展报告 2001-2004 (Chen, Jiagui/Wang, Yanzhong (Hrsg.), China Social Security System Development Report 2001-2004), S. 198; 郑秉文, 社会保障体制改 革攻坚 (Zheng, Bingwen, Reform der sozialen Sicherheit), S. 15; 高书生, 关于搭建中国社会保 障新平台的设想 (Gao, Shusheng, Ein neuer Plan für die chinesische soziale Sicherheit), in: 经济 研究参考 (Review of Economic Research), 2003/4, S. 35.

542 Nr. 4. 6 des Beschlusses des Zentralkomitees der KP Chinas über einige wichtige Fragen zur Strukturierung einer harmonischen sozialistischen Gesellschaft von 2006. 
lichen Unausgewogenheiten verschiedener Gebiete und des Lokalpatriotismus noch nicht realisiert werden. Im Beschluss des Staatrates über die Vervollkommnung des Grundrentenversicherungssystems von 2005 wurde nur gefordert, dass die Verlagerung der Planungsebene der Rentenversicherungsfonds von der Stadtebene auf die Provinzebene verwirklicht werden müsste. ${ }^{543}$ Durch die einheitliche Planung auf der Provinzebene werden die Beitragsraten und die Leistungsniveaus innerhalb einer Provinz vereinheitlicht, die Einnahmen und Umverteilung von Geldmitteln werden auch einheitlich durchgeführt. Damit können die Diskrepanzen der Rentensysteme besser ausgeglichen und die Mobilität der Arbeitnehmer verbessert werden. Ferner sollte die einheitliche Planung der Rentenversicherungsfonds auf nationaler Ebene verlagert werden ${ }^{544}$, um den Ausgleichsrahmen der Rentenversicherungsfonds weiter zu vergrößern und um damit die notwendigen Bedingungen für den Aufbau eines landesweit einheitlichen Arbeitsmarkts schaffen zu können. 545

Bis Ende 2006 wurde die einheitliche Planung auf Provinzebene in 13 Provinzen, in den Autonomen Gebieten und regierungsunmittelbaren Städten durchgeführt. ${ }^{546}$ Seit 2008 wird diese Arbeit beschleunigt. Die zentrale Regierung hat geplant, 2010 die einheitliche Planung der Rentenversicherung auf Provinzebene landesweit zu vervollkommnen. 547 Darüber hinaus versucht die Regierung nun auch, einen überregionalen Mechanismus für die Übertragung und Fortsetzung der Sozialversicherungsbeziehungen der Arbeitnehmer zu schaffen. Dies wurde als eine staatliche Aufgabe im Arbeitsvertragsgesetz und später im Sozialversicherungsgesetz festgelegt. 548 Die „Vorläufigen Maßnahmen zur Übertragung und Fortsetzung der Rentenversicherungsbeziehungen der Arbeitnehmer in städtischen Unternehmen" wurden Ende 2009 erlassen. 549

Nach dieser Regelung wird eine Datenbank der Rentenversicherung auf nationaler Ebene errichtet. Die versicherte Person kann einen Sozialversicherungsausweis erhalten, der landesweit gültig ist. ${ }^{550}$ Nach Erfüllung der Voraussetzungen für den Bezug der Grundrente werden die Beschäftigungszeiten mit der Beitragszahlung des Arbeit-

543 Nr. 8 des Beschlusses des Staatsrats über die Vervollkommnung des Grundrentenversicherungssystems für Beschäftigte in Unternehmen von 2005.

$544 \S 64$ Abs. 3 Sozialversicherungsgesetz von 2010.

545 何平, 让农民工退保成为历史 (He, Ping, Beseitigung des Phänomens „Austritt der Wanderarbeiter aus der sozialen Versicherungen“), in: 中国报道 (China Report), 2008/3, S. 26ff.

546 劳动和社会保障部, 近年来我国社会保险基本情况 (Ministerium für Arbeit und soziale Sicherheit, Zustand der Sozialversicherung in den letzten Jahren), http://www.molss.gov.cn/gb/news/2007-11/29/content_212193.htm (Stand: 15. 07. 2010).

547 白天亮, 养老保险省级统筹力争两年内实现 (Bai, Tianliang, Verwirklichung der einheitlichen Planung der Rentenversicherung auf Provinzebene in zwei Jahren), in: 人民日报 (RMRB), vom 09. 01. 2008.

$548 \S 49$ Arbeitsvertragesgesetz von 2007; § 64 Abs. 3 Sozialversicherungsgesetz von 2010.

549 人力资源社会保障部, 财政部, 城镇企业职工基本养老保险关系转移接续暂行办法 (Ministerium für Personalwesen und soziale Sicherheit, Finanzministerium, Voläufige Maßnahmen zur Übertragung und Fortsetzung der Rentenversicherungsbeziehungen der Arbeitnehmer in städtischen Unternehmen), 国办发 (2009) 66号, vom 28. 12.2009, ab 01. 01. 2010 in Kraft.

$550 § 10$ der Voläufigen Maßnahmen zur Übertragung und Fortsetzung der Rentenversicherungsbeziehungen der Arbeitnehmer in städtischen Unternehmen von 2009. 
nehmers in verschiedenen Provinzen zusammengerechnet. ${ }^{551}$ Die Rente wird vom Sozialversicherungsträger an einem der Beschäftigungsorte des Arbeitnehmers ausgezahlt. 552

\section{Zusammenführung der Alterssicherungssysteme}

Bei der weiteren Reform der Grundrentenversicherung für Beschäftigte in Unternehmen sollen zurzeit nicht nur die Verbesserung des Systems, sondern auch die Verknüpfung und Koordinierung mit anderen Alterssicherungssystemen, wie die Alterssicherung der Beamten und die ländliche Alterssicherung berücksichtigt werden.

Die Reformpläne der beiden Systeme werden seit 1992 in einigen Gebieten erprobt. ${ }^{553}$ Die Beamtenalterssicherung hat sich in den vergangenen Jahren nicht wesentlich verändert. Sie wird weiterhin nach der Regelung über die Pensionierung der Beamten von 1978 durchgeführt. Bei der ländlichen Alterssicherung spielen die Sicherung innerhalb der Familie und die Bodensicherung nach wie vor die größte Rolle. Im neuen Reformplan übernimmt der Staat nun mehr Verantwortung für die Altersversorgung der ländlichen Bevölkerung. 554

Tendenziell lehnen sich die Reformpläne der beiden Systeme an die Rentenversicherung der Unternehmen an, kennzeichnend dafür sind die Betonung der Verantwortung des Einzelnen und die Einführung des Individualkontos.

\section{a) Reform des Pensionssystems für Staatsbedienstete}

1992 wurde in der Bekanntmachung des damaligen Personalministeriums über einige Fragen der Altersversicherungsreform für öffentliche Bedienstete geregelt, dass die Rentenversicherungsreform der Staatsorgane und der öffentlichen Institutionen nach dem Prinzip „gemeinsame Verantwortung und rationale Pflichtbeteiligung von Staat, Kollektiv und Einzelnen“ aufgrund des derzeitig geltenden Pensionssystems ausgeführt würde. Der nach dem Umlageverfahren finanzierte Pensionsfonds wird von einem Kapitaldeckungsfonds ergänzt. 555

Die Pilotprojekte der Rentenversicherung für die Staatsorgane und öffentlichen Institutionen wurden danach allmählich in 230 Bezirken und Städten entfaltet. Die Zahl

$551 \S 3$ der Voläufigen Maßnahmen zur Übertragung und Fortsetzung der Rentenversicherungsbeziehungen der Arbeitnehmer in städtischen Unternehmen von 2009.

$552 \S 3$ der Voläufigen Maßnahmen zur Übertragung und Fortsetzung der Rentenversicherungsbeziehungen der Arbeitnehmer in städtischen Unternehmen von 2009.

553 县级农村社会养老保险基本方案 (试行) (Basisplan für ein ländliches Altersversicherungssystem auf Kreisebene) (Pilotplan), 民办发 (1992) 2号, vom 03.01. 1992; 关于机关事业单位养老保险 制度改革有关问题的通知 (Bekanntmachung über einige Fragen der Altersversicherungsreform für öffentliche Bedienstete), 人退发 (1992) 2号, vom 27.01. 1992.

554 国务院关于开展新型农村社会养老保险试点的指导意见 (Leitansichten des Staatsrats über das Pilotprojekt der neuen ländlichen Altersversicherung)，国发 (2009) 32号, vom 01. 09. 2009.

555 Nr. 2 der Bekanntmachung über einige Fragen der Altersversicherungsreform für öffentliche Bedienstete von 1992. 
der versicherten Personen betrug bis 2007 schon 17.96 Millionen (ca. 16\% der Gesamtzahl von Beamten und Angestellten der öffentlichen Institutionen). 556 Die Grundsätze der Bekanntmachung von 1992, nämlich die Beitragszahlungspflicht des Individuums und die Einführung der Individualkonten, werden allgemein befolgt, abgesehen davon sind die Pilotpläne verschiedener Gebiete hinsichtlich Versichertenkreis, Deckungsbereich und Beitragsrate sehr unterschiedlich. Die Renten werden weiter nach den „Maßnahmen des Staatsrats zur Versorgung alter und kranker Kader“" von 1978557 ausgezahlt. Das bedeutet, dass die Lohnersatzrate der Beamtenrenten deutlich höher als für Unternehmensbeschäftigte ist. Dies führt zu der steigenden Unzufriedenheit der Beschäftigten in Unternehmen.

Die Ursachen für die Verzögerung der Pensionsreform liegen darin, dass für die Wirtschaftsreform die Pensionsreform nicht direkt erforderlich ist. Außerdem sind die Übergangskosten für die Einführung des Individualkontos ebenso wie bei der Sozialversicherungsreform der Unternehmen für die meisten Finanzhaushalte der verschiedenen Regierungsebenen nicht finanzierbar. Ferner werden die Vereinheitlichung der Lohnersatzrate mit der Grundrentenversicherung für Unternehmensbeschäftigte nicht von den Beamten und Angestellten akzeptiert, weil das Rentenniveau damit deutlich sinken würde. 558

Trotz aller Hindernisse werden die Grundrentensysteme von Unternehmen und Staatsorganen tendenziell zusammengeführt, weil die Unterschiede und der Mangel an Koordinierung zwischen beiden Systemen die Arbeitsmobilität behindert haben. Die Vereinigung des Personalministeriums und des Ministeriums für Arbeit und soziale Sicherheit im Jahre 2008 kennzeichnet den Beginn der einheitlichen Planung und Verwaltung für Beschäftigung und soziale Sicherheit. 559 Am 14. 03. 2008 wurde der Pilotplan der Rentenversicherungsreform für die Beschäftigten in öffentlichen Institutionen veröffentlicht, 560 damit begann eine neue Runde der Rentenreform. Diesmal wurden fünf Provinzen und regierungsunmittelbare Städte (Shanxi, Shanghai, Zhejiang, Guangdong, Chongqing) für das Pilotprojekt ausgewählt.

Gemäß dem Pilotplan soll ein Rentensystem der öffentlichen Institutionen, das dem Modell der Unternehmen ähnelt, aufgebaut werden. Neben der Grundrentenversicherung, die gleich wie das betriebliche Modell eine Verbindung von Solidarfonds mit Individualkonto ist, soll eine Zusatzrentenversicherung errichtet werden. Nach dem Vor-

556 劳动和社会保障部社会保障研究所, 机关事业单位养老保险制度改革调研报告 (Forschungsinstitut für soziale Sicherheit beim Ministerium für Arbeit und soziale Sicherheit, Forschungsbericht über die Reform des Altersversicherungssystems der Staatsorgane und öffentlichen Institutionen), in: 社会保障研究 (Forschung über sozialen Sicherheit), 2007/5, S. 2.

557 国务院关于安置老弱病残干部的暂行办法 (Vorläufige Maßnahmen des Staatsrats zur Versorgung alter und kranker Kader), 国发 (1978) 104号, vom 02. 06. 1978.

$558 \mathrm{Vgl}$. 卢驰文, 机关事业单位养老保险制度转轨的财政压力分析 (Lu, Chiwen, Analyse über die Finanzbelastung der Umgestaltung des Pensionssystems für Staatsorgane und öffentliche Institutionen), in: 理论探索 (Theoretical Exploration), 2008/1, S. 78ff.

559 Ausführlich: 华建敏, 关于国务院机构改革方案的说明 (Hua, Jianmin, Erläuterung über den Reformplan der Verwaltungsorgane des Staatsrats), vom 11. 03. 2008.

560 国务院，事业单位工作人员养老保险制度改革试点方案，国发 (2008) 10号, vom 18. 03. 2008. 
schlag des Forschungsinstituts für soziale Sicherheit soll die Lohnersatzrate der Zusatzrente der Staatsorgane und öffentlichen Institutionen höher als die betriebliche Zusatzrente sein. Wenn die Lohnersatzrate bei Unternehmen $70 \%$ liegt, soll die gesamte Lohnersatzrate für Beamte ca. $80 \%$ betragen. 561

\section{b) Koordinierung der Altersversicherungssysteme}

Wegen der unzureichenden wirtschaftlichen Kapazität auf dem Land und der Entwicklungsdisparitäten verschiedener Gebiete stagnierte der Versuch der Regierung in den 1990er Jahren, ein soziales Altersversicherungssystem für die ländliche Bevölkerung zu etablieren.562 Aber die demographische und wirtschaftliche Entwicklung führt allmählich zu einer tiefen Änderung der Sozialstruktur der ländlichen Gebiete und erfordert eine Fortsetzung der Alterssicherung. Mit der Industrialisierung und Urbanisierung hat der Anteil der ländlichen Bevölkerung an der Gesamtbevölkerung von $87 \%$ im Jahre 1953 auf 56\% im Jahre 2006 abgenommen. ${ }^{563}$ Die ständige Arbeitskraftmigration in die Städte beschleunigt den Überalterungsprozess der ländlichen Bevölkerung und erfordert den Aufbau eines ländlichen Altersversicherungssystems mit Verknüpfung an die städtische Grundrentenversicherung. Da es zurzeit an Verknüpfungen zwischen den Grundrentenversicherungssystemen der verschiedenen Gebieten und an der Koordinierung zwischen den ländlichen und städtischen Altersversicherungssystemen fehlt, wird die Initiative der Wanderarbeiter, am städtischen Grundrentenversicherungssystem teilzunehmen, stark behindert. Dies ist ungünstig für das Streben der Regierung nach der Erhöhung des Deckungsgrads der Grundrentenversicherung für Unternehmen.

Während die Regierung mit der Errichtung einer ländlichen Altersversicherung zögerte, haben Experten in der Literatur die Möglichkeiten, den Basisplan von 1992 weiter durchzuführen, Verknüpfung zwischen städtischen und ländlichen Systemen zu schaffen und sogar eine einheitliche Basisrente für alle Bürger zu errichten, untersucht. 564 Die Ansichten in diesen Fragen divergieren sehr.

Der Soziologe Li, Yingsheng vertritt die Meinung, dass das im Basisplan von 1992 festgelegte Modell der ländlichen Altersversicherung durch einen kommerziellen Sparplan ersetzt werden solle. Er glaubt dadurch, Korruption und Zweckentfremdung durch

561 劳动和社会保障部社会保障研究所, 机关事业单位养老保险制度改革调研报告 (Forschungsinstitut für soziale Sicherheit beim Ministerium für Arbeit und soziale Sicherheit, Forschungsbericht über die Reform des Altersversicherungssystems der Staatsorgane und öffentlichen Institutionen), in: 社会保障研究 (Forschung über sozialen Sicherheit), 2007/5, S. 19ff.

562 Ausführlich: Dritter Teil, Altersversicherung für die ländliche Bevölkerung.

563 中国统计年鉴 2007 (China Statistical Yearbook 2007), http://www.stats.gov.cn/tjsj/ndsj/2007/indexch.htm (Stand: 15. 07. 2010).

564 Vgl. Leisering/Sen/Hussain, People's Republic of China, Old-Age Pensions for the Rural Areas: From Land Reform to Globalization, S. xviiiff; 李迎生，立足现实，面向未来：农村养老保障制 度改革的过渡模式设计 (Li, Yingsheng, Ein Übergangsmodell der ländlichen Alterssicherungsreform), in: 社会保障制度 (Social Security System), 2006/2, S. 27ff; 课题组, 河北省农村社会养 老保障制度建设研究 (Forschungsgruppe, Forschungsbericht über den Aufbau des sozialen ländlichen Alterssicherungssystems in der Provinz Hebei), in: 社会保障制度 (Social Security System), 2006/5, S. 49. 
die Sozialversicherungsträger, wie sie bei den individuellen Konten der städtischen Grundrentenversicherung auftraten, zu vermeiden. Zukünftig würde der Sparplan die zweite Säule der ländlichen Alterssicherung sein. Die erste Säule sei ein einheitliches System der Basisrente für alle Bürger, die durch Steuern und staatliche Zuschüsse finanziert werde. 565

Demgegenüber haben Leisering und seine Forschungsgruppe den Basisplan von 1992 positiv bewertet. Sie tendieren dazu, dass die soziale Altersversicherung nur in den reichen Gebieten aufgebaut werden könne, in den armen Gebieten könne die Sozialhilfe eine größere Rolle für die Alterssicherung spielen.566 Sie schlagen vor, einen nationalen Plan für die Koordinierung der städtischen und ländlichen Altersversicherungen einzuführen. Dafür müssten drei Probleme gelöst werden: die Übertragbarkeit der Leistungsansprüche zwischen den beiden Systemen, die finanzielle Unterstützung der armen Beteiligten und die Beseitigung der Ungerechtigkeit, die sich aus der strukturellen Ungleichmäßigkeit ergeben würde. 567

Der Ökonom $M u$, Huaizhong und seine Forschungsgruppe haben unter den gegenwärtig geltenden Systemen die möglichen Verknüpfungsmodelle diskutiert und eine Theorie ,gradient linkage“ aufgestellt. Nach ihrer Theorie wird das chinesische System der sozialen Altersversicherung auf vier Ebenen abgestuft: die Rentenversicherung für Beamte und Angestellte der öffentlichen Institutionen (die erste Stufe), die Rentenversicherung für Beschäftigte in Unternehmen (die zweite Stufe), die Altersversicherung für Selbständige und Teilzeitarbeiter (die dritte Stufe) und die ländliche Altersversicherung (die vierte Stufe). Zwischen den Stufen würden Verknüpfungen geschaffen, damit die Leistungsansprüche übertragen werden können. 568

Seit dem Jahre 2009 wurde der Integrationsprozess der Altersversicherung beschleunigt. Die „Leitansichten über das Pilotprojekt der neuen ländlichen Altersversicherung “569 wurde im September 2009 erlassen, danach wird ein Versicherungsmodell „Basisrente mit Individualkonto“ für die ländliche Bevölkerung aufgebaut. Die Basisrente wird - wie beim Vorschlag von Li, Yingsheng - durch Steuern finanziert. ${ }^{570}$ Später wurden die „Vorläufigen Maßnahmen zur Übertragung und Fortsetzung der Rentenversicherungsbeziehungen der Arbeitnehmer der städtischen Unternehmen“ Ende 2009

565 李迎生, 立足现实, 面向未来: 农村养老保障制度改革的过渡模式设计 (Li, Yingsheng, Ein Übergangsmodell der ländlichen Alterssicherungsreform), in: 社会保障制度 (Social Security System), 2006/2, S. 27ff.

566 Leisering/Gong/Hussain, People's Republic of China, Old-Age Pensions for the Rural Areas: From Land Reform to Globalization, S. xix.

567 Leisering/Gong/Hussain, People's Republic of China, Old-Age Pensions for the Rural Areas: From Land Reform to Globalization, S. xviii.

568 穆怀中/柳清瑞, 中国养老保险制度改革关键问题研究 (Mu, Huaizhong/Liu, Qingrui, The Research on the Key Issues about China's Pension System Reforms), S. 111, 236.

569 国务院关于开展新型农村社会养老保险试点的指导意见 (Leitansichten des Staatsrats über das Pilotprojekt der neuen ländlichen Altersversicherung), 国发 (2009) 32号, vom 01. 09. 2009.

570 Nr. 6 der Leitansichten des Staatsrats über das Pilotprojekt der neuen ländlichen Altersversicherung von 2009, ausführlich siehe: Dritter Teil, Systemanalyse, Altersversicherung für die ländliche Bevölkerung. 
erlassen, in der auch die Rentenversicherung der ländlichen Wanderarbeiter geregelt wird. ${ }^{571}$ Daher hat der Prozess einer Zusammenführung beider Systeme bereits begonnen.

\section{Würdigung}

Im Integrationsprozess der sozialen Altersversicherungen wurde ein Grundmodell ausgearbeitet. Nun werden alle sozialen Altersversicherungen nach dem Modell „Solidarfonds mit Individualkonto“ errichtet. Der Solidarfonds der städtischen Rentenversicherung ist weiterhin beitragsfinanziert, allerdings existiert nun eine steuerfinanzierte Basisrente auf dem Land. Ob eine einheitliche Basisrente für alle Bürger auf dieser Grundlage entwickelt wird, ist zurzeit noch unklar. Aber die Errichtung einer einheitlichen Basisrente wurde schon von einigen Experten vorgeschlagen. ${ }^{572}$ Die Koordinierung der Altersversicherungen könnte meines Erachtens damit weiter geführt werden, dass der Solidarfonds der städtischen Rentenversicherungen durch eine Basissicherung, die durch Beiträge der Arbeitgeber und Steuern finanziert würden, ersetzt würde. Sie sollte leistungsdefiniert sein und im Umlageverfahren verwaltet werden. Auf dem Land könnten die Basisrente, die Bodensicherung und die Steuerermäßigung eine Basissicherung bilden. Je nach Beruf könnten unterschiedliche beitragsdefinierte Zusatzsicherungen greifen.

Mit der Einführung der Basisrente ist es nach meiner Ansicht sehr fraglich, ob die chinesischen Altersversicherungen weiter als „Sozialversicherung (社会保险 shèhuì băoxiān)“ bezeichnet werden können. Sie umfassen jetzt Solidarfonds, Basisrente und Individualkonten, die jeweils im Umlageverfahren oder im Kapitaldeckungsverfahren verwaltet werden. Die Teilnahme an der ländlichen Altersversicherung ist nun freiwillig. Dies differenziert sie schon sehr von der klassischen Sozialversicherung.

\section{Gesundheitssicherung}

Sowohl der Aufbau der Alterssicherung gestaltet sich als schwierig, als auch die Gesundheitssicherung. Keine andere Reform der sozialen Sicherung hat wie die Gesundheitsreform direkt unter der Umwandlung der staatlichen Verantwortung mehr gelitten.

$571 \S 2$ Abs. 1 der Vorläufigen Maßnahmen zur Übertragung und Fortsetzung der Rentenversicherungsbeziehungen der Arbeitnehmer in städtischen Unternehmen von 2009.

572 李迎生, 立足现实, 面向未来: 农村养老保障制度改革的过渡模式设计 (Li, Yingsheng, Ein Übergangsmodell der ländlichen Alterssicherungsreform), in: 社会保障制度 (Social Security System), 2006/2, S. 27ff.; 葛延风, 完善城镇职工养老保险制度的思路与对策 (Ge, Yanfeng, Approaches and Policies to Enhance the Workers' Pension System in Urban Areas), in: 陈佳贵/王延 中, 中国社会保障发展报告2001-2004 (Chen, Jiagui/Wang, Yanzhong (Hrsg.), China Social Security System Development Report 2001-2004), S. 197ff.; 唐钧, 中国的社会保障政策评析 (Tang, Jun, Kommentar zur chinesischen Sozialpolitik), in: 东岳论从 (Dong Yue Tribune), 2008/1, S. $12 \mathrm{ff}$. 
Die Kosten für eine „rationale Verantwortungsbeteiligung zwischen Staat, Gesellschaft und dem Einzelnen“"wurden lange Zeit von den Bürgern allein getragen.

\section{Tradition des Gesundheitswesens}

Seit Gründung der Volksrepublik hat die chinesische Regierung sich bemüht, durch die einheitliche Planung ein umfassendes Gesundheitssystem für alle Bürger aufzubauen. Ein Drei-Stufen-Netz von Krankenhäusern und Sanitätsstationen gewährleistete als Einrichtungen des öffentlichen Gemeinwohls eine primäre medizinische Versorgung mit Prävention und medizinischer Behandlung. Durch das kostenlose Gesundheitsabsicherungssystem in den Städten und das kooperative medizinische System auf dem Land, die den größten Teil der Bevölkerung umfassten, wurden die medizinischen Dienstleistungen hauptsächlich vom Staat und Kollektiv finanziert. Bis 1980 übernahmen die Regierung und die soziale Gesundheitsabsicherung ca. 80\% der Gesamtausgaben des Gesundheitswesens. 573

Das Gesundheitssystem in der Periode der Planwirtschaft entsprach den damaligen wirtschaftlichen, politischen und gesellschaftlichen Grundlagen. Mit dem Finanzsystem der einheitlichen Einnahmen und Ausgaben konnte die staatliche Umverteilungsfunktion sich voll entfalten. Die überwiegende Rolle des Volks- und Kollektivseigentums vereinfachte das Aufbringen des Gesundheitsabsicherungsfonds. Die große Mobilisierungsfähigkeit der Regierung gewährleistete die Teilnahme der Bürger an der patriotischen Hygienebewegung. ${ }^{574}$ In der Periode der Planwirtschaft wurden nur ca. 3\% BIP in China für die medizinischen Aufwendungen ausgegeben, damit wurden die Bedürfnisse der Bevölkerung an medizinischer Versorgung grundsätzlich befriedigt. 575 Dieses System wurde deswegen von internationalen Organisationen wie der WHO und der Weltbank als Vorbild für Entwicklungsländer bezeichnet. 576

Die Partei wollte in der Wirtschaftsreform die Erfolge des Gesundheitswesens weiter ausbauen. „Jeder genießt medizinische Versorgung“ wurde als „ein wichtiges Ziel der sozialistischen Modernisierung“ und „eine wichtige Voraussetzung der nachhaltigen wirtschaftlichen und gesellschaftlichen Entwicklung“ im „Beschluss des Zentralkomitees der KP Chinas und des Staatsrats über die Reform und die Entwicklung des Gesundheitswesens“ von 1997577 formuliert. Dieser Beschluss hielt an den konsequenten

573 卫生部, 2004年中国卫生统计提要 (Gesundheitsministerium, Health Expenditure Report 2004), http://www.moh.gov.cn/publicfiles/business/htmlfiles/zwgkzt/ptjty/digest2004/s30.htm (Stand: 15. 07. 2010).

574 葛延风/贡森, 中国医改: 问题, 根源, 出路 (Ge, Yanfeng/Gong, Sen, Chinese Healthcare Reform), S. 79.

575 Ausführlich vgl: 王绍光, 政策导向, 汲取能力与卫生公平 (Wang, Shaoguang, State Policy Orientation, Extractive Capacity and the Equality of Healthcare in Urban China), in: 中国社会科学 (Social Sciences in China), 2005/6, S. 101ff; 葛延风/贡森, 中国医改: 问题, 根源, 出路 (Ge, Yanfeng/Gong, Sen, Chinese Healthcare Reform), S. $2 \mathrm{ff}$.

576 World Bank, Financing Health Care: Issues and Options for China. S. 2ff.

577 中共中央，国务院关于卫生改革与发展的决定，中发 (1997) 3号, vom 15. 01. 1997. 
Richtlinien „das Gesundheitswesen ist ein öffentliches Wohlfahrtswesen, dafür muss die Regierung wichtige Verantwortung übernehmen“ fest und verlangte „die gesellschaftliche Effizienz an die erste Stelle zu stellen, um der einseitigen Berücksichtigung von wirtschaftlicher Effizienz vorzubeugen“. 578 Wie früher das ländliche Gesundheitssystem und die Prävention Arbeitsschwerpunkte des Gesundheitswesens waren, sind sie dies auch heute noch. Die Regierungen verschiedener Ebenen haben für das Gesundheitswesen mehr Geldmittel anzulegen, bis Ende des 20. Jahrhunderts sollte die Gesamtsumme der Gesundheitskosten ca. 5\% BIP betragen. 579

Allerdings standen die Regierungsmaßnahmen in dieser Phase im Gegensatz zu den im Parteibeschluss von 1997 festgelegten Richtlinien. Die Gesundheitsreform wurde seit den 1980er Jahren tief beeinflusst durch das liberale Reformmodell der Staatsunternehmen - marktorientierte Reform und Kommerzialisierung, und wich daher lange Zeit von dem „öffentlichen Wohlfahrtswesen“ ab.

\section{Gesundheitsreform $1985-2005$}

\section{a) Wirtschaftlicher Hintergrund und Orientierungslinien}

Die Hauptaufgabe der Wirtschaftsreform in den 1980er Jahren lag darin, durch die wirtschaftliche Dezentralisierung die Vitalität der Unternehmen anzureizen. Die Gesundheitsreform kopierte im Wesentlichen das Modell der Unternehmensreform. ${ }^{580}$ Die Regierung versuchte mittlerweile durch Einführung der freien Konkurrenz auf dem Markt die wirtschaftliche Effizienz der Krankenhäuser zu steigern. Mit der Parole „Effizienz genießt Priorität" wurden die finanzielle Entlastung des Staates und die Selbstverantwortung der Einzelnen für die Gesundheitskosten besonders bevorzugt. 581

Auf der anderen Seite hatte die seit 1980 eingeleitete Finanzreform 582 auf die Ausrichtung der Gesundheitsreform unmittelbar eingewirkt. Mit der finanziellen Dezentralisierung in den 1980er Jahren waren die lokalen Regierungen für ihr Finanzwesen die voll verantwortlich. Die regionalen Regierungen, insbesondere die Regierungen auf Kreisebene übernahmen die Hauptverantwortung für das Gesundheitswesen. Demgegenüber wurde die Finanzfähigkeit der Zentralregierung stark geschwächt. ${ }^{583}$ Die Einnahmenquote des Staates ist von 31.2\% BIP 1978 auf 10.7\% BIP 1995 stetig gesunken,

578 Nr. 1 des Beschlusses des Zentralkomitees der KP Chinas und des Staatsrats über die Reform und Entwicklung des Gesundheitswesens von 1997: Ziele und Richtlinien.

579 Nr. 1 des Beschlusses des Zentralkomitees der KP Chinas und des Staatsrats über die Reform und Entwicklung des Gesundheitswesens von 1997: Ziele und Richtlinien.

580 Ausführlich vgl. 劳动和社会保障部社会保障研究所, 中国卫生改革的方向与总体思路 (Forschungsinstitut für soziale Sicherheit beim Ministerium für Arbeit und soziale Sicherheit, Vorschläge zur Gesundheitsreform), in: 社会保障研究 (Forschung über sozialen Sicherheit), 2007/3, S. 19.

581 Vgl. 王绍光, 政策导向, 汲取能力与卫生公平 (Wang, Shaoguang, State Policy Orientation, Extractive Capacity and the Equality of Healthcare in Urban China), in: 中国社会科学 (Social Sciences in China), 2005/6, S. 105.

582 Ausführlich: Erster Teil, Finanzsystem.

583 Ausführlich: Erster Teil, Wirtschaftsreform. 
davon betrug die Einnahmenquote der Zentralregierung nur knapp 5\% BIP.584 Die Zentralregierung war lange Zeit nicht fähig, die finanzielle Verantwortung für das Gesundheitssystem zu übernehmen.

Mit dem Aufbau des Systems der Steuereinnahmenaufteilung flossen die Einnahmen seit 1994 wieder zur Zentralregierung, allerdings blieb die Ausgabenverantwortung für das Sozialwesen noch bei den regionalen Regierungen. Wegen den finanziellen Schwierigkeiten reduzierten die regionalen Regierungen ihre Ausgaben für den öffentlichen Gesundheitsdienst. Um die finanzielle Lücke zu füllen, haben die Regierungen den öffentlichen Krankenhäusern erlaubt, durch Preiserhöhung ihre Kosten auszugleichen. Die Gesundheitseinrichtungen beschritten seitdem den Weg der Kommerzialisierung.

Im Jahre 2002 betrugen die Ausgaben des Staates für das Gesundheitswesen nur $15.2 \%$ der gesamten Gesundheitsausgaben, demgegenüber haben die sozialen Versicherungen und die Arbeitseinheiten 26.5\%, die Einzelnen 58.3\% der gesamten Gesundheitsausgaben getragen. 585

\section{Tabelle 14: Gesamte Gesundheitsausgaben 1980-2006}

\begin{tabular}{|l|r|r|r|r|r|r|}
\hline & \multicolumn{1}{|c|}{1980} & \multicolumn{1}{|c|}{1990} & \multicolumn{1}{|c|}{1995} & \multicolumn{1}{|c|}{2000} & \multicolumn{1}{|c|}{2005} & \multicolumn{1}{|c|}{2006} \\
\hline $\begin{array}{l}\text { Gesamte Gesundheitsausgaben (100 } \\
\text { Mio. RMB) }\end{array}$ & 143.2 & 747.4 & 2155.1 & 4586.6 & 8659.9 & 9843.3 \\
\hline Gesundheitsausgaben der Regierung & 51.9 & 187.3 & 387.3 & 709.5 & 1552.5 & 1778.9 \\
\hline $\begin{array}{l}\text { Gesundheitsausgaben der Sozialversi- } \\
\text { cherungen und Arbeitseinheiten }\end{array}$ & 61.0 & 293.1 & 767.8 & 1171.9 & 2586.4 & 3210.9 \\
\hline Gesundheitsausgaben der Einzelnen & 30.3 & 267.0 & 1000.0 & 2705.2 & 4521.0 & 4853.5 \\
\hline & & & & & & \\
\hline Prozentsatz der Gesundheitsausgaben & 100.0 & 100.0 & 100.0 & 100.0 & 100.0 & 100.0 \\
\hline Gesundheitsausgaben der Regierung & 36.2 & 25.1 & 18.0 & 15.5 & 17.9 & 18.1 \\
\hline $\begin{array}{l}\text { Gesundheitsausgaben der Sozialversi- } \\
\text { cherungen und Arbeitseinheiten }\end{array}$ & 42.6 & 39.2 & 35.6 & 25.5 & 29.9 & 32.6 \\
\hline Gesundheitsausgaben der Einzelnen & 21.2 & 35.7 & 46.4 & 59.0 & 52.2 & 49.3 \\
\hline $\begin{array}{l}\text { Anteil der Gesundheitsausgaben an } \\
\text { BIP }\end{array}$ & 3.15 & 4.00 & 3.54 & 4.62 & 4.73 & 4.67 \\
\hline Gesundheitsausgaben pro Kopf & 14.51 & 65.4 & 177.9 & 361.9 & 662.3 & 748.8 \\
\hline in den Städten & $\ldots$ & 158.8 & 401.3 & 828.6 & 1122.8 & 1248.3 \\
\hline auf dem Land & $\ldots$ & 38.8 & 112.9 & 209.4 & 318.5 & 361.9 \\
\hline
\end{tabular}

Quelle: http://www.moh.gov.cn/publicfiles/business/htmlfiles/zwgkzt/ptjty/digest2008/q119.htm.

b) An der Selbstverantwortung orientierte Reform der Gesundheitsabsicherung

Der Zusammenbruch des alten Gesundheitsabsicherungssystems fing mit der Dekollektivierung der Landwirtschaft an und erreichte seinen Tiefpunkt mit der Einführung der Grundkrankenversicherung für Arbeitnehmer in den Städten. Der größte Teil der

584 国家统计局, 中国统计摘要2004 (National Bureau of Statistics of China, China Statistical Abstract 2004), S. 69.

585 Gesundheitsministerium, Health Expenditure Report 2002,

http://www.moh.gov.cn/publicfiles/business/htmlfiles/zwgkzt/ptjty/digest2004/s30.htm (Stand: 15. 07. 2010). 
Bauern und die nicht beschäftigten Stadtbewohner genossen seitdem lange Zeit keine staatliche und kollektive Unterstützungen für die medizinische Versorgung, sie mussten hierfür selbst zahlen. Nach dem Bericht des Gesundheitsministeriums waren ca. 50\% der städtischen Bevölkerung und ca. 80\% der ländlichen Bevölkerung im Jahre 2003 überhaupt nicht von den Krankenversicherungen und anderen Absicherungsmaßnahmen erfasst. 586

Die Versicherten der neu eingeführten sozialen Krankenversicherungen (Grundkrankenversicherung für Arbeitnehmer in den Städten, Grundkrankenversicherung für die städtischen Bewohner sowie das ländliche kooperative medizinischen System ${ }^{587}$ ) leiden unter der deutlichen Absenkung des Leistungsniveaus. Diese sozialen Krankenversicherungen wurden hauptsächlich nur für die medizinische Behandlung schwerer Krankheiten errichtet. Das bedeutet, dass die ambulanten Behandlungen meistens von den Versicherten selbst finanziert werden müssen. ${ }^{588}$ Außerdem sind die Regelungen über die Leistungsniveaus auch sehr streng. Mit der Einführung der Höchst- und Mindestauszahlungsgrenzen müssen bei der Grundkrankenversicherung für Arbeitnehmer durchschnittlich ca. $40 \%$ der Behandlungskosten, 589 bei der neuen kooperativen medizinischen Sicherung über $70 \%$ der Kosten 590 von den Versicherten selber getragen werden.

\section{Tabelle 15: Prozentuale Aufteilung der Bevölkerung nach Zweigen der Gesundheitssicherung (2003)}

\begin{tabular}{|l|c|c|c|}
\hline & Total (\%) & Stadt (\%) & Land (\%) \\
\hline $\begin{array}{l}\text { Kooperative Krankenversiche- } \\
\text { rung }\end{array}$ & 8.8 & 6.6 & 9.5 \\
\hline Grundkrankenversicherung & 8.9 & 30.4 & 1.5 \\
\hline $\begin{array}{l}\text { Versicherung für schwere } \\
\text { Krankheiten }\end{array}$ & 0.6 & 1.8 & 0.1 \\
\hline Beamtensicherung & 1.2 & 4.0 & 0.2 \\
\hline Arbeiterversicherung & 1.3 & 4.6 & 0.1 \\
\hline Andere soziale Versicherungen & 1.4 & 2.2 & 1.2 \\
\hline Private Krankenversicherung & 7.6 & 5.6 & 8.3 \\
\hline Selbstfinanzierung & 70.3 & 44.8 & 79.0 \\
\hline
\end{tabular}

Quelle: http://www.moh.gov.cn/publicfiles/business/htmlfiles/zwgkzt/ptjty/digest2004/s55.htm.

586 卫生部统计信息中心, 第三次国家卫生服务调查分析报告 (Statistikzentrum des Gesundheitsministeriums, Abstract of the Report on the 3rd National Health Service Investigation and Analysis), in: 中国医院 (Chinese Hospitals), 2005/1, S. 7.

587 Ausführlich vgl. Dritter Teil, Vorsorgesysteme.

588 葛延风/贡森, 中国医改: 问题, 根源, 出路 (Ge, Yanfeng/Gong, Sen, Chinese Healthcare Reform), S. 12.

589 高书生, 社会保障改革何去何从 (Gao, Shusheng, Die Reform der sozialen Sicherheit steht am Scheideweg), S. 296.

590 新型农村合作医疗试点工作评估组, 发展中的中国新型农村合作医疗 一 新型农村合作医疗 试点工作评估报告 (Abschätzungsgruppe für die Pilotprojekte des neuen kooperativen medizinischen Systems, Das chinesische neue kooperative medizinische System in der Entwicklungsphase Abschätzungsbericht über das neue kooperative medizinische System), S. 12. 
Die Ausgabenkontrolle der oben erwähnten sozialen Krankenversicherungen wird hauptsächlich durch strikte Beschränkung der Leistungen von versicherten Personen erreicht. Die Krankenhäuser hingegen werden nicht kontrolliert. Die versicherten Personen der Krankenversicherungen müssen die medizinischen Kosten zuerst selbst bezahlen, dann erhalten sie mit umständlichen Formalitäten von den Sozialversicherungsträgern die Erstattung. Für die Landbewohner ist dies besonders umständlich. ${ }^{591}$ Bei der Grundkrankenversicherung für Arbeitnehmer in Städten wird ein Individualkonto für die Kosten der ambulanten Behandlungen eingeführt, in das knapp 50\% der Gesamtbeiträge von Arbeitnehmer und Arbeitgeber eingezahlt werden. Dieses aus der gesetzlichen Rentenversicherung kopierte Modell wird von Anfang an von den Experten kritisiert. ${ }^{592}$ Die Solidaritätsfunktion der sozialen Krankversicherung wird wegen der Einführung des Individualkontos beschränkt, da der Solidarfonds nur über $4.2 \%$ der Lohnsumme und damit knapp über 50\% der Gesamtbeiträge verfügt. Für die Versicherten, die oft krank sind, ist die Summe des individuellen Kontos zu niedrig. Das bedeutet, dass er die Basiskrankenversorgung hauptsächlich selbst finanzieren muss. ${ }^{593}$ In der Tat sind die Verwaltungskosten für die individuellen Konten ziemlich hoch, die Zinsen aber zu niedrig. Die Gelder werden oft von den Versicherten für andere Zwecke oder von anderen Personen benutzt. 594

Die Betonung von Selbstverantwortung des Einzelnen ist sogar der Leitgedanke des Aufbaus der medizinischen Hilfe geworden. Manche Regelungen der sozialen Krankenversicherungen, wie die Regelungen über die Höchst- und Mindestauszahlungsgrenzen, und die Beschränkung der Leistungen auf die schweren Krankheiten wurden auch in den meisten Pilotplänen der medizinischen Hilfe eingeführt. ${ }^{595}$ Wegen den strengen

591 葛延风/贡森, 中国医改: 问题, 根源, 出路 (Ge, Yanfeng/Gong, Sen, Chinese Healthcare Reform), S. 13; 新型农村合作医疗试点工作评估组, 发展中的中国新型农村合作医疗 一 新型 农村合作医疗试点工作评估报告 (Gesundheitsministerium, Abschätzungsgruppe für die Pilotprojekte des neuen kooperativen medizinischen Systems, Das chinesische neue kooperative medizinische System in der Entwicklungsphase - Abschätzungsbericht über das neue kooperative medizinische System), S. 3.

592 Siehe: 高书生, 社会保障改革何去何从 (Gao, Shusheng, Die Reform der sozialen Sicherheit steht am Scheideweg), S. 171.

593 劳动和社会保障部社会保障研究所, 关于中国医疗保障制度改革的框架性建议 (Forschungsinstitut für soziale Sicherheit beim Ministerium für Arbeit und soziale Sicherheit, Vorschläge für die Reform des chinesischen Gesundheitssystem), in: 社会保障研究 (Forschung über sozialen Sicherheit), 2007/5, S.16; 林嘉, 社会保障法的理念, 实践与创新 (Lin, Jia, Theory, Practice and Innovation on Social Security Law), S. 228ff.; 高书生, 社会保障改革何去何从 (Gao, Shusheng, Die Reform der sozialen Sicherheit steht am Scheideweg), S. 171; 葛延风贡森, 中国医改: 问题, 根源, 出路 (Ge, Yanfeng/Gong, Sen, Chinese Healthcare Reform), S. 12.

594 Beispielsweise werden mit Hilfe der Versicherungskarte, die eine Bankkarte gleicht, in Apotheken neben Medikamente auch Hautpflegeprodukte gekauft. Die Versichertenkarte wird beispielsweise auch an Familienmitglieder verliehen. 劳动和社会保障部社会保障研究所, 关于中国医疗保障 制度改革的框架性建议 (Forschungsinstitut für soziale Sicherheit beim Ministerium für Arbeit und soziale Sicherheit, Vorschläge für die Reform des chinesischen Gesundheitssystem), in: 社会 保障研究 (Forschung über sozialen Sicherheit), 2007/5, S.16.

595 Ausführlich vgl. 陈佳贵/王延中, 中国社会保障发展报告 (2007) No. 3 (Chen, Jiagui/Wang, Yanzhong (Hrsg.), China Social Security System Development Report (2007) No. 3), S. 134. 
Beschränkungen ist das Leistungsniveau der medizinischen Hilfe sehr gering. Das Phänomen „Krankheit führt zur Armut“ wurde dadurch nicht wie erwartet vermindert.

Das niedrige Leistungsniveau beeinträchtigte die Motivation der Bürger, an den neuen Krankenversicherungen teilzunehmen. Insbesondere bei dem neuen ländlichen kooperativen medizinischen System, bei dem die Teilnahme freiwillig ist, blieb die Teilnahmerate lange Zeit auf niedrigem Niveau. 2003 lag die Deckungsrate des neuen kooperativen medizinischen Systems bei nur $8.8 \%$, der Grundkrankenversicherung für Beschäftigte in Städten bei nur 8.9\% der Bevölkerung. 596

\section{c) Marktorientierte Reform der öffentlichen Gesundheitsdienste}

In der Periode der Planwirtschaft wurde das öffentliche Gesundheitswesen als ein Teil der sozialen Wohlfahrt behandelt. Der Staat kontrollierte die Preise der medizinischen Dienstleistungen und der Arzneimittel, damit die Gesundheitsleistungen im Rahmen des Möglichen für alle Bürger finanzierbar waren. Vor 1978 bekamen die Krankenhäuser über 50\% ihrer Einnahmen aus dem Regierungshaushalt. ${ }^{597}$ Um die Finanzbelastung zu mindern, hat die Regierung ab 1985 die Reform des Gesundheitswesens eingeleitet. 598 Als Schwerpunkt der Reform wurde die Erweiterung der autonomen Befugnisse der Krankenhäuser im Bericht des Gesundheitsministeriums über die Gesundheitsreform von 1985 vorgebracht. 599

Mit der Einführung eines Haushaltsverantwortungssystems in den öffentlichen Krankenhäusern wurden die staatlichen Finanzierungen für den Gesundheitsdienst deutlich verringert, bis Ende der 1990er Jahre betrugen die Zuschüsse der Regierung nur 6\% der Einkommen der Krankenhäuser. ${ }^{600}$ Statt der finanziellen Unterstützung wurden die Krankenhäuser von der Regierung ermächtigt, die Preise der medizinischen Dienstleistungen und der Arzneimittel zu erhöhen, ${ }^{601}$ damit die Finanzlücke geschlossen werden konnte. Die Einkommen aus Dienstleistungen und Arzneimittel sind seitdem die Haupteinnahmequellen der öffentlichen Krankenhäuser geworden.

Die Bewirtschaftungsautonomie mit der Erlaubnis zur Festsetzung und Erhöhung der Preise führte zu einem Missbrauch in den öffentlichen Krankenhäusern, indem die

596 Gesundheitsministerium, Health Expenditure Report 2004, http://www.moh.gov.cn/publicfiles/ business/htmlfiles/zwgkzt/ptjty/200805/35311.html (Stand: 15. 07. 2010).

597 王绍光, 政策导向, 汲取能力与卫生公平 (Wang, Shaoguang, State Policy Orientation, Extractive Capacity and the Equality of Healthcare in Urban China), in: 中国社会科学 (Social Sciences in China), 2005/6, S. 109.

598 卫生部，关于卫生工作改革若干政策问题的报告 (Bericht des Gesundheitsministeriums über einige politische Linien der Gesundheitsreform), 国发 (1985) 62号, vom 25. 04. 1985, in: 中国卫 生年鉴 (Yearbook of Public Health in The People's Republic of China), S. 389ff.

599 Bericht des Gesundheitsministeriums über einige politische Linien der Gesundheitsreform von 1985.

600 王绍光, 政策导向, 汲取能力与卫生公平 (Wang, Shaoguang, State Policy Orientation, Extractive Capacity and the Equality of Healthcare in Urban China), in: 中国社会科学 (Social Sciences in China), 2005/6, S. 109.

601 Nr. 8 des Berichts des Gesundheitsministeriums über einige politische Richtlinien der Gesundheitsreform von 1985 . 
Krankenhäuser den Patienten aus Profitmotiven nicht bedarfsgerechte Dienste und Arzneimittel anboten und daraufhin hohe Rechnungen erstellten. Die Behandlungskosten stiegen deshalb in den 1990er Jahren enorm. Mangels ausreichenden Krankenversicherungsschutzes konnten viele Patienten die Kosten der medizinischen Behandlung nicht tragen. Sie blieben entweder der Behandlung fern oder gerieten wegen der hohen Belastung in Armut.

Während die städtischen Krankenhäuser durch die marktorientierte Reform expandierten, schrumpfte das Gesundheitsnetz für Prävention und Gesundheitserhaltung mangels staatlicher finanzieller Unterstützung, da es gerade nicht kommerziell bewirtschaftet wird. Demzufolge erhöhte sich das Auftreten von Infektionskrankheiten und Epidemien in den letzten Jahren erheblich. 602

\section{d) „ein ungerechtes Gesundheitssystem“}

Das chinesische Gesundheitssystem geriet seit der Reform in einen Teufelskreis. Einerseits erhöhten sich die Behandlungskosten rasant, andererseits sanken das Leistungsniveau und die Deckungsrate der Gesundheitsabsicherung deutlich ab. Dies führte zu dem Verzicht der armen Bevölkerung auf medizinische Behandlung und zu neuer Armut wegen der hohen finanziellen Belastung. Nach einem Untersuchungsbericht des Ministeriums für Zivile Angelegenheiten sind Krankheiten am Anfang des 21. Jahrhunderts die häufigste Ursache für Armut in China geworden.603 Der Gesundheitszustand der Bevölkerung, der im Allgemeinen durch die durchschnittliche Lebenserwartung und die Säuglingssterblichkeit widergespiegelt wird, verbesserte sich seit den 1980er Jahren nicht mehr deutlich wie vor der Reform. 604

In der Gesundheitsreform hat der Staat nur eines seiner Hauptziele - Reduzierung der staatlichen Finanzbelastung für das Gesundheitssystem - erreicht. Die Gesamtsumme der Gesundheitsausgaben ist von 3.17\% BIP im Jahre 1980 auf 5.62 \% BIP im Jahre 2003 gestiegen, davon wurden nur 17\% der Gesundheitskosten im Jahre 2003 aus dem Regierungshaushalt finanziert. ${ }^{605}$ Der Anstieg der Gesundheitsausgaben wurde von den Bürgern getragen, die Gesundheitskosten sind an die dritte Stelle der Familienausgaben (hinter Lebensmittel, Bildung) gerückt. 606 Mangels ausreichender sozialer Sicherung sind die Bürger dazu gezwungen, mehr Geld für das Alter und Krankheiten zu

602 Ausführlich: 王绍光, 中国公共卫生的危机与转机 (Wang, Shaoguang, Krise und Wendung des öffentlichen Gesundheitsdienstes in China), in: 比较 (Comparative Studies), 2003/7, S. 52ff.

603 民政部, 全国百城万户低保抽查结果 (Ministerium für Zivile Angelegenheiten, Untersuchungsergebnisse der Stichprobe für das städtische System des Existenzminimums), 2002, http://www1.mca.gov.cn/mca/news/news2002112701.html (Stand: 15. 07. 2010).

604 王绍光, 中国公共卫生的危机与转机 (Wang, Shaoguang, Krise und Wendung des öffentlichen Gesundheitsdienstes in China), in: 比较 (Comparative Studies), 2003/7, S. 54.

605 陈佳贵/王延中, 中国社会保障发展报告 (2007) No. 3 (Chen, Jiagui/Wang, Yanzhong (Hrsg.), China Social Security System Development Report 2007 No. 3), S. 3, 14.

606 卫生部统计信息中心, 第三次国家卫生服务调查分析报告 (Statistikzentrum des Gesundheitsministeriums, Abstract of the Report on the 3rd National Health Service Investigation and Analysis), in: 中国医院 (Chinese Hospitals), 2005/1, S. 3. 
sparen. Die Ausweitung der Inlandsnachfrage - eine wichtige Strategie der chinesischen Regierung für das nachhaltige Wirtschaftswachstum - wird dadurch eingeschränkt.

Nur die Krankenhäuser und die medizinischen Unternehmen sind die Nutznießer der Gesundheitsreform. Obwohl die Nutzungsrate der medizinischen Einrichtungen Jahr für Jahr stetig gesunken ist, stiegen die Einkommen der Krankenhäuser deutlich. ${ }^{607}$ Die Leitlinie der Gesundheitsreform, durch die marktorientierte Konkurrenz die Effizienz der Gesundheitseinrichtungen zu erhöhen sowie die Preise der medizinischen Dienstleistungen zu reduzieren, erwies sich in der Praxis als undurchführbar.

Aus der zwanzigjährigen Reformerfahrung wurde der Schluss gezogen, dass der Aufbau eines gerechten und effektiven Gesundheitssystems nicht durch die marktorientierte Reform in China verwirklicht wurde. Die Öffentlichkeit kritisiert übereinstimmend, dass die Regierung ihre Verantwortung für die Finanzierung und die Erhaltung des Gesundheitssystems nicht wahrnimmt. ${ }^{608}$ Nicht nur die Bürger akzeptierten die Folgen der Gesundheitsreform nicht. Auch die staatlichen Forschungsinstitute und die Experten kritisierten vehement die Gesundheitsreform. Sie sind der Auffassung, dass die Reform im Wesentlichen gescheitert ist. 609 Im Jahre 2000 stellte die WHO ihre 191 Mitgliedstaaten nach der Gerechtigkeit des Gesundheitssystems in eine Reihe, China rangierte an 188. Stelle. 610

\section{Neue Runde der Gesundheitsreform}

Die zunehmende Kritik hat die Regierung dazu gezwungen, seit 2006 eine neue Runde der Gesundheitsreform in Gang zu setzen. Eine Koordinationsgruppe für die Gesundheitsreform, an der 16 Ministerien und Kommissionen des Staatsrats beteiligt sind, wurde im Jahre 2006 errichtet. Die Staatskommission für Entwicklung und Reform und das Gesundheitsministerium leiten die Ausarbeitung des Reformplans. Am Ende des Jahres 2007 hat der Staatsrat in einem Bericht an den Ständigen Ausschuss des Nationalen Volkskongresses die Richtlinien der neuen Gesundheitsreform aufgrund der von der KP Chinas seit 2006 aufgestellten Leitgedanken und die Schwerpunkte der Arbeit ver-

607 卫生部统计信息中心, 第三次国家卫生服务调查分析报告 (Statistikzentrum des Gesundheitsministeriums, Abstract of the Report on the 3rd National Health Service Investigation and Analysis), in: 中国医院 (Chinese Hospitals), 2005/1, S. 10.

608 Ausführlich: 劳动和社会保障部社会保障研究所, 中国卫生改革的方向与总体思路 (Forschungsinstitut für soziale Sicherheit beim Ministerium für Arbeit und soziale Sicherheit, Die Richtung und die Gesamtlinien der chinesischen Gesundheitsreform), in: 社会保障研究 (Forschung über sozialen Sicherheit), 2007/2, S. 3.

609 国务院发展研究中心课题组, 对中国医疗卫生体制改革的评价与建议 (Forschungszentrum des Staatsrats für Entwicklung, Kommentar und Vorschläge zur Reform des Gesundheitssystems Chinas), in: 中国发展评论 (China Development Review), 2005/3, Heft 7-1; 王绍光, 中国公共卫生 的危机与转机 (Wang, Shaoguang, Krise und Wendung des öffentlichen Gesundheitsdienstes in China), in: 比较 (Comparative Studies), 2003/7, S. 52ff.

610 World Health Organization, The World Health Report 2000: Health System: Improving Performance, S. 152. 
öffentlicht. 611 Wegen des heftigen Streits über die Reformmodelle wurden erst am 17. März 2009 der Reformplan von dem Zentralkomitee der Partei und dem Staatsrat festgelegt. ${ }^{612}$ Gleichzeitig hat der Staatsrat die Durchführungsmaßnahmen der Gesundheitsreform (2009 - 2011) ausgearbeitet. 613

\section{a) Übereinstimmung: Verstärkung der Regierungsverantwortung}

Da die gegenwärtige schwierige Lage der Gesundheitsreform sich hauptsächlich aus den Finanzproblemen der Regierung und den falschen Leitlinien ergibt, herrscht in den akademischen Kreisen Optimismus, dass die Gesundheitsreform durch die Aufstockung der staatlichen finanziellen Unterstützung und die Regulierung der Gesundheitspolitik aus der schwierigen momentanen Lage befreit werden kann. 614

Die Leitgedanken der neuen Gesundheitsreform wurden zuerst von der KP Chinas im Beschluss über den Aufbau einer sozialistischen harmonischen Gesellschaft von $2006^{615}$ veröffentlicht:

„Der gemeinnützige Charakter des öffentlichen Gesundheitssystems ist festzuhalten, die Verantwortung der Regierung ist zu verstärken.“

Die neue Gesundheitsreform kehrt grundlegend wieder zu den im Beschluss von 1997616 festgelegten Richtlinien zurück. Die Richtlinie „Kommerzialisierung des Gesundheitssystems“ wird zurzeit von der ,überwiegenden Rolle der Regierung im Bereich der öffentlichen Gesundheitsversorgung und medizinischen Dienstleistungen" 617 ersetzt. Die Regierungsverantwortung beinhaltet hauptsächlich zwei Aspekte. Einer ist die Rolle der Regierung für Aufbringen und Verteilung der Geldmittel, der andere ist

611 国务院关于城乡医疗卫生体制改革和加强食品药品安全监管情况的报告 (Bericht des Staatsrats über die Gesundheitsreform sowie die Überwachung- und Verwaltungsarbeit von Lebensmittel und Arzneimittel), vom 26. 12. 2007, in: 健康报 (JKB), vom 27. 12. 2007;

612 中共中央, 国务院关于深化卫生体制改革的意见 (Mitteilungen des Zentralkomitees der KP Chinas und des Staatsrats über die Vertiefung der Gesundheitsreform), 中发 (2009) 6号, vom 17. 03. 2009.

613 国务院医药卫生体制改革近期重点实施方案 (2009-2011) (Durchführungsplan des Staatsrats für die Gesundheitsreform 2009-2011)，国发 (2009) 12号, vom 18. 03. 2009.

614 王绍光, 政策导向, 汲取能力与卫生公平 (Wang, Shaoguang, State Policy Orientation, Extractive Capacity and the Equality of Healthcare in Urban China), in: 中国社会科学 (Social Sciences in China), 2005/6, S. 120.

615 中共中央关于构建社会主义和谐社会若干重大问题的决定 (Beschluss des Zentralkomitees der KP Chinas über einige wichtigen Fragen zur Strukturierung einer harmonischen sozialistischen Gesellschaft), vom 11. 10. 2006.

616 中共中央, 国务院关于卫生改革与发展的决定 (Beschluss des Zentralkomitees der KP Chinas und des Staatsrats über die Reform und Entwicklung des Gesundheitswesens), 中发 (1997) 3号, vom 15. 01. 1997.

617 国务院关于城乡医疗卫生体制改革和加强食品药品安全监管情况的报告 (Bericht des Staatsrats über die Gesundheitsreform sowie die Überwachung- und Verwaltungsarbeit von Lebensmittel und Arzneimittel), vom 26. 12. 2007, in: 健康报 (JKB), vom 27. 12. 2007; 中共中央, 国务院关 于深化卫生体制改革的意见 (Mitteilungen des Zentralkomitees der KP Chinas und des Staatsrats über die Vertiefung der Gesundheitsreform)，中发 (2009) 6号, vom 17. 03. 2009. 
der allseitige Eingriff der Regierung in den Aufbau des Gesundheitssystems. ${ }^{618}$ Durch den Eingriff und die Führung der Regierung wird der gemeinnützliche Charakter des Gesundheitssystems gewährleistet, während der Markt weiter eine Regulierungsfunktion ausübt. 619

Die Ziele der neuen Gesundheitsreform sind zum einen ein grundlegendes medizinisches System zu errichten, zum anderen den Bürgern sichere, wirksame und preiswerte Gesundheitsdienstleistungen anzubieten. ${ }^{620}$ In dem Beschluss von 2006 wurde der Umfang eines grundlegenden Gesundheitssystems vollständig dargestellt. Es umfasst zunächst ein System der Gesundheitsabsicherung, dazu gehören die Grundkrankenversicherung für Arbeitnehmer in Städten, das neue kooperative medizinische System für die ländliche Bevölkerung, die Grundkrankenversicherung für die städtischen Bewohner und die medizinische Hilfe. Ferner beinhaltet es ein System der grundlegenden öffentlichen Gesundheitsversorgung, welches Krankheitsprävention, Beseitigung der Infektionskrankheiten und Epidemien, Erhaltung der Sozialhygiene sowie spezielle Gesundheitsfürsorge für Mütter und Kinder erfasst. Außerdem zählt das System der medizinischen Dienste dazu. Ein Netz der öffentlichen medizinischen Einrichtungen und ein Überweisungsmechanismus werden von der Regierung aufgebaut, alle medizinischen Einrichtungen werden von den lokalen Gesundheitsbehörden einheitlich geplant und verwaltet. Schließlich existiert ein System der Arzneiversorgung. Die Liste und Preise der unentbehrlichen Arzneimittel werden von der Regierung festgelegt, die öffentlichen Gesundheitseinrichtungen dürfen zukünftig nicht mehr durch den Verkauf von Arzneimitteln Gewinne erzielen. 621

Hinsichtlich der Finanzierungsverantwortung für das Gesundheitssystem wurde ein Rahmen im Jahre 2007 festgelegt:

„Die Regierung spielt eine Hauptrolle für die grundlegende öffentliche Gesundheitsversorgung und die grundlegenden medizinischen Dienstleistungen. Die grundlegende öffentliche Gesund-

618 Ausführlich vgl. 葛延风/贡森, 中国医改: 问题, 根源, 出路 (Ge, Yanfeng/Gong, Sen, Chinese Healthcare Reform), S. 18.

619 中共中央, 国务院关于深化卫生体制改革的意见 (Mitteilungen des Zentralkomitees der KP Chinas und des Staatsrats über die Vertiefung der Gesundheitsreform), 中发 (2009) 6号, vom 17. 03. 2009.

620 In: 中共中央关于构建社会主义和谐社会若干重大问题的决定 (Beschluss des Zentralkomitees der KP Chinas über einige wichtige Fragen zur Strukturierung einer harmonischen sozialistischen Gesellschaft), vom 11. 10. 2006; 胡锦涛, 在中国共产党第十七次全国代表大会上的报告 $(H u$, Jintao, Bericht auf dem 17. Parteitag der KP Chinas), vom 15. 10. 2007, in: 人民日报 (RMRB), 25. 10. 2007; 温家宝，2008年政府工作报告 (Wen, Jiabao, Tätigkeitsbericht des Staatsrates 2008), vom 05. 03. 2008, in: 人民日报 (RMRB), 20. 03. 2008.

621 中共中央关于构建社会主义和谐社会若干重大问题的决定 (Beschluss des Zentralkomitees der KP Chinas über einige wichtige Fragen zur Strukturierung einer harmonischen sozialistischen Gesellschaft), vom 11. 10. 2006; 高强, 努力保证人民公平享有基本卫生保健 (Gao, Qiang, Kampf mit vollem Einsatz für die Gewährleistung eines gerechten grundlegenden Gesundheitssystems für alle Bürger), in: 人民日报 (RMRB), vom 23. 11. 2006; 国务院关于城乡医疗卫生体制改革和加 强食品药品安全监管情况的报告 (Bericht des Staatsrats über die Gesundheitsreform sowie die Überwachung- und Verwaltungsarbeit von Lebensmittel und Arzneimittel), vom 26. 12. 2007, in: 健康报 (JKB), vom 27. 12. 2007. 
heitsversorgung wird hauptsächlich von der Regierung finanziert. Die Kosten der grundlegenden medizinischen Dienstleistungen werden von der Regierung, der Gesellschaft und dem Einzelnen rational verteilt. Die besonderen medizinischen Dienstleistungen werden durch den Einzelnen oder durch die kommerzielle Gesundheitsversicherung bezahlt. ... Die Regierung berücksichtigt bei ihrer finanziellen Unterstützung gleichzeitig sowohl die Forderungen von Lieferanten als auch von Nachfragern (,supplier and demander", dies sind nämlich die Gesundheitseinrichtungen und die Bürger) der medizinischen Dienstleistungen“. 622

In den Mitteilungen der KP Chinas und der Regierung von 2009 wurde dieses „von der Regierung geführte Multi-Modell“" weiter konkretisiert: Die Regierungen verschiedener Ebenen sind für die Finanzierung der grundlegenden öffentlichen Gesundheitsversorgung und der öffentlichen medizinischen Einrichtungen, die Zuschüsse für die öffentlichen Krankenhäuser sowie die Unterstützungen für die Gesundheitsabsicherung verantwortlich. Das grundlegende Gesundheitssystem wurde in den Mitteilungen von 2009 zum ersten Mal als „öffentliches Gut für alle Bürger“ bezeichnet. ${ }^{623}$ Dies wurde als der bislang wichtigste Schritt der Gesundheitsreform angesehen. ${ }^{624}$

\section{b) Kontroverse: Finanzierungsmodell der Gesundheitsabsicherung}

Nach der Festlegung der „Hauptrolle der Regierung für die grundlegende öffentliche Gesundheitsversorgung und die grundlegenden medizinischen Dienstleistungen" konzentriert sich die Diskussion hauptsächlich darauf, wie die Richtlinie ,rationale Kostenverteilung von der Regierung, der Gesellschaft und dem Einzelnen für die grundlegenden medizinischen Dienstleistungen" durchgeführt wird. Es geht nicht nur um die Verteilungsquoten der Regierung, der Gesellschaft und der Bürger, sondern auch um das Finanzierungsmodell der Gesundheitsabsicherung. Konkret stellt sich die Frage: Wird das System hauptsächlich durch Steuermittel oder durch soziale Versicherungen finanziert? In dieser Frage gingen die Ansichten des Gesundheitsministeriums und des Ministeriums für Arbeit und soziale Sicherheit sowie der Experten sehr auseinander.

Nach der Meinung von Ge, Yanfeng und seiner Forschungsgruppe (Forschungszentrum des Staatsrats für Entwicklung) sollte ein Grundabsicherungssystem in die bestehenden Gesundheitsabsicherungssysteme (Krankenversicherungen, medizinische Hilfe) eingeführt werden. Dieses System wird vom Staat durch Steuermittel finanziert. Die häufig auftretenden Krankheiten werden in den öffentlichen Gesundheitseinrichtungen der Wohnviertel der Städte oder in den Gesundheitsstationen auf der Gemeindeebene und Sanitätsstationen auf der Dorfebene kostenlos behandelt. Die sozialen Krankenver-

622 国务院关于城乡医疗卫生体制改革和加强食品药品安全监管情况的报告 (Bericht des Staatsrats über die Gesundheitsreform sowie die Überwachung- und Verwaltungsarbeit von Lebensmittel und Arzneimittel), vom 26. 12. 2007, in: 健康报 (JKB), vom 27. 12. 2007.

623 中共中央, 国务院关于深化卫生体制改革的意见 (Mitteilungen des Zentralkomitees der KP Chinas und des Staatsrats über die Vertiefung der Gesundheitsreform), 中发 (2009) 6号, vom 17. 03. 2009.

624 王军, 新医改负重启程 (Wang, Jun, Die neue Gesundheitsreform), in: 瞭望 (Liaowang), vom 07. 04. 2009. 
sicherungen beinhalten die Sicherung für schwere Krankheiten, die nicht vom Grundabsicherungssystem übernommen werden. Zwischen beiden Systemen wird ein Überweisungsmechanismus aufgebaut. ${ }^{625}$

Diese Vorschläge basieren auf der gegenwärtigen gesellschaftlichen Lage Chinas. Die Einkommensdisparitäten der Bevölkerung sind derzeitig noch sehr hoch, viele arme Bürger, insbesondere die Bauern in den armen Gebieten besitzen nicht die Finanzen, an einer Krankenversicherung teilzunehmen. Die Regierung könnte durch staatliche $\mathrm{Zu}$ schüsse und medizinische Hilfe dieses Problem lösen, aber die Verwaltungskosten auf dem Land wären ziemlich hoch. ${ }^{626}$ Andererseits entsprechen die derzeitige chinesische Beschäftigungsstruktur und die Organisations- sowie Verwaltungsfähigkeit der Sozialversicherungsträger noch nicht den Anforderungen eines effektiven Systems für Beschaffung und Bewirtschaftung der Krankenversicherungsfonds. Deshalb sei die Errichtung einer steuerfinanzierten medizinischen Grundabsicherung vorteilhaft. 627

Dieser Reformplan wird als ein „gemischtes System“ bezeichnet, vom dem die Krankenversicherungen noch umfasst werden. Die Einführung eines steuerfinanzierten Sicherungssystems wird als eine „Rückkehr zur chinesischen Tradition der staatlichen Verantwortung“" angesehen.628 Sie profitiert allerdings auch von der Erfahrung des britischen National Health Systems. 629 Die sozialistische Tradition, die europäischen Erfahrungen der Gesundheitsabsicherung sowie der liberale Einfluss sind auf dieser Weise verschmolzen.

Der Reformentwurf des Gesundheitsministeriums erfasst im Großen und Ganzen den Plan von $G e$ 's Forschungsgruppe; in dem ein dreistufiges Gesundheitsabsicherungssystem vorgeschlagen wurden. ${ }^{630}$ Die erste Stufe ist die einheitliche steuerfinanzierte Absicherung der grundlegenden medizinischen Dienstleistungen für alle Bürger. Die zweite Stufe sind die obligatorischen Krankenversicherungen für schwere Krankheiten. Die Grundkrankenversicherung für Arbeitnehmer wird von Arbeitnehmern und Arbeitgebern gemeinsam finanziert, sie umfasst auch die Familienangehörigen der Arbeitnehmer. Schließlich ist die dritte Stufe die kommerzielle Krankenversicherung.

Das Modell „steuerfinanzierte medizinische Grundabsicherung“ wurde auch von vielen anderen Experten vorgeschlagen. ${ }^{631}$ Demgegenüber hat der Soziologe Gu, Xin eine

625 葛延风/贡森, 中国医改: 问题, 根源, 出路 (Ge, Yanfeng/Gong, Sen, Chinese Healthcare Reform), S. 240ff.

626 葛延风/贡森, 中国医改: 问题, 根源, 出路 (Ge, Yanfeng/Gong, Sen, Chinese Healthcare Reform), S. 232.

627 葛延风/贡森, 中国医改: 问题, 根源, 出路 (Ge, Yanfeng/Gong, Sen, Chinese Healthcare Reform), S. 256.

628 王绍光, 医改不存在迷局: 理性回归中国传统 (Wang, Shaoguang, Gesundheitsreform: Rückkehr zur chinesischen Tradition), in: 书城 (Booktown), 2005/10, S. 33ff.

629 王世玲定军, 关于医改新方案的报道 (Wang, Shiling/Ding, Jun, Bericht über die neuen Pläne der Gesundheitsreform), in: 21世纪经济报道 (21CBH), vom 23.09. 2006.

630 王世玲定军, 关于医改新方案的报道 (Wang, Shiling/Ding, Jun, Bericht über die neuen Pläne der Gesundheitsreform), in: 21世纪经济报道 (21CBH), vom 23. 09. 2006.

631 Siehe: 王绍光, 医改不存在迷局：理性回归中国传统 (Wang, Shaoguang, Gesundheitsreform: Rückkehr zur chinesischen Tradition), in: 书城 (Booktown), S. 33ff; 刘军民, 过度市场化与高度 
andere Meinung geäußert: Durch ein soziales Krankenversicherungssystem, das in China als ,deutsches Modell“ bezeichnet wird, könnte das Ziel „Jeder genießt medizinische Versorgung" schrittweise vervollkommnet werden. Im Vergleich mit dem Aufbau eines neuen Absicherungssystems könnten die Übergangskosten der Gesundheitsreform durch die Verbesserung der bestehenden Krankenversicherungssysteme (Grundkrankenversicherung für Arbeitnehmer, Grundkrankenversicherung für die städtischen Bewohner und das neue kooperative medizinische System für die ländliche Bevölkerung) in großem Maßstab reduziert werden, und die Gesundheitsreform würde damit stabiler vorangehen. ${ }^{632}$ Nach dem Reformplan von $G u$ sollten folgende Maßnahmen durchgeführt werden: ${ }^{633}$ Die Deckungsrate der sozialen Krankenversicherungen ist durch die Erhöhung der staatlichen Zuschüsse und die Umwandlung der freiwilligen Systeme zu den obligatorischen Systemen zu erhöhen. Die Leistungen der sozialen Krankenversicherungen umfassen nicht nur die Behandlung der schweren Krankheiten, sondern auch die grundlegenden medizinischen Dienstleistungen. Das Leistungsniveau der sozialen Krankenversicherungen wird auf 70\%-80\% angehoben.

Das Ministerium für Arbeit und soziale Sicherheit neigte auch zu dem Modell der „Krankenversicherungen für alle Bürger“.634 In einem Forschungsbericht hat das Forschungsinstitut für soziale Sicherheit erklärt, dass die Regierung ein steuerfinanziertes Grundabsicherungssystem der medizinischen Dienstleistungen nicht finanzieren könne. Mit einem solchen System könne die hohe Belastung der Regierung oder die Unzufriedenheit der Bürger für die Gesundheitsleistungen zur direkten Konfrontation zwischen Regierung und Bürger führen, die allerdings durch die Einführung eines Dritten - der Sozialversicherungsträger - vermieden werden könne. ${ }^{635}$

Um die Stabilität der Gesellschaft in der Wirtschaftsreform aufrechtzuerhalten, wird das Prinzip „Stabilität und Kontinuität der gegebenen politischen Richtlinien sind festzuhalten“ immer von der KP Chinas und der Regierung betont. Angesichts dieser Situation wird die Gesundheitsabsicherung in gewissem Maße im Rahmen des bestehenden Systems vorangetrieben. Die sozialen Krankenversicherungen spielen bei der Festlegung des neuen Reformplans der Gesundheitsabsicherung weiter die wichtigste Rolle.

分权化: 中国医疗卫生改革的双重误区 (Liu, Junmin, Over Marketization and high Decentralization: Double Error in China's Health Care), in: 开放导报 (China Opening Herald), 2005/5, S. 42; 李玲, 医改方向: 政府主导下市场补充 ( $L i$, Ling, Gesundheitsreform: Hauptverantwortung der Regierung mit dem Marktsystem als Ergänzung), in: 中国医疗前沿 (China Healthcare Innovation), 2006/1, S. 33ff.

632 顾昕, 通向全民医保的渐进主义之路 (Gu, Xin, Ein Weg zur Gesundheitsabsicherung für alle Bürger), in: 东岳论丛 (Dong Yue Tribune), 2008/1, S. 11.

633 顾昕, 通向全民医保的渐进主义之路 ( $G u$, Xin, Ein Weg zur Gesundheitsabsicherung für alle Bürger), in: 东岳论丛 (Dong Yue Tribune), 2008/1, S. 8ff.

634 王世玲定军, 关于医改新方案的报道 (Wang, Shiling/Ding, Jun, Bericht über die neuen Pläne der Gesundheitsreform), in: 21世纪经济报道 (21CBH), vom 23. 09. 2006.

635 劳动和社会保障部社会保障研究所, 中国卫生改革的方向与总体思路 (Forschungsinstitut für soziale Sicherheit beim Ministerium für Arbeit und soziale Sicherheit, Die Richtung und die Gesamtlinien der chinesischen Gesundheitsreform), in: 社会保障研究 (Forschung über die soziale Sicherheit), 2007/2, S. 34ff. 
Ein deutliches Anzeichen dafür ist die Beschleunigung des Aufbaus der Grundkrankenversicherung für die städtischen Bewohner und des neuen kooperativen medizinischen Systems für die ländliche Bevölkerung seit 2008. In den Mitteilungen von 2009 wurde gefordert, bis 2011 die Teilnahmerate der Grundkrankenversicherungen auf 90\% der gesamten Bevölkerung zu steigern. Das Leistungsniveau verschiedener Krankenversicherungen und die staatlichen Zuschüsse für die Gesundheitsversicherungen werden Schritt für Schritt erhöht. Schließlich werden die Rahmen der Versicherungszweige grundlegend vereinheitlicht. 636

\section{Ein gemischtes System?}

Hinsichtlich der Konkretisierung der Richtlinie „gleiche Berücksichtigung der Forderungen von Lieferanten und Nachfragern der medizinischen Dienstleistungen" wurden die Schwerpunkte auch in den Mitteilungen erwähnt. Während die staatlichen Zuschüsse für die öffentlichen Krankenhäuser erhöht werden, wird das Leistungsniveau der Krankenversicherungen ebenfalls allmählich erhöht, um die Belastung des Einzelnen zu mindern. 637 Von 2009 bis 2011 sollen insgesamt 850 Mrd. RMB von den Regierungen für das Gesundheitssystem investiert werden (davon $332 \mathrm{Mrd}$. RMB von der Zentralregierung), davon werden zwei Drittel der Geldmittel für die Bedürftigen genutzt. ${ }^{638} \mathrm{Im}$ Jahre 2010 werden die Zuschüsse für das neue kooperative medizinische System der ländlichen Bevölkerung und die Grundkrankenversicherung der städtischen Bewohner auf 120 RMB pro Person erhöht. ${ }^{639}$ Das heißt, dass obwohl die sozialen Krankenversicherungen beim Aufbau der Gesundheitsabsicherung weiter die wichtigste Rolle spielen sollen, nehmen der Gemeinwohlcharakter des Gesundheitssystems und die staatliche Verantwortung deutlich zu. Die Regierung übernimmt in gewissem Maß (zumindest im Zeitraum 2009-2011) die Finanzierung der Gesundheitsabsicherung.

Andererseits wird die „Funktion des Marktmechanismus“640 in der neuen Reformrunde - insbesondere beim Aufbau des Arzneimittelsystems - weiter betont. Im „Ent-

636 中共中央, 国务院关于深化卫生体制改革的意见 (Mitteilungen des Zentralkomitees der KP Chinas und des Staatsrats über die Vertiefung der Gesundheitsreform), 中发 (2009) 6号, vom 17. 03. 2009.

637 国务院关于城乡医疗卫生体制改革和加强食品药品安全监管情况的报告 (Bericht des Staatsrats über die Gesundheitsreform sowie die Überwachung- und Verwaltungsarbeit von Lebensmittel und Arzneimittel), vom 26. 12. 2007, in: 健康报 (JKB), vom 27. 12. 2007; 中共中央, 国务院关 于深化卫生体制改革的意见 (Mitteilungen des Zentralkomitees der KP Chinas und des Staatsrats über die Vertiefung der Gesundheitsreform)，中发 (2009) 6号, vom 17. 03. 2009.

638 国务院医药卫生体制改革近期重点实施方案 (2009-2011) (Durchführungsplan des Staatsrats für die Gesundheitsreform 2009-2011)，国发 (2009) 12号, vom 18.03. 2009.

639 Durchführungsplan des Staatsrats für die Gesundheitsreform 2009-2011.

640 中共中央, 国务院关于深化卫生体制改革的意见 (Mitteilungen des Zentralkomitees der KP Chinas und des Staatsrats über die Vertiefung der Gesundheitsreform), 中发 (2009) 6号, vom 17. 03. 2009. 
wurf der Mitteilungen über die Gesundheitsreform"641 wurde festgestellt, dass die unentbehrlichen Arzneimittel durch die vom Staat festgelegten Hersteller produziert werden sollten. Dies wurde allerdings wegen des heftigen Einwandes der Arzneimittelhersteller und Apotheken aus der endgültigen Fassung gestrichen. ${ }^{642}$ In diesem Bereich wird ,die Funktion des Markts unter der Makro-Kontrolle der Regierung voll entfaltet".643 Beim Ankaufen der unentbehrlichen Arzneimittel wird ein Wettbewerbsmechanismus eingeführt. Der Staat legt nur die empfohlenen Preise der Arzneimittel fest.

Zusammengefasst ist der gegenwärtige Reformplan ein Verbesserungsplan für einen kurzen Zeitraum und keine völlige Neuerung des Gesundheitssystems. Staatliche Verantwortung, Marktmechanismus, Gesundheitsversicherungen und Steuerfinanzierung wurden gemischt im Reformplan geregelt, ein Konsens über das Finanzierungsmodell existiert zurzeit noch nicht. Im Reformplan wurden die Aufhebung des Individualkontos der Grundkrankenversicherung 644 und die Ersetzung der Kostenerstattung durch Vorauszahlung, ${ }^{645}$ die von vielen Experten vorgeschlagen wurde, auch nicht erwähnt.

Die Regierung hat versprochen, bis 2011 den Rahmen des grundlegenden Gesundheitssystems aufzubauen, 2020 ein alle städtische und ländliche Bewohner erfassendes Gesundheitssystem zu vervollkommnen. 646 Dafür hat die Regierung seit 2006 die Ausgaben für das Gesundheitssystem in großem Maßstab aufgestockt und eine Reihe von Maßnahmen durchgeführt. Die Schwerpunkte der Reform liegen zurzeit in der Vervollkommnung des Systems der öffentlichen Gesundheitsversorgung, des ländlichen Drei-

641 关于深化卫生体制改革的意见 (征求意见稿) (Entwurf zun den Mitteilungen über die Vertiefung der Gesundheitsreform), vom 14. 10. 2008. http://shs.ndrc.gov.cn/yg/qwll/t20081014_240214.htm (Stand: 15. 07. 2010).

642 杨中旭, 新医改最后博峦: 围绕市场化与回归计划激烈交锋 (Yang, Zhongxü, Die neue Gesundheitsreform: Kommerzialisierung oder Planwirtschaft?), in: 中国新闻周刊 (China Newsweek), 2009/13, S. 22ff.

643 中共中央, 国务院关于深化卫生体制改革的意见 (Mitteilungen des Zentralkomitees der KP Chinas und des Staatsrats über die Vertiefung der Gesundheitsreform), 中发 (2009) 6号, vom 17. 03. 2009.

644 高书生, 社会保障改革何去何从 (Gao, Shusheng, Die Reform der sozialen Sicherheit steht am Scheideweg), S. 171; 葛延风/贡森, 中国医改: 问题, 根源, 出路 (Ge, Yanfeng/Gong, Sen, Chinese Healthcare Reform), S. 110; 劳动和社会保障部社会保障研究所, 关于中国医疗保障制度 改革的框架性建议 (Forschungsinstitut für soziale Sicherheit beim Ministerium für Arbeit und soziale Sicherheit, Vorschläge für die Reform des chinesischen Gesundheitssystem), in: 社会保障 研究 (Forschung über die soziale Sicherheit), 2007/5, S. 16.

645 劳动和社会保障部社会保障研究所, 关于中国医疗保障制度改革的框架性建议 (Forschungsinstitut für soziale Sicherheit beim Ministerium für Arbeit und soziale Sicherheit, Vorschläge für die Reform des chinesischen Gesundheitssystem), in: 社会保障研究 (Forschung über die soziale Sicherheit), 2007/5, S. 16; 顾昕, 中国医疗服务体制的改革后果与政府角色 (Consequences of Reform and Government Role in China's Health Care System), in: 陈佳贵/王延中, 中 国社会保障发展报告 (2007) No. 3 (Chen, Jiagui/Wang, Yanzhong (Hrsg.), China Social Security System Development Report (2007) No. 3), S. 244.

646 中共中央, 国务院关于深化卫生体制改革的意见 (Mitteilungen des Zentralkomitees der KP Chinas und des Staatsrats über die Vertiefung der Gesundheitsreform), 中发 (2009) 6号, vom 17. 03. 2009. 
Stufen-Netzes und der städtischen Gesundheitseinrichtungen in Wohnvierteln sowie des Systems der Gesundheitsabsicherung. 647

Aufgrund der hohen Finanzkraft der Zentralregierung ist vorauszusehen, dass diese Ziele in absehbarer Zeit erreicht werden können. Die Deckungsrate des neuen kooperativen medizinischen Systems für die ländliche Bevölkerung erreichte im Jahre 2009 schon über 90\%. Allerdings kann die nachhaltige Entwicklung des Gesundheitssystems nicht nur mit ausreichender finanzieller Unterstützung gewährleistet werden, es bedarf eines umfassenden Reformplans. Zurzeit muss die Regierung manche wichtige Aspekte des Reformplans, wie ein vernünftiges Umverteilungssystem zwischen der Zentralregierung und den lokalen Regierungen, ein der Realität und den Anforderungen der Öffentlichkeit entsprechendes Grundmodell des Krankenversicherungssystems, sowie ein Kontrollmechanismus der medizinischen Dienstleistungen und der Arzneimittelversorgung konkretisieren. Die oben genannten Aspekte überschreiten in gewissem Umfang den Rahmen der Gesundheitsreform, betreffen die weitere Reform des Finanzsystems, die Entwicklung der sozialistischen Marktwirtschaft sowie den Aufbau der Staatstheorien.

\section{Beschäftigungsförderung und Arbeitslosensicherung}

Als der bevölkerungsreichste Staat der Erde steht die Volksrepublik China in ihren wirtschaftlichen Umstrukturierungsprozessen oft unter hohem Druck, Beschäftigung zu schaffen. Die Arbeitslosigkeit erreichte Anfang der 1950er Jahre, Ende der 1970er Jahre und Mitte der 1990er Jahre ihre Höchstwerte. Die Beschäftigungspolitik hatte sich den wirtschaftlichen und politischen Grundlagen entsprechend oft verändert. In der Periode der Planwirtschaft lag der Schwerpunkt der Beschäftigungspolitik in der Beseitigung der Arbeitslosigkeit, seit der Phase „Reform und Öffnung“ ändert der Schwerpunkt sich zu einer aktiven Beschäftigungsförderung, ${ }^{648}$ die zurzeit in Verbindung mit der Arbeitslosenversicherung und der Sicherung des Existenzminimums ein soziales Sicherungsnetz für die Bevölkerung im erwerbsfähigen Alter bildet.

\section{Beschäftigungspolitik in der Periode der Planwirtschaft}

Am Anfang der 1950er Jahre kam es zum ersten Höhepunkt der Arbeitslosigkeit in der Volksrepublik. Die Zahl der Arbeitslosen in den Städten betrug über vier Millionen.

647 2008年政府工作报告 (Tätigkeitsbericht des Staatsrats 2008), vom 05. 03. 2008; 中共中央, 国务 院关于深化卫生体制改革的意见 (Mitteilungen des Zentralkomitees der KP Chinas und des Staatsrats über die Vertiefung der Gesundheitsreform), 中发 (2009) 6号, vom 17. 03. 2009.

648 Ausführlich siehe: 胡鞍钢/程永宏, 从计划体制转向市场机制: 对中国就业政策的评估 (19492001) (Hu, angang/Cheng, Yonghong, Vom planwirtschaftlichen System zum marktwirtschaftlichen System - Kommentar zur chinesischen Beschäftigungspolitik (1949-2001), in: 胡鞍钢/程永宏/杨 韵新, 扩大就业与挑战失业 (Hu, Angang/Cheng, Yonghong/Yang, Yunxin (Hrsg.), Beschäftigungsförderung und Arbeitslosigkeitsbeseitigung), S. 3 ff. 
Die Regierung hatte durch Übergangsmaßnahmen, 649 wie Schaffung der Arbeitsplätze und Gewährung von Hilfsgeld, die Arbeitslosigkeit gesenkt. ${ }^{650}$ Im Jahre 1958 proklamierte die Regierung, dass die Arbeitslosigkeit in der Volksrepublik völlig abgeschafft worden sei. 651

In der Tat war der Beschäftigungsdruck in der Periode der Planwirtschaft stets hoch. Die überflüssigen städtischen Arbeitskräfte wurden von der Regierung aufs Land geschickt, um die damalige Industrialisierungsstrategie nicht durch das Beschäftigungsproblem zu behindern. ${ }^{652}$ 1962-1979 wanderten insgesamt 17.76 Millionen städtische Jugendliche mit Schulbildung auf das Land ab. 653

In den Städten kontrollierte die Regierung durch die ,zentralisierte Anwerbung und Zuweisung"654 die Einsetzung der Arbeitskräfte. Die Arbeitsbehörden verschiedener Regierungsebenen waren für die Beschäftigung aller städtischen Arbeitskräfte verantwortlich, der freie Arbeitsmarkt existierte in der Periode der Planwirtschaft nicht mehr. Die Regierung gewährleistete den Arbeitnehmern durch das strikte Kündigungsverbot $^{655}$ und das soziale Sicherungssystem eine umfassende Sicherung. „Beschäftigung“ bedeutete damals für die Arbeitenden nicht nur eine Sicherung der Arbeit und des Lohnes, sondern beinhaltete auch soziale Förderungs- sowie Wohlfahrtsmaßnahmen.

649 劳动部, 救济失业工人暂行办法 (Arbeitsministerium, Vorläufige Maßnahmen für Hilfe der Arbeitslosen), vom 17. 06. 1950.

650 Ausführlich vgl. 程永宏, 中国就业制度演变与评估 (Cheng, Yonghong, Kommentar zur Wandlung des Beschäftigungssystems Chinas), in: 胡鞍钢/程永宏/杨韵新, 扩大就业与挑战失业 ( $\mathrm{Hu}$, Angang/Cheng, Yonghong/Yang, Yunxin (Hrsg.), Beschäftigungsförderung und Arbeitslosigkeitsbeseitigung), S. 45; 游钧, 2006 - 2007年: 中国就业报告 (You, Jun (Hrsg.), 2006 - 2007: Blue Book of the Chinese Emploment), S. 154.

651 Siehe: 张车伟, 扩大与促进就业的思路与对策 (Zhang, Chewei, Approaches and Policies to Promote Employment, in: 陈佳贵/王延中，中国社会保障发展报告 2001-2004 (Chen, Jiagui/Wang, Yanzhong (Hrsg.), China Social Security System Development Report 2001-2004), S. $153 \mathrm{ff}$.

652 Vgl. 张车伟, 扩大与促进就业的思路与对策 (Zhang, Chewei, Approaches and Policies to Promote Employment, in: 陈佳贵/王延中，中国社会保障发展报告 2001-2004 (Chen, Jiagui/Wang, Yanzhong (Hrsg.), China Social Security System Development Report 2001-2004), S. 153; 程永宏, 中国就业制度演变与评估 (Cheng, Yonghong, Kommentar zur Wandlung des Beschäftigungssystems Chinas), in: 胡鞍钢/程永宏/杨韵新, 扩大就业与挑战失业 (Hu, Angang/Cheng, Yonghong/Yang, Yunxin (Hrsg.), Beschäftigungsförderung und Arbeitslosigkeitsbeseitigung), S. 45.

653 张车伟, 扩大与促进就业的思路与对策 (Zhang, Chewei, Approaches and Policies to Promote Em-ployment, in: 陈佳贵/王延中，中国社会保障发展报告 2001-2004 (Chen, Jiagui/Wang, Yanzhong (Hrsg.), China Social Security System Development Report 2001-2004), S. 154.

654 中央人民政府政务院关于劳动就业问题的决定 (Beschluss des Staatsverwaltungsrats zu Fragen von Arbeit und Beschäftigung), vom 06. 08. 1952.

655 Nr. 1 des Beschlusses des Staatsverwaltungsrats zu den Fragen von Arbeit und Beschäftigung), vom 06. 08. 1952. 


\section{a) 1980 - 2002: Flexible Beschäftigungspolitik und Arbeitslosensicherung}

Nach der Kulturrevolution wurde die Beschäftigungspolitik korrigiert. Die überflüssigen städtischen Arbeitskräfte wurden nicht mehr auf das Land geschickt. Den Jugendlichen aus den Städten, die sich schon auf dem Land niedergelassen hatten, wurde zugestanden, in die Städte zurückzukehren. Sie strömten in ihre Heimatstädte, warteten auf Arbeitsplätze. Dies führte zu dem zweiten Höhepunkt der Arbeitslosigkeit der Volksrepublik. Weil der Begriff „Arbeitslose“ damals in China nicht verwendet wurde, wurden sie als „Auf-Arbeit-Wartenden“ genannt. Im Jahre 1979 erreichte die Zahl der „AufArbeit-Wartenden“ in den Städten 15 Millionen Personen. 656 Die Richtlinie ,zentralisierte Anwerbung und Zuweisung" konnte nicht mehr durchgeführt werden, sie wurde von einer vorläufigen Beschäftigungsrichtlinie - die sogenannten „Drei-Bindungen“ ersetzt. Die „Drei-Bindungen“ bedeuten eine Bindung der drei Hauptmaßnahmen der Beschäftigungsförderung. Diese Hauptmaßnahmen sind die Arbeitsvermittlung der Arbeitsbehörden, die freiwillige Zusammenarbeit sowie die selbständige Arbeit der Erwerbsfähigen. Sie werden von der Regierung durch eine einheitliche Planung verwaltet. 657 Die „Drei-Bindungen“-Richtlinie war eigentlich eine Zulassung für die Entwicklung der privaten Wirtschaft, die in der Periode der Planwirtschaft verboten war. Diese neue flexiblere Beschäftigungspolitik erzielte beachtliche Ergebnisse. Die offizielle Arbeitslosenrate sank deutlich von 5.5\% im Jahre 1979 auf 1.8\% im Jahre 1985. ${ }^{658}$

Aufgrund der Wirtschaftsreformen begann die Regierung, nach dem zweiten Höhepunkt der Arbeitslosigkeit, das alte Beschäftigungssystem durch ein Arbeitsvertragssystem zu ersetzen. Die seit 1986 aufgebaute Arbeitslosenversicherung war anfänglich eine Zusatzmaßnahme für die Durchführung des neuen Arbeitsvertragssystems und die Reform der staatlichen Unternehmen. Ziel der Errichtung der Arbeitslosenversicherung war es, bei der Strukturänderung der Staatsunternehmen und damit verbundenen Kündigungen den Lebensunterhalt der Arbeitslosen zu sichern, damit die gesellschaftliche Unruhe vermindert wird. ${ }^{659}$

656 程永宏, 中国就业制度演变与评估 (Cheng, Yonghong, Kommentar zur Wandlung des Beschäftigungssystems Chinas), in: 胡鞍钢/程永宏/杨韵新, 扩大就业与挑战失业 (Hu, Angang/Cheng, Yonghong/Yang, Yunxin (Hrsg.), Beschäftigungsförderung und Arbeitslosigkeitsbeseitigung), S. 50.

657 中共中央关于进一步做好城镇劳动就业工作的通知 (Bekanntmachung des Zentralkomitees der KP Chinas über die Verbesserung der Beschäftigungsarbeit in den Städten und Gemeinden), vom 17. 08. 1980; ausführlich auch: 程永宏，中国就业制度演变与评估 (Cheng, Yonghong, Kommentar zur Wandlung des Beschäftigungssystems Chinas), in: 胡鞍钢程永宏/杨韵新, 扩大就业与挑 战失业 (Hu, Angang/Cheng, Yonghong/Yang, Yunxin (Hrsg.), Beschäftigungsförderung und Arbeitslosigkeitsbeseitigung), S. 52ff.

658 程永宏, 中国就业制度演变与评估 (Cheng, Yonghong, Kommentar zur Wandlung des Beschäftigungssystems Chinas), in: 胡鞍钢/程永宏/杨韵新, 扩大就业与挑战失业 (Hu, Angang/Cheng, Yonghong/Yang, Yunxin (Hrsg.), Beschäftigungsförderung und Arbeitslosigkeitsbeseitigung), S. 53.

659 Siehe: 高书生, 社会保障改革何去何从 (Gao, Shusheng, Die Reform der sozialen Sicherheit steht am Scheideweg), S. $92 \mathrm{ff}$. 
Mitte der 1990er Jahre kam es zum dritten Höhepunkt der Arbeitslosigkeit mit der Strukturänderung der Staatsunternehmen. Bis Ende 1994 wurden 12 Millionen Arbeitnehmer (ca. 12\% der gesamten Arbeiternehmer in den Staatsunternehmen) von den Betrieben ausgegliedert. 660 Das heißt, dass die Arbeitnehmer formell noch Arbeitsverhältnisse mit den Betrieben hatten, aber sie erhielten keine Arbeitsplätze und damit nur einen geringfügigen Lohn, weil die Betriebe selbst in wirtschaftliche Schwierigkeiten geraten waren. In dieser prekären Lage wurden die Übergangsmaßnahmen „Zwei Garantien“ und „Drei Sicherungslinien“ im Jahre 1998 eingerichtet, um den ausgegliederten Arbeitern eine Mindestlebenssicherung zu garantieren und ihnen bei der Suche nach einer neuen Stelle zu helfen661. Dafür hatte die Arbeitslosenversicherung nur einen geringfügigen Teil der Geldmittel gewährt, die meisten Geldmittel wurden von der Regierung und den Unternehmen übertragen. 662

Die „Zwei Garantien“ bezogen sich auf die Garantie des Grundlebensstandards für die ausgegliederten Arbeitnehmer der Staatsbetriebe sowie die Garantie der rechtzeitigen und vollen Bezahlung der Renten für die Rentner der Staatsbetriebe. 663 Die „Drei Sicherungslinien" umfassten die Grundlebenssicherung für die ausgegliederten Arbeitnehmer der staatlichen Unternehmen, die Arbeitslosenversicherung und die Existenzsicherung für städtische Bedürftige. Gemäß der Bekanntmachung des Zentralkomitees der KP und des Staatsrats mussten Staatsbetriebe, die Arbeitnehmer ausgegliedert hatten, ein Wiederbeschäftigungszentrum einrichten, an das sich die ausgegliederten Arbeitnehmer wenden konnten, und mit dem sie Vereinbarungen über ihre Grundlebenssicherung sowie Wiederbeschäftigung abschließen. Das Wiederbeschäftigungszentrum war verantwortlich für die Auszahlung von Grundlebenssicherungsgeld, die Entrichtung der Sozialversicherungsbeiträge und die Wiederbeschäftigungsprogramme. In einem Zeitraum von maximal drei Jahren konnte der ausgegliederte Arbeitnehmer Grundlebenssicherungsgeld erhalten, das höher als das Arbeitslosengeld war. Wenn er nach drei Jahren nicht wiederbeschäftigt wurde, wurde das Arbeitverhältnis mit dem Unternehmen

660 程永宏, 中国就业制度演变与评估 (Cheng, Yonghong, Kommentar zur Umgestaltung des Beschäftigungssystems Chinas), in: 胡鞍钢/程永宏/杨韵新, 扩大就业与挑战失业 $(\mathrm{Hu}, \mathrm{An}$ gang/Cheng, Yonghong/Yang, Yunxin (Hrsg.), Beschäftigungsförderung und Arbeitslosigkeitsbeseitigung), S. 71.

661 中共中央, 国务院关于切实做好国有企业下岗职工基本生活保障和再就业工作的通知 (Bekanntmachung des Zentralkomitees der KP Chinas und des Staatsrats über die Durchführung der Garantie des Grundlegenden Lebensstandards für die entlassenen Arbeitnehmer der Staatsbetriebe und der Arbeit der Wiederbeschäftigung), 中发 (1998)10号, vom 09. 06. 1998.

662 Ausführlich siehe: 孙炳耀, 完善失业保障制度的思路与对策 (Sun, Bingyao, Approaches and Policies to Enhance Unemployment Benefit System), in: 陈佳贵/王延中，中国社会保障发展报告 (2001-2004) No. 2 (Chen, Jiagui/Wang, Yanzhong (Hrsg.), China Social Security System Development Report (2001-2004) No. 2), S. 135.

663 Nr. 5 der Bekanntmachung des Zentralkomitees der KP Chinas und des Staatsrats über die Durchführung der Garantie des Grundlegenden Lebensstandards für die entlassenen Arbeitnehmer der Staatsbetriebe und der Arbeit der Wiederbeschäftigung von 1998. 
beendet, er erhielt für nicht länger als zwei Jahre Arbeitslosengeld und danach die Sicherung des Existenzminimums für städtische Bedürftige. 664

Die Funktionen des Wiederbeschäftigungszentrums wurden allmählich durch die öffentlichen Beschäftigungsdienstleistungen und die Arbeitslosenversicherung ersetzt. Seit 2006 existieren die Wiederbeschäftigungszentren landesweit nicht mehr. Die Arbeitslosen der Staatsunternehmen werden nun direkt in die Arbeitslosenversicherung aufgenommen und suchen selbst oder über die Arbeitsvermittlungsagenturen neue Arbeit auf dem Arbeitsmarkt. 665

\section{b) Die aktive Beschäftigungspolitik}

Von 1998 bis 2003 wurden ca. 27 Millionen Arbeitnehmer von den Staatsunternehmen entlassen. ${ }^{666}$ Die Quote der registrierten städtischen Arbeitslosen lag seit vielen Jahren offiziell nur bei ca. 4\%,667 allerdings nach der Schätzung der Ökonomen hatte die durchschnittliche Arbeitslosenrate in Städten schon $8 \%$ überschritten. 668 Nach den Forschungsergebnissen von der Chinese Academy of Social Sciences betrug die Arbeitslosenrate 2002 in fünf großen Städten 669 durchschnittlich 14.3\%.670 Gemäß dem Weißbuch der Zentralregierung „Chinas Beschäftigungslage und -politik“ von 2004671 war die Zahl der Bevölkerung im erwerbsfähigen Alter von 2001 bis 2005 jährlich um 13.6 Millionen Personen gewachsen, bis 2020 wird es landesweit 940 Millionen Menschen im erwerbsfähigen Alter geben.

664 Nr. 3 der Bekanntmachung des Zentralkomitees der KP Chinas und des Staatsrats über die Durchführung der Garantie des Grundlegenden Lebensstandards für die entlassenen Arbeitnehmer der Staatsbetriebe und der Arbeit der Wiederbeschäftigung von 1998.

665 国务院关于进一步加强就业再就业工作的通知 (Bekanntmachung des Staatsrats über die weitere Verstärkung der Beschäftigungs- und Wiederbeschäftigungsarbeit), 国发 (2005) 36号, vom 08. 11. 2005.

666 张车伟, 失业率定义的国际比较及中国城镇失业率 (Zhang, Chewei, An International Comparison of the Definition for Unemployment and the Rate of Unemployment in Urban China), in: 世界 经济 (World Economic), 2003/5, S. 47.

667 劳动和社会保障事业发展统计公报 (Statistisches Bulletin über Arbeit und soziale Sicherheit), http://w1.mohrss.gov.cn/gb/zwxx/node_5436.html (Stand: 15. 07. 2010).

668 张车伟, 失业率定义的国际比较及中国城镇失业率 (Zhang, Chewei, An International Comparison of the Definition for Unemployment and the Rate of Unemployment in Urban China), in: 世界 经济 (World Economic), 2003/5, S. 54; 胡鞍钢/杨韵新，结构变革的创造性摧毁：中国城镇失 业与失业保障 (1993-2000) (Hu, Angang/Yang, Yunxin, Schaffung und Zerstörung in der Strukturänderung: die Arbeitslosigkeit in den chinesischen Städten und Gemeinden 1993-2000), in: 胡鞍钢 /程永宏/杨韵新，扩大就业与挑战失业 (Hu, Angang/Cheng, Yonghong/Yang, Yunxin (Hrsg.), Beschäftigungsförderung und Arbeitslosigkeitsbeseitigung), S. 210.

669 Shanghai (8.9\%), Wuhan (22.3\%), Shenyang (17.6\%), Xi'an (16.5\%), Fuzhou (12.3\%).

670 张车伟, 扩大与促进就业的思路与对策 (Zhang, Chewei, Approaches and Policies to Promote Employment，in: 陈佳贵/王延中，中国社会保障发展报告 2001-2004 (Chen, Jiagui/Wang, Yanzhong (Hrsg.), China Social Security System Development Report 2001-2004), S. 164.

671 国务院新闻办公室, 中国的就业状况和政策 (Presseamt des Staatsrats, Weißbuch über Chinas Beschäftigungslage und -politik), vom 26. 04. 2004. http://www.china.com.cn/ch-book/20040426/ index.html (Stand: 15. 07. 2010). 
Schließlich wurde 2002 in den Dokumenten der KP Chinas und der Zentralregierung darauf hingewiesen, dass die Beschäftigungslage Chinas zurzeit prekär ist und es für eine gewisse Zeitspanne so bleiben wird. ${ }^{672}$ Die Diskrepanzen der Beschäftigungslage werden hauptsächlich ,in der riesigen Nachfrage der Werktätigen nach Beschäftigung, der enorm großen Menge an Arbeitskräften sowie der breiten Kluft zwischen der Qualität der Arbeitssuchenden und den beruflichen Anforderungen" bestehen, die durch folgende Merkmale gekennzeichnet sind:673 Die Diskrepanzen zwischen der Beschäftigungsnachfrage und dem Angebot sowie die Widersprüche der Beschäftigungsstruktur existieren nebeneinander. Während die Städte weiter unter starkem Beschäftigungsdruck stehen, beschleunigt sich die Abwanderung ländlicher überschüssiger Arbeitskräfte in die Sekundär- und Tertiärsektoren. Das Problem der Beschäftigung der Berufseinsteige und die Wiederbeschäftigung der Arbeitslosen hängen eng miteinander zusammen.

\section{aa) Beschäftigungspolitik 2002 - 2005}

Angesichts dieser Situation werden der Abbau der Arbeitslosigkeit und die Schaffung mehrerer Arbeitsplätze seit dem Anfang des 21. Jahrhunderts als die vorrangigen Aufgaben für das wirtschaftliche Wachstum und die gesellschaftliche Stabilität Chinas betrachtet. Dafür wurde die „aktive Beschäftigungspolitik“ als eine langfristige Politik im Jahre 2002 festgelegt. ${ }^{674}$ Die Richtlinie für Beschäftigung in dieser Periode lautet: „Die Arbeitenden entscheiden selbständig über die Beschäftigung. Sie wird ebenfalls durch den Markt reguliert und durch die Regierung gefördert." 675

Die chinesische Beschäftigungsrichtlinie kennzeichnet den Wandel von einer inaktiven Lebensunterstützung der Arbeitslosen zur aktiven Beschäftigungsförderung. Die aktive Beschäftigungspolitik von 2002 umfasste alle Maßnahmen, die für die Verminderung des Beschäftigungsdrucks und den Aufbau eines zu der gegenwärtigen Wirtschaftslage passenden Arbeitskräftemarkts relevant waren. Die Hauptaufgabe war die Wiederbeschäftigung der ausgegliederten Arbeitnehmer sowie Arbeitslosen der Staatsunternehmen, die als eine kurzfristige Maßnahme in der „Bekanntmachung des Zentralkomitees der KP Chinas und des Staatsrats über die weitere Durchführung der Wiederbeschäftigungsmaßnahmen für die entlassenen Arbeitnehmer und die Arbeitslosen“ bis Ende 2005 befristet war. Die Arbeitsschwerpunkte waren:

672 中共中央, 国务院关于进一步做好下岗失业人员再就业工作的通知 (Bekanntmachung des Zentralkomitees der KP Chinas und des Staatsrats über die weitere Durchführung der Wiederbeschäftigungsmaßnahmen für die entlassenen Arbeitnehmer und die Arbeitslosen), 中发 (2002) 12号, vom 30. 09. 2002.

673 Bekanntmachung des Zentralkomitees der KP Chinas und des Staatsrats über die Durchführung der Wiederbeschäftigungsmaßnahmen für die entlassenen Arbeitnehmer und die Arbeitslosen von 2002; Weißbuch über Chinas Beschäftigungslage und -politik von 2004.

674 江泽民，在中国共产党第十六次全国代表大会上的报告 (Jiang, Zemin, Bericht auf dem 16. Parteitag der KP Chinas), vom 08. 11. 2002.

675 国务院新闻办公室, 中国的就业状况和政策 (Presseamt des Staatsrats, Weißbuch über Chinas Beschäftigungslage und -politik), vom 26. 04. 2004. 
- durch die makrowirtschaftlichen Maßnahmen, wie Erweiterung der Inlandsnachfrage, Verbesserung der Wirtschaftsstruktur sowie Bewahrung von Wirtschaftswachstum die Beschäftigung zu erweitern, ${ }^{676}$

- durch die Förderungsmaßnahmen für die Handels- und Dienstleistungssektoren, die arbeitsintensiven Industriebranchen sowie durch die flexible Beschäftigung mehr Arbeitsplätze zu schaffen, 677

durch die Finanz- und Steuerpolitik, wie Steuerbefreiung, Kreditgewährung und staatliche Zuschüsse, die Wiederbeschäftigung und die Selbständigkeit der Arbeitslosen zu unterstützen, 678

durch den Aufbau eines öffentlichen Dienstleistungssystems für Beschäftigung den Arbeitslosen kostenlose Umschulung und Arbeitsvermittlung zu bieten, ${ }^{679}$ durch die Makrokontrollmaßnahmen wie Kontrolle der Personalverringerung von großen Unternehmen, Errichtung eines Frühwarnsystems der Arbeitslosigkeit sowie eines Berufsbildungssystems die Arbeitslosigkeit zu vermindern, 680 durch die sozialen Sicherungssysteme wie Arbeitslosenversicherung, Sicherung des Existenzminimums für die städtische Bevölkerung die Lebenssicherung der Arbeitslosen zu gewährleisten. 681

Von 2003 bis 2005 wurden ca. 14 Millionen Arbeitslose wiederbeschäftigt. ${ }^{682} \mathrm{Al}-$ lerdings wird die Beschäftigungssituation noch lange Zeit angespannt bleiben. Die Strukturänderung der Staatsunternehmen dauert noch an, in einem Zeitraum von mehreren Jahren werden eine große Anzahl von Arbeitnehmer aus den Unternehmen entlassen; der Beschäftigungsdruck der Hochschulabsolventen und der überschüssigen ländlichen Arbeitskräfte wird in Zukunft stärker. Angesichts dieser Lage nimmt die Erweiterung der Beschäftigung zurzeit einen wichtigen Platz in dem Arbeitsplan der Partei und der Regierung ein.

\section{bb) Beschäftigungspolitik seit 2006}

Am Ende 2005 hat der Staatsrat die „Bekanntmachung über die weitere Verstärkung der Beschäftigungs- und Wiederbeschäftigungsarbeit" 683 erlassen, damit verfolgt die Regierung weiter die aktive Beschäftigungspolitik. Die neuen Maßnahmen sind auf drei

676 Nr. 4 der Bekanntmachung des Zentralkomitees der KP Chinas und des Staatsrats über die Durchführung der Wiederbeschäftigungsmaßnahmen für die entlassenen Arbeitnehmer und die Arbeitslosen von 2002.

677 Nr. 5 der Bekanntmachung von 2002.

678 Nr. 6-15 der Bekanntmachung von 2002.

679 Nr. 16-18 der Bekanntmachung von 2002.

680 Nr. 19-21 der Bekanntmachung 2002.

681 Nr. 22, 23 der Bekanntmachung von 2002.

682 2003-2005 劳动和社会保障事业发展统计公报 (Statistisches Bulletin über Arbeit und soziale Sicherheit 2003-2005), http://w1.mohrss.gov.cn/gb/zwxx/node_5436.htm (Stand: 15. 07. 2010).

683 国务院关于进一步加强就业再就业工作的通知，国发 (2005) 36号, vom 08. 11. 2005. 
Jahre befristet. ${ }^{684}$ Der Schwerpunkt der Arbeit liegt nach wie vor in der Wiederbeschäftigung der ausgegliederten Arbeitnehmer und der Arbeitslosen der Staatsunternehmen, allerdings erweitert sich der Geltungsbereich der Förderungsmaßnahmen nun auf die kollektiven Betriebe in den Städten.685 Darüber hinaus werden die Beschäftigung von Jugendlichen in den Städten und die Beschäftigung von ländlichen Wanderarbeitern, die zukünftig die Masse der Arbeitskräfte stellen werden, 686 auch als Arbeitsschwerpunkte in dieser Bekanntmachung erwähnt. 687

In der Bekanntmachung von 2005 wird eine „Kombination mehrer Stufen“ von Beschäftigung und sozialer Sicherung festgelegt: 688

„Die aktive Beschäftigungsförderung, die Arbeitslosenversicherung und die Sicherung des Existenzminimums für die städtische Bevölkerung bilden zusammen ein Sicherungsnetz für Erwerbsfähige. Hierzu wird ein dreistufiges System von Mindestlohn, Arbeitslosengeld sowie Sicherung des Existenzminimums errichtet, um die Initiative der Erwerbsfähigen zur Beschäftigung zu entfalten."689

Nach der Bekanntmachung wird der Arbeitslosenversicherungsfonds auch für die Förderung der Wiederbeschäftigung verwendet. ${ }^{690}$ Seit 2006 werden im reichen Küstengebiet (sieben Provinzen und Regierungsunmittelbare Städte) Pilotprojekte für die Erweiterung von Ausgaben des Arbeitslosenversicherungsfonds durchgeführt, die Fonds dürfen in diesen Gebieten für die Zuschüsse der beruflichen Weiterbildung, der Arbeitsvermittlung, der sozialen Versicherung sowie das Darlehen für Firmenneugründung benutzt werden. 691

In dem Beschluss der KP Chinas über den Aufbau einer sozialistischen harmonischen Gesellschaft von 2006 wurde vorgebracht, dass die „relative Vollbeschäftigung“ eine der Hauptaufgaben ist, die bis 2020 erfüllt werden sollte. ${ }^{692}$ Mit der Entwicklung der massiven wirtschaftlichen Strukturänderung wird sich der Schwerpunkt der Beschäftigungspolitik von der Förderung der Wiederbeschäftigung der Arbeitslosen allmählich zu allgemeinen Förderungsleistungen für alle Erwerbsfähigen wandeln. Die Gesetzgebungsarbeit des Arbeitsrechts wird zurzeit beschleunigt. 2007 wurde die aktive

684 Nr. 32 der Bekanntmachung über die weitere Verstärkung der Beschäftigungs- und Wiederbeschäftigungsarbeit von 2005.

685 Nr. 2 der Bekanntmachung von 2005.

686 张车伟, 当前就业新趋势与对策建议 (Zhang, Chewei, Die neue Beschäftigungstendenz und Vorschläge), in: 中国经贸导刊 (China Economic \& Trade Herald), 2006/9, S. $28 \mathrm{ff}$.

687 Nr. 2 der Bekanntmachung von 2005.

688 Nr. 2 der Bekanntmachung von 2005.

689 Nr. 22 der Bekanntmachung von 2005.

690 Nr. 25 der Bekanntmachung von 2005.

691 劳动和社会保障部/财政部, 关于适当扩大失业保险基金支出范围试点有关问题的通知 (Ministerium für Arbeit und soziale Sicherheit/Finanzministerium, Bekanntmachung über einige Frage zum Pilotprojekt der zweckmäßigen Erweiterung von Ausgaben des Arbeitslosenversicherungsfonds), 劳社部发 (2006) 5 号, vom 11.01.2006.

692 Nr. 2 des Beschlusses des Zentralkomitees der KP Chinas über einige wichtigen Fragen zur Strukturierung einer harmonischen sozialistischen Gesellschaft von 2006. 
Beschäftigungspolitik als eine langfristige und stabile politische Richtlinie in das Beschäftigungsförderungsgesetz aufgenommen, das ebenso wie das Arbeitsvertragsgesetz am 1. Januar 2008 in Kraft getreten war.

Das Beschäftigungsförderungsgesetz von 2007 konkretisiert und erweitert die im Arbeitsgesetz von 1994 vorgeschriebenen Regelungen über die Beschäftigungsförderung, die berufliche Fortbildung sowie die soziale Versicherung693 und führt die in den Bekanntmachungen von 2002 und 2005 festgelegten Richtlinien weiter. Es umfasst folgende inhaltliche Schwerpunkte:

- $\quad$ Festlegung der Priorität der Beschäftigungserweiterung in der wirtschaftlichen und gesellschaftlichen Entwicklung und der Durchführung der aktiven Beschäftigungspolitik, 694

- Verantwortungsverteilung zwischen verschiedenen Regierungsebenen, Institutionen und Arbeitseinheiten, 695

- $\quad$ Förderungsmaßnahmen, 696

- $\quad$ Gleichstellung, 697

- $\quad$ öffentliche Dienstleistungen und Verwaltung, 698

- $\quad$ berufliche Ausbildung und Weiterbildung, 699

- $\quad$ Hilfsmaßnahmen für Bürger, die nicht in der Lage sind, selbst einen Job zu finden, 700

- $\quad$ Aufsicht und Kontrolle, 701

- Rechtsfolgen.702

Das Beschäftigungsförderungsgesetz enthält jedoch nur die grundsätzlichen Richtlinien. Es bedarf zur weiteren Umsetzung die konkreten Vorschriften und Maßnahmen der verschiedenen Regierungsebenen.

\section{c) Arbeitslosensicherung}

Während die aktive Beschäftigungspolitik zurzeit als Hauptmaßnahme für die Beseitigung der massiven Arbeitslosigkeit vorangetrieben wird, übernehmen die Sicherung des Existenzminimums für die städtische Bevölkerung und die Arbeitslosenversicherung die Aufgabe, die Unterhaltssicherung für Arbeitslose zu gewährleisten. In diesem Zusammenhang spielt die Arbeitslosenversicherung eine kleine Rolle im Vergleich zur Sicherung des Existenzminimums.

\footnotetext{
$693 \S 10$ - 15 Arbeitsgesetz von 1994.

$694 \S 2$ Beschäftigungsförderungsgesetz von 2007.

695 § 4-10 Beschäftigungsförderungsgesetz von 2007.

696 § 11-24 Beschäftigungsförderungsgesetz von 2007.

697 § 25-31 Beschäftigungsförderungsgesetz von 2007.

698 § 32-43 Beschäftigungsförderungsgesetz von 2007.

$699 \S 44-51$ Beschäftigungsförderungsgesetz von 2007.

$700 § 52-57$ Beschäftigungsförderungsgesetz von 2007.

$701 \S 58-60$ Beschäftigungsförderungsgesetz von 2007.

$702 \S 60-68$ Beschäftigungsförderungsgesetz von 2007.
} 
Seit der Errichtung der Auf-Arbeit-Wartenden-Versicherung im Jahre $1986^{703}$ ist ständig umstritten, ob eine Arbeitslosenversicherung in dieser Reformphase für die wirtschaftliche Umgestaltung wirklich notwendig ist. ${ }^{704}$ Einige Experten waren der Meinung, dass die Arbeitslosenversicherung sich vor dem Hintergrund der durch die wirtschaftliche Strukturänderung verursachten massiven Arbeitslosigkeit nur gering auswirken könnte. 705

Bis Anfang des 21. Jahrhunderts wurde die Unterhaltssicherung der Arbeitslosen hauptsächlich durch die Übergangsmaßnahmen „Zwei Garantien“ und „Drei Sicherungslinien“ garantiert. Die „Auf-Arbeit-Wartenden-Versicherung" wurde schließlich durch die „Regeln über die Arbeitslosenversicherung“ von 1999706 ersetzt. Wegen der Erweiterung des Deckungsbereichs erhöhte sich die Deckungsrate der Arbeitslosenversicherung im Jahre 1999 deutlich. Sie stagniert allerdings nach der Durchführung der aktiven Beschäftigungspolitik und der Erweiterung der Existenzminimumsicherung seit 2002. Die Funktion der Unterhaltssicherung wird hauptsächlich durch die Sicherung des Existenzminimums übernommen, während die Förderungsfunktion durch die aktiven Beschäftigungsmaßnahmen übernommen werden.

Es hat sich nicht nur herausgestellt, dass die klassische Arbeitslosenversicherung nur eine geringe Rolle bei der massiven Strukturänderung des chinesischen Wirtschaftssystems spielen kann. Die Mängel der gegenwärtigen Arbeitslosenversicherung behindern auch ihre weitere Entwicklung. Einer dieser Mängel ist der geringe Deckungsbereich. Der Deckungsbereich der Arbeitslosenversicherung, der früher nur die Staatsunternehmen und deren Arbeitnehmer umfasst hatte, ${ }^{707}$ wurde mit In-Kraft-Treten der „Regeln über die Arbeitslosenversicherung" von 1999 auf alle Unternehmen und öffentliche Institutionen in Städten und Gemeinden erweitert. Als „Unternehmen in Städten und Gemeinden“ im Sinne der Arbeitslosenversicherungsregeln werden Staatsunternehmen, Kollektivunternehmen, Unternehmen mit ausländischer Kapitalbeteiligung, Privatunternehmen und weitere Unternehmen in Städten und Gemeinden bezeichnet. ${ }^{708}$ Außerdem dürfen die Regierungen auf Provinzebene selbst bestimmen, ob die gesellschaftlichen Vereinigungen und deren Fachkräfte, die von den Einwohnern betriebenen nicht-

703 Ausführlich: Dritte Teil, Umgestaltung der Systeme der sozialen Sicherheit seit 1985, Soziale Sicherheit als Notwendigkeit für die Wirtschaftsreform.

704 Siehe: 高书生, 社会保障改革何去何从 (Gao, Shusheng, Die Reform der sozialen Sicherheit steht am Scheideweg), S. 91ff.

705 高书生, 社会保障改革何去何从 (Gao, Shusheng, Die Reform der sozialen Sicherheit steht am Scheideweg), S. 92, 171; 国务院发展研究中心社会保障制度改革研究课题组, 中国城镇失业保 障制度改革的回顾与前瞻 (Forschungsgruppe des Staatsrats für Reform der sozialen Sicherheit, Rückschau und Vorschau auf die Reform der Arbeitslosensicherung), in: 管理世界 (Management World), 2001/1, S. 82ff.

706 Ausführlich: Dritter Teil, Sozialversicherung für Beschäftigte in Unternehmen, Arbeitslosenversicherung.

$707 \S 2$ Bestimmung zur Auf-Arbeit-Wartenden-Versicherung der staatseigenen Unternehmen von 1993.

$708 \S 2$ Regeln über die Arbeitslosenversicherung von 1999. 
betrieblichen Arbeitseinheiten sowie die Kleingewerbetreibenden in ihrer Verwaltungsregion und deren Personal in die Arbeitslosenversicherung aufgenommen werden können. ${ }^{709}$ Als „Arbeitnehmer“ werden die Personen, die einen formellen Arbeitsplatz und ein stabiles Arbeitsverhältnis bei den Unternehmen oder den bestimmten Arbeitseinheiten haben, bezeichnet. ${ }^{710}$ Die in der informellen Ökonomie beschäftigten Personen und die Wanderarbeiter werden grundsätzlich nicht von der Arbeitslosenversicherung umgefasst.

Wegen der Erweiterung des Deckungsbereiches von 1999 war die Zahl der teilnehmenden Arbeitnehmer an der Arbeitslosenversicherung von 79.28 Mio. im Jahre 1998 auf 98.52 Mio. im Jahre 1999 um $24.3 \%$ gestiegen. ${ }^{711}$ Danach hatte sich die Zahl der teilnehmenden Arbeitnehmer nur allmählich erhöht, 2007 betrug die Summe der Teilnehmenden 116.45 Millionen, die Deckungsrate der Arbeitslosenversicherung erreichte schon durchschnittlich 97\% des formellen Personals der Unternehmen und öffentlichen Institutionen in Städten und Gemeinden. ${ }^{712}$ Daraus kann gefolgert werden, dass die Erweiterung der Deckungsrate im Rahmen der gegenwärtigen Arbeitslosenversicherungsregeln die Grenze erreicht hat. Die weitere Erweiterungsmöglichkeit der Arbeitslosenversicherung liegt darin, dass andere Arbeitnehmergruppen, wie z. B. informelle Arbeitnehmer, durch die Änderung der Regeln von 1999 in den Deckungsbereich der Arbeitslosenversicherung einbezogen werden.

Während der Versichertenanteil in der Arbeitslosenversicherung hinsichtlich der Arbeitnehmer der formellen Arbeitseinheiten die Grenze erreichte, sank der Anteil der Versicherten an den gesamten städtischen Arbeitnehmern von 49\% im Jahre 2000 auf knapp 40\% im Jahre 2007.713 Die Ursache dafür ist, dass ein Großteil der neuen Arbeitsplätze in den letzten Jahren in der informellen Ökonomie geschaffen wurde, da die gegenwärtige Politik die flexible Beschäftigung besonders fördert. Die ausgegliederten Arbeiter und die Wanderarbeiter strömen in das Dienstleistungsgewerbe und in die Kleinunternehmen. Viele von ihnen arbeiten als Teilzeitarbeiter oder Selbständige. ${ }^{714}$

709 § 32 Regeln über die Arbeitslosenversicherung von 1999.

710 王延中/张车伟, 我国失业保险制度的主要问题与对策 (Wang, Yanzhong/Zhang, Chewei, Die Hauptprobleme des chinesischen Arbeitslosenversicherungssystems und Vorschläge), in: 中国经贸 导刊 (China Economic \& Trade Herald), 2005/11, S. 22.

711 1998，1999劳动和社会保障事业发展统计公报 (Statistisches Bulletin über Arbeit und soziale Sicherheit 1998, 1999), http://w1.mohrss.gov.cn/gb/zwxx/node_5436.htm (Stand: 15. 07. 2010).

7122007 劳动和社会保障事业发展统计公报 (Statistisches Bulletin über Arbeit und soziale Sicherheit 2007), http://w1.mohrss.gov.cn/gb/zwxx/2008-06/05/content_240415.htm (Stand: 15. 07. 2010).

713 Statistisches Bulletin über Arbeit und soziale Sicherheit 2007.

714 Ausführlich vgl. 吴要武/蔡肪, 中国城镇非正规就业规模与特征 (Wu, Yaowu/Cai, Fang, Informal Employment in Urban China: Size and Characteristics); 姚宇, 中国非正规就业规模与现状 研究 (The Size and Status of Informal Employment in China), beide in: 中国劳动经济学 (China Labor Economics), 2006, Vol.3 No.2, S. 67ff, 85ff. 
Die Zahl der informell beschäftigten Personen betrug nach Wu und Cai im Jahre 2002 schon über 120 Millionen Menschen. ${ }^{715}$

\section{Tabelle 16: Arbeitslosenversicherung}

\begin{tabular}{|l|l|l|l|l|l|l|l|l|l|l|}
\hline $\begin{array}{l}\text { Anteil der Ver- } \\
\text { sicherten an den }\end{array}$ & 1998 & 1999 & 2000 & 2001 & 2002 & 2003 & 2004 & 2005 & 2006 & 2007 \\
\hline $\begin{array}{l}\text { gesamten be- } \\
\text { schäftigten } \\
\text { Personen in } \\
\text { Städten und } \\
\text { Gemeinden }\end{array}$ & $38 \%$ & $47 \%$ & $49 \%$ & $43 \%$ & $41 \%$ & $40 \%$ & $40 \%$ & $39 \%$ & $40 \%$ & $40 \%$ \\
\hline $\begin{array}{l}\text { beschäftigten } \\
\text { Personen der } \\
\text { formellen Ar- } \\
\text { beitseinheiten in } \\
\begin{array}{l}\text { Städten und } \\
\text { Gemeinden }\end{array}\end{array}$ & $64 \%$ & $81 \%$ & $90 \%$ & $93 \%$ & $93 \%$ & $95 \%$ & $95 \%$ & $93 \%$ & $96 \%$ & $97 \%$ \\
\hline
\end{tabular}

Quelle: 劳动和社会保障事业发展统计公报 (Statistisches Bulletin über Arbeit und soziale Sicherheit), http://www.molss.gov.cn/index/index.htm.

Allerdings haben die Beschäftigten in der informellen Wirtschaft und die Wanderarbeiter kein Interesse, an der Arbeitslosenversicherung teilzunehmen, weil die Arbeitslosenversicherung für die Teilnehmer ungünstig ist. Einerseits sind die Leistungen verschiedener Verwaltungsgebiete sehr unterschiedlich, die Leistungsansprüche sind zwischen den Verwaltungsgebieten nicht übertragbar. Andererseits ist die Lohnersatzquote der Arbeitslosenversicherung ziemlich niedrig. Das Arbeitslosengeld wird nach dem Prinzip „Einkommen bestimmen Ausgaben“ ausgezahlt. ${ }^{716}$ Gemäß den Arbeitslosenversicherungsregeln von 1999 liegt das Niveau des Arbeitslosengeldes unter dem Niveau des lokalen Mindestlohnes und über der städtischen Existenzminimumssicherung. ${ }^{717}$ In der Realität ist die Lohnersatzquote in vielen Städten geringfügig höher als das Niveau des Existenzminimums, sie beträgt ca. 30\%-40\% des lokalen Durchschnittslohns. 7182003 entsprach das durchschnittliche Arbeitslosengeld sogar nur ca. 12.7\% des Durchschnittslohns. ${ }^{719}$ Außerdem werden andere Leistungen der Arbeitslosenver-

715 吴要武/蔡肪, 中国城镇非正规就业规模与特征 ( $W u$, Yaowu/Cai, Fang, Informal Employment in Urban China: Size and Characteristics); in: 中国劳动经济学 (China Labor Economics), 2006, Vol.3 No.2, S. 81.

716 孙炳耀, 完善失业保障制度的思路与对策 (Sun, Bingyao, Approaches and Policies to Enhance Unemployment Benefit System), in: 陈佳贵/王延中，中国社会保障发展报告 (2001-2004) No. 2 (Chen, Jiagui/Wang, Yanzhong (Hrsg.), China Social Security System Development Report 20012004), S. 140.

717 § 18 Regeln über die Arbeitslosenversicherung von 1999.

718 孙炳耀, 完善失业保障制度的思路与对策 (Sun, Bingyao, Approaches and Policies to Enhance Unemployment Benefit System), in: 陈佳贵/王延中，中国社会保障发展报告 (2001-2004) No. 2 (Chen, Jiagui/Wang, Yanzhong (Hrsg.), China Social Security System Development Report 20012004), S. 147. Nach Wang, Shaoguang entspricht das Arbeitslosengeld 20\%-30\% des durchschnittlichen Lohns, in: 王绍光, 大转型: 1980年代以来中国的双向运动 (Wang, Shaoguang, The Great Transformation: Double Movement in China since the 1980s), in: 中国社会科学 (Social Science in China), 2008/1, S. 147.

719 Siehe: 游钧, 2006 - 2007年: 中国就业报告 (You, Jun (Hrsg.), 2006 - 2007: Blue Book of the Chinese Employment), Beijing, 2008, S. 157; 王延中/张车伟, 我国失业保险制度的主要问题与 对策 (Wang, Yanzhong/Zhang, Chewei, Die Hauptprobleme des chinesischen Arbeitslosenversi- 
sicherung, wie Zuschüsse für Krankenkosten und für Berufsausbildung und Arbeitsvermittlung außer Acht gelassen. 720

Wegen den oben genannten Mängeln zögern die obligatorisch teilnehmenden Arbeitseinheiten, insbesondere die Staatsunternehmen, oft die Beitragszahlung hinaus. Die Isteinnahmequote der Arbeitslosenversicherung lag bis 2003 bei nur knapp 60\% der Solleinnahmequote. ${ }^{721}$ Seit 2005 erhöhte sich langsam die Zahl der registrierten Arbeitslosen. 2009 betrug die Zahl 9.21 Mio. Personen (Arbeitslosenrate ca. 4.3\%). Allerdings nahm die Zahl der das Arbeitslosengeld beziehenden Personen stets ab, 2009 lag sie bei nur 2.35 Mio. Personen. ${ }^{722}$

\section{bb) Sicherung des Existenzminimums für die städtische Bevölkerung}

Die Zahl der armen Stadtbewohner war wegen der Vollbeschäftigungspolitik in der Periode der Planwirtschaft ziemlich niedrig. Die Bedürftigen der Existenzsicherung waren hauptsächlich die städtischen Bewohner, die arbeitsunfähig waren und auch keine familiäre Unterstützung hatten. Seit Mitte der 1990er Jahre explodierte die Zahl der armen Stadtbewohner mit der massiven Strukturänderung der Staatsunternehmen. Die überwiegende Zahl der armen Stadtbewohner besteht zurzeit aus den Arbeitslosen und ihren Familienangehörigen. ${ }^{723}$

Im Jahre 1997 entschied der Staatsrat, ein Sicherungssystem des Existenzminimums für die städtische Bevölkerung landesweit zu errichten. ${ }^{724}$ Gemäß den Regeln zur Sicherung des Existenzminimums für die städtische Bevölkerung von 1999 sind die Berechtigten der Existenzminimumssicherung die Bewohner mit Stadt-Hukou, bei denen das Pro-Kopf-Einkommen der zusammenlebenden Familienangehörigen unter dem lo-

cherungssystems und Vorschläge), in: 中国经贸导刊 (China Economic \& Trade Herald), 2005/11, S. 22.

720 Ausführlich: 孙炳耀, 完善失业保障制度的思路与对策 (Sun, Bingyao, Approaches and Policies to Enhance Unemployment Benefit System), in: 陈佳贵/王延中, 中国社会保障发展报告 (20012004) No. 2 (Chen, Jiagui/Wang, Yanzhong (Hrsg.), China Social Security System Development Report 2001-2004), S. 141.

721 张车伟, 当前失业保险制度需要新的发展定位 (Zhang, Chewei, Reformbedarf in der Arbeitslosenversicherung), in: 中国党政干部论坛 (Politische Tribüne), 2005/7, S. 23.

722 劳动和社会保障事业发展统计公报 (Statistisches Bulletin über Arbeit und soziale Sicherheit), http://w1.mohrss.gov.cn/gb/zwxx/node_5436.htm (Stand: 15. 07. 2010).

723 Nach Forschungsergebnissen von $\mathrm{Hu}$, Angang betrug die Zahl der Arbeitslosen bis Anfang 2002 schon ca. 93\% der städtischen Bedürftigen. Ausführlich vgl. 胡鞍钢/杨韵新, 结构变革的创造性 摧毁: 中国城镇失业与失业保障 (1993-2000) (Hu, Angang/Yang, Yunxin, Schaffung und Zerstörung in der Strukturänderung: die Arbeitslosigkeit in den chinesischen Städten und Gemeinden 1993-2000), in: 胡鞍钢/程永宏/杨韵新, 扩大就业与挑战失业 (Hu, Angang/Cheng, Yonghong/Yang, Yunxin (Hrsg.), Beschäftigungsförderung und Arbeitslosigkeitsbeseitigung), S. 231.

724 国务院关于在全国建立城市居民最低生活保障制度的通知 (Mitteilung des Staatsrats über die Errichtung des Sicherungssystems des Existenzminimums für die städtische Bevölkerung), 国发 (1997) 29号, vom 02. 09. 1997, ausführlich: Dritter Teil, Hilfesysteme, Sicherung des Existenzminimums für die städtischen Bevölkerung. 
kalen Standard des Existenzminimums liegt. ${ }^{725}$ Außerdem werden die städtischen Bewohner, die über keine Einkünfte verfügen, keine Arbeitsfähigkeit besitzen und auch keine gesetzliche Unterhaltspflichtigen haben, auch von dieser Sicherung erfasst. ${ }^{726}$

1997 betrug die Zahl der in diese Sicherung aufgenommen Bedürftigen nur 0.89 Mio. Personen.727 Wegen des sich ständig verschlechternden Problems der ausgegliederten Arbeitnehmer forderte der Staatsrat im Jahre 2001 die lokalen Regierungen dazu auf, die durch die wirtschaftliche Strukturänderung verursachte Bedürftigkeit von bestimmten Personengruppen, insbesondere die bedürftigen Arbeitnehmer der staatlichen und kollektiven Unternehmen, die ausgegliederten Arbeitnehmer sowie die Arbeitslosen, unverzüglich in die Sicherung des Existenzminimums aufzunehmen. ${ }^{728} \mathrm{Im} \mathrm{Ge}-$ genzug wurden die staatlichen Zuschüsse deutlich erhöht. ${ }^{729}$ Demzufolge vergrößerte sich die Zahl der aufgenommen Bedürftigen vom Jahr 2000 mit 4 Mio. Personen auf 11.7 Mio. im Jahre 2001 und steigerte sich damit um 190.8\%.730 2002 wuchs die Zahl auf 20.65 Mio. Personen an. ${ }^{731}$ Seit 2003 trat die Sicherung des Existenzminimums für die städtische Bevölkerung in eine stabile Phase ein. Die Zahl der städtischen Bedürftigen liegt seitdem stabil bei ca. 22 Millionen. ${ }^{732}$ Davon betrug der Anteil der erwerbsunfähigen armen Stadtbewohner nur ca. 4\%. Die übrigen Bedürftigen sind arme Arbeitnehmer, ausgegliederte Arbeitnehmer und Rentner der Unternehmen sowie ihre Familienangehörigen. 733 Das Leistungsniveau stieg seit 2002 Jahr für Jahr stetig an. 2002 betrug die landesweit durchschnittliche Pro-Kopf-Leistung monatlich 52 RMB, 734 2008 erreichte sie schon 144 RMB pro Monat. ${ }^{735}$

$725 \S 2$ Abs. 1 der Regeln zur Sicherung des Existenzminimums für die städtische Bevölkerung von 1999.

726 国务院关于在全国建立城市居民最低生活保障制度的通知 (Mitteilung des Staatsrats über die Errichtung des Sicherungssystems des Existenzminimums für die städtische Bevölkerung), 国发 (1997) 29号, vom 02.09.1997.

727 1997年民政事业发展统计报告 (Statistisches Bulletin über die Zivilen Angelegenheiten 1997), http://cws.mca.gov.cn/article/tjbg/200801/20080100009420.shtml (Stand: 15. 07. 2010).

728 国务院办公厅关于进一步加强城市居民最低生活保障工作的通知 (Mitteilung der Generalkanzlei des Staatsrats über die weitere Durchführung der Sicherung des Existenzminimums für die städtische Bevölkerung)，国办发 (2001) 87号, vom 12.11. 2001.

729 唐钧, 完善社会救助制度的思路与对策 (Approaches and Policies to Enhance Social Assistance System), in: 陈佳贵/王延中, 中国社会保障发展报告 (2001-2004) No. 2 (Chen, Jiagui/Wang, Yanzhong (Hrsg.), China Social Security System Development Report (2001-2004) No. 2), S. 32.

730 2001年民政事业发展统计报告 (Statistisches Bulletin über die Zivilen Angelegenheiten 2001), http://cws.mca.gov.cn/article/tjbg/200801/20080100009394.shtml (Stand: 15. 07. 2010).

731 2002年民政事业发展统计报告 (Statistisches Bulletin über die Zivilen Angelegenheiten 2002), http://cws.mca.gov.cn/article/tjbg/200801/20080100009382.shtml (Stand: 15. 07. 2010).

732 2006年民政事业发展统计报告 (Statistisches Bulletin über die Zivilen Angelegenheiten 2006). http://cws.mca.gov.cn/accessory/200712/1198139083975.doc (Stand: 15. 07. 2010).

733 Statistisches Bulletin über die Zivilen Angelegenheiten 2006.

734 Statistisches Bulletin über die Zivilen Angelegenheiten 2006.

735 2008年民政事业发展统计报告 (Statistisches Bulletin über die Zivilen Angelegenheiten 2008), http://cws.mca.gov.cn/article/tjbg/200906/20090600031762.shtml (Stand: 15. 07. 2010). 


\section{Zwischenergebnis}

Die Behauptung der Experten, dass die Arbeitslosenversicherung sich bei der durch die wirtschaftliche Strukturänderung verursachten massiven Arbeitslosigkeit nur gering auswirken kann, ${ }^{736}$ fand in der Praxis Zustimmung. Die Realität hat gezeigt, dass die Arbeitslosenversicherung in China bislang keine große Rolle für die Unterhaltssicherung der Arbeitslosen 737 gespielt hat. Vor der Durchführung der aktiven Beschäftigungspolitik haben die Regierung und die Unternehmen durch „Zwei Garantien“ die Verantwortung der Unterhaltssicherung der Arbeitslosen übernommen. Seit 2003 gewährleistet die Sicherung des Existenzminimums für die städtische Bevölkerung den existentiellen Lebensunterhalt von ca. 22 Millionen städtischen Bedürftigen. ${ }^{738}$ Demgegenüber hat die Zahl der Arbeitslosen, die aus der Arbeitslosenversicherung Leistungen erhalten haben, abgenommen. Sie erreichte im Jahre 2002 ihren Höhepunkt (4.4 Millionen) und sank anschließend von Jahr zu Jahr, bis sie im Jahre 20072.86 Millionen Personen betrug. ${ }^{739}$

\section{Tabelle 17: Unterhaltssicherung für Arbeitslose in den Städten}

\begin{tabular}{|l|l|l|l|l|l|l|l|l|}
\hline & 2000 & 2001 & 2002 & 2003 & 2004 & 2005 & 2006 & 2007 \\
\hline $\begin{array}{l}\text { Zahl der Bedürftigen, die in } \\
\text { die städtische Existenzmini- } \\
\text { mumssicherung aufgenom- } \\
\text { men wurden (Mio.) }\end{array}$ & 4.03 & 11.71 & 20.65 & 22.47 & 22.05 & 22.34 & 22.4 & 22.72 \\
\hline $\begin{array}{l}\text { Zahl der Arbeitslosen, die } \\
\text { von der Arbeitslosenversi- } \\
\text { cherung Leistungen erhalten } \\
\text { haben (Mio.) }\end{array}$ & 3.3 & 3.21 & 4.4 & 4.15 & 4.19 & 3.62 & 3.27 & 2.86 \\
\hline
\end{tabular}

Quelle: 民政事业发展统计报告 (Statistisches Bulletin über die Zivilen Angelegenheiten), http://cws.mca.gov.cn/article/tjbg/.

736 高书生, 社会保障改革何去何从 (Gao, Shusheng, Die Reform der sozialen Sicherheit steht am Scheideweg), S. 92, 171; 国务院发展研究中心社会保障制度改革研究课题组, 中国城镇失业保 障制度改革的回顾与前瞻 (Forschungsgruppe des Staatsrats für Reform der sozialen Sicherheit, Rückschau und Vorschau auf die Reform der Arbeitslosensicherung), in: 管理世界 (Management World), 2001/1, S. 82ff.

737 孙炳耀, 完善失业保障制度的思路与对策 (Sun, Bingyao, Approaches and Policies to Enhance Unemployment Benefit System), in: 陈佳贵王延中, 中国社会保障发展报告 (2001-2004) No. 2 (Chen, Jiagui/Wang, Yanzhong (Hrsg.), China Social Security System Development Report 20012004, No. 2), S. 134.

738 王绍光, 大转型: 1980年代以来中国的双向运动 (Wang, Shaoguang, The Great Transformation: Double Movement in China since the 1980s), in: 中国社会科学 (Social Science in China), 2008/1, S. 138; 2007年民政事业发展统计报告 (Statistisches Bulletin über die Zivilen Angelegenheiten 2007), http://cws.mca.gov.cn/accessory/200806/1214811949213.doc (Stand: 15. 07. 2010).

739 2001-2007年劳动和社会保障事业发展统计公报 (Statistisches Bulletin über Arbeit und soziale Sicherheit, 2001-2007), http://w1.mohrss.gov.cn/gb/zwxx/node_5436.htm (Stand: 15. 07. 2010). 
Die chinesische Arbeitslosenversicherung wurde anfänglich hauptsächlich als eine Art Hilfsmaßnahme für die Grundlebenssicherung der Arbeitslosen aufgebaut. In den Arbeitslosenversicherungsregeln von 1999 wurden keine Förderungsmaßnahmen festgelegt, so dass die Arbeitslosenversicherung zu dieser Zeit keine Förderungsfunktion besaß. Nachdem die Funktion der Lebensunterhaltssicherung durch die städtische Existenzminimumssicherung ersetzt wurde, und die Förderungsfunktion durch die aktive Beschäftigungspolitik ausgeübt wird, stellt sich die Frage, ob die Arbeitslosenversicherung, die der gegenwärtigen Beschäftigungslage nicht entspricht, weiter existieren soll. ${ }^{740}$ Einige Experten haben vorgeschlagen, durch Erhöhung des Leistungsniveaus die Motivation zur Teilnahme zu steigern. ${ }^{741}$ Allerdings nimmt die Regierung zurzeit noch keinen klaren Standpunkt hierzu ein. Der Überschuss des Arbeitslosenversicherungsfonds wird nun in Pilotprojekten für die Beschäftigungsförderung genutzt. ${ }^{742}$

\section{Zwischen Land und Stadt: Soziale Sicherung für die Wanderarbeiter}

Der Urbanisierungsprozess Chinas, der wegen der chinesischen sozialistischen Industrialisierungsstrategie in den $1950 \mathrm{er}$ bis $1970 \mathrm{er}$ Jahren stagnierte, ${ }^{743}$ beschleunigt sich seit Anfang der 1980er Jahre mit der Wirtschaftsreform. Die durch die Landwirtschaftsreform freigesetzten ländlichen Arbeitskräfte strömen in die Städte und arbeiten als formelle oder informelle Beschäftigte in verschiedenen Industrie- sowie Dienstleistungssektoren. Allerdings sind sie durch das Hukou-Registrierungssystem und die Bodenpolitik weiterhin an ihr Ackerland gebunden. Deswegen wandert der Großteil von ihnen oft wie Zugvögel zwischen Land und Stadt. Die ständige Wanderschaft der ländlichen überschüssigen Arbeitskräfte, die als ein charakteristisches Phänomen des chine-

740 Siehe: 王绍光, 大转型：1980年代以来中国的双向运动 (Wang, Shaoguang, The Great Transformation: Double Movement in China since the 1980s), in: 中国社会科学 (Social Science in China), 2008, 1, S. 147, vgl. auch: 国务院发展研究中心社会保障制度改革研究课题组, 中国城 镇失业保障制度改革的回顾与前瞻 (Forschungsgruppe des Staatsrats für Reform der sozialen Sicherheit, Rückschau und Vorschau auf die Reform der Arbeitslosensicherung), in: 管理世界 (Management World), 2001/1, S. 84ff.

741 Siehe: 顾昕, 通向普遍主义的艰难之路: 中国城镇失业保险制度的覆盖面分析 ( $\mathrm{Gu}$, Xin, Analyse zum Deckungsbereich der chinesischen Arbeitslosenversicherung in Städten und Gemeinden), in: 东岳论丛 (Dong Yue Tribune), 2006/5, S. 32; 孙炳耀, 完善失业保障制度的思路与对策 (Sun, Bingyao, Approaches and Policies to Enhance Unemployment Benefit System), in: 陈佳贵/ 王延中，中国社会保障发展报告 (2001-2004) No. 2 (Chen, Jiagui/Wang, Yanzhong (Hrsg.), China Social Security System Development Report), S. 145ff; 王延中/张车伟, 我国失业保险制度的 主要问题与对策 (Wang, Yanzhong/Zhang, Chewei, Die Hauptprobleme des chinesischen Arbeitslosenversicherungssystems und Vorschläge), in: 中国经贸导刊 (China Economic \& Trade Herald), 2005/11, S. 23.

742 劳动和社会保障部财政部, 关于适当扩大失业保险基金支出范围试点有关问题的通知 $(M i-$ nisterium für Arbeit und soziale Sicherheit/Finanzministerium, Bekanntmachung über einige Frage zum Pilotprojekt der zweckmäßigen Erweiterung von Ausgaben des Arbeitslosenversicherungsfonds), 劳社部发 (2006) 5 号, vom 11.01. 2006.

743 Ausführlich in: Erster Teil, Industrialisierung und Hukou-Registrierung. 
sischen Urbanisierungsprozesses bezeichnet wird, führt zu einer Reihe von Frage bezüglich der Beschäftigung und der sozialen Sicherheit. ${ }^{744}$

\title{
1. Begriff und Geschichte
}

Der chinesische Begriff ,农民工 (nóngmíngōng)“, der im Deutschen oft als „Wanderarbeiter“ übersetzt wird, wird in den „Ansichten des Staatsrats zur Lösung der Probleme der Wanderarbeiter" 745 wie folgend definiert:

\begin{abstract}
„Wanderarbeiter sind eine neue Arbeitergruppe, die im Prozess von Reform und Öffnung, Industrialisierung sowie Urbanisierung Chinas aufgetreten sind. Ihre Hukous bleiben noch auf dem Land, dennoch sind sie hauptsächlich in nicht landwirtschaftlichen Bereichen beschäftigt. Manche von ihnen sind sowohl als Bauer als auch als Arbeiter mobil tätig, sie wandern außerhalb der Saisonzeit zum Arbeiten in die Städte. Manche sind lange Zeit in den Städten beschäftigt und ein wichtiger Bestandteil der Industriearbeiter geworden.“
\end{abstract}

Als Wanderarbeiter im engeren Sinne werden die ländlichen Arbeitskräfte erfasst, die ihre Heimat verlassen und in den Städten arbeiten. Im weiteren Sinne werden die in den nicht landwirtschaftlichen Bereichen ihrer Heimatkreise - hauptsächlich in Dorfunternehmen und in der Privatwirtschaft - beschäftigten ländlichen Arbeitskräften auch als Wanderarbeiter bezeichnet. ${ }^{746}$

Der Begriff „Wanderarbeiter“ erschien zum ersten Mal 1984 in einer Zeitschrift der Chinesischen Akademie für Sozialwissenschaft. ${ }^{747}$ Damals entwickelten sich die Dorfunternehmen rasant, weshalb eine große Anzahl der ländlichen Arbeitskräfte in die Dorfunternehmen ging. Dieses Beschäftigungsmodel wird als „den Boden verlassen, aber in der Heimat bleiben“"748 bezeichnet. Von 1983 bis 1988 arbeiteten insgesamt 63 Millionen ländliche Arbeiter in den Dorfunternehmen. ${ }^{749}$

Die massenhafte Wanderung der ländlichen Arbeitskräfte hat zu Beginn der 1990er Jahre angefangen. Der Erfolg der Landwirtschaftsreform - das ausreichende Lebensmittelangebot - führte zu der Aufhebung der städtischen Getreide- und Warenzulagen, die früher ein Haupthindernis der Mobilität der Arbeitskräfte zwischen Stadt und Land waren. Andererseits fand ein Wirtschaftsaufschwung Ende der 1980er Jahre in den Küstengebieten statt, daraus resultierte der große Arbeitskräftebedarf in der Produktions-

744 国务院研究室课题组, 中国农民工研究总报告 (Forschungsgruppe des Staatsrats, Reporting on the Problems of Chinese Farmer-turned Workers), S. 2ff.

745 国务院关于解决农民工问题的若干意见，国发 (2006) 5号, vom 27.03. 2006.

$746 \mathrm{Vgl}$. 国务院研究室课题组, 中国农民工研究总报告 (Forschungsgruppe des Staatsrats, Reporting on the Problems of Chinese Farmer-turned Workers), S. 1; 游钧, 2006 - 2007年: 中国就业报 告 (You, Jun (Hrsg.), 2006 - 2007: Blue Book of the Chinese Employment), S. 320.

747 国务院研究室课题组, 中国农民工研究总报告 (Forschungsgruppe des Staatsrats, Reporting on the Problems of Chinese Farmer-turned Workers), S. 2ff.

748 Ausführlich siehe: 温铁军, 我们是怎样重新得到迁徙自由的 (Wen, Tiejun, Wie wir die Freizügigkeit wieder bekommen haben), in: 中国改革 (China Reform), 2002/5, S. 12ff.

749 国务院研究室课题组, 中国农民工研究总报告 (Forschungsgruppe des Staatsrats, Reporting on the Problems of Chinese Farmer-turned Workers), S.2. 
sowie Bauindustrie. ${ }^{750}$ Aus diesem Grund ist der städtische Arbeitsmarkt für die ländlichen Arbeitskräfte zugänglich gemacht worden. Die Zahl der überregional wandernden Arbeitskräfte war von zwei Millionen am Anfang der Wirtschaftsreform auf 62 Millionen im Jahre 1993 rasant gestiegen. ${ }^{751}$

Seit Mitte der 1990er Jahre wurde die Immigration der Wanderarbeiter in einigen Städten beschränkt, da die großen Städte damals schon wegen der Strukturänderung der Staatsunternehmen mit hoher Arbeitslosigkeit belastet waren. Demgegenüber hat die Zentrale vom Standpunkt der einheitlichen Entwicklungsplanung von Stadt und Land die Migration der ländlichen Arbeiter positiv beurteilt. Aus ihrer Sicht verändert die Migration der ländlichen Arbeitskräfte die dualistische Stadt-Land-Struktur, verkleinert die Einkommenskluft zwischen Stadt und Land und beschleunigt den Aufbau einer landesweit einheitlichen Beschäftigungspolitik. Daher hat die Zentralregierung bestimmt, die Migration der Wanderarbeiter zu lenken, dafür wurden eine Reihe von Maßnahmen für die Verbesserung der Beschäftigungs- und Lebenssituation der Wanderarbeiter ergriffen. 752

Die Wanderarbeiter sind meistens junge Landbewohner aus der Mitte und dem Westen Chinas. Ihr durchschnittliches Alter betrug 2004 28.6 Jahre. ${ }^{753}$ Sie betätigen sich in verschiedenen Branchen der Volkswirtschaft. In der Produktions-, Bau-, Bergbauindustrie sowie im Dienstleistungsgewerbe liegt die Anzahl der Wanderarbeiter bei über 50\% der Beschäftigten. 7542006 betrug die Zahl der außerhalb ihrer Heimatkreise (länger als einen Monat) arbeitenden Wanderarbeiter ca. 132 Millionen, ${ }^{755}$ außerdem wurden knapp 50 Millionen ländliche Arbeiter in nicht landwirtschaftlichen Bereichen ihrer Heimatkreise beschäftigt. ${ }^{756}$

Wegen ihrer geringen beruflichen Qualifikation werden die Wanderarbeiter normalerweise schlecht bezahlt, ihre Arbeitsverhältnisse sind nicht fest. Ohne Stadt-Hukou werden sie in vielen Bereichen, wie der sozialen Sicherung, der Schulbildung ihrer Kinder sowie der Wohnungsversorgung, im Vergleich zu den städtischen Arbeitern ungleich behandelt. Aus diesen Gründen ist es für die Wanderarbeiter schwierig, sich in den Städten lange aufzuhalten und zu integrieren. Allerdings wird das Entstehen einer armen wandernden Bevölkerungsgruppe durch die chinesische Bodenpolitik verhindert. Der Wanderarbeiter hat wegen seines Land-Hukous Anspruch darauf, das von seiner

750 Siehe: 温铁军, 我们是怎样重新得到迁徙自由的 (Wen, Tiejun, Wie wir die Freizügigkeit wieder bekommen haben), in: 中国改革 (China Reform), 2002/5, S. 13.

751 国务院研究室课题组, 中国农民工研究总报告 (Forschungsgruppe des Staatsrats, Reporting on the Problems of Chinese Farmer-turned Workers), S. 3.

752 Nr. 1 der Ansichten des Staatsrats zur Lösung der Probleme der Wanderarbeiter von 2006.

753 国务院研究室课题组, 中国农民工研究总报告 (Forschungsgruppe des Staatsrats, Reporting on the Problems of Chinese Farmer-turned Workers), S. $4 \mathrm{ff}$.

754 Nr. 1 der Ansichten des Staatsrats zur Lösung der Probleme der Wanderarbeiter von 2006.

755 第二次全国农业普查主要数据公报第五号 (Statistisches Bulletin Nr. 5 der 2. landwirtschaftlichen Untersuchung Chinas), http://www.stats.gov.cn/tjgb/nypcgb/qgnypcgb/t20080227_402464718.html (Stand: 15. 07. 2010).

756 游钧, 2006 - 2007年: 中国就业报告 (You, Jun (Hrsg.), 2006 - 2007: Blue Book of the Chinese Employment), S. 320. 
Familie bewirtschafte Ackerland ${ }^{757}$ weiter zu behalten, das seit der Bodenreform in den 1950er Jahren nicht nur ein Produktfaktor, sondern auch als eine Grundlebenssicherung angesehen wird. ${ }^{758}$ Deshalb haben sich die meisten von ihnen für ein „ZugvogelArbeitsmodell“" entschieden.

\section{Leitlinien für die Wanderarbeiterfrage}

Die Zahl der Erwerbsfähigen in China wird im Jahre 2020 ihren Höhepunkt erreichen und wird ab dann voraussichtlich ca. zehn Jahre lang anhalten. ${ }^{759}$ Wegen der riesigen ländlichen Bevölkerungszahl dauert die chinesische Urbanisierung noch lange an. Aufgrund der aktiven Position der Regierung zur Urbanisierung werden sich immer mehr Wanderarbeiter in den Städten niederlassen. Dieser Prozess wird allerdings unter Führung und Kontrolle der Regierung durchgeführt. Erst im Jahre 2006 wurden die politischen Richtlinien für die Wanderarbeiter von der Zentralregierung festgelegt. $760 \mathrm{Sie}$ sind ihrem Wesen nach Übergangsmaßnahmen für diesen Prozess, wegen der langen zeitlichen Periode verfügen sie aber auch über einen langfristigen Charakter. Die Schwerpunkte liegen zurzeit in den folgenden Aspekten:

- $\quad$ Festhalten des Bodennutzungsrechts der Wanderarbeiter und des Haushaltsverantwortungssystems, ${ }^{761}$ damit die Grundlebenssicherung der Wanderarbeiter gewährleistet wird, ${ }^{762}$

- $\quad$ Förderung der Migration der Wanderarbeiter in kleine Städte oder Gemeinden ihrer Heimatkreise, 763

- Verbesserung der Beschäftigungssituation und der sozialen Sicherung der Wanderarbeiter, 764

- $\quad$ Schutz der Rechte und Interessen der Wanderarbeiter.765

Für die soziale Sicherung der Wanderarbeiter wurden einige Arbeitsschwerpunkte, bei denen es hauptsächlich um soziale Versicherungen geht, in dem oben genannten Dokument festgelegt. Zuerst haben die Arbeitsunfallversicherung und die Sicherung für

757 In China gehört das Ackerland aufgrund des Kollektiveigentums nicht der Bauernfamilie sondern dem Dorf. Art. 10 Abs. 2 der Verfassung von 1982.

758 Nr. 27 der Ansichten des Staatsrats zur Lösung der Probleme der Wanderarbeiter von 2006; vgl. 温 铁军，农民社会保障与土地制度改革 (Wen, Tiejun, Soziale Sicherung der ländlichen Bevölkerung und Reform der Bodenpolitik), in: 学习月刊 (Study Monthly), 2006/10, S. 20.

759 Siehe: 韩长赋, 关于农民工问题调研后的几点思考 (Han, Changfu, Einige Gedanken über die Frage der Wanderarbeiter), in: 国务院研究室课题组, 中国农民工研究总报告 (Forschungsgruppe des Staatsrats, Reporting on the Problems of Chinese Farmer-turned Workers), S. 63.

760 Ansichten des Staatsrats zur Lösung der Probleme der Wanderarbeiter von 2006.

761 Ausführlich: Erster Teil, Wirtschaftsreform.

762 Nr. 27 der Ansichten des Staatsrats zur Lösung der Probleme der Wanderarbeiter von 2006.

763 Nr. 26, 31, 32, 33, 34 der Ansichten des Staatsrats zur Lösung der Probleme der Wanderarbeiter von 2006.

764 Abschnitt 3, 4, 5, 6, 7 der Ansichten des Staatsrats zur Lösung der Probleme der Wanderarbeiter von 2006.

765 Abschnitt 8 der Ansichten des Staatsrats zur Lösung der Probleme der Wanderarbeiter von 2006. 
schwere Krankheiten Priorität gehabt. Die Wanderarbeiter sollen wie die städtischen Beschäftigten von der Arbeitsunfallversicherung erfasst werden. Alle Arbeitseinheiten müssen unverzüglich für ihre Wanderarbeiter die Formalitäten der Arbeitsunfallversicherung erledigen und rechtzeitig die Beiträge zahlen. ${ }^{766}$ Hinsichtlich der Gesundheitssicherung kann ein Solidarfonds für die Krankenversicherung der Wanderarbeiter errichtet werden. In manchen Regionen können die Wanderarbeiter, die schon fest beschäftigt sind, direkt in die Grundkrankenversicherung der städtischen Beschäftigten integriert werden. Die Wanderarbeiter können auch an dem ländlichen kooperativen medizinischen System teilnehmen. ${ }^{767}$ Es wird untersucht werden, wie eine der hohen Mobilität der Wanderarbeiter entsprechende Altersversicherung zu errichten ist. Die Altersversicherung der Wanderarbeiter soll mit anderen Alterssicherungssystemen verknüpf- und übertragbar sein, und der Beitragssatz soll relativ niedrig sein. ${ }^{768}$

Für die Regierung ist es schwierig, in einem langen Übergangsprozess für eine wandernde Arbeiter-Bauern-Gruppe ein soziales Sicherungssystem zu errichten, weil es nicht nur um die Auswahl der geeigneten Sicherungsmodelle, sondern besonders um die Verknüpfungen mit den sozialen Sicherungen anderer Gruppen geht. Dafür hat der Staatsrat noch keinen einheitlichen Plan vorgelegt. Die derzeitigen Leitlinien des Staatsrats erkennen im gewissen Maße die bisherige Praxis der lokalen Regierungen in diesem Bereich an. Damit wird den lokalen Regierungen genehmigt, sich weiter selbst für das Modell der Wanderarbeiterversicherung zu entscheiden.

\section{Soziale Versicherungen für die Wanderarbeiter}

\section{a) Modelle der Wanderarbeiterversicherung}

Während die Wanderarbeiter die ländlichen sozialen Sicherungen weiter genießen können, entwickeln die Stadtregierungen soziale Versicherungen für die in den städtischen Unternehmen beschäftigten Wanderarbeiter. Da die Zentralregierung lange Zeit zögerte, landesweit einheitliche Leitlinien für die Wanderarbeiterversicherung festzulegen, entwickelten die lokalen Regierungen seit Ende der 1990er Jahre separat Modelle der Wanderarbeiterversicherung, die sehr unterschiedlich voneinander sind.

Die Wanderarbeiterversicherungsmodelle können grob in zwei Gruppen eingeteilt werden. Eine ist das sogenannte „Shanghai-Modell“, dabei baut die lokale Regierung ein eigenes soziales Versicherungssystem für Wanderarbeiter auf. Die andere Variante wird als „Shenzhen-Modell“ oder „Guangdong-Modell“ bezeichnet, bei dieser werden die Wanderarbeiter in das Versicherungssystem der städtischen Beschäftigten einbezogen. 769

766 Nr. 16, 17 der Ansichten des Staatsrats zur Lösung der Probleme der Wanderarbeiter von 2006.

767 Nr. 16, 18 der Ansichten des Staatsrats zur Lösung der Probleme der Wanderarbeiter von 2006.

768 Nr. 16, 19 der Ansichten des Staatsrats zur Lösung der Probleme der Wanderarbeiter von 2006.

769 Ausführlich vgl. 都阳/高文书, 中国离一元社会保障体系有多远 (Du, Yang/Gao, Wenshu, How far is china away from an intergrated social security system), in: 中国劳动经济学 (China Labor Economics), 2005, Vol. 2 No. 2, S. 48ff.; 游钧, 2006 - 2007年: 中国就业报告 (You, Jun (Hrsg.), 
Im Jahre 2002 hat die Regierung der Stadt Shanghai die „Vorläufigen Maßnahmen der Stadt Shanghai zur Gesamtversicherung für die auswärtigen Beschäftigten"770 veröffentlicht. Bei diesem Versicherungsmodell werden Arbeitsunfallversicherung und Krankenversicherung zusammen mit Altersversicherungszuschüssen in eine umfassende Versicherung erfasst. ${ }^{771}$ Nach dieser Verordnung wird 60\% des Durchschnittslohns aller lokalen Beschäftigten des vergangenen Jahres als Beitragsgrundlage genommen. Der Arbeitergeber zahlt 12.5\% von der Beitragsgrundlage als Beitrag (7\% für Altersversicherung, 5.5\% für Kranken- und Arbeitsunfallversicherung) für jeden seiner auswärtigen Arbeitnehmer, die keinen Shanghai-Hukou haben, in den Fonds der Gesamtversicherung. ${ }^{772}$ Die versicherten Arbeitnehmer sind beitragsfrei. Demgegenüber zahlen die auswärtigen Selbständigen selbst den Beitrag (auch 12.5\% von der Beitragsgrundlage). Bei der Gesamtversicherung sind die Leistungsniveaus und der Beitragssatz von den Versicherungen für Beschäftigte in städtischen Unternehmen unterschiedlich und vergleichweise niedrig. ${ }^{773}$

Weil die Beitragszahlung und die Verwaltung dieses Modells ziemlich einfach sind, wird es von den Arbeitgebern und Wanderarbeitern leichter akzeptiert. Allerdings hat die Shanghai-Regierung keine Verknüpfungen zwischen der Gesamtversicherung der Wanderarbeiter und den städtischen sowie ländlichen Versicherungssystemen geschaffen. Außerdem ist das Leistungsniveau der Altersversicherungszuschüsse wegen der geringen Beitragshöhe so niedrig, dass das Altersrisiko der Versicherten nicht dadurch abgedeckt werden kann. 774

Die Stadt Chengdu hat im Jahr 2003 aufgrund der Shanghai-Erfahrung auch eine Gesamtversicherung für die Beschäftigten mit Land-Hukou aufgebaut, die ebenfalls Unfall-, Kranken- sowie Altersversicherung umfasst. ${ }^{775}$ Nach der Veröffentlichung der

2006 - 2007: Blue Book of the Chinese Employment), S. 362ff; 国务院研究室课题组, 中国农民 工研究总报告 (Forschungsgruppe des Staatsrats, Reporting on the Problems of Chinese Farmerturned Workers), S. 35; 劳动和社会保障部社会保障研究所, 城镇化进程加快过程中农民工社 会保障制度研究 (Forschungsinstitut für soziale Sicherheit beim Ministerium für Arbeit und soziale Sicherheit, Das soziale Sicherungssystem für die Wanderarbeiter im Urbanisierungsprozess), in: 社会保障研究 (Forschung über die soziale Sicherheit), 2006/1, S. 4.

770 上海市外来从业人员综合保险暂行办法, 上海市人民政府令第 123 号, vom 22. 07. 2002, geändert am 30. 08. 2004, http://www.shanghai.gov.cn/shanghai/node2314/node3124/node3125/node3129/userobject6ai1130.html (Stand: 15. 07. 2010).

$771 \S 2$ der Vorläufigen Maßnahmen zur Gesamtversicherung für die auswärtigen Beschäftigten in Shanghai von 2002.

$772 \S 9$ Abs. 1 der Vorläufigen Maßnahmen in Shanghai von 2002.

$773 \S 14,15,16$ der Vorläufigen Maßnahmen in Shanghai von 2002.

774 劳动和社会保障部社会保障研究所, 城镇化进程加快过程中农民工社会保障制度研究 (Forschungsinstitut für soziale Sicherheit beim Ministerium für Arbeit und soziale Sicherheit, Das soziale Sicherungssystem für die Wanderarbeiter im Urbanisierungsprozess), in: 社会保障研究 (Forschung über die soziale Sicherheit), 2006/1, S. 14.

775 成都市非城镇户籍从业人员综合社会保险暂行办法 (Vorläufige Maßnahmen der Stadt Chengdu zur Gesamtversicherung der Beschäftigten ohne Stadt-Hukou), 成府发 (2003) 7号, vom 21. 01. 2003, http://www.51labour.com/lawcenter/lawshow-67712.html (Stand: 15. 07. 2010). 
Ansichten des Staatsrats zur Lösung der Probleme der Wanderarbeiter von 2006 wurden spezielle Maßnahmen zur Unfall- und Krankenversicherungen der Wanderarbeiter auch in den Küstenstädten Tianjin ${ }^{776}$ sowie Dalian ${ }^{777}$ ausgearbeitet.

\section{bb) Shenzhen-Modell}

Als die erste Sonderwirtschaftsregion Chinas hatte die Stadt Shenzhen im Jahr 1993 angefangen, die Wanderarbeiter formell im städtischen System der sozialen Sicherungen einzubeziehen. 778 Aufgrund der staatlichen Normen und der lokalen Verordnungen der Provinz Guangdong, in der die Stadt Shenzhen liegt, wurden die Regelungen über die Wanderarbeiterversicherung von der Stadtregierung allmählich verbessert. Zurzeit ist das Versicherungssystem relativ ausgearbeitet.

Bei dem Shenzhen-Modell gibt es keine speziellen Verordnungen über die Wanderarbeiterversicherung. Die Renten-, Kranken-, und Arbeitsunfallversicherungen der Wanderarbeiter werden mit den Versicherungen der städtischen Beschäftigten zusammen geregelt, aber die Wanderarbeitnehmer werden gleich wie bei dem ShanghaiModell nicht von der Arbeitslosenversicherung und der Mutterschaftsversicherung erfasst. Die Teilnahmebedingungen der Wanderarbeiter an den sozialen Versicherungen sind grundsätzlich gleich wie die Bedingungen für die Arbeiternehmer mit Stadt-Hukou, allerdings sind die Beitragssätze und die Leistungen der Renten- und Krankenversicherung für sie vergleichweise niedrig (ähnlich wie beim Shanghai-Modell). Außerdem durften die Wanderarbeiter vor Erlass der „Vorläufigen Maßnahmen zur Übertragung und Fortsetzung der Rentenversicherungsbeziehungen“, die die Wanderarbeiter auch betreffen, 779 freiwillig aus der Grundrentenversicherung austreten. 780

Das Shenzhen-Modell wird in der Provinz Guangdong provinzweit durchgeführt. Die Provinz Zhejiang hat auch einen ähnlichen Mechanismus aufgebaut. ${ }^{781}$ Demgegenüber hat die Stadt Beijing die sozialen Versicherungen der Wanderarbeiter, die grundsätzlich

776 天津市农民工参加医疗工伤综合保险办法 (Maßnahmen der Stadt Tianjin zur gesamten Kranken- und Arbeitsunfallversicherung der Wanderarbeiter), vom 25. 06. 2008, http://csi.tjftz.gov.cn/system/2008/08/21/010017023.shtml (Stand: 15. 07. 2010).

777 大连市农民工基本医疗保险暂行办法 (Vorläufige Maßnahmen der Stadt Dalian zur Grundkrankenversicherung der Wanderarbeiter), vom 01. 10. 2006, http://www.51labour.com/lawcenter/lawshow-46832.html (Stand: 15. 07. 2010).

778 Ausführlich vgl. 费平, 深圳市农民工社会保险制度 (Fei, Ping, Das soziale Sicherungssystem der Wanderarbeiter in der Stadt Shenzhen), in: 中国劳动 (China Labor), 2006/10, S. 13ff.

$779 \S 2$ Abs. 1 der Vorläufigen Maßnahmen zur Übertragung und Fortsetzung der Rentenversicherungsbeziehungen der Arbeitnehmer in städtischen Unternehmen von 2009.

780 费平, 深圳市农民工社会保险制度 (Fei, Ping, Das System der soziale Sicherung der Wanderarbeiter in der Stadt Shenzhen), in: 中国劳动 (China Labor), 2006/10, S. 13ff; 劳动和社会保障部 社会保障研究所, 城镇化进程加快过程中农民工社会保障制度研究 (Forschungsinstitut für soziale Sicherheit beim Ministerium für Arbeit und soziale Sicherheit, Das soziale Sicherungssystem für die Wanderarbeiter im Urbanisierungsprozess), in: 社会保障研究 (Forschung über die soziale Sicherheit), 2006/1, S. 9ff.

781 Ausführlich vgl. 国务院研究室课题组, 中国农民工研究总报告 (Forschungsgruppe des Staatsrats, Reporting on the Problems of Chinese Farmer-turned Workers), S. 35. 
in das Versicherungssystem der städtischen Beschäftigten aufgenommen wurden, in verschiedenen lokalen Verordnungen separat geregelt. ${ }^{782}$

\section{cc) Vergleich der Modelle}

Die beiden Versicherungsmodelle der Wanderarbeiter sind in manchen Aspekten miteinander identisch. ${ }^{783}$ Sie umfassen normalerweise nur Unfallversicherung, Krankenversicherung und Alterssicherung. Die Unfallversicherung ist mit dem System der städtischen Beschäftigten identisch. Die Beitragssätze und die Leistungen sind niedriger als die der städtischen Systeme.

In den Bereichen der Kranken- und Altersversicherungen sind die Modelle verschiedener Regionen sehr unterschiedlich. Zum Beispiel können die Wanderarbeiter in Shenzhen an der Grundkrankenversicherung der städtischen Beschäftigten oder der Krankenversicherung für Wanderarbeiter teilnehmen, ihre Altersversicherung funktioniert ähnlich wie die Rentenversicherung der städtischen Beschäftigten. Demgegenüber gibt es bei dem Shanghai-Modell nur eine spezielle Pauschalkrankenversicherung und die Altersversicherungszuschüsse für Wanderarbeiter.

Der Grund dafür, dass Shenzhen und Shanghai jeweils unterschiedliche Wanderarbeiterversicherungsmodelle ausgewählt haben, liegt darin, dass die zwei Städte zwei verschiedene Stadttypen repräsentieren. Die Stadt Shenzhen wurde erst im Jahre 1979 gegründet und im Jahre 1980 zur Sonderwirtschaftsregion erklärt. Sie entwickelte sich seitdem rasant. Bis 2006 betrug die Bevölkerungszahl in Shenzhen bereits 8.46 Mio., davon sind nur ca. 23\% der Bevölkerung ,formelle“ Shenzhen-Bewohner, also ca. 77\% der Bevölkerung haben keinen Shenzhen-Hukou und die meisten davon sind Wanderarbeiter. ${ }^{784}$ Diese große Bevölkerungsgruppe in das städtische soziale Versicherungssystem einzubeziehen, ist für die Stadtentwicklung und die Erweiterung der städtischen sozialen Versicherungen sinnvoll.

In der Stadt Shanghai ist die Situation umgekehrt. 2006 betrug die Bevölkerungszahl in Shanghai 18 Mio., davon haben 75\% der Bevölkerung Shanghai-Hukou. ${ }^{785}$ Als die größte Industriestadt und eine der bevölkerungsreichsten Städte Chinas stößt Shanghai

782 Siehe: 游钧, 2006 - 2007年: 中国就业报告 (You, Jun (Hrsg.), 2006 - 2007: Blue Book of the Chinese Employment), S. 365; 都阴/高文书, 中国离一元社会保障体系有多远 $(\mathrm{Du}, \mathrm{Yang} / \mathrm{Gao}$, Wenshu, How far is china away from an intergrated social security system), in: 中国劳动经济学 (China Labor Economics), 2005, Vol. 2 No. 2, S. 49.

783 Ausführlich vgl. 劳动和社会保障部社会保障研究所, 农民工社会保障的新情况新问题 - 基于 深圳上海的实地调研 (Forschungsinstitut für soziale Sicherheit beim Ministerium für Arbeit und soziale Sicherheit, Gegenwärtiger Zustand und neue Probleme der Wanderarbeitersicherung - aufgrund der Untersuchungen in Shenzhen und Shanghai), in: 社会保障研究 (Forschung über die soziale Sicherheit), 2008/1, S. 5.

784 深圳市2006年国民经济和社会发展统计公报 (Statistisches Bulletin Shenzhen über die Entwicklung der Volkswirtschaft und der Gesellschaft 2006), http://old.csrc.gov.cn/n575458/n870654/n1334575/3720976.html (Stand: 15. 07. 2010).

785 2006年上海市国民经济和社会发展统计公报 (Statistisches Bulletin Shanghai über die Entwicklung der Volkswirtschaft und der Gesellschaft 2006), http://www.stats.gov.cn/tjgb/ndtjgb/dfndtjgb/t20070420_402400624.htm (Stand: 15. 07. 2010). 
bereits an die Grenzen ihrer Kapazitäten, ${ }^{786}$ deswegen kontrolliert die ShanghaiRegierung streng die Immigration und errichtete das Shanghai-Modell. Dadurch werden die „formellen“ Stadtbewohner und die Wanderarbeiter voneinander getrennt. Mit den geringen Altersversicherungszuschüssen ist es für die Wanderarbeiter kaum möglich, in Shanghai im Ruhestand zu leben.

Gegenüber den Wanderarbeitern in den großen Städten wird ein großer Teil der ländlichen Arbeitskräfte in Dorfunternehmen noch von der ländlichen Altersversicherung erfasst. Allerdings haben mit der sich beschleunigenden Urbanisierung der reichen Landgebiete - zum Beispiel im Süden der Provinz Jiangsu - viele ländliche Arbeiter zeitweise an den städtischen Versicherungssystemen teilgenommen. ${ }^{787}$

\section{b) Entwicklungen der Wanderarbeiterversicherung}

Nach dem Bericht des Ministeriums für Arbeit und soziale Sicherheit wurden bis 2005 landesweit knapp 20\% der Wanderarbeiter von dem sozialen Versicherungssystem erfasst, davon haben nur ca. 15\% der gesamten Wanderarbeiter an der Rentenversicherung und $10 \%$ an der Krankenversicherung teilgenommen. ${ }^{788}$ Gemäß der Erklärung über die Arbeitsunfall- und Krankenversicherung in den „Ansichten des Staatsrats zur Lösung der Probleme der Wanderarbeiter" von 2006 hatte das Ministerium für Arbeit und soziale Sicherheit im selben Jahr die Pläne zur Vergrößerung des Versichertenkreises der Arbeitsunfall- und Krankenversicherung ausgearbeitet, ${ }^{789}$ dadurch haben sich die beiden Versicherungen der Wanderarbeiter kontinuierlich entwickelt.

In der Stadt Shenzhen werden die Wanderarbeiter zurzeit schon im Großen und Ganzen von der Arbeitsunfall- und Krankenversicherung erfasst. Die Deckungsrate der Ge-

786 劳动和社会保障部社会保障研究所, 农民工社会保障的新情况新问题 - 基于深圳上海的实地 调研 (Forschungsinstitut für soziale Sicherheit beim Ministerium für Arbeit und soziale Sicherheit, Gegenwärtiger Zustand und neue Probleme der Wanderarbeitersicherung - aufgrund der Untersuchungen in Shenzhen und Shanghai), in: 社会保障研究 (Forschung über die soziale Sicherheit), 2008/1, S. 2.

787 游钧, 2006 - 2007年: 中国就业报告 (You, Jun (Hrsg.), 2006 - 2007: Blue Book of the Chinese Employment), S. 362.

788 Zitiert nach: 劳动和社会保障部社会保障研究所, 城镇化进程加快过程中农民工社会保障制度 研究 (Forschungsinstitut für soziale Sicherheit beim Ministerium für Arbeit und soziale Sicherheit, Das soziale Sicherungssystem für die Wanderarbeiter im Urbanisierungsprozess), in: 社会保障研 究 (Forschung über die soziale Sicherheit), 2006/1, S.6; 游钧, 2006 - 2007年: 中国就业报告 (You, Jun (Hrsg.), 2006 - 2007: Blue Book of the Chinese Employment), S. 363; 劳动和社会保障 部调研组, 农民工社会保障问题研究报告 (Forschungsgruppe des Ministerium für Arbeit und soziale Sicherheit, Forschungsbericht über die soziale Sicherung der Wanderarbeiter), in: 国务院研 究室课题组, 中国农民工调研报告 (Forschungsgruppe des Staatsrats, Reporting on the Problems of Chinese Farmer-turned Workers), S. 248.

789 劳动和社会保障部, 关于实施农民工平安计划, 加快推进农民工参加工伤保险工作的通知 (Mitteilung über die Durchführung des Ping'an-Plans der Arbeitsunfallversicherung für die Wanderarbeiter), 劳社部发(2006)19号, vom 17. 05. 2006, http://www.molss.gov.cn/gb/zxwj/200606/12/content_119251.htm（Stand: 15. 07. 2010); 关于开展农民工参加医疗保险专项扩面行动 的通知 (Mitteilung über die spezielle Aktion zur Vergrößerung der Krankenversicherung für die Wanderarbeiter), 劳社厅发 (2006) 11 号, vom 16. 05. 2006, http://www.molss.gov.cn/gb/zxwj/2006-05/19/content_116904.htm (Stand: 15. 07. 2010). 
samtversicherung in Shanghai war von 56\% aller Wanderarbeiter im Jahre 2005 auf 70\% im Jahre 2007 gestiegen. 790 Bei der Arbeitsunfallversicherung werden die Wanderarbeiter landesweit gleich wie die städtischen Beschäftigten behandelt. Das Leistungsniveau der Krankenversicherung der Wanderarbeiter ist nun sowohl in Shanghai als auch in Shenzhen erhöht worden. Obwohl das Niveau im Vergleich zur Grundkrankenversicherung der städtischen Beschäftigten niedriger ist, wird es von den Wanderarbeitern, die hauptsächlich aus jungen und gesunden Bauern bestehen, grundsätzlich akzeptiert. ${ }^{791}$

Die weitere Entwicklung der Wanderarbeiterversicherung wird nun hauptsächlich durch die Altersversicherung behindert. Im Jahre 2007 lag die Teilnahmerate der Wanderarbeiter an der Altersversicherung landesweit bei knapp 20\%.792 Bis Ende 2007 wurden ca. 50\% der Wanderarbeiter in Shenzhen von der Rentenversicherung erfasst. In Shanghai ist die Deckungsrate wegen dem Zwangscharakter der drei Versicherungen höher $(70 \%)$, allerdings sind die Versicherten mit dem niedrigen Leistungsniveau nicht zufrieden, denn 2006 betrugen die jährlichen Altersversicherungszuschüsse nur 1200 RMB pro Person. Das entsprach nur 52\% der Rente aus dem Individualkonto des städtischen Arbeitsnehmers. ${ }^{793}$

Beim Shenzhen-Modell leidet die Altersversicherung der Wanderarbeiter unter den eigenen Mängeln der Grundrentenversicherung, insbesondere an dem hohen Beitragssatz und der fehlenden Übertragbarkeit des Leistungsanspruchs zwischen verschiedenen Altersversicherungssystemen, die für die Wanderarbeitergruppe besonders ungünstig sind. Weil der freiwillige Austritt der Versicherten beim Shenzhen-Modell bis Ende 2009 erlaubt war, hatten sich die meisten Wanderarbeiter beim Abbruch ihrer Beschäftigung in der Stadt entschieden, aus der Altersversicherung auszutreten und sich ihre Beiträge in bar zurückerstatten zu lassen. Vor dem chinesischen Neujahr kehrten viele

790 劳动和社会保障部社会保障研究所, 农民工社会保障的新情况新问题 - 基于深圳上海的实地 调研 (Forschungsinstitut für soziale Sicherheit beim Ministerium für Arbeit und soziale Sicherheit, Gegenwärtiger Zustand und neue Probleme der Wanderarbeitersicherung - aufgrund der Untersuchungen in Shenzhen und Shanghai), in: 社会保障研究 (Forschung über die soziale Sicherheit), 2008/1, S. 4.

791 劳动和社会保障部社会保障研究所, 农民工社会保障的新情况新问题 - 基于深圳上海的实地 调研 (Forschungsinstitut für soziale Sicherheit beim Ministerium für Arbeit und soziale Sicherheit, Gegenwärtiger Zustand und neue Probleme der Wanderarbeitersicherung - aufgrund der Untersuchungen in Shenzhen und Shanghai), in: 社会保障研究 (Forschung über die soziale Sicherheit), 2008/1, S. 5.

792 劳动和社会保障部社会保障研究所, 农民工社会保障的新情况新问题 - 基于深圳上海的实地 调研 (Forschungsinstitut für soziale Sicherheit beim Ministerium für Arbeit und soziale Sicherheit, Gegenwärtiger Zustand und neue Probleme der Wanderarbeitersicherung - aufgrund der Untersuchungen in Shenzhen und Shanghai), in: 社会保障研究 (Forschung über die soziale Sicherheit), 2008/1, S. 6.

793 劳动和社会保障部社会保障研究所, 农民工社会保障的新情况新问题 - 基于深圳上海的实地 调研 (Forschungsinstitut für soziale Sicherheit beim Ministerium für Arbeit und soziale Sicherheit, Gegenwärtiger Zustand und neue Probleme der Wanderarbeitersicherung - aufgrund der Untersuchungen in Shenzhen und Shanghai), in: 社会保障研究 (Forschung über die soziale Sicherheit), 2008/1, S. 5. 
Wanderarbeiter in ihre Heimat zurïck, in manchen Gebieten der Provinz Guangdong erreichte die Austrittquote in dieser Zeit sogar 95\%.794

Nach dem Inkrafttreten der „Vorläufigen Maßnahmen zur Übertragung und Fortsetzung der Rentenversicherungsbeziehungen“ im Jahre 2010 ist der Austritt der Wanderarbeiter grundsätzlich nicht mehr erlaubt, ${ }^{795}$ da die Versicherungsverhältnisse der Wanderarbeiter nun überregional übertragen werden können. Der Aufbau einer Verknüpfung zwischen der städtischen Grundrentenversicherung und der ländlichen Altersversicherung wird auch in dieser Vorschrift gefordert. ${ }^{796}$ Bislang wurden allerdings noch keine konkreten Maßnahmen dafür ausgearbeitet.

Darüber hinaus hat das Ministerium für Personalwesen und soziale Sicherheit ein Entwurf über die Teilnahme der Wanderarbeiter an der Grundrentenversicherung veröffentlicht. ${ }^{797}$ Damit könnte die Altersversicherung der Wanderarbeiter einheitlich in die Rentenversicherung der städtischen Beschäftigten einbezogen werden. 798 Allerdings wurde dieser Entwurf bislang nicht vom Staatsrat genehmigt. Demzufolge ist die Altersversicherung der Wanderarbeiter zurzeit noch nicht vereinheitlicht.

Das von dem Urbanisierungsprozess Chinas verursachte Phänomen der Wanderarbeiter wirkt auf den Abbau der dualistischen Struktur der Gesellschaft zurück. Es fördert die Ausgestaltung eines landesweit einheitlichen Arbeitsmarktes und die Koordinierung der städtischen und ländlichen sozialen Sicherungssysteme. Unter dem Druck des Wanderarbeiterproblems wird die Beschäftigungsförderung der Wanderarbeiter seit $2005^{799}$ und die Verlagerung der Planungsebene der Altersversicherung seit 2007800 beschleunigt. Es ist vorauszusehen, dass das Phänomen der massiven Migration der ländlichen Arbeitskräfte allmählich mit der Vollendung des Urbanisierungsprozesses verschwinden wird. Ferner werden die meisten Wanderarbeiter zu Stadtbewohnern. Deswegen ist die Schaffung der Verknüpfungen zwischen den ländlichen und städtischen Systemen der sozialen Sicherung notwendig, damit die in den Städten fest beschäftigten Wanderarbeiter unbehindert in das städtische System wechseln können.

794 何平, 让农民工退保成为历史 (He, Ping, Wie beseitigen wir das Phänomen ,Austritt der Wanderarbeiter aus der sozialen Versicherungen“), in: 中国报道 (China Report), 2008/3, S. 26ff.

$795 \S 2$ Abs. 2 der Voläufigen Maßnahmen zum Übertragen der Grundrentenversicherung der Arbeitnehmer in städtischen Unternehmen von 2009.

$796 \S 9$ der Voläufigen Maßnahmen zum Übertragen der Grundrentenversicherung von 2009.

797 人力资源和社会保障部，农民工参加基本养老保险办法征求意见稿 (Ministerium für Personalwesen und soziale Sicherheit, Entwurf über die Teilnahme der Wanderarbeiter an der Grundrentenversicherung), vom 05. 02. 2009, http://www.gov.cn/gzdt/2009-02/05/content_1222469.htm (Stand: 15. 07. 2010).

$798 \S 1$ des Entwurfs über die Teilnahme der Wanderarbeiter an der Grundrentenversicherung von 2009.

799 Nr. 2 der Bekanntmachung über die weitere Verstärkung der Beschäftigungs- und Wiederbeschäftigungsarbeit von 2005.

800 白天亮, 养老保险省级统筹力争两年内实现 (Bai, Tianliang, Verwirklichung der einheitlichen Verwaltung der Rentenversicherung auf Provinzebene in zwei Jahren), in: 人民日报 (RMRB), vom 09. 01. 2008. 
Der chinesische Politologe Wang, Shaoguang hat von Karl Polanyi den Begriff „double movement" ${ }^{801}$ übernommen, ${ }^{802}$ um den wesentlichen Charakter der chinesischen Transformation seit den 1980er Jahren darzustellen. Er ist der Ansicht, dass nach der kurzfristigen Bewegung von einer „,market society“ in den 1990er Jahren die Gegenbewegung (counter-movement) nun in China einen „social market" vorantreibe, in dem der Staat durch seine Umverteilungsfunktion den Markt wieder in die sozialen und ethischen Verhältnisse einbette. Die jüngeren Leitgedanken für die Reform der sozialen Sicherheit zeigen, dass die chinesische Regierung dafür sowohl den politischen Willen als auch die Finanzierungsfähigkeit hat, obwohl beides noch verstärkt werden sollte.

Die Tendenz, durch die Selbstregulierung des freien Marktes eine „market society“ in China aufzubauen, wurde nach der rasanten Vergrößerung der gesellschaftlichen Ungleichheit ${ }^{803}$ gebremst. Als ein Staat mit langer Tradition von Totalitarismus und Zentralismus ${ }^{804}$ ist die „Wiederkehr der staatlichen Verantwortung“ für China eine logische Folge. Seit Ende der 1990er Jahre hat die Zentralregierung angefangen, durch Verstärkung der finanziellen Unterstützung für die armen mittleren und westlichen Gebiete, für die ländlichen Gebiete und für die soziale Sicherheit die Polarisierung zwischen Arm und Reich, die Disparitäten zwischen Stadt und Land sowie die regionalen Entwicklungsdisparitäten auszugleichen. ${ }^{805}$ Die Experten diskutieren seit dem Anfang des 20. Jahrhunderts ausführlich über die staatliche Verantwortung und die führende Rolle der Regierung für Systemkonstruierung, Finanzierung sowie Verwaltung und Aufsicht im Bereich der sozialen Sicherheit. 806

Die Entwicklungstendenz dieser Gegenbewegung wird durch die Darstellung und Analyse der wichtigen Reformen verdeutlicht. Die Untersuchung zeigt, dass der ausschlaggebende Wendepunkt mit der Aufstellung der Theorie der „Harmonischen Gesellschaft“ im Jahre 2006 eingetreten ist. Seitdem haben neue Reformrunden vieler Si-

801 Polanyi, The Great Transformation - the political and economic origins of our time.

802 Wang, Shaoguang, Great social Transformation, A Foot in China, in: China Economist, 2008/7, S. 55ff., auch: 王绍光, 大转型: 1980年代以来中国的双向运动 (Wang, Shaoguang, The Great Transformation: Double Movement in China since the 1980s), in: 中国社会科学 (Social Science in China), 2008/1, S. 129ff.

803 Ausführlich: Erster Teil, Gleichheit und Effizienz.

804 Ausführlich: Erster Teil, Politik- und Wirtschaftssystem.

805 王绍光, 顺应民心的变化: 从财政资金流向看中国政府政策调整 (Wang, Shaoguang, Politische Regulierung der chinesischen Regierung: unter dem Blickwinkel von Fließrichtung der Finanzmittel), in: 战略与管理 (Strategy \& Management), 2004/2, S. $51 \mathrm{ff}$.

806 Siehe: 李绍光, 政府在社会保障中的责任 (Li, Shaoguang, Die Verantwortung der Regierung im Bereich der sozialen Sicherheit), in: 经济社会体制比较 (Comparative Economic \& Social Systems), 2002/5, S. 34ff; 杨方方, 从缺位到归位 - 中国转型期社会保险中的政府责任 (Yang, Fangfang, Von der Abkehr bis zur Wiederkehr - die staatliche Verantwortung für die Sozialversicherung im chinesischen Transformationsprozess); 潘屹, 论中国国家福利的重构 (Pan, Yi, Wiederaufbau des Wohlfahrtssystems in China), in: 经济社会体制比较 (Comparative Economic \& Social Systems), 2007/2, S. 58ff. 
cherungszweige wie die der Rentenreform, Gesundheitsreform, Beschäftigungspolitik usw. begonnen, die entweder eine Korrektur oder eine Verbesserung der alten Regelungen und Maßnahmen sind, bei denen die Funktion des freien Marktes und die Selbstverantwortung der Bürger betont wurden. Im Gegensatz dazu werden gegenwärtig die staatliche Verantwortung und die Existenz- sowie Förderungsrechte der Bürger in den Vordergrund gestellt.

Die Umwandlungen der chinesischen sozialen Sicherheit - insbesondere der neue Aufbau der sozialen Versicherungssysteme - spiegeln die wichtige Frage der chinesischen Transformation wieder. Diese lautet: Wie ist das Verhältnis zwischen Staat, Gesellschaft und Einzelnen entsprechend der neuen Lage anzupassen? Angesichts der Umstände, dass eine neue Staatstheorie bisher noch nicht festgelegt ist, und die Wirtschaftssowie Gesellschaftsgrundlagen noch in dem Entwicklungsprozess sind, bleibt die soziale Sicherheit noch lange Zeit unbestimmt und bedarf weiterer Regulierung.

Bei verschiedenen Sicherungszweigen sind die Schwerpunkte unterschiedlich. Während die Alterssicherung in großem Umfang unter strukturellen Problemen leidet, konzentriert sich die Kritik an der Gesundheitssicherung hauptsächlich auf die Verstärkung der staatlichen Verantwortung. Demgegenüber bedürfen die Beschäftigungspolitik und die Wanderarbeitersicherung mehr Flexibilität, da es sich häufig um kurz- oder mittelfristige Maßnahmen handelt und die betreffenden Situationen sich schnell ändern.

Es gibt heutzutage noch große Schwierigkeiten mit den sozialen Sicherungssystemen. Aber die kontinuierliche Verbesserung der Lebenssituation, die der wirtschaftliche und gesellschaftliche Fortschritt mit sich bringt, mildert in einem gewissen Grad die aus dem Absinken des Sicherungsniveaus resultierende Unzufriedenheit der Bürger. Die Verbesserung der Lebenssituation weckt bei den Bürgern die Hoffnung, dass die Mängel der sozialen Sicherheit schließlich - wie andere Schwierigkeiten in diesem enormen Transformationsprozess auch - in der Zukunft vom Staat beseitigt werden können. 


\section{Vierter Teil : Einfluss internationaler Organisationen}

- äußere Faktoren der Umwandlung der sozialen Sicherheit

Das Prinzip der Souveränität der Staaten, das seit dem 17. Jahrhundert durch das Westfälische System institutionalisiert wurde, wird nach dem zweiten Weltkrieg von der Entwicklung der internationalen Institutionen - insbesondere die Gründung der Vereinten Nationen - immer mehr ergänzt und geschwächt. ${ }^{1}$ Diese Tendenz wird verstärkt durch die zunehmende wirtschaftliche Globalisierung. ${ }^{2}$ Die internationalen Institutionen und Organisationen intervenieren durch Normensetzung und andere Aktivitäten auf verschiedene Art und Weise in die Gestaltung der Innenpolitik des Staates und spielen bei der Verstärkung der Interdependenz zwischen den Staaten eine bedeutende Rolle. Im Bereich der sozialen Sicherheit haben sie ebenso Einfluss auf die politischen Entscheidungen und die Gesetzgebungen der Mitgliedstaaten ausgeübt.

Der Umbau der chinesischen sozialen Sicherungssysteme, die in den 1980er Jahren parallel mit der Durchführung der Öffnungspolitik begonnen wurde, bewegt sich in der Periode der „Reform und Öffnung“ unter einem beachtlichen Einfluss von äußeren Faktoren. Davon haben die internationalen Organisationen als internationale Normengeber und als Plattform für Wissenstransfer und Kooperation eine sehr aktive Rolle gespielt. Da die Darstellung und Analyse des Einflusses der internationalen Institutionen für das Verständnis der derzeitigen sozialen Sicherheit in China und ihres Entwicklungswegs notwendig sind, werden die Fragen, wie und inwieweit die chinesische soziale Sicherheit und das Sozialleistungsrecht von den internationalen Institutionen beeinflusst werden, in diesem Teil erörtert.

\section{A. Beteiligung Chinas an den internationalen Organisationen}

Da die Einführung der internationalen Standards und Modelle über soziale Sicherheit in China abhängig von den außenpolitischen Entscheidungen des Staates ist, werden die Veränderung der chinesischen Außenpolitik und der Beziehung zwischen China und den internationalen Institutionen zuerst dargestellt.

„Hegemonismus und Machtpolitik zu bekämpfen, Errichtung neuer internationaler Politik- und Wirtschaftsordnungen zu fördern" 3 sind die bisherigen außenpolitischen Prinzipien der Volksrepublik China. Aufgrund dieser grundlegenden Prinzipien wurde die chinesische Außenpolitik der Veränderung der internationalen Lage und der Innenpolitik entsprechend mehrfach korrigiert.

1 Vgl. Mishra, Globalization and the Welfare State, S. 11ff; Huntington, The Clash of Civilizations and the Remaking of World Order. S. 35.

2 Ipsen, Völkerrecht, S. 50.

3 邓小平文选第三卷 (Deng, Xiaoping, Ausgewählte Werke von Deng, Xiaoping, Dritter Band), S. 353. 
In den 1950-60er Jahren war die Volksrepublik wegen der starken ideologischen Färbung des kalten Kriegs und der Wirtschaftsblockade der westlichen Staaten von den internationalen Institutionen isoliert. Die Volkspartei-Regierung Chinas (1911 - 1949), die nach drei Jahren Bürgerkrieg (1945 - 1949) die Führungsmacht verlor, flüchtete im Jahre 1949 auf die Insel Taiwan. Die Volksrepublik wurde im Jahre 1949 gegründet. Bis 1971 vertrat in den Vereinten Nationen (UNO) die Volkspartei-Regierung weiter als legale Regierung das chinesische Volk. Demgegenüber stellte die Volksrepublik sich auf die Seite des internationalen Kommunismus und schloss einen Freundschaftspakt mit der Sowjetunion. ${ }^{4}$ In dieser Zeit war die Volksrepublik China ein „Gegner der internationalen Ordnung“. Sie kritisierte die Vereinten Nationen heftig und schlug im Jahre 1965 die neue internationale Organisation der „Revolutionären Vereinten Nationen“ vor. $^{5}$

Die chinesisch-sowjetischen Beziehungen zerbrachen in den 1960er Jahren weitestgehend. China trat seitdem aus der Konfrontation zwischen den USA und der Sowjetunion aus und verbesserte allmählich die Beziehung mit den westlichen Staaten. Im Jahre 1971 wurde die Volksrepublik schließlich als der einzig legitimierte Vertreter des chinesischen Volks von der UN-Generalversammlung anerkannt. ${ }^{6}$ Dies kennzeichnet den Beginn der Beteiligung der Volksrepublik China an den internationalen Organisationen. Seit dem Jahr 1971 ist sie Mitglied der Organisationen der Vereinten Nationen geworden und baute mit internationalen Organisationen kooperative Beziehungen auf. Von 1971 bis 1978 wurden die Entwicklungserfolge hauptsächlich auf der politischen Ebene erzielt, im Bereich von Handeln und Wirtschaft waren die Beziehungen noch nicht ausgeprägt. ${ }^{7}$

Mit der Festlegung der Richtlinie „Reform und Öffnung“ hat China seit 1978 ihre außenpolitischen Richtlinien korrigiert, die eine aktive Teilnahme an den internationalen Organisationen fordern. Die Richtlinie ,begrenzte Beteiligung an den internationalen Institutionen“ wurde durch die ,allseitige Beteiligung und Kooperation“ ersetzt. In der Verfassung von 1982 wurde geschrieben: „Die Zukunft Chinas ist mit der der ganzen Welt eng verbunden“. 8 Von 1978 bis 1989 hat die Volksrepublik China kooperative Beziehungen zu den meisten internationalen Organisationen aufgenommen, insbesondere wurden die Beziehungen mit den Wirtschafts- und Handelsorganisationen wie

4 中苏友好同盟互助条约 (Der Sowjet-Chinesische Freundschaftspakt) vom 14.02.1950, im: 人民 日报 (RMRB), vom 25.02. 1950.

5 Siehe: Kim, in: Economy/Oksenberg, China joins the World, New York, 1999, S. 45; Johnston, 美 国学者关于中国与国际组织关系研究概述 (Forschungsüberblick über die Beziehungen zwischen China und den internationalen Organisationen), in: 世界经济与政治 (World Economics Politics), 2001/8, S. 52.

6 UNO, Resolution 2758 der UN-Generalversammlung vom 25. 10. 1971.

7 Ausführlich vgl. 王逸舟, 中国与国际组织关系研究的若干问题 (Wang, Yizhou, Einige Fragen in der Forschung über die Beziehungen zwischen China und den internationalen Organisationen), in: 社会科学论坛 (Tribune of Social Sciences), 2002/8, S. 7.

8 Präambel der Verfassung von 1982, 12 Abschnitt. 
die Bretton-Woods-Organisationen entwickelt, um nützliche Kenntnisse und moderne Technologien für die wirtschaftliche Modernisierung zu erlangen. ${ }^{9}$

Die Beziehung zwischen China und den internationalen Organisationen war nach dem Tiananmen-Vorfall von 1989 beeinträchtigt. Wegen dem Auftrag der G-7-Staaten wurde die Kreditvergabe der Weltbank an China bis 1991 unterbrochen. ${ }^{10}$ Die ChinaILO-Beziehung befand sich bis 1999 auf einem Tiefstand seit zehn Jahren. ${ }^{11}$ Allerdings hat die politische Entscheidung Chinas, am internationalen System sich weiter aktiv und konstruktiv zu beteiligen, sich dadurch nicht verändert. Seit den 1990er Jahren ist China Mitglied der meisten internationalen Organisationen geworden. Der Eintritt Chinas in die Welthandelsorganisation im Jahre 2001 ist ein Meilenstein und kennzeichnet die enge Verknüpfung mit dem internationalen Wirtschaftssystem.

Der Kern der derzeitigen chinesischen Außenpolitik ist es, im Rahmen des gegenwärtigen internationalen Systems die eigenen Entwicklungsziele, insbesondere die wirtschaftlichen Strategien zu erreichen, und nach den Fünf Prinzipien der Friedlichen Koexisten $^{12}$ die Errichtung neuer internationaler Politik- und Wirtschaftsordnungen zu fördern. ${ }^{13}$ Der Standpunkt der chinesischen Regierung für die Beteiligung an den internationalen Organisationen geht hauptsächlich von folgenden Motiven aus: 14

- von den internationalen Organisationen nützliche Informationen, finanzielle und technische Unterstützungen zu erwerben, um die eigene Wirtschaftsentwicklung zu fördern (wie bei der Weltbank),

- $\quad$ durch Beitritt in internationale Organisationen die Handelsbarrieren zu überwinden, die Wirtschaftsreform zu beschleunigen (wie bei der WTO),

- das Ansehen eines „Verantwortungsvollen Großstaats“ zu erreichen.

Die westlichen Staaten und internationale Organisationen führen zurzeit auch eine aktive Beteiligungspolitik mit strategischen Hilfsplänen in der Volksrepublik China durch, um die Innenpolitik Chinas zu beeinflussen und diesen Staat weiter in die inter-

9 Vgl. 王逸舟, 中国与国际组织关系研究的若干问题 (Wang, Yizhou, Einige Fragen in der Forschung über die Beziehungen zwischen China und den internationalen Organisationen), in: 社会科 学论坛 (Tribune of Social Sciences), 2002/8, S. 7; Johnston, 美国学者关于中国与国际组织关系 研究概述 (Forschungsüberblick über die Beziehungen zwischen China und den internationalen Organisationen), in: 世界经济与政治 (World Economics Politics), 2001/8, S. 49.

10 World Bank, China, An Evaluation of World Bank Assistance, S. 6.

11 刘旭, 国际劳工标准概述 ( $L i u, X \ddot{u}$, Introduktion to International Labour Standards), S. 135.

12 Die Fünf Prinzipien der Friedlichen Koexistenz (和平共处五项原则) wurden zurerst in “Agreement between the People's Republic of China and the Republic of India on Trade and Intercourse between the Tibet Region of China and India" von 1954 eingeschrieben. Sie sind: Achtung der Souveränität und territorialen Integrität, gegenseitiger Nichtangriff, gegenseitige Nichteinmischung in die inneren Angelegenheiten, Gleichberechtigung und gegenseitigen Nutzen sowie friedliche Koexistenz trotz unterschiedlicher Systeme.

13 Siehe: 邓小平文选第三卷 (Deng, Xiaoping, Ausgewählte Werke von Deng Xiaoping, Dritter Band), S. 363; vgl. auch: 王逸舟, 中国与国际组织关系研究的若干问题 (Wang, Yizhou, Einige Fragen in der Forschung über die Beziehungen zwischen China und den internationalen Organisationen), in: 社会科学论坛 (Tribune of Social Sciences), 2002/8, S. 8.

14 Vgl. Johnston, 简论国际机制对国家行为的影响 (Einfluss der internationalen Institutionen auf die staatlichen Handlungen), in: 世界经济与政治 (World Economics Politics), 2002/12, S. 12. 
nationalen Institutionen einzubinden. ${ }^{15}$ Mit ihren völkerrechtlichen Kompetenzen und Kooperationsmechanismen spielen die internationalen Organisationen in diesem Prozess eine sehr aktive Rolle.

\section{B. Forschungsumfang}

Unter internationalen Organisationen werden im Völkerrecht zumeist zwischenstaatliche Organisationen verstanden, die von Staaten errichtet werden und Subjekte völkerrechtlicher Beziehungen sind. ${ }^{16}$ Durch die internationalen Organisationen wird die internationale Kooperation aufgrund der völkerrechtlichen Verhaltensnormen institutionalisiert. Die Kompetenzen der internationalen Organisationen werden ausdrücklich in dem Gründungsvertrag festgelegt. Darüber hinaus hat der Internationale Gerichtshof (IGH) anerkannt, dass weitere Kompetenzen der internationalen Organisationen aus den vertraglich festgeschriebenen Aufgaben und Zwecken hergeleitet werden können, soweit sie zur Erfüllung ihrer Aufgaben erforderlich sind (implied powers). ${ }^{17}$

In der Lehre von den internationalen Beziehungen hat sich im Rahmen der Theorie des internationalen Regimes ${ }^{18}$ ein Gefüge gebildet, das über rechtlich verbindliche Normen hinaus auch die rechtlich unverbindlichen Verhaltensprinzipien erfasst, ebenso die Entscheidungsmechanismen, die ein bestimmtes Gebiet internationaler Beziehungen ordnen. ${ }^{19}$ Um die Einflüsse der internationalen Organisationen umfassend darstellen zu können, bewegt sich diese Forschungsarbeit in einem ähnlichen Gefüge. Die Forschung beschränkt sich nicht nur auf die Umsetzung der Rechtsnormen der internationalen Organisationen im chinesischen Recht, sondern betrifft auch ihre sozialrechtlichen und sozialpolitischen Aktivitäten in China. Internationale Organisationen, ihre Rechtsnor-

15 Siehe: Clinton, China's Opportunity and Ours, in: New York Times, vom 24. 09. 2000; Johnston, in: International Security, 2003, Vol. 27, No. 4; chinesische Version in: 国际政治科学 (Science of International Politics), 2005/2, S. 26ff; Johnston, 中国参与国际体制的若干思考 (China’s Beteiligung in den internationalen Institutionen), in: 世界经济与政治 (World Economics Politics), 1999/7, S. 4ff.

16 Ipsen, Völkerrecht, S. 84; Herdegen, Völkerrecht, S. 98.

$17 I G H$, Reparation for Injuries Suffered in the Service of the United Nations, ICJ, Bernadotte-Fall, Reports 1949, 182: "Under international law, the organisation must be deemed to have those powers which, though not expressly provided in the charter, are conferred upon it by necessary implication as being essential to the performance of its duties".

18 Krasner, in: International Organization 36, 1982, S. 186; Keohane, After Hegemony: Cooperation and Discord in the World Political Economy, S. 57; siehe auch: Kohler-Koch, in: ders. (Hrsg.), Regime in den internationalen Beziehungen, S. 18.

19 Dabei werden Rechtsnormen und sonstige Verhaltenserwartungen in vier Typen unterschieden: Prinzipien (principles: beliefs of fact, causation, rectitude), Normen (norms: standards of behavior defined in terms of rights and obligations), Regeln (rules: specific prescriptions or proscriptions for action), und Entscheidungsverfahren (decision-making procedures: prevailing practices for making and implementing collective choice), siehe: Krasner, in: International Organization 36, 1982, S. 186; Herdegen, Völkerrecht, S. 70. 
men, die Handlungsgrundsätze sowie die Praxis zur Aufgabenerfüllung werden allgemein unter dem Begriff „Internationale Institutionen“ zusammengefasst und erforscht. Ferner werden nur die Vereinten Nationen (UNO), die Internationale Arbeitsorganisation (ILO), die Weltbank und ihre dazugehörigen sozialrechtlichen Normen sowie sozialpolitischen Aktivitäten untersucht. Diese Auswahl findet darin ihre Rechtfertigung, weil diese Organisationen den weltweiten Fortschritt im Bereich der sozialen Sicherheit als eine ihrer Hauptaufgaben begreifen, und ihr Einfluss auf die sozialpolitische und sozialrechtliche Praxis in China nachweislich vorhanden ist. Dieser Einfluss vollzieht sich in der Ausarbeitung von rechtlichen Regelungen und politischen Entscheidungen bis hin zur Durchführung von Pilotprojekten in einzelnen Gebieten.

Besonderes Augenmerk wird auf die Ratifizierung und Umsetzung von Normen und Regeln, die von der UNO und der ILO seit dem Ende des ersten Weltkriegs erlassen worden sind, gelegt. Die Ausarbeitung internationaler sozialrechtlicher Normen wird als wesentliches Instrument zur Aufgabenerfüllung der internationalen Organisationen angesehen. ${ }^{20}$ Damit werden die Grundprinzipien der sozialen Sicherheit festgelegt, sowie der Rahmen der sozialen Sicherungssysteme geregelt, um international einheitliche soziale Standards zu schaffen und zu entwickeln. Die Untersuchung widmet sich besonders den folgenden Rechtsnormen und ihrer Umsetzung ins chinesische Recht: Normen der Vereinten Nationen, insbesondere der Sozialpakt und der Zivilpakt von 1966, Konventionen und Übereinkommen, die von der internationalen Arbeitsorganisation im Bereich der sozialen Sicherheit entwickelt wurden.

Für die Entwicklungsländer wird eine Strategie zur internationalen Kooperation im Bereich der sozialen Sicherheit von den internationalen Organisationen verfolgt. Sie ist eine Kombination von ,hard and soft power". ${ }^{21}$ Diese Strategie unterstützt die Durchführung der sozialpolitischen Normen durch eine Kombination aus finanziellen Anreizen, Beratungen sowie technischer Hilfe. ${ }^{22}$ In China führen die UNO und die ILO Entwicklungsprojekte und Beratungen durch, um die Ratifizierung und Umsetzung der sozialrechtlichen Regelungen voranzutreiben. Darüber hinaus beteiligt sich die Weltbank mit finanziellen Mitteln am Aufbau der sozialen Sicherungssysteme in China.

Zwischen der ILO und der Weltbank, die beide Sonderorganisationen der UNO sind, besteht keine klare Aufgabenverteilung im Bereich der sozialen Sicherheit. Ihre Arbeitsweisen und Modelle sind unterschiedlich. Während die Weltbank mit Kreditvergaben ihr liberales Modell 23 in China forciert, vertritt die ILO ein sozialdemokratisches Modell, ${ }^{24}$ bei dem die Ausweitung der sozialen Sicherheit und die Rolle des Staates hervorgehoben werden. Die Politiken der beiden Organisationen stehen daher konträr zueinander.

20 Ausführlich: Nußberger, in: Maydell/Ruland/Becker (Hrsg.), Sozialrechtshandbuch, S. 1410ff.

21 Siehe: Brooks, in: International Studies Quarterly 49 (2), S. $273 \mathrm{ff}$.

22 Über die Sozialpolitik der internationalen Organisationen siehe: Deacon, Global Social Policy \& Governance, S. 24ff.

23 Ramia/Davies/Nyland, in: International Social Security Review, Volume 61, No. 1, 2008, S. 6.

24 Ramia/Davies/Nyland, in: International Social Security Review, Volume 61, No. 1, 2008, S. 6. 
Die Schwierigkeit der vorliegenden Arbeit besteht im Nachweis, dass die Veränderungen der chinesischen Normen tatsächlich durch internationale Faktoren initiiert wurden, oder durch die chinesische Situation begründet sind. Es stellt sich die Frage, ob die Änderungen freiwillig in Übereinstimmung mit den internationalen Konventionen durchgeführt wurden oder lediglich eine oberflächliche Konzession aufgrund von internationalen Interventionen darstellen. Ein weiteres Problem besteht in der gegenwärtigen Instabilität der chinesischen sozialen Sicherheit. Die chinesische Modernisierung vollzieht sich seit den 1980er Jahren und wird voraussichtlich erst in der Mitte des 21. Jahrhunderts abgeschlossen sein. Die Systeme der sozialen Sicherheit werden sich in dieser Zeit deshalb den wirtschaftlichen und gesellschaftlichen Grundlagen entsprechend enorm ändern und manche Entwicklungen sind in ihrer Reichweite nicht absehbar. Es ist noch nicht ersichtlich, welche Konzepte und Maßnahmen die chinesische soziale Sicherheit endgültig übernehmen wird. In der Konsequenz ist zum jetzigen Zeitpunkt deshalb nicht möglich, die Intensität des Einflusses der internationalen Institutionen endgültig und genau festzustellen.

\section{Wirkungsweise und Einfluss internationaler Organisationen}

\section{Menschenrechte als grundlegende Prinzipien}

Die ursprüngliche Zielsetzung zur internationalen Harmonisierung von Sozialschutzsystemen durch die internationalen Institutionen ging auf die wettbewerbspolitischen Erwägungen der Industriestaaten im 19. Jahrhundert zurück. ${ }^{25}$ Die menschenrechtliche Bedeutung des Schutzes des Einzelnen im Bereich der sozialen Sicherheit ist erst nach dem zweiten Weltkrieg mit der Allgemeinen Erklärung der Menschenrechte ${ }^{26}$ der UNO weltweit prinzipiell anerkannt worden. Mit dem im Jahre 1966 ausgearbeiteten Sozialpakt und Zivilpakt ${ }^{27}$ wurde eine menschenrechtliche Grundlage für die Ausgestaltung eines internationalen Sozialsystems gebildet.

\section{Menschenrechtliche Regelungen der UNO über soziale Sicherheit}

Die Allgemeine Erklärung der Menschenrechte, der Internationale Pakt über Bürgerliche und Politische Rechte (ICCPR) und der Internationale Pakt über Wirtschaftliche, Soziale und Kulturelle Rechte (ICESCR) bilden zurzeit die maßgeblichen Quellen im

25 Nußberger, in: Maydell/Ruland/Becker (Hrsg.), Sozialrechtshandbuch, S. 1411; 余云霞, 国际劳工 标准: 演变与争议 (She, Yünxia, International Labour Standards: Evolution and Controversy), S. $41 \mathrm{ff}$.

26 Universal Declaration of Human Rights, vom 10. 12. 1948.

27 International Covenant on Economic, Social and Cultural Rights, International Covenant on Civil and Political Rights, vom 16. 12. 1966. 
Bereich der internationalen menschenrechtlichen Regelungen. Bei der im Jahre 1948 von der Generalversammlung der UNO ausgearbeiteten Allgemeinen Erklärung der Menschenrechte handelt es sich nicht um einen völkerrechtlichen Vertrag. Sie ist ursprünglich als eine Vorbereitung für eine umfassende „International Bill of Human Rights"28 zu werten, an deren Stelle schließlich zwei Pakte, nämlich der Zivilpakt und der Sozialpakt, traten. ${ }^{29}$

Nun wird die Menschenrechtsdeklaration als Vorläufer der beiden Pakte und grundlegender Schritt für die Kodifizierung des Rechts der sozialen Sicherheit angesehen. ${ }^{30}$ Die sozialen Menschenrechte, d.h. das Recht auf soziale Sicherheit (Art. 22), auf Arbeit (Art. 23), auf Erholung und Freizeit (Art. 24), auf soziale Betreuung (Art. 25), auf Bildung (Art. 26) und auf Kulturleben (Art. 27), werden in der Allgemeinen Menschenrechtserklärung wie die klassischen Freiheitsrechte und die politischen Rechte als „Jedermannrecht" festgelegt, deren ursprüngliche Bedeutung auf der westlichen Geschichte und Tradition gegründet ist. Dabei kommt Art. 22 (das Recht auf soziale Sicherheit) eine Präambelfunktion $\mathrm{zu}: 31$

„Jeder Mensch hat als Mitglied der Gesellschaft das Recht auf soziale Sicherheit; er hat Anspruch darauf, durch innerstaatliche Maßnahmen und internationale Zusammenarbeit unter Berücksichtigung der Organisation und der Hilfsmittel jedes Staates in den Genuss der für seine Würde und die freie Entwicklung seiner Persönlichkeit unentbehrlichen wirtschaftlichen, sozialen und kulturellen Rechte zu gelangen“.

Die in der Allgemeinen Erklärung der Menschenrechte enthaltenen Bestimmungen wurden später in zwei völkerrechtlichen Konventionen differenziert und konkretisiert. Der Zivilpakt und der Sozialpakt wurden von der UNO-Generalversammlung im Jahre 1966 zur Ratifikation vorgelegt. Sie traten zehn Jahre später in Kraft. Das Recht auf soziale Sicherheit wird im Sozialpakt ausdrücklich erwähnt. Nach Art. 2 des Sozialpaktes begründen die sozialen Menschenrechte allgemein keine unmittelbaren Rechte und Ansprüche des Einzelnen, sondern die Pflichten der Vertragsstaaten, mit allen geeigneten Mitteln, vor allem durch gesetzgeberische Maßnahmen die Verwirklichung der in diesem Pakt anerkannten Rechte zu erreichen. ${ }^{32}$ Aufgrund des allgemeinen Kommentars Nr. 3 des Ausschusses für wirtschaftliche, soziale und kulturelle Rechte ${ }^{33}$ wurden

28 Siehe: ECOSOC/Res. 5 (I) vom 21. 06. 1946.

29 Zum Entstehungsprozess vgl. Köhler, Sozialpolitische und sozialrechtliche Aktivitäten in den Vereinten Nationen, S. 265ff., $911 \mathrm{ff}$.

30 Nußberger, Sozialstandards im Völkerrecht, S. 64.

31 Ausführlich: Köhler, Sozialpolitische und sozialrechtliche Aktivitäten in den Vereinten Nationen, S. 279ff.

32 Art. 2 Abs. 1 des Sozialpaktes.

33 General Comment No. 3. The nature of States parties obligations (Art. 2, par.1), 14/12/90; Simma, Die vergessenden Rechte: Bemühungen zur Stärkung des VN-Sozialpakts, in: Ruland/Maydell/Papier (Hrsg.), Verfassung, Theorie und Praxis des Sozialstaats, FS für Hans F. Zacher, S. 867-882. 
einzelne der im Sozialpakt enthaltenen Rechte für unmittelbar anwendbar erklärt, allerdings betraf dies nicht die sozialrechtsrelevanten Artikel des Paktes. ${ }^{34}$

Die sozialrechtsrelevanten Artikel sind Art. 9 - 12, die die in den Art. 22 - 25 der allgemeinen Erklärung der Menschenrechte proklamierten Rechte präzisiert. ${ }^{35}$ In Art. 9 ist das Recht auf soziale Sicherheit einschließlich der Sozialversicherung geregelt. Da der Inhalt und Umfang des Begriffs ,soziale Sicherheit“ schon international festgelegt wurde, werden hier die Rechte auf soziale Sicherheit nicht mehr konkret aufgezählt. Ausdrücklich wird die Sozialversicherung als möglichen Weg zur sozialen Sicherheit betont. Mit den Schutzrechten für die Familie, Mütter, Kinder und Jugendliche befasst sich Art. 10. Die in Art. 25 Abs. 2 der Allgemeinen Erklärung geregelten Schutzrechte für Mütter und Kinder werden in Art. 10 des Sozialpakts als gruppenspezifische Bestimmungen in drei Ziffern konkretisiert. Das Recht auf einen angemessenen Lebensstandard ist in Art. 11 festgelegt. Nach Art. 11 Abs.1 Satz 1 bedeutet ,angemessener Lebensstandard“ die Sicherung existenznotwendiger Ernährung, Bekleidung und Unterbringung in Verbindung mit einer ständigen Verbesserung der Lebensbedingungen. In Satz 2 wird die „entscheidende Bedeutung der internationalen Zusammenarbeit“ für die Verwirklichung dieses Rechts betont. Damit hat dieser Artikel eine rechtliche Verbindung von Menschenrechten und internationaler Zusammenarbeit hergestellt. ${ }^{36}$ Schließlich ist in Art. 12 das Recht auf Gesundheit geregelt.

Der Zivilpakt enthält aufgrund der ideologisch verfestigten Trennlinie zwischen bürgerlich-politischen und sozialen Rechten ${ }^{37}$ hauptsächlich eine Garantie der klassischen Freiheitsrechte und Unverletzlichkeit der Einzelpersonen. Die Rechte auf soziale Sicherheit und soziale Betreuung werden in diesem Pakt nicht erwähnt.

Allerdings hat der Zivilpakt mit einer Auslegung von Art. 26 seit Mitte der 1980er Jahren im Bereich der sozialen Sicherheit an Bedeutung gewonnen. ${ }^{38}$ Art. 26 des Zivilpakts enthält ein allgemeines Diskriminierungsverbot, wonach alle Menschen gleicher und wirksamer Schutz gegen jede Art von Diskriminierung zu gewährleisten ist, insbesondere wegen der Rasse, der Hautfarbe, des Geschlechts, der Sprache, der Religion, der politischen oder sonstigen Anschauung, der nationalen oder sozialen Herkunft, des Vermögens, der Geburt oder des sonstigen Status. Mit den Grundsatzentscheidun-

34 Nußberger, in: Maydell/Ruland/Becker (Hrsg.), Sozialrechtshandbuch, S. 1417.

35 Ausführlich: Köhler, Sozialpolitische und sozialrechtliche Aktivitäten in den Vereinten Nationen, S. 973ff.

36 Art. 11 Abs. 1 des Sozialpakts: Die Vertragsstaaten erkennen das Recht eines jeden auf einen angemessenen Lebensstandard für sich und seine Familie an, einschließlich ausreichender Ernährung, Bekleidung und Unterbringung, sowie auf eine ständige Verbesserung der Lebensbedingungen. Die Vertragsstaaten unternehmen geeignete Schritte, um die Verwirklichung dieses Rechts zu gewährleisten, und erkennen zu diesem Zweck die entscheidende Bedeutung einer internationalen, auf freier Zustimmung beruhenden Zusammenarbeit an. Vgl. Köhler, Sozialpolitische und sozialrechtliche Aktivitäten in den Vereinten Nationen, S. 977.

37 Vgl. Nußberger, Sozialstandards im Völkerrecht, S. 70ff; Köhler, Sozialpolitische und sozialrechtliche Aktivitäten in den Vereinten Nationen, S. 908ff.

38 Nußberger, in: Maydell/Ruland/Becker (Hrsg.), Sozialrechtshandbuch, S. 1417; Nußberger, Sozialstandards im Völkerrecht, S. 27ff. 
gen des Menschenrechtsausschusses im Jahre $1984^{39}$ umfasst Art. 26 auch ein Diskriminierungsverbot bei Leistungen der sozialen Sicherheit.

Darüber hinaus findet das Recht auf soziale Sicherheit eine weitere Ausprägung mit spezifischen Schutzanliegen in verschiedenen Menschenrechtsübereinkommen wie in dem Internationalen Übereinkommen zur Beseitigung jeder Form von Rassendiskriminierung von 1965 (Art. 5 e iv), 40 dem Übereinkommen zur Beseitigung jeder Form von Diskriminierung der Frau von 1979 (Art. 11 Abs. 1 e), ${ }^{41}$ dem Übereinkommen über die Rechte des Kindes von 1989 (Art. 26), ${ }^{42}$ der Internationalen Konvention zum Schutz der Rechte aller Wanderarbeitnehmer und ihrer Familienangehörigen von 1990 (Art. 27) ${ }^{43}$ und der Konvention über die Rechte von Menschen mit Behinderungen von 2006 (Art. 28). ${ }^{44}$

Die Kontrolle für die innerstaatliche Durchsetzung der UNO-Konventionen ist schwach: Hauptsächlich wird ein Berichtsverfahren von den zuständigen UNO-Organen eingeleitet. Die Vertragsstaaten haben Berichte über die Durchsetzung der Konventionen vorzulegen, die Expertengremien analysieren die Staatsberichte, zum Schluss werden Bemerkungen oder Folgemaßnahmen beschlossen. ${ }^{45}$

\section{Umsetzung der Menschenrechtskonventionen in China}

\section{a) Ratifikation der Menschenrechtskonventionen}

Internationale Konventionen erlangen in China durch Ratifikation innerstaatliche Verbindlichkeit. Gemäß Art. 67 Abs. 14 der chinesischen Verfassung von 1982 ist der Ständige Ausschuss des Nationalen Volkskongresses das einzige Organ, das die Befugnis über die Ratifikation der internationalen Konventionen besitzt. Die ratifizierten internationalen Menschenrechtskonventionen sind durch Umsetzung im innerstaatlichen Recht durchzuführen. Sie dürfen also nicht beim Entscheidungsverfahren des Gerichts direkt als Rechtsgrundlage zitiert werden. Hinsichtlich der Durchsetzungs- und Überwachungsmechanismen der UNO-Konventionen wird zurzeit nur das Berichtsverfahren von China anerkannt. ${ }^{46}$

39 Communication No. 172/1984, Communication No. 182/1984.

40 International Convention on the Elimination of All Forms of Racial Discrimination (ICERD), vom 21. 12. 1965.

41 Convention on the Elimination of all Forms of Discrimination against Women, vom 18. 12. 1979.

42 Convention on the Rights of the Child (CRC), vom 20. 11. 1989.

43 International Convention on the Protection of the Rights of All Migrant Workers and Members of Their Families, vom 18. 12. 1990.

44 Convention of the Rights of Persons with Disabilities, vom 13. 12. 2006.

45 Ausführlich vgl. Riedel, in: Becker/Maydell/Nußberger (Hrsg.), Die Implementierung internationaler Sozialstandards, zur Durchsetzung und Herausbildung von Standards auf überstaatlicher Ebene, S. $21 \mathrm{ff}$.

46 Ausführlich vgl. 莫纪宏, 国际人权公约在中国的实施 (Mo, Jihong, Durchführung der internationalen Menschenrechtskonventionen in China), in: 人权 (Menschenrechte), 2008/1, S. 23. 
Bis 2010 hat China insgesamt 18 UNO-Menschenrechtskonventionen und Fakultativprotokolle ratifiziert. ${ }^{47}$ Diese Liste enthält fünf für die soziale Sicherheit relevante Konventionen. Die Unterzeichnung der Internationalen Konvention zum Schutz der Rechte aller Wanderarbeitnehmer und ihrer Familienangehörigen liegt zurzeit noch nicht vor. Der internationale Pakt über bürgerliche und politische Rechte wurde im Jahre 1998 von der chinesischen Regierung unterzeichnet. Er bleibt aber bislang noch im Prüfungsverfahren. 48

Der Verzögerungsgrund für die Ratifizierung des Zivilpakts liegt hauptsächlich darin, dass die Regelungen des Zivilpakts mit manchen chinesischen Verordnungen kollidieren. Z. B. kollidiert das chinesische Recht der „Umerziehung durch Arbeit“ mit Art. 9 Abs. 1 Satz $1^{49}$ und Art. 8 Abs. $3^{50}$ des Zivilpakts. Bei diesem System handelt es sich um Haftanstalten, die direkt durch Verfügung der Polizeibehörde für die kriminellen Jugendlichen oder „kleine Verbrechen“ wie Diebstahl, Prostitution und Drogen verwendet werden.

Ein anderes Hindernis ist der Konflikt zwischen der chinesischen Regelung über die Freizügigkeit des Einzelnen im Art. 12 Abs. 1 des Zivilpakts. Die Freizügigkeit der Bürger wurde wegen der Ausführung des strikten Hukou-Registrierungssystems seit 1975 aus der chinesischen Verfassung (Art. 90 Abs. 2 der Verfassung von 1954) gestrichen ${ }^{51}$ und bislang noch nicht wiederhergestellt. Darüber hinaus kolliediert das chinesische Recht mit den zwei Fakultativprotokollen des Zivilpakts, weil in China keine „Verfassungsbeschwerde“ existiert und die „Abschaffung der Todesstrafe“ noch aussteht. Demzufolge wurde der Zivilpakt mit seinen Protokollen vom chinesischen Parlament nicht ratifiziert. 52

47 Vgl. 莫纪宏, 国际人权公约在中国的实施 (Mo, Jihong, Durchführung der internationalen Menschenrechtskonventionen in China), in: 人权 (Menschenrechte), 2008/1, S. 21ff; auch siehe: 国务 院新闻办公室, 2004年中国人权事业的进展 (Presseamt des Staatsrats, Menschenrechtswesen in China 2004), vom 03. 2004, 董云虎, 中国人权30年 (Dong, Yunhu, 30 Jahre Menschenrechte in China), in: 新京报 (XJB), vom 10.01.2009.

48 国务院新闻办公室, 2004年中国人权事业的进展 (Presseamt des Staatsrats der Volksrepublik China, Menschenrechtswesen in China 2004), 03/2004.

49 Art. 9 Abs. 1 Satz 1 des Zivilpakts: Niemand darf seiner Freiheit entzogen werden, es sei denn aus gesetzlich bestimmten Gründen und unter Beachtung des im Gesetz vorgeschriebenen Verfahrens.

50 Art. 8 Abs. 3 des Zivilpakts: Zwangs- oder Pflichtarbeit.

51 Ausführlich siehe: Erster Teil, Seit Gründung der Volksrepublik: Industrialisierung und HukouRegistrierungssystem.

$52 \mathrm{Vgl}$. 莫纪宏, 两个国际人权公约下缔约国的义务与中国 (Mo, Jihong, Pflicht des Vertragsstaates zur Durchsetzung der zwei internationalen Menschenrechtskonventionen), in: 世界经济与政治 (World Economics Politics), 2002/8, S. 28ff. 


\begin{tabular}{|c|c|c|}
\hline Name der internationalen Konventionen & Unterzeichnung & Ratifikation \\
\hline $\begin{array}{l}\text { Genfer Abkommen zur Verbesserung des Loses der Verwundeten } \\
\text { und Kranken der Streitkräfte im Felde, } 1949\end{array}$ & & 28. 12.1956 \\
\hline $\begin{array}{l}\text { Genfer Abkommen von } 1949 \text { zur Verbesserung des Loses der Ver- } \\
\text { wundeten, Kranken und Schiffbrüchigen der Streitkräfte zur See, } \\
1949\end{array}$ & & 28. 12. 1956 \\
\hline $\begin{array}{l}\text { Genfer Abkommen von } 1949 \text { über die Behandlung der Kriegsge- } \\
\text { fangenen, } 1949\end{array}$ & & 28. 12.1956 \\
\hline $\begin{array}{l}\text { Genfer Abkommen von } 1949 \text { zum Schutze von Zivilpersonen in } \\
\text { Kriegszeiten, } 1949\end{array}$ & & 28. 12. 1956 \\
\hline $\begin{array}{l}\text { Übereinkommen zur Beseitigung jeder Form von Diskriminierung } \\
\text { der Frau, } 1979\end{array}$ & 17. 07. 1980 & 04.11 .1980 \\
\hline $\begin{array}{l}\text { Internationales Übereinkommen zur Beseitigung jeder Form von } \\
\text { Rassendiskriminierung, } 1966\end{array}$ & & 29. 12. 1981 \\
\hline Übereinkommen über die Rechtsstellung der Flüchtlinge, 1951 & & 24. 09. 1982 \\
\hline Protokoll über die Rechtsstellung der Flüchtlinge, 1967 & & 24. 09. 1982 \\
\hline $\begin{array}{l}\text { Protokoll zu den Genfer Abkommen vom 12. August } 1949 \text { über den } \\
\text { Schutz der Opfer internationaler bewaffneter Konflikte (Protokoll } \\
\text { I), } 1977\end{array}$ & & 14.09. 1983 \\
\hline $\begin{array}{l}\text { Protokoll zu den Genfer Abkommen vom 12. August } 1949 \text { über den } \\
\text { Schutz der Opfer nicht internationaler bewaffneter Konflikte (Pro- } \\
\text { tokoll II), } 1977\end{array}$ & & 14. 09. 1983 \\
\hline $\begin{array}{l}\text { Konvention über die Verhütung und Bestrafung des Verbrechens } \\
\text { des Völkermordes, } 1949\end{array}$ & 20.07. 1949 & 18.04 .1983 \\
\hline $\begin{array}{l}\text { Internationale Konvention über die Bekämpfung und Bestrafung } \\
\text { des Verbrechens der Apartheid, } 1973\end{array}$ & & 18. 04.1983 \\
\hline $\begin{array}{l}\text { Übereinkommen gegen Folter und andere grausame, unmenschliche } \\
\text { oder erniedrigende Behandlung oder Strafe, } 1984\end{array}$ & 12. 12.1986 & 04. 10.1988 \\
\hline Internationale Konvention gegen Apartheid im Sport, 1985 & & 03. 04. 1988 \\
\hline Übereinkommen über die Rechte des Kindes, 1989 & 29.08 .1990 & 31.01 .1992 \\
\hline $\begin{array}{l}\text { Internationaler Pakt über wirtschaftliche, soziale und kulturelle } \\
\text { Recht } 1966\end{array}$ & 27. 10.1997 & 27. 03. 2001 \\
\hline $\begin{array}{l}\text { Fakultativprotokoll zum Übereinkommen über die Rechte des Kin- } \\
\text { des betreffend den Verkauf von Kindern, die Kinderprostitution } \\
\text { und die Kinderpornographie, } 2000\end{array}$ & 09.2000 & 03. 12. 2002 \\
\hline Internationaler Pakt über bürgerliche und politische Rechte,1966 & 05.10 .1998 & \\
\hline $\begin{array}{l}\text { Fakultativprotokoll zum Übereinkommen über die Rechte des Kin- } \\
\text { des betreffend die Beteiligung von Kindern an bewaffneten Kon- } \\
\text { flikten, } 2000\end{array}$ & 15. 03. 2001 & \\
\hline $\begin{array}{l}\text { Übereinkommen über die Rechte von Menschen mit Behinderun- } \\
\text { gen, } 2006\end{array}$ & 30. 03. 2007 & 26. 06. 2008 \\
\hline
\end{tabular}

Quelle: http://www.humanrights.cn/cn/rqfg/fgjd/t20070321_220575.htm;

UN Country Team in China, Common Country Assessment 2004. 


\section{aa) In die Verfassung von 1982}

Die speziellen Verfassungsregelungen über die subjektiven Rechte der Bürger auf Arbeit und soziale Sicherheit werden in Art. 45 der Verfassung von 1982 geregelt. Sie sind auf Art. 93 der Verfassung von 1954 zurückzuführen. ${ }^{53}$ Das bedeutet, dass die chinesischen Verfassungsregelungen über das Recht der Bürger auf soziale Sicherung historisch betrachtet ein Ergebnis der Rezeption von Art. 120 der sowjetischen Verfassung von 1936 darstellt. ${ }^{54}$ Andere sozialrechtsrelevante Regelungen wie Schutz für Frauen (Art. 48 der Verfassung von 1982), für Alte, Kinder und Familien (Art. 49 der Verfassung von 1982) wurden ebenso seit 1954 in die Verfassung (Art. 96 der Verfassung von 1954) geschrieben.

Die Umsetzung der sozialrechtlichen Regelungen der UNO in der chinesischen Verfassung hat erst nach der Ratifikation des Internationalen Paktes über Wirtschaftliche, Soziale und Kulturelle Rechte begonnen. Im Jahre 2004 wurden „Menschenrechte“ als Grundrechte der Bürger ${ }^{55}$ und die Errichtung der Systeme der sozialen Sicherheit als eine der staatlichen Aufgaben 56 in die Verfassung eingeführt. ${ }^{57}$ Damit haben die internationalen Institutionen, die seit dem Ende der 1980er Jahre auf die Volksrepublik China Einfluss und Druck bezüglich der Menschenrechte ausgeübt haben, einen großen Erfolg in China erlangt.

Allerdings darf dieser Erfolg wegen dem besonderen Charakter der chinesischen Verfassung nicht überschätzt werden, da es an einer Umsetzung mangelt. Erstens spielt die chinesische Verfassung bisher keine entscheidende Rolle im ganzen Staatssystem. ${ }^{58}$ Zweitens erzeugen die Grundrechte mangels einer wirksamen Institution für Verfassungsbeschwerden oder -klagen keine unmittelbare Bindungswirkung der Staatsgewalt, sie bilden vielmehr die Grundlage für die weitere Gesetzgebungsarbeit. 59

Andererseits wird die Einführung der menschenrechtlichen Regelungen direkt durch die politischen Entscheidungen der KP Chinas gesteuert. 60 Die Klarstellung der staatlichen Verantwortung für die Errichtung der Systeme der sozialen Sicherheit und „Re-

53 Ausführlich: Zweiter Teil, soziale Sicherheit in der Verfassung.

54 Die sowjetische Verfassung von 1936, Art. 118: Das Recht der Bürger auf Arbeit. Art. 119: Das Recht der Bürger auf Erholung. Art. 120: Das Recht der Bürger auf materielle Sicherung im Alter sowie im Falle von Krankheit und Invalidität.“ Die chinesische Verfassung von 1954, Art. 91: Das Recht der Bürger auf Arbeit. Art. 92: Das Recht der Werktätigen auf Erholung. Art. 93: Das Recht der Werktätigen auf materielle Unterstützung im Alter, in Krankheitsfällen oder bei Arbeitsunfähigkeit. Über die Verfassungsrezeption in den 1950er Jahren ausführlich siehe: 蔡定剑, 宪法精解 (Cai, Dingjian, Constitution: A intensive Reading), S. 22ff.

55 Art. 33 Abs. 3: Der Staat respektiert und gewährleistet Menschenrechte.

56 Art. 14 Abs. 4: Der Staat errichtet und vervollständigt ein System der sozialen Sicherheit, das dem Niveau der wirtschaftlichen Entwicklung entspricht.

57 Ausführlich: Zweiter Teil, Die Verfassung von 1982.

58 Ausführlich: Zweiter Teil, Normen der Volksrepublik China.

59 Ausführlich: Zweiter Teil, Grundrechte und Grundpflichten der Bürger.

60 Ausführlich: Zweiter Teil, Die politischen Richtlinien der KP Chinas. 
spekt und Schutz der Menschenrechte" ist in erster Linie eine unmittelbare Umsetzung der Partei-Entscheidungen, die im Bericht des 16. Parteitags festgelegt wurden. ${ }^{61}$ Die Einführung des Menschenrechtsbegriffs in die Verfassung zielt darauf, „die grundlegenden Anforderungen des Sozialismus zu verkörpern, die sozialistischen Menschenrechte in China voranzutreiben, Austausch und Zusammenarbeit mit internationalen Menschenrechtsorganisationen zu fördern". 62

Ein eigenes theoretisches System der Menschenrechte wurde seit den 1990er Jahren in China aufgebaut, das mit der UNO-Charta der Menschenrechte und der Erklärung über das Recht auf Entwicklung von $1986^{63}$ verknüpft wurde. In der Erklärung von 1986 wird das Recht auf Entwicklung als ein unveräußerliches Menschenrecht jedes Menschen und aller Völker bestätigt. ${ }^{64}$ Aufgrund dieses Prozesses werden „das Recht auf Existenz“ und „das Recht auf Entwicklung“ als die vorrangigen Menschenrechte in China bezeichnet. 65

Der Begriff der "Menschenrechte" wurde wegen der marxistischen Ideologie66 lange Zeit in China nicht benutzt. Nach dem Tiananmen-Vorfall von 1989 haben die westlichen Staaten starken Druck zur Einhaltung internationaler Menschenrechtsstandards auf China ausgeübt. 67 Als Reaktion hat die chinesische Regierung im Jahre 1991 das erste Weißbuch zu den Menschenrechten in China ${ }^{68}$ herausgegeben und zum ersten Mal diesen Begriff offiziell verwendet. ${ }^{69}$ In diesem Weißbuch wurde der Begriff der Menschenrechte nicht unter Hinweis auf die ideologische und kulturelle Unterschiede abgelehnt, sondern positiv bewertet 70 - allerdings mit einer auffallenden Betonung der „Priorität des Existenzrechts des chinesischen Volkes“. ${ }^{71}$ In dem Text wurde die chinesische Auffassung ausdrücklich geäußert, dass ohne Selbständigkeit, Stabilität und Wirtschaftsentwicklung des Staates keine Möglichkeit besteht, das Existenzrecht des Volks und andere nachrangige Menschenrechte zu gewährleisten.

61 江泽民, 在中国共产党第十六次全国代表大会上的报告 (Jiang, Zemin, Bericht auf dem 16. Parteitag der Kommunistischen Partei Chinas) vom 08. 11. 2002; siehe auch: 王兆国, 宪法修正案草 案的说明 (Wang, Zhaoguo, Erklärung über den Entwurf der Verfassungsänderung), in: 人民日报 (RMRB), vom 09. 03. 2004.

62 王兆国, 宪法修正案草案的说明 (Wang, Zhaoguo, Erklärung über den Entwurf der Verfassungsänderung), in: 人民日报 (RMRB), vom 09. 03. 2004.

63 Declaration on the Right to Development, Resolution 41/128, vom 04. 12. 1986.

64 Art. 1 der Erklärung über das Recht auf Entwicklung von 1986.

65 Siehe: 生存权和发展权是首要的基本人权 (Das Recht auf Existenz und das Recht auf Entwicklung sind die erstrangigen Menschenrechte), in: 人民日报 (RMRB), vom 27. 06. 2005.

66 马克思恩格斯全集第三卷 (Karl Marx and Friedrich Engels, Vol. 3 ), S. 228.

67 Vgl. Nathan, China and the International Human Rights Regime, in: Economy/Oksenberg (Hrsg.), China Joins the World: Progress and Prospects, S. 146.

68 国务院新闻办公室, 中国的人权状况 (Presseamt des Staatsrats der Volksrepublik China, Menschenrechtssituation in China), vom 01. 11. 1991.

$69 \mathrm{Vgl}$. 董云虎, 中国人权30年 (Dong, Yunhu, 30 Jahre Menschenrechte in China), in: 新京报 (XJB), vom 10.01.2009.

70 Vgl. Nathan, in: Economy/Oksenberg (Hrsg.), China Joins the World: Progress and Prospects, S. 137.

71 Teil 1 des Weißbuches zur Menschenrechtssituation in China von 1991. 
In den folgenden Jahren hat die chinesische Regierung insgesamt acht Weißbücher über Menschenrechte (1991, 1995, 1997, 1999, 2000, 2001, 2004, 2005) veröffentlicht. Damit werden die kollektiven Menschenrechte aufgrund der historischen, gesellschaftlichen, wirtschaftlichen sowie kulturellen Besonderheiten Chinas ${ }^{72}$ weiter entwickelt: 73

\begin{abstract}
„Das Recht auf Existenz und das Recht auf Entwicklung sind die erstrangigen Menschenrechte und die Grundlage anderer Menschenrechte. ... Das Recht auf Existenz bezieht sich nicht nur auf das Lebensrecht des Einzelnen, sondern auch auf die Gewährleistung des Existenzrechts eines Staates und seines Volkes im Sinne der Gesellschaft. ... Das Recht auf Entwicklung ist eine Erweiterung des Existenzrechts und eine Zusammensetzung von individuellen und kollektiven Rechten. Als Recht des Einzelnen bezeichnet das Entwicklungsrecht die Rechte, die in den internationalen Menschenrechtsdokumenten anerkannt wurden, ... als kollektives Recht bezeichnet es die Rechte der Staaten - insbesondere der Entwicklungsländer - wirtschaftliche, politische, kulturelle und gesellschaftliche Fortschritte und Entwicklungen zu erlangen.“
\end{abstract}

Mit dieser Erläuterung wurde eine Verknüpfung zwischen den traditionellen chinesischen Werten wie Betonung der Pflicht, Vorrang des Kollektives sowie einer harmonischen Gemeinsamkeit und der westlichen Idee der Menschenrechte, die sich grundsätzlich auf die Grundrechte des Einzelnen bezieht, gebildet. Aus diesem Grund tritt der Begriff „Menschenrechte“ als ein positiver Begriff in die Staats- und Parteidokumente. „Respekt und Schutz der Menschenrechte“ wurde in die Verfassung (2004), in die Theorie der harmonischen Gesellschaft (2006) ${ }^{74}$ sowie in das Statut der KP Chinas (2007) eingeführt.

Die kollektive Färbung der Menschenrechte ist einer der Rechtfertigungsgründe für die derzeitige Beschränkung auf die Verwirklichung der Grundrechte und die enge Abhängigkeit der sozialen Sicherheit von der wirtschaftlichen Entwicklung (Art. 14 Abs. 4). Sie reflektiert ebenso die moderne Gestaltung der chinesischen „Ti-Yong“:75 Bei der Verwirklichung der Modernisierungsaufgabe und der Bewahrung der traditionellen Werte nutzt China gleichzeitig die westlichen Ideen in praktischer Weise.

\title{
bb) In andere Gesetze
}

Drei der wichtigsten menschenrechtlichen UNO-Übereinkommen, nämlich das Übereinkommen zur Beseitigung jeder Form von Diskriminierung der Frau von 1979, das Übereinkommen über die Rechte des Kindes von 1989 und die Konvention über die Rechte von Menschen mit Behinderungen von 2006, wurden jeweils nach den Ratifikationen in chinesischen Gesetzen umgesetzt. Aufgrund der Einführung des Menschen-

72 国务院新闻办公室, 中国人权事业的进展1995 (Presseamt des Staatsrats der Volksrepublik China, Entwicklung des Menschenrechtswesens in China), 1995.

73 生存权和发展权是首要的基本人权 (Das Recht auf Existenz und das Recht auf Entwicklung sind die erstrangigen Menschenrechte), in: 人民日报 (RMRB), vom 27. 06. 2005.

74 Eine theoretische Darlegung über die Beziehung zwischen der harmonischen Gesellschaft und den Menschenrechte siehe: 夏勇, 人权概念起源 - 权利的历史哲学 (Xia, Yong, The Origin of Human Rights Idea - A Philosophy on the History of Rights), S. 145ff.

75 Ausführlich: Erster Teil, Beginn des Transformationsprozesses seit 1840. 
rechtsbegriffs besteht seit Anfang des 21. Jahrhunderts eine Tendenz, bei der Gesetzgebungsarbeit die Gewährleistung der Menschenrechte, insbesondere die Verwirklichung der wirtschaftlichen, sozialen und kulturellen Rechte der Bürger zu betonen. Darin findet das Recht der geschützten bestimmten Menschengruppen auf soziale Sicherheit Eingang. Mit der verfassungsrechtlichen Festlegung eines sozialen Sicherungssystems in das Staatssystem ist die Stellung dieses Rechts bei den Veränderungen der jeweiligen Gesetze hervorgehoben.

\section{(1) Gesetz zum Schutz von Minderjährigen}

Das „Gesetz der Volksrepublik zum Schutz von Minderjährigen“ wurde im September 1991 vom Nationalen Volkskongress verabschiedet und trat am 01. 01. 1992 in Kraft. Im selben Monat wurde das UNO-Übereinkommen über die Rechte des Kindes unter Vorbehalt (Art. 6: Recht auf Leben) vom Nationalen Volkskongress ratifiziert. Es trat am 02. 04. 1992 in China in Kraft.

Die Nähe des Zeitpunkts des Inkrafttretens bedeutet aber nicht, dass der Gesetzgeber die Kerngedanken und die Formulierung des Gesetzes mit dem UNO-Übereinkommen in Einklang gebracht hat. Als „Minderjährige“ gelten gemäß § 11 Abs. 1 der Allgemeinen Grundsätze des Zivilrechts von $1986^{76}$ Personen unter 18 Jahren. Dies ist identisch mit dem Begriff „Kinder“ in Art. 1 des UNO-Übereinkommens. ${ }^{77}$ Die Verschiedenheit zwischen beiden Dokumenten ist allerdings deutlich. Der wesentliche Unterschied liegt darin, dass der Ausgangspunkt dieses chinesischen Gesetzes nicht die Gewährleistung von „Würde, Gleichheit und Unveräußerlichkeit der Rechte“78 von Kindern ist, sondern die Pflicht des Staates und der Gesellschaft, das ,allseitige gesunde Aufwachsen der nachfolgenden Generationen"79 zu schützen und zu fördern. Das in Art. 26 des Übereinkommens festgelegte Recht des Kindes auf soziale Sicherheit findet im Text des chinesischen Gesetzes zum Schutz von Minderjährigen von 1991 keinen gleichnamigen Ausdruck. In diesem Gesetz wurde nur allgemein geregelt, dass der Staat das Recht der Minderjährigen auf Unverletzlichkeit der Person, auf Eigentum und andere Rechte sowie legale Interessen gewährleistet. 80

Erst bei der Revision im Jahre 2006 wurden bestimmte Regelungen des Übereinkommens über die Rechte des Kindes im Gesetz zum Schutz von Minderjährigen umgesetzt. Die Rechte des Kindes - einschließlich Recht auf Leben, Freiheitsrecht, Recht auf Gesundheitsversorgung, Recht auf soziale Sicherheit und Bildungsrecht - die im ersten Teil des Übereinkommens geregelt sind, werden in Art. 3 Abs. 1, 2 des chinesischen Gesetzes zusammengefasst als Lebensrecht, Entwicklungsrecht, Recht auf Schutz, Teil-

76 中华人民共和国民法通则 vom 12.04. 1986.

77 Art. 1 des Übereinkommens über die Rechte des Kindes von 1989:

„Im Sinne dieses Übereinkommens ist ein Kind jeder Mensch, der das achtzehnte Lebensjahr noch nicht vollendet hat, soweit die Volljährigkeit nach dem auf das Kind anzuwendenden Recht nicht früher eintritt.“

78 Präambel des Übereinkommens über die Rechte des Kindes von 1989.

$79 \S 1$ des Gesetzes zum Schutz der Minderjährige von 1991.

$80 § 5$ Abs. 1 des Gesetzes zum Schutz der Minderjährige von 1991. 
haberecht und Recht auf Bildung eingeführt. 81 Allerdings wird diese allgemeine Regelung über die Rechte der Minderjährigen nicht aus Sicht des internationalen Menschenrechtsbegriffs weiter konkretisiert. In dem folgenden Text liegt der Schwerpunkt des Gesetzes wie in der Version von 1991 bei der Schutzpflicht

- der Familie ( $\S 10-16)$,

- $\quad$ der Schule ( $\S \S 17-26)$,

- $\quad$ der Gesellschaft und des Staates (§§ 27-49)

- $\quad$ sowie der Justizorgane ( $\$ \S 50-59$ ).

Folglich spiegelt sich beim Schutz der Minderjährigen besonders die chinesische Tradition wider, nämlich die Betonung der Pflicht von Familie, Gesellschaft und Staat für die Kinder.

\section{(2) Gesetz zur Gewährleistung der Rechte von Frauen}

Das UNO-Übereinkommen zur Beseitigung jeder Form von Diskriminierung der Frau von 1979 wurde im Jahre 1980 vom Nationalen Volkskongress Chinas ratifiziert und trat am 03. 09. 1981 in Kraft. Allerdings erfolgte die Umsetzung dieser internationalen Konvention in ein spezielles chinesisches innerstaatliches Gesetz erst nach acht Jahren. Am 03. 04. 1992 wurde das Gesetz zur Gewährleistung der Rechte von Frauen, das in gewisser Weise der „Erfüllung der Pflicht zur Durchsetzung der internationalen Konvention" 82 dient, vom Nationalen Volkskongress angenommen.

Von der wörtlichen Bedeutung des Gesetztitels her wird deutlich, dass dieses Gesetz seinen Schwerpunkt auf die „Gewährleistung der Rechte von Frauen“ legt. Es handelt sich hauptsächlich um die Gleichbehandlungsrechte der Frauen in den politischen, wirtschaftlichen, kulturellen sowie gesellschaftlichen Bereichen und in der Familie gegenüber Männern. ${ }^{83}$ Der „Schutz der besonderen Rechte und Interessen von Frauen“ und die „Verbesserung der sozialen Sicherung für Frauen“ spielen daneben auch eine Rolle. ${ }^{84}$ Das Gesetz ist nämlich dem Wesen nach vielmehr eine rechtliche Regelung zur Beseitigung der Ungleichbehandlung zwischen Frauen und Männern, und keine reine Schutzmaßnahme für eine schwache Personengruppe. Demzufolge hat der Gesetzgeber dafür eine andere Form gegenüber dem Gesetz zum Schutz von Minderjährigen gewählt, die sich dem Übereinkommen zur Beseitigung jeder Form von Diskriminierung der Frau von 1979 nähert. Der Text des Gesetzes wird nach Arten der Grundrechte von Frauen unterteilt:

politische Rechte ( $\S 9-14)$,

81 Siehe: 于建伟, 未成年人保护法修订的背景, 思路和主要内容 (Yü, Jianwei, Background, Thoughts and Main Contents of the Revision of Juvenile Protection Law), in: 青少年犯罪问 题 (Issues on Juvenile Crimes and Delinquency), 2007/2. S. 4ff.

82 邹瑜, 关于中华人民共和国妇女权益保障法 (草案) 的说明 (Zou, Yü, Erklärung über den Entwurf des Gesetzes der Volksrepublik China zur Gewährleistung der Rechte von Frauen), gesprochen in der 5. Sitzung des VII. NVK am 27. 03. 1992, http://www.law-lib.com/fzdt/newshtml/20/20050725155948.htm (Stand: 15. 07. 2010).

83 § 2 Abs. 1 des Gesetzes zur Gewährleistung der Rechte von Frauen von 1992.

$84 \S 2$ Abs. 2 des Gesetzes zur Gewährleistung der Rechte von Frauen von 1992. 
- $\quad$ Rechte auf Bildung und Kultur ( $\S 15-21)$,

- $\quad$ Recht auf Arbeit (\$§ 22-27),

- $\quad$ Eigentumsrechte ( $\S 28-32)$,

- $\quad$ Rechte auf Unverletzlichkeit und Freiheit der Person (§§ 33-39),

- $\quad$ Rechte in der Familie ( $\S ~ 40-47)$.

Art. 11 Abs. 1e des Übereinkommens, in dem das Recht der Frauen auf soziale Sicherheit, insbesondere auf Leistungen bei Eintritt in den Ruhestand, bei Arbeitslosigkeit, Krankheit, Invalidität und im Alter oder bei sonstiger Arbeitsunfähigkeit, geregelt wird, wird im vierten Kapitel (Recht auf Arbeit) des chinesischen Gesetzes umgesetzt. § 27 des Gesetzes zur Gewährleistung der Rechte und Interessen von Frauen lautet: „Der Staat hat die Pflicht, soziale Versicherung, Sozialhilfe und Gesundheitswesen zu entwickeln. Damit wird die materielle Hilfe für alte, kranke oder arbeitsunfähige Frauen verwirklicht."

Bei der umfangreichen Revision dieses Gesetzes im Jahre 2005 wurde das Recht der Frauen auf soziale Sicherheit besonders betont. Der Titel des vierten Kapitels (Recht auf Arbeit) wurde in „Recht auf Arbeit und soziale Sicherheit“ umbenannt. Dabei wurden den Frauen in $\S 22$ die gleichen Rechte auf Arbeit und soziale Sicherheit wie den Männern zugesichert. Darüber hinaus wurde das Recht auf soziale Wohlfahrt neben Sozialversicherung, Sozialhilfe und Gesundheitswesen in den $§ 28$ (ehemalig § 27) neu eingeführt.

\section{(3) Gesetz zum Schutz von behinderten Menschen}

Der Grundsatz des am 28. 12. 1990 vom Nationalen Volkskongress verabschiedeten Gesetzes zum Schutz von behinderten Menschen ist im $\S 1$ des Gesetzes festgeschrieben: „Die Gewährleistung des Gleichbehandlungsrechts der behinderten Menschen und ihre Teilhabe am Leben in der Gemeinschaft". Das Gleichbehandlungsrecht wurde als die primäre Zielsetzung bezeichnet. ${ }^{85}$ Allerdings wurden im folgenden Text vielmehr die staatlichen Hilfsmaßnahmen für die Verminderung oder Beseitigung von Behinderung und äußeren Barrieren ${ }^{86}$ erwähnt. Die Form des Gesetzes zum Schutz von behinderten Menschen ist demzufolge weder mit der des Gesetzes zum Schutz von Minderjährigen noch mit der des Gesetzes zur Gewährleistung der Rechte von Frauen identisch. Es unterteilt sich nach Schutzbereichen, dabei wurden die subjektiven Rechte von behinderten Menschen und die staatliche Verantwortung geregelt:

- die Pflicht von Staat und Gesellschaft zur Durchsetzung von Rehabilitationsmaßnahmen (§§ 13-17),

- $\quad$ das Bildungsrecht der behinderten Menschen, die staatliche Verantwortung hinsichtlich der Errichtung spezieller Bildungseinrichtungen für behinderte Menschen $(\S \S 18-26)$,

- das Recht der behinderten Menschen auf Arbeit, Hilfs- und Förderungsmaßnahmen des Staates auf Beschäftigung ( $\S 27-35)$,

$85 \S 3$ des Gesetzes zum Schutz von behinderten Menschen von 1990.

$86 \S 4$ des Gesetzes zum Schutz von behinderten Menschen von 1990. 
- $\quad$ Hilfen und Förderungen von Staat und Gesellschaft für die Teilhabe der behinderten Menschen an kulturellem Leben, Sport sowie Vergnügung (§§ 36-39),

- $\quad$ staatliche und gesellschaftliche Unterstützungen, Hilfen sowie andere Maßnahmen, die das Leben der behinderten Menschen schützen und verbessern, Hilfe zur Teilnahme an der sozialen Versicherung ( $\$ 40-44)$,

- $\quad$ Verbesserung der Teilhabe am Leben in der Gesellschaft (\$§ 45-48).

Die UNO-Konvention über die Rechte von Menschen mit Behinderungen wurde am 13. 12. 2006 angenommen. Sie trat am 03. 05. 2008 in Kraft. Inzwischen hat China nach bestimmten Regelungen der UNO-Konvention von 2006 das Gesetz zum Schutz von behinderten Menschen, das seit 2004 schon im Revisionsverfahren war, korrigiert. Der Nationale Volkskongress nahm am 24. 04. 2008 die revidierte Version des Gesetzes an, danach ratifizierte er am 26. 06. 2008 die UNO-Konvention über die Rechte von Menschen mit Behinderungen.

Im Entwurf der Leitgruppe für die Revision des Gesetzes von behinderten Menschen 87 wurde die Verstärkung des menschenrechtlichen Charakters ausdrücklich betont. Es wurde vorgeschlagen, den Namen des Gesetzes in „Gesetz zur Gewährleistung der Rechte von behinderten Menschen“ umzuändern. Dementsprechend hätte der Text des Gesetzes nach Arten der Rechte differenziert werden müssen: politische Rechte, Rechte auf Unverletzlichkeit und Freiheit der Personen, Eigentumsrechte, Rechte in der Familie, Rechte auf Rehabilitation, Bildungsrechte, Recht auf Arbeit und Beschäftigung, Recht auf kulturelles Leben, Recht auf soziale Sicherheit sowie Recht auf barrierefreie Zugänge.

In den „Ansichten des Zentralkomitees der KP Chinas und des Staatsrats über die Förderung des Behindertenwesens", 88 die ein Monat vor der Annahme der Gesetzesrevision veröffentlicht wurden, werden die behinderten Menschen als „eine gesellschaftliche Gruppe, die besonders hilfsbedürftig ist", bezeichnet. Das Behindertenwesen umfasst hauptsächlich „Rehabilitation und Prävention, soziale Sicherung, Förderung der allseitigen Entfaltung sowie Verbesserung des öffentlichen Diensts". 89 Die Ratifikation und Umsetzung der Konvention über die Rechte von Menschen mit Behinderungen wurden in den Ansichten gefordert. ${ }^{90}$

Die oben erwähnten Vorschläge der Leitgruppe wurden nicht vom Ständigen Ausschuss des Nationalen Volkskongresses akzeptiert. Im revidierten Gesetz wurden der Name des ursprünglichen Gesetzes und der alte Rahmen der Schutzmaßnahmen beibehalten. Die Verknüpfungen mit der UNO-Konvention von 2006 werden hauptsächlich

87 关于残疾人保障法修改总体框架的方案及其说明 (征求意见稿) (Erklärungsentwurf über den allgemeinen Revisionsrahmen des Gesetzes zum Schutz von behinderten Menschen), 2005, http://temp.cdpj.cn/bzfxg/2005-04/05/content_3933.htm (Stand: 15. 07. 2010).

88 中共中央国务院关于促进残疾人事业发展的意见, vom 28.03.2008.

89 Ansichten des Zentralkomitees der KP und Staatsrats über die Förderung von Behindertenwesen von 2008.

90 Nr. 18 der Ansichten des Zentralkomitees der KPC und Staatsrats über die Förderung von Behindertenwesen von 2008. 
durch folgende Änderungen verwirklicht: 91 Das Gleichbehandlungsrecht der behinderten Menschen in verschiedenen Bereichen wird gleich zu Beginn der Kapitel II-VI erklärt. Das 6. Kapitel wurde dem Art. 28 der UNO-Konvention entsprechend umbenannt und heißt jetzt „soziale Sicherheit“ anstatt „soziale Leistungen“. Darin wird die Teilnahme der behinderten Menschen an der Sozialversicherung ( $\$ 47)$, Sozialhilfe für behinderte Menschen $(\S \S 48,49)$ sowie an sozialen Förderungsmaßnahmen $(\S 50)$ geregelt. Das 7. Kapitel, das früher die Verbesserung der Teilhabe am Leben in der Gesellschaft nur allgemein regelte, wurde nach Art. 9 der UNO-Konvention von 2006 modernisiert und beinhaltet nun unter dem Titel „,barrierefreie Zugänge“ ein Verbot der Mobilitätseinschränkung von Behinderten. Es enthält zurzeit konkrete staatliche Maßnahmen wie bauliche Einrichtungen ( $\$ 53)$, technische Gebrauchsgegenstände ( 54 ), öffentliche Informations- und Kommunikationssysteme (§ 55).

\section{Einflussanalyse}

In den chinesischen Gesetzen zur sozialen Sicherheit haben, wie oben erwähnt, die internationalen Menschenrechtskonventionen seit dem Anfang des 21. Jahrhunderts Wirkung gezeigt. Die Gründe dafür sind die Rezeption und die Umwandlung des Menschenrechtsbegriffs in dem chinesischen System. Darüber hinaus hat die Einführung der Marktwirtschaft in China dazu geführt, dass sich der Begriff der sozialen Sicherheit dem der westlichen Welt angenährt hat.

Der Einfluss der Menschenrechtskonventionen ist nur oberflächlich. Die Revisionen berührten den Kern der Gesetze nicht. Der Rahmen des jeweiligen Gesetzes blieb bei der Revision erhalten. Die Betonung der Schutzfunktion des Staates gegenüber den Bürgern und seiner leitenden Rolle im Bereich der sozialen Sicherheit, insbesondere für die schwachen Bevölkerungsgruppen, bleib aufgrund der chinesischen Vorstellung vom Staat und dem Einzelne auch nach wie vor erhalten. Z. B. wurden die Vorschläge zur Revision des Gesetzes zum Schutz von behinderten Menschen, die vornehmlich aus Sicht der Menschenrechte argumentierten, nicht angenommen.

Die Revisionen der Gesetze zum Schutz von bestimmten schwachen Bevölkerungsgruppen seit 2005 sind nicht nur die staatlichen Aktivitäten für die Umsetzung der ratifizierten UNO-Konventionen, sondern auch die Konkretisierung der Verfassungsrevision von 2004 in einfachen Gesetzen. Durch menschenrechtliche Aktivitäten wird versucht, ,die Überlegenheit der sozialistischen Ordnung zu verkörpern, und die Legitimation des Staates im internationalen System zu schaffen“.92 Die Ratifizierung und Umsetzung der internationalen Menschenrechtskonventionen wird also als Teil der chinesischen Außenpolitik betrachtet, um die Stellung Chinas auf der internationalen Ebene zu

91 残疾人权利公约及与残疾人保障法修订的衔接 (Die Umsetzung der Konvention über die Rechte von Menschen mit Behinderungen durch die Revision des Gesetzes zum Schutz von behinderten Menschen), http://www.npc.gov.cn/npc/zt/2008-02/27/content_1400289.htm (Stand: 15. 07. 2010).

92 Ansichten des Zentralkomitees der KP Chinas und des Staatsrats über die Förderung von Behindertenwesen von 2008. 
verbessern und dadurch die staatliche Entwicklungsziele zu erreichen, wie z. B. Überwindung von Handelsbarrieren, Erlangung von Technik und Information aus dem Ausland.

\section{ILO-Standards als Rahmen der sozialen Sicherheit}

Im Vergleich mit dem Einfluss der UNO-Menschenrechtskonventionen, der hauptsächlich zur Errichtung einer menschenrechtlichen Grundlage der Gesetze beigetragen hat, beschäftigt sich die ILO im Wesentlichen mit der Ausarbeitung und Verbreitung von Sozialstandards, die einen Rahmen für das Sozialschutzsystem geschaffen haben. Aufgrund ihrer Ziele und Zwecke sowie ihrer triparitärischen Organisationsstruktur (Regierungs-, Arbeitnehmer- und Arbeitgebervertreter) konzentriert sich die ILO grundsätzlich auf Sozialstandards, die hauptsächlich die Beschäftigten im formellen Sektor betreffen. ${ }^{93}$ Dennoch hat sich die ILO auch seit langer Zeit für ein umfassendes Standard-System eingesetzt, damit jeder von den Sozialleistungssystemen erfasst werden kann. ${ }^{94}$

\section{Ziele und Aufgaben der ILO}

Die im Jahre 1919 gegründete Internationale Arbeitsorganisation ist seit 1946 eine der Sonderorganisationen der UNO. Gemäß der Präambel der ILO-Verfassung ist ihre grundlegende Zielsetzung die Sicherung des Weltfriedens auf Basis der sozialen Gerechtigkeit und durch Verbesserung der Arbeits- und Lebensbedingungen der Werktätigen. ${ }^{95}$ Aufgrund handelspolitischer Interessen wurde geregelt, dass die Nichteinführung menschenwürdiger Arbeitsbedingungen, um Marktvorteile am internationalen Handel gegenüber anderen Nationen zu erhalten, durch weltweit anerkannte Sozialstandards verhindert werden soll. 96

Als Hauptaufgabe erarbeitet die ILO internationale Arbeits- und Sozialstandards mit Konventionen und Empfehlungen in den Bereichen Beschäftigung, Arbeitsbedingung, Arbeitsschutz und soziale Sicherung. Die Mitgliedstaaten der ILO haben die Pflicht,

93 ILO, Social Security: A New Consensus, Geneva, 2001, S. 72; Nußberger, Sozialstandards im Völkerrecht, S. 94ff; Köhler, Sozialpolitische und sozialrechtliche Aktivitäten in den Vereinten Nationen, S. 286ff.

94 ILO, Social Security: A New Consensus, S. 1ff; Deacon, Global Social Policy \& Governance, S. 63ff; Nußberger, in: Maydell/Ruland/Becker (Hrsg.), Sozialrechtshandbuch, S. 1413ff.

95 Präambel der ILO-Verfassung:

„Der Weltfriede kann auf die Dauer nur auf sozialer Gerechtigkeit aufgebaut werden. Nun bestehen aber Arbeitsbedingungen, die für eine große Anzahl von Menschen mit so viel Ungerechtigkeit, Elend und Entbehrungen verbunden sind, dass eine Unzufriedenheit entsteht, die den Weltfrieden und die Welteintracht gefährdet. Eine Verbesserung dieser Bedingungen ist dringend erforderlich, ..." http://www.ilo.org/public/german/region/eurpro/bonn/download/iloverfassungde.03.pdf (Stand: 15. 07. 2010).

96 Vgl. Präambel der ILO-Verfassung von 1919. 
Maßnahmen zur Durchführung der ratifizierten ILO-Übereinkommen zu ergreifen und darüber zu berichten. Um diese Ziele zu erreichen unterstützt die ILO ihre Mitglieder durch technische Zusammenarbeit und Beratungsdienste sowie andere Hilfsmaßnahmen, 97 weil viele Länder wegen realer Probleme wie wirtschaftliche Rückständigkeit, Massenarbeitslosigkeit sowie historische Bedingungen nicht in der Lage sind, die Übereinkommen zu ratifizieren und durchzuführen.

\section{Die ILO-Standards für soziale Sicherheit}

Vor den 1940er Jahren hat die ILO bereits eine Reihe von Konventionen zu den Risiken Alter, 98 Krankheit, ${ }^{99}$ Mutterschaft, ${ }^{100}$ Invalidität, ${ }^{101}$ Arbeitslosigkeit, ${ }^{102}$ Arbeitsunfall103 sowie für Hinterbliebene 104 ausgearbeitet, die auf dem Sozialversicherungskonzept aufgebaut wurden. Der Versichertenkreis beschränkte sich hauptsächlich auf die Erwerbstätigen in bestimmten Sekundärsektoren, insbesondere auf die Industriearbeiter.

Seit den 1940er Jahren hat die ILO ein neues Konzept für die soziale Sicherheit entwickelt. In der Erklärung über die Ziele und Zwecke der Internationalen Arbeitsorganisation (Erklärung von Philadelphia) von 1944 wurde der Ausbau von Maßnahmen der sozialen Sicherheit, um ein Mindesteinkommen und umfassende ärztliche Betreuung für alle Arbeitende zu sichern, 105 neben der Vollbeschäftigung und Verbesserung der Lebenshaltung 106 als Ziele der ILO, die weltweit durch Programme zu fördern sind, festgelegt. Die im selben Jahr ausgearbeiteten Empfehlungen der ILO über Einkommenssicherung (Konvention Nr. 67) und medizinische Betreuung (Konvention Nr. 69) propagierten eine umfassende Form der sozialen Sicherung für jeden Einzelnen, in dem Sozialversicherung und Sozialhilfe als Einheit gesehen wird. ${ }^{107}$

Im Jahre 1952 hat die ILO in der Konvention Nr. 102 über die Mindestnormen der sozialen Sicherheit ein umfangreiches Programm für Gewährleistung der sozialen Sicherheit ausgearbeitet und in neue verschiedene Zweige eingeteilt:

- $\quad$ Ärztliche Betreuung (Teil II),

- $\quad$ Krankengeld (Tei III),

- $\quad$ Leistungen bei Arbeitslosigkeit (Teil IV),

- $\quad$ Leistungen bei Alter (Teil V),

97 Art. 3 der Erklärung der ILO über Grundlegende Prinzipien und Rechte bei der Arbeit von 1998.

98 Konvention Nr. 35, 36 der ILO.

99 Konvention Nr. 24, 25, 56 der ILO.

100 Konvention Nr. 3 der ILO.

101 Konvention Nr. 37, 38 der ILO.

102 Konvention Nr. 8, 44 der ILO.

103 Konvention Nr. 17, 18, 42 der ILO.

104 Konvention Nr. 39, 40 der ILO.

105 III f) der Erklärung von Philadelphia, vom 10. 05. 1944.

106 III a) der Erklärung von Philadelphia von 1944.

107 Ausführlich vgl. Nußberger, Sozialstandards im Völkerrecht, S. 60ff. 
- $\quad$ Familienleistung (Teil VII),

- $\quad$ Leistungen bei Mutterschaft (Teil VIII),

- $\quad$ Leistungen bei Invalidität (Teil IX),

- $\quad$ Leistungen an Hinterbliebene (Teil X).

Die in der Konvention Nr. 102 enthaltenen Regelungen wurden in den folgenden Jahren durch spezielle Konventionen und Empfehlungen weiter konkretisiert. Damit wird ein grundsätzlicher Rahmen der Systeme der sozialen Sicherheit, bei dem die Mindeststandards über die sozialen Risiken, der Leistungsumfang sowie der Kreis der geschützten Personen vorgegeben werden, ${ }^{108}$ von der ILO normiert.

\section{Tabelle 19: ILO-Konventionen über soziale Sicherheit seit 1952}

\begin{tabular}{|l|l|}
\hline Nummer & Konvention \\
\hline C102 & Übereinkommen über die Mindestnormen der Sozialen Sicherheit, 1952 \\
\hline C118 & $\begin{array}{l}\text { Übereinkommen über die Gleichbehandlung von Inländern und Ausländern in der Sozialen } \\
\text { Sicherheit, 1962 }\end{array}$ \\
\hline C121 & Übereinkommen über Leistungen bei Arbeitsunfällen und Berufskrankheiten, 1964 \\
\hline C128 & Übereinkommen über Leistungen bei Invalidität und Alter und an Hinterbliebene, 1967 \\
\hline C130 & Übereinkommen über ärztliche Betreuung und Krankengeld, 1969 \\
\hline C157 & $\begin{array}{l}\text { Übereinkommen über die Einrichtung eines internationalen Systems zur Wahrung der } \\
\text { Rechte in der Sozialen Sicherheit, 1982 }\end{array}$ \\
\hline C168 & $\begin{array}{l}\text { Übereinkommen über Beschäftigungsförderung und den Schutz gegen Arbeitslosigkeit, } \\
1988\end{array}$ \\
\hline C183 & $\begin{array}{l}\text { Übereinkommen über die Neufassung } \\
\text { des Übereinkommens über den Mutterschutz } \\
\text { (Neufassung), 2000 }\end{array}$ \\
\hline
\end{tabular}

Quelle: ILO, Social Security: A New Consensus, 2001.

Der Ausbau der sozialen Sicherung wird als eine der grundlegenden Ziele von „,decent work", also gute und menschenwürdige Arbeit für alle, die im Jahre 1999 von Juan Somavia, dem Generaldirektor der International Labour Office vorgebracht und seitdem weiter entwickelt wurde, bezeichnet. ${ }^{109}$ In den "Schlussfolgerungen über die soziale Sicherheit" von $2001^{110}$ stellt die ILO die wichtige Rolle der sozialen Sicherungssysteme im Staatsleben zusammenfassend dar ${ }^{111}$ und vertritt die Ansicht, dass die An-

108 Vgl. Nußberger, in: Becker/Maydell/Nußberger (Hrsg.), Die Implementierung internationaler Sozialstandards, zur Durchsetzung und Herausbildung von Standards auf überstaatlicher Ebene, S. 61.

109 International Labour Conference 1999, Report of the Director-General: "Decent Work. Die vier grundlegenden Ziele von „decent work“, die sich für die ILO aus der Allgemeinen Erklärung der Menschenrechte ergeben, sind: (1) Mehr und bessere Beschäftigungsmöglichkeiten schaffen, (2) Arbeitnehmerrechte respektieren und gesetzlich absichern, (3) System der sozialen Sicherung aufund ausbauen, (4) Den sozialen Dialog zwischen Arbeitgebern und Gewerkschaften fördern.“

110 ILO, Social Security: A new consensus, 2001.

111 2. Conclusions concerning social security: "Social security is very important for the well-being of workers, their families and the entire community. It is a basic human right and a fundamental means for creating social cohesion, thereby helping to ensure social peace and social inclusion. It is an indispensable part of government social policy and an important tool to prevent and alleviate poverty. 
strengung des Staates, ,soziale Sicherheit für alle“ zu verwirklichen, eng mit der Beschäftigungsstrategie und den anderen Sozialpolitiken verknüpft werden sollte. ${ }^{112}$ Die ILO ist darüber hinaus der Auffassung, dass es nicht ein richtiges Modell der sozialen Sicherheit gibt. Jede Gesellschaft müsse sich selbst für die effektivsten Modelle der Einkommenssicherung und medizinischen Versorgung entscheiden, dies reflektiere die sozialen und kulturellen Werte, die Geschichte, die Institutionen sowie das Niveau der wirtschaftlichen Entwicklung einer Gesellschaft. ${ }^{113}$

\section{Einführung der ILO-Standards in China}

a) Ratifizierung der ILO-Konventionen in China

China hat die Verfassung der ILO im Jahr 1919 unterzeichnet und ist seitdem Mitglied der ILO. Nach dem chinesischen Bürgerkrieg (1945-1949) blieb die TaiwanRegierung in der ILO bis 1971. Im November 1971 wurde der Sitz der Volksrepublik China in der ILO wiederhergestellt. ${ }^{114}$ Allerdings nimmt China erst seit 1983 offiziell an den Aktivitäten der ILO teil. Das ILO-Beijing-Büro wurde im Jahre 1985 errichtet. ${ }^{115}$

Von 1919 bis 1949 hat die Republik China insgesamt 14 ILO-Konventionen ratifiziert, alle wurden von der Volksrepublik im Jahre 1983 anerkannt. Von 1983 bis 2010 hat China 11 ILO-Konventionen ratifiziert, davon vier Kernarbeitsnormen.

It can, through national solidarity and fair burden sharing, contribute to human dignity, equity and social justice. It is also important for political inclusion, empowerment and the development of democracy." in: ILO, Social Security: A new consensus, , S. 1-2.

112 16. Conclusions concerning social security, ILO, Social Security: A new consensus, S. 4-5.

113 4. Conclusions concerning social security, ILO, Social Security: A new consensus, S. 2.

114 Ausführlich vgl. 刘旭, 国际劳工标准概述 (Liu, X ̈̈, Introduction to International Labour Standards), S. 133.

115 Vgl. 刘旭, 国际劳工标准概述 (Liu, X ̈̈, Introduction to International Labour Standards), S. 133ff. 


\section{Tabelle 20: Die von China ratifizierten ILO-Konventionen}

Konvention

C7 Übereinkommen über das Mindestalter für die Zulassung von Kindern zur Arbeit auf See, 1920

C11 Übereinkommen über das Vereinigungs- und Koalitionsrecht der landwirtschaft-

lichen Arbeitnehmer, 1921

C14 Übereinkommen über den wöchentlichen Ruhetag in gewerblichen Betrieben, 1921

C15 Übereinkommen über das Mindestalter für die Zulassung von Jugendlichen zur

Beschäftigung als Kohlenzieher (Trimmer) oder Heizer, 1921

C16 Übereinkommen über die pflichtmäßige ärztliche Untersuchung der in der Seeschifffahrt beschäftigten Kinder und Jugendlichen, 1921

C19 Übereinkommen über die Gleichbehandlung einheimischer und ausländischer Arbeitnehmer in der Entschädigung bei Betriebsunfällen, 1925

C22 Übereinkommen über den Heuervertrag der Schiffsleute, 1926

C23 Übereinkommen über die Heimschaffung der Schiffsleute, 1926

C26 Übereinkommen über die Einrichtung von Verfahren zur Festsetzung von Mindestlöhnen, 1928

C27 Übereinkommen über die Gewichtsbezeichnung an schweren, auf Schiffen beförderten Frachtstücken, 1929

C32 Übereinkommen über den Schutz der mit dem Beladen und Entladen von Schiffen beschäftigten Arbeitnehmer gegen Unfälle (abgeänderter Wortlaut vom Jahre 1932), 1932

C45 Übereinkommen über die Beschäftigung von Frauen bei Untertagearbeiten in Bergwerken jeder Art, 1935

C59 Übereinkommen über das Mindestalter für die Zulassung von Kindern zur gewerblichen Arbeit (abgeänderter Wortlaut vom Jahre 1937), 1937

C80 Übereinkommen über die teilweise Abänderung der von der Allgemeinen Konferenz der Internationalen Arbeitsorganisation auf ihren ersten achtundzwanzig Tagungen angenommenen Übereinkommen zur Sicherstellung der künftigen Durchführung bestimmter in den bezeichneten Übereinkommen dem Generalsekretär des Völkerbundes übertragener Kanzleiaufgaben und zur Ausnahme zusätzlicher Abänderungen, die sich durch die Auflösung des Völkerbundes und die Abänderung der Verfassung der Internationalen Arbeitsorganisation als notwendig erwiesen haben, 1946

C100 Übereinkommen über die Gleichheit des Entgelts männlicher und weiblicher Arbeitskräfte für gleichwertige Arbeit, 1951

C111 Übereinkommen über die Diskriminierung in Beschäftigung und Beruf, 1958 C122 Übereinkommen über die Beschäftigungspolitik, 1964

C138 Übereinkommen über das Mindestalter für die Zulassung zur Beschäftigung, 1973

C144 Übereinkommen über dreigliedrige Beratungen zur Förderung der Durchführung internationaler Arbeitsnormen, 1976

C150 Übereinkommen über die Arbeitsverwaltung: Rolle, Aufgaben, Aufbau, 1978

C155 Übereinkommen über Arbeitsschutz und Arbeitsumwelt, 1981

C159 Übereinkommen über die berufliche Rehabilitation und die Beschäftigung der Behinderten, 1983

C167 Übereinkommen über den Arbeitsschutz im Bauwesen, 1988

C170 Übereinkommen über Sicherheit bei der Verwendung chemischer Stoffe bei der Arbeit, 1990

C182 Übereinkommen über das Verbot und unverzügliche Maßnahmen zur Beseitigung der schlimmsten Formen der Kinderarbeit, 1999 
Das chinesische Prinzip für die Ratifizierung der ILO-Konventionen liegt darin, dass die Ratifizierung der nationalen Lage und dem Niveau der politischen, wirtschaftlichen und gesellschaftlichen Entwicklungen entsprechend sowie aufgrund des nationalen Rechts ausgeführt werden muss. ${ }^{116}$ In der Praxis umgeht China gewöhnlich die politischen Konventionen der ILO und neigt zu Konventionen mit technischem Charakter. ${ }^{117}$ Demzufolge ratifiziert China umsichtig und langsam Konventionen der ILO. Die von China ratifizierten Konventionen betreffen hauptsächlich Mindestalter, Mindestlohn, Gleichheit des Entgelts, Diskriminierung sowie Beschäftigungsförderung.

Das grundlegende Hindernis für die weitere Einsetzung der ILO-Normen in China ist, dass das Organisationsprinzip und die Struktur der chinesischen Gewerkschaften, die aufgrund des sozialistischen Staatssystems festgelegt wurden, gegen die ILOKonventionen über das Vereinigungsrecht verstoßen.

Im Gewerkschaftsgesetz von 1992 werden die grundlegenden Aufgaben der chinesischen Gewerkschaften wie folgend geregelt:

„Die Gewerkschaften sollen die Beschäftigten organisieren und aufklären, damit sie nach den Regelungen der Verfassung und Gesetze ihre demokratischen Rechte ausüben, als die Herren des Staates durch verschiedene Arten und Weisen an der Verwaltung des Staatswesens, der wirtschaftlichen, kulturellen und gesellschaftlichen Angelegenheiten beteiligen, die Volksregierung bei ihrer Arbeit assistieren, die sozialistische Staatsmacht unter der demokratischen Diktatur des Volkes, der von der Arbeiterklasse geführt wird und auf dem Bündnis der Arbeiter und Bauern beruht, gewährleisten." 118

Darüber hinaus wird „die Gewährleistung der legalen Rechte und Interessen der Beschäftigten während der Gewährleistung der gemeinsamen Interessen des chinesischen Volks" als die Grundpflicht der Gewerkschaften geregelt. 119

In der Periode der Planwirtschaft wurde das Gewerkschaftssystem völlig auf dem sozialistischen Gemeineigentum aufgebaut. Eine Kollektivverhandlungsfunktion der Gewerkschaft gegenüber dem Unternehmer existierte nicht. Erst als Privatunternehmen und Unternehmen mit ausländischem Kapital in der Periode der Marktwirtschaft eingeführt und durch die Verfassungsrevision von 1988 anerkannt wurden, wurde es notwendig, durch die gesetzliche Festlegung des Kollektivverhandlungsrechts der Beschäftigten die Verschlechterung der Arbeitsbedingungen und die Verletzung der Arbeitnehmerrechte zu beseitigen. Seit den 1990er Jahren wird die Befugnis der Gewerkschaft, durch den Kollektivvertrag die Rechte und Interessen der Arbeitnehmer zu gewährleisten, in das Arbeitsgesetz, ${ }^{120}$ das Gewerkschaftsgesetz, ${ }^{121}$ das Arbeitsvertragsgesetz ${ }^{122}$

116 刘旭, 国际劳工标准概述 (Liu, Xü, Introduction to International Labour Standards), S. 137.

117 余云霞, 国际劳工标准: 演变与争议 (She, Yünxia, International Labor Standards: Evolution and Controversy), S. 391.

$118 \S 5$ des Gewerkschaftsgesetzes von 1992, revidiert im Jahre 2001.

$119 \S 6$ Abs. 1 des Gewerkschaftsgesetzes von 1992.

120 §33ff. des Arbeitsgesetzes von 1994.

$121 \S 6$ Abs. 2 des Gewerkschaftsgesetzes von 1992, revidiert im Jahre 2001.

$122 \S 51-56$ des Arbeitsvertragsgesetzes von 2007. 
und die anderen arbeitsrechtlichen Verordnungen geschrieben. Eine anfängliche Rechtslage über den Aufbau eines ,triparitärischen Konsultationssystems des Arbeitsverhältnisses" wurde auch bei der Revision des Gewerkschaftsgesetzes im Jahre 2001 eingeführt. ${ }^{123}$ Das Streikrecht der Beschäftigten wurde aber bisher noch nicht gesetzlich geregelt.

Allerdings ist das chinesische Gewerkschaftssystem wie immer nach dem Organisationsprinzip des ,demokratischen Zentralismus“124 hierarchisch aufgebaut. Die Gründung von Gewerkschaft auf lokaler, nationaler oder sektoraler Ebene ist von der Gewerkschaft auf der nächsthöheren Ebene zu billigen. ${ }^{125}$ Der Gewerkschaft auf höherer Ebene kommt eine Führungsaufgabe gegenüber derjenigen auf der niedrigeren Ebene zu. ${ }^{126}$ Der Allchinesische Gewerkschaftsbund (ACGB) ist die oberste Organisation des Gewerkschaftssystems. ${ }^{127}$ Dies verstößt gegen die Regelungen der ILO-Konvention Nr. 87, wonach die Arbeitnehmer ohne vorherige Genehmigung Organisationen nach eigener Wahl bilden können. ${ }^{128}$ Es ist für die Volksrepublik China unmöglich, im Rahmen des gegenwärtigen Staats- und Gewerkschaftssystems eine grundlegende Übereinstimmung mit der Konvention Nr. 87 zu erreichen. ${ }^{129}$

Ein anderes Haupthindernis liegt in der Zwangsarbeit. Die strikten Regelungen der ILO über die Beseitigung der Zwangsarbeit (Übereinkommen Nr. 29, Nr. 105) behindern ihre Ratifizierung in der Volksrepublik China, in der Zwangsarbeit im Gefängnis üblich ist.

In der Tat ist die Ratifizierungsrate der ILO-Konventionen wegen ihrer hohen Anforderung in den Entwicklungsländern im Durchschnitt niedrig. ${ }^{130}$ Eine andere Ursache bildet der Umstand, dass die Sozialrechtsnormen der ILO hauptsächlich von den kulturellen und gesellschaftlichen Vorstellungen Westeuropas und Nordamerikas getragen werden. ${ }^{131}$ Allerdings sind manche der westlichen Werte wie z. B. pluralistische Gesellschaft oder der Liberalismus kaum mit den Traditionen anderer Kulturkreise vereinbar. Die ILO hat auch zugegeben, dass die Ratifikation der ILO-Konvention über soziale Sicherheit weltweit „entmutigend (not encouraging)“ sei. 132

$123 \S 34$ des Gewerkschaftsgesetzes von 1992, revidiert im Jahre 2001.

$124 \S 9$ Abs. 1 des Gewerkschaftsgesetzes von 1992.

$125 \S 11$ Abs. 1 des Gewerkschaftsgesetzes von 1992.

$126 \S 9$ Abs. 5 des Gewerkschaftsgesetzes von 1992.

$127 \S 10$ Abs. 5 des Gewerkschaftsgesetzes von 1992.

128 Art. 2 der Konvention Nr. 87.

$129 \mathrm{Vgl}$. 余云霞, 国际劳工标准: 演变与争议 (She, Yünxia, International Labor Standards: Evolution and Controversy), S. 392.

130 刘旭, 我对国际劳工标准的一些看法 (Liu, Xü, Einige Ansichten an den internationalen Arbeitsstandards), in: 石美遐/Stearns, 全球化背景下的国际劳工标准与劳动法研究 (Shi/Stearns, Untersuchung der internationalen Arbeitsstandards und des Arbeitsrechts unter dem Einfluss der Globalisierung), S. 6.

131 Vgl. Schregle, in: Zacher (Hrsg.), Sozialrechtsvergleich im Bezugsrahmen internationalen und supranationalen Rechts, S. 137.

132 ILO, Social Security: A new consensus, S. 28. 
b) Einfluss der ILO-Standards auf das chinesische Recht

Wie oben erwähnt, konzentriert sich die Ratifizierungsarbeit Chinas bisher hauptsächlich auf die arbeitsrechtlichen Regelungen der ILO. Bei der Ausarbeitung des Arbeitsgesetzes von 1994 wurde die Anknüpfung an internationale Arbeitsstandards besonders berücksichtigt. ${ }^{133}$ Die ratifizierten Normen finden jeweils Umsetzungen in den speziellen Regelungen wie das Gesetz zur Arbeitssicherheit von 2002, ${ }^{134}$ das Gesetz zur Verhütung und Bekämpfung beruflicher Krankheiten von $2001^{135}$ und die Regeln über das Verbot der Kinderarbeit von 2002.136

In den von China ratifizierten Konventionen beziehen sich nur die Konvention Nr. 122 (Konvention über Beschäftigungspolitik von 1964) und die Konvention Nr. 159 (Konvention zur beruflichen Rehabilitation und Beschäftigung behinderter Menschen von 1983) auf die Maßnahmen der sozialen Sicherheit. Die acht wichtigsten ILOKonventionen über die soziale Sicherheit sind bisher noch nicht von China ratifiziert worden.

\section{aa) Einfluss auf das Arbeitsgesetz}

Das Arbeitsgesetz von 1994 bildet die Grundlagen des chinesischen Arbeitsrechts. Die Maßnahmen zum Schutz und zur Gewährleistung der legalen Rechte und Interessen der Arbeitenden ${ }^{137}$ in den Arbeitseinheiten (Unternehmen und Individualwirtschaft) ${ }^{138}$ werden in neun Kapiteln eingeteilt (Beschäftigungsförderung, Arbeitsvertrag und Kollektivvertrag, Arbeitszeiten, Ruhezeiten und Urlaub, Lohn, Arbeitssicherheit und Ge-

133 Siehe: 刘铁民/朱常有/杨乃莲, 国际劳工组织与职业安全卫生 (Liu/Zhu/Yang, ILO and OSH), S. 74; 林静, 一部具有鲜明中国特色的劳动法 - 记贾俊玲教授分析我国劳动法 (Lin, Jing, Arbeitsgesetz mit chinesischer Prägung - Interview mit Prof. Jia Junling), in: 劳动保护 (Labour Protection), 1994/9, S. 13; 林燕玲, 国际劳工标准 (Lin, Yanling (Hrsg.), Internationale Arbeitsstandards), S. 15 .

134 中华人民共和国安全生产法, vom 29.04. 2002. Siehe: 刘铁民/朱常有/杨乃莲, 国际劳工组织 与职业安全卫生 (Liu/Zhu/Yang, ILO and OSH), S. 74; ILO, 中国职业安全卫生概况 (National Profile Report on Occupational Safety and Health in China), S. 5; 王纪元, 仅有经济增长不足以 保障社会公平与正义 (Wang, Jiyuan, Soziale Gerechtigkeit kann nicht lediglich durch die Wirtschaftsentwicklung gewährleistet werden ), in: 石美遐/Stearns, 全球化背景下的国际劳工标 准与劳动法研究 (Shi/Stearns, Untersuchung der internationalen Arbeitsstandards und des Arbeitsrechts unter dem Einfluss der Globalisierung), S. 9.

135 中华人民共和国职业病防治法, vom 27. 10. 2001. 刘铁民/朱常有/杨乃莲, 国际劳工组织与职 业安全卫生 (Liu/Zhu/Yang, ILO and OSH), S. 74; ILO, 中国职业安全卫生概况 (National Profile Report on Occupational Safety and Health in China), S. 5; 王纪元, 仅有经济增长不足以保障 社会公平与正义 (Wang, Jiyuan, Soziale Gerechtigkeit kann nicht lediglich durch die Wirtschaftsentwicklung gewährleistet werden), in: 石美遐/Stearns, 全球化背景下的国际劳工标准与劳动法 研究 (Shi/Stearns, Untersuchung der internationalen Arbeitsstandards und des Arbeitsrechts unter dem Einfluss der Globalisierung), S. 9.

136 禁止使用童工规定, vom 18. 09. 2002. Siehe: ILO, The end of child labour: Within reach, Global Report under the follow-up to the ILO Declaration on Fundamental Principles and Rights at Work, S. 13.

$137 \S 3$ des Arbeitsgesetzes von 1994.

$138 \S 2$ des Arbeitsgesetzes von 1994. 
sundheit, besonderer Schutz weiblicher Beschäftigter und minderjähriger Arbeiter, Berufsausbildung, Sozialversicherung und Sozialwohlfahrt, Arbeitsstreitigkeiten) und jeweils durch spezielle rechtliche Regelungen konkretisiert. Bis Ende 2008 traten

- Gesetz zur Berufsausbildung am 01. 09. 1996,

- Gesetz zur Arbeitssicherheit am 01. 11. 2002,

- Gesetz zur Verhütung und Bekämpfung beruflicher Krankheiten am 01. 05. 2002,

- Beschäftigungsförderungsgesetz am 01. 01. 2008,

- $\quad$ Arbeitsvertragsgesetz am 01. 01. 2008,

- Gesetz zur Schlichtung und zum Schiedsverfahren der Arbeitsstreitigkeiten am 01. 05. 2008 und

in Kraft. Das im Oktober 2010 verabschiedete Sozialversicherungsgesetz enthält auch Regelungen bezüglich Sozialversicherungen der Beschäftigten. Dieses Gesetz war wegen heftigen Kontroversen 15 Jahre lang im Gesetzgebungsverfahren. Ein Entwurf wurde im Dezember 2008 veröffentlicht, damit alle Bürger sich an der Diskussion beteiligen können. 139

Die Regelungen im Kapitel IX des Arbeitsgesetzes (§ 70-76, Sozialversicherung und Sozialwohlfahrt) sind sozialrechtlich relevant. In $\S 73$ des Arbeitsgesetzes wurde ein grundsätzlicher Rahmen der Sozialversicherungssysteme für die Beschäftigten errichtet, der die ILO-Mindestnormen der sozialen Sicherheit rezipiert:

„Arbeitende erhalten bei Vorliegen der folgenden Umstände Leistungen der Sozialversicherung:

1. im Ruhestand,

2. bei Krankheit,

3. bei berufsbedingter Invalidität oder Berufskrankheit,

4. bei Arbeitslosigkeit,

5. bei Mutterschaft.

Nach dem Tode des Arbeitenden erhalten hinterbliebene Abhängige einen Hinterbliebenenzuschuss."

Im Vergleich mit der in der Konvention Nr. 102 und ihren Folgekonventionen enthaltenen ILO-Standards über soziale Sicherheit fehlt es beim chinesischen Arbeitsgesetz wegen der Familienpolitik nur an einer Regelung über Familienleistung. 140

Gemäß dem Arbeitsgesetz werden die Rentenversicherung, die Krankenversicherung, die Arbeitsunfallversicherung, die Arbeitslosenversicherung sowie die Mutterschaftsversicherung aufgebaut. ${ }^{141}$ Die ländliche Bevölkerung und die städtischen Be-

139 Entwurf des Sozialversicherungsgesetzes, vom 28. 12. 2008, in: 人民日报 (RMRB), 29. 12. 2008.

140 林静, 一部具有鲜明中国特色的劳动法 - 记贾俊玲教授分析我国劳动法 (Lin, Jing, Arbeitsgesetz mit chinesischer Prägung - Interview mit Prof. Jia Junling), in: 劳动保护 (Labour Protection), 1994/9, S. 13.

$141 \S 2$ des Entwurfs des Sozialversicherungsgesetzes. 
wohner, die nicht in Arbeitseinheiten beschäftigt sind, werden durch den Systemausbau schrittweise in die sozialen Versicherungssysteme eingezogen. 142

Der weitere Systemausbau ist die Errichtung eines „Kombinationsmechanismus“ von Beschäftigung und sozialer Sicherung, das die Beschäftigungsförderung, die Arbeitslosenversicherung und die Sicherung des Existenzminimums für die städtische Bevölkerung sowie eine Einkommenssicherung durch Mindestlohn, Arbeitslosengeld und Existenzminimum umfasst. ${ }^{143}$ Dies entspricht der Forderung der ILO in der Konvention Nr. 122 über Beschäftigungspolitik von 1964:

„Jedes Mitglied hat als eines der Hauptziele eine aktive Politik festzulegen und zu verfolgen, die dazu bestimmt ist, die volle, produktive und frei gewählte Beschäftigung zu fördern“. 144

und der neuen Schlussfolgerung von 2001:

„Within the framework of the basic principles set out earlier, each country should determine a national strategy for working towards social security for all. This should be closely linked to its employment strategy and to it other social policies. Targeted social assistance programmes could be one means to commence the introduction of social security for excluded groups. ..."145

Im chinesischen Beschäftigungsförderungsgesetz von 2007 wird geregelt: „Der Staat stellt die Erweiterung der Beschäftigung auf einen vorrangigen Platz der Wirtschaftsund Gesellschaftsentwicklung, führt eine aktive Beschäftigungspolitik und die Richtlinie durch, nach der die Arbeitenden selbständig über ihre Beschäftigung entscheiden, der Markt die Beschäftigung regelt, die Regierung die Beschäftigung fördert“. ${ }^{146}$

Allerdings ist diese Entwicklung primär eine Reaktion auf den eigenen hohen Beschäftigungsdruck als die Umsetzung der ILO-Standards. Bevor die aktive Beschäftigungspolitik ins Gesetz geschrieben wurde, ist sie schon lange Zeit als eine politische Richtlinie in den Partei- sowie Regierungsdokumenten festgelegt worden. 147 Ziele der Beschäftigungsförderung sind die von der umfangreichen wirtschaftlichen Strukturanpassung verursachte massive Arbeitslosigkeit und den sehr hohe Bevölkerungsdruck, der für eine bestimmte Zeitspanne in China bleiben werden, zu beseitigen. Die ILO hat anerkannt, dass die chinesische Beschäftigungspolitik ,chinesisch geprägt“ ist. Der Ar-

$142 \S 18$ des Entwurfs des Sozialversicherungsgesetzes: „Der Staat errichtet und vervollkommnt schrittweise die Grundaltersversicherung für die städtischen Bewohner, die Grundaltersversicherung für die ländlichen Bewohner“; § 19: „Die Grundkrankenversicherung umfasst die Grundkrankenversicherung für die Beschäftigten in Unternehmen, die Grundkrankenversicherung für die städtischen Bewohner sowie das neue ländliche kooperative medizinische System.“ in: 人民日报 (RMRB), 29. 12. 2008.

143 Ausführlich vgl. Dritter Teil, Beschäftigungspolitik seit 2006.

144 Art. 1 Abs. 1 der Konvention Nr. 122 von 1964.

145 16. Conclusions concerning social security, ILO, Social Security: A new consensus, S. 4-5.

$146 \S 2$ des Beschäftigungsförderungsgesetzes von 2007.

147 国务院新闻办公室, 中国的就业状况和政策 (Presseamt des Staatsrats, Weißbuch über Chinas Beschäftigungslage und -politik), vom 26. 04. 2004, http://www.china.com.cn/ch-book/20040426/index.htm (Stand: 15. 07. 2010). 
beitsschwerpunkt lag lange Zeit in der Wiederbeschäftigung der ausgegliederten Arbeitnehmer. ${ }^{148}$

In der ILO-Konvention über Beschäftigungspolitik von 1964, die China im Jahre 1997 ratifiziert hat, wurden keine konkreten Standards vorgelegt, sondern lediglich eine prinzipielle Forderung an die Mitgliedstaaten. Wenn man die Konvention Nr. 122 zur Konvention Nr. 168 über Beschäftigungsförderung und den Schutz gegen Arbeitslosigkeit miteinander vergleicht, wird deutlich, dass die ILO-Standards über Beschäftigungsförderung und Arbeitslosensicherung vielmehr an die Lage der Industriestaaten angepasst sind und das hohe Leistungsniveau derzeit nicht von China akzeptiert werden kann. Ein Einfluss kann demzufolge in diesem Fall kaum festgestellt werden.

\section{bb) Einfluss auf die Regelungen zum Arbeitsunfall}

Bei der Ausarbeitung der Regelungen über die Arbeitsunfallversicherung wurden ILO-Vorgaben berücksichtigt, obwohl die ILO-Konvention Nr. 121 über Leistungen bei Arbeitsunfällen und Berufskrankheiten bisher noch nicht von China ratifiziert wurde. § 14 der Regeln über die Arbeitsunfallversicherung von 2003 führt eine Reihe von Arbeitsunfällen auf, die nach den Artikel 5 und 6 der ILO-Empfehlung 121 festgelegt wurden. 149

Darüber hinaus hat China den ILO-Maßnahmenrahmen betreffend Arbeitsunfälle und Berufskrankheiten, nämlich eine Kombination von Prävention, Entschädigung, Rehabilitation und Beschäftigungsförderung für Verletzte ${ }^{150}$ rezipiert. § 1 der Regeln über die Arbeitsunfallversicherung von 2003 regelt:

„Um Arbeitnehmern, die Arbeitsunfälle und Berufskrankheiten erlitten haben, medizinische Behandlung und wirtschaftliche Entschädigung zu sichern, und um die Unfallprävention sowie die berufliche Rehabilitation zu fördern, ....“

In den Regeln werden hauptsächlich die Leistungen der Unfallversicherung einschließlich medizinischer Behandlung, Entschädigung sowie Rehabilitation geregelt. Die Maßnahmen zur Prävention und Beschäftigungsförderung werden jeweils durch das Gesetz zur Arbeitssicherheit, das Gesetz zur Verhütung und Bekämpfung beruflicher Krankheiten sowie das Beschäftigungsförderungsgesetz konkretisiert.

Das Gesetz zur Arbeitssicherheit und das Gesetz zur Verhütung und Bekämpfung beruflicher Krankheiten waren im Jahre 2002 in Kraft getreten. Die ILO-Konvention Nr. 167 und Nr. 170 wurden dadurch in chinesisches Recht umgesetzt. ${ }^{151}$ Die Konvention Nr. 155 wurde damals noch nicht von China ratifiziert, aber sie hat die Ausarbeitung der

148 ILO, China Employment Forum, Summary Proceedings, S. 59.

149 林嘉/魏丽, 工伤认定一般条款之立法思考 ( Lin, Jia/Wei, Li, Legislative Thinking about the General Articles for Industrial Injury Determination), in: 法学杂志 (Law Science Magazine), 2008/1, S. 87.

150 Art. 26 der Konvention Nr. 121 von 1964.

151 ILO, 中国职业安全卫生概况 (National Profile Report on Occupational Safety and Health in China), S. 5. 
beiden Gesetze tief beeinflusst. ${ }^{152}$ Außerdem wurde das chinesische Verwaltungssystem für berufliche Sicherheit und Gesundheitsschutz aufgrund der „Guidelines on occupational safety and health management systems (ILO-OSH 2001)“" aufgebaut. ${ }^{153}$

\section{cc) Umsetzung im Gesetz zum Schutz von behinderten Menschen}

Die Ausarbeitung und Verabschiedung des Gesetzes zum Schutz von behinderten Menschen wurden direkt von den internationalen Aktivitäten für Behindertenwesen in den 1980er Jahren vorangetrieben. ${ }^{154}$ Die UNO proklamierte im Jahre 1981 ein umfassendes Aktionsprogramm, um das Ziel „volle Teilhabe und Gleichstellung“ der behinderten Menschen im gesellschaftlichen Leben zu verwirklichen. Demzufolge arbeitete die ILO im Jahre 1983 die Konvention Nr. 159 über berufliche Rehabilitation und Beschäftigung der behinderten Menschen aus. Damit werden die Mitgliederstaaten aufgefordert, „eine innerstaatliche Politik auf dem Gebiet der beruflichen Rehabilitation und der Beschäftigung Behinderter festzulegen, durchzuführen und regelmäßig zu überprüfen“. 155 Diese Konvention trat am 20. 06. 1985 in Kraft.

Im Jahre 1988 hat China die ILO-Konvention Nr. 159 ratifiziert. Das Gesetz zum Schutz von behinderten Menschen war zu dieser Zeit schon in der Entwurfsarbeit und wurde nach zwei Jahren verabschiedet, dafür dienten die internationalen Standards in vielen Beziehungen als Vorbild. ${ }^{156}$ Die Rehabilitation, die berufliche Bildung und die Beschäftigung der behinderten Menschen werden jeweils im Kapitel II, III und IV (§ 13-35) geregelt. Damit wird ein Förderungscharakter des Gesetzes deutlich, der dem Ziel des UNO-Programms und der ILO-Konvention Nr. 159 entspricht.

Die enge Gefolgschaft der chinesischen Behindertengesetzgebung zu den internationalen Konventionen ergibt sich im gewissen Maße aus dem aktiven Vorantreiben des im Jahre 1988 gegründeten Chinesischen Behindertenverbandes (CDPF) und des Verbandführers. ${ }^{157}$ Der CDPF wird als eine öffentliche Körperschaft von der Regierung

152 安全科学技术研究中心, 加入职业安全卫生及工作环境公约的可行性研究报告 (Forschungszentrum für Technik und Arbeitssicherheit, Bericht über die Ratifikationsmöglichkeit der ILOKonvention Nr. 155), S. 51.

$153 I L O$, 中国职业安全卫生概况 (National Profile Report on Occupational Safety and Health in China), S. 4.

154 Siehe: 王纪元, 仅有经济增长不足以保障社会公平与正义 (Wang, Jiyuan, Soziale Gerechtigkeit kann nicht lediglich durch die Wirtschaftsentwicklung gewährleistet werden), in: 石美遐/ Stearns, 全球化背景下的国际劳工标准与劳动法研究 (Shi/Stearns, Untersuchung der internationalen Arbeitsstandards und des Arbeitsrechts unter dem Einfluss der Globalisierung), S. 8; 崔乃夫，关于中 华人民共和国残疾人保障法 (草案) 的说明 (Cui, Naifu, Erklärung über den Entwurf des Gesetzes zum Schutz von behinderten Menschen der Volksrepublik China), vom 25. 10. 1990, http://www.lawbook.com.cn/fzdt/newshtml/20/20050722194037.htm (Stand: 15. 07. 2010).

155 Art. 2 der Konvention Nr. 159.

156 崔乃夫, 关于中华人民共和国残疾人保障法 (草案) 的说明 (Cui, Naifu, Erklärung über den Entwurf des Gesetzes zum Schutz von behinderten Menschen der Volksrepublik China), vom 25. 10. 1990.

157 王纪元, 仅有经济增长不足以保障社会公平与正义 (Wang, Jiyuan, Soziale Gerechtigkeit kann nicht lediglich durch die Wirtschaftsentwicklung gewährleistet werden ), in: 石美遐/ Stearns, 全球 
beauftragt, das Behindertenwesen durchzuführen. ${ }^{158}$ Er nimmt auch aktiv an der Entwurfsarbeit des Behindertengesetzes teil. ${ }^{159}$ Die ungewöhnliche Aktivität dieses Verbands und seine sehr aktive Position zur Verknüpfung mit internationalen Standards des Behindertenwesens ist eine Seltenheit in China. Kaum ein anderes chinesisches Gesetz hat in diesem Ausmaß von den internationalen Erfahrungen profitiert.

\section{Einflussanalyse}

Zusammenfassend lässt sich sagen, dass bei der Einsetzung der Sozialstandards in China die ILO seit den 1980er Jahren hauptsächlich im Bereich der technischen Arbeitsstandards Erfolge erlangt hat. Bisher wurden noch keine wichtigen Konventionen über soziale Sicherung von China ratifiziert. Trotzdem haben die ILO-Normen über soziale Sicherheit in China zum Aufbau eines Rahmens der sozialen Sicherungen - die insbesondere die abhängige Arbeit betreffen - beigetragen. Bei der Ausarbeitung der arbeits- und sozialrechtlichen Regelungen, wie bei dem Arbeitsgesetz, den Arbeitsunfallregeln und dem Behindertengesetz, wurden die ILO-Standards besonders berücksichtigt. Die Forderung der ILO, „Soziale Sicherheit für alle“ als Ziel der staatlichen Strategie durchzuführen, hat auch ein entsprechendes Äquivalent in den chinesischen sozialpolitischen Entscheidungen wie z. B. das Motto „Jeder soll soziale Sicherheit genießen". 160

Im Vergleich mit der Rezeption der Menschenrechtskonventionen, die im Wesentlichen prinzipielle Regelungen enthalten, wird die Einführung der internationalen Sozialstandards durch wirtschaftliche und gesellschaftliche Bedingungen beschränkt. Je konkreter und höher die Standards sind, desto geringer werden die Ratifikationsmöglichkeiten in den Mitgliedstaaten. Die geringe Ratifizierungsrate der ILO-Standards über soziale Sicherheit ${ }^{161}$ zeigt, dass die Standardniveaus für die Entwicklungsländer zu konkret und/oder zu hoch sind. Diese Situation kann nicht lediglich durch Beratung und technische Hilfe der ILO an die Mitglieder (hauptsächlich an die Entwicklungsländer) verbessert werden. Demzufolge hat China im Wesentlichen nur die ILO-Standardrahmen und die grundsätzlichen Prinzipien akzeptiert. Die konkreten Modelle und Leistungsniveaus hat der Staat eigenständig entschieden.

化背景下的国际劳工标准与劳动法研究 (Shi/Stearns, Untersuchung der internationalen Arbeitsstandards und des Arbeitsrechts unter dem Einfluss der Globalisierung), S. 8.

$158 \S 8$ des Gesetzes zum Schutz von behinderten Menschen von 1990.

159 崔乃夫, 关于中华人民共和国残疾人保障法 (草案) 的说明 (Cui, Naifu, Erklärung über den Entwurf des Gesetzes zum Schutz von behinderten Menschen der Volksrepublik China), vom 25. 10. 1990.

160 胡锦涛, 在中国共产党第十七次全国代表大会上的报告 $(H u$, Jintao, Bericht auf dem 17. Parteitag der KP Chinas), vom 15. 10. 2007, in: 人民日报 (RMRB), 25. 10. 2007.

161 Die Konvention Nr. 102 über die soziale Sicherheit wurde bis jetzt nur von 46, die Konvention Nr. 130 über ärztliche Betreuung und Krankengeld von 15 und die Konvention Nr. 168 über Beschäftigungsförderung von 7 der insgesamt 178 ILO-Mitgliedsstaaten ratifiziert, http://www.ilo.org/ilolex/english/newratframeE.htm (Stand: 15. 07. 2010). 
Die Umsetzung der oben erwähnten Prinzipien, Rahmen und Standards der sozialen Sicherheit in China wird durch die Aktivitäten der internationalen Organisationen gefördert. Im Hinblick auf die rasanten Entwicklungen Chinas in der internationalen Wirtschaft und in den internationalen Beziehungen haben die UNO und ihre untergeordneten Organisationen mit den Bretton-Woods-Institutionen in den letzten zwanzig Jahren ihre China-Aktivitäten erheblich verstärkt. Dafür geben die zunehmende Globalisierung und die Öffnungspolitik der Volksrepublik China auch eine günstige Gelegenheit.

Die internationalen Organisationen haben seit den 1990er Jahren durch fachliche Beratung, technische Hilfe sowie finanzielle Unterstützung in den Umbau der chinesischen sozialen Sicherheit tief eingegriffen. In der Praxis allerdings, insbesondere beim Aufbau der Rentenversicherung kann der Einfluss der internationalen Organisationen nicht immer als positiv bewertet werden.

\section{Aktionsprogramme der UNO-Organisationen in China}

Seit 1979 richteten die UNO-Organisationen jeweils Büros in China ein und widmen sich auf verschiedene Weise bei der Transformation Chinas. Die UNDP (United Nation Development Programme) arbeitet ab 1982 China-Landesprogramme aus, bisher wurden schon sechs Country Programme/Country Cooperation Frameworks in China durchgeführt.

Das Resident-Coordinator-System in China umfasst zurzeit 21 Organisationen einschließlich der Bretton-Woods-Institutionen. Jede Organisation hat ihre eigenen Aufgaben und Programme. Von 1961 bis 2000 hatten die UNO vier Entwicklungsdekaden ausgearbeitet. Die von den UNO-Organisationen angestrebten Entwicklungsstrategien und Ziele wurden allerdings oft nur ungenügend erfüllt. ${ }^{162}$ Im Jahre 1997 forderte der ehemalige UNO-Generalsekretär Kofi Annan die UNO-Organisationen auf - als ein Teil der UNO-Reform 163 - die Strategien und Aktivitäten der verschiedenen Kooperationsbereiche auf der Nationsebene zu koordinieren, um eine gemeinsame Entwicklung zu erreichen. ${ }^{164}$ Dies wird in den folgenden Jahren in den Development Assistance Framework (UNDAF), die von der chinesischen Regierung und dem UNO-ResidentCoordinator-System zusammen veröffentlicht werden, artikuliert. Die Aktivitäten der UNO-Organisationen in China werden seitdem einheitlich innerhalb der UNO-

162 Ausführlich vgl. Köhler, Sozialpolitische und sozialrechtliche Aktivitäten in den Vereinten Nationen, S. 555ff.

163 In seinem Bericht vom 14. Juli 1997 „Renewing the United Nations: A Programme for Reform“ (A/51/950) forderte Annan die Schaffung der Koordination der Aktivitäten der verschiedenen UNOBereiche.

164 Siehe: United Nations Development Assistance Framework for the People's Republic of China (2006-2010), S. 1. 
Organisationen organisiert, dadurch werden unnötige Wiederholungen vermieden und die Zusammenarbeit der UNO-Organisationen verstärkt.

Für die Koordinationsarbeit sind die UNDP und das UNO-Landesteam, die sich aus den Vertretern aller UNO-Organisationen zusammensetzen, zuständig. Das UNOLandesteam, das aus sechs Themengruppen und drei Management-Teams besteht, veröffentlicht die Gemeinsamen Landesbewertungen (Common Country Assessment). Auf dieser Grundlage werden die Aktionsstrategien in den UNDAF ausgearbeitet, dabei werden die Ziele und die wichtigsten Arbeitsbereiche in einem bestimmten Zeitraum gestellt. Darüber hinaus beaufsichtigt es durch die häufigen Treffen und Dialoge der Mitglieder die Umsetzung der Programme und Projekte und unterbreitet auch Vorschläge für die notwendigen Verbesserungen der UNDAP. 165

\section{Gemeinsame Aktionen der UNO-Organisationen}

a) Millenniums-Entwicklungsziele und „Gesellschaft des Kleinen Wohlstands“

Im Jahre 2000 verabschiedeten die 189 Mitgliedsländer der UNO gemeinsam eine Millenniumserklärung und verpflichteten sich, bis 2015 acht MillenniumsEntwicklungsziele zu erreichen: 166

- extreme Armut und Hunger beseitigen,

- Grundschulausbildung für alle Kinder gewährleisten,

- Gleichstellung und größeren Einfluss der Frauen fördern,

- die Kindersterblichkeit senken,

- die Gesundheit der Mütter verbessern,

- $\quad$ HIV/AIDS, Malaria und andere Krankheiten bekämpfen,

- $\quad$ eine nachhaltige Umwelt gewährleisten,

- $\quad$ eine globale Partnerschaft im Dienst der Entwicklung schaffen.

Die Millenniums-Entwicklungsziele bilden seitdem als Kern der globalen Agenda einen gemeinsamen Rahmen für die Zielsetzungen der UNO-Organisationen.

Gleichzeitig erfahren die chinesischen wirtschaftlichen und gesellschaftlichen Entwicklungen eine wichtige Wendephase. Die rasante Polarisierung zwischen Arm und Reich, die Disparitäten zwischen Stadt und Land und die regionalen Entwicklungsdisparitäten müssen durch einheitliche und umfassende Regulierung angeglichen werden. Im Bericht des 16. Parteitags der KP Chinas ${ }^{167}$ von 2002 wurde das Staatsziel, bis 2020

165 Siehe: United Nations Resident Coordinator in China, UN Partnership in China, Balancing Development to Achieve Xiaokang and Millennium Development Goals, 2006; UNDP China, Supports growth with equity, gender equality and environmental sustainability, 2003.

166 Siehe: United Nations Resident Coordinator in China, UN Partnership in China, Balancing Development to Achieve Xiaokang and Millennium Development Goals, S. 6.

167 江泽民在中国共产党第十六次全国代表大会上的报告 (Jiang, Zemin, Bericht auf dem 16. Parteitag der KP Chinas). 
eine „Gesellschaft des Kleinen Wohlstands"168 allseitig aufzubauen, mit folgenden konkreten Zielsetzungen aufgestellt:

- $\quad$ Vervierfachung des BSP von 2000,

- Vervollkommnung der Industrialisierung und der sozialistischen Marktwirtschaft, Verbesserung des Lebensstandards der Bevölkerung,

- Vervollständigung der sozialistischen Demokratie und Rechtsstaatlichkeit,

- Aufbau eines Systems für sozialen Sicherheit, Beschäftigung, Bildungswesen, Gesundheitswesen,

- $\quad$ Nachhaltige Entwicklungsfähigkeit des Staates.

Das UNO-Landesteam ist der Meinung, dass der chinesische Begriff „Gesellschaft des allseitigen Kleinen Wohlstands“ und die Millenniumserklärung beide „menschenorientiert (people-centred)" sind. 169 Wegen dieser Konvergenzen zwischen den Millenniums-Entwickungszielen und den politischen Zielen der „Gesellschaft des Kleinen Wohlstands" 170 wird diese Wendephase vom UNO-System als eine ,unprecedented opportunity"171 für die Erweiterung des Einflusses der UNO in China angesehen. Aus diesem Grund hat das UNO-Landesteam eine engere Verknüpfung zwischen den Aktivitäten der UNO-Organisationen und den Entwicklungsstrategien sowie -planungen der chinesischen Regierung geschaffen. Es versucht durch technische Hilfe, politischen Dialog, Forschungsarbeit sowie Propaganda die Kooperationen mit den chinesischen Regierungsorganisationen, NGOs und Forschungsinstitutionen zu verstärken.

Die Bekämpfung von Armut und sozialer Ungleichheit wird als die deutlichste Ähnlichkeit zwischen den China- und UNO-Zielsetzungen 172 und als der wichtigste Kooperationsbereich ${ }^{173}$ bezeichnet. Dafür hat das UNO-Team wirtschafts- und sozialpolitische Beratungen ausgearbeitet, ${ }^{174}$ um die ,tieferen strukturellen und sozialkulturellen

168 Über „Kleinen Wohlstand“ siehe: Erster Teil: die traditionelle Sozialstruktur und Kultur, die Strategie der sozialistischen Modernisierung.

169 United Nations Resident Coordinator in China, UN Partnership in China, Balancing Development to Achieve Xiaokang and Millennium Development Goals, S. 6:

„Das “menschenorientierte” Prinzip bedeutet: bei allem den Menschen in den Mittelpunkt zu stellen. Dieser aus der traditionellen chinesischen Kultur stammende Begriff wird zurzeit als der Kern des modernen Konzepts ,wissenschaftliche Entwicklung“ betrachtet. Das menschenorientierte Prinzip ist die Grundlage für das Gedanke, dass die Regulierungen in den Bereichen Beschäftigung, Einkommensverteilung, Sozialabsicherung, medizinische Betreuung und Bildung tatkräftig gefördert werden sollen, damit das ganze Volk die Errungenschaften der Reform und Entwicklung genieBen kann.“

170 UN Country Team in China, Common Country Assessment 2004, Balancing Development to Achieve An All-Round Xiaokang and Harmonious Society in China.

171 United Nations Resident Coordinator in China, UN Partnership in China, Balancing Development to Achieve Xiaokang and Millennium Development Goals, S. 4.

172 United Nations Resident Coordinator in China, UN Partnership in China, Balancing Development to Achieve Xiaokang and Millennium Development Goals, S. 8.

173 United Nations Development Assistance Framework for the People's Republic of China (20062010), S. 17.

174 UN Country Team in China, Common Country Assessment 2004, Balancing Development to Achieve An All-Round Xiaokang and Harmonious Society in China, Chapter 2: Balancing Economic Growth and Social Development, S. 9 ff. 
Ungleichheiten "175 zu beseitigen. Die meisten Kooperationsarbeiten wurden diesem Ziel entsprechend ausgeführt. Sozialpolitisch relevant sind die Kooperationen in den Bereichen von Bildungswesen einschließlich Berufsbildung für Arbeitslose, Wanderarbeiter und Absolventen, aktiver Beschäftigungspolitik, Gesundheitssicherung, Erweiterung der Deckungsrate der sozialen Sicherung sowie Schutz für sozial schwache Menschengruppen. ${ }^{176}$

\section{b) UNDAF und Fünfjahrespläne}

Die langfristigen Ziele der UNO werden im Rahmen des UNDAF (United Nations Development Assistance Framework) durch die kurz- und mittelfristigen Planungen umgesetzt. Im Vergleich mit der außergewöhnlichen Konvergenz zwischen den Millenniums-Entwicklungszielen und der „Gesellschaft des Kleinen Wohlstands“ basiert der UNDAF von Anfang an auf den Gemeinsamen Landesbewertungen (Common Country Assessment) und auf den chinesischen Fünfjahresplänen für die volkswirtschaftliche und gesellschaftliche Entwicklung, um eine engere Verknüpfung mit den chinesischen staatlichen Planungen zu erreichen, damit die UNO-Organisationen ihre Aktivitäten auf die Programme, die große Wirkung auf die politische Entwicklung Chinas ausüben können, konzentrieren können.

Der UNDAF für China wird dem Zeitraum des chinesischen Fünfjahresplans entsprechend ausgearbeitet. Der erste UNDAF (UNDAF 2001-2005) wurde im Jahre 2000 veröffentlicht. Davor hat das UNO-Team sich mit der chinesischen Regierung und den anderen Kooperationspartnern über die Arbeitsziele und die zu ergreifenden Maßnahmen beraten. Der UNDAF (2001-2005) enthält fünf vorrangige Themen, die als Hauptbereiche der UNO-Entwicklungshilfe fungieren: 177

- Armutsbekämpfung,

- Aufbau des Rechtsstaats,

- Beseitigung von Geschlechterdiskriminierung,

- $\quad$ Soziale Sicherheit,

- $\quad$ Umweltschutz.

Bei diesen Themen handelt es sich hauptsächlich um soziale Fragen, bei denen im gegenwärtigen Entwicklungsprozess Chinas große Umwandlungen bevorstehen. Die UNO-Vorschläge sind derart konzipiert, dass sie in dem 10. Fünfjahresplan (20012005) jeweils Äquivalente (außer der Beseitigung von Geschlechterdiskriminierung) im Kapitel 3 (Landwirtschaft), Kapitel 15 (Umweltschutz), Kapitel 18 (Beschäftigungsför-

175 United Nations Resident Coordinator in China, UN Partnership in China, Balancing Development to Achieve Xiaokang and Millennium Development Goals, S. 8.

176 United Nations Resident Coordinator in China, UN Partnership in China, Balancing Development to Achieve Xiaokang and Millennium Development Goals, S. 8-15.

177 United Nations Development Assistance Framework for the People's Republic of China (20012005) (Auszüge), http://www.nwccw.gov.cn/html/51/n-126851.html (Stand: 15. 07. 2010). 
derung und soziale Sicherheit) und Kapitel 23 (Aufbau eines sozialistischen Rechtsstaats) haben. 178

Als wichtiger Arbeitsbereich der Regierung wurde der Aufbau der sozialen Sicherungssysteme in den bisherigen Fünfjahresplänen kontinuierlich einbezogen: Der Rahmen der sozialen Sicherheit wurde im 9. Fünfjahresplan vorgelegt. Im 10. Fünfjahresplan liegt der Arbeitsschwerpunkt der chinesischen Regierung in der Einrichtung und Vervollkommnung der Sozialversicherung für die Beschäftigten der städtischen Unternehmen. Im 11. Fünfjahresplan (2006-2010) wurde soziale Sicherheit mit der „Erhöhung des Lebensniveaus des Volkes“ (Kapitel 39) neben Beschäftigungsförderung, Einkommensverteilung, Armutsbekämpfung aufgenommen und damit ein anfänglicher Rahmen der chinesischen Sozialpolitik gestaltet. Die Arbeitsschwerpunkte in diesem Zeitraum sind die Erweiterung des Deckungsbereichs der Sozialversicherung und der Sozialhilfe sowie die Erhöhung der Leistungsniveaus.

Diese Entwicklung in den offiziellen Plänen, dass soziale Sicherheit wichtiger wird und expandiert, erscheint auch in den UNDAF-Dokumenten. Im UNDAF (2001-2005) wurden die von den wirtschaftlichen und gesellschaftlichen Veränderungen verursachten neuen Sozialrisiken und die Konstruierung der neuen Sicherungssysteme für alle Bürger erwähnt. Später wurden die Notwendigkeit der Erweiterung des Deckungsbereiches und die Nachhaltigkeit der sozialen Sicherheit in der Gemeinsamen Landesbewertung 2004 dargestellt, ${ }^{179}$ die wichtigsten Bereiche der internationalen Kooperation sind die Einbeziehung der schwachen Bevölkerungsgruppen in die Sozialleistungssysteme und der Aufbau einer Verwaltung für den Schutz der schwachen Bevölkerungsgruppen. Der Arbeitsschwerpunkt der Gemeinsamen Landesbewertung 2004 liegt in der Verbesserung des Gesetzes zum Schutz von behinderten Menschen. ${ }^{180}$ Im UNDAF (20062010) wurde die Erweiterung des Deckungsbereiches der sozialen Sicherung als ein Schwerpunkt der Kooperationsarbeit für „Promoting growth with equity by reducing disparities, balancing economic and social development and focusing on poverty reduction" bezeichnet. 181

Wie oben gezeigt, entspricht der Rahmen der UNO-Entwicklungshilfen den chinesischen staatlichen Planungen, aber die Vorschläge gehen weiter als die Fünfjahrespläne. Die Ziele werden im größeren Zusammenhang von Wirtschaft und Gesellschaft gesehen und als umfassende Lösungspläne gefördert. Kennzeichnend für die UNO-Vorschläge sind deren langfristige und leitungsorientierte Perspektive.

178 国民经济和社会发展第十个五年计划 (Der 10. Fünfjahresplan für die volkswirtschaftliche und gesellschaftliche Entwicklung 2001-2005), gebilligt vom NVK am 15. 03. 2001.

179 UN Country Team in China, Common Country Assessment 2004, Balancing Development to Achieve An All-Round Xiaokang and Harmonious Society in China, Chapter 4: Social Protection, S. $27 \mathrm{ff}$.

180 Siehe: United Nations Development Assistance Framework for the People's Republic of China (2006-2010), S. 31.

181 UN Country Team in China, Common Country Assessment 2004, Balancing Development to Achieve An All-Round Xiaokang and Harmonious Society in China, Chapter 4: Social Protection, S. 31. 
Diese Merkmale manifestieren sich deutlicher und konkreter im UNO-Beitrag zur gesellschaftlichen Entwicklung des 11. Fünfjahresplans (2006-2010). ${ }^{182}$ In diesem Beitrag wurde die Beziehung zwischen Wirtschaftswachstum, Armut und gesellschaftlicher Entwicklung aufgrund der Gemeinsamen Landesbewertung 2004 ausführlich analysiert. Auf dieser Basis versuchte das UNO-Landesteam, politische Beratungen bezüglich der Herausforderungen und Probleme der gesellschaftlichen Entwicklung durchzuführen. Dabei handelt es sich um Gesundheit, Bildung, Beschäftigung, soziale Sicherheit und HIV/AIDS. Sozialpolitisch relevant sind die folgenden Themen:

Für den Aufbau eines nachhaltigen Systems der sozialen Sicherheit sollen die Bauern, Arbeiter in Dorfunternehmen und im informellen Sektor sowie in flexiblen Arbeitsformen in die soziale Sicherung einbezogen werden. Die lokalen Behörden für soziale Sicherheit sollen expandieren. Finanzielle Quellen für die Übergangskosten und die geplanten Kosten sind aufzufinden. Ein Umverteilungsmechanismus auf der Nationalebene soll errichtet werden. Systeme für Statistik, finanzielle Information und Planung sind nach den ILO-Standards aufzubauen, dafür müssen die Ratifikation und Durchführung der ILO-Standards gefördert werden. ${ }^{183}$ Ferner ist ein soziales Sicherungssystem für die ländliche Bevölkerung aufzubauen, das die Sicherung des Existenzminimums auf dem Land, soziale Altersversicherung und Krankheitsversicherung umfasst. ${ }^{184}$ Für die Wanderarbeiter sind Alters- und Krankheitsversicherungen aufzubauen, deren Kinder ist Bildung zu gewähren und der Arbeitschutz für die Wanderarbeiter sind zu optimieren. ${ }^{185}$ Das Gesetz zum Schutz von behinderten Menschen und die Integration der Standards für Behinderte sind zu verbessern. ${ }^{186}$ Die Beschäftigungsförderung ist aufgrund der „Decent Work Agenda“ der ILO zu praktizieren. ${ }^{187}$ Eine öffentliche Gesundheitsversorgung für alle Bürger wird allein von der Regierung unterstützt und die grundlegenden medizinischen Dienstleistungen werden von der Krankenversicherung finanziert. ${ }^{188}$

Im 11. Fünfjahresplan (2006-2010) der Volksrepublik China sind die Arbeitsschwerpunkte der Regierung über die soziale Sicherung in den künftigen fünf Jahren wie folgt festgelegt:

Ausweitung des Deckungsbereichs der sozialen Sicherheit (Kapitel 3),

182 UN Coutry Team China, Advancing Social Development in China, Contribution to the 11th Year Plan, Occasional Paper, Vol. 1, 10/2005.

183 UN Coutry Team China, Advancing Social Development in China, Contribution to the 11th Year Plan, Occasional Paper, Vol. 1, 10/2005, S. 18-19.

184 UN Coutry Team China, Advancing Social Development in China, Contribution to the 11th Year Plan, Occasional Paper, Vol. 1, 10/2005, S. 19.

185 UN Coutry Team China, Advancing Social Development in China, Contribution to the 11th Year Plan, Occasional Paper, Vol. 1, 10/2005, S. 19.

186 UN Coutry Team China, Advancing Social Development in China, Contribution to the 11th Year Plan, Occasional Paper, Vol. 1, 10/2005, S. 19.

187 UN Coutry Team China, Advancing Social Development in China, Contribution to the 11th Year Plan, Occasional Paper, Vol. 1, 10/2005, S. 14-15.

188 UN Coutry Team China, Advancing Social Development in China, Contribution to the 11th Year Plan, Occasional Paper, Vol. 1, 10/2005, S. 8-9. 
- $\quad$ Aufbau sozialer Sicherungssysteme für die ländliche Bevölkerung (Kapitel 6),

- besondere Schutzmaßnahmen für Frauen, Kinder und behinderte Menschen (Kapitel 38),

- $\quad$ aktive Beschäftigungspolitik (Kapitel 39),

- Verbesserung der öffentlichen Gesundheitsversorgung und der medizinischen Dienstleistungen (Kapitel 40).

Wie oben gezeigt, existiert zwischen den derzeitigen chinesischen sozialpolitischen Entwicklungszielen und den UNO-Beratungen eine hohe Übereinstimmung. Es lässt sich jedoch nicht feststellen, dass die derzeitige chinesische Sozialpolitik von den UNOBeratungen beeinflusst wurde, da es an einer offiziellen Stellungnahme fehlt. Allerdings zeigen die beiden Dokumenten zumindest Ähnlichkeiten von Ansichten der chinesischen Regierung und des UNO-Landesteams über den Zustand und die Konstruierung der sozialen Sicherheit. Mit dieser Übereinstimmung haben die UNO-Organisationen mehr Möglichkeiten, an dem konkreten Systemaufbau mitzuwirken, als bei der Debatte um die grundlegenden Staatsprinzipien.

\section{Einzelne Aktivitäten der UNO-Organisationen}

Im Rahmen der gemeinsamen Ziele und Aktivitäten beschäftigen sich die UNOOrganisationen in verschiedenen sozialen Bereichen mit unterschiedlichen Arbeitsschwerpunkten. Z. B. widmet sich die ILO den Arbeitsbedingungen, der Gleichstellung, der Beschäftigungsförderung und der sozialen Sicherung. Die Weltbank beschäftigt sich mit der Armutsbekämpfung und der Rentenversicherung. Wie der Name vermuten lässt, befasst sich die WHO mit der öffentlichen Gesundheitsversorgung. Es gibt keine klare Kompetenzabgrenzung zwischen den betreffenden Organisationen. Aus verschiedenen Gründen sind der Umfang und das Niveau ihres Einflusses unterschiedlich. Neben der ILO, die traditionell eine wichtige Rolle im Bereich der Sozialversicherung spielt, bewährt sich die Weltbank auch als ein sehr aktiver Teilnehmer in der Reform der chinesischen sozialen Sicherheit wie in anderen Transformations- und Entwicklungsländern.

\section{a) Aktivitäten der ILO}

Seit der Mitte der 1980er Jahre beteiligt sich die ILO in enger Kooperation mit der chinesischen Regierung an der Umstrukturierung und Entwicklung der sozialen Sicherheit. Ihr Arbeitsschwerpunkt lag in den frühen 1990er Jahren hauptsächlich auf Projekten für den Kapazitätsaufbau, seit Mitte der 1990er Jahre auf der Gesetzgebung und der Politik. Aufgrund einer umfassenden Untersuchung konzentriert die ILO ihre Förderung zurzeit auf die Strukturregulierung und Ausweitung des Deckungsbereiches der sozialen Sicherung in enger Verknüpfung mit der Beschäftigungsförderung, die im Rahmen der Decent Work Agenda durch die vielfältigen technischen Hilfen zusammen durchgeführt werden. 189

189 Ausführlich: ILO, An Employment Agenda for China, S. 83ff. 


\section{(1) Die Decent Work Agenda}

Um ihre führende Rolle bei der Meinungsbildung im Bereich der Beschäftigungsund Sozialpolitik im Zuge der zunehmenden Globalisierung weiter zu behalten, hat die ILO sich bemüht, außer der stetigen Ausweitung ihrer Kompetenzbereiche und Aktionsfelder im Rahmen der gemeinsamen Aktionen der UNO-Organisationen ein eigenes Aktionsprogramm aufzubauen. Die Veröffentlichung der „Erklärung über die grundlegenden Prinzipien und Rechte bei der Arbeit“ im Jahre 1998 unterstreicht die Kernarbeitsnormen als Grundprinzipien der ILO-Aktivitäten im Zeitalter der Globalisierung. Diese werden auch nochmals mit der Decent Work Agenda seit 1999 bekräftigt. 190

Mit der Decent Work Agenda hat die ILO ihre Aufgaben auf vier strategische Ziele ausgerichtet: 191

- Förderung und Umsetzung der Internationalen Arbeitsstandards und Arbeitnehmerrechte,

- $\quad$ Schaffung von mehreren und besseren menschenwürdigen Beschäftigungsmöglichkeiten,

- Ausbau der sozialen Sicherheit,

- $\quad$ Stärkung des sozialen Dialogs.

Im Bericht des International Labour Office von 2004 - „A fair globalization, the role of the ILO" - wurde ferner vorgeschlagen, dass menschenwürdige Arbeit ein von allen Staaten und der internationalen Gemeinschaft verfolgtes globales Ziel werden sollte, um eine faire Globalisierung, die Chancen für alle schafft, zu erreichen. ${ }^{192}$ Aufgrund dieses Berichts wurde die Decent Work Agenda als eines der zentralen Ziele der ILOPolitik festgelegt. Danach wurde diese Agenda in verschiedene Programme der internationalen Organisationen integriert. Seit 2008 wurde sie in die MillenniumsEntwicklungsziele der UNO aufgenommen und als effektives Mittel zur Armutsbekämpfung anerkannt.

Nach einem Rundschreiben der ILO im Jahre 2004193 wird ein umfassendes Aktionsprogramm für menschenwürdige Arbeit für die einzelnen Länder (Decent Work Country Programme, DWCPs) erarbeitet, um Decent Work als einen wesentlichern Bestandteil der nationalen Entwicklungspolitik zu fördern. Die ILO-DWCP in der Volksrepublik China wird aufgrund der im Jahre 2001 unterzeichneten Vereinbarung (Memorandums of Understanding, MOU) zwischen dem damaligen Ministerium für Arbeit und soziale Sicherheit und der ILO sowie des 11. Fünfjahresplans ausgearbeitet. Hierfür

190 Siehe: International Labour Conference 2007, Fifth Item on the Agenda: Strengtheming the ILO's capacity to assist its Members' efforts to reach its objectives in the context of globalization, S. viii.

191 International Labour Conference 1999, Report of the Director-General: Decent Work, 1999, http://www.ilo.org/public/english/standards/relm/ilc/ilc87/rep-i.htm (Stand: 15. 07. 2010).

192 International Labour Conference, Report of the Director-General on the World Commission on the Social Dimension of Globalization: A fair Globalization, the Role of the ILO, S. 3.

193 ILO Circular No. 599, Series 1, vom 20. 05. 2004. 
werden die UNDAF und die ILO-Programme der technischen Zusammenarbeit in Erwägung gezogen. ${ }^{194}$

\section{(2) Kooperationsprogramme in China: MOU und DWCP}

Am 17. 05. 2001 unterzeichneten das Ministerium für Arbeit und soziale Sicherheit und die ILO ein MOU über ihre Kooperation im Bereich der menschenwürdigen Arbeit. 195 Das Memorandum basiert auf der Decent Work Agenda und setzt die politischen Prioritäten für die Zusammenarbeit über die Durchführung der vier strategischen Ziele der menschenwürdigen Arbeit in China um. Die Zusammenarbeit umfasst ein breites Spektrum von Aktivitäten einschließlich politischer Konsultation, politischer Seminare, technischer Workshops, technischer Hilfe, Beratungen über Standards, Ausbildung, Forschung und Entwicklung von Projekten. 196

Die vier vereinbarten Prioritätsbereiche sind:

- $\quad$ internationale Arbeitsstandards und die ILO-Erklärung über die grundlegenden Prinzipien und Rechte bei der Arbeit,

- Beschäftigung,

- $\quad$ Sozialschutz,

- $\quad$ sozialer Dialog.

Die Zusammenarbeit im Bereich der sozialen Sicherheit wurde hauptsächlich in den folgenden acht Bereichen entfaltet: 197

- $\quad$ Beratung und Unterstützung für die politischen Fragen über soziale Sicherheit, einschließlich der Gesetzgebungsarbeit und der Ausführung von Pilotprogrammen,

- Förderung der Ausweitung der Deckungsrate der sozialen Sicherungssysteme, einschließlich der Verbesserung des sozialen Schutzes für die schwachen Personengruppen,

- Verbesserung der Verwaltung der sozialen Sicherungssysteme, insbesondere die Einhaltung der Regelungen; die Sozialversicherungsfonds, die Auszahlung von Leistungen und die betriebliche Altersversicherung,

- Verbesserung der Arbeitslosensicherung, einschließlich der Integration der Arbeitslosenversicherung mit der aktiven Arbeitsmarktpolitik,

- Förderung der Krankenversicherungsreform,

- $\quad$ Beratung und Unterstützung bei der Stärkung der beruflichen Sicherheit und Gesundheitsschutz am Arbeitsplatz, die auf Prävention, Schutz und Rehabilitation zielt, wobei die gefährlichen Arbeitsbedingungen besonders berücksichtigt werden,

194 Siehe: ILO, Decent Work Country Programme in the People's Republic of China 2006-2010, S. 1.

195 Memorandum of Understanding between MOLSS and the ILO, vom 17. 05. 2001, http://www.ilo.org/public/chinese/region/asro/beijing/info/memo.htm (Stand: 15. 07. 2010).

196 Siehe: ILO, Third Meeting of the Joint Committee on Cooperation, Review of activities under the Memorandum of Understanding, 05/2005, S. 2.

197 Memorandum of Understanding between MOLSS and the ILO von 2001. 
- Stärkung der Durchführung von Regeln über die Arbeitsunfallversicherung,

- $\quad$ Unterstützung der triparitätischen Anstrengungen zur Überprüfung und Stärkung der nationalen Sicherheits- und Gesundheitsprogramme.

Die Unterzeichung des Memorandums 2001 kennzeichnet die Festlegung der Zusammenarbeit der chinesischen Regierung mit der ILO im Rahmen der Decent Work Agenda. Allerdings wurden die Arbeitnehmer- und Arbeitgeber-Organisationen nicht in das Memorandum einbezogen. Erst im Jahre 2007 wurde das ILO-DWCP China (20062010), das aufgrund des MOU, des 11. Fünfjahresplans sowie der UNDAF ausgearbeitet wurde, von der ILO und den triparitärischen Partnern, nämlich der chinesischen Regierung, dem Allchinesischen Gewerkschaftsbund sowie der China Enterprise Confederation zusammen unterzeichnet. 198

In dem DWCP (2006-2010) wurde die Ausweitung und Verbesserung der sozialen Sicherheit weiterhin als eine der Prioritätsbereiche bezeichnet, die Zusammenarbeit konzentriert sich aber hauptsächlich auf die Beschäftigungsförderung. ${ }^{199}$ Beratung bei der Ausarbeitung des Beschäftigungsgesetzes, Bewertung der Auswirkungen der aktiven Beschäftigungspolitik sowie Förderungsaktionen für die benachteiligten Arbeitnehmergruppen einschließlich Behinderter, Jugendlicher, Alter, Frauen und Wanderarbeiter wurden als die wichtigsten Kooperationsbereiche betont. ${ }^{200}$ Für die Ausweitung der sozialen Sicherheit wurden folgende Kooperationsbereiche vorgebracht:

- Kapazitätsaufbau versicherungsmathematischer Services,

- Förderung und Verbreitung der bewährten Verfahren,

- Konsultation zum Sozialversicherungsrecht,

- Forschung über die Errichtung eines Rentensystems für die Wanderarbeiter,

- $\quad$ Forschung über die Verbindungen zwischen der Unfallversicherung und den OSH-Präventionsmaßnahmen.

\section{bb) Kooperationen}

(1) Aufbau und Ausweitung der Sozialversicherung

Die Kooperationsarbeit zwischen der chinesischen Regierung und der ILO hat erst mit der Errichtung des ILO-Beijing-Office seit Mitte der 1980er Jahren begonnen. Beim Aufbau der sozialen Versicherungssysteme - insbesondere im Bereich der Rentenversicherung - hat die ILO in den 1990er Jahren viel Forschung und Beratung in China

198 ILO, Decent Work Country Programme in the People's Republic of China 2006-2010, S. 1.

199 DWCP Priority Areas (2001-2006): 1. Promoting employment, employability and reducing inequalities with focus on unemployed and internal rural migrants. 2. Promoting harmonious labourmanagement relations and effectiveness of labour market institutions and labour laws. 3. Extension and improvement of social protection (social security, safe work, HIVAIDS). 4. Promoting workers rights and fundamental labour principles and rights. In: ILO, Decent Work Country Programme in the People's Republic of China 2006-2010, S. 5.

200 ILO, Decent Work Country Programme in the People's Republic of China 2006-2010, S. 7. 
durchgeführt. ${ }^{201}$ Allerdings entschied sich die chinesische Regierung inzwischen für ein Weltbank-Modell der Rentenversicherung.

Mit der Ausführung des MOU und DWCP konzentrierte sich die ILO hauptsächlich auf den Ausbau der sozialen Sicherungssysteme. ${ }^{202}$ Die Aktivität „Ausweitung der sozialen Sicherheit auf die städtischen informellen Arbeitnehmer und die ländliche Bevölkerung" wurde inzwischen umgesetzt. Die Arbeitsschwerpunkte lagen in der Forschung über die Finanzierung und die Deckung der sozialen Sicherheit in China, den strategischen Vorschlägen für die Ausweitung der städtischen und ländlichen Rentensysteme sowie dem Kapazitätsaufbau zur Ausweitung der sozialen Sicherheit. Aufgrund der Zusammenarbeit hat das Ministerium für Arbeit und soziale Sicherheit den Ausweitungsplan der sozialen Sicherheit in einen nationalen Bericht festgelegt. ${ }^{203}$ Später wurden der Ausbau der sozialen Sicherheit und die Ausweitung des Deckungsbereiches der Grundrentenversicherung in dem 11. Fünfjahresplan aufgenommen.

Außer der Forschungsarbeit und der technischen Hilfe für die Ausarbeitung des Sozialversicherungsgesetzes ${ }^{204}$ und die Reform der Rentenversicherung ${ }^{205}$ hat die ILO in diesem Zeitraum auch Unterstützungsarbeit für den Chinesischen Frauenverband $(\mathrm{ACWF})^{206}$ und den Chinesischen Behindertenverband (CDPF) ${ }^{207}$ durchgeführt.

\section{(2) Beschäftigungsförderung und soziale Sicherung}

Die Beschäftigungsförderung wird zurzeit von der ILO als ihre Kernarbeit in China angesehen. Außer den Konsultationen für die Ausarbeitung des Beschäftigungsförderungsgesetzes 208 und anderen Aktivitäten hat die ILO im Jahre 2004 zusammen mit dem Ministerium für Arbeit und soziale Sicherheit das China Employment Forum (CEF) als das wichtigste Projekt des MOU veranstaltet, um einen umfassenden strategischen Rahmen für die zukünftige chinesische Beschäftigungspolitik aufzustellen. In diesem Rahmen werden nicht nur die Beschäftigungsförderung und die mit der Beschäftigungspolitik eng verbundenen sozialen Sicherungsmaßnahmen, sondern auch der soziale Dialog, die berufliche Fortbildung, die Arbeitsmarktpolitik, die Arbeitssicherheit

201 高书生, 社会保障改革何去何从 (Gao, Shusheng, Die Reform der sozialen Sicherheit steht am Scheideweg), S. 82, 83, 167.

202 ILO, Third Meeting of the Joint Committee on Cooperation, Review of activities under the Memorandum of Understanding, 05/2005, S. 18, http://www.ilo.org/public/chinese/region/asro/beijing/download/mou_impl.pdf (Stand: 15. 07. 2010).

203 ILO Third Meeting of the Joint Committee on Cooperation, Review of activities under the Memorandum of Understanding, 05/2005, S. $18 \mathrm{ff}$.

204 ILO, Decent Work Country Programme in the People's Republic of China 2006-2010, S. 11.

205 ILO, Decent Work in Asia: Reporting on results 2001-2005, S. 67; ILO, Extending Old-age Insurance Coverage in the People's Republic of China, 01/2006, http://www.ilo.org/public/english/region/asro/beijing/download/training/old_insur.pdf (Stand: 15. 07. 2010).

206 ILO, Decent Work in Asia: Reporting on results 2001-2005, S. 40.

207 ILO, Decent Work in Asia: Reporting on results 2001-2005, S. 42.

208 ILO, Decent Work Country Programme in the People's Republic of China 2006-2010, S. 7. 
sowie der Umweltschutz als Bestandteile einer umfassenden Beschäftigungspolitik bezeichnet. $^{209}$

Diese Veranstaltung wurde von der ILO als „,complete success“ und „ein Meilenstein in der Geschichte der Zusammenarbeit zwischen China und der ILO" bezeichnet. ${ }^{210} \mathrm{Im}$ „Common Understanding of the China Employment Forum“211 wurden folgenden Übereinstimmungen erreichtet:

Beschäftigungsförderung als eine Kernaufgabe bei der Ausarbeitung der Wirtschafts- und Sozialpolitik sowie Maßnahmen für Armutsbekämpfung zu fördern,

- Beschäftigungsförderung mit der sozialen Sicherung zu verknüpfen,

- $\quad$ Reform und Ausbau der sozialen Sicherheit weiter durchzuführen.

Sie sind in dem 11. Fünfjahresplan niedergeschrieben ${ }^{212}$ und spiegeln die derzeitigen Leitgedanken der chinesischen Sozialpolitik wieder. Entsprechend wurden die Schwerpunktbereiche und die Strategien der China-ILO-Kooperation bei der Ausarbeitung des DWCP reguliert. Insbesondere wurden die Integration der städtischen und ländlichen Arbeitsmärkte und Sicherungssysteme ${ }^{213}$ sowie die Errichtung von Sicherungssystemen für die Wanderarbeiter und Bauern ${ }^{214}$ betont. Dies wurde auch als ein wichtiger Bestandteil des ersten prioritären Entwicklungsbereiches im UNDAF (20062010) festgeschrieben. 215

\section{b) Aktivitäten der Weltbank}

\section{aa) Aufgaben und Arbeitsweisen der Weltbank}

Die im Jahre 1944 zusammen mit dem Internationalen Währungsfonds (IMF) gegründete Weltbank beschäftigte sich nach dem zweiten Weltkrieg als unabhängige Sonderorganisation der UNO hauptsächlich mit dem Wiederaufbau. Seit den 1960er Jahren betrachtet sie die Armutsbekämpfung in der Welt - insbesondere in den Entwicklungsländern - als ihre Hauptaufgabe. Nach der Festlegung der Millenniums-Entwicklungsziele hat die Weltbank ihre Aufgaben diesen Zielen angepasst. Die Armutsbekämpfung stellt weiter die Kernaufgabe der Weltbank dar. Darüber hinaus bemüht sie sich, zusammen mit den anderen UNO-Organisationen, die Millenniums-Entwicklungsziele zu erreichen.

Als „Wissensbank“ und „Entwicklungsbank“ mischt die Weltbank sich nicht nur durch Kreditvergabe sondern auch durch Analyse, Beratung, technische Hilfe für Kapa-

209 ILO, China Employment Forum, Summary Proceedings, S. 59.

210 ILO, Third Meeting of the Joint Committee on Cooperation, Review of activities under the Memorandum of Understanding, 05/2005.

211 ILO, China Employment Forum, Summary Proceedings, S. 58ff.

212 Siehe: ILO, Decent Work Country Programme in the People's Republic of China 2006-2010, S. 4ff.

213 ILO, Decent Work Country Programme in the People's Republic of China 2006-2010, S. 6, 7, 11.

214 ILO, Decent Work Country Programme in the People's Republic of China 2006-2010, S. 6ff.

215 United Nations Development Assistance Framework for the People's Republic of China (20062010), S. 17. 
zitätsaufbau sowie globale Überwachung in die nationale Politik der Mitgliedstaaten ein. Sie veröffentlicht auch den Weltentwicklungsbericht und spezielle Länderberichte, die die übergreifenden aktuellen Entwicklungsthemen betreffen. Damit versucht die Weltbank ihre liberalen Wirtschaftsideen bei der Weltentwicklung zu verbreiten und hat eine bedeutende Rolle bei der Festlegung der Entwicklungsrichtung der Mitgliedstaaten gespielt. 216 Die Arbeitsbereiche der Weltbank umfassen Investitionsklima, Infrastruktur, Bildung, Gesundheit, Sozialschutz sowie nachhaltige Entwicklung.

In Afrika, Südamerika und den ehemaligen kommunistischen Ländern hat die Weltbank durch die wirtschaftliche Überwachung und die Gewährung von Darlehen sowie finanziellen Hilfen intensiven Einfluss auf die Wirtschafts- und Sozialpolitik dieser Länder ausgeübt. ${ }^{217}$ Diese Praxis der Weltbank wird allerdings wegen ihrer liberalen Färbung von manchen Wissenschaftlern und NGOs kritisiert. ${ }^{218}$ Die Privatisierung und die Marktwirtschaft zerstöre oftmals die eigene Wirtschaftsordnung der Entwicklungsländer. Die sozialpolitische Steuerung der Weltbank beschränke die Handlungsalternativen der Nationalstaaten, weil sie bestimmte Gestaltungen der sozialen Sicherungssysteme für die Kreditvergaben voraussetze. Auch wird kritisiert, 219 dass die USA die Bretton-Woods-Institutionen faktisch kontrolliere, und dass die Weltbank deshalb ein politisches Instrument sei, wodurch die USA ihre außenpolitischen Ziele erreiche.

\section{bb) Die Beziehung zwischen China und der Weltbank}

Die Kooperationsbeziehung zwischen der Weltbank und der Volksrepublik China wurde seit 1980 entwickelt. In diesem Jahr trat die Volksrepublik der Weltbank und dem IMF bei und nahm zugleich Konsultationen mit dem Weltbankpräsidenten auf. Dieses Ereignis wurde von beiden Seiten als sehr positiv bewertet. Für die Volksrepublik ist der Beitritt zur Weltbank ein Teil ihrer Öffnungspolitik, womit sie sich Zugang zur Quelle an Technik und Information verschaffen und sich andererseits der Welt öffnen kann. Der damalige Vize-Ministerpräsident Deng, Xiaoping äußerte gegenüber der Weltbank: ,We can do it with or without the Bank, but with you we can do it faster".220 Für die Weltbank ist dies eine große Chance, ihre liberalen Ideen in einen sozialistischen Staat einzuführen und mit dem Eintritt eines der größten Staaten der Welt eine wirkliche „Weltbank“" zu werden. 221

In den 1980er Jahren hat die Weltbank hohes Ansehen - hauptsächlich wegen ihrer umfassenden Forschungsarbeit und Länderberichte - in China genossen. Ihr erster und zweiter Länderbericht haben die große Aufmerksamkeit der Regierung an sich gezogen, manche Vorschläge im zweiten Bericht von 1985 (China: Long-Term Development Is-

216 Über die Rolle der Weltbank im Bereich der Sozialpolitik ausführlich vgl. Deacon, Global Social Policy \& Governance, S. 26ff.

217 Mishra, Globalization and the Welfare State, S. 123.

218 Vgl. Mishra, Globalization and the Welfare State, S. 124; Deacon, in: Hurrell/Woods (Hrsg.), Inequality, Globalization, and World Politics, S. 223ff.

219 Mishra, Globalization and the Welfare State, S. 124.

220 Zitiert nach: World Bank, China: An Evaluation of World Bank Assistance, S. 5.

221 World Bank, China: An Evaluation of World Bank Assistance, S. 5. 
sues and Options) wurden sogar nach der Anweisung des damaligen Ministerpräsidenten Zhao, Ziyang in den Fünfjahresplan aufgenommen. ${ }^{222}$ Die Beziehung mit der Volksrepublik China in den 1980er Jahren wurde von der Bank als „one of the most successful interactions of the World Bank with a borrower" und „one of the Bank's prouder achievements in the 1980" " bezeichnet. 223

Allerdings existieren in einer solchen Beziehung zwischen einem kommunistischen Staat und der Weltbank auch Verdächtigungen und Befürchtungen. In den frühen Jahren der Zusammenarbeit hatte die chinesische Regierung den Verdacht, dass die Weltbank eine ideologische Agenda in China verfolgen würde. Demgegenüber hatte die Weltbank die Befürchtung, dass sie von China ausgenutzt werden würde. Projekte oder Maßnahmen würden nur aufgrund der Zusicherung der Regierung durchgeführt und nicht aufgrund ihrer unabhängigen Untersuchung und Analyse. ${ }^{224}$ Dieses Problem war in den 1980er Jahren wegen den guten Beziehungen zwischen China und der USA und der positiven Bewertung der damaligen Staatsoberhäupter für die liberalen Ideen nicht sehr auffällig. Mit dem Tiananmen-Vorfall von 1989 ging diese ,successful interaction“ aber schließlich zu Ende. In diesem Jahr wurde die Kreditvergabe der Weltbank an China unterbrochen. ${ }^{225}$ Obwohl sie seit dem Jahr 1991 wieder hergestellt wurde, ist der Einfluss der Weltbank in China seit den 1990er Jahren stetig gesunken. Viele Forschungsberichte erhielten von der chinesischen Seite keine Aufmerksamkeit mehr. Nach $L u$, Mai existieren hierfür drei Gründe:226 Die Wissenskluft zwischen der Weltbank und den chinesischen Experten habe sich verringert, die Reform in den 1990er Jahren sei viel schwieriger als früher und die Bank benutze keine effektiven Methoden mehr, die in der Vergangenheit große Erfolge gebracht hätten.

In $L u$ 's Bericht wird dem politischen Faktor ausgewichen. In der Tat erhöhte China nach dem Tiananmen-Vorfall und dem Zerfall der Sowjetunion deutlich seine Wachsamkeit für die Infiltration der ausländischen Kräfte durch internationale Organisationen. Trotzdem vertrat China weiter einen positiven Standpunkt zur Öffnungspolitik, anstatt die Tür wieder zu schließen. Die Weltbank konnte deshalb weiter eine aktive Rolle in der chinesischen Reform und Entwicklung spielen, insbesondere in manchen Bereichen wie das makroökonomische Management, die Reform der Staatsunternehmen sowie die Reform der Systeme der sozialen Sicherheit.

Im Vergleich mit ihrer Arbeit in anderen Entwicklungsländern hat die Weltbank in China eine unterschiedliche Kombination ihrer verschiedenen Arbeitsweisen entwickelt. Zuerst spielt die Kreditvergabe allein keine bedeutende Rolle in diesem großen Staat obwohl China am Anfang der 1990er Jahre der größte Kreditnehmer der Weltbank war

222 Siehe: Lu, Mai, Evaluation of the Effectiveness of the World Bank's Analytical and Advisory Services to China since 1990, S. 2.

223 Kapur/Lewis/Webb, The World Bank: Its first half Century, Volume 1: History, S. 24, 25.

224 World Bank, China: An Evaluation of World Bank Assistance, S. 5.

225 World Bank, An Evaluation of World Bank Assistance, S. 6.

$226 \mathrm{Lu}, \mathrm{Mai}$, Evaluation of the Effectiveness of the World Bank's Analytical and Advisory Services to China since 1990, S. 12. 
(1994 erreichte das Darlehen \$ 3.3 Billionen), 227 hat die Auszahlungshöhe der Bank zu keinem Zeitpunkt 1\% des BSP Chinas überschritten. Nur in der Mitte der 1990er Jahre, weil damals die Regierung wegen der wirtschaftlichen Dezentralisierung in Finanzschwierigkeiten geriet, ${ }^{228}$ hatte die Kreditvergabe der Weltbank für einen kurzen Zeitraum einen spürbaren Beitrag zu den Haushaltsmitteln der Regierung. 229

Die Weltbank hat in ihrem China-Bewertungsbericht 2004 ihre Arbeitsmethoden ausführlich zusammengefasst. Sie wendet hauptsächlich ein „,dual-track-approach“ in China an: durch die Darlehen das Vertrauen der chinesischen Regierung zu bilden, während durch die Sektorarbeit der politische Dialog unterstützt wird (building trust through lending and supporting policy dialogue through sector work). Dies wird von der Bank als „ein wesentlicher Erfolgsfaktor“ bezeichnet. ${ }^{230}$ Aus diesem Grund sucht die Weltbank Partner in China, die die Technologie - die bei der Kreditvergabe der Bank angeboten wird - wollen, und die offen für die politischen Vorschläge der Bank sind. Eine wichtige Methode dafür ist die Überzeugungsarbeit an hohe Beamte und ihre Politikberater durch Workshops und Beratungen. Aufgrund der erfolgreichen Projekte werden neue Technologien, Verwaltungsmethoden oder politische Reformen eingeführt - das bedeutet, dass der Einfluss der Weltbank sich hauptsächlich durch Erweiterung der Vorbilder von unten (Pilotprojekte auf Regionalebene) nach oben (politische Richtlinien und rechtliche Regelungen auf Staatsebene) verbreitet. ${ }^{231}$

Für die bisherigen Ergebnisse hat die Weltbank ihre große Zufriedenheit geäußert. ${ }^{232}$ Sie hat mit der chinesischen Regierung in den meisten Provinzen Projekte durchgeführt, die viele volkswirtschaftliche Sektoren und soziale Bereiche betreffen. ${ }^{233}$ Manche Projekte werden von der Bank über langen Zeitraum hinweg nachhaltig unterstützt, womit die Bank eine wesentlich kumulative Wirkung in diesen Bereichen ausüben kann. ${ }^{234}$ Die chinesische Regierung hat sich auch anerkennend dazu geäußert, dass die Weltbank im Entwicklungsprozess Chinas seit 1978 eine wichtige Rolle gespielt habe. ${ }^{235}$

Parallel mit der Entwicklung Chinas hat sich die China-Weltbank-Beziehung in den vergangenen 30 Jahren ständig verändert. Anfänglich exportierte die Bank moderne Verwaltungsmethoden und neue Technologien nach China. Mit der Zeit konzentrierte

227 World Bank, China: An Evaluation of World Bank Assistance, S. 1.

228 Ausführlich siehe: Erster Teil, Finanzsystem.

229 World Bank, An Evaluation of World Bank Assistance, S. 8.

230 World Bank, Country Partnership Strategy for the People's Republic of China, for the Period 20062010, S.13.

231 Siehe: World Bank, China: An Evaluation of World Bank Assistance, S. 8-9.

232 World Bank, Country Partnership Strategy for the People's Republic of China, for the Period 20062010, S. 57: "In general, these reviews found that the Bank continues to make a substantial contribution to China's development (OECD found that the Bank in China continues to "punch above its weight")"; World Bank, China: An Evaluation of World Bank Assistance, S. 49: "On balance, the Bank has performed well in China, and overall Bank performance is rated satisfactory".

233 Siehe: World Bank, China and World Bank: A Partnership for Innovation, 2007.

234 World Bank, China: An Evaluation of World Bank Assistance, S. 49.

235 Comments from the Government of China on Draft China Country Assistance Evaluation, in: China: An Evaluation of World Bank Assistance, S. 115. 
sich die Kooperation zunehmend auf den institutionellen Aufbau und den Wissenstransfer. Zurzeit existiert zwischen den beiden Seiten eine Zwei-Wege-AustauschBeziehung, die von der Weltbank als ,eine Partnerschaft für Innovation“236 bezeichnet wird. Entsprechend hat die Bank ihre Länderstrategie für China seit 2006 von der reinen „Hilfe-Strategie“ zur „Strategie der Partnerschaft“ geändert. ${ }^{237}$

\section{cc) Aktivitäten im Bereich der sozialen Sicherheit}

Als Sonderorganisation der UNO hat die Weltbank seit dem Anfang des 21. Jahrhunderts - wie bei der UNO und ILO - im Rahmen der Millenniums-Entwickungsziele Verknüpfungen zwischen ihren Länderprogrammen und den chinesischen Fünfjahresplänen gebildet. Im Gegensatz zur ILO hat die Weltbank jedoch keine Agenda, wie die „Decent Work Agenda“, als weltweites Aktionsprogramm formuliert. Obwohl sie die Armutsbekämpfung immer als Schwerpunkt ihrer Arbeit erklärt, beschäftigt sie sich in China hauptsächlich mit wirtschaftlichen Themen. Seit den 1980er Jahren beteiligt sich die Weltbank stets sehr aktiv in folgenden Bereichen: öffentliche Investitionen, Umweltschutz, Bildungswesen, soziale Sicherheit, Gesundheitswesen, Infrastruktur, makroökonomischem Management, Finanzsektor, Liberalisierung des Handels, Landesentwicklung und Armutsbekämpfung. ${ }^{238}$ Die Bank legt aufgrund ihrer eigenen Einschätzung der künftigen Entwicklungstendenz und Programmbewertungen sowie Ergebnisse der Client-Konsultationen ihre Hauptthemen fest, und korrigiert die Themen flexibel nach der sich ständig verändernden Situation. Z. B. wurden die drei Hauptthemen der Country Assistance Strategy (2003-2005), ${ }^{239}$ nämlich die Förderung der Transformation zur Marktwirtschaft, die Hilfen der armen und schwachen Menschengruppen sowie der Regionen mit Entwicklungsrückstand und die Förderung der nachhaltigen Umwelt im Jahre 2006 durch die fünf Themen der Country Partnership Strategy (2006-2010) ersetzt: 240

Integrierung Chinas in die Weltwirtschaft,

- Verringerung von Armut, Ungleichheit, sozialer Ausgrenzung,

- Behandlung von Ressourcenknappheit und ökologischen Herausforderungen,

- $\quad$ Finanzierung von nachhaltigem und effizientem Wachstum,

- $\quad$ Verbesserung der öffentlichen Institutionen und des Marktsystems.

Parallel zur flexiblen Regulierung ihrer Arbeitsschwerpunkte behält die Weltbank die Kontinuität ihrer langfristigen Strategie für China bei, um durch ihre ständige Infiltration in den wirtschaftlichen, gesellschaftlichen und ökologischen Bereichen die politische Richtung und die institutionelle Reform Chinas zu beeinflussen. Die Ausarbeitung und

236 World Bank, China and World Bank: A Partnership for Innovation, 2007.

237 World Bank, Country Partnership Strategy for the People's Republic of China, for the Period 20062010, S. 1.

238 World Bank, China and World Bank: A Partnership for Innovation, 2007.

239 World Bank, China Country Assistance Strategy (2003-2005), S. 23.

240 World Bank, Country Partnership Strategy for the People's Republic of China, for the Period 20062010, S. $15 \mathrm{ff}$. 
Durchführung der Kooperationsprogramme sind nicht durch die Dauer der StrategiePläne von fünf Jahren befristet. ${ }^{241}$

Unter der Säule der Armutsbekämpfung und Verringerung der sozialen Ungleichheit wird die Reform der sozialen Sicherheit seit langem als eine wichtige Aufgabe von der Weltbank behandelt. Die Arbeitsschwerpunkte sind die Rentenversicherung, die Armutsbekämpfung sowie die Gesundheitsreform.

\section{(1) Rentenversicherung}

In ihrem Bericht von $1985^{242}$ hat die Weltbank bereits darauf hingewiesen, dass es dringend erforderlich sei, eine finanziell unabhängige Rentenversicherung den Wirtschaftsreformen entsprechend in China aufzubauen. In den ganzen 1990er Jahren diskutierten die Experten kontrovers über das Modell der Rentenversicherung. Im Jahre 1991 hat die chinesische Regierung sich dazu entschieden, ein Drei-Säulen-Modell der Alterssicherung durchzuführen: eine Grundrentenversicherung, eine betriebliche Zusatzaltersversicherung und eine private Altersversicherung. Darin praktizierte die Grundrentenversicherung ein Umlageverfahren. ${ }^{243}$ Allerdings wurde von einigen Experten die Ansicht vertreten 244 und von der Weltbank durch ihren Forschungsbericht von 1994245 unterstützt, dass die Einführung eines Kapitaldeckungsverfahrens in die Grundrentenversicherung sinnvoll sei, da durch die demographische Entwicklung eine Überalterung der Gesellschaft zu erwarten sei. Im Jahre 1995 kam die Forschungsgruppe der Weltbank nach China und legte im nächsten Jahr der Regierung ihren ersten wichtigen Bericht über die chinesische Rentenversicherungsreform vor. ${ }^{246}$ Im Jahre 1997 wurde dieser Bericht als ein Teil der Weltbank-Serie „China 2020“ veröffentlicht. ${ }^{247}$

Die Forschungsgruppe hat im Bericht folgende Ansichten und Vorschläge geäußert: Das gegenwärtige leistungsdefinierte Rentensystem mit dem Umlageverfahren sei finanziell nicht nachhaltig. ${ }^{248}$ Ein kapitalgedecktes Individualkonto sei in die Rentenversicherung einzuführen, das zusammen mit dem Solidarfonds eine Grundrentenversicherung bilde. Die Altersversicherung der städtischen Unternehmen umfasse drei Säulen, nämlich eine Grundversicherung mit dem Unlageverfahren, ein Individualkonto mit Kapitaldeckungsverfahren und eine betriebliche Zusatzaltersversicherung. ${ }^{249}$ Zurzeit habe China eine einmalige Chance für die Errichtung eines solchen Rentensystems, da

241 World Bank, Country Partnership Strategy for the People's Republic of China, for the Period 20062010, S. 58.

242 World Bank, China: Long-Term Development Issues and Options, S. 16-17.

243 国务院关于企业职工养老保险制度改革的决定 (Beschluss des Staatsrats zur Reform des Rentenversicherungssystems für Beschäftigte in Unternehmen), 国发 (1991) 33号, vom 26. 06. 1991.

244 高书生, 社会保障改革何去何从 (Gao, Shusheng, Die Reform der sozialen Sicherheit steht am Scheideweg), S.81ff.

245 World Bank, Averting the Old Age Crisis: Policies to Protect the Old and Promote Growth, 1994.

246 World Bank, China Pension System Reform, Report No: 15121-CHA, August 22, 1996.

247 World Bank, Old Age Security: Pension Reform in China, 1997.

248 Ausführlich: World Bank, Old Age Security: Pension Reform in China, 1997, S. $2 \mathrm{ff}$.

249 World Bank, Old Age Security: Pension Reform in China, 1997, S. 6-7. 
die Übergangskosten in China niedriger als bei anderen Staaten seien, aber dieser Vorteil werde nur für 15-20 Jahre lang anhalten. ${ }^{250}$ Außerdem seien die flankierenden Reformen in den legislativen, administrativen und finanziellen Bereichen zusammen durchzuführen. ${ }^{251}$

Das Drei-Säulen-Modell der Weltbank ist nicht mit dem Drei-Säulen-Modell im Beschluss von 1991 identisch. Die private Altersversicherung wird davon nicht umfasst. Aufgrund dieses Weltbank-Berichts hat die chinesische Regierung im Jahre 1997 das System der Grundrentenversicherung landesweit vereinheitlicht. Allerdings bestand die „goldene Chance“ in China nicht. Das Problem der Übergangskosten hat die Regierung nicht gelöst, die Grundrentenversicherung funktioniert im Wesentlichen nach einem faktischen Umlageverfahren. 252

Im Workshop „China Entwicklungsforum: Reform der Systeme der sozialen Sicherheit" von 2000 wurde die Frage, ob China auf das Individualkonto und das Kapitaldeckungsverfahren verzichten und zum Umlageverfahren zurückkehren sollte, von dem damaligen Ministerpräsident Zhu, Rongji gestellt. ${ }^{253}$ Dafür hat die Weltbank weitere Beratungen durchgeführt. Die Regierung entschied sich schließlich für die weitere Durchführung des Teilkapitaldeckungsverfahrens, damit die Weltbank sich seit 2000 am Plan für die Verbesserung der städtischen Systeme der sozialen Sicherheit beteiligen konnte. 254

Von 1995 bis 2006 hat die Weltbank durch Forschungsberichte (China Pension System Reform 1996; China Evaluation of the Liaoning Social Security Reform Pilot 2006 255), politische Beratungen, Kreditvergaben (Pension Reform 1999, Liaoning Social Security Reform 2002) und eine Reihe von technischen Hilfen die Entwicklung des chinesischen Rentensystems grundlegend beeinflusst. ${ }^{256}$ Im Bericht der Weltbank von 2004 wurde die Rolle der Weltbank in der chinesischen Rentenreform als ,eine der häufigsten zitierten Erfolge der Bank“ bezeichnet. ${ }^{257}$ Allerdings funktioniert das von der

250 World Bank, Old Age Security: Pension Reform in China, 1997, S. 9-10.

251 World Bank, Old Age Security: Pension Reform in China, 1997, S. 10-11.

252 Ausführlich: Dritter Teil, Umwandlung zum Modell „Solidarfonds mit Individualkonto“.

253 高书生, 社会保障改革何去何从 (Gao, Shusheng, Die Reform der sozialen Sicherheit steht am Scheideweg), S.157ff.

$254 \mathrm{Lu}, \mathrm{Mai}$, Evaluation of the Effectiveness of the World Bank's Analytical and Advisory Services to China since 1990, S. 10.

255 World Bank, China Evaluation of the Liaoning Social Security Reform Pilot, Report No. 38183-CN, December 2006.

256 Siehe: World Bank, China and World Bank: A Partnership for Innovation, S. 22-25; Lu, Mai, Evaluation of the Effectiveness of the World Bank's Analytical and Advisory Services to China since 1990, S. 9-10; ausführlich auch: Piggott /Lu, Pension Reform and the Development of Pension Systems: An Evaluation of World Bank Assistance, Background Paper China Country Study, 2007, http://lnweb90.worldbank.org/OED/oeddoclib.nsf/DocUNIDViewForJavaSearch/D590B2A77AE65 B6E85257236007A88B4/\$file/asia_pensions_wp.pdf (Stand: 15. 07. 2010).

257 World Bank, China: An Evaluation of World Bank Assistance, S. 14: "One of the most frequently cited areas of successful Bank assistance by Chinese sources is pension reform." 
Weltbank eingeführte Modell zurzeit in China nicht optimal. ${ }^{258} \mathrm{Ob}$ das Teilkapitaldeckungsverfahren der Grundrentenversicherung in der Zukunft noch bleibt, ist sehr fraglich. In der Partnerschaft-Strategie 2006-2010 gibt es kein Programm für die städtische Rentenversicherung mehr. Die Weltbank wendet sich zurzeit der Altersversicherung auf dem Land zu. ${ }^{259}$

\section{(2) Armutsbekämpfung}

Die chinesische Regierung hat ihre Strategie zur ländlichen Armutsminderung seit Mitte der 1980er Jahre reformiert. Die traditionelle Armutshilfe wandelte sich mit der Errichtung der Leitungsgruppe für Armutsbekämpfung und Entwicklung des Staatsrats zur aktiven Armutsbekämpfung, ${ }^{260}$ um die wirtschaftliche Entwicklung der ländlichen Gebiete zu beschleunigen. Aufgrund des Mangels an einem effektiven statistischen System und umfassenden Reformplänen erreichte das Projekt allerdings in den 1980er Jahren nur langsam Fortschritte. Die Regierung wendete sich deshalb an die Weltbank, eine langjährige Partnerschaft wurde somit seit dem Beginn der 1990er Jahre zwischen den beiden Seiten begründet.

Im Jahre 1992 veröffentlichte die Weltbank zusammen mit der Abteilung des Staatsrats für Armutsbekämpfung einen Bericht über die staatlichen Strategien für Armutsminderung. 261 Aus diesem Grund führte die Regierung seit 1994 den „8-7-Plan zur Armutsbekämpfung“ ein, um in sieben Jahren (1994-2000) das Lebensniveau der 80 Millionen armen ländlichen Bevölkerung über die Armutsgrenze heben zu können. ${ }^{262}$ Der zweite wichtige Bericht der Weltbank über die Armutsbekämpfung in China wurde im Jahre 2000 ausgearbeitet. ${ }^{263}$ Danach veröffentlichte die Regierung die „Programme der Armutsbekämpfung auf dem Land 2001-2010“.264 Die durchgeführten Pläne stimmen grundsätzlich mit den Empfehlungen der Weltbank überein, einschließlich der Änderung der Ausrichtung der Hilfsobjekte, Verstärkung der finanziellen Überwachung, Erhöhung der Beteilung der lokalen Regierung an den Projekten, besonderer Hilfen für die schwachen Bürgergruppen, Erweiterung der Dienstleistungen beim Gesundheitssowie Bildungswesen. ${ }^{265}$

Außer den Analyse- und Beratungsarbeiten hat die Weltbank mit den technischen Hilfen und Kreditvergaben folgende Erfolge erreicht. 266 Ein Armut-Monitoring-

258 Ausführlich: Dritter Teil, Systemwechsel der Grundrentenversicherung für Beschäftigte in Unternehmen: Probleme und Maßnahmen.

259 World Bank, Country Partnership Strategy for the People's Republic of China, for the Period 20062010, S. 47.

260 Ausführlich: Dritter Teil, Sozialhilfe auf dem Land.

261 World Bank, China: Strategies for Reducing Poverty in the 1990s, Report No. 11245, 1992.

262 国家八七扶贫攻坚计划 (8-7-Plan des Staatsrats zur Armutsbekämpfung), vom 15. 04. 1994.

263 World Bank, China: Overcoming Rural Poverty, Report No. 21105-CHA, October 18, 2000.

264 中国农村扶贫开发纲要 2001-2010, vom 19.09. 2001.

265 World Bank, Country Partnership Strategy for the People's Republic of China, for the Period 20062010, S. 69.

266 World Bank, China and World Bank: A Partnership for Innovation, S. 68-72. 
System wurde durch das Südwesten-Projekt (Southwest Poverty Reduction Project) der Bank aufgebaut und landesweit popularisiert. Die Bank hat dazu beigetragen, auf dem Land einen neuen Institutionen-übergreifenden-Ansatz, bei dem die Beschäftigungsförderung, Verstärkung der sozialen Dienste und Förderungsmaßnahmen für die Landwirtschaft mit der Armutsbekämpfung in einem umfassenden Entwicklungsprojekt verknüpft werden, zu errichten.

Die chinesische Regierung hat die Arbeiten der Weltbank für die chinesische Armutsbekämpfung sehr geschätzt und im Jahre 2004 die Bank zum ersten Empfänger der „Auszeichnung für die Armutsbeseitigung“ gewählt. ${ }^{267}$ Neben der Armutsbekämpfung strebt die Weltbank jedoch auch an, die chinesische Regierung bezüglich ihrer allgemeinen Politik, insbesondere einer umfassenden Entwicklungspolitik, die das Finanzmodell, das Gesundheitssystem, die Getreidepolitik, die Migrationspolitik umfasst, zu überzeugen, den Empfehlungen der Weltbank zu folgen. Die Weltbank argumentiert, dass auch diese Politikbereiche für die Armutsbekämpfung unerlässlich seien. ${ }^{268}$ Diese Ansichten wurden von der chinesischen Regierung lange Zeit ignoriert, allerdings konnte die Weltbank bezüglich des Umbaus der ländlichen Gesundheitssysteme ihre Vorstellung gegenüber China durchsetzten.

Wenn die Staatspläne betrachtet werden, scheint die Weltbank, eine erfolgreiche Politik der Armutsbekämpfung zu betreiben. In ihrem jüngsten Bericht über die Armut in China $^{269}$ beschränkt sich die Bank nicht mehr auf die ländliche Armutsbekämpfung, sondern diskutiert auch über die Armut in den Städten. Durch den Rückblick auf die Reform der chinesischen Armutsbekämpfungspolitik hat die Bank in diesem Bericht eine umfassende Agenda vorgelegt, die die Armutsbekämpfung, die soziale Sicherung (insbesondere die Sozialhilfe), die Beschäftigungs- sowie Migrationspolitik integriert und auch andere Bereiche der Humanentwicklung, wie Bildungs- und Gesundheitswesen, betrifft. ${ }^{270}$ Wenn die politischen Empfehlungen dieses Berichts von der Regierung akzeptiert werden würden, ist voraussehbar, dass die Weltbank dadurch eine noch gröBere Rolle im Bereich der chinesischen Sozialpolitik spielen würde.

\section{(3) Gesundheitssicherung auf dem Land}

Als die Weltbank sich Ende der 1990er Jahre durch Kooperationsprogramme an der Gesundheitsreform Chinas beteiligte, war sie ein sehr ambitionierter Teilnehmer in diesem Bereich. Ihr Bericht von 1997, Financing Health Care: Issues and Options for China, ${ }^{271}$ bezog sich auf alle Gebiete des Gesundheitswesens. Die Hilfsstrategie umfasste auch viele Programme, die landesweit ausgeführt wurden. ${ }^{272}$ Allerdings war der

267 World Bank, China and World Bank: A Partnership for Innovation, S. 72.

268 World Bank, China: An Evaluation of World Bank Assistance, S. 23.

269 World Bank, China: From Poor Areas to Poor People, China's Evolving Poverty Reduction Agenda, Report No. 47349-CN, March 5, 2009.

270 Ausführlich siehe: World Bank, China: From Poor Areas to Poor People, China's Evolving Poverty Reduction Agenda, Report No. 47349-CN, March 5, 2009, S. 177ff.

271 World Bank, China 2020: Financing Health Care, Issues and Options for China, 1997.

272 World Bank, China Country Assistance Strategy (2003-2005), S. 96-97. 
Einfluss der Bank im Vergleich mit ihren ehrgeizigen Zielen ziemlich gering. ${ }^{273}$ Das Programm für den Kapazitätsaufbau der städtischen Krankenversicherungsreform wurde abgeschafft, weil die Regierung kein Interesse daran hatte. ${ }^{274}$ Das Hauptziel der Bank, das Finanzierungssystem des chinesischen Gesundheitswesens zu reformieren, wurde nicht erreicht.

Die größten Erfolge der Weltbank ergaben sich aus einem Pilotprojekt von Basic Health Services, das in der Mitte und im Westen Chinas für die Verbesserung der Gesundheitssituation der armen Landbewohner durchgeführt wurde. Bei diesem Projekt wurden die medizinische Hilfe und ein neues Finanzierungsmodell des ländlichen kooperativen medizinischen Systems entwickelt. Aus den Erfahrungen dieses Projekts hat die chinesische Regierung ein System der medizinischen Hilfe errichtet und landesweit popularisiert. ${ }^{275}$

Angesichts dieser Situation hat die Weltbank schon in der Periode der Hilfsstrategie (2003-2005) die Schwerpunkte ihrer Arbeit korrigiert. Sie zielt zurzeit nicht mehr auf die Projekt-Interventionen und das städtische Gesundheitssystem, sondern konzentriert sich auf die politischen Fragen des ländlichen Gesundheitswesens, nämlich die Möglichkeiten für die Erweiterung der ländlichen Krankenversicherung und der medizinischen Hilfe. Dies wird im Rahmen der Armutsbeseitigung und des ländlichen Sicherheitsnetzes durchgeführt. ${ }^{276}$

\section{Einflussanalyse}

Seit den 1980er Jahren beteiligen sich die internationalen Organisationen mit unterschiedlichen inhaltlichen Ausrichtungen an der Reform der chinesischen sozialen Sicherheit. Durch die UNO-Reform und die Festlegung der Millenniums-Entwicklungsziele haben die UNO-Organisationen am Anfang des 21. Jahrhunderts ein gemeinsames Aktionsprogramm in China gebildet. Dadurch können die jeweiligen Aktivitäten der betreffenden Organisationen besser koordiniert werden und effektiver wirken. Außer der ILO und der Weltbank beschäftigen sich die WHO, der IMF und die anderen UNOOrganisationen auch in diesem Rahmen mit den Fragen der sozialen Sicherheit. Ihre Tätigkeiten werden allerdings nicht ausführlich in dieser Arbeit analysiert, weil sie sich auf spezielle Gebiete beschränken und es dabei stets an bedeutendem Einfluss fehlt.

Da viele internationale und ausländische „Triebkräfte der Reformen“ in diesem Zeitraum bei der Umgestaltung der sozialen Sicherheit und des Sozialleistungsrechts in China nebeneinander wirken, ist es schwierig, ihre Einflüsse in diesem Bereich genau zu identifizieren. Allgemein übt die UNO besonderen Nachdruck auf die langfristigen

273 World Bank, Country Partnership Strategy for the People's Republic of China, for the Period 20062010, S. 67.

274 World Bank, Country Partnership Strategy for the People's Republic of China, for the Period 20062010, S. 106.

275 World Bank, China and World Bank: A Partnership for Innovation, S. 25-27.

276 World Bank, Country Partnership Strategy for the People's Republic of China, for the Period 20062010, S. 47-48. 
Staatsziele und die Entwicklungsrichtung Chinas aus, dafür hat die ILO einen Grundrahmen der sozialen Sicherheit aufgebaut. Darüber hinaus beschäftigt sie sich in ihren eigenen Aktionsprogrammen mit den mit der Beschäftigung eng verbundenen Fragen der sozialen Versicherungen und der Ausweitung der Deckungsbereiche und -raten der sozialen Sicherungssysteme. Die sozialpolitischen Entscheidungen der chinesischen Regierung hat eine hohe Übereinstimmung mit den politischen Beratungen der beiden Organisationen gezeigt.

Die Einflüsse der UNO und ILO erscheinen hauptsächlich auf der Ebene der politischen und rechtlichen Entscheidungen, demgegenüber ist die Weltbank ein sehr aktiver Teilnehmer beim konkreten Aufbau der sozialen Sicherungsmodelle. Ihr Einfluss verbreitet sich oft von der Ebene der konkreten Maßnahmen der bestimmten Regierungsgebiete nach oben. Die Bank erscheint unabhängiger und ehrgeiziger als die ILO. Sie beschränkt sich nicht auf ihren klassischen Bereich der Armutsbekämpfung, sondern greift auch in viele andere Gebiete ein. Sie berücksichtigt auch nicht allzu sehr die Verbindlichkeit ihrer Aktivitäten mit den chinesischen Staatsplänen, sondern setzt sich gerne für eine Rolle als „Wissensführer und Verbreiter der guten Praxis“277 ein. Die Strategien der Weltbank wurden in den vergangenen Jahren den politischen und wirtschaftlichen Lagen Chinas entsprechend flexibel verändert. In den 1990er Jahren verstärkte die Bank durch ihre Aktivitäten die liberale Färbung der neu gebauten Sozialversicherungssysteme. Zurzeit zeigt ihr Arbeitsplan eine Tendenz auf, dass ihre Arbeitsschwerpunkte nun im Umfeld der Armutsbekämpfung und der ländlichen sozialen Sicherung liegen. Die hohe Flexibilität hat aber auch eine nachteilige Seite. Es scheint, dass es der Bank stets an langfristigen strategischen Zielen - oder an einer deutlichen Darstellung ihrer langfristigen Strategie in China fehlt.

Obwohl es Meinungsverschiedenheiten zwischen den erwähnten internationalen Organisationen gibt, hat die Gestaltung dieses allseitigen Aktionsprogramms die Kooperationsarbeit der internationalen Organisationen in China begünstigt. Durch Verknüpfung mit den chinesischen Staatsplänen sowie durch den Transfer der fortgeschrittenen Technologie, die von der chinesischen Modernisierung dringend gebraucht werden, haben die internationalen Organisationen ihre Ziele in gewissem Maße erreicht. Sowohl die Gedanken des Sozialstaates als auch des Liberalismus haben beachtliche Spuren in der chinesischen Politik sowie den rechtlichen Regelungen hinterlassen. Für die bisherigen Erfolge ihrer Kooperationen mit der chinesischen Regierung haben die ILO und die Weltbank ihre Zufriedenheit geäußert.

Andererseits ist die Volksrepublik China - insbesondere im Vergleich mit der überaus großen Zurückhaltung bei der Ratifikation der internationalen Konventionen - auch sehr offen bei der Rezeption der westlichen Erfahrungen für die konkrete Rahmensetzung. China führt dazu die entwicklungspolitische Richtlinie an, die lautet: Unter der Voraussetzung von Bewahrung der Unabhängigkeit und Selbständigkeit ,,von den nützlichen Ergebnissen der Zivilisationen der ganzen Menschheit zu profitieren“. Die Wi-

277 World Bank, Country Partnership Strategy for the People's Republic of China, for the Period 20062010, S. 98. 
dersprüche, die in der früheren Phase der Rezeption von der Reform verursacht wurden, werden im Entwicklungsprozess durch die ständige Regulierung der inneren Bedingungen und der eingeführten Modelle nach und nach gelöst. Ferner ist das auch ein Teil des strategischen Ziels Chinas, sich vom „Gegner der Weltordnung“ zum ,aktiven Beteiligten des internationalen Systems" zu wandeln und schließlich eine bedeutende Wirkung auf die Weltordnung auszuüben.

\section{Zusammenfassung}

Durch eine selektive Rezeption an Erfahrungen und Modellen der westlichen Staaten sowie der internationalen Organisationen baut die Volksrepublik China ihre sozialen Sicherungssysteme um. Auf dieser Grundlage konnten die internationalen Organisationen für die Kooperationsarbeit mit der Volksrepublik China einen Mehrebenenmechanismus der Einflussnahme bilden. Zuerst üben die Menschenrechtskonventionen der UNO als Grundprinzipien des internationalen Sozialrechts einen Ratifizierungs- und Durchsetzungsdruck auf das innerstaatliche Recht aus. Durch die ILO-Sozialstandards wurde ein Grundrahmen der sozialen Sicherheit gebildet. Durch die gemeinsamen und die einzelnen Aktivitätsrahmen haben die internationalen Organisationen zwischen ihren Aktivitäten und den chinesischen Entwicklungsstrategien sowie Maßnahmen enge Verknüpfungen geschaffen.

Die Untersuchung zeigt, dass die Kooperationen zwischen der chinesischen Regierung und den internationalen Organisationen von der staatlichen Außenpolitik und der Änderung der internationalen Beziehungen bedingt werden. Sie sind auch mit den staatlichen Entwicklungsplänen und den strategischen Zielen der internationalen Organisationen eng verknüpft. Aus historischen, kulturellen und ideologischen Gründen existieren noch Interessenskollisionen und Meinungsverschiedenheiten zwischen den beiden Seiten. Die Einführung der Menschenrechtskonventionen und der Sozialstandards bleiben bisher auf eine oberflächliche Ebene. Beim Verständnis des Begriffs der Menschenrechte existiert eine Wertekollision zwischen dem chinesischen und internationalen System, während das Hindernis bei der Ratifikation der ILO-Übereinkommen hauptsächlich beim hohen Leistungsniveau der Sozialstandards liegt.

Trotzdem haben die internationalen Institutionen sich in der Periode der Reform und Öffnung an der sozialrechtlichen und sozialpolitischen Praxis Chinas aktiv beteiligt. Die Kooperationsarbeit auf der politischen und technischen Ebene ist erfolgreich. Die Einflussweise, durch Dialog, gemeinsame Forschungsarbeit sowie Kenntnisaustausch die Verschmelzung der verschiedenen menschlichen Kulturen zu fördern, ist für beide Seiten eine positive Erfahrung. 
Tabelle 21: Wege und Formen der Einflussnahme

\begin{tabular}{|l|l|l|l|}
\hline $\begin{array}{l}\text { Mechanismus- } \\
\text { Ebene }\end{array}$ & Organisation & Instrument & Einfluss \\
\hline $\begin{array}{l}\text { Grundlegende } \\
\text { Prinzipien }\end{array}$ & UNO & $\begin{array}{l}\text { Ausarbeitung und Ratifizie- } \\
\text { rung internationaler Konven- } \\
\text { tionen }\end{array}$ & $\begin{array}{l}\text { Verfassungsänderung, sozial- } \\
\text { rechtliche Gesetzgebung }\end{array}$ \\
\hline $\begin{array}{l}\text { Grundrahmen } \\
\text { sozialer Si- } \\
\text { cherheit }\end{array}$ & ILO & $\begin{array}{l}\text { Ausarbeitung internationaler } \\
\text { Sozialstandards und sozial- } \\
\text { rechtlicher Konventionen }\end{array}$ & Sozialrechtliche Gesetzgebung \\
\hline \multirow{2}{*}{ Aktivitäten } & UNO & $\begin{array}{l}\text { Festlegung internationaler } \\
\text { Entwicklungsziele und des } \\
\text { gemeinsamen Aktivitätsrah- } \\
\text { men }\end{array}$ & $\begin{array}{l}\text { staatliche Entwicklungsstrate- } \\
\text { gien und -pläne }\end{array}$ \\
\cline { 2 - 4 } & ILO & $\begin{array}{l}\text { politischer Dialog, Beratung, } \\
\text { Forschungsarbeit, technische } \\
\text { Hilfe }\end{array}$ & $\begin{array}{l}\text { Aufbau und Verbesserung der } \\
\text { sozialen Sicherungssysteme, } \\
\text { Beschäftigungsförderung }\end{array}$ \\
\cline { 2 - 4 } & Weltbank & $\begin{array}{l}\text { politischer Dialog, } \\
\text { Beratung, Forschungsbericht, } \\
\text { Kreditvergabe, } \\
\text { technische Hilfe }\end{array}$ & $\begin{array}{l}\text { Rentenversicherung, Armuts- } \\
\text { bekämpfung, } \\
\text { Gesundheitssicherung }\end{array}$ \\
\hline
\end{tabular}

Die verschiedenen internationalen Organisationen haben unterschiedliche Arbeitsschwerpunkte und Modelle in China entwickelt. Es ist schwer zu entscheiden, welche dieser Modelle erfolgreicher sind. Die Rezeption bestimmter Modelle und Ideen der sozialen Sicherheit steht in einem unmittelbaren Zusammenhang mit den staatlichen Entwicklungszielen und -strategien, die den wirtschaftlichen und gesellschaftlichen Veränderungen entsprechend ständig neu reguliert werden. In den 1980er und 1990er Jahren war die liberale Wirtschaftspolitik die Haupttendenz in China, dementsprechend neigte die Regierung zum Drei-Säulen-Rentenversicherungsmodell der Weltbank. Die marktorientierte Gesundheitsreform wurde von den liberalen Ideen beeinflusst. Diese Reformen gerieten allerdings in Schwierigkeiten und führten zu einer Reihe an Sozialproblemen. Demzufolge haben die „menschenorientierten“ Entwicklungsstrategien der UNO und die ILO-Ideen über den Ausbau der sozialen Sicherheit sowie die Beschäftigungsförderung in den ersten zehn Jahren des 21. Jahrhunderts in China große Aufmerksamkeit bekommen.

Aufgrund der Öffnungspolitik wird die Kooperation der beiden Seiten weitergeführt. Die zukünftige Tendenz der Zusammenarbeit wird von den politischen Entscheidungen bestimmt. Dazu spielen die ideologischen Trends, die staatlichen Entwicklungsstrategien sowie das Integrationsniveau der eingeführten Ideen und Modelle jeweils wichtige Rollen. 


\section{Fünfter Teil: Schlussbetrachtung}

Die 60-jährige Geschichte der sozialen Sicherheit in China zeigt, dass die bisherigen wichtigen Entwicklungen in diesem Bereich hauptsächlich von der Änderung der Wirtschaftsordnung bestimmt wurden. Zwei wichtige Wendepunkte sind die Festlegung des sozialistischen Gemeineigentums und der Planwirtschaft in den 1950er Jahren sowie die Umwandlung der Wirtschaft als staatliche Hauptaufgabe seit Ende der 1970er Jahre. Aufgrund der Festlegung des sozialistischen Gemeineigentums wurden staatlich und kollektiv verantwortete Sicherungssysteme zusammen mit der Vollbeschäftigungspolitik aufgebaut. Bezüglich der Wirtschaftsreform sind das gemischte Eigentumssystem und die sozialistische Marktwirtschaft, die durch die Verfassungsänderungen in den 1980er und 1990er Jahren legitimiert wurden, zurzeit die Hauptelemente des Wirtschaftssystems. Entsprechend wurde versucht, vom Staat, von der Gesellschaft und dem Individuum zusammen verantwortete soziale Sicherungssysteme einzuführen.

In der ersten Dekade des 21. Jahrhunderts zeigt sich eine neue Tendenz, die die Vervollkommnung der Staatsordnung neben dem Wirtschaftsaufbau als eine der staatlichen Hauptaufgaben ansieht. ${ }^{1}$ Ein Meilenstein in dieser Entwicklung ist die Aufstellung der Theorie der „harmonischen Gesellschaft“ im Jahre 2006. Mit ihr wurden die Kernelemente einer idealen Gesellschaft dargestellt. ${ }^{2}$ Die Systeme der sozialen Sicherheit, die früher hauptsächlich als Notwendigkeiten der Wirtschaftsreformen angesehen wurden, werden als ein wichtiger Bestandteil der Staatsordnung bezeichnet. ${ }^{3}$ Diese Veränderung fordert, dass der Aufbau der sozialen Sicherheit vor allem mit den grundlegenden Prinzipien des Staates vereinbar sein muss, und sich nicht nur an der wirtschaftlichen Entwicklung orientieren darf. Dabei geht es auch um die berechtigte Frage nach der Entwicklungsrichtung der Reform. Über die Grundfrage des Systemaufbaus - welche Prinzipien und Grundmodelle die soziale Sicherheit enthalten sollte - wurde bislang nach 30 Jahre andauernder Diskussion noch keine eindeutige Übereinstimmung erreicht.

Um die Grundzüge erfassen zu können, werden zuerst die ideologischen Trends der bisherigen Reformrunden aufgezeigt.

\section{A. Ideologische Trends}

Die wirtschaftliche Entwicklungsrichtung wurde in den 1990er Jahren von der neoliberalen Wirtschaftslehre, die damals in China die sogenannte „Mainstream-Ökonomie“

$1 \mathrm{Vgl}$. 胡鞍钢, 第二次转型: 以制度建设为中心 $(H u$, Angang, Die zweite Transformation: Aufbau der Staatsordnung ist die Hauptaufgabe), in: 战略与管理 (Strategy \& Management), 2002/3, S. 34.

2 Ausführlich: Erster Teil, Aufbau einer harmonischen Gesellschaft.

3 Ausführlich: Dritter Teil, Umwandlung der sozialen Sicherheit seit 1985. 
war, beeinflusst. Im Jahre 1992 veröffentlichte die Forschungsgruppe für die Gesamtplanung der Wirtschaftsreform Chinas, die von den liberalen Ökonomen $\mathrm{Wu}$, Jinglian und Rong, Jingben geleitet wurde, ihren Forschungsbericht über den neuen Aufbau der sozialen Sicherungssysteme. ${ }^{4}$ In diesem Bericht wurden einige Vorschläge dargestellt: ${ }^{5}$ Zuerst solle die Regierung in dieser Phase hauptsächlich die Verantwortung für die „Armenunterstützung“ und die Errichtung der sozialen Versicherungssysteme für die Beschäftigten in den städtischen Unternehmen übernehmen. Die Regierung solle verantwortlich für die Planung, die Organisation und die Makrokontrolle des Systemaufbaus sein. Die konkreten Arbeiten sollten von den Nichtregierungsorganisationen übernommen werden. Um Effektivität und Effizienz zu gewährleisten, seien die Leistungen der sozialen Sicherung auf ein angemessenes Niveau zu beschränken. Z. B. solle die Sozialversicherung nur ein Grundlebensniveau der Versicherten gewährleisten. Ziel der Sozialhilfe solle die Sicherung eines Existenzminimums sein. Die Systeme der sozialen Sicherheit, insbesondere die Sozialversicherungssysteme, sollten vom Staat, den Unternehmen und dem Einzelnen zusammen finanziert werden. Die Verantwortung des Einzelnen solle sich ständig an die Erhöhung seines Einkommensniveaus anpassen. Als Ergänzung der nur eine Grund- oder Minimumssicherung gewährleistenden sozialen Sicherungssysteme sollten die betriebliche Sicherung, die gegenwärtige Hilfe, die Familiensicherung sowie die kommerzielle Versicherung entwickelt werden. Damit werde ein gesamtes Mehrebenensystem für soziale Sicherheit aufgebaut.

Letztlich wurde in diesem Bericht eine Minimierung des Leistungsniveaus und der staatlichen Aufgaben vorgeschlagen. Diese Vorschläge und das von der Weltbank vertretene Modell ${ }^{6}$ lagen nahe beieinander. Aus diesem Grund hat die Forschungsgruppe für soziale Sicherheit im Jahre 1994 ein gemischtes Modell der sozialen Sicherheit konstruiert, worin die beitragsdefinierte Systeme eine wichtige Rolle spielen. ${ }^{7}$ Der Ausgangspunkt dieser Entscheidung war, dass der Umbau der sozialen Sicherheit der Errichtung und Entwicklung einer Marktwirtschaft dienen solle. ${ }^{8}$ Darüber hinaus wurde ein System der Bewertungsmaßstäbe für soziale Sicherheit vorgeschlagen, mit dem wird soziale Sicherheit als ein multifunktionales System bezeichnet. Es dient der gesell-

4 中国经济体制改革总体设计课题组, 变革时期的中国社会安全体系 (Forschungsgruppe für die Gesamtplanung der Wirtschaftsreform Chinas, Das chinesische soziale Sicherungssystem in der Umwandlungsperiode), in: 经济社会体制比较 (Comparative Economic \& Social Systems), 1992/5, S. 29ff.

5 中国经济体制改革总体设计课题组, 变革时期的中国社会安全体系 (Forschungsgruppe für die Gesamtplanung der Wirtschaftsreform Chinas, Das chinesische soziale Sicherungssystem in der Umwandlungsperiode), in: 经济社会体制比较 (Comparative Economic \& Social Systems), 1992/5, S. 31ff.

6 Ausführlich vgl. Ramia/Davies/Nyland, in: International Social Security Review, Vol. 61, Nr. 1, 2008, S. 4ff.

7 中国社会保障的体制选择与经济分析课题组, 社会保障: 经济分析与体制建议 (Forschungsgruppe des Staatsrats für soziale Sicherheit, Soziale Sicherheit: Wirtschaftsanalysen und Vorschläge für die Systementscheidung), in: 改革 (Reform), 1994/6, S. 71.

8 中国社会保障的体制选择与经济分析课题组, 社会保障: 经济分析与体制建议 (Forschungsgruppe des Staatsrats für soziale Sicherheit, Soziale Sicherheit: Wirtschaftsanalysen und Vorschläge für die Systementscheidung), in: 改革 (Reform), 1994/5, S. 20. 
schaftlichen Stabilität und Sicherheit, der sozialen Gerechtigkeit, der Motivation des Einzelnen, der Akkumulation, dem Wirtschaftswachstum sowie der Entwicklung des Kapitalmarkts. ${ }^{9}$

Ein Rückblick auf die früheren Reformrunden zeigt, dass diese Vorschläge bis Ende der 1990er Jahre von den politischen Entscheidungsorganen im Großen und Ganzen verfolgt wurden. Im Bericht des 15. Parteitags wurde der Aufbau der sozialen Sicherungssysteme als „Zusatzprojekt der Reform der Staatsunternehmen“ bezeichnet. Der Staat gewährleistete den Bürgern nur eine „Minimumsicherung“.10 Soziale Sicherheit diente also damals erstrangig dem Wirtschaftswachstum.

Inzwischen hat die Wirtschaft eine erfolgreiche Entwicklung zurückgelegt. Das durchschnittliche Lebensniveau hat sich deutlich erhöht. Allerdings haben die Bürger gleichzeitig auch unter der großen Arbeitslosigkeit gelitten, den zunehmenden Disparitäten zwischen Arm und Reich, und der deutlichen Senkung des Leistungsniveaus der sozialen Sicherung. Die neu errichteten sozialen Versicherungssysteme gerieten in Schwierigkeiten. ${ }^{11} \mathrm{Zu}$ Beginn des 21. Jahrhunderts hat eine Forschungsgruppe der „Neuen Linken“12 in ihrem Forschungsbericht davor gewarnt, dass die zunehmende soziale Ungleichheit und Ungerechtigkeit in der Volksrepublik zu ,einer Phase der sozialen Instabilität" geführt hätten. ${ }^{13}$

In ihren Berichten hat diese Forschungsgruppe ihre Meinung deutlich geäußert. Die Verwirklichung des „gemeinsamen Wohlstands“, die von Deng, Xiaoping als Wesen des Sozialismus bezeichnet wurde, ${ }^{14}$ sei der entscheidende Maßstab der chinesischen Reformen. Aber die wirtschaftlichen Erfolge könnten soziale Gleichheit und gesellschaftliche Stabilität nicht automatisch gewährleisten. Die großen gesellschaftlichen Disparitäten und die zunehmende soziale Ungerechtigkeit müssten durch den Aufbau

9 中国社会保障的体制选择与经济分析课题组, 社会保障: 经济分析与体制建议 (Forschungsgruppe des Staatsrats für soziale Sicherheit, Soziale Sicherheit: Wirtschaftsanalysen und Vorschläge für die Systementscheidung), in: 改革 (Reform), 1994/6, S. 64ff.

10 江泽民，在中国共产党第十五次全国代表大会上的报告 (Jiang, Zemin, Bericht auf dem 15. Parteitag der KP Chinas), vom 12. 09. 1997.

11 唐钧, 中国的社会保障政策评析 (Tang, Jun, Kommentar zur chinesischen Sozialpolitik), in: 东 岳论丛 (Dong Yue Tribune), 2008/1, S. 12ff.

12 Die chinesische "Neue Linke" ist seit den späten 1990er Jahren aufgetreten. Sie vertritt teilweise sozialistische Vorstellungen, grenzt sich hauptsächlich beim Verständnis der sozialistischen Demokratie von den klassischen Linken ab. Die neuen linken Intellektuellen kritisieren heftig die neoliberalen Meinungen wie Privatisierung des Staatseigentums, marktorientierte Reformen der sozialen Sicherung sowie die neoliberalen Modernisierungstheorien. Die meisten von ihnen gehören zur „neuen Generation“, die in der Periode von Reform und Öffnung gewachsen sind und in den westlichen Staaten studiert haben. Die Vertreter sind Wang Hui, Wang Shaoguang, Hu Angang, Gan Yang. Ausführlich vgl. 房宁, 影响当代中国的三大社会思潮 (Fang, Ning, Die drei wichtigsten ideologischen Tendenzen in der gegenwärtigen Epoche Chinas), in: 陈明明, 权利, 责任与国家 (Chen, Mingming (Hrsg.), Recht, Verantwortung und Staat), S. 265ff.

13 王绍光/胡鞍钢丁元竹, 经济繁荣背后的社会不稳定 (Wang, Shaoguang/Hu, Angang/Ding, Yuanzhu, Hinter der blühenden Wirtschaft ist die soziale Instabilität), in: 战略与管理 (Strategy \& Management), 2002/3, S. 26.

14 邓小平文选第三卷 (Deng, Xiaoping, Ausgewählte Werke von Deng Xiaoping, Dritter Band), S. 364. 
staatlicher Institutionen einschließlich Systeme der Einkommensverteilung, der sozialen Sicherheit, der finanziellen Umverteilung sowie der demokratischen Beteiligung der Bürger beseitigt werden. ${ }^{15}$

Die politischen Richtlinien der KP Chinas näherten sich seit dem 16. Parteitag allmählich den Vorschlägen der linken Intellektuellen an. ${ }^{16}$ Im Bericht des 16. Parteitags wurden die Festigung und Entwicklung des Volkseigentums, die Vertiefung der Reform der Einkommensverteilung, die Verbesserung der sozialen Sicherheit sowie die aktive Beschäftigungspolitik zum ersten Mal vorgebracht. ${ }^{17}$ Bis zum 17. Parteitag wurden die Förderung der sozialen Gerechtigkeit und die Vervollkommnung eines Gesamtsystems der sozialen Sicherheit, das die gesamte Stadt- und Landbevölkerung erfasst, festgelegt. 18

Bei der Darstellung der staatlichen Institutionen hat die Neue Linke erläutert, dass die wirtschaftlichen und sozialen Rechte der Bürger die Grundlagen für den Aufbau der Systeme der Umverteilung und sozialer Sicherung seien. Alle gesellschaftlichen Mitglieder hätten das Recht, die Erfolge der wirtschaftlichen und gesellschaftlichen Fortschritte gemeinsam zu genießen. ${ }^{19}$ Der Einfluss des UNO-Sozialpakts sowie der UNOErklärung über Fortschritt und Entwicklung auf sozialem Gebiet von 1969 ist hier schon deutlich. Aber ein theoretisches System der Umverteilung und sozialen Sicherheit auf Basis dieser Grundsätze tritt bislang noch nicht zum Vorschein. Die sozialistische Betonung der Gleichheit, die internationalen Übereinstimmungen über die sozialen Rechte sowie die wirtschaftlichen und politischen Grundsätze des Staates wurden noch nicht in den Systemaufbau integriert. Allgemein befürwortet die Neue Linke die Verstärkung der staatlichen Verantwortung einschließlich der finanziellen Unterstützung für den Systemaufbau. Sie bekämpft die marktorientierten Reformen im Bereich des Gesundheitswesens sowie des Bildungswesens und fordert eine bestimmte Wiederkehr der sozialistischen Tradition. ${ }^{20}$

15 胡鞍钢, 第二次转型: 以制度建设为中心 (Hu, Angang, Die zweite Transformation: Aufbau der Staatsordnung ist die Hauptaufgabe), in: 战略与管理 (Strategy \& Management), 2002/3, S. 34ff; 王绍光/胡鞍钢/周建明, 第二代改革战略: 积极推进国家制度建设 (Wang, Shaoguang/Hu, Angang/Zhou, Jianming, Neue Reformstrategien: Förderung der Strukturierung des Staatssystems), in: 战略与管理 (Strategy and Management), 2003/2, S. 90ff.

16 房宁, 影响当代中国的三大社会思潮 (Fang, Ning, Die drei wichtigsten ideologischen Tendenzen in der gegenwärtigen Epoche Chinas), in: 陈明明, 权利, 责任与国家 (Chen, Mingming (Hrsg.), Recht, Verantwortung und Staat), S. 265ff.

17 江泽民, 在中国共产党第十六次全国代表大会上的报告 (Jiang, Zemin, Bericht auf dem 16. Parteitag der KP Chinas), vom 08. 11. 2002.

18 胡锦涛, 在中国共产党第十七次全国代表大会上的报告 (Hu, Jintao, Bericht auf dem 17. Parteitag der KP Chinas), vom 15. 10. 2007

19 胡鞍钢, 第二次转型: 以制度建设为中心 (Hu, Angang, Die zweite Transformation: Aufbau der Staatsordnung ist die Hauptaufgabe), in: 战略与管理 (Strategy \& Management), 2002/3, S. 38.

20 王绍光, 医改不存在迷局: 理性回归中国传统 (Wang, Shaoguang, Gesundheitsreform: Wiederkehr zur chinesischen Tradition), in: 书城 (Booktown), 2005/10, S. 33ff; 葛延风, 完善城镇职工 养老保险制度的思路与对策 (Ge, Yanfeng, Approaches and Policies to Enhance the Workers' Pension System in Urban Areas), in: 陈佳贵/王延中，中国社会保障发展报告2001-2004 (Chen, Jiagui/Wang, Yanzhong (Hrsg.), China Social Security System Development Report 2001-2004), S. 
In den jüngeren Reformrunden verstärkt sich der Einfluss der oben erwähnten linken Befürworter auf die Gesundheitsreform und die Alterssicherung der ländlichen Bevölkerung, bei denen die staatliche Verantwortung deutlich verstärkt wurde. ${ }^{21}$ Zwar ist der Einfluss der Liberalen schwächer geworden, aber in der Parteipolitik sind ihre Stimmen immer noch ersichtlich. In den Entscheidungen der Partei und Regierung wurde „die Funktion des Marktmechanismus“ weiterhin als eines der Reformprinzipien bezeichnet:

„Gleichheit und Effizienz sollen gleich berücksichtigt werden. Die Hauptverantwortung der Regierung wird mit der Funktion des Marktmechanismus verbunden. ... um einen ordentlichen Wettbewerbsmechanismus aufzubauen“.22

Während der wirtschaftlichen und gesellschaftlichen Pluralisierung ist das Spektrum der chinesischen ideologischen Kreise seit Ende des 20. Jahrhunderts vielfältiger geworden. Außer den neoliberalen und sozialistischen Gedanken findet der sogenannte „Demokratische Sozialismus“ auch Anhänger in China. Die Konstruktion des Demokratischen Sozialismus wurde im Jahre 2007 als „,demokratischer Konstitutionalismus, gemischtes Privateigentumssystem, soziale Marktwirtschaft und Wohlfahrtssystem" formuliert. ${ }^{23}$ Die schwedischen Erfahrungen wurden als ein hochgeschätztes Vorbild bezeichnet. ${ }^{24}$ Diese Idee ist allerdings keine ideologische Haupttendenz in China. Obwohl der Einfluss der darin enthaltenen europäischen wohlfahrtstaatlichen Gedanken und Modelle in der Reform der chinesischen sozialen Sicherheit spürbar ist, wird ein solcher „dritter Weg“ in China kaum akzeptiert, da für die Sozialisten das Privateigentum grundsätzlich nicht annehmbar ist und für die Liberalen die in diesen Ideen vorgesehenen Änderungen nicht weit genug gehen.

178ff., 葛延风贡森, 中国医改: 问题, 根源, 出路 (Ge, Yanfeng/Gong, Sen, Chinese Healthcare Reform), S. $7 \mathrm{ff}$.

21 Siehe: 中共中央, 国务院关于深化卫生体制改革的意见 (Mitteilungen des Zentralkomitees der KP Chinas und des Staatsrats über die Vertiefung der Gesundheitsreform): Die Verantwortung der Regierung für das grundlegende hygienische und medizinische System wird verstärkt. Für die Planung, Finanzierung, Dienstleistung sowie Überwachung des Systems soll die Regierung mehr Pflichten übernehmen. 中发 (2009) 6号, vom 17. 03. 2009.

22 中共中央, 国务院关于深化卫生体制改革的意见 (Mitteilungen des Zentralkomitees der KP Chinas und des Staatsrats über die Vertiefung der Gesundheitsreform): Leitlinien, Grundprinzipien und Gesamtziele der Reform.

23 谢蹈, 民主社会主义模式与中国前途 (Xie, Tao, Demokratischer Sozialismus und die Zukunft Chinas), in: 炎黄春秋 (Yanhuang Chunqiu), 2007/2, S. 8.

24 谢蹈, 民主社会主义模式与中国前途 (Xie, Tao, Demokratischer Sozialismus und die Zukunft Chinas), in: 炎黄春秋 (Yanhuang Chunqiu), 2007/2, S. 8. 


\section{B. Modellvorschläge}

Nachdem das Forschungszentrum des Staatsrats im Jahre 2005 in seinem Forschungsbericht die Gesundheitsreform als „,nicht gelungen“ beurteilt hat, ${ }^{25}$ wurde die Kritik an den Modellen der sozialen Sicherungssysteme - insbesondere an den Rentenund Krankversicherungen - zunehmend lauter. Der Umbau der sozialen Sicherheit wurde als sehr lückenhaft angesehen. ${ }^{26}$ Die Experten versuchen nun, ein neues Grundmodell der sozialen Sicherheit zu konstruieren. Die Vorschläge zur Modellauswahl sind ebenso wie das breite Spektrum der ideologischen Haltungen sehr unterschiedlich. Eine übereinstimmende Meinung für die zukünftige Entwicklung ist bislang nicht erkennbar.

Manche Experten halten weiter an den in den 1990ern Jahren herrschenden Leitlinien fest, dass der Staat nur hauptsächlich für die grundlegendste Sicherung verantwortlich sein sollte. Jing, Tiankui, ein Mitglied der Chinesischen Akademie der Sozialwissenschaften, schlägt vor, ein Sicherungsmodell der „Gleichheit aufgrund der Minimumsicherung“ aufzubauen. ${ }^{27}$ „Minimumsicherung“ umfasst hier eine Sicherung des Existenzminimums, eine grundlegende Gesundheitssicherung (einschließlich eines grundlegenden öffentlichen Systems der Gesundheitsversorgung und eines Systems der medizinischen Hilfe) sowie die neunjährige Schulpflicht. Die finanzielle Verantwortung der Minimumsicherung solle vollständig vom Staat übernommen werden. Außerdem würden die Individuallkonten und die Sozialversicherungen entwickelt, bei denen die Pflichten der Unternehmen und des Einzelnen verstärkt werden sollten.

Der Soziologe Li, Yingsheng ist der Meinung, dass das Leistungsniveau der Sozialversicherungen für Beschäftigte in Unternehmen gesenkt, die Belastung des Einzelnen erhöht werden solle. Aufgrund dieser „kleinen Sicherung“ könnten Verknüpfungen zwischen den städtischen und ländlichen Sicherungsprogrammen geschaffen werden. Die Solidarfonds der Renten- und Gesundheitsversicherung sowie die Sozialhilfe würden als Sicherung für alle Bürger landesweit vereinheitlicht. Die finanziellen Mittel dieser Sicherung würden in den Städten weiterhin von Unternehmen und Einzelnen übernommen, demgegenüber unterstützten die Staatsfinanzen die ländliche Bevölkerung. ${ }^{28}$

Der Ökonom Zheng, Bingwen unterstützt ein sogenanntes USA-Modell, bei dem die staatliche Verantwortung vergleichsweise auf ein niedriges Niveau beschränkt wird. Die staatliche Unterstützung solle sich auf die Existenzsicherung, die Grundrente und das

25 国务院发展研究中心课题组, 对中国医疗卫生体制改革的评价与建议 (Forschungszentrum des Staatsrats für Entwicklung, Kommentar und Vorschläge zur Reform des Gesundheitssystems Chinas), in: 中国发展评论 (China Development Review), 2005/3, Heft 7-1.

$26 \mathrm{Vgl}$. 葛延风, 问题与对策: 中国社保制度改革 (Ge, Yanfeng, Probleme und Gegenmaßnahmen: Die Reform der sozialen Sicherheit in China), in: 中国行政管理 (Chinese Public Administration), 2003, 9, S. 17ff.

27 景天鬼, 大力推进与国情相适应的社会保障制度建设 (Jing, Tiankui, Vorantreiben des Aufbaus eines der Lage des Staates anpassenden System der sozialen Sicherheit), in: 理论前沿 (Theory Front), 2007/18, S. 5ff.

28 李迎生, 中国社会保障制度改革的目标定位新探 ( $L i$, Yingsheng, An Exploration of the Basic Goals of Social Security System Reform in China), in: 社会 (Society), 2006/2, S. 175ff. 
Gesundheitswesen konzentrieren. Die Funktion des Markts und der Familie sei weiter zu entfalten. Allerdings stellt er auch fest, dass die staatliche Unterstützung für die Grundsicherung zurzeit noch nicht ausreiche. Für die Integrierung und Verstärkung der Grundsicherung, zum Beispiel die Umgestaltung des Solidarfonds zu einer Grundrente, solle der Staat mehr Verantwortung übernehmen. ${ }^{29}$

Die Einführung des Individualkontos in das Sozialversicherungssystem war lange Zeit umstritten. Ge, Yanfeng hat bereits im Jahre 2003 vorgeschlagen, das Individualkonto aus der Grundrentenversicherung herauszunehmen und nach kommerziellem Modell zu verwalten. ${ }^{30}$ Auf dieser Grundlage hat Tang, Jun einen neuen Grundrahmen der sozialen Sicherung gebildet: eine Grundsicherung mit einer Zusatzsicherung. Die Grundsicherung solle die Sicherung des Existenzminimums, die grundlegende medizinische Versorgung, die Beschäftigungsförderung sowie die nach Umlageverfahren organisierten und leistungsdefinierten Grundversicherungen umfassen. Damit werde das „grundlegende Lebensniveau“ der Bürger garantiert. Die Zusatzsicherung sei ein „Individualentwicklungskonto“, das mit dem Einkommensniveau des Teilnehmers verbunden und kommerziell bewirtschaftet werden solle. Das Geld auf dem Konto werde hauptsächlich für den Ruhestand geplant. Aber es könne auch für die individuellen oder familiären Entwicklungsziele wie Wohnung, Ausbildung, Gesundheit oder sogar als Gründung eines kleinen Geschäfts benutzt werden. Das für Wohnung, Ausbildung usw. benutzte Geld werde nach dem Kreditverfahren behandelt. ${ }^{31}$

Insgesamt tendieren die Modellentwürfe dahin, das Gesamtsystem der sozialen Sicherheit in zwei Elemente aufzuteilen. Ein Teil ist die Grundversorgung, die die Existenzsicherung und die Grundsozialversicherung erfasst. Die Grundversicherung wird steuer- und beitragsfinanziert und nach dem Umlageverfahren leistungsdefiniert verwaltet. Der Staat übernimmt die Hauptverantwortung für die Grundversorgung. Um eine einheitliche Plattform der sozialen Sicherung aufzubauen, sollen alle städtischen und ländlichen Bewohner durch diese Grundversorgung abgedeckt werden, und das Leistungsniveau für alle Bürger soll gleichmäßig sein. Der andere Teil ist ein System des beitragsdefinierten Individualkontos. Das Individualkonto wird von dem Einzelnen und dem Unternehmen durch Beiträge finanziert und kommerziell bewirtschaftet.

Der Meinungsunterschied der Experten liegt hauptsächlich in Umfang und Niveau der Grundversorgung. Während manche die Grundversorgung als „Minimumsicherung“ konstruieren, neigen die linksorientierten Intellektuellen dazu, den Charakter des allgemeinen Wohls hervorzuheben. Zum Beispiel haben die Linken ausdrücklich bekundet, dass ein System der grundlegenden Gesundheitsdienstleistungen, die die medizinische

29 郑秉文, 建立社会保障长效机制的12点思考 (Zheng, Bingwen, Vorschläge zur Errichtung eines langfristig funktionierenden Mechanismus der sozialen Sicherheit), in: 管理世界 (Management World), 2005/10, S. 60ff.

30 葛延风, 问题与对策: 中国社保制度改革 (Ge, Yanfeng, Probleme und Gegenmaßnahmen: Die Reform der sozialen Sicherheit in China), in: 中国行政管理 (Chinese Public Administration), 2003/9, S. 20.

31 唐钧, 中国的社会保障政策评析 (Tang, Jun, Kommentar zur chinesischen Sozialpolitik), in: 东 岳论丛 (Dong Yue Tribune), 2008/1, S. 12ff. 
Hilfe, die öffentliche Gesundheitsversorgung und die grundlegende Gesundheitsabsicherung umfasst, mit Steuern finanziert und landesweit vereinheitlicht werden solle. ${ }^{32}$

Das Spektrum der Modellvorschläge zeigt, dass die ILO- und Weltbank-Modelle sowie die verschiedenen Modelle westlicher Industriestaaten bei der Modellkonstruierung oft als Muster erwogen werden. Allerdings hat die sozialistische Tradition der Gleichheit immer noch einen tief verwurzelten Einfluss und eine große Anhängerschaft. Die Auffassung der gleichmäßigen Grundversorgung für alle Bürger beinhaltet in großem Umfang diese Tradition. Die theoretische Grundlage der Grundversorgung ist nicht die Sicherung der sozialen Stabilität und des Wirtschaftswachstums, sondern die Gewährleistung der Gleichheitsrechte und des gemeinsamen Wohlstands aller Bürger. Wenn ein solches Modell in der Zukunft aufgebaut werden würde, erhielte nach meiner Meinung die chinesische soziale Sicherheit im Vergleich mit dem derzeitigen Modell noch mehr Gemeinwohlcharakter.

\section{Forderung nach einer neuen theoretischen Grundlage}

Die theoretischen Kontroversen und die Vielfältigkeit an Modellvorschlägen reflektieren den Zustand der chinesischen sozialen Sicherheit, für das die Entwicklung eines neuen fundamentalen Theoriensystems notwendig ist. Für die weitere Reform ist es erforderlich, auf Grundlage der bisherigen Erfahrungen eine überwiegende Übereinstimmung über das theoretische Fundament zu erreichen.

Die Forderung nach Schaffung neuer Theorien und Systeme ist nicht nur eine Frage der sozialen Sicherheit, sondern auch eine Kernfrage der chinesischen Modernisierung, die schon lange Zeit diskutiert wird. Der Philosoph Wang, Hui hat im Jahre 1997 die Notwendigkeit theoretischer Erneuerung erläutert. ${ }^{33}$ Er vertritt die Auffassung, dass der chinesische Begriff der Modernisierung zunächst neben dem Ziel des Aufbaus eines wohlhabenden und mächtigen Staates gerade die sozialistische Wertorientierung - eine Gesellschaft auf der Basis der Gleichberechtigung aufzubauen - enthält. Das Wirtschaftssystem Chinas wurde allerdings durch den Aufbau der Marktwirtschaft in die Produktionsbeziehung des globalen Kapitalismus eingeführt. Neue Konflikte und gegenseitige Einflüsse zwischen Staat, Gesellschaft und Markt fordern es, über die ideologischen Voraussetzungen der chinesischen Modernisierung erneut nachzudenken.

Der Philosoph Gan, Yang versucht, aus den traditionellen chinesischen Lehren und der 60 Jahre alten Geschichte der Volksrepublik die fundamentalen Elemente eines neu-

32 王绍光, 医改不存在迷局: 理性回归中国传统 (Wang, Shaoguang, Gesundheitsreform: Wiederkehr zur chinesischen Tradition), in: 书城 (Booktown), 2005/10, S. 33; 李玲, 医改关键是政府职 能转变 ( $L i$, Ling, Schwerpunkt der Gesundheitsreform: Veränderung der Regierungsfunktion), in: 中国改革 (China Reform), 2009/8, S. 63; 葛延风/贡森, 中国医改: 问题, 根源, 出路 (Ge, Yanfeng/Gong, Sen, Chinese Healthcare Reform), S. 18ff.

33 Siehe: 汪晖, 当代中国的思想状况与现代性问题 (Wang, Hui, Die ideelle Verfassung im heutigen China und die Frage der Modernität), in: 天涯 (Tianya), 1997/5, S. 133ff. 
en ideologischen Systems herauszufiltern. Er ist der Meinung, dass drei Traditionen zurzeit in China nebeneinander existieren. Eine entsteht aus den marktwirtschaftlichen Erfahrungen der Periode „Reform und Öffnung“. Diese Tradition enthält hauptsächlich die Forderung nach mehr Freiheit. Eine Andere ist die sozialistische Tradition der Gleichheit, die in der Mao-Zedong-Ära gebildet und seit Ende der 1990er Jahre wieder betont wird. Die Dritte ist die traditionelle chinesische Kultur. Der Hauptteil dieser Kultur ist der Konfuzianismus. ${ }^{34}$ Gan, Yang vertritt die Ansicht, dass die Legitimitäten der drei Traditionen zunächst gleichzeitig anzuerkennen seien, um eine neue Übereinstimmung bilden zu können. 35

Eine wichtige Reaktion der Regierungspartei auf diese Forderung ist die Aufstellung der Theorie der „Harmonischen Gesellschaft“ vom Jahre 2006. ${ }^{36}$ Mit ihr wurde eine Übereinstimmung über die Legitimation und Harmonisierung der „drei Traditionen“ erreicht. Als Kernelemente des aus der konfuzianischen Tradition stammenden Begriffs „Harmonische Gesellschaft“ werden die sozialistischen Kernwerte, die sozialistische Marktwirtschaft und die Errichtung der staatlichen Grundsysteme bezeichnet. Die staatlichen Grundsysteme umfassen die demokratische Politik, das Recht, das Justizsystem, das öffentliche Finanzwesen, die Einkommensverteilung sowie die soziale Sicherung. ${ }^{37}$ Um die zunehmende gesellschaftliche Ungleichheit zu dezimieren, wird der Aufbau der sozialen Sicherheit in dieser Phase besonders berücksichtigt. 38

Wie bereits oben erwähnt, wird die Haupttendenz der derzeitigen theoretischen Entwicklung dadurch charakterisiert, dass die linksorientierten Intellektuellen und die Regierungspartei versuchen, eine neue theoretische Grundlage aufgrund der Harmonisierung verschiedener Traditionsströmungen aufzubauen. Im Bericht des 17. Parteitags wurde diese Einstellung noch deutlicher geäußert. Das Verbinden des Festhaltens an den „Vier Grundprinzipien“ mit dem Festhalten an der Reform und Öffnung, das Verbinden des grundlegenden sozialistischen Systems mit dem Aufbau der Marktwirtschaft sowie das Verbinden der Erhöhung der Effizienz mit der Förderung der sozialen Gleichheit und Gerechtigkeit werden als wertvolle Erfahrungen der chinesischen Modernisierung und der Entwicklung des Sozialismus bezeichnet. ${ }^{39}$ Gegenüber der ver-

34 甘阳, 新时代的通三统: 中国三种传统的融会 (Gan, Yang, Verschmelzung der drei Traditionen in China), in: 书城 (Booktown), 2005/6, S. 29.

35 甘阳, 中国道路: 三十年与六十年 (Gan, Yang, Der chinesische Weg: 30 Jahre und 60 Jahre), in: 读书 (Read), 2007/6, S. 4ff.

36 中共中央关于构建社会主义和谐社会若干重大问题的决定 (Beschluss des Zentralkomitees der KP Chinas über einige wichtige Fragen zur Strukturierung einer harmonischen sozialistischen Gesellschaft), vom 11. 10. 2006, ausführlich vgl. Erster Teil, Aufbau einer „harmonischer Gesellschaft".

37 Nr. 4 des Beschlusses des Zentralkomitees der KP Chinas über einige wichtige Fragen zur Strukturierung einer harmonischen sozialistischen Gesellschaft.

38 Nr. 3 des Beschlusses des Zentralkomitees der KP Chinas über einige wichtige Fragen zur Strukturierung einer harmonischen sozialistischen Gesellschaft.

39 胡锦涛, 在中国共产党第十七次全国代表大会上的报告 (Hu, Jintao, Bericht auf dem 17. Parteitag der KP Chinas), vom 15. 10. 2007, in: 人民日报 (RMRB), 25. 10. 2007 
neinenden Haltung der Neoliberalen zur Mao-Zedong-Ära 40 bewertet die Regierungspartei die Etablierung des sozialistischen Systems in der Mao-Zedong-Ära als ,die grundlegende politische Voraussetzung und die Systemgrundlage“ des modernen Chinas. 41

Diese theoretische Entwicklung entspricht den Verfassungsänderungen seit 1982, bei denen die wirtschaftliche Grundlage des ,grundlegenden sozialistischen Systems“, nämlich das Gemeineigentumssystem und die Planwirtschaft, durch die Einführung eines gemischten Eigentumssystems und der Marktwirtschaft verändert wurde. Allerdings bleiben die anderen Grundsteine des chinesischen sozialistischen Systems, wie das staatliche Organisations- und Führungsprinzip des Demokratischen Zentralismus und die sozialistische Ideologie, weiterhin in der Verfassung fest verankert. ${ }^{42}$ Obwohl der Anteil des Gemeineigentums an der gesamten Volkswirtschaft in dieser Phase deutlich gesunken ist, nimmt der sozialistische Charakter des chinesischen Eigentumssystems dadurch keinen gründlichen Schaden an. ${ }^{43}$ Bei der Ausarbeitung der Richtlinien für die Entwicklung der Volkswirtschaft wurde ,die gemeineigene Wirtschaft unbeirrt zu konsolidieren und zu entwickeln, die Kontrollkraft und der Einfluss der staatseigenen Wirtschaft zu erhöhen" betont. ${ }^{44}$ Hierin zeigt sich, dass die sozialistische Strömung wieder stärker geworden ist. Während die KP Chinas versucht, die liberale Tendenzen unter Kontrolle zu halten.

\section{Ausblick: Soziale Sicherheit als Bestandteil der Staatsordnung}

Zusammengefasst bildet das Zusammenwirken der gesellschaftlichen, wirtschaftlichen und kulturellen Rahmenbedingungen, die bestehenden Institutionen, ${ }^{45}$ die politischen Entscheidungen sowie die gesellschaftlichen Anforderungen allmählich eine neue Form der sozialen Sicherheit in China. Die Einführung von Verantwortung der Gesellschaft und des Einzelnen für die soziale Sicherheit wurde schon durch die verfassungsrechtliche Legitimierung des gemischten Eigentumssystems und der Marktwirtschaft festgelegt. Zurzeit ist eine neue Tendenz bemerkbar, dass die sozialistische Färbung im

40 Siehe: 吴敬琏, 中国经济六十年 (Wu, Jinglian, 60 Jahre Geschichte der chinesischen Wirtschaft), in: 财经杂志 (Caijing Magazine), 2009/20, S. 76ff.

$41 \mathrm{Hu}$, Jintao, Bericht auf dem 17. Parteitag der KP Chinas, vom 15. 10. 2007.

42 Ausführlich: Zweiter Teil, die Verfassung von 1982.

43 Ausführlich Vgl. 王绍光, 坚守方向, 探索道路: 中国社会主义实践60年 (Wang, Shaoguang, From the Global Perspective Adhering to the Right Direction and Exploring New Paths: Reflections on Sixty Years of Socialist Practice in China), in: 中国社会科学 (Social Science in China), 2009/5, S. 16ff.

$44 \mathrm{Hu}$, Jintao, Bericht auf dem 17. Parteitag der KP Chinas, vom 15. 10. 2007.

45 Vgl. Becker, in: Becker/Kaufmann/Maydell/Schmähl/Zacher (Hrsg.), Alterssicherung in Deutschland, Festschrift für Franz Ruland zum 65. Geburtstag, S. 575; auch: Becker, Cultural Background of Social Security in Germany, the influence of values and of the constitution on social protection, in: 中国人民大学学报 (Journal of Remin University of China), 2010/1, S. 31. 
Vergleich mit dem in den 1990er Jahren geplanten Systemmodell verstärkt wird. Die Konstruktion der sozialen Sicherheit ist zurzeit noch nicht ausgereift, allerdings haben sich einige Kernelemente allmählich verfestigt:

1. Ein alle Bürger umfassendes System:

„Jeder Bürger genießt Grundlebenssicherung und medizinische Grundversorgung“. 46 Diese politische Parole reflektiert die sozialistischen Gleichheits- und Gerechtigkeitsideen, die zusammen mit dem Einfluss des chinesischen Ideals der „Großen Gemeinsamkeit“ eine theoretische Grundlage für den Systemaufbau bilden. Das sozialistische Gemeineigentum gewährleistet diese Grundlage.

2. Die überwiegende Rolle des Staates für soziale Sicherheit:

Als ein zentralisierter Staat hat China eine lange Tradition von „Verantwortung des Staates“ im Bereich der sozialen Sicherheit. Mit dem staatlichen Organisationsprinzip des Demokratischen Zentralismus hat die Volksrepublik ein mächtiges Regierungssystem entwickelt, das seit langer Zeit eine starke Rolle im öffentlichen Leben spielt. Demgegenüber ist die Entwicklung der gesellschaftlichen Selbstverwaltung begrenzt. Für die Konstruierung, die Verwaltung sowie die Finanzierung der sozialen Sicherung sollte der Staat in Zukunft weiterhin die Hauptverantwortung übernehmen.

3. Die Einführung der Selbstverantwortung des Einzelnen:

Die Förderung der Selbstverantwortung der Bürger wird den marktwirtschaftlichen Faktoren entsprechend forciert.

Die weitere Entwicklung der sozialen Sicherheit und des Sozialleistungsrechts in China wird von vielen Faktoren beeinflusst, wie die Geschichte und Tradition, die politischen und wirtschaftlichen Systeme, die staatliche Entwicklungsstrategien sowie die internationalen Einflüsse. Als eines der Grundsysteme des Staates kann die soziale Sicherheit nicht mehr nach den Maßstäben von 1994, die hauptsächlich dem Aufbau der Marktwirtschaft dienen, bewertet werden. Diese dient auch nicht nur der gesellschaftlichen Stabilität und der Beseitigung sozialer Disparitäten. Als eine staatliche Institution, die den ,gemeinsamen Wohlstand“ und die soziale Gleichheit - die wesentlichen Ziele des chinesischen Sozialismus - verkörpert, übernimmt die soziale Sicherheit die wichtige Aufgabe, zusammen mit anderen staatlichen Institutionen als gemeinsame Wertgrundlage des Staates zu dienen.

$46 \mathrm{Hu}$, Jintao, Bericht auf dem 17. Parteitag der KP Chinas, vom 15. 10. 2007. 


\section{Literaturverzeichnis}

\section{Chinesische Literatur}

安全科学技术研究中心, 加入职业安全卫生及工作环境公约的可行性研究报告 (Forschungszentrum für Technik und Arbeitssicherheit, Bericht über die Ratifikationsmöglichkeit der ILOKonvention Nr. 155), Beijing, 2004.

白天亮, 养老保险省级统筹力争两年内实现 (Bai, Tianliang, Verwirklichung der einheitlichen Planung der Rentenversicherung auf Provinzebene in zwei Jahren), in: 人民日报 (Renmin Zeitung) (RMRB) vom 09. 01. 2008.

Becker, Ulrich, 德国社会保障制度的文化背景 (Cultural Background of Social Security in Germany, the influence of values and of the constitution on social protection), in: 中国人民大学学报 (Journal of Remin University of China), 2010/1, S. 30-34.

Diamond/Barr, 中国社会保障制度改革: 问题及对策选择 (Social Security Reform in China: Issues and Options II), in: 比较 (Comparative Studies), 2006/7, Nr. 25, S. 99-103.

蔡定剑刘丹，从政策社会到法治社会 - 兼论政策对法制建设的消极影响 (Cai, Dingjian/Liu, Dan, From the Society in Policy to the Society in Rule of Law), in: 黄之英, 中国法治之路 (Huang, Zhiying, The Road to The China's Rule of Law), Beijing, 2000, S. 83-93.

蔡定剑, 宪法精解 (Cai, Dingjian, Constitution: A intensive Reading), Beijing, 2006.

蔡定剑, 中国人民代表大会制度 (Cai, Dingjian, The Institution of the Chinese People's Congress), 4. Aufl., Beijing, 2003.

蔡定剑, 中国社会转型时期的宪政发展 (Cai Dingjian, Die konstitutionelle Entwicklung im Transformationsprozess der chinesischen Gesellschaft), in: 华东政法学院学报 (Journal of the East China University of Political Science and Law), 2006/4, S. 3-18.

残疾人权利公约及与残疾人保障法修订的衔接 (Die Umsetzung der Konvention über die Rechte von Menschen mit Behinderungen durch die Revision des Gesetzes zum Schutz von behinderten Menschen), http://temp.cdpj.cn/bzfxg/2005-04/05/content_3933.htm (Stand: 15. 07. 2010).

陈端洪，宪治与主权 (Chen, Duanhong, Constitutionality and Sovereignty), Beijing, 2007.

陈端洪, 由富强到自由: 中国宪法的价值取向与司法化的可能 (Chen, Duanhong, Von Wohlstand bis Freiheit: Wertorientierung der chinesischen Verfassung und die Möglichkeit der unmittelbaren Anwendung durch die Gerichte), in: 法制日报 (Fazhi Zeitung) (FZRB), 05. 12. 2002.

陈顾远, 中国文化与中国法系 (Chen, Guyuan, Die chinesische Kultur und das chinesische Rechtssystem), Beijing, 2006.

陈佳贵, 中国社会保障发展报告 1997-2001 (Chen, Jiagui (Hrsg.), China Social Security System Development Report 1997-2001), Beijing, 2001.

陈佳贵/王延中, 中国社会保障发展报告 2001-2004 (Chen, Jiagui/Wang, Yanzhong (Hrsg.), China Social Security System Development Report 2001-2004), Beijing, 2004.

陈佳贵/王延中，中国社会保障发展报告 (2007) No. 3 (Chen, Jiagui/Wang, Yanzhong (Hrsg.), China Social Security System Development Report, 2007, No. 3), Beijing, 2007.

陈建国, 新议题与多边贸易体系 (Chen, Jianguo, Ein neues Thema und das multilaterale Handelssystem), Tianjin, 2003. 
陈金永, 中国户籍制度改革和城乡人口迁移 (Chen, Jinyong, The Hukou-System and Rural-Urban Migration in China), in: 中国劳动经济学 (China Labor Economics), 2004/1, S. 108-123.

陈良谨, 社会保障教程 (Chen, Liangjin (Hrsg.), Soziale Sicherheit), Beijing, 1990.

陈云, 经济形势与经验教训 (Chen, Yun, Wirtschaftslage und Erfahrungen), in: 陈云文选第三卷 (Ausgewählte Werke von Chen, Yun, Vol. 3), Beijing, 1995, S. 279-280.

程永宏, 中国就业制度演变与评估 (Cheng, Yonghong, Kommentar zur Umgestaltung des Beschäftigungssystems Chinas), in: 胡鞍钢/程永宏/杨韵新, 扩大就业与挑战失业 (Hu, Angang/Cheng, Yonghong/Yang, Yunxin (Hrsg.), Beschäftigungsförderung und Arbeitslosigkeitsbeseitigung), Beijing, 2002, S. 43-162.

崔风/孙启泮，从历次制宪与修宪看中国社会保障的发展 (Cui, Feng/Sun, Qipan, Eine Betrachtung der Entwicklung der sozialen Sicherheit Chinas von den Verfassungsänderungen aus), in: 社会保 障制度 (Social Security System), 2006/2, S. 56-60.

崔乃夫, 关于中华人民共和国残疾人保障法 (草案) 的说明 (Cui, Naifu, Erklärung über den Entwurf des Gesetzes zum Schutz von behinderten Menschen der Volksrepublik China), vom 25. 10. 1990, http://www.lawbook.com.cn/fzdt/newshtml/20/20050722194037.htm (Stand: 15. 07. 2010).

邓小平文选 (1975-1982), (Deng, Xiaoping, Ausgewählte Werke von Deng, Xiaoping, 1975-1982), Beijing, 1993.

邓小平文选第三卷 (Deng, Xiaoping, Ausgewählte Werke von Deng Xiaoping, Dritter Band), Beijing, 1993.

董保华, 社会法元论 (Dong, Baohua, Sozialrecht), Beijing, 2001.

董云虎，中国人权30年 (Dong, Yunhu, 30 Jahre Menschenrechte in China), in: 新京报 (XJB), 10. 01. 2009.

都阳/高文书，中国离一元社会保障体系有多远 (Du, Yang/Gao, Wenshu, How Far is China Away From an Intergrated Social Security System), in: 中国劳动经济学 (China Labor Economics), 2005, Vol.2 No.2, S. 45-59.

房宁, 影响当代中国的三大社会思潮 (Fang, Ning, Die drei wichtigsten ideologischen Tendenzen in der gegenwärtigen Epoche Chinas), in: 陈明明, 权利, 责任与国家 (Chen, Mingming (Hrsg.), Recht, Verantwortung und Staat), Shanghai, 2006, S. 265-292.

费平, 深圳市农民工社会保险制度 (Fei, Ping, Das soziale Sicherungssystem der Wanderarbeiter in der Stadt Shenzhen), in: 中国劳动 (China Labor), 2006/10, S. 13-14.

\#阴，从民族国家走向文明国家 (Gan, Yang, From Nation-State to Civilization-State), in: 书城 (Booktown), 2005/5, S. 35-40.

甘阳, 新时代的通三统: 中国三种传统的融会 (Gan, Yang, Verschmelzung der drei Traditionen in China), in: 书城 (Booktown), 2005/6, S. 29-33.

甘阳，中国道路: 三十年与六十年 (Gan, Yang, Der chinesische Weg: 30 Jahre und 60 Jahre), in: 读书 (Read), 2007/6, S. 3-13.

高强, 努力保证人民公平衣有基本卫生保健 (Gao, Qiang, Kampf mit vollem Einsatz für die Gewährleistung eines gerechten grundlegenden Gesundheitssystems für alle Bürger), in: 人民日报 (RMRB), 23. 11. 2006.

高书生, 关于搭建中国社会保障新平台的设想 (Gao, Shusheng, Ein neuer Plan für die chinesische soziale Sicherheit), in. 经济研究参考 (Review of Economic Research), 2003/4, S. 25-35.

高书生, 社会保障改革何去何从 (Gao, Shusheng, Die Reform der sozialen Sicherheit steht am Scheideweg), Beijing, 2006. 
高西庆/徐菁, 对个人账户管理体制的思考- 对下一步改革的一个建议 (Gao, Xiqing/Xu, Jing, The Trading Platform for Social Security Products: A Reform Proposal), in: 比较 (Comparative Studies), 2007/7, Nr. 31, S. 89-106.

葛延风, 社会保障制度遭遇变局 (Ge, Yanfeng, Notstand der Systeme der sozialen Sicherheit), in: 中 国改革 (Reform), 2005/1, S. 31-33.

葛延风/贡森，中国医改：问题，根源，出路 (Ge, Yanfeng/Gong, Sen, Chinese Healthcare Reform), Beijing, 2007.

葛延风, 问题与对策: 中国社保制度改革 (Ge, Yanfeng, Probleme und Gegenmaßnahmen: Reforme der sozialen Sicherheit in China), in: 中国行政管理 (Chinese Public Administration), 2003/9, S. 17-22.

葛延风, 完善城镇职工养老保险制度的思路与对策 (Ge, Yanfeng, Approaches and Policies to Enhance the Workers' Pension System in Urban Areas), in: 陈佳贵/王延中，中国社会保障发展报告 2001-2004 (Chen, Jiagui/Wang, Yanzhong (Hrsg.), China Social Security System Development Report 2001-2004), Beijing, 2004, S. 178-226.

顾所, 通向普遍主义的艰难之路：中国城镇失业保险制度的覆盖面分析 $(G u, X i n$, Analyse zum Deckungsbereich der chinesischen Arbeitslosenversicherung in Städten und Gemeinden), in: 东岳 论从 (Dong Yue Tribune), 2006/5, S. 27-32.

顾昕，通向全民医保的渐进主义之路 ( $G u$, Xin, Ein Weg zur Gesundheitsabsicherung für alle Bürger), in: 东岳论丛 (Dong Yue Tribune), 2008/1, S. 6-11.

顾所，中国医疗服务体制的改革后果与政府角色 (Consequences of Reform and Government Role in China's Health Care System), in: 陈佳贵/王延中，中国社会保障发展报告 (2007) No. 3 (Chen, Jiagui/Wang, Yanzhong (Hrsg.), China Social Security System Development Report (2007) No. 3), Beijing, 2007, S. 218-245.

关海庭, 文化大革命与当代中国改革模式的选择 (Guan, Haiting, The Cultural Revolution and the Selection of Contemporary China's Reform Model), in: 当代中国史研究 (Contemporary China History Studies), 2007/7, Nr. 4, S. 58-71.

关信平黄晓燕，中国农村居民最低生活保障制度及运行机制（Guan, Xinping/Huang, Xiaoyan, The Running Mechanics of the Minimum Living Standard System for Rural Residents in China), in: 社会保障研究 (Social Security Studies), 2006/1, S. 195-207.

关于残疾人保障法修改总体框架的方案及其说明 (征求意见稿) (Erklärung über den allgemeinen Revisionsrahmen des Gesetzes zum Schutz von behinderten Menschen) (Entwurf), 2005, http://temp.cdpj.cn/bzfxg/2005-04/05/content_3933.htm (Stand: 15. 07. 2010).

国家发改委小康项目课题组，全面建设小康社会指标体系 (Forschungsgruppe des Staatskommission für Entwicklung und Reform, Das System der Planziffern über den allseitigen Kleinen Wohlstand), in: 经济日报 (Economic Daily), 14. 10. 2009.

国务院，关于城乡医疗卫生体制改革和加强食品药品安全监管情况的报告 (Bericht des Staatsrats über die Gesundheitsreform sowie die Überwachung- und Verwaltungsarbeit von Lebensmittel und Arzneimittel), vom 26. 12. 2007, in: 健康报 (Jiangkang Zeitung), 27. 12. 2007.

国务院发展研究中心课题组, 对中国医疗卫生体制改革的评价与建议 (Forschungszentrum des Staatsrats für Entwicklung, Kommentar und Vorschläge zur Reform des Gesundheitssystems Chinas), in: 中国发展评论 (China Development Review), 2005/3, Heft 7-1.

国务院发展研究中心课题组，中国政府间财政转移支付制度的现状，问题与完善 (Forschungszentrum des Staatsrats für Entwicklung, Zustand und Probleme des fiskalischen Umverteilungssystems zwischen Regierungen und Verbesserungsvorschläge), in: 经济要参 (Economic Reference), 2005/28.

国务院发展研究中心社会保障制度改革研究课题组, 中国城镇失业保障制度改革的回顾与前瞻 (Forschungsgruppe des Staatsrats für Reform der sozialen Sicherheit, Rückschau und Vorschau auf die Reform der Arbeitslosensicherung), in: 管理世界 (Management World), 2001/1, S. 7786. 
国务院扶贫办, 中国农村扶贫开发概要 (Abteilung für Armutsbekämpfung und Entwicklung beim Staatsrat, Übersicht über Armutsbekämpfung und Erschließung auf dem Land), vom 28. 09. 2006, http://www.cpad.gov.cn/data/2006/1120/article_331600.htm (Stand: 15. 07. 2010)

国务院新闻办公室, 中国的人权状况 (Presseamt des Staatsrats, Menschenrechtssituation in China), vom 01. 11. 1991, Beijing, 1991.

国务院新闻办公室, 中国人权事业的进展1995 (Presseamt des Staatsrats, Entwicklung des Menschenrechtswesens in China), Beijing, 1995.

国务院新闻办公室, 中国的农村扶贫开发白皮书 (Presseamt des Staatsrats, Weißbuch über die ländliche Armutsbekämpfung und Erschließung in China), Beijing, 2001.

国务院新闻办公室, 中国的劳动和社会保障状况的白皮书 (Presseamt des Staatsrats, Arbeit und Sozialabsicherung in China), Beijing, 2002, Übersetzung in: Beijing Rundschau 2002.

国务院新闻办公室, 2004年中国人权事业的进展 (Presseamt des Staatsrats, Menschenrechtswesen in China 2004), Beijing, 2004.

国务院新闻办公室, 中国的就业状况和政策 (Presseamt des Staatsrats, Weißbuch über Chinas Beschäftigungslage und -politik), vom 26. 04. 2004, Beijing, 2004.

国务院新闻办公室, 中国的社会保障状况和政策白皮书 (Presseamt des Staatsrats, Soziale Sicherheit und Sozialpolitik in China), vom 07. 06. 2005, Beijing, 2005.

国务院新闻办公室, 中国的民主政治建设白皮书 (Presseamt des Staatsrats, Aufbau der politischen Demokratie in China), vom 19. 10. 2005, Beijing, 2005.

国务院研究室课题组, 中国农民工调研报告 (Forschungsgruppe des Staatsrats, Reporting on the Problems of Chinese Farmer-turned Workers), Beijing, 2006.

海瑞，海瑞集 (Hai, Rui, Das Gesamtwerk von Hai Rui), Beijing, 1962.

韩长赋, 关于农民工问题调研后的几点思考 (Han, Changfu, Einige Gedanken über die Frage der Wanderarbeiter), in: 国务院研究室课题组, 中国农民工调研报告 (Forschungsgruppe des Staatsrats, Reporting on the Problems of Chinese Farmer-turned Workers), Beijing, 2006, S. 6266.

韩君玲, 劳动与社会保障法简明教程 (Han, Junling, Grundlage des Arbeitsrechts und des Sozialrechts), Beijing, 2005.

何平, 加入WTO对中国社会保障的影响与对策 (He, Ping, Einfluss des WTO-Beitritts auf die chinesische Sozialsicherung), in: 宏观经济研究 (Macroeconomics), 2002/3, S. 17-22.

何平, 让农民工退保成为历史 (He, Ping, Beseitigung des Phänomens ,Austritt der Wanderarbeiter aus der sozialen Versicherungen“), in: 中国报道 (China Report), 2008/3, S. 26-27.

何勤华/李秀清, 外国法与中国法 一 二十世纪中国移植外国法反思 (He, Qinhua/Li, Xiuqing, Der chinesische Rezeptionsprozess des ausländischen Rechts im 20. Jahrhundert), Beijing, 2003.

何增科, 20世纪80年代末以来中国关于政治改革和民主化的探讨 (He, Zengke, About China's Political System Reform and Democratization since 1980's), in: 北京行政学院学报 (Journal of Beijing Administrative College), 2002/6, S. 18-24.

何增科，渐进政治改革与民主的转型 (He, Zengke, Progressive Political Reform and Transformation of Democracy), in: 北京行政学院学报 (Journal of Beijing Administrative College), 2004/3, S. 1014.

胡鞍钢, 第二次转型: 以制度建设为中心 (Hu, Angang, Die zweite Transformation: Aufbau der Staatsordnung ist die Hauptaufgabe), in: 战略与管理 (Strategy \& Management), 2002/3, S. 34-38.

胡鞍钢/程永宏，从计划体制转向市场机制：对中国就业政策的评估 (1949-2001) ( Hu, angang/Cheng, Yonghong, Vom planwirtschaftlichen System zum marktwirtschaftlichen System Kommentar zur chinesischen Beschäftigungspolitik (1949-2001), in: 胡鞍钢/程永宏/杨韵新, 扩 大就业与挑战失业 (Hu, Angang/Cheng, Yonghong/Yang, Yunxin (Hrsg.), Beschäftigungsförderung und Arbeitslosigkeitsbeseitigung), Beijing, 2002, S. 3-39. 
胡鞍钢/杨韵新, 结构变革的创造性摧毁: 中国城镇失业与失业保障 (1993-2000) (Hu, Angang/Yang, Yunxin, Schaffung und Zerstörung in der Strukturänderung: die Arbeitslosigkeit in den chinesischen Städten und Gemeinden 1993-2000), in: 胡鞍钢/程永宏/杨韵新, 扩大就业与挑战失业 (Hu, Angang/Cheng, Yonghong/Yang, Yunxin (Hrsg.), Beschäftigungsförderung und Arbeitslosigkeitsbeseitigung), Beijing, 2002, S. 209-247.

胡鞍钢, 中国政治经济史论 (1949-1976) (Hu, Angang, Geschichte der politischen Ökonomie in China 1949-1976), 2. Aufl., Beijing, 2008.

胡福明, 实践是检验真理的唯一标准 (Hu, Fuming, Die Praxis ist das einzige Kriterium der Wahrheit), in: 光明日报 (GMRB), 11.05. 1978.

胡锦涛, 在中国共产党第十七次全国代表大会上的报告 $(\mathrm{Hu}$, Jintao, Bericht auf dem 17. Parteitag der KP Chinas), vom 15. 10. 2007, in: 人民日报 (RMRB), 25. 10. 2007.

华建敏, 加快建设中国特色社会保障体系 (Hua, Jianmin, Soziale Sicherheit chinesischer Prägung), in: 社会保障制度 (Social Security System), 2008/03, S. 3-10.

华建敏, 关于国务院机构改革方案的说明 (Hua, Jianmin, Erläuterung über den Reformplan der Verwaltungsorgane des Staatsrats), vom 11.03.2008, in: 人民日报 (RMRB), 12.03. 2008.

华迎放，社会保障 (Hua, Yingfang (Hrsg.), Soziale Sicherheit), Beijing, 2007.

黄仁宇, 资本主义与二十一世纪 (Huang, Ray, Kapitalismus und das 21. Jahrhundert), Beijing, 1997.

黄松有, 宪法司法化及其意义 (Huang, Songyou, Die unmittelbare Anwendung der Verfassung durch die Gerichte und deren Bedeutung), in: 人民法院报 (Volksgerichtszeitung), 13. 08. 2001.

$I L O$, 中国职业安全卫生概况 (National Profile Report on Occupational Safety and Health in China), Beijing, 2005.

贾俊玲, 劳动法和社会保障法学 (Jia, Junling (Hrsg.), Arbeitsrecht und Recht der sozialen Sicherheit), Beijing, 2005.

江平, 宪法司法化四人谈 (Gespräche von vier Juristen über die Anwendung der Verfassung durch die Gerichte), in: 南方周末 (Nanfang Zeitung) (NFZM), 13. 09. 2001.

江泽民，在中国共产党第十四次全国代表大会上的报告 (Jiang, Zemin, Bericht auf dem 14. Parteitag der KP Chinas), vom12. 10. 1992, in: 人民日报 (RMRB), 21. 10. 1992.

江泽民，在中国共产党第十五次全国代表大会上的报告 (Jiang, Zemin, Bericht auf dem 15. Parteitag der KP Chinas), vom 12.09. 1997, in: 人民日报 (RMRB), 22.09. 1997.

江泽民, 在庆祝建党八十周年大会上的讲话 (The Speeches at the Symposium on the Talk at the Celebration Meeting for the 80th Anniversary of CCP Founding by Jiang Zemin), in: 人民日报 (RMRB), 02. 07. 2001.

江泽民，在中国共产党第十六次全国代表大会上的报告 (Jiang, Zemin, Bericht auf dem 16. Parteitag der KP Chinas), vom 08. 11. 2002, in: 人民日报 (RMRB), 17. 11. 2002.

景天鬼, 大力推进与国情相适应的社会保障制度建设 (Jing, Tiankui, Vorantreiben des Aufbaus eines der Lage des Staates anpassenden System der sozialen Sicherheit), in: 理论前沿 (Theory Front), 2007/18, S. 5-9.

景天鬼/唐均/张时飞, 城乡统筹就业 一 浙江省义乌市的实践 (Jing, Tiankui/Tang, Jun/Zhang, Shi$f e i$, Eine einheitliche Beschäftigungspolitik für Stadt und Land - die Praxis aus Yiwu in der Provinz Zhejiang), in: 浙江经济 (Zhejiang Economy), 2002/19, S. 14-15.

Johnston, Alastair Iain, 美国学者关于中国与国际组织关系研究概述 (Forschungsüberblick über die Beziehungen zwischen China und den internationalen Organisationen), in: 世界经济与政治 (World Economics Politics), 2001/8, S. 48-53.

Johnston, Alastair Iain, 简论国际机制对国家行为的影响 (Einfluss der internationalen Institutionen auf die staatlichen Handlungen), in: 世界经济与政治 (World Economics Politics), 2002/12, S. 21-27. 
课题组, 河北省农村社会养老保障制度建设研究 (Forschungsgruppe, Forschungsbericht über den Aufbau des sozialen ländlichen Alterssicherungssystems in der Provinz Hebei), in: 社会保障制度 (Social Security System), 2006/5, S. 39-50.

劳动和社会保障部, 近年来我国社会保险基本情况 (Ministerium für Arbeit und soziale Sicherheit, Zustand der Sozialversicherung in den letzten Jahren), in: 人民日报 (RMRB), 15. 12. 2007.

劳动部/联合国开发计划署/国际劳工组织北京局, 中国社会保险制度改革与立法 (Arbeitsministeri$u m / U N D P / I L O$, Reform und Gesetzgebung des chinesischen Sozialversicherungssystems), Beijing, 1996.

劳动和社会保障部社会保障研究所, 城镇化进程加快过程中农民工社会保障制度研究 (Forschungsinstitut für soziale Sicherheit beim Ministerium für Arbeit und soziale Sicherheit, Das soziale Sicherungssystem für die Wanderarbeiter im Urbanisierungsprozess), in: 社会保障研究 (Forschung über die soziale Sicherheit), 2006/1, S. 2-27.

劳动和社会保障部社会保障研究所, 关于中国医疗保障制度改革的框架性建议 (Forschungsinstitut für soziale Sicherheit beim Ministerium für Arbeit und soziale Sicherheit, Vorschläge für die Reform des chinesischen Gesundheitssystem), in: 社会保障研究 (Forschung über die soziale Sicherheit), 2007/5.

劳动和社会保障部社会保障研究所, 机关事业单位养老保险制度改革调研报告 (Forschungsinstitut für soziale Sicherheit beim Ministerium für Arbeit und soziale Sicherheit, Forschungsbericht über die Reform des Altersversicherungssystems der Staatsorgane und öffentlichen Institutionen), in: 社会保障研究 (Forschung über die soziale Sicherheit), 2007/5.

劳动和社会保障部社会保障研究所, 农民工社会保障的新情况新问题 - 基于深圳上海的实地调研 (Forschungsinstitut für soziale Sicherheit beim Ministerium für Arbeit und soziale Sicherheit, Gegenwärtiger Zustand und neue Probleme der Wanderarbeitersicherung - aufgrund der Untersuchungen in Shenzhen und Shanghai), in: 社会保障研究 (Forschung über die soziale Sicherheit), 2008/1.

劳动和社会保障部调研组，农民工社会保障问题研究报告 (Forschungsgruppe des Ministerium für Arbeit und soziale Sicherheit, Forschungsbericht über die soziale Sicherung der Wanderarbeiter), in: 国务院研究室课题组, 中国农民工调研报告 (Forschungsgruppe des Staatsrates, Reporting on the Problems of Chinese Farmer-turned Workers), Beijing, 2006, S. 248-259.

劳动和社会保障部社会保障研究所, 中国卫生改革的方向与总体思路 (Forschungsinstitut für soziale Sicherheit beim Ministerium für Arbeit und soziale Sicherheit, Vorschläge zur Gesundheitsreform), in: 社会保障研究 (Forschung über die soziale Sicherheit), 2007/3.

礼记 (Das Buch der Sitte), übersetzt von Wilhelm, Richard, Jena, 1930.

黎建飞, 社会保障法 (Li, Jianfei (Hrsg.), Recht der sozialen Sicherheit), 2. Aufl., Beijing, 2006.

李步云, 法理学 (Li, Buyun (Hrsg.), Rechtstheorie), Beijing, 2001.

李玲, 医改方向: 政府主导下市场补充 ( $L i$, Ling, Gesundheitsreform: Hauptverantwortung der Regierung mit dem Marktsystem als Ergänzung), in: 中国医疗前沿 (China Healthcare Innovation), 2006/1, S. 33-36.

李玲, 医改关键是政府职能转变 ( $L i$, Ling, Schwerpunkt der Gesundheitsreform: Veränderung der Regierungsfunktion), in: 中国改革 (China Reform), 2009/8, S. 62-63.

李绍光, 政府在社会保障中的责任 (Li, Shaoguang, Die Verantwortung der Regierung im Bereich der sozialen Sicherheit), in: 经济社会体制比较 (Comparative Economic \& Social Systems), 2002/5, S. 34-37.

李迎生, 立足现实, 面向未来: 农村养老保障制度改革的过渡模式设计 (Li, Yingsheng, Ein Übergangsmodell der ländlichen Alterssicherungsreform), in: 社会保障制度 (Social Security System), 2006/2, S. 27-31.

李迎生, 中国社会保障制度改革的目标定位新探 ( Li, Yingsheng, An Exploration of the Basic Goals of Social Security System Reform in China), in: 社会 (Society), 2006/2, S. 175-188. 
梁慧星, 最高法院关于侵犯受教育权案的法释 (2001) 25号批复评析 (Liang, Huixing, Kommentar zur Rechtssprechung (2001) Nr. 25), in: 法学天地 (Rechtswissenschaft), 2002/4, S. 11-13.

辽宁省做实基本养老保险个人账户工作评估报告 (Bericht der Provinz Liaoning über die Arbeit von Auffüllung der Individualkonten der Grundrentenversicherung), in: 完善城镇社会保障体系试点 辽宁篇 (Vervollkommnung der sozialen Sicherheit in den Städten: Liaoning-Pilotprojekt), Beijing, 2004, S. 377-384.

Levenson, Joseph Richmond, 儒教中国及其现代命运 (Confucian China and its modern Fate), Beijing, 2000.

林嘉, 社会保障法的理念, 实践与创新 (Lin, Jia, Theory, Practice and Innovation on Social Security Law), Beijing, 2002.

林嘉, 社会保障法的社会法本质 - 兼论劳动法与社会法的关系 (Lin, Jia, Das sozialrechtliche Wesen des Rechts der sozialen Sicherheit und das Verhältnis zwischen Arbeitsrecht und Recht der sozialen Sicherheit), in: 法学家 (Jurists' Review), 2002/1, S. 116-121.

林嘉/魏丽, 工伤认定一般条款之立法思考 ( $\mathrm{Lin}, \mathrm{Jia} / \mathrm{Wei}, \mathrm{Li}$, Legislative Thinking about the General Articles for Industrial Injury Determination), in: 法学杂志 (Law Science Magazine), 2008/1, S. $85-88$.

林燕玲, 国际劳工标准 (Lin, Yanling (Hrsg.), Internationale Arbeitsstandards), Beijing, 2007.

林义, 经济全球化背景下社会保障制度的挑战与对策 (Lin, Yi, Soziale Sicherheit in Zeiten der Wirtschaftsglobalisierung), in: 郑功成/郑宇硕, 全球化下的劳工与社会保障 (Zheng, Gongcheng/Zheng, Yüshuo (Hrsg.), Arbeiter und soziale Sicherheit in Zeiten der Globalisierung), Beijing, 2002, S. 409-418.

刘波, 国际贸易与国际劳工标准问题的历史演进及理论评析 (Liu, Bo, Historical Evolution and Theoretical Analysis of International Trade and Labour Standards), in: 现代法学 (Modern Law Science), 2006/3, S. 121-129.

刘军民，过度市场化与高度分权化：中国医疗卫生改革的双重误区 (Liu, Junmin, Over Marketization and high Decentralization: Double Error in China's Health Care), in: 开放导报 (China Opening Herald), 2005/5, S. 48-53.

刘铁民/朱常有/杨乃莲, 国际劳工组织与职业安全卫生 (Liu, Tiemin/Zhu, Changyou/Yang, Nailian ILO and OSH), Beijing, 2003.

刘旭，国际劳工标准概述 (Liu, X $\ddot{u}$, Introduction to International Labour Standards), Beijing, 2003.

刘旭, 我对国际劳工标准的一些看法 (Liu, Xü, Einige Ansichten an den internationalen Arbeitsstandards), in: 石美遐/Stearns, Lisa, 全球化背景下的国际劳工标准与劳动法研究 (Shi, Meixia/Stearns, Lisa, Untersuchung der internationalen Arbeitsstandards und des Arbeitsrechts unter dem Einfluss der Globalisierung), Beijing, 2005, S. 6-7.

刘遵义, 关于中国社会养老保障体系的基本构想 (Liu, Zunyi, Grundplan über das soziale Altersversorgungssystem Chinas), in: 比较 (Comparative Studies), 2003/6, Nr. 6, S. 3-28.

刘作翔，民主乎？集权乎? - 理论界关于新威权主义的论争 (Liu, Zuoxiang, Demokratie oder Autorität? - Die theoretische Diskussion über „Neo-Autorität”), in: 理论导刊 (Journal of Socialist Theory Guide), 1989/4, S. 42-43.

龙朝晖/邓建新, 政府间财政转移支付: 问题及政策建议 (Long, Zhaohui/Deng, Jianxin, Chinese Intergovernmental Fiscal Transfer System: Problems and Policy Suggestions), in: 改革 (Reform), 2005/7, S. 38-44.

卢驰文, 机关事业单位养老保险制度转轨的财政压力分析 ( $L u$, Chiwen, Analyse über die Finanzbelastung der Umgestaltung des Pensionssystems für Staatsorgane und öffentliche Institutionen), in: 理论探索 (Theoretical Exploration), 2008/1, S. 78-81.

吕炜，公平增长与公共支出的政策安排 (Lü, Wei, Policy Arrangement for Fair Growth and Public Expenditure), in: 经济社会体制比较 (Comparative Ecomonic \& Social Systems), 2004/5, S. 1229.

论语 ( Konsfuzius Gespräche der Meisters Kung), übersetzt von Ernst Schwarz, München, 1994. 
罗瑞卿, 关于中华人民共和国户口登记条例草案的说明 (Luo, Ruiqing, Erklärung über den Entwurf der ,Regeln über die Hukou-Registrierung“), in: 人民日报 (RMRB), 10. 01. 1958.

马克思恩格斯全集第三卷 (Karl Marx and Friedrich Engels, Vol. 3), Beijing, 2002.

毛泽东, 论人民民主专政 (Mao, Zedong, On the People's Democratic Dictatorship), in: 毛泽东选集第 四卷 (Ausgewählte Werke von Mao Zengdong, Vol. 4), Beijing, 1991.

毛泽东文集 (Gesamtwerk von Mao Zedong), Beijing, 1999.

门洪华, 国际机制与中国的战略选择 (Men, Honghua, International Mechanisms and Strategic Choices for China), in: 中国社会科学 (Social Sciences in China), 2001/2, S. 178-187.

孟子 (Mong Dsi, Die Lehrgespräche des Meisters Meng K’o), übersetzt von Wilhelm, Richard, Köln, 1982.

莫纪宏，两个国际人权公约下缔约国的义务与中国 (Mo, Jihong, Pflicht des Vertragsstaates zur Durchsetzung der zwei internationalen Menschenrechtskonventionen), in: 世界经济与政治 (World Economics Politics), 2002/8, S. 28-33.

莫纪宏, 国际人权公约在中国的实施 (Mo, Jihong, Durchführung der internationalen Menschenrechtskonventionen in China), in: 人权 (Menschenrechte), 2008/1.

莫荣, 当前中国就业形势与加入WTO后的政策建议 (Mo, Rong, Vorschläge zur Beschäftigungspolitik nach dem Eintritt in die WTO), in: 郑功成/郑宇硕, 全球化下的劳工与社会保障 (Zheng, Gongcheng/Zheng, Yüshuo (Hrsg.), Arbeiter und soziale Sicherheit in Zeiten der Globalisierung), Beijing, 2002, S. 257-274.

莫荣，中国就业报告 2001-2002 (Mo, Rong (Hrsg.), China Employment Report 2001-2002), Beijing, 2002.

穆怀中/柳清瑞, 中国养老保险制度改革关键问题研究 (Mu, Huaizhong/Liu, Qingrui, The Research on the Key Issues about China's Pension System Reforms), Beijing, 2006.

牛龙云, 从孙志刚事件透视中国违宪审查制度 (Niu, Longyun, Perspektive des chinesischen Systems der Kontrolle der Verfassungsmäßigkeit aus Sung-Zhigang Fall), in: 瞭望 (Liaowang), vom 05. 06. 2004.

潘屹, 论中国国家福利的重构 (Pan, $Y i$, Wiederaufbau der sozialen Sicherung in China), in: 经济与社 会体制比较 (Comparative Economic \& Social Systems), 2007/2, S. 58-64.

彭真, 关于中华人民共和国宪法修改草案的报告 (Peng, Zhen, Bericht über den Revisionsentwurf der Verfassung der Volksrepublik China), vom 26. 11. 1982, in: 王培英, 中国宪法文献通编 (Wang, Peiying (Hrsg.), Dokumentensammlung über die chinesischen Verfassungen), Beijing, 2007, S. 54-74.

全国人民代表大会常务委员会工作报告 2001 (Tätigkeitsbericht des Ständigen Ausschusses des Nationalen Volkskongresses 2001), vom 09. 03. 2001, in: 人民日报 (RMRB), 20. 03. 2001.

强世功, 宪法司法化的悖论 (Qiang, Shigong, Paradoxes in Discourse of Constitutional Adjudication), in: 中国社会科学 (Social Sciences in China), 2003/3. No. 2, S. 18-28.

乔哓阴, 关于中国特色社会主义法律体系的构成, 特征和内容 (Qiao, Xiaoyang, Das sozialistische Rechtssystem chinesischer Prägung), in: 全国人大干部培训讲义 (Lehrmaterial des Nationalen Volkskongresses), Beijing, 2004, S. 156ff.

覃有土/焚启荣, 社会保障法 (Qin, Youtu/Fan, Qirong, Recht der sozialen Sicherheit), Beijing, 1997.

余云霞, 国际劳工标准: 演变与争议 (She, Yunxia, International Labor Standards: Evolution and Controversy), Beijing, 2006. 
生存权和发展权是首要的基本人权 (Das Recht auf Existenz und das Recht auf Entwicklung sind die erstrangigen Menschenrechte), in: 人民日报 (RMRB), vom 27. 06. 2005.

史探径, 我国社会保障法的几个理论问题 (Shi, Tanjing, Einige theoretische Fragen über das chinesische Recht der sozialen Sicherheit), in: 法学研究 (Journal of Law), 1998/4, S. 18-35.

孙炳耀，完善失业保障制度的思路与对策 (Sun, Bingyao, Approaches and Policies to Enhance Unemployment Benefit System), in: 陈佳贵/王延中，中国社会保障发展报告 (2001-2004) No. 2 (Chen, Jiagui/Wang, Yanzhong (Hrsg.), China Social Security System Development Report (20012004) No. 2), Beijing, 2004, S. 134-152.

唐钧, 中国社会救助制度的变迁与评估 (Tang, Jun, Kommentar über das chinesische System der Sozialhilfe), in: 郑功成, 中国社会保障制度变迁与评估 (Zheng, Gongcheng (Hrsg.), Kommentar über die chinesischen Systeme der Sozialen Sicherheit), Beijing, 2002, S. 204-237.

唐钧, 完善社会救助制度的思路与对策 (Approaches and Policies to Enhance Social Assistance System), in: 陈佳贵/王延中，中国社会保障发展报告 (2001-2004) No. 2 (Chen, Jiagui/Wang, Yanzhong (Hrsg.), China Social Security System Development Report 2001-2004 No. 2), Beijing, 2004, S. 21-46.

唐钧, 中国的社会保障政策评析 (Tang, Jun, Kommentar zur chinesischen Sozialpolitik), in: 东岳论丛 (Dong Yue Tribune), 2008/1, S. 12-34.

汤耀国，中国法律体系将如期形成 (Tang, Yaoguo, Ausgestaltung des chinesischen Rechtssystems), in: 瞭望新闻周刊 (Liaowang Newsweek), vom 12.03. 2007.

童之伟, 宪法司法化引出的是是非非 - 宪法司法适用研究中的几个问题 (Tong, Zhiwei, Einige Fragen über die Untersuchung der Anwendung der Verfassung), in: 法学 (Law Science), 2001/11, S. 3-8.

汪晖, 当代中国的思想状况与现代性问题 (Wang, Hui, Die ideale Verfassung im heutigen China und die Frage der Modernität), in: 天涯 (Tianya), 1997/5, S. 133-150.

王纪元, 仅有经济增长不足以保障社会公平与正义 (Wang, Jiyuan, Soziale Gerechtigkeit kann nicht lediglich durch die Wirtschaftsentwicklung gewährleistet werden ), in: 石美遐 Stearns, Lisa, 全 球化背景下的国际劳工标准与劳动法研究 (Shi, Meixia/Stearns, Lisa, Untersuchung der internationalen Arbeitsstandards und des Arbeitsrechts unter dem Einfluss der Globalisierung), Beijing, 2005, S. 8-10.

王军, 新医改负重启程 (Wang, Jun, Die neue Gesundheitsreform), in: 瞭望 (Liaowang), 07. 04. 2009. 王培英, 中国宪法文献通编 (Wang, Peiying (Hrsg.), Dokumentensammlung über die chinesischen Verfassungen), Beijing, 2007.

王全兴/管斌, 经济法与社会法关系初探 (Wang, Quanxing/Guan, Bin, A study on the relationship between ecomonic law and social law), in: 现代法学 (Modern Law Science), 2003/04, S. 113118.

王人博, 宪政的中国语境 (Wang, Renbo, Chinese Understanding of Constitutionalism), in: 法学研究 (Journal of Law), Beijing, 2001/2, S. 133-147.

王人博, 中国近代的宪政思潮 (Wang, Renbo, Constitutional Trend in modern China), Beijing, 2003.

王世玲定军, 关于医改新方案的报道 (Wang, Shiling/Ding, Jun, Bericht über die neuen Pläne der Gesundheitsreform), in: 21世纪经济报道 (21CBH), vom 23. 09. 2006.

王逸舟, 中国与国际组织关系研究的若干问题 (Wang, Yizhou, Einige Fragen in der Forschung über die Beziehungen zwischen China und den internationalen Organisationen), in: 社会科学论坛 (Tribune of Social Sciences), 2002/8, S. 4-13.

王绍光, 大转型：1980年代以来中国的双向运动 (Wang, Shaoguang, The Great Transformation: Double Movement in China since the 1980s), in: 中国社会科学 (Social Science in China), 2008/1, S. 129-148. 
王绍光 (Wang, Shaoguang), Great social Transformation, A Foot in China, in: China Economist, 2008/7, S. 55-69.

王绍光, 分权的底限 (Wang, Shaoguang, Die Untergrenze der wirtschaftlichen Dezentralisierung), Beijing, 1997.

王绍光/潘维, 共和国60年: 回顾与展望 (Wang, Shaoguang/Pan, Wei, 60 Jahre Volksrepublik: Rückblick und Ausblick), in: 开放时代 (Opentimes), 2008/1, S. 5-41.

王绍光胡鞍钢/丁元竹, 经济繁荣背后的社会不稳定 (Wang, Shaoguang/Hu, Angang/Ding, Yuanzhu, Hinter der blühenden Wirtschaft ist die soziale Instabilität), in: 战略与管理 (Strategy \& Management), 2002/3, S. 26-33.

王绍光/胡鞍钢/周建明, 第二代改革战略: 积极推进国家制度建设 (Wang, Shaoguang/Hu, Angang/Zhou, Jianming, Neue Reformstrategien: Förderung der Strukturierung des Staatssystems), in: 战略与管理 (Strategy and Management), 2003/2, S. 90-95.

王绍光，民主四讲 (Wang, Shaoguang, Gespräche über ,Demokratie“), Beijing, 2008.

王绍光, 顺应民心的变化: 从财政资金流向看中国政府政策调整 (Wang, Shaoguang, Politische Regulierung der chinesischen Regierung: unter dem Blickwinkel von Fließrichtung der Finanzmittel), in: 战略与管理 (Strategy \& Management), 2004/2, S. 51-60.

王绍光, 政策导向, 汲取能力与卫生公平 (Wang, Shaoguang, State Policy Orientation, Extractive Capacity and the Equality of Healthcare in Urban China), in: 中国社会科学 (Social Sciences in China), 2005/6, S. 101-120.

王绍光, 医改不存在迷局: 理性回归中国传统 (Wang, Shaoguang, Gesundheitsreform: Wiederkehr zur chinesischen Tradition), in: 书城 (Booktown), 2005/10, S. 33-35.

王绍光, 中国公共卫生的危机与转机 (Wang, Shaoguang, Krise und Wendung des öffentlichen Gesundheitsdienstes in China), in: 比较 (Comparative Studies), 2003/7, S. 52-88.

王绍光, 坚守方向, 探索道路: 中国社会主义实践60年 (Wang, Shaoguang, From the Global Perspective Adhering to the Right Direction and Exploring New Paths: Reflections on Sixty Years of Socialist Practice in China), in: 中国社会科学 (Social Science in China), 2009/5, S. 4-19.

王延中/胡继晔，划拨国有股充实社保基金的思路与对策 (Wang, Yanzhong/Hu, Jiye, Approaches and Policies to Appropriate State-Shares to Transfer to Social Security Fund), in: 中国社会保障发展 报告2001-2004 (China Social Security System Development Report 2001-2004), Beijing, 2004, S. 240-260.

王延中/张车伟, 我国失业保险制度的主要问题与对策 (Wang, Yanzhong/Zhang, Chewei, Die Hauptprobleme des chinesischen Arbeitslosenversicherungssystems und Vorschläge), in: 中国经贸导 刊 (China Economic \& Trade Herald), 2005/11, S. 22.

王禹, 中国宪法司法化: 案例评析 (Wang, Yü, Anwendung der Verfassung durch die Gerichte in China: Fallanalysen), Beijing, 2005.

王兆国, 宪法修正案草案的说明 (Wang, Zhaoguo, Erklärung über den Entwurf der Verfassungsänderung), in: 人民日报 (RMRB), 09.03.2004.

王振民, 中国违宪审查制度 (Wang, Zhenmin, Das chinesische System der Kontrolle der Verfassungsmäßigkeit), Beijing, 2004.

温家宝, 2008 年政府工作报告 (Wen Jiabao, Tätigkeitsbericht des Staatsrates 2008), vom 05. 03. 2008. in: 人民日报 (RMRB), 20.03. 2008.

温家宝, 关于社会主义初级阶段的历史任务和我国对外政策的几个问题 (Wen, Jiabao, Über die historischen Aufgaben der sozialistischen Anfangsphase und einige Fragen der Außerpolitik Chinas), in: 光明日报 (Guangming Zeitung) (GMRB), 26. 2. 2007.

温家宝, 在第十届全国人民代表大会第二次会议上的政府工作报告 (Wen, Jiabao, Report on the Work of the Government at the Second Session of the Tenth National People's Congress on March 5, 2004), in: 人民日报 (RMRB), 17.03. 2004.

温铁军, 农民社会保障与土地制度改革 (Wen, Tiejun, Soziale Sicherung der ländlichen Bevölkerung und Reform der Bodenpolitik), in: 学习月刊 (Study Monthly), 2006/10, S. 20-22. 
温铁军, 我们到底要什么 (Wen, Tiejun, Was wollen wir eigentlich?), Beijing, 2004.

温铁军, 我们是怎样重新得到迁徙自由的 (Wen, Tiejun, Wie wir die Freizügigkeit wieder bekommen haben), in: 中国改革 (China Reform), 2002/5, S. 12-14.

Williamson, John B./孙策，中国养老保险制度改革：从FDC层次向NDC层次转换 (Williamson, John B./Sun, $C e$, Do Notional Defined Contribution Accounts Make Sense as Part of the Old-Age Security Mix for China?), in: 经济社会体制比较 (Comparative Economic \& Social Systems), 2004/3, S. 71-77.

吴邦国, 在十届全国人大常委会第二次会议上的讲话 (Wu, Bangguo, Gespräche in der zweiten Versammlung des ständigen Ausschusses des zehnten Volkskongresses vom 26. 04. 2003). in: 人 民日报 (RMRB), 27.04. 2003.

吴敬琏/林毅夫，关于划拨国有资产归还国家对老职工社会保障基金欠账的建议（Wu，Jinglian/Lin,Yifu, Vorschlag zur Bezahlung der Staatsschulden beim Übertragen staatlicher Vermögenswerte in den Fonds der sozialen Sicherheit für die ,alten“ Arbeitsnehmer, in: 比较 (Comparative Studies), 2003/6, Nr. 6, S. 1-2.

吴敬琏, 中国经济六十年 (Wu, Jinglian, 60 Jahre Geschichte der chinesischen Wirtschaft), in: 财经杂 志 (Caijing Magazine), 2009/20, S. 76-103.

吴要武/蔡昉，中国城镇非正规就业规模与特征 (Wu, Yaowu/Cai, Fang, Informal Employment in Urban China: Size and Characteristics), in: 中国劳动经济学 (China Labor Economics), 2006, Vol.3 No.2, S. 67-84.

夏勇, 中国宪法改革的几个基本理论问题 (Xia, Yong, Several Theoretical Issues Confronting Constitutional Reform in China), in: 中国社会科学 (Social Sciences in China), 2003/3, Nr. 2. S. 4 -17.

项怀诚，关于全国社会保障基金的几个问题 (Xiang, Huaicheng, Über einige Fragen des Nationalen Fonds für soziale Sicherheit), in: 社会保障制度 (Social Security System), 2006/6, S. 10-16.

萧功秦, 从发展政治学看中国转型体制 (Xiao, Gongqin, China' politische Transformation vom Standpunkt der Entwicklungspolitologie), in: 浙江学刊 (Zhejiang Academic Journal), 2005/5, S. 100107.

萧功秦, 中国后全能型的权威政治 (Xiao, Gongqin, China's Post totalitarian Regime), in: 战略与管理 (Strategy \& Management), 2002/6, S. 82-88.

席斯, 新财税体制改革发力, 事权上移是短期重点 ( $X i, S i$, Die neue Runde der Finanz- und Steuerreform), in: 经济观察报 (The Economic Observer), vom 18. 03. 2007.

谢蹈，民主社会主义模式与中国前途 (Xie, Tao, Demokratischer Sozialismus und die Zukunft Chinas), in: 炎黄春秋 (Yanhuang Chunqiu), 2007/2, S. 1-8.

新型农村合作医疗试点工作评估组, 发展中的中国新型农村合作医疗一 新型农村合作医疗试点工 作评估报告 (Abschätzungsgruppe für die Pilotprojekte des neuen kooperativen medizinischen Systems auf dem Land, Abschätzungsbericht über das neue kooperative medizinische System), Beijing, 2006.

许国庆/邵宏华夏申, 论贸易竞争与劳工标准 (Xu, Guoqing/Shao, Honghua/Xia, Shen, Handelswettbewerb und Sozialklauseln), in: 国际贸易 (Intertrade), 1996/9, S. 28-29.

徐湘林, 以政治稳定为基础的中国渐进政治改革 (Xu, Xianglin, China's Progressive Political Reform on the Basic of Political Stability), in: 战略与管理 (Strategy and Management), 2000/5, S. 1626.

杨方方, 关于中央政府和地方政府社会保障责任划分的几点看法 (Yang, Fangfang, Über die Verteilung der Verantwortung für soziale Sicherheit zwischen zentraler und lokaler Regierung), in: 经济 体制改革 (Reform of Economic System), 2003/3, S. 18-20. 
杨方方, 从缺位到归位 - 中国转型期社会保险中的政府责任 (Yang, Fangfang, Von der Abkehr bis zur Wiederkehr - die staatliche Verantwortung für die Sozialversicherung im chinesischen Transformationsprozess), Beijing, 2006.

杨飞, 试论劳动宪法 (Yang, Fei, On Labor Constitution), in: 林嘉, 社会法评论 (Lin, Jia (Hrsg.), Social Law Review), Beijing, 2008, Vol. 3, S. 70-95.

杨华云, 养老金空账规模约为 1.3 万亿 (Yang, Huayun, Die Schulden der Individualkonten betragen ca.1300 Mrd. RMB), in: 新京报 (XJB), vom 14. 07. 2010.

杨景宇, 宪法的稳定和与时俱进 (Yang, Jingyü, Die Stabilität der Verfassung und die fortsetzende Entwicklung), vom 16. 12. 2003, http://www.people.com.cn/GB/shizheng/1026/2249281.html.

杨中旭, 新医改最后博亦: 围绕市场化与回归计划激烈交锋 (Yang, Zhongxü, Die neue Gesundheitsreform: Kommerzialisierung oder Planwirtschaft?), in: 中国新闻周刊 (China Newsweek), 2009/13.

姚宇, 中国非正规就业规模与现状研究 (The Size and Status of Informal Employment in China), in: 中国劳动经济学 (China Labor Economics), 2006, Vol.3 No.2, S. 85-109.

易纲/李凯, 转型名义账户制: 探索中国养老保障体制改革的新思路 ( Yi, Gang/Li, Kai, Transitional Notional Defined Contribution Scheme: A new Potion of China's Social Security Pension Reform), in: 比较 (Comparative Studies), 2007/3, Nr. 29, S. 33-56.

游钧, 2006-2007年: 中国就业报告 (You, Jun (Hrsg.), 2006-2007: Blue Book of the Chinese Employment), Beijing, 2008.

于建伟, 未成年人保护法修订的背景, 思路和主要内容 (Yü, Jianwei, Background, Thoughts and Main Contents of the Revision of Juvenile Protection Law), in: 青少年犯罪问题 (Issues on Juvenile Crimes and Delinquency), 2007/2, S. 4-9

俞可平, 民主是个好东西 (Yü, Keping, Democracy is a Good Thing), in: 北京日报 (Beijing Zeitung), 23. 10. 2006.

俞可平, 中国公民社会的制度环境 (Yü, Keping, Institutional Environment of China's Civil Society), Beijing, 2006.

俞可平, 现代化和全球化双重变奏下的中国文化发展逻辑 (Yü, Keping, The Logic of Chinese Cultural Development under Variation of Modernization and Globalization), in: 学术月刊 (Academic Monthly), 2006/4, S. 14-24.

张车伟, 当前就业新趋势与对策建议 (Zhang, Chewei, Die neue Beschäftigungstendenz und Vorschläge), in: 中国经贸导刊 (China Economic \& Trade Herald), 2006/9, S. 28-29.

张车伟, 扩大与促进就业的思路与对策 (Zhang, Chewei, Approaches and Policies to Promote Employment), in: 陈佳贵/王延中，中国社会保障发展报告 2001-2004 (Chen, Jiagui/Wang, Yanzhong (Hrsg.), China Social Security System Development Report 2001-2004), Beijing, 2004, S. 153-177.

张车伟, 失业率定义的国际比较及中国城镇失业率 (Zhang, Chewei, An International Comparison of the Definition for Unemployment and the Rate of Unemployment in Urban China), in: 世界经济 (World Economic), 2003/5, S. 47-54.

张车伟, 当前失业保险制度需要新的发展定位 (Zhang, Chewei, Reformbedarf in der Arbeitslosenversicherung), in: 中国党政干部论坛 (Politische Tribüne), 2005/7, S. 22-24.

张晋藩, 中国法律的传统与近代转型 (Zhang, Jinfan, The Tradition and Modern Transition of Chinese Law), Beijing, 2004.

张文显, 法理学 (Zhang, Wenxian (Hrsg.), Jurisprudence), 3. Aufl., Beijing, 2007.

张翔/胡润峰/任波/付涛, 社保抉择 (Zhang, Xiang/Hu, Runfeng/Ren, Bo/Fu, Tao, Eine neue Entscheidung für soziale Sicherheit steht bevor ), in: 财经 (Caijing Magazine), 2006/26. 
赵紫阳, 在中国共产党第十三次全国代表大会上的报告 (Zhao, Ziyang, Report at the 13th National Congress of the Communist Party of China), vom 12. 10. 1987, in: 光明日报 (GMRB), 04. 11. 1987.

郑秉文, 关于加快推进省级社保统筹的建议 (Zheng, Bingwen, Vorschlag über Beschleunigung der einheitlichen Planung und Verwaltung der Sozialversicherungsfonds auf Provinzebene), in: 中国 经贸导刊(China Economic \& Trade Herald) 2007/18, S. 9-10.

郑秉文, 建立社会保障长效机制的12点思考 (Zheng, Bingwen, Vorschläge zur Errichtung eines langfristig funktionierenden Mechanismus der sozialen Sicherheit), in: 管理世界 (Management World), 2005/10, S. 58-66.

郑秉文，社会保障体制改革攻坚 (Zheng, Bingwen, Reform der sozialen Sicherheit), Beijing, 2004.

郑秉文, 中国产生社保案的制度原因及解决办法 (Zheng, Bingwen, Zu den Ursachen der gegenwärtigen Krise der Sozialversicherungsfonds und die Lösungsmöglichkeiten), in: 国际经济评论 (International Economic Review), 2007/5-6, S. 46.

郑功成, 社会保障学 (Zheng, Gongcheng (Hrsg.), Social Security), Beijing, 2006.

郑功成, 自然灾害与社会安全 (Zheng, Gongcheng, Naturkatastrophe und soziale Sicherheit), in: 郑杭 生, 中国社会发展研究报告 (Zheng, Hangsheng ( Hrsg.), Research Reports on China Social Development 2004), Beijing, 2004, S. 29.

郑尚元, 社会法的存在与社会法理论探索 (Zheng, Shangyuan, The Existence of Social Law and the Theoretical Detective of Social Law), in: 法律科学 (Law Science), 2003/3, S. 40-48.

郑尚元, 社会法的定位和未来 (Zheng, Shangyuan, On the Status and Future of Social Law), in: 中国 法学 (China Legal Science), 2003/5, S. 124-135.

郑贤君, 20世纪中国宪政思想体系及演进特征(Zheng, Xianjün, Der chinesische Konstitutionalismus im 20. Jahrhundert), in: 法商研究 (Journal of Law and Commerce), 2001/3, S. 124-131.

郑贤君, 论我国宪政模式的走向 (Zheng, Xianjun, Verfassungsmodell der Volksrepublik China), in: 中 国法学 (China Legal Science), 2003/1, S. 14-23.

中国共产党第十一届三中全会公报 (Bulletin des 3. Plenums des 11. Zentralkomitees der KP Chinas), vom 22. 12. 1978, in: 人民日报 (RMRB), 24. 12. 1978.

中国共产党第十六届五中全会公报 (Bulletin des 5. Plenums des 16. Zentralkomitees der KP Chinas), vom 11. 10. 2005, in: 人民日报 (RMRB), 12. 10. 2005.

中国共产党十六届六中全会公报 (Bulletin des 6. Plenums des 16. Zentralkomitees der KP Chinas), vom 11. 10. 2006, in: 人民日报 (RMRB), 12. 10. 2006.

中国共产党第十七届中央委员会第三次全体会议公报 (Bulletin des 3. Plenums des 17. Zentralkomitees der KP Chinas), vom 12. 10. 2008, in: 人民日报 (RMRB), 13. 10. 2008.

中国经济体制改革总体设计课题组, 变革时期的中国社会安全体系 (Forschungsgruppe für die Gesamtplanung der Wirtschaftsreform Chinas, Das chinesische soziale Sicherungssystem in der Umwandlungsperiode), in: 经济社会体制比较 (Comparative Economic \& Social Systems), 1992/5, S. 29-36.

中国社会保障的体制选择与经济分析课题组, 社会保障: 经济分析与体制建议 (Forschungsgruppe des Staatsrats für soziale Sicherheit, Soziale Sicherheit: Wirtschaftsanalysen und Vorschläge für die Systementscheidung), in: 改革 (Reform), 1994/5, S. 17-28; 1994/6, S. 64-78.

中国社会科学院法学所课题组, 建立社会主义市场经济法律体系的理论思考和对策建议 (Studiengruppe des Forschungsinstituts für Rechtswissenschaft an der Chinesischen Akademie für Sozialwissenschaft, Theoretische Überlegung und Vorschläge zum Aufbau des sozialistisch marktwirtschaftlichen Rechtssystems), in: 法学研究 (Journal of Law), 1993/6, S. 11ff.

中华人民共和国公务员法释义 (Auslegung des Beamtengesetzes der VR China), Beijing, 2005.

周冰/李美嵩, 策略性过渡性制度安排 - 中国财政大包干体制研究 (Zhou, Bing/Li, Meisong, A Strategic Transitional Institution Arrangement - A Case about Fiscal All-Round Responsibility System of China in 1980s), in: 浙江大学学报 (Journal of Zhejiang University), 2006/11, S. 59-66. 
邹瑜, 关于中华人民共和国妇女权益保障法 (草案) 的说明 (Zou, Yü, Erklärung über den Entwurf des Gesetzes der Volksrepublik China zur Gewährleistung der Rechte von Frauen), gesprochen in der 5. Sitzung des VII. NVK am 27. 03. 1992.

\section{Westliche Literatur}

Ahl, Björn, Ein Rechtsstaat chinesischen Typs? Zur Verfassungsentwicklung in der Volksrepublik China, in: Blätter für deutsche und internationale Politik, 11/2006. S. 1381-1388.

Anderson, Kym/Huang, Jikun/Ianchovichina, Elena, The Impacts of WTO Accession on Chinese Agriculture and Rural Poverty, in: Bhattasali, Deepak/Li, Shantong/Martin, Will (Hrsg.), China and the WTO, Accession, Policy Reform, and Poverty Reduction Strategies, Oxford, 2004, S. 101-116.

Becker, Ulrich, Alterssicherung im internationalen Vergleich, in: Becker, Ulrich/Kaufmann Franz-Xaver/ Maydell, Bernd Baron von/Schmähl, Winfried/Zacher, Hans F. (Hrsg.), Alterssicherung in Deutschland, Festschrift für Franz, Ruland zum 65. Geburtstag, Baden-Baden, 2007, S. 575-610.

Becker, Ulrich, Einleitung, in: Becker, Ulrich/Zheng, Gongcheng/Darimont, Barbara (Hrsg.), Grundfragen und Organisation der Sozialversicherung in China und Deutschland, Baden-Baden, 2005, S. 11-17.

Becker, Ulrich, Rechtsdogmatik und Rechtsvergleich im Sozialrecht, in: ders. (Hrsg.), Rechtsdogmatik und Rechtsvergleich im Sozialrecht, Baden-Baden, 2010, S. 11-59.

Beveridge, W. II., Social Insurance and Allied Services: Report by Sir Willian Beveridge, London, 1942.

Bhattasali, Deepak/Li, Shantong/Martin, Will (Hrsg.), China and the WTO, Accession, Policy Reform, and Poverty Reduction Strategies, Oxford, 2004.

Blüthner, Andreas, Sozialstandards im Welthandelssystem, in: Becker, Ulrich/Maydell, Bernd Bareon von/Nußberger, Angelika (Hrsg.), Die Implementierung internationaler Sozialstandards: Zur Durchsetzung und Herausbildung von Standards auf überstaatlicher Ebene, Baden-Baden, 2006, S. 213-242.

Brooks, Sarah M. Interdependent and Domestic Foundations of Policy Change: The Diffusion of Privatization around the World, in: International Studies Quarterly 2005, 49 (2), S. 273-294.

Brupbacher, Stefan, Fundamentale Arbeitsnormen der Internationalen Arbeitsorganisation, Bern, 2002.

Chen, Jianfu, Chinese Law: Towards an Understanding of Chinese Law, it's Nature and Development, The Hague, 1999.

Clinton, William Jefferson, China's Opportunity and Ours, in: New York Times, vom 24. 09. 2000

Darimont, Barbara, Antworten aus Beijing: „Die Sozialpolitik der chinesischen Regierung“, in: Kupfer, Kristin (Hrsg.), " Sozialer Sprengstoff in China?" - Dimensionen sozialer Herausforderungen in der Volksrepublik, Essen, 2004, S. 67-78.

Darimont, Barbara, Sozialversicherungsrecht der V. R. China, Baden-Baden, 2004.

Deacon, Bob, Social Policy in a Global Context, in: Hurrell, Andrew/Woods, Ngaire (Hrsg.), Inequality, Globalization and World Politics, Oxford, 1999, S. 210-247.

Deacon, Bob, Global Social Policy \& Governance, London, 2007.

Fan, Jinming, Alterssicherung in China, Frankfurt am Main, 1999.

Fox, Louise/Palmer, Edward, New Approaches to Multipillar Pension Systems: What in the World is Going On? in: Holzmann, Robert/Stiglitz, Joseph E. (Hrsg.), New Ideas about Old Age Security, 2001, Washington D. C., S. 90-132. 
Giddens, Anthony, The Third Way, Cambrige, 1998.

Heilmann, Sebastian, Das politische System der Volksrepublik China, Wiesbaden, 2002.

Herdegen, Matthias, Völkerrecht, 9. Aufl., München, 2010.

Heuser, Robert, Einführung in die Chinesische Rechtskultur, Hamburg, 1999.

Heuser, Robert, „sozialistischer Rechtsstaat“ und Verwaltungsrecht in der VR China (1982-2003), Hamburg, 2003.

Holbig, Heike, Auf dem Weg zur konstitutionellen Einparteienherrschaft? - Die Verfassungsänderungen vom März 2004, in: China aktuell, 2004/4, S. 259-270.

Holbig, Heike, „Wissenschaftliches Entwicklungskonzept“, „Harmonische Gesellschaft“ und „Eigenständige Innovation“: Neue parteipolitische Prioritäten unter Hu Jintao, in: China aktuell, 2005/6, S. 13-19.

Holzmann/Palmer, The Status of the NDC Discussion: Introduction and Overview, in: Holzmann, Robert/Palmer, Edward (Hrsg.), Pension Reform - Issues and Prospects for Non-Financial Defined Contribution (NDC) Schemes, Washington D.C., 2006, S. 1-15.

Huang, Ray, China: A Macro-History, New York, 1997.

Huntington, Samuel P., The Clash of Civilizations and the Remaking of World Order. New York, 1996.

Hussain, Athar, Coping with and Adapting to Job Losses and Declines in Farm Earnings in China, in: Bhattasali, Deepak/Li, Shantong/Martin, Will (Hrsg.), China and the WTO, Accession, Policy Reform and Poverty Reduction Strategies, Oxford, 2004, S. 305-324.

ILO, Social Security: A New Consensus, Geneva, 2001.

$I L O$, The end of child labour: Within reach, Global Report under the follow-up to the ILO Declaration on Fundamental Principles and Rights at Work, Geneva, 2006.

ILO, An Employment Agenda for China, Beijing, 2004.

ILO Circular No. 599, Series 1, vom 20. 05. 2004.

$I L O$, Decent Work in Asia: Reporting on results 2001-05, Geneva, 2006.

ILO, China Employment Forum, Summary Proceedings, Beijing, 2004.

ILO, Extending Old-age Insurance Coverage in the People's Republic of China, 01/2006, http://www.ilo.org/public/english/region/asro/beijing/download/training/old_insur.pdf (Stand: 15. 07. 2010).

$I L O$, Third Meeting of the Joint Committee on Cooperation, Review of activities under the Memorandum of Understanding, 05/2005,

http://www.ilo.org/public/english/region/asro/beijing/download/mou_impl.pdf (Stand: 15. 07. 2010).

International Labour Conference 1999, Report of the Director-General: Decent Work, http://www.ilo.org/public/english/standards/relm/ilc/ilc87/rep-i.htm (Stand: 15. 07. 2010).

International Labour Conference, Report of the Director-General on the World Commission on the Social Dimension of Globalization: A fair Globalization, the Role of the ILO, Geneva, 2004.

International Labour Conference 2007, Fifth Item on the Agenda: Strengtheming the ILO's capacity to assist its Members' efforts to reach its objectives in the context of globalization, Beijing, 2007.

International Labour Office, Introduction to social security, 1984.

Ipsen, Knut, Völkerrecht, 6. Aufl., München, 2008.

Johnston, Alastair Iain, Is China a Status Quo Power? in: International Security, 2003, Vol. 27, No. 4. 
Kapur/Lewis/Webb, The World Bank: Its first half Century, Volume 1: History, Washington D. C., 1997.

Katzenstein, Peter J./Keohane Robert O./Krasner, Stephen D., International Organization and the Study of World Politics, in: International Organisation, 1998, Volume 52, Number 4, S. 645-685.

Kaufmann, Franz-Xaver, Sicherheit als soziologisches und sozialpolitisches Problem, 2. Aufl. Stuttgart, 1973.

Keller, Perry, Sources of Order in Chinese Law, in: American Journal of Comparative Law, 4/1994, S. 711-759.

Keohane, Robert O., After Hegemony: Cooperation and Discord in the World Political Economy. Princeton, 1984.

Kim, Samuel S., China and the United Nations, in: Economy, Elizabeth/Oksenberg, Michel (Hrsg.), China joins the World: Progress and Prospects, New York, 1999, S. 42-89.

Köck, Heribert Franz, Die „,implied powers“ der Europäischen Gemeinschaft als Anwendungsfall der „,implied powers“ internationaler Organisationen überhaupt, in: Völkerrecht - Recht der Internationalen Organisationen - Weltwirtschaftsrecht: Festschriften für Seidl-Hohenveldern, Köln, 1988, 279-299.

Köhler, Peter A, Grundrentensysteme im Rechtsvergleich, in: Zeitschrift für die gesamte Versicherungswissenschaft, 1998, Band 87, S. 653-684.

Köhler, Peter A. Sozialpolitische und sozialrechtliche Aktivitäten in den Vereinten Nationen, BadenBaden, 1987.

Köhler/Zacher, Sozialversicherung: Pfade der Entwicklung, in: Köhler, Peter A./Zacher, Hans F. (Hrsg.), Ein Jahrhundert Sozialversicherung: in der Bundesrepublik Deutschland, Frankreich, Großbritannien, Österreich und der Schweiz, Berlin, 1981, S. 9-41.

Kohler-Koch, Beate, Zur Empirie und Theorie internationaler Regime, in: Kohler-Koch, Beate (Hrsg.), Regime in den internationalen Beziehungen,, Baden-Baden, 1989, S. 17-85.

Krasner, Stephen D., Structural causes and regime consequences: regimes as intervening variables, in: International Organization, 36/1982, S. 185-205.

Leisering, Lutz/Gong, Sen/Hussain, Athar, People's Republic of China, Old-Age Pensions for the Rural Areas: From Land Reform to Globalization, Manila, 2002.

Lin, Yi/Zhang, Song, Verwaltungsstruktur der chinesischen Sozialversicherung und deren Probleme, in: Becker/Zheng/Darimont, Grundfragen und Organisation der Sozialversicherung in China und Deutschland, Baden-Baden, 2005, S. 181-196.

$\mathrm{Lu}, \mathrm{Mai}$, Evaluation of the Effectiveness of the World Bank's Analytical and Advisory Services to China since 1990, Washington D. C., 2005.

Maydell, Bernd Baron von, Einführung, in: Becker, Ulrich/Maydell, Bernd Baron von/Nußberger, Angelika (Hrsg.), Die Implementierung internationaler Sozialstandards: Zur Durchsetzung und Herausbildung von Standards auf überstaatlicher Ebene, Baden-Baden, 2006.

Meisner, Maurice, The Deng Xiaoping Era, New York, 1996.

Memorandum of Understanding between MOLSS and the ILO, vom 17. 05. 2001.

Mi, Jian, Die chinesische traditionelle Kultur und das gegenwärtige Rechtssystem. in: ZfRV,1989, S. 2438.

Mishra, Ramesh, Globalization and the Welfare State, Northampton, 1999.

Max-Planck-Institut für ausländisches und internationales Sozialrecht, Kernarbeitsnormen in Verträgen der Entwicklungszusammenarbeit, Eschborn, 2004.

Münzel, Frank, People's Republic of China, in: International Encyclopedia of Comparative Law, 1996, Volume 1, S. 67. 
Nathan, Andrew J., China and the International Human Rights Regime, in: Economy Elizabeth/Oksenberg, Michel (Hrsg.), China Joins the World: Progress and Prospects, New York, 1999, S. 136-160.

Nußberger, Angelika, Das Sozialrecht der internationalen Organisationen, in: Maydell, Bernd Baron von/Ruland, Franz/Becker, Ulrich (Hrsg.), Sozialrechtshandbuch, 4. Aufl., Baden-Baden, 2008, S. 1410-1430.

Nußberger, Angelika, Die Implementierung der sozialrechtlichen Konventionen der Internationalen Arbeitsorganisation und des Europarats, in: Becker, Ulrich/Maydell, Bernd Baron von/Nußberger, Angelika (Hrsg.), Die Implementierung internationaler Sozialstandards, zur Durchsetzung und Herausbildung von Standards auf überstaatlicher Ebene, Baden-Baden, 2006, S. 59-78.

Nußberger, Angelika, Sozialstandards im Völkerrecht, Berlin, 2005.

Palmer, Edward, What ist NDC? in: Holzmann, Robert/Palmer, Edward (Hrsg.), Pension Reform - Issues and Prospects for Non-Financial Defined Contribution (NDC) Schemes, Washington D. C., 2006, S. 17-34.

Peerenboom, Randall, China's Long March toward Rule of Law, Cambridge, 2002.

Piggott /Lu, Pension Reform and the Development of Pension Systems: An Evaluation of World Bank Assistance, Background Paper China Country Study, 2007.

Pye, Lusien, How China's Nationalism Was Shanghaied, in: Unger, Jonathan (Hrsg.), Chinese Nationalism, New York, 1996.

Ramia, Gaby/Davies, Gloria/Nyland, Chris The compliance challenge: Implications for social security in the People's Republic of China, in: International Social Security Review, 2008, Vol. 61 Nr. 1, S. $1-20$.

Reimann, Axel, Vergleich des chinesischen und deutschen Rechts des Managements der Sozialversicherungsfonds, in: Arbeits- und Sozialversicherung in China und Deutschland: Rechtsvergleichende Betrachtungen, Beijing, 2003, S. 531-550.

Riedel, Eibe, Die Implementierung des Internationalen Paktes über wirtschaftliche, soziale und kulturelle Rechte, in: Becker, Ulrich/Maydell, Bernd Baron von/Nußberger, Angelika (Hrsg.), Die Implementierung internationaler Sozialstandards: Zur Durchsetzung und Herausbildung von Standards auf überstaatlicher Ebene, Baden-Baden, 2006, S. 21-30.

Schmid, Felix, Sozialrecht und Recht der sozialen Sicherheit, Berlin, 1981.

Schregle, Johannes, Internationale Sozialrechtsvergleichung in der normenschaffenden Tätigkeit der Internationalen Arbeitsorgaisation, in: Zacher, Hans F. (Hrsg.), Sozialrechtsvergleich im Bezugsrahmen internationalen und supranationalen Rechts, Berlin, 1978, S. 133-152.

Von Senger, Harro, Einführung in das chinesische Recht, München, 1994.

Von Senger, Harro, Von der Vergleichung des Rechts zur Vergleichung de Gesellschaftsführung, in: ZfRV, 2006/7, S. 43-64.

Simma, Bruno, Die vergessenden Rechte: Bemühungen zur Stärkung des VN-Sozialpakts, in: Ruland, Franz/Maydell, Bernd Baron von/Papier, Hans-Jürgen (Hrsg.), Verfassung, Theorie und Praxis des Sozialstaats, FS für Hans F. Zacher, 1998, S. 867-882.

United Nations Resident Coordinator in China, UN Partnership in China, Balancing Development to Achieve Xiaokang and Millennium Development Goals, 2006, Beijing.

UNDP, China Human Development Report 2005, Beijing, 2005.

$U N D P$, China, Supports growth with equity, gender equality and environmental sustainability, Beijing, 2003. 
UN Country Team in China, Common Country Assessment 2004, Balancing Development to Achieve an All-Round Xiaokang and Harmonious Society in China, http://www.un.org.cn/cms/p/resources/30/311/content.html (Stand: 15. 07. 2010).

UN Coutry Team China, Advancing Social Development in China, Contribution to the 11th Year Plan, Occasional Paper Vol.1, Beijing, 2005.

UNO, Resolution 2758 der UN-Generalversammlung, vom 25. 10. 1971. http://www.un.org/documents/ga/docs/53/plenary/a53-145.htm (Stand: 15. 07. 2010).

UNO, United Nations Development Assistance Framework for the People's Republic of China (20062010), Beijing, 2005.

UNO, United Nations Development Assistance Framework for the People's Republic of China (20012005) (Auszüge), http://www.nwccw.gov.cn/html/51/n-126851.html (Stand. 15. 07. 2010).

World Bank, China: Revenue Mobilization and Tax Policy, Washington D.C., 1990.

World Bank, China: Strategies for Reducing Poverty in the 1990s, Washington D.C., 1992.

World Bank, Averting the Old Age Crisis: Policies to Protect the Old and Promote Growth, New York, 1994.

World Bank, China Pension System Reform, Report No. 15121-CHA, vom 22. 08. 1996.

World Bank, China 2020: Financing Health Care, Issues and Options for China, Washington D.C., 1997.

World Bank, China 2020: Old Age Security: Pension Reform in China, Washington, D.C., 1997.

World Bank, China: Overcoming Rural Poverty, Report No. 21105-CHA, vom 18.10. 2000.

World Bank, China National Development and Sub-National Finance, Beijing, 2002.

World Bank, China Country Assistance Strategy (2003-2005), Beijing, 2003.

World Bank, China, An Evaluation of World Bank Assistance, Beijing, 2005.

World Bank, China Evaluation of the Liaoning Social Security Reform Pilot, Report No. 38183-CN, Beijing, 2006.

World Bank, Country Partnership Strategy for the People's Republic of China -for the Period 2006-2010, Beijing, 2006.

World Bank, China and World Bank: A Partnership for Innovation, Washington, D.C., 2007.

World Bank, China: From Poor Areas to Poor People, China's Evolving Poverty Reduction Agenda, Report No. 47349-CN, 05/2009.

World Health Organization, The World Health Report 2000: Health System: Improving Performance, Geneva, 2000.

Zacher, Hans F., Horizontaler und vertikaler Sozialrechtsvergleich, in: Zacher, Hans F. (Hrsg.), Sozialrechtsvergleich im Bezugsrahmen internationalen und supranationalen Rerchts, Berlin, 1978, S. 970.

Zacher, Hans F., Ziele der Alterssicherung und Formen ihrer Verwirklichung, in: Zacher, Hans $F$. (Hrsg.), Alterssicherung im Rechtsvergleich, Baden-Baden, 1991.

Zacher, Hans F., Grundtypen des Sozialrechts, in: Maydell, Bernd Baron von/Eichenhofer, Eberhard (Hrsg.), Abhandlungen zum Sozialrecht, Heidelberg, 1993, S. 257-278.

Zhang, Wei, Sozialwesen in China, Hamburg, 2005. 


\section{Politische Normen}

\section{Politische Richtlinien der KP Chinas}

中共中央关于废除国民党六法全书与确定解放区司法原则的指示 (Anweisung des Zentralkomitees der KP Chinas über die Abschaffung der Vollständigen Sammlung der Sechs Gesetze der Volkspartei und die Festlegung der Grundsätze der Justiz in den befreiten Gebieten), vom 22. 02. 1949, in: 中共中央文件选集第十八册 (Ausgewählte Dokumente des Zentralkomitees der KP Chinas, Vol. 18), Beijing, 1992, S. 150-153.

中共中央关于进一步做好城镇劳动就业工作的通知 (Bekanntmachung des Zentralkomitees der KP Chinas über die Verbesserung der Beschäftigungsarbeit in den Städten und Gemeinden), vom 17. 08. 1980, in: 新时期劳动和社会保障重要文献选编 (Ausgewählte wichtige Dokumente über Arbeit und soziale Sicherheit), Beijing, 2002.

中共中央关于建国以来党的若干历史问题的决议 (Beschluss des Zentralkomitees der KP Chinas über einige historische Fragen der KP Chinas seit der Gründung der Volksrepublik), vom 27. 06. 1981, in: 人民日报 (RMRB), 06.07. 1981.

中共中央关于经济体制改革的决定 (Beschluss des Zentralkomitees der KP Chinas über die Wirtschaftsreform), vom 20.10.1984, in: 人民日报 (RMRB), 21.20. 1984.

中共中央关于制定国民经济和社会发展第七个五年计划的建议 (Vorschlag des Zentralkomitees der KP Chinas zur Ausarbeitung des 7. Fünfjahresplans für die wirtschaftliche und gesellschaftliche Entwicklung), vom 23. 09. 1985, Beijing, 1985.

中共中央关于修改中华人民共和国宪法个别条款的建议 (Vorschlag des Zentralkomitees der KP Chinas zur Revision von Teile der Verfassung), vom 28. 02. 1988, in: 中国宪法文献通编 (Dokumentensammlung über die chinesischen Verfassungen), Beijing, 2007, S. 85.

中共中央关于修改中华人民共和国宪法个别条款的建议 (Vorschlag des Zentralkomitees der KP Chinas zur Revision von Teile der Verfassung), vom 14. 02. 1993, in: 中国宪法文献通编 (Dokumentensammlung über die chinesischen Verfassungen), Beijing, 2007, S. 95-97.

中共中央关于建立社会主义市场经济体制若干问题的决定 (Beschluss des Zentralkomitees der KP Chinas über einige Fragen zur Errichtung einer sozialistischen Marktwirtschaft), vom 14. 11. 1993, in: 人民日报 (RMRB), 17. 11. 1993.

中共中央, 国务院关于卫生改革与发展的决定 (Beschluss des Zentralkomitees der KP Chinas und des Staatsrats über die Gesundheitsreform), 中发 (1997) 3号, vom 15. 01. 1997, http://www.moh. gov.cn/publicfiles/business/htmlfiles/wsb/pM30115/200804/18540.htm (Stand: 15. 07. 2010).

中共中央, 国务院关于切实做好国有企业下岗职工基本生活保障和再就业工作的通知 (Bekanntmachung des Zentralkomitees der KP Chinas und des Staatsrats über die Durchführung der Garantie des Grundlegenden Lebensstandards für die entlassenen Arbeitnehmer der Staatsbetriebe und der Arbeit der Wiederbeschäftigung), 中发 (1998) 10号，vom 09.06. 1998，in: 人民日报 (RMRB), 23. 06. 1998.

中共中央关于修改中华人民共和国宪法个别条款的建议 (Vorschlag des Zentralkomitees der KP Chinas zur Revision von Teile der Verfassung), vom 22. 01. 1999, in: 中国宪法文献通编 (Dokumentensammlung über die chinesischen Verfassungen), Beijing, 2007, S. 108-110.

中共中央, 国务院关于进一步做好下岗失业人员再就业工作的通知 (Bekanntmachung des Zentralkomitees der KP Chinas und des Staatsrats über die weitere Durchführung der Wiederbeschäftigungsmaßnahmen für die entlassenen Arbeitnehmer und die Arbeitslosen), 中发 (2002) 12号, vom 30. 09. 2002, http://www.molss.gov.cn/gb/zt/2006-02/06/content_105535.htm (Stand: 15. 07. 2010). 
中共中央, 国务院关于进一步加强农村卫生工作的决定 (Beschluss des Zentralkomitees der KP Chinas und des Staatsrats über Festigung der Gesundheitsarbeit auf dem Land), 中发 (2002) 13号, vom 19. 10. 2002, in: 人民日报 (RMRB), 29. 10. 2002.

中共中央关于完善社会主义市场经济体制若干问题的决定 (Beschluss des Zentralkomitees der KP Chinas über einige Fragen zur Vervollkommnung einer sozialistischen Marktwirtschaft), vom 21. 10. 2003, in: 人民日报 (RMRB), 21. 10. 2003.

中共中央关于修改中华人民共和国宪法个别条款的建议 (Vorschlag des Zentralkomitees der KP Chinas zur Revision von Teile der Verfassung), vom 12. 12. 2003, in: 中国宪法文献通编 (Dokumentensammlung über die chinesischen Verfassungen), Beijing, 2007, S. 124-126.

中共中央关于制定国民经济和社会发展第11个五年规划的建议 (Vorschlag des Zentralkomitees der KP Chinas zum 11. Fünfjahresplan), vom 11. 10. 2005, in: 人民日报（RMRB), 19. 10. 2005.

中共中央关于构建社会主义和谐社会若干重大问题的决定 (Beschluss des Zentralkomitees der KP Chinas über einige wichtige Fragen zur Strukturierung einer harmonischen sozialistischen Gesellschaft), vom 11. 10. 2006, in: 人民日报 (RMRB), 19. 10. 2006.

中共中央, 国务院关于促进残疾人事业发展的意见 (Ansichten des Zentralkomitees der KP Chinas und Staatsrats über die Förderung von Behindertenwesen), vom 28. 03. 2008, in: 人民日报 (RMRB), 24. 04. 2008

中共中央, 国务院关于深化医药卫生体制改革的意见 (Mitteilungen des Zentralkomitees der KP Chinas und des Staatsrats über die Vertiefung der Gesundheitsreform), 中发 (2009) 6号, vom 17. 03. 2009, in: 人民日报 (RMRB), 07. 07. 2009.

\section{Staatliche Politnormen}

a) Staatliche Entwicklungspläne

1956-1967年全国农业发展纲要 (1956-1967 Grundriss für die Entwicklung der Landwirtschaft), vom 23. 01. 1956, Beijing, 1956.

国民经济和社会发展第七个五年计划 (1986-1990) (Der 7. Fünfjahresplan für die wirtschaftliche und gesellschaftliche Entwicklung 1986-1990), Beijing, 1986.

国家体改委, 1989年经济体制改革要点 (Ausschuss des Staatsrats für Reformplanung, Schwerpunkte der Wirtschaftsreform von 1989), vom 04. 03. 1989, in: 十三大以来重要文献选编 (Dokumentenversammlung seit dem 13. Parteitag der KP Chinas), Beijing, 1991, S. 398-412.

国民经济和社会发展第九个五年计划 (Der 9. Fünfjahresplan für die volkswirtschaftliche und gesellschaftliche Entwicklung 1996-2000), gebilligt vom NVK im März 1996, Beijing, 1996.

国民经济和社会发展第十个五年计划 (Der 10. Fünfjahresplan für die volkswirtschaftliche und gesellschaftliche Entwicklung 2001-2005), gebilligt vom NVK am 15. 03. 2001, Beijing, 2001.

国民经济和社会发展第十一个五年规划 (Der 11. Fünfjahresplan für die volkswirtschaftliche und gesellschaftliche Entwicklung 2006-2010), gebilligt vom NVK am 14. 03. 2006, Beijing, 2006.

劳动和社会保障部, 劳动和社会保障事业发展十一五规划 (Ministerium für Arbeit und Soziale Sicherheit, Der 11. Fünfjahresentwicklungsplan für Arbeit und soziale Sicherheit 2006-2010), 国发 (2006) 35号, vom 13. 10. 2006, in: 劳动和社会保障政策法规汇编 2006 (Rechtssammlung für Arbeit und soziale Sicherheit 2006), Beijing, 2007, S. 64-83.

b) Beschäftigungs- und Wanderarbeiterpolitik

中央人民政府政务院关于劳动就业问题的决定 (Beschluss des Staatsverwaltungsrats zu den Fragen über Arbeit und Beschäftigung), vom 06. 08. 1952, Beijing, 1952. 
国务院关于进一步加强就业再就业工作的通知 (Mitteilung des Staatsrats über die Verstärkung der Beschäftigungs- und Wiederbeschäftigungsarbeit), 国发 (2005) 36号, vom 04. 11. 2005, in: 劳 动和社会保障政策法规汇编 2005 (Rechtssammlung für Arbeit und soziale Sicherheit 2005), Beijing, 2006, S. 395-406.

劳动和社会保障部财政部, 关于适当扩大失业保险基金支出范围试点有关问题的通知 (Ministerium für Arbeit und soziale Sicherheit/Finanzministerium, Bekanntmachung über einige Frage zum Pilotprojekt der zweckmäßigen Erweiterung von Ausgaben des Arbeitslosenversicherungsfonds), 劳社部发 (2006) 5号, vom 11. 01. 2006, in: 劳动和社会保障政策法规汇编 2006 (Rechtssammlung für Arbeit und soziale Sicherheit 2006), Beijing, 2007, S. 875-876.

国务院关于解决农民工问题的若干意见 (Ansichten des Staatsrates zur Lösung der Probleme der Wanderarbeiter), 国发 (2006) 5号, vom 27.03. 2006, in: 劳动和社会保障政策法规汇编 2006 (Rechtssammlung für Arbeit und soziale Sicherheit 2006), Beijing, 2007, S. 43-55.

劳动和社会保障部, 关于实施农民工平安计划, 加快推进农民工参加工伤保险工作的通知 (Mitteilung über die Durchführung des Ping'an-Plans der Arbeitsunfallversicherung für die Wanderarbeiter), 劳社部发 (2006) 19号, vom 17. 05. 2006, http://w1.mohrss.gov.cn/gb/zxwj/2006-

06/12/content_119251.htm (Stand: 15.07.2010).

劳动和社会保障部, 关于开展农民工参加医疗保险专项扩面行动的通知 (Ministerium für Arbeit und soziale Sicherheit, Mitteilung über die spezielle Aktion zur Vergrößerung der Krankenversicherung für die Wanderarbeiter), 劳社厅发 (2006) 11号, vom 16. 05. 2006, in: 劳动和社会保障 政策法规汇编 2006 (Rechtssammlung für Arbeit und soziale Sicherheit 2006), Beijing, 2007, S. 913-916.

c) Armutsbekämpfung und Sozialhilfe

第八次全国民政会议 (1983) 会议纪要 (Protokoll der 8. nationalen Sitzung für zivile Angelegenheiten 1983)，中办发 (1983) 53号, Beijing, 1983.

民政部，关于抓紧进行救灾合作保险试点准备工作的通知 (Mitteilung des Ministeriums für zivile Angelegenheiten über Vorbereitung der Pilotarbeit der kooperativen Katastrophenversicherung), 民农函 (1988) 第13号, vom 12.01. 1988, http://www.law-lib.com/Law/law_view.asp?id=49055 (Stand: 15. 07. 2010).

国务院关于在全国建立城市居民最低生活保障制度的通知 (Mitteilung des Staatsrates über die Errichtung des Sicherungssystems des Existenzminimums für die städtische Bevölkerung), 国发 (1997) 29号, vom 02. 09. 1997, in: 劳动与社会保障法规全书 1949-1999 (Rechtssammlung für Arbeit und soziale Sicherheit 1949-1999), Beijing, 2000, S. 600-601.

国务院扶贫办，中国农村扶贫开发纲要2001-2010 (Abteilung für Armutsbekämpfung und Entwicklung beim Staatsrat, Programme der Armutsbekämpfung auf dem Land 2001-2010), vom 19. 09. 2001. http://www.cpad.gov.cn/data/2006/0303/article_232.htm (Stand: 15. 07. 2010).

国务院办公厅关于进一步加强城市居民最低生活保障工作的通知 (Mitteilung der Generalkanzlei des

Staatsrats über die weitere Durchführung der Sicherung des Existenzminimums für die städtische Bevölkerung), 国办发 (2001) 87号, vom 12.11. 2001, in: 劳动和社会保障政策法规汇编 2001 (Rechtssammlung für Arbeit und soziale Sicherheit 2001), Beijing, 2002, S. 214-217.

国务院关于在全国建立农村最低生活保障制度的通知 (Mitteilung des Staatsrats über die landesweite Errichtung des Sicherungssystems des Existenzminimums für die ländliche Bevölkerung), 国发 (2007) 19号, vom 11. 07. 2007, in: 劳动和社会保障政策法规汇编 2007 (Rechtssammlung für Arbeit und soziale Sicherheit 2007), Beijing, 2008, S. 46-50. 
国务院关于企业职工养老保险制度改革的决定 (Beschluss des Staatsrats zur Reform des Rentenversicherungssystems für Beschäftigte in Unternehmen), 国发 (1991) 33号, vom 26. 06. 1991, in: 国 务院公报 (GGB), 1991, S. 967-968.

县级农村社会养老保险基本方案 (试行) (Basisplan für die ländliche Altersversicherung auf Kreisebene)(Pilotplan), 民办发 (1992) 2 号, vom 03. 01. 1992, http://www.gov.cn/banshi/200508/04/content_20283.html (Stand: 15.07.2010).

关于机关事业单位养老保险制度改革有关问题的通知 (Bekanntmachung über einige Fragen der Altersversicherungsreform für öffentliche Bedienstete), 人退发 (1992) 2号, vom 27.01. 1992, http://www.51labour.com/lawcenter/lawshow-21367.html (Stand: 15. 07. 2010).

关于深化企业职工养老保险制度改革的通知 (Bekanntmachung des Staatsrats über die Vertiefung der Reform des Rentenversicherungssystems für Beschäftigte in Unternehmen), 国发 (1995) 6号, vom 01. 03. 1995, in: 人民日报 (RMRB), 17.03. 1995.

国务院关于建立统一的企业职工基本养老保险制度的决定 (Beschluss des Staatsrats über die Errichtung eines einheitlichen Grundrentenversicherungssystems für Beschäftigte in Unternehmen), 国 发 (1997) 26号, vom 16.07. 1997, in: 国务院公报 (GGB), 1997, S. 1268.

国务院批转整顿保险业工作小组保险业整顿与改革方案的通知 (Mitteilung des Staatsrats über die Regulierung und die Reform des Versicherungswesens), 国发 (1999) 14号, vom 02.07. 1999, http://www.51labour.com/lawcenter/lawshow-20428.html (Stand: 15. 07. 2010).

国务院关于印发完善城镇社会保障体系的试点方案的通知 (Mitteilung des Staatsrats über den Pilotplan zur Verbesserung der sozialen Sicherheit in den Städten), 国发 (2000) 42号, vom 25. 12. 2000, in: 完善城镇社会保障体系试点辽宁篇 (Vervollkommnung der sozialen Sicherheit in den Städten: Liaoning-Pilotprojekt), Beijing, 2004, S. 6-14.

国务院关于完善企业职工养老保险制度改革的决定 (Beschluss des Staatsrats über die Vervollkommnung des Grundrentenversicherungssystems für Beschäftigte in Unternehmen), 国发 (2005) 38 号, vom 03. 12. 2005, in: 人民日报 (RMRB), 15. 12. 2005.

事业单位工作人员养老保险制度改革试点方案 (Pilotplan des Staatsrats über die Rentenversicherungsreform für die Beschäftigten in öffentlichen Institutionen), 国发 (2008) 10号, vom 18. 03. 2008, http://www.51labour.com/lawcenter/lawshow-78334.html (Stand: 15. 07. 2010).

国务院关于开展新型农村社会养老保险试点的指导意见 (Leitansichten des Staatsrats über das Pilotprojekt der neuen ländlichen Altersversicherung), 国发 (2009) 32 号, vom 01.09. 2009, http://www.gov.cn/zwgk/2009-09/04/content_1409216.html (Stand: 15. 07. 2010).

\section{e) Gesundheitswesen}

卫生部, 关于把卫生工作重点放到农村的报告 (Gesundheitsministerium, Bericht über das Legen vom Hauptgewicht auf die ländlichen Gebiete bei der Arbeit für das Gesundheitswesen), vom 11. 08. 1965, http://news.xinhuanet.com/ziliao/2005-02/02/content_2538494.html (Stand: 15. 07. 2010).

卫生部，关于卫生工作改革若干政策问题的报告 (Bericht des Gesundheitsministeriums über einige politische Linien der Gesundheitsreform), 国发 (1985) 62号, vom 25. 04. 1985, in: 中国卫生年 鉴 (Yearbook of Public Health in The People's Republic of China), S. 389-391.

国务院关于建立城镇职工基本医疗保险制度的决定 (Beschluss des Staatsrats über die Errichtung eines Grundkrankenversicherungssystems für Arbeitnehmer in Städten und Gemeinden), 国发 (1998) 44号, vom 14. 12. 1998, in: 劳动和社会保障政策法规汇编 1998 (Rechtssammlung für Arbeit und soziale Sicherheit 1998), Beijing, 1999, S. 455-459.

劳动保障部, 财政部, 关于实行国家公务员医疗补助的意见 (Ministerium für Arbeit und soziale Sicherheit, Finanzministerium, Ansichten über die Gewährung der Zuschüsse bei Krankenbehand- 
lungen der Beamten), vom 29. 04. 2000, http://www.law-lib.com/law/law_view.asp?id=38 (Stand: 15. 07. 2010).

卫生部，财政部，农业部，关于建立新型农村合作医疗制度的意见 (Gesundheitsministerium, Finanzministerium, Landwirtschaftsministerium, Vorschläge zum Aufbau des neuen ländlichen kooperativen medizinischen Systems), 国办发 (2003) Nr. 3, vom 10. 03. 2003, GGB 2003/6, S. 1214.

民政部，卫生部，财政部，关于实施农村医疗救助的意见 (Gesundheitsministerium, Finanzministerium, Ministerium für Zivile Angelegenheiten, Vorschläge zur Durchführung der ländlichen medizinischen Hilfe), 民发 (2003) 158 号, vom 18. 11. 2003, http://dbs.mca.gov.cn/article/ csyljz/zcfg/200712/20071200005478.shtml (Stand: 15. 07. 2010).

民政部，卫生部，劳动保障部，财政部，关于建立城市医疗救助制度试点工作的意见 (Ministerium für zivile Angelegenheiten, Gesundheitsministerium, Ministerium für Arbeit und soziale Sicherheit, Finanzministerium, Mitteilung über den Pilotplan der städtischen medizinischen Hilfe), vom 26. 02. 2005, http://www.gov.cn/zwgk/2005-08/15/content_21817.html (Stand: 15. 07. 2010).

民政部，卫生部，财政部，关于加快推进农村医疗救助工作的通知 (Ministerium für Zivile Angelegenheiten, Gesundheitsministerium, Finanzministerium, Bekanntmachung über die Beschleunigung der Arbeit der ländlichen medizinischen Hilfe), 民发 (2005) 121号, vom 15. 08. 2005, http://dbs.mca.gov.cn/article/csyljz/zcfg/200712/20071200005816.shtml (Stand: 15. 07. 2010).

卫生部, 关于加快推进新型农村合作医疗试点工作的通知 (Gesundheitsministerium, Bekanntmachung über die Beschleunigung der Arbeit der Pilotprojekte des neuen ländlichen kooperativen medizinischen Systems), 卫农卫发 (2006) 13 号， vom 10. 01. 2006, http://www.sda.gov.cn/WS01/CL0056/10761.html (Stand: 15. 07. 2010).

国务院关于发展城市社区卫生服务的指导意见 (Leitlinien des Staatsrats über die Entwicklung der städtischen kommunalen medizinischen Dienstleistungen), 国发 (2006)10号, vom 21. 02. 2006, http://www.gov.cn/zwgk/2006-02/23/content_208882.html (Stand: 15. 07. 2010).

国务院关于开展城镇居民基本医疗保险试点的指导意见 (Leitlinien des Staatsrats über die Entfaltung des Pilotprojekts der Grundkrankenversicherung für städtische Bewohner), 国发 (2007) 20 号, vom 10. 07. 2007, in: 劳动和社会保障政策法规汇编 2007 (Rechtssammlung für Arbeit und soziale Sicherheit 2007), Beijing, 2008, S. 619-624.

卫生部，财政部，关于做好2008年新型农村合作医疗工作的通知 (Bekanntmachung des Gesundheitsministeriums und Finanzministeriums über die Arbeit des neuen ländlichen kooperativen medizinischen Systems im Jahre 2008 )，卫农卫发 (2008) 17 号，vom 13.03. 2008, http://www.moh.gov.cn/publicfiles/business/htmlfiles/mohncwsgls/s3581/200804/31097.html (Stand. 15. 07. 2010).

人力资源与社会保障部, 关于做好 2008年城镇居民基本医疗保险试点工作的通知 (Ministerium für Personalwesen und soziale Sicherheit, Bekanntmachung über die weitere Durchführung des Pilotprojekts der Grundkrankenversicherung für die städtischen Bewohner im Jahr 2008 ), 人社部发 (2008) 39号, in: 劳动和社会保障法规政策专刊 (Zeitschrift für rechtliche Regelungen und politische Richtlinien über Arbeit und soziale Sicherheit), 2008/7, S. 27-29.

国务院医药卫生体制改革近期重点实施方案 (2009-2011) (Durchführungsplan des Staatsrats für die Gesundheitsreform 2009-2011)，国发 (2009) 12号，vom 18.03.2009，in: 人民日报 (RMRB), 08. 04. 2009.

人力资源和社会保障部，财政部，关于全面开展城镇居民基本医疗保险工作的通知 (Ministerium für Personalwesen und soziale Sicherheit, Finanzministerium, Bekanntmachung über die landesweite Entfaltung der Grundkrankenversicherung für die städtischen Bewohner), 人社部发 2009 (35) 号, vom 08. 04. 2009, http://www.gov.cn/zwgk/2009-08/05/content_1383950.html (Stand: 15. 07. 2010). 
民政部，关于国家机关工作人员，人民警察伤亡抚恤有关问题的通知 (Ministerium für zivile Angelegenheiten, Mitteilung über die Sonderversorgung für Staatsbeamte und Polizisten), 民函 (2004) 334 号， vom 14. 12. 2004, http://www.mps.gov.cn/n16/n1960670/n1960726/n1960898/ 2272877.html (Stand: 15. 07. 2010).

军人保险制度实施方案 (Durchführungsplan des Sozialversicherungssystems für Armeeangehörige), zitiert nach: 郑功成, 社会保障学 (Zheng, Gongcheng (Hrsg.), Social Security), Beijing, 2006.

\section{g) Soziale Wohlfahrt}

民政部, 关于加快实现社会福利社会化的意见 (Ansichten des Ministerium für zivile Angelegenheiten zur Beschleunigung der Sozialisierung der sozialen Wohlfahrt), 国办发 (2000) 19号, vom 27. 02. 2000, in: 劳动和社会保障政策法规汇编 2001 (Rechtssammlung für Arbeit und soziale Sicherheit 2001), Beijing, 2002, S. 32-38.

国家经贸委, 财政部, 教育部, 卫生部, 劳动和社会保障部, 关于进一步推进国有企业分离办社会 职能工作的意见 (Kommission für Wirtschaft und Handel, Finanzministerium, Ministerium für Bildungswesen, Gesundheitsministerium, Ministerium für Arbeit und soziale Sicherheit, Ansichten zur Befreiung der Staatsunternehmen von den sozialen Aufgaben), 国经贸企改 (2002) 267号, vom 26. 04. 2002, http://www.jincao.com/gq.05.html (Stand: 15. 07. 2010).

\section{h) Finanzwesen}

国务院关于地方实行财政包干办法的决定 (Beschluss des Staatsrats über die volle finanzielle Verantwortlichkeit der lokalen Regierungen), 国 发 (1988), vom 28. 07. 1988, http://www.chinabaike.com/law/zy/xz/gwy/1332528.html (Stand: 15. 07. 2010).

国务院关于实行分税制财政管理体制的决定 (Beschluss des Staatsrats über die Durchführung des Finanzverwaltungssystems der Steuereinnahmenaufteilung), vom 15. 12. 1993, in: 劳动和社会保 障法规全书 1949-1999 (Rechtssammlung für Arbeit und soziale Sicherheit 1949-1999), Bejing, 2000, S. 480-483.

\section{Rechtliche Normen}

\section{Gesetze}

中华人民共和国宪法 $(1954,1975,1978,1982)$ (Verfassung der Volksrepublik China), in: 中国宪法文 献通编 (Dokumentensammlung über die chinesischen Verfassungen), Beijing, 2007.

中华人民共和国兵役法, vom 31. 05. 1984, revidiert am 29. 12. 1998, in: 人民日报 (RMRB), 31. 12. 1998.

中华人民共和国民法通则 (Allgemeine Grundsätze des Zivilrechts), vom 12. 04. 1986, in: GGB 1986, S. 371.

中华人民共和国义务教育法 (Schulpflichtgesetz), vom 12.04. 1986, revidiert am 29. 06. 2006. in: 人 民日报 (RMRB), 29.06. 2006.

中华人民共和国行政诉讼法 (Verwaltungsprozessgesetz), vom 04. 04. 1989, in Kraft ab 01. 10. 1990. in: Laws of the People's Republic of China 1987-1989, S. 283. 
中华人民共和国城市居民委员会组织法 (Gesetz über die Organisation der städtischen Wohnbevölkerungsausschüsse), vom 26. 12. 1989, in: 全国人民代表大会常务委员会公报 (Amtsblatt des Ständigen Ausschusses des NVK), 1989. S. 443.

中华人民共和国残疾人保障法 (Gesetz zum Schutz von behinderten Menschen), vom 28. 12. 1990, revidiert im Jahre 2008, in: 人民日报 (RMRB), 25. 04. 2008.

中华人民共和国未成年人保护法 (Gesetz zum Schutz der Minderjährige), von 1991, revidiert im Jahre 2006, in: 劳动和社会保障法规全书 1949-1999 (Rechtssammlung für Arbeit und soziale Sicherheit 1949-1999), Beijing, 2000, S. 253-257.

中华人民共和国妇女权益保障法 (Gesetz zur Gewährleistung der Rechte von Frauen), vom 03. 04. 1992, revidiert im Jahre 2005, in: 劳动和社会保障法规全书 1949-1999 (Rechtssammlung für Arbeit und soziale Sicherheit 1949-1999), Beijing, 2000, S. 258-261.

中华人民共和国国家赔偿法 (Staatsentschädigungsgesetz), vom 12.05. 1994, in Kraft ab 01. 01. 1995, revidiert am 29. 04. 2010, in: 人民日报 (RMRB), 30. 04. 2010.

中华人民共和国劳动法 (Arbeitsgesetz), vom 05. 07. 1994, in: GGB 1994, S. 678.

中华人民共和国职业教育法 (Gesetz zur Berufsausbildung)，vom 15．05．1996，in：人民日报 (RMRB), 23. 05. 1996.

中华人民共和国老年人权益保障法 (Gesetz zur Gewährleistung der Rechte von alten Menschen), vom 29. 08. 1996, in: 人民日报 (RMRB), 23. 09. 1996.

中华人民共和国国防法 (Landesverteidigungsgesetz)，vom 14.03. 1997，in：人民日报 (RMRB)，19. 03.1997 .

中华人民共和国高等教育法 (Ausbildungsgesetz), vom 29.08. 1998, in Kraft ab 01.01. 1999, in: 人民 日报 (RMRB), 31.08. 1998 .

中华人民共和国村民委员会组织法 (Gesetz über die Organisation der Ortsausschüsse auf dem Land), vom 04. 11. 1998, in: 人民日报 (RMRB), 05. 11. 1998.

中华人民共和国立法法 (Gesetzgebungsgesetz), vom 15. 03. 2000, in Kraft ab 01. 07. 2000, in: 人民日 报 (RMRB), 19.03.2000.

中华人民共和国职业病防治法 (Gesetz zur Verhütung und Bekämpfung beruflicher Krankheit), vom 27. 10. 2001, in: 劳动和社会保障政策法规汇编 2001 (Rechtssammlung für Arbeit und soziale Sicherheit 2001), Beijing, 2002, S. 16-35.

中华人民共和国工会法 (Gewerkschaftsgesetz), vom 03. 04. 1992, revidiert am 27. 10. 2001, in: 劳动 和社会保障政策法规汇编 2001 (Rechtssammlung für Arbeit und soziale Sicherheit 2001), Beijing, 2002, S. 36-46.

中华人民共和国安全生产法 (Gesetz zur Arbeitssicherheit), vom 29.04. 2002, in: 全国人民代表大会 常务委员会公报 (Amtsblatt des Ständigen Ausschusses des NVK), 2002.

中华人民共和国公务员法 (Beamtengesetz), vom 27. 04. 2005, in Kraft ab 01. 01. 2006, in: 人民日报 (RMRB), 11. 05. 2005.

中华人民共和国物权法 (Sachenrechtsgesetz), vom 16. 03. 2007, in Kraft ab 01. 10. 2007, in: 人民日 报 (RMRB), 19.03. 2007.

中华人民共和国劳动合同法 (Arbeitsvertragsgesetz), vom 29.06. 2007, in: 劳动和社会保障政策法规 汇编 2007 (Rechtssammlung für Arbeit und soziale Sicherheit 2007), Beijing, 2008, S. 3-22.

中华人民共和国就业促进法 (Beschäftigungsförderungsgesetz), vom 30. 08. 2007, in: 劳动和社会保 障政策法规汇编 2007 (Rechtssammlung für Arbeit und soziale Sicherheit 2007), Beijing, 2008, S. 23-34.

中华人民共和国劳动争议调解仲裁法 (Gesetz zur Schlichtung und zum Schiedsverfahren der Arbeitsstreitigkeiten), vom 29. 12. 2007, in: 劳动和社会保障政策法规汇编 2007 (Rechtssammlung für Arbeit und soziale Sicherheit 2007), Beijing, 2008, S. 35-45.

中华人民共和国社会保险法 (Sozialversicherungsgesetz), vom 28. 10. 2010,

http://www.gov.cn/jrzg/2010-10/28/content_1732870.htm 
救济失业工人暂行办法 (Vorläufige Maßnahmen für Hilfe der Arbeitslosen), vom 17. 06. 1950, http://china.findlaw.cn/laodongfa/sfbzzhbx/9232.html (Stand: 15. 07. 2010).

革命工作人员伤亡襄恤暂行条例 (Vorläufige Regeln für Auszeichnung und Entschädigung von revolutionärer Verwundeten und Gefallenden), vom 11. 12. 1950, in: 人民日报 (RMRB), 14. 12. 1950.

高级农业生产合作社示范章程 (Mustersatzung für die landwirtschaftlichen Produktionsgenossenschaften höherer Stufe), vom 30. 06. 1956, in: 中华人民共和国法规汇编 (Rechtssammlung der VR China), 1956, 1-6.

中华人民共和国劳动保险条例 (Regeln über die Arbeiterversicherung), vom 26. 02. 1951, in: 新华月 报 (Xinhua Yuebao), 2/1953.

关于全国各级人民政府、党派、团体及所属事业单位的国家工作人员实行公费医疗预防措施的指 示 (Anordnung des Staatsverwaltungsrats über die Durchführung der kostenfreien medizinischen Behandlung und Vorsorge für Staatsbedienstete in den Regierungen der verschiedenen Ebenen, in den Parteien, in den Institutionen und den dazugehörigen Arbeitseinheiten - dies kennzeichnet die Einführung des kostenlosen medizinischen Systems für Beamte), vom 27. 06. 1952, in: 人民日报 (RMRB), 28. 06. 1952.

关于女工作人员生产假期的通知 (Bekanntmachung über den Mutterschaftsurlaub für Beamtinnen), vom 26. 04. 1955. http://www.docin.com/p-1034825.html (Stand: 15. 07. 2010).

关于国家机关工作人员子女医疗问题的通知 (Bekanntmachung über die medizinische Behandlung der Kinder der Beamten in den Staatsorganen) von 1955,

http://www.chinabaike.com/law/zy/bw/gw/czb/1346049.html (Stand: 15. 07. 2010).

国家机关工作人员病假期间生活待遇试行办法 (Vorläufige Maßnahmen über die Leistungen während Krankheit für Beamte in den Staatsorganen), vom 29. 12. 1955, http://www.docin.com/p1034831.html (Stand: 15. 07. 2010).

国家机关工作人员退休处理暂行办法 (Vorläufige Maßnahmen über Pensionierung für Beamte in den Staatsorganen), vom 29. 12. 1955, aufgehoben am 09.02.1958, in: 人民日报 (RMRB), 11. 02. 1958.

关于处理牺牲病故的国家机关工作人员的补助问题的暂行规定 (Vorläufige Bestimmungen über Zuwendungen der gefallenen und an Krankheit gestorbener Beamten in den Staatsorgane) von 1956, zitiert nach: 郑功成, 社会保障学 (Zheng Gongcheng (Hrsg.), Social Security), Beijing, 2005, S. 68.

中华人民共和国户口登记条例 (Regeln über Hukou-Registrierung), vom 09. 01. 1958, in: 人民日报 (RMRB), 10.01. 1958.

国务院关于工人职员退休处理的暂行规定 (Vorläufige Bestimmung des Staatsrats über die Regelung des Ruhestandes von Arbeitern und Bediensteten), vom 09. 02. 1958, in: 人民日报 (RMRB), 11. 02. 1958.

国务院关于工人退休退职的暂行办法 (Vorläufigen Maßnahmen des Staatsrats zur Pensionierung und zum Ausscheiden von Arbeitern), 国发 (1978) 104号, vom 02. 06. 1978, in: 劳动和社会保障法 规全书 1949-1999 (Rechtssammlung für Arbeit und soziale Sicherheit 1949-1999), Bejing, 2000, S. 327-328.

国务院关于安置老弱病残干部的暂行办法 (Vorläufige Maßnahmen des Staatsrats zur Versorgung alter und kranker Kader), 国发 (1978) 104号, vom 02. 06. 1978, in: 劳动和社会保障法规全书 1949-1999 (Rechtssammlung für Arbeit und soziale Sicherheit 1949-1999), Beijing, 2000, S. 410412.

革命烈士裹扬条例 (Regeln zur Auszeichnung der revolutionären Märtyrer), vom 04. 06. 1980, 国发 (1980)152号, http://www.mod.gov.cn/policy/2009-07/14/content_4088085.htm (Stand: 15. 07. 2010). 
城市流浪乞讨人员收容遣送办法 (Maßnahmen zur Unterbringung und Rückführung von Obdachlosen in den Städten), 国发 (1982) 79号, vom 12.05.1982, aufgehoben am 01.08. 2003,

http://www.people.com.cn/GB/shizheng/1026/1923232.html (Stand: 15. 07. 2010).

国营企业职工待业保险暂行规定 (Vorläufige Bestimmung zur Auf-Arbeit-Wartenden-Versicherung der staatlichen Unternehmen), vom 12. 07. 1986, in: GGB 1986, S. 747-748.

国营企业实行劳动合同制暂行规定 (Vorläufige Bestimmung zur Durchsetzung vom Arbeitsvertragssystem in staatlichen Unternehmen), vom 12. 07. 1986, in. GGB 1986, S. 739-740.

全民所有制工业企业转换经营机制条例 (Regeln über die Änderung des Wirtschaftsführungssystems der Industrieunternehmen im Volkseigentum), vom 23.07. 1992, 国务院令第103号, in: 劳动和 社会保障法规全书 1949-1999 (Rechtssammlung für Arbeit und soziale Sicherheit 1949-1999), Beijing, 2000, S. 453-462.

国有企业职工待业保险规定 (Bestimmung zur Auf-Arbeit-Wartenden-Versicherung für Beschäftigte der staatlichen Unternehmen), vom 12.04.1993，国务院令第110号，in：中国社会保险工作全书 (Gesamtwerk zur Sozialversicherung), Beijing, 1995. S. 811-813.

企业职工养老保险基金管理规定 (Regeln über die Verwaltung des Rentenversicherungsfonds für Beschäftigte in Unternehmen), veröffentlicht vom Arbeitsministerium am 02. 07. 1993, in: 劳动和 社会保障法规全书 1949-1999 (Rechtssammlung für Arbeit und soziale Sicherheit 1949-1999), Beijing, 2000, S. 508-514.

农村五保供养工作条例 (Regeln über die Fünf-Garantien-Versorgung auf dem Land), vom 23. 01. 1994，国务院令 (1994) 第141号, in: 人民日报 (RMRB), 28.01.1994.

关于加强企业职工社会保险基金投资管理的规定 (Regeln über die Investition des Sozialversicherungsfonds für Beschäftigte in Unternehmen), vom 22. 11. 1994, 财社字 (1994) 第59号, http://www.51labour.com/lawcenter/lawshow-18134.html (Stand: 15. 07. 2010).

企业职工生育保险试行办法 (Vorläufige Maßnahmen über die Mutterschaftsversicherung von Beschäftigten in Betrieben), vom 14. 12. 1994，劳部发 (1994) Nr. 504, in. Enzyklopädie 1999, S. 2235.

企业职工工伤保险试行办法 (Vorläufige Maßnahmen über die Arbeitsunfallversicherung von Beschäftigten in Betrieben), vom 12. 08. 1996, 劳部发 (1996) Nr. 266, in: 法规汇编 1996 (Gesetzessammlung 1996), S. 295.

企业职工基本养老保险基金实行收支两条线管理暂行规定 (Vorläufige Regeln über die ,zwei Verwaltungslinien von Einnahmen und Ausgaben“ des Fonds der Grundrentenversicherung für Beschäftigte in Unternehmen), vom 27. 01. 1998, 财 社字 (1998) 6 号， http://wenku.baidu.com/view/9a3897c30c22590102029d3d.html (Stand: 15. 07. 2010).

事业单位登记管理暂行条例 (Vorläufige Regeln über die Registrierung und Verwaltung der öffentlichen Institutionen), vom 25. 10. 1998, 国务院令第 252 号, revidiert in 2004, http://www.moc.gov.cn/zhuzhan/renshixinxi/shetuanguanli/200802/t20080225_468807.html

(Stand: 15. 07. 2010).

失业保险条例 (Regeln über die Arbeitslosenversicherung), vom 22. 01. 1999, in: 劳动和社会保障政 策法规汇编 1999 (Rechtssammlung für Arbeit und soziale Sicherheit 1999), Beijing, 2000, S. 671-677.

社会保险基金财务制度 (Finanzordnung des Sozialversicherungsfonds)，财社字( 1999) 60号, vom 15.

06. 1999, http://www.molss.gov.cn/gb/ywzn/2005-12/02/content_95623.htm (Stand: 15. 07.

2010).

城市居民最低生活保障条例 (Regeln zur Sicherung des Existenzminimums für die städtische Bevölkerung), 国发 (1999) Nr. 271, vom 28. 09. 1999, in: 劳动和社会保障政策法规汇编 1999 (Rechtssammlung für Arbeit und soziale Sicherheit 1999), Beijing, 2000, S. 36-40.

中国人民解放军军人退役医疗保险暂行办法 (Vorläufige Maßnahmen über die Krankenversicherung für demobilisierte Soldaten), vom 01. 01. 2001, http://www.molss.gov.cn/gb/ywzn/200602/14/content_106443.htm (Stand: 15. 07. 2010). 
减持国有股筹集社会保障资金管理暂行办法 (Vorläufige Verwaltungsmaßnahmen zur Verringerung der Staatsanteile und zur Finanzierung des Fonds der sozialen Sicherheit), 国发 (2001) 22号, vom 06. 06. 2001, in: 劳动和社会保障政策法规汇编 2001 (Rechtssammlung für Arbeit und soziale Sicherheit 2001), Beijing, 2002, S. 671-674.

行政法规制定程序条例 (Regeln für das Verfahren zur Festsetzung von Exekutivrechtsnormen), 国务 院令第321号, vom 16. 11. 2001, ab 01. 01. 2002 in Kraft, http://www.law-lib.com/law/law_view. asp?id=16619 (Stand: 15. 07. 2010).

全国社会保障基金投资管理暂行办法 (Vorläufige Maßnahmen zur Verwaltung und Investition des Nationalen Fonds für soziale Sicherheit), 第12号, vom 13. 12. 2001, in: 劳动和社会保障政策法 规汇编 2001 (Rechtssammlung für Arbeit und soziale Sicherheit 2001), Beijing, 2002, S. 693703.

禁止使用童工规定 (Regeln über Verbot der Kinderarbeit), vom 18. 09. 2002, in: 劳动和社会保障政策 法规汇编 2002 (Rechtssammlung für Arbeit und soziale Sicherheit 2002), Beijing, 2003.

工伤保险条例 (Regeln über die Arbeitsunfallversicherung), vom 27. 04. 2003, in: 劳动和社会保障政 策法规汇编 2003 (Rechtssammlung für Arbeit und soziale Sicherheit 2003), Beijing, 2004, S. 605-620.

城市生活无着的流浪乞讨人员救助管理办法 (Verwaltungsmaßnahmen zur Hilfe von Obdachlosen in den Städten), 国务院令第381号, vom 18. 06. 2003, in: 劳动和社会保障政策法规汇编 2003 (Rechtssammlung für Arbeit und soziale Sicherheit 2003), Beijing, 2004, S. 31-34.

城市生活无着的流浪乞讨人员救助管理办法实施细则 (Detaillierte Vorschrift über Verwaltungsmaßnahmen zur Hilfe von Obdachlosen in den Städten), vom 21. 07. 2003, in: 中华人民共 和国法规汇编 2003 (Rechtssammlung der VR China 2003), Beijing, 2004, S. 98-101.

中国人民解放军军人配偶随军未就业期间社会保险暂行办法 (Vorläufige Maßnahmen über die Sozialversicherung für die nicht beschäftigten Ehepartner der Armeeangehörige in der Zeit der Begleitung)，vom 25. 12. 2003，国办发 (2003) 102号，in：劳动和社会保障政策法规汇编 2003 (Rechtssammlung für Arbeit und soziale Sicherheit 2003), Beijing, 2004, S. 77-82.

城镇最低收入家庭廉租住房管理办法 (Maßnahmen zur Wohnungshilfe mit niedriger Miete für Familien mit niedrigem Einkommen in den Städten), vom 31. 12. 2003, http://www1.china.com.cn/chinese/PI-c/484552.html (Stand: 15. 07. 2010).

军人抚恤优待条例 (Regeln zur Entschädigung, Unterstützung und Vorzugsbehandlung für Armeeangehörige), vom 01. 10. 2004, in: 劳动和社会保障政策法规汇编 2004 (Rechtssammlung für Arbeit und soziale Sicherheit 2004), Beijing, 2005, S. 9-20.

农村五保供养工作条例 (Regeln über die Arbeit der Versorgung mit den Fünf-Garantien auf dem Land), 国务院令第456号, vom 01. 03. 2006, in: GGB, 2006/7, S. 24-27.

廉租住房保障办法 (Maßnahmen zur Sicherung der Wohnungen mit niedriger Miete)，建设部，国家发 展和改革委员会，监察部，民政部，财政部，国土资源部，中国人民银行，国家税务总局，国 家统计局令第162号, vom 08. 11.2007, http://www.gov.cn/flfg/2007-11/27/content_816644.html (Stand: 15. 07. 2010).

中国人民解放军军人伤亡保险暂行规定 (Vorläufige Bestimmung über die Versicherung für verwundete und gefallene Armeeangehörige), vom 01.08 .2008 , http://bbs.mca.gov.cn/viewthread.php?tid=10158 (Stand: 15. 07. 2010).

境内证券市场转持部分国有股充实全国社会保障基金实施办法 (Durchführungsmaßnahmen zum Übertragen der Staatsanteile auf den Nationalen Fonds für soziale Sicherheit), 财企 (2009) 94号, vom 19. 06. 2009, in: GGB, 2010/4, S. 31-32.

城镇企业职工基本养老保险关系转移接续暂行办法 (Voläufige Maßnahmen zur Übertragung und Fortsetzung der Rentenversicherungsbeziehungen der Arbeitnehmer in städtischen Unternehmen), 国办发 (2009) 66号, vom 28. 12. 2009, ab 01.01. 2010 in Kraft, in: GGB, 2010/1, S. 16-17. 
劳动和社会保障事业发展统计公报 (Statistisches Bulletin über Arbeit und soziale Sicherheit), http://www.cnss.cn/zlzx/sjtj/ldbzbtj/ (Stand: 15. 07. 2010).

民政事业发展统计报告 (Statistisches Bulletin über die Zivilen Angelegenheiten), http://cws.mca.gov.cn/article/tjbg/ (Stand: 15. 07. 2010).

中国统计年鉴1996 (China Statistical Yearbook 1996), Beijing, 1996.

中国卫生统计提要 (Health Expenditure Report), http://www.moh.gov.cn/publicfiles/business/htmlfiles/ zwgkzt/ptjty/index.html (Stand: 15. 07. 2010).

民政部, 全国百城万户低保抽查结果 (Ministerium für Zivile Angelegenheiten, Untersuchungsergebnisse der Stichprobe für das städtische System des Existenzminimums), in: 北京青年报 (BJQNB), 28. 12. 2002.

中国统计年鉴2002 (China Statistical Yearbook 2002), Beijing, 2002.

国家统计局, 中国统计摘要2004 (National Bureau of Statistics of China, China Statistical Abstract 2004), Beijing, 2004.

中国财政年鉴2004 (Finanzjahresbuch China2004), Beijing, 2004

卫生部统计信息中心, 第三次国家卫生服务调查分析报告 (Statistikzentrum des Gesundheitsministeriums, Abstract of the Report on the 3rd National Health Service Investigation and Analysis), Beijing, 2004.

中国统计年鉴2005 (China Statistical Yearbook 2005), Beijing, 2005.

国家审计署, 审计结果公告2006第6号 (Staatsrechnungsprüfungsbüro, Rechnungsprüfungsankündigung 2006, Nr. 6), http://www.audit.gov.cn/cysite/chpage/c516/doclist.html (Stand: 15. 07. 2010).

2006年全国社会保障基金年度报告 (Jahresbericht des Nationalen Fonds für soziale Sicherheit 2006), http://www.ssf.gov.cn/xxgk/tzycb/cwbg/200904/t20090427_905.html (Stand: 15. 07. 2010).

深圳市2006年国民经济和社会发展统计公报 (Statistisches Bulletin Shenzhen über die Entwicklung der Volkswirtschaft und der Gesellschaft 2006), http://www.sztj.com/main/xxgk/tjsj/tjgb/ gmjjhshfzgb/ 200704131585.shtml (Stand: 15. 07. 2010).

2006年上海市国民经济和社会发展统计公报 (Statistisches Bulletin Shanghai über die Entwicklung der Volkswirtschaft und der Gesellschaft 2006), http://www.statssh.gov.cn/2004shtj/tjgb/ tjgb2006.html (Stand: 15. 07. 2010).

民政部，中华人民共和国行政区划统计表 (Ministerium für Zivile Angelegenheiten, Verwaltungsaufbau der Volksrepublik China), http://www.xzqh.cn/ONEWS_zq.asp?id=1150 (Stand: 15. 07. 2010).

劳动和社会保障部, 近年来我国社会保险基本情况 (Ministerium für Arbeit und soziale Sicherheit, Zustand der Sozialversicherungen in den letzten Jahren), http://www.cnss.cn/xwzx/jdxw/200711/ t20071129_167939.html (Stand: 15. 07. 2010).

中国统计年鉴2007 (China Statistical Yearbook 2007), Beijing, 2007.

第二次全国农业普查主要数据公报第五号 (Statistisches Bulletin Nr. 5 der 2. landwirtschaftlichen Untersuchung Chinas ), http://stats.gov.cn/tjgb/nypcgb/ (Stand: 15. 07. 2010).

民政部，2010年4月份全国县以上城市低保数据 (Ministerium für zivile Angelegenheiten, Statistische Daten der städtischen Existenzsicherung vom 04. 2010), http://www.mca.gov.cn/article/zwgk/tjsj/ (Stand: 15. 07. 2010). 